\title{
PETER VERSTRATEN
}

\section{HUMOUR AND IRONY IN DUTCH POST-WAR FICTION FILM}

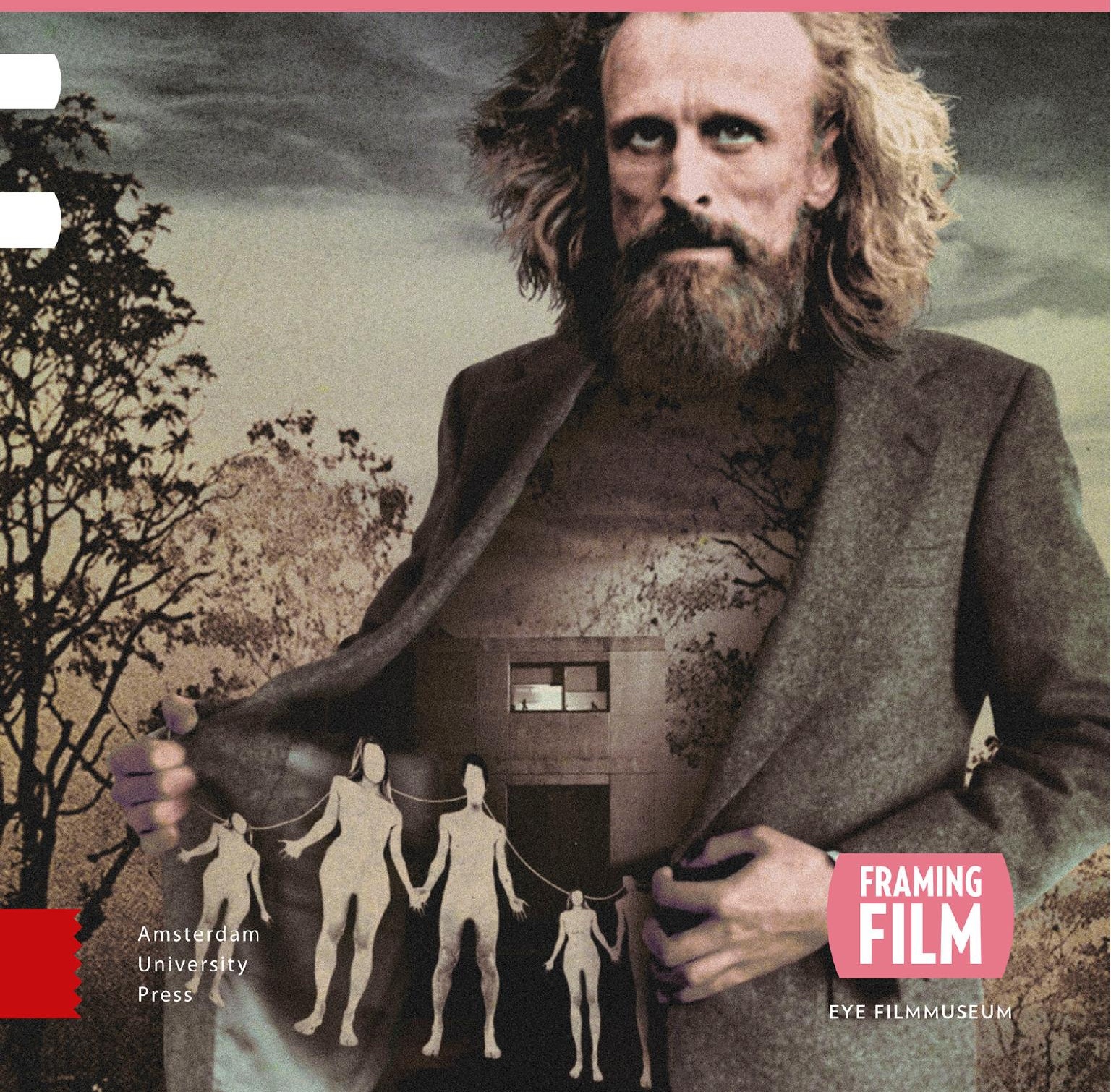


HUMOUR AND IRONY IN DUTCH POST-WAR FICTION FILM 


\section{FRAMING FllM}

FRAMING FILM is a book series dedicated to theoretical and analytical studies in restoration, collection, archival, and exhibition practices in line with the existing archive of EYE Filmmuseum. With this series, Amsterdam University Press and EYE aim to support the academic research community, as well as practitioners in archive and restoration.

\section{SERIES EDITORS}

Giovanna Fossati, EYE Filmmuseum \& University of Amsterdam, the Netherlands

Leo van Hee, EYE Filmmuseum

Frank Kessler, Utrecht University, the Netherlands

Patricia Pisters, University of Amsterdam, the Netherlands

Dan Streible, New York University, United States

Nanna Verhoeff, Utrecht University, the Netherlands

\section{EDITORIAL BOARD}

Richard Abel, University of Michigan, United States Jane Gaines, Columbia University, United States Tom Gunning, University of Chicago, United States Vinzenz Hediger, Goethe University Frankfurt, Germany

Martin Koerber, Deutsche Kinemathek, Germany Ann-Sophie Lehmann, University of Groningen, the Netherlands

Charles Musser, Yale University, United States

Julia Noordegraaf, University of Amsterdam, the Netherlands

William Uricchio, Massachusetts Institute of Technology, United States

Linda Williams, University of California at Berkeley, United States 


\section{PETER VERSTRATEN \\ HUMOUR AND IRONY \\ IN DUTCH POST-WAR \\ FICTION FILM}

AMSTERDAM UNIVERSITY PRESS 


\section{NL FILM
FONDS}

This publication is made possible by grants from the Nederlands Filmfonds and the Netherlands Society of Cinematographers.

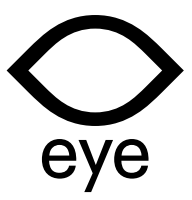

Published by EYE Filmmuseum / Amsterdam University Press

Cover illustration: Borgman @ Drafthouse Films. Design: Brandon Schaefer.

Cover design and lay-out: Magenta Ontwerpers, Bussum

Amsterdam University Press English-language titles are distributed in the US and Canada by the University of Chicago Press.
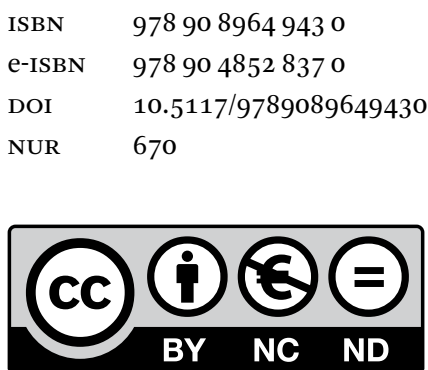

Creative Commons License CC BY NC ND

(http://creativecommons.org/licenses/by-nc-nd/3.o)

(c) P. Verstraten / Amsterdam University Press B.V., Amsterdam 2016

Some rights reserved. Without limiting the rights under copyright reserved above, any part of this book may be reproduced, stored in or introduced into a retrieval system, or transmitted, in any form or by any means (electronic, mechanical, photocopying, recording or otherwise).

Every effort has been made to obtain permission to use all copyrighted illustrations reproduced in this book. Nonetheless, whosoever believes to have rights to this material is advised to contact the publisher. 


\section{TABLE OF CONTENTS}

Preface 9

INTRODUCTION 13

Overview of Studies on Dutch Cinema 15

Like Sharing a Secret Code 19

Three Theories of Humour: FLODDER IN AMERIKA! 25

From 'Jokes' to 'Humour' 35

1 LOW-CLASS COMEDIES 45

A Prostitute and a Chambermaid: WAT ZIEN IK?! 48

(No) Ordinary People: HOGE HAKKEN, ECHTE LIEFdE and SCHATJES! 52

Be Thyself (or Act Like a Person): FLODDER 58

Carnivalesque 63

Forrest Gone Berserk: NEW KIDS TURBO 66

Social 'Ragging' 72

Over-the-top: VET HARD, MOORDWIJVEN, FILMPJE! 75

Long Live 'Sjakie' 79

2 MULTicultural COMEdies 83

The Joie de Vivre of the Right-wing: vOX POPULI 85

Strategic Ambiguity: ALLEEN MAAR NETTE MENSEN 87

100\% Halal: HET SCHNITZELPARADIJS 92

Primal Dutch: SHOUF SHOUF HABIBI! 95

A Dutch Road Movie: DUNYA \& DESIE 101

Kebab Sutra: RABAT 106

Flouting Moral Rules 108 
3 FROM 'KIND-HEARTED’ COMEDIES TO NEUROTIC ROMANCES 113

Feel-good Tragedies: KOMEDIE OM GELD and CISKE DE RAT 115

Playful Parallel Editing: FANFARE 120

Bergman 'Light': DORP AAN DE RIVIER and MAKKERS STAAKT UW WILD GERAAS 123

Sticks of Satay in the Theater: EEN ZWOELE ZOMERAVOND and TUSSENSTAND 128

Pursuits of Happiness: ALLES IS LIEFDE and ALLES IS FAMILIE 132

Free-floating Irony: DE GELUKKIGE HUISVROUW and GOOISCHE VROUWEN 138

Post-Feminism: PHILEINE ZEGT SORRY 143

Women Who Know Too Much 144

Epilogue: A Note on Tolerance 146

6 | 4 DELIBERATE CAMP 151

A Faggot's Fairy Tale: THEO \& THEO EN DE ONTMASKERING VAN HET TENENKAASIMPERIUM 153

Demy Revisited: DE TRANEN VAN MARIA MACHITA 162

Double Entendres: JA ZUSTER, NEE ZUSTER 165

The Detour of Postmodern Irony: FLORIS 167

Gay Pride: CHEZ NOUS 170

The Risk of Mere Witticism 173

5 HUMOUR AS AN AFTERMATH EFFECT 177

A Discrepancy between Story and Number: BLUE MOVIE 178

A Bohemian Display of Sex and Decay: TURKS FRUIT 182

Once Provocative, Now Obsolete: Pim \& Wim Movies 187

Band of Outsiders: CHA CHA 191

Agent Provocateur: 06 and BLIND DATE 192

The Humour of Horror: SINT 195

6 HOMOSOCIAL JOKES 201

Ironic Distance: SPETTERS 203

Homosexual Panic as Baloney: ALL STARS 210

Bonding between a Gay Yuppie and a He-Man: SIMON 214

Dead Man 'Walking' as a Comedy: DE MARATHON 217

A Wannabe Tarantino Bromance: BROS BEFORE HOS 219

Poetic Homosociality: WILDE MOSSELS 226 
7 FROM LUDIC HUMOUR TO COSMIC IRONY 229

A Stilled Form of Catholic Slapstick: DE ILLUSIONIST and

DE WISSELWACHTER 230

A Buster Keaton Lookalike on and off the Set: OH BOY! 236

The Brother with a Movie Camera: zUSJE 240

Play with Ontological Levels: HET ECHTE LEVEN and Mockumentaries 242

Baudelaire's Ironic Doubling: RENT A FRIEND 246

A Metafictional Joke Played On a Serious Man: OBER 250

A Rom-com with Peter Pan: AANMODDERFAKKER 254

8 FROM INSUBORDINATE PLAYFULNESS TO SUBVERSIVE IRONY 261

Ludic Paranoia: DE MINDER GELUKKIGE TERUGKEER VAN JOSZEF KATÚS

NAAR HET LAND VAN REMBRANDT 262

A Tongue-in-Cheek Short: BODY AND SOUL 265

Anti-Bourgeois Satire: DE VERLOEDERING VAN DE SWIEPS 268

Buñuelian Desires: DE NOORDERLINGEN 270

Pervaded with Role-Playing: KLEINE TEUN and DE LAATSTE DAGEN VAN

EMMA BLANK 274

Middle-of-the-Road Absurdism: DE JURK and GRIMM 280

A Black Horror-Pastiche: BORGMAN 284

Deadpan Irony 288

9 FROM GROTESQUE CARICATURE TO GROTESQUE SATIRE 293

The Grotesque as a Concept 295

A Wannabe Tarantino Caper Movie: BLACK OUT 296

(Not) a Tarantino Dance Movie: NAAR DE KLOTE! 300

Comic Strip Meets Tarantino and Tarkovsky: DE WEDEROPSTANDING VAN

EEN KLOOTZAK 302

Irony of Fate: PLAN C 305

Metafilm as a Vengeful Satire: DE MANTEL DER LIEFDE 311

Fantastic Irony: DE VIERDE MAN 317

Almost Full Circle $\quad 324$

CONCLUSION 327

Notes 333

Bibliography 367

Filmography 377

Photo Credits 389

Index of Concepts 393

Index of Titles 397

Index of Names 405 



\section{PREFACE}

If the 'comedian is the anthropologist of our humdrum everyday lives,' as Simon Critchley remarks in his On Humour (66), then it would make sense to take this study on humour and irony in Dutch fiction film as an (oblique) 'mirror of Holland.' Let me say right here that I would not discourage readers to consider this study as a 'metaphoric barometer' of certain Dutch mentalities, but do not succumb to that temptation too easily. For humorous remarks and comic scenes can have 'local and historical' dimensions, indeed, but they can also be (relatively) 'universal and timeless' as well, and the boundaries are very difficult to draw. Moreover, any crystal clear claim would perhaps meet the obvious objection that humour is not just a cultural phenomenon, but also a matter of personal taste. Suppose that I were to argue that the people in the vicinity of Maaskantje are more likely to appreciate the crude jokes of the 'New Kids' from Maaskantje than people from Amsterdam, then of course anyone would be right to protest 'I am from Maaskantje myself, and I do not like them at all' or 'I am from Amsterdam, and I think them very funny.' Thus, if I had set myself the task of pinpointing to what extent humour and irony can be called 'typical' for a specific region or exemplary of a particular decade, I would have moved onto very shaky ground.

My main reason for taking up this project was more modest. First, as I will explain in the Introduction, the subject of Dutch fiction cinema has been blatantly underrepresented in the academy so far, and this neglect becomes all the more unfair with the increase in popularity of Dutch films at the box office in recent years. Second, it struck me that a healthy - unhealthy to others, perhaps - dose of humour and irony seems to be a key ingredient of the most noteworthy titles in the history of Dutch fiction cinema, from the phenomenal commercial successes of CISKE DE RAT and FANFARE in the 1950s to more recent winners of the Golden Calf for Best Film, such as the deadpan horror- 
pastiche BORGMAN and the happy slacker rom-com AANMODDERFAKKER. Combining these two facts, it felt as if the subject of this book was handed to me on a plate. Moreover, in response to academic tendencies since the mid1990 s that have convincingly proposed the methods of 'cultural analysis' over strict cultural-historical approaches, I decided to include what Mieke Bal has called 'rigorously, perhaps provocatively contemporary readings' of the films (129). I did not want to restrict myself to discuss film $\mathrm{X}$ as merely a product of a particular era, since I can neither know nor fully understand what it is to watch a film from the 1960 s with eyes of a 'hippie.' Viewing habits have changed considerably - and the films in chapter 5 clearly give proof of this and therefore I chose to favour a certain deliberate anachronism. Cinephiles with a preference for cult are much aware of this mechanism in the practice of their spectatorship: in retrospect, a once-derided picture does not seem that bad at all, and it thus deserves re-appreciation as a curious but wonderful case or as an underestimated forerunner of later developments. I am much more interested in detecting affinities between films on the basis of the forms of humour they share than in sticking to chronological accounts or in reconstructions of historical contexts, which both have been quite common in journalistic books on Dutch cinema. Hence, for me, films enter 'in dialogue' with one another, potentially travelling in a time machine: discovering common denominators between a film from 1967 and one from 2013 can make us see them both 'anew.'

The reader has to bear in mind that the language of these films is Dutch. That means that when I use quotation marks to indicate the words of a character, the quotation is not exact. The translation is either provided by me or it comes from the English-language subtitles from the DVD. In situations where characters use English terms, as they do occasionally, I have italicized the quotation or part of the statement.

It was impossible to navigate through all these films, including the many anecdotes that surround them, without the help of many others who were often all too happy to converse about their experience with Dutch cinema, either as makers and/or consumers. My gratitude in particular goes to my two proofreaders, Ernst van Alphen, professor of Literary Studies in Leiden, and Hans Beerekamp, a journalist at NRC Handelsblad, writing on film since 1977. Though his main subject has become television from 2003 onwards, Beerekamp continues to exercise his keen expertise on cinema for the website schimmenrijk.nl, dedicated to obituaries of film actors, directors, producers, cinematographers and composers. I am much obliged to filmmaker Dave Schram, who filled many gaps in my collection of Dutch films by offering me a number of missing titles. I would also like to thank Het Nederlands Filmfonds [The Netherlands Film Fund] for their generous subsidy and I am grateful that 
the board members of the NSC [Netherlands Society of Cinematographers] were kind enough to support this project, both mentally and financially.

While writing this book, my father, Theo Verstraten, passed away, and it is to his memory that I dedicate this study. In January 2014 I made a trip with him and my mother to London to visit their then newly born grandchildren, the twins Hero and River Ejiofor. And, of course, many thanks to two of their other grandchildren who happen to be my very own daughters, Febe and Bodil, cinephiles-to-be. You know how to brighten up my life, just as my sevgilim Fatma does. 


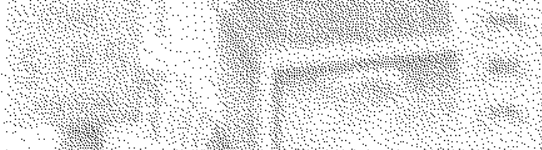

sex

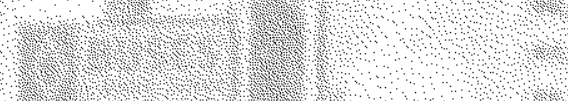

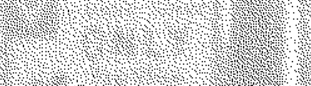

rescis

Lan

$x=$

$-\frac{1}{20}$

४े

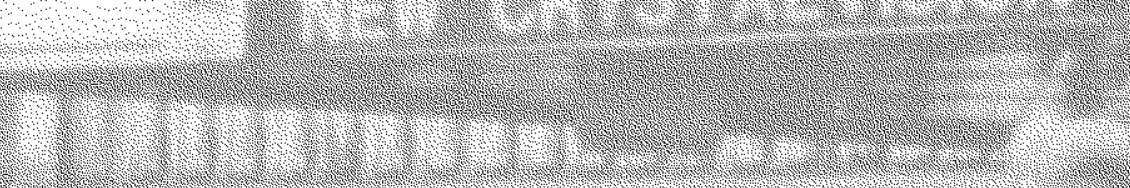

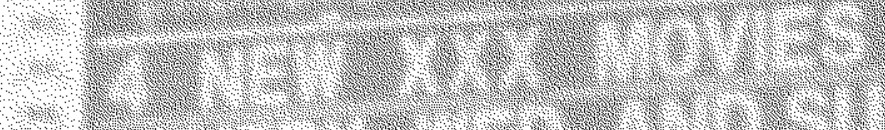

l.

-

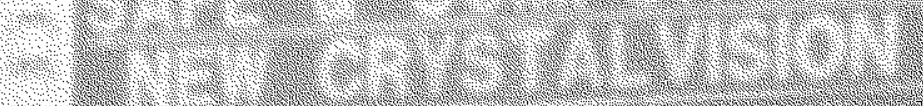

30

3.t.
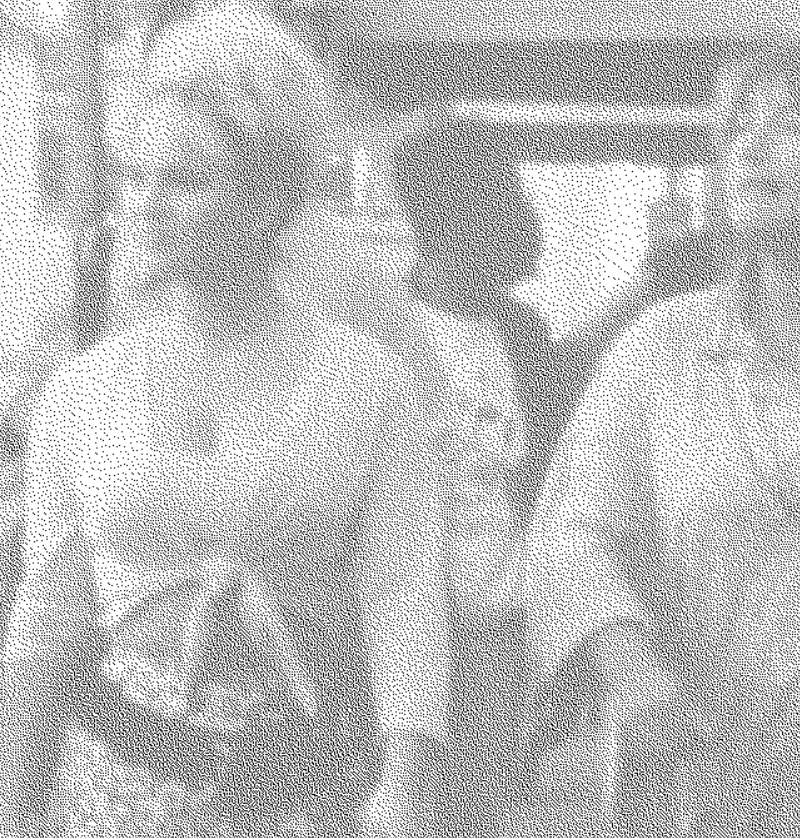

(2)

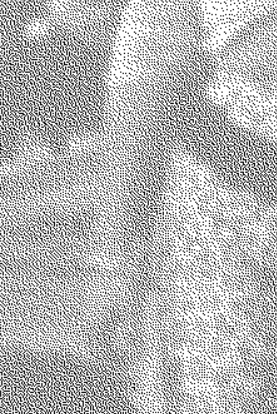

1.t) 


\section{Introduction}

Apart from the art-house cinema Het Ketelhuis, the self-declared 'canteen of

Dutch film' founded in 1999, Dutch film is only consistently celebrated during the ten days of the annual Netherlands Film Festival (NFF), which started as the Netherlands Film Days in 1981. In the 2007 festival, a jury chaired by Jeltje van Nieuwenhoven presented the Canon of Dutch Cinema (Canon van de Nederlandse Film) in order to stimulate an interest in national productions. The jury decided to restrict the list to only 16 titles, covering a huge diversity of types and genres: shorts, documentaries, black \& white, silent films, boxoffice hits, comedy, animation, experimental films, film festival successes and youth cinema. On the one hand, the canon bows to popular entertainment - the 'low-class' humour of FLODdER (Dick Maas, 1986) and the 'parochial' comedy FANFARE (Bert Haanstra, 1958) being the most obvious examples. On the other hand, the canon includes ('serious') artistic cinema - with the experimental shorts IK KOM WAT LATER NAAR MADRA [THAT WAY TO MADRA] (Adriaan Ditvoorst, 1965) and LIVING (Frans Zwartjes, 1971) at the other end of the spectrum of commercial endeavours. Except for some critical remarks about a few missing titles - such as Paul Verhoeven's SOldaAt VAN ORANJE [SOldiER OF ORANGE] (1977), George Sluizer's SPOORLOOS [THE VANISHING] (1988) or Mike van Diem's KaraKTER [CHARACTER] (1997) - the Canon of Dutch Cinema has met remarkably little controversy. ${ }^{1}$

In addition to congratulating the jury on its balanced selection, the absence of a heated debate about the canon can be taken as a sign that both critics and the general public are no longer as adverse to Dutch cinema as in previous decades. There has always been ample admiration for a strong documentary tradition in the Netherlands (by, among others, Joris Ivens, Herman van der Horst, Johan van der Keuken, Heddy Honigmann). ${ }^{2}$ There has also always been sympathy for the so-called 'family films,' aimed at a young audi- 
ence and their parents. This genre of the family films, pioneered at first by Henk van der Linden and then by Karst van der Meulen, ${ }^{3}$ has gradually grown into full-blown maturity since Ben Sombogaart's MIJN VADER WOONT IN RIO [My FATHER Lives in Rio] (1989) and Het ZAKMES [The POCKET-KNIFE] (1992), with Minoes [Miss Minoes] (Vincent Bal, 2001), Het PAARD VAN SINTERKLAAS [WINKY'S HORSE] (Mischa Kamp, 2005), KAUWBOY (Boudewijn Koole, 2012), and the adaptations of Carry Slee novels, produced by Shooting Star Filmcompany. ${ }^{4}$ The Dutch (narrative) fiction feature, however, has in general met less enthusiasm, and if a canonical list had been presented in the mid-1990s, the overall reaction would probably have been one of considerable derision. In that period, Dutch cinema was so strikingly unpopular that the idea of a canon alone would have been greeted with jeers and might have provoked a contemptuous remark like: Is the idea of publishing a selected number of titles a means to cover up for the lack of quality of the non-selected 14 films?

Even though the attitude towards Dutch cinema has become much more positive over the years, in critical reception as well as at the box office, the persistent prejudices have not died out, as websites with a film forum, like moviemeter.nl, testify to. Among the responses to Dutch narrative fiction films, which not always exceed the level of a gut feeling, there are two recurring ones. The first one can be paraphrased like this: 'Dutch cinema consists of a too frank display of nudity and sex, which it tries to legitimize as a functional display.' The portrayal of sex in the notable box-office successes of BLUE Movie (Wim Verstappen, 1971) and TURKS FRUIT [TURKISH DELIGHT] (Paul Verhoeven, 1973), deeply ingrained in collective memory, led to a series of subsequent pictures over the years which also played this card, betting on it that the pair of 'nudity and sex' offers a road to fame. Every attempt to make a film that even remotely resembles TURKS FRUIT - from KORT AMERIKAANS (Guido Pieters, 1979) to Brandende Liefde [Burning Love] (Ate de Jong, 1983), and from De Gulle MiNNAAR [The Generous Lover] (Mady Saks, 1990) to ZOMERHITTE [SUMMER HEAT] (Monique van de Ven, 2008) - only worsened the reputation of Dutch cinema and reinforced the prejudice that nudity and sex are part and parcel of it, regardless of the many films which do without this combination. ${ }^{5}$ The second one goes like this: 'In principle, I am not a fan of Dutch films, but I would like to make an exception for this one.' Apparently, a good or decent Dutch picture is considered to be a deviation from the general rule that the quality is below average.

This study is not meant to correct the eventual unjustness of these prejudices, for that would be Sisyphean labour. For every great Dutch picture, critics can easily respond with a number of failures. For every international success - like Academy Awards for 'Best Foreign Language Film' for DE AANSLAG [THE 
ASSAUlT] (Fons Rademakers, 1986), ANTONIA [ANTONIA'S LINE] (Marleen Gorris, 1995), and KARAKTER - sceptics might cite the embarrassing statistics that BORGMAN (Alex van Warmerdam, 2013) was the first Dutch film to be selected for the main competition in Cannes in 38 years. Instead of combating prejudices, I intend to address the fact that there is no proper educational forum to debate Dutch cinema. Hence, Humour and Irony in Dutch Post-war Fiction Film has to be considered as only a 'modest proposal' to address the almost total neglect of Dutch cinema in the academy.

\section{OVERVIEW OF STUDIES ON DUTCH CINEMA}

In order to illustrate that Dutch cinema lacks a proper institutionalization, let me sketch the programmes of the various departments of Language and Culture at Leiden University. In Japanese studies some attention is devoted to Japanese cinema; in Chinese studies the same for Chinese cinema, and this list can easily be extended: Korean cinema, Turkish cinema, Iranian cinema, Brazilian cinema are all covered in Leiden - not very comprehensively, but nonetheless. Even though the films are not much valued for their specific cinematic potential, but as a means to deepen students' understanding of the culture in which they have been produced, the attention to cinema in foreign language departments is more consistent than in Dutch studies, although there are signs that this might change for the better in the near future.

It is perhaps a matter of looking at tea leaves, but a (Western) scholar with an interest in Japanese, Chinese or Iranian culture is like an 'omnivore': fascinated by any peculiarity of that faraway country - not only literature and films but also popular songs, sports, food, up to the Japanese obsession with manga comics and Hello Kitty. ${ }^{6}$ These preferences are not strictly hierarchically marked in advance. By contrast, a Dutch scholar studying his own culture behaves like someone with refined taste, steeped in a tradition in which one is educated to distinguish high from low culture. Due to a conventional bias favouring literature over film - let alone, comic strips or popular (dance) music - scholars in Dutch studies have, at least until recently, a blind spot for (the national) cinema.

If Dutch cinema is addressed at universities, it usually takes place in an incidental course under the umbrella of literature, like 'Novel and Film.' The policy which underlies such a course seems obvious: Dutch film can only be made to fit the curriculum on the condition that it is associated with the more venerable belles-lettres. And even if such a course were to give film (adaptations) pride of place over novels, it risks affording film the role of sidekick to literature, the more since the status of the written-source texts predominantly 
determines the selection of films. This aside, however, is not meant to strike a sour tone, because a course like 'Novel and Film' at least offers a way for Dutch film to position itself in the academy.

Given the fact that there is no substantial interest in Dutch cinema at universities, it is no wonder that the output of studies on Dutch cinema has been quite meagre over the years. The most profound academic publications are not dedicated to the post-war feature films, but to film culture preceding 1940, like the introduction of sound in Dutch cinema (Karel Dibbets); a study called Hollywood in Holland on 'Filmfactory' Hollandia which produced 60 films in between 1912 and 1923, the year of its bankruptcy (Ruud Bishoff); a study on the Nederlandsche Filmliga (Céline Linssen, Hans Schoots, Tom Gunning); a dissertation inspired by the collection of Jean Desmet (Ivo Blom), which was also the basis for an exhibition in EYE and an accompanying volume (Rommy Albers and Soeluh van den Berg); reactions to film as a new medium in the Netherlands in the period 1895-1940 (Ansje van Beusekom), and a study on the role of German emigrants on the Dutch film industry in the 1930s (Kathinka Dittrich). And of course, the internationally oriented Joris Ivens - whose work spans several decades, from the short DE WIGWAM [THE WigWAM] (1911) to UNE HISTOIRE DE VENT [A TALE OF THE WIND] (1988) - has attracted some bookish attention (Kees Bakker on the documentary context, André Stufkens on Ivens' connection to art, Hans Schoots' biography, Living Dangerously). Dorothee Verdaasdonk wrote a dissertation on Dutch cinema, covering the years from 1960 to 1983 , but her approach was sociological rather than textual-analytic. In Beroep: FilmMaKer [Profession: FilmMAKeR] (1990), she examined under what socio-economic conditions Dutch filmmakers could practice their profession: what financial resources were available; what was the role of the Dutch Vocational School for Film and Television; does the family background of the director have an influence? Another sociological perspective was adopted by Bart Hofstede who examined the influence of the government and of film organizations like the Bioscoopbond as well as the growing impact of critics upon Dutch film production in the post-war period. Notwithstanding these studies, when the narrative fiction film in the last five decades has been addressed, it was much more common to adopt a journalistic perspective than an academic one: Rob van Scheers on Paul Verhoeven, Mieke Bernink on Fons Rademakers, Joost Ramaer on Alex van Warmerdam, Hans Heesen on George Sluizer, Ruud den Drijver on Wim Verstappen, Hans Schoots on Bert Haanstra, although the latter was a biography, published in the form of a dissertation. ${ }^{7}$ Moreover, a number of websites focuses on Dutch cinema, of which Neerlands Filmdoek (http://www.nlfilmdoek.nl/) and the Nederlandse Film Database by René van Dam (http://www.filmtotaal.nl/ nederlandse_film) are the most noteworthy. 
Further, in his Hollands Hollywood (1995), freelance journalist of NRC Handelsblad Henk van Gelder gave a solid overview of 60 years of Dutch feature films, starting with Willem VAN ORANJE (G.J. Teunissen, 1934) and ending with 06 (Theo van Gogh, 1994). It catalogued 337 films with brief descriptions, (amusing) anecdotes and an impression of their reception; only 27 of the films were considered so relevant that they got more than one page. Van Gelder does not resist the temptation to cite the lines from particularly damning reviews, which, it must be said, can offer amusing reading. In defence of the slightly sarcastic perspective of Van Gelder, who originally had in mind to use for a motto Wim T. Schippers' hilarious phrase, 'A Dutch film is no guarantee of an empty auditorium,' I would like to point at the year he wrote his book: 1994 is about the worst year for Dutch cinema in the post-war era. As the last line of Van Gelder's study mentions: That very year, no more than 126,000 tickets, which is less than 1 per cent of the total number of tickets, were sold for films made in the Netherlands (372). This statistic turns the title Hollands Hollywood into an ironic pun: while Hollywood is known for its commercial policy, the adjective 'Hollands' is rather associated with box-office poison.

In 1995, Robert Jan Westdijk's low-budget ZusJe [LITTLE SisTER] was hailed as an innovative debut feature, which marked the beginning of a recovery from the annus horribilis 1994. This film is the starting point for a survey of Dutch cinema between 1995 and 2005 in the book De broertjes van Zusje [The Little Brothers of Little Sister], edited by film critics Mariska Graveland, Fritz de Jong and Paul Kempers. The tone is one of moderate optimism, justified by some critical successes - De Poolse Bruid [The Polish BRIDE] (Karim Traïdia, 1998), WiLdE MOSSEls [Wild Mussels] (Erik de Bruyn, 2000), VAN GoD LOS [GoDFORSAKEN!] (Pieter Kuijpers, 2003) and SIMON (Eddy Terstall, 2004) - which outweigh the failures and for the fact that the numbers of viewers for Dutch cinema have risen, from the 1 per cent in 1994 to 13.6 per cent in 2005. Since then, the situation has further signs of improvement. In the year 2013, for instance, the share was 20.5 per cent, and 21 Dutch films attracted more than 100,000 moviegoers.

In addition to the books mentioned above, three studies, all from the year 2004, deserve special mention as particularly penetrating contributions. The first one is Schoots' enjoyable study VAn FANFARE tot SPETTERS, which took a cultural-historical approach. Sketching the cinema between the years 1958 and 1980 Schoots relates the predominantly provocative themes in a number of movies to the revolutionary atmosphere in this period. Hence, he considers national cinema as an expression of contemporary issues within society. Do the films under analysis succeed in capturing the so-called zeitgeist and can the white screen function as a 'mirror of Holland' ${ }^{8}$ This cultural-historical perspective offers an insight into a possible relation between art and society, 
but the drawback of this approach is the tendency to analyze the films insofar as they can illuminate their (social) context. Hence, the films are not primarily debated for their intrinsic value, but they are rather used as a kind of reflection of the context as its original model. The Cinema of the Low Countries, edited by Ernest Mathijs, presents itself as a volume that seeks a balance between contextual readings and textual analysis. The 24 articles of about ten pages each put a particular film central stage. Half of the contributions are devoted to Dutch films, and in addition to the 'usual suspects' like TURKS FRUIT and SoldaAt van ORANJe, films like Komedie om Geld [The Trouble With Money] (Max Ophüls, 1936) and TweE Vrouwen [TwiCE A WoMAN] (George Sluizer, 1979) were included in the selection. The volume is significant, since it attempts to fill such a yawning gap that one is willing to accept the 'glaring omissions' of which Mathijs himself is so well aware (2).

A study which is at the same time very ambitious in its effort at comple18 tion and strikingly unpretentious in its deliberate choice for a totally random structure, is Film in Nederland, compiled by a number of researchers affiliated with the former Filmmuseum, now called EYE. It contains in alphabetical order brief descriptions, anecdotes and some thematic similarities regarding 200 Dutch films. The sheer breadth of subjects covered is necessarily at the cost of in-depth analyses. Due to its wide range, Film in Nederland reads like a database, but one of the advantages of this book is to see how flexible the term 'Dutch cinema' is interpreted by the editors. They endorse elastic criteria for the obvious problem of deciding when a film is to be considered as 'Dutch.' CISKE DE RAT (1955) was directed by the German Wolfgang Staudte and some of the crew members were German as well, but the film counts as Dutch, if only for the Dutch actors, the Dutch producer, the Dutch locations, and the Dutch novel it was based upon. Another entry is more or less the opposite, since MASSACRE AT CENTRAL High (1976) is shot in California with an American cast and crew, except for camera man Bert van Munster and director René Daalder. Prospero's Books (Peter Greenaway, 1991) is included as a Dutch film because this international co-production had set designers Jan Roelfs and Ben van Os on board, was produced by Kees Kasander and Denis Wigman, and had some Dutch actors in minor parts. Hence, the editors of Film in Nederland used flexible guidance for selection as entries, which is comparable to the criteria the Netherlands Film Festival has set for its competition. In 1989 the Golden Calf for Best Film at the festival was awarded to the Spanishlanguage film BOdA SECRETA [SECRET WEDDing] by the Argentinian-born Alejandro Agresti, because of the nationality of its producers, Kasander and Wigman. The Dutch-Palestinian Hany Abu-Assad won the same main prize in 2005 for PARADISE Now, but it could not be the Dutch submission to the Academy Award for Best Foreign Language Film, because in that case the rules 
are stricter. Since the film is in Arabic, it could only be submitted on behalf of Palestine. And what about the career of the cosmopolitan director George Sluizer, who made his stunning debut feature JOÃO EN HET MES [JOÃO AND THE KNIFE] (1972) in Brazil and LA BALSA DE PIEDRA [THE STONE RAFT] (2002) in Portugal and Spain; UTz (1992) was shot in the Czech Republic with Armin Mueller-Stahl, THE VANishing (1993) was the American remake of his aforementioned SPOORLOOS, THE COMMISSIONER (1998) was set in Brussels, and just before his death he finally finished DARK BLOOD (2012), starring the late River Phoenix who had passed away in 1993 during shooting. These are just a few examples of many borderline cases, which illustrate how problematic it is to think in terms of absolute and strict national demarcations. Since the practice of international co-productions is becoming more customary than ever, this is all the more reason to see Dutch film along a continuum. ${ }^{9}$

\section{LIKE SHARING A SECRET CODE}

A main rationale behind this study is to countervail the underrepresentation of Dutch narrative cinema in the academic world, but one has to prevent oneself from 'drowning by numbers.' It would be overambitious to cover the whole domain from (action) comedy to avant-garde cinema. Writing a study on national cinema always risks being an arbitrary endeavour. The concept of national cinema erroneously suggests that the country of origin of the filmmaker, cast and/or crew is a more predominant factor for a useful taxonomy than economic, industrial, artistic and/or generic ones. It is easier to mention the differences in subject matter, film style, target audience and so on, of the films of Paul Verhoeven, Nouchka van Brakel, Dick Maas, Nanouk Leopold, Mijke de Jong and Alex van Warmerdam than to sum up what unites them. Maas has perhaps more in common with the Farrelly brothers who made THERE'S SOMETHING ABOUT MARY (1998) than with any of the other mentioned here; Leopold with French director Bruno Dumont; De Jong with the Belgian Dardenne brothers; Van Warmerdam with the Finnish Aki Kaurismäki.

Even though 'national cinema' may not be the best criterion for analysis, in common parlance it is still a vibrant concept. Each and every national cinema is haunted by the question: Which films are characteristic of the country at hand $?^{10}$ From an academic perspective, it is a daring, almost impertinent, question, because any hint at a clear-cut answer always already sounds too definitive. By contrast, from a journalistic perspective, it seems the most obvious of questions to ask whether there is such a thing as a typically Dutch film. Three global positions to this question can be derived from the first epi- 
sode of the documentary series consisting of nine parts, ALLEMAAL FILM: DE NEDERLANDSE FILM VAN 1945 TOT NU TOE [IT'S ALL FILM: DUTCH FILM SINCE 1945]. ${ }^{11}$ First, Frans Weisz replies with a rhetorical question: Does the label of Dutch cinema not denote limitations as if a filmmaker has to be caught in a straitjacket? It is not surprising that the label is not productive for Weisz, since he has always adored Italian cinema, which is most evident from his grandiose film Het gangstermeisje [A GAngstergirl] (1966). Second, as Paul Verhoeven states, the fact that he himself is rooted in Dutch culture shows unmistakably in his pictures, but at the same time he also has a preference for American cinema, to which he adds that SOLDAAT VAN ORANJE is very American in its framing and in its editing. This is implicitly proven by the rumour that Steven Spielberg was very enthusiastic about this picture.

So, if the concept of Dutch cinema is restrictive according to Weisz and if, as Verhoeven claims, Dutch influences are only one among many others, then only the third position, hesitantly mentioned by Alex van Warmerdam, presumes that there indeed may reside something 'typically Dutch' in films. In order to articulate a 'Dutch' accent, Van Warmerdam tentatively points at a distinction with his own canonical film DE NOORDERLINGEN [THE NORTHERNERS] (1992) and the work of Federico Fellini. Whereas Fellini's cinema is marked by a certain Catholicism in an exuberant and baroque way, the Christianity of DE NOORDERLINGEN is rather Calvinist, meaning very sober and puritan. This does not only show itself in the plot of the film about a woman who is worshipped as a saint, but also in the mise-en-scène of the film: the square windows look straight on to the pavement and the scenery is framed and delineated, as if to emphasize a suffocating atmosphere. As a consequence, Van Warmerdam says, his film is miserly, the opposite of baroque, and 'may be that is what is so Dutch about it.'

Although Van Warmerdam describes his film as steeped in a puritan Christian tradition, DE NOORDERLINGEN is at the same time in polar opposite to Calvinism. It is a characteristic of Calvinism to distrust visual culture, because in the eyes of Calvinists images can never be reduced to only a single meaning. Whereas the deadly serious Calvinists adhere to a strong textual unilaterality (' $\mathrm{X}$ means this and nothing else'), the wilfully visual minimalism of Van Warmerdam's cinema lends itself to ambiguity. ${ }^{12}$ This deadpan kind of cinema excels in consistently portraying introvert and often even taciturn male loners whom we never can truly fathom. Journalist Hans Beerekamp coined the term 'Hollandse School' [Dutch School] to characterize the many enigmatic outsiders in films from the 1980s, made by not only Van Warmerdam, but also Jos Stelling, Orlow Seunke, Danniel Danniel, and Joost Ranzijn. The work of the first three will be discussed at length in later chapters, so let me at this stage just refer to Ranzijn's 45-minute MAN IN DE WAR [MAN IN 
TROUBLE] (1984) for a thumbnail sketch of its chief characteristics. Though it is a little known and underrated film, it can function as an exemplary case.

Its main protagonist is a guy who has difficulty expressing his emotions: the shy Henk works as a gardener in a public park and has to make sure the visitors leave in time. Its plot is fairly absurd: One day Henk is on the tram when a woman hands him a bag to hold for her while she buys a ticket. She does not return, and before long the sound of a crying baby can be heard coming from the bag. He goes to visit his parents, but while his mother wants to take care of the baby, his father is fiercely against it. In subsequent scenes, we see how Henk tries to get rid of his unexpected asset, but to no avail. ${ }^{13}$ Father tells child protection about his son's situation and the baby is taken away from him by a policeman. Then, there is the twist: he starts stealing babies, not just one, but very many, often aided by his friend who is a boxer. We can only guess that he does so for the joy of raising them, together with his mother who by now has divorced her husband. ${ }^{14}$ The humour is basically deadpan and slightly morbid. In the beginning of MAN IN DE WAR, preceding the tram scene, Henk is getting married. During the taking of the wedding picture, the photographer busily arranges the guests for the photograph. At the very moment when the chaos has been transformed into calm and the photo can be taken, the bride collapses and eventually dies. Moreover, the film works with ironic parallels. One of Henk's attempts to get rid of the baby is to put the boy next to another kid in an unguarded pram on the pavement, but a bunch of women starts chasing him as an irresponsible 'father' - an irresponsibility which seems further proven when he takes the baby to a boxing match. In a later scene Henk takes a baby from another unguarded pram, and once again people start chasing him, this time as a vile kidnapper.

Some of the chases recall the tradition of early slapstick movies from the silent era, when a sparse use of editing was common. At one point, a very highangle shot of a crossroad shows that Henk is indecisive about which direction to go: first to the left, oh no to the right, oh no to the left. A bit later we see the crowd chasing him as indecisive as he was, leading to a chaotic bumping into each other. Then we get an extreme long shot of the front of a gallery apartments: Henk is running to the right on the gallery at the second floor, while the crowd is running to the right on the ground floor, and via jump-cuts, this pattern repeats itself a few times. At one point, we see Henk hiding behind a pillar, while everyone of his chasers is frenetically passing behind him, suggesting that a crowd often functions like a blind horde. If spoken text is used in films of the 'Hollandse School,' it usually accentuates the insignificance of language. To track down the kidnapper, the local police force is called upon, when all of a sudden the policeman who had taken the baby from Henk at the time remembers that his last name was related to something with a tree. He 
starts mentioning a huge variety of tree types until he finally arrives at 'birch' and reminiscences correctly 'Berkhout,' literally meaning 'birch-wood.' The importance of language in Ranzijn's film is further trivialized via a montage sequence of frontally staged shots of mothers who behave like the scream queens from horror films upon discovering their baby is gone. And at the end of the film, when the police have recovered only some of the children, all the talk at the station becomes a chaotic buzz because parents whose kid has not been returned just grab a baby girl as if it is their own. This noise contrasts greatly with the final shot of the movie: Henk has been able to take a great number of children to a boat, which peacefully sails on the water, against a beautiful, but artificially created, sunrise, suggesting that the introvert abductor proves himself a better father after all than all those biological parents who mainly produce a cacophony.

In seeking to understanding what identifies Dutch cinema or a 'Hollandse 22 School,' how these films use humour and irony might be the key. Oh yes, humour is 'universal,' in the sense that, as Simon Critchley observes, there is 'no society thus far discovered that did not have humour' (28). And yes, there are jokes or comic scenes which are appreciated by practically everyone. Who does not like the short film comedy THE Music-Box (James Parrott, 1932), in which Laurel and Hardy have to deliver a piano? The scene in which Charlie Chaplin as a factory worker is being fed by the eating machine in MODERN Times (Charles Chaplin, 1936) is still considered incredibly funny, by young and old. Despite these wonderful examples, it is fairly common to believe that humour, much more so than adventure stories or drama, is culture-bound. This assumption is confirmed in the idea that 'British humour,' rooted in hearty insults and self-depreciation (Bloxham), is of an entirely different nature than, let us say, 'German humour.' In making a claim for the locality of humour, Critchley argues that having a common sense of humour is 'like sharing a secret code' (68). Laughing at the same types of comedy creates a bond among people, strengthening the impression that one is culturally distinct from, not to say superior to those who remain silent, or worse, who do not get 'it.' And to make matters slightly more complicated: some variants of national humour are widely appreciated, like 'British humour' or 'Jewish humour,', but some variants fall absolutely flat when 'exported' to another country. To the question 'What is the smallest book in the world?' the answer, according to a Dutch joke is: 'One Hundred Years of German Humour,' which expresses how huge a gap the Dutch believe there is between the German and the Dutch sense of humour.

The nomination of KARAKTER as the Dutch candidate for the Academy Award for Best Foreign Language Film may count as a fine example of the hypothesis that humour is culture-bound, and therefore difficult to 'export' 
to other countries. Six members of a jury voted in October 1997 for Jean van de Velde's ALL STARS and only five for KARAKTER. Rolf Koot, producer of ALL STARs, turned down the honour, because he claimed that his comic film about the male camaraderie in a football team was well-attended in the Netherlands, but lacked any international appeal. By contrast, the serious coming-of-age drama KARAKTER would probably cater to both a Dutch and an American audience, as was confirmed by Laurens Geels, producer of Van Diem's film (and Koot's father-in-law): American actor William Hurt had already seen the film twice, Geels said, 'leaving the theatre in tears. ${ }^{.16}$ The rest is history, for KARAKTER won the Academy Award for Best Foreign Language Film.

The suggestion underlying Koot's position is that the humour of ALL STARS was too local to be appreciated by an American public. Despite this emphasis on the cultural dimension of humour, one should not commit the fallacy of identifying humour too closely with nationalities. The thesis that humour is culture-bound may as such meet little resistance, but any attempt to delineate the contours of Dutch, British, Italian, etc., comedy is impractical. If the films by Van Warmerdam are perhaps 'typically Dutch' because of their humour/ irony, then one should not forget that his DE NOORDERLINGEN turned out to be remarkably successful in France in the 1990s and was even re-released in French theatres in 2012. Moreover, his cinema seems to have affinities with Scandinavian films, like the ones by the Swedish Roy Andersson, the Norwegian Bent Hamer and, as already mentioned above, the Finnish Kaurismäki. Even more striking is the fact that the dryly comic DE WISSELWACHTER [THE PoIntsman] (Jos Stelling, 1986) turned out to be much more successful in Rome than in Amsterdam. ${ }^{17}$

Humour is marked by a cultural dimension, but simultaneously always in excess of it. The same goes for the historicity of comedy. People may still laugh at the comedies of Preston Sturges or Billy Wilder (at least I do), or at the Dutch cabaret performer Toon Hermans, but much humour does not stand the test of time and people today will shrug at many comic sketches which made people laugh their brains out in earlier decades. Humour can become 'curiously outdated' for one and the same person: what one considered funny in the 1980s, might come across as stale these days.

So, when this study ventures in the subject of humour and irony in Dutch feature cinema, it is with the proviso that its local flavour, its Dutchness, cannot be described and pinpointed in exact terms, but only circumscribed at most. What in the end proved decisive for examining the humorous potential of Dutch post-war feature films, was the quite banal factor of box-office appeal. Take a cursory glance at the list of box-office hits in Dutch cinema and be amazed at the relatively high number of downright comic films. Of the 25 titles that have attracted more than a million viewers, one can men- 
tion FANFARE (Bert Haanstra, 1958), WAT ZIEN IK!? [BUSINESS Is BUSINESS] (Paul Verhoeven, 1971), HelP! De DOKTER VERzuipt [HelP! THE Doctor Is DrownING] (Nikolai van der Heyde, 1974), FLODDER (Dick Maas, 1986) and its sequel FlODDER IN AMERIKA! [FlODDER DOES MANHATTAN!] (1992), FilMPJE! [VERY SHORT Film] (Paul Ruven, 1995), Alles IS LIEFde [All Is LOVE] (Joram Lürsen, 2007), NEw KIDS Turbo (Steffen Haars and Flip van der Kuil, 2010), and GOOISCHE VROUWEN [VIPER'S NEST] (Will Koopman, 2011) as well as its sequel Gooische VRouWen 2 (Will Koopman, 2014), and this list is not yet exhaustive. One might say of several other titles that they either have humorous tones - like TURKS FRUIT and the two versions of CISKE DE RAT [CISKE THE RAT] (Wolfgang Staudte, 1955/Guido Pieters, 1984) - or they can be retrospectively read from an ironic perspective, like BLUE MOVIE (Wim Verstappen, 1971) and SPETTERs (Paul Verhoeven, 1980). Apparently, Dutch films strike a chord among the general public in case they contain some dose of humour 24 and irony. Moreover, several films with comic elements which did not sell that many tickets as the titles mentioned above, have received a favourable reception, like the work by Alex van Warmerdam, some titles by Eddy Terstall, Pieter Kramer or Paula van der Oest. ${ }^{18}$ It is highly significant that DENNIS P. (Pieter Kuijpers, 2007), based upon a true crime, does not take the form of a gangster picture or an art-house drama. Instead, this film about a big diamond heist by an employee of a trading company, is made as a comedy with cartoonish effects. Hence, an emphasis is put upon the representation of the thief as a merry simpleton, who naively thinks that he can buy the striptease girl's affection with money. The gaudy colours of his clothes further accentuate that he is a pathetic and bulky oddball. Moreover, it is perhaps no coincidence that a film like Het Diner [The Dinner] (Menno Meyjes, 2013), which in essence is a serious drama about high-class parents whose children have committed a horrible crime, is littered with many funny one-liners, often uttered by protagonist Paul. 'Only Roger Federer rakes his fingers through his hair more than Serge,' he comments upon his brother's vanity. Or he remarks about a man standing next to him in the lavatory: 'It's the kind of stream that is full of its own importance. A stream that wants to testify to its own indestructible health. The stream of a man with a young wife.' His comically sarcastic reflections in voice-over arrest the progress of the actual story, and thus edgy humour is the film's special attraction, outbalancing its serious theme.

The sheer fact that so many Dutch films contain a fair amount of humour is perhaps culturally ingrained. This fact might be taken as a cheeky homage to one of the best-known Dutch achievements in the academic world, the publication of Johan Huizinga's Homo Ludens (1938), a study which garnered international fame. The implication of his study that the fun of playing can function as a welcome antidote to a predominance of seriousness seems to 
be taken to heart by a relatively great number of Dutch filmmakers. ${ }^{19}$ Against this background it makes sense to read Dutch cinema through the conceptual lens of humour and irony. Whereas the reference to Huizinga bears historical weight, the publication of this study also has an initially unforeseen actual value: the killing of the cartoonists of the Paris-based satirical magazine Charlie Hebdo in January 2015 , has particularly highlighted the issue of freedom of speech, which has been - due to the tragic occasion - converted into proclaiming the freedom to make transgressive humour.

\section{THREE THEORIES OF HUMOUR: FLODDER IN AMERIKA!}

In FLODDER IN AMERIKA! (Dick Maas, 1992), the successful sequel to Maas' immensely popular FLODDER (1986), two representatives of America discuss with the mayor of the 'blossoming city' Zonnedael the conditions for a programme of cultural exchange between America and the Netherlands - one 'average family' from the US for an 'average family' from Holland. Thereupon, two American delegates proudly present that they have selected a 'well-educated, cultured and attractive' family that will come to visit Holland in order to explore the Dutch lifestyle. The Johnsons have been voted 'family of the year': the father is a prominent lawyer, the mother sells real estate and the oldest son is a stockbroker on Wall Street. It is rumoured that the family is already preparing for the trip by clumping around in wooden shoes. The two representatives are anxious to hear which Dutch family, in turn, will be travelling to America, for they have high expectations of the initiative. As the American male says, after it has been explained that this is supposed to be the beginning of a long-lasting series: 'If the programme is successful, one day we might be living' in a world of peace,' to which the American female adds 'and love,' whereupon the man completes the reference to the Nick Lowe/Elvis Costello song: '... and understanding. ${ }^{20}$

When the mayor asks about whether the stay abroad is 'only for one year,' the response is that if things go well, the families may possibly remain longer. Medium close-up of the mayor who says, with a sparkle of hope in his voice: 'May be forever.' When the mayor then hears from his guests that America is a big, beautiful country one might easily get lost in, we are given a medium close-up again of the mayor, repeating the words: 'Get lost.' He folds his hands and as the camera then shows the Americans in two-shot, he says: 'Well, I think we have the perfect family for you.'

At this point there is a cut from the mayor's office to a wealthy bungalow with conifers and a green lawn, but from below the frame the head of a woman with unkempt hair suddenly pops up. This woman will be plainly called ' $\mathrm{Ma}$ ' 
Flodder. This Ma, which is shorthand for Mama or Mother, a first name is never given, yells at her children - 'bunch of assholes' ['stelletje klerelijers'] - and puts a big cigar between her lips. While she starts to walk to the left of the frame, the camera tracks to a high-angle establishing shot, revealing that the bungalow does not belong to her, but that her own residence has become a total ruin. In one of the subsequent shots we see the neighbours spying on the Flodder family through the curtains of the expensive bungalow. The woman is glad they will be delivered from that 'riff-raff' ['schorriemorrie'] who has been a 'disgrace' to the neighbourhood, for, as she says, the Flodders terrorized them, were walking around naked, and the mother even ate dog food. The camera goes back outside again, and one of the Flodder children carries a heavy suitcase which bursts open. As a result, a great number of whisky bottles break, prompting the anger of Ma, who tries to smack the kid, but in vain. She then also attempts to kick the dog, because of its single bark, but when the animal bites her in the leg, she hits it on the head with a bottle.

Immediately thereafter there is a cut back to the mayor's office, who recommends the family Flodder. The Americans consider it a peculiar name, because it sounds like 'fodder,' but the mayor reassures them that it is a 'typically Dutch name.' When he later takes a photograph of the Flodders from their file, the Americans react by saying that they 'sure are ... different,' and their clothes look so 'ragged and dirty.' The mayor tells them that the photo shows the Flodders dressed for a costume party and that they were the highlight of the evening. When the American woman notes that the Flodders lack a father, the mayor closes the case by stating: 'Well, nobody's perfect.'

Anyone who has seen (or only read my account of) the scene above, which is derived from the first 6 minutes and 20 seconds of FLODDER IN AMERIKA!, will acknowledge that this film is a comedy (in terms of genre) in that it attempts to produce humour (as an effect). In plain terms, humour is, as the Oxford English Dictionary defines it, the 'quality of being amusing or comic.' Comedy can be defined as the dramatic genre characterized by a humorous tone. At the heart of much comedy, as critics like Mikhail Bakhtin, in his study on carnival laughter, and French philosopher Henri Bergson have taught us, is a (visual) awkwardness with one's body, in its many possible manifestations: from the scatological 'humour' of farting to slipping over a banana peel or to the performance of 'silly walks' (to recall a famous sketch from the British television series MONTy PyTHON's FLYING CiRCUS). In the scene from the FlodDER film, bodily humour shows itself on the one hand in the absolutely plump dress code of Ma Flodder, best signified by both her cigar and the shabby rubber boots she is wearing at all times and at all places. On the other hand, her rude physical manners become silly, because she lacks the athletic ability to justify her threats. She gets mad at both her daughter and the dog but she fails 
to actually hit anything because she is so physically unfit. To make matters worse for Ma Flodder, the counterattack by the dog makes her tumble onto the ground with the animal's teeth in her leg. She can only liberate herself from her uncomfortable position by breaking one more bottle of whisky, whereas the fact that some bottles had been broken happened to have been the cause for her bad temper in the first place.

In his seminal study Le rire [Laughter], Bergson has famously argued that a comic effect is produced when a human being, visibly at unease with his/her body, acts so clumsy or stiff that he/she begins to appear machine-like. The 'mechanical rigidity' of the tramp played by Charlie Chaplin, as cited by Simon Critchley in his insightful study On Humour (57), comes to mind as a perfect example, but it is noteworthy to distinguish the tramp's inflexibility from Ma Flodder's stiffness. The machine-like appearance of Chaplin is a combination of an apparently gawky nature and the art of (slapstick) timing. In many scenes from THE GOLD RusH (1925), to name one of his masterpieces, it seems like the tramp is bound to take a nasty fall, but time and again he is able to save himself miraculously. Performers like Chaplin (or Harold Lloyd or Buster Keaton) act in the tradition of the circus clown walking a tightrope - and one has to be very good at walking the tightrope in order to pretend to be about to fall down, but never do. ${ }^{21}$ If Chaplin, Lloyd and Keaton are counted among the great artists in cinema, it is on account of their quality of being inflexible but surprisingly agile as well, whereas the stiff gestures by Ma Flodder are, by contrast, a mere consequence of her lack of control over her overweight body.

Except for noting that humour often involves a bodily aspect, I have selected the first scene of FLODDER IN AMERIKA! in this introductory chapter of this study since it addresses, in a nutshell, the three basic theories of humour. The scene is compatible with the so-called superiority thesis, which of the three theories comes first in historical order. The Greek philosophers Plato and Aristotle made some observations on the nature of comedy which are too scattered to be truly called a theory, but their remarks can be taken as a stepping stone to the insights of the 17th-century British philosopher Thomas Hobbes (Billig, 38). According to Aristotle, in comedies people are normally depicted as worse than the average and, as he famously postulated in The Poetics, the ridiculous is a species of the ugly (qtd. in Billig, 43). A character may commit a kind of silly 'error,' but since he himself is not aware of his own improper behaviour, he is not injured by his mistake or deformity. For Aristotle, comedy lacks pathos since the errors do not bear severe consequences for the ridiculous characters. It takes little imagination to see that the Flodder family from Maas' comedy conforms to this Aristotelian pattern. Even though their neighbours cast disapproving glances at them and consider them both maladjusted and utterly silly, they are so unconcerned about everything that they are 
immune to derision and insults. So, the fact that they are called 'riff-raff' does not bother them at all, as anyone who has seen the first film will already know. In the case of the Flodders, the spectators are perfectly aware of the ridiculous nature of, to paraphrase Aristotle, the 'inferior action,' practised by the family. Obviously, the viewers laugh at the dysfunctional family Flodder, who do not care about any rule of decorum, best illustrated by the total absence of decency on the part of Ma Flodder.

The grounding principle of the superiority theory is best summed up by Hobbes' famous quote from chapter 9 in his Elements of Law, Natural and Politic (1640) that the 'passion of laughter is nothing else but sudden glory arising from some sudden conception of some eminency in ourselves, by comparison with the infirmity of others, or with our own formerly' (qtd. in Billig, 52). This 'sudden glory' presumes that a group (or a person) laughs because a joke is made at the expense of someone else, which potentially can also include one's former self.

28 Laughing at another person's stupidity or misfortune is both a pretext and an affirmation to feel oneself elevated over the scapegoated other. In the case of the FLODDER films, the family's stubborn naivety only contributes to the audience's pleasure, for it implicitly emphasizes the smartness as well as the good manners of the viewers. In Maas' comedy, every single family member is so stereotypically rude and vulgar that practically all spectators can feel themselves 'more civilized' than the Flodders. In short, the family has set a yardstick for inappropriate behaviour to which anyone else will be a favourable contrast.

According to the superiority theory, the function of humour is predominantly reactionary, for the effect of the scene is that we, as viewers, can feel 'better' than any of the characters. We might consider ourselves to be not as careless as Ma Flodder, more upright than the mayor and not as credulous as the Americans. The confrontation with the presumed stupidity, arrogance, disarray, laziness, or whatever negative character trait of someone we can safely count as 'other,' can yield pleasure, because it works to emphasize our own elevated status. In such a case, humour is used as 'an insulation layer against the surrounding alien environment' (Critchley, 68), or as Noël Carroll put it, humour is primarily 'involved in the construction (or, more aptly, the permanent reconstruction) and maintenance of what we might call an Us the us that abides by the pertinent norms' (77). Against that backdrop we can comprehend the final words of Giselinde Kuipers' study on the sociology of the joke that humour, even when it is good, 'always implies some bad taste' (248). For, as she asserts, humour is not only to be associated with uplifting feelings - like (the majority of) art and beauty - but also, if not primarily, with the vile and lower things of life. In case that art (cinema) is wilfully provocative in addressing gut feelings, as in LA GRANDE Bouffe [THE Big FEAST] (Marco Ferreri, 1973) or FunNY GAMES (Michael Haneke, 1997), the predominant and 
preferred response might at least be contemplation, but the primary reaction to humour is, Kuipers observes, 'always visible, physical and to a certain extent, unrestrained' (248), from a (faint) smile to a guffaw.

Notwithstanding the fact that Hobbes' ideas on humour have been quite influential, they will only figure at the margins of this study, for the simple reason that he is distrustful of comedy: humour is for him no laughing matter at all. He argued that humans are basically driven by selfish motives, which are expressed by emotions and passions, including joyful laughter. A person had better guard his balance and not burst into a laugh, which in his eyes is always already (too) undisciplined. One had better repress one's 'sudden glory,' for, Hobbes postulates, laughter is an anti-social force. It is, as Billig notes, potentially rebellious, but for Hobbes it is without any benefit. In his hands, 'all humour stands ostensibly condemned' (Billig, 56) and can only serve narcissistic demands. Had Hobbes seen FlODDER IN AMERIKA!, he would have confirmed that this comedy worked to provide its viewers with superior feelings, which is seldom, if ever, a condition to improve social inequality.

The main objective for mentioning Hobbes is that many subsequent reflections on humour have struggled with the 'Hobbesian daemon' (Billig, 58). His critics made an effort to circumvent his general suspicion at laughter, among others by trying to distinguish a witty remark from a vulgar one, as was a preoccupation of a number of 18th-century British philosophers of humour like James Beattie, Sydney Smith or the Earl of Shaftesbury. For these philosophers laughter became first of all a practical problem. To begin with, they made a distinction between 'wit' and 'humour.' The first term referred to clever verbal sayings and wordplay - and 'clever' here means that downright puns and jokes are excluded. ${ }^{22}$ Humour, which was then used in a more restricted sense, denoted a laughable person, turned into an object of ridicule (Billig, 61-62). These philosophers aimed to walk the middle ground between indecorous humour for the uncouth masses and the overaestheticism of the idle aristocracy (62). The kind of wit they pursued was to create something incongruous by bringing dissimilarities together, or, in a definition of wit by Henry Home, who acquired the title Lord Kames: 'A junction of things by distant and fanciful relations, which surprise because they are unexpected' (173). According to the incongruity theory, laughter is provoked when something great or serious is juxtaposed with something small or frivolous. In an attempt to keep any association with Hobbes at bay, some 18th-century philosophers emphasized that an analysis of such juxtapositions was basically a cognitive process. The social and psychological dimensions of laughter were not to be ignored, however, and the third Earl of Shaftesbury - real name: Anthony Ashley Cooper - highlighted the connection between incongruity and ridicule. Since ridicule is always aimed at something or someone, it is inherently social. ${ }^{23}$ 
In the case of the scene from FLODDER IN AMERIKA!, two different kinds of ridicule have to be kept apart: one which potentially may have some sanitizing effect on a person's moral sense, and another one whose effect will probably be nil. As regards the latter, the Flodder family is represented as utterly coarse. Conventionally, a (single) mother, as head of a household, is responsible for nurturing her children and teaching them decent manners, but Ma Flodder acts contrary to this image of a mother. The point is: she does not care at all about what others think of her unorthodox lifestyle, and disregarding outside opinion would imply that she is quite immune to ridicule. The 18 th-century adherents of the incongruity theory were more interested in the option that ridicule might remedy some social wrong, or in the beautiful phrasing of Sydney Smith that ridicule was 'the great cure of extravagance, folly, and impertinence; it curbs the sallies of eccentricity ...' (qtd. in Billig, 79). In case some self-conceited character - which Ma Flodder is obviously not - is made to look

30 ludicrous, then ridicule can become effective. On account of his profession, a mayor has to be an upright representative of his city, hospitable to his guests. The mayor of Zonnedael, however, behaves in an opportunistic way for he misuses the exchange programme to get rid of the troublesome family. One might argue that he does his own community a great service - as a mayor is supposed to do - but it is also a foul trick at the expense of the American guests. Because of the cross-cutting between the mayor's office and the ruined residence of the Flodders, we understand the mayor's vicious strategy in selling his guests a pup. We know what the Americans do not know (yet), namely that the mayor has told them a lie: the pictures of the Flodders were not of them at a costume party, but of them in their habitual clothing. In his modern reinterpretation of the incongruity theory, Critchley remarks that 'insofar as the joke plays with the symbolic forms of society' - in FLODDER: the mother turns family life into a total mess, the mayor deceives his foreign guests - 'jokes are anti-rites' (5). This type of humour, mocking symbolic practices, reveals 'the sheer contingency or arbitrariness of the social rites in which we engage' (10). In the case of Maas' comedy, this contingency is exposed because the mayor, who is an official dignitary, violates social customs by selecting the vulgar family for the trip abroad.

Though the mayor formally exceeds his duty, his action can nonetheless be legitimized. If the mean gesture of the mayor is to be pardoned, then it is because the American leaders of the exchange programme are represented as self-righteous. If the original idea was to opt for an average family, they pride themselves on having selected the 'family of the year.' Further, they make fun of the Flodders' name and they criticize fatherless families in passing. Since the American visitors are so overtly complacent - and it is to be expected that the Johnsons are flowers from the same garden - it is somehow excused 
that the mayor turns the tables on the Americans by sending the Flodders in return. Thus, persons with pretensions of superiority, like Americans whose pomposity is symbolized by the Johnsons, will get their comeuppance (Billig, 72). Formulated this way, it is clear how this variant of the incongruity thesis is to be distinguished from Hobbes' theory. The latter was cautious about laughter, since it usually testifies to one's superiority towards 'silly' people: the well-behaved poke fun at the non-adjusted (the Flodders). Thinkers like Shaftesbury and Smith rather celebrate the kind of (true) raillery, aimed at highfalutin' people - at those who display an arrogant stance.

It deserves emphasis that a 'banal' example, such as the scene from FLODDER IN AMERIKA!, would have been too blunt for the critics of both the superiority and the incongruity theory. By contrast, the pioneers of the so-called relief theory, the third one on the list, were less strict on the requirements of 'refined taste' but took laughter as a bodily response quite seriously. For the philosopher Alexander Bain, laughter indicates, as a surge of pent-up energy, a momentary release from habitual constraint (Billig, 97). According to Bain in his The Emotions and the Will, the comic, in fact, starts from the serious. On many (official) occasions, the general setting of dignity coerces people into a 'certain posture of rigid constraint': one has to be quiet in a church, a classroom, a court of justice. People who tend to take themselves very seriously will often be deeply offended if the solemn atmosphere is disrupted, but those who take the sentiment of self-importance lightly, Bain says, will respond with 'uproarious delight' to any 'contact with triviality or vulgarity' (283). When the required attitude of reverence does not correspond to one's inward feelings, any sudden disturbance of protocol can be experienced as a 'blessed relief' from tension, for, as Bain asserts, it is 'always a gratifying deliverance to pass from the serious to the easy side of affairs' (284).

According to that other pioneering thinker of the relief theory, Herbert Spencer, laughter serves no other purpose than 'expending an accumulation of nervous energy' (Billig, 99). When an official ceremony is all of a sudden interrupted by the presence of a young kid or a dog, then some elevated event is briefly displayed as petty. In the eyes of Bain, however, laughter is not harmless but represents a rebellion - albeit only a temporary one - against authority and establishment. His ideas presume that humour is pervaded with streaks of malice and that one takes glee in mocking that which should not be mocked (Billig, 98). One's laughter at a person or an institution is genial on the surface, but, in fact, it covers up one's feelings of disgust for the person or institution at hand. According to this logic, a joke about a minister or a member of parliament is considered the better, the less popular the politician is. One's pleasure is increased the more the object of humour deserves degradation and humiliation in one's eyes. It is but a small step from Bain's relief theory to the 
comedy FLODDER IN AMERIKA! On the one hand, it is reassuring to laugh at the family for they can be used as a yardstick of inappropriate behaviour that any viewer will meet. On the other hand, as the first chapter will clarify, Maas' films position the carefree family as the perfect tool for a mild mockery of anything that connotes an air of (solemn) conventions. On their way to America, they start to occupy the business class, which makes perfect sense to them for the seats are available and much more comfortable than in economy class. The argument that this is not permitted does not impress them, for they have an inbred resistance to anything which is justified by a mere reference to rules and conventions. Insofar as we laugh at the Flodders in a sympathizing way rather than a condescending manner, this is owing to the fact that they never take conventions very seriously - a 'positive' side to their rudeness. Thus, they perform a relief from conventions, and our laughter is to be taken as a consent to this performance. In a similar vein, the scene I described above from

32 FLODDER IN AMERIKA! is the prelude to ridiculing the whole idea of a 'family of the year' contest, which, as one can read between the lines, can only originate from a country that wants to show itself off as the most wonderful nation in the world. And thus the Americans do not send their 'average family,' as was the original plan, but they nominate a family which is far above the average according to their standards, 'the family of the year,' as if to suggest that all 'normal' American families are this fabulous.

Attempts to rethink the pitfalls of the relief theory have resulted into two thought-provoking studies on humour at the beginning of the 2oth century. Though he himself did not consider laughter a very important subject, the aforementioned Bergson wrote the remarkable Le rire in 1900. At this stage I restrict myself to his observation that Bain's ideas actually work the other way around, because Bergson focuses upon the object of the joke rather than upon the laugher. Yes, people tend to laugh at a person's rigid behaviour or at a hilarious deviation from strict conventions, but Bergson stresses the point that anyone will avoid the risk of being laughed at. Hence, laughter is not a 'release from social authority,' as Bain asserted, but laughter is experienced as humiliating, as 'the punishment in the classroom of life' (Billig, 128). There is, Billig mentions, a 'cold cruelty' at the heart of Bergson's theory: because people dread being made fun of, they try to avoid peculiar behaviour. In order to prevent coming across as ridiculous - neither too rigid nor too frivolous - they choose the middle ground, i.e., sticking to conventions. Hence, for Bergson, laughter has a corrective and disciplinary function. At first sight, his ideas do not seem to tie in with the case of the Flodder family. Oblivious to everything, Ma Flodder and her children are immune to humiliation, but at the same time, this feature turns them into extraordinary characters. Hence, they are the comic exception that somehow 'proves' Bergson's rule. 
Unlike Bergson, Sigmund Freud did not emphasize the disciplinary function, but he attributed a rebellious nature to humour, or to Der Witz ('the joke,' both good and 'bad'), as found in the full title of his 1905 study, Der Witz und seine Beziehung zum Unbewußten (Jokes and Their Relation to the Unconscious). Psychoanalysis presumes that a subject's repressed desires and unconscious motives manifest themselves in distorted form, particularly in seemingly minor expressions, like dreams, slips of the tongue, and jokes. Even though Freud spoke of 'innocent jokes,' which do no more than yield pleasure, the category of 'tendentious jokes' is of greater interest. Whereas the innocent joke is merely appreciated for the joke-technique, people derive enjoyment from the tendentious joke on the basis of its underlying content rather than the joke-form. ${ }^{24}$ Thus, Freud would suspect the usual excuse of a joker when he claims that absolutely no harm was intended and that it was a mere prank. In cases where a taboo topic is addressed as the object of a witty remark, it depends upon the listener's attitude towards the target of the joke whether one appreciates the joke or not - the technique of telling is irrelevant. If a man experiences the fact that he is married as a confinement, he might laugh at jokes about the frigidity of a wife or about a too meddlesome mother-in-law. Elaborating upon this Freudian idea that the content presides over form, Critchley mentions that there is a radical feminist joke about men, which runs like this: 'How many men does it take to tile a bathroom?' Answer: 'It depends how thinly you slice them.' However, as soon as one replaces the men in this riddle by blacks or Jews, the technical wit is the same, but its content becomes quite disconcerting all of a sudden. ${ }^{25}$

If we laugh at the tendentious thought behind the joke, as was one of Freud's seminal insights, then one can only consider FLODDER truly funny on condition that one adheres to the film's tendentious politics. According to a psychoanalytic logic, this politics goes beyond the fact that the film ridicules conventions like violating the separation between business and economy class. Jokes always backfire at the teller/laugher and implicitly reveal their (social, gender, class, cultural, etc.) positions. There is a scene in FLODDER IN AMERIKA! when each and every family member is subjected to a full body search at the airport after the ringing of an alarm. Only in the case of Kees, the big-breasted blonde daughter, the alarm remains mute. Since most members carried a weapon, the guard asks her whether she has none. No, Kees replies in a seductive tone, but 'you are permitted to search me anyway,' which clearly hints at her sexual availability for men. In this scene as well as in several others, Kees uses her body as a sexual commodity in such an obvious manner that it might offend anyone with only the slightest feminist sensibilities. Those who regard sexism as a serious and problematic issue will be inclined to reject the comic value of such a scene, but as the suggestion runs, those who laugh heartily are apparently more indifferent to sexism. 
Freud's take on jokes teaches us that humour potentially functions as a metaphoric barometer, exposing one's (unacknowledged) instincts. Whether one enjoys FLODDER as amusing then depends upon one's sentiments on 'uncivilized' behaviour: if one takes heavy drinking, insulting dignitaries, foul language or using sexuality for opportunistic ends as pardonable acts, then one is more likely to enjoy FLODDER than those viewers who are attached to general rules of proper conduct. My main reason for selecting FLODDER IN AMERIKA! as an introductory example is not because of its sordid jokes, but because its comic scenario of a cultural clash between the Netherlands and America exposes some characteristics that might be considered 'typically Dutch.'

When Ma and her five children arrive in New York, they are mistaken for the members of a Russian delegation of medical doctors invited by the Roosevelt Foundation. Since their proficiency of English is too poor to understand why

34 they are driven by limousine to the expensive Plaza hotel, they simply presume that this first-rate treatment is part of the exchange programme. The Americans do regard the Flodders as weird, as can be gathered from a comment by one of the hotel clerks: 'I knew it was bad over there [in Russia], but this is ridiculous.' The Americans remain hospitable throughout, however, which can on the one hand be seen as a positive signal: they are courteous even when faced with rude people. On the other hand, the opening scene suggests, as the spectator may remember, that Americans tend to see themselves as naturally and 'simply the best.' Their hospitality can then be built upon the prejudice that for them, everyone outside America is entitled to a certain dose of outlandishness. In overdoing this eccentricity, the Flodders are for Americans just an extreme case of their self-conception that not everyone can be as 'perfectly normal' as they are. That a great doctor from Russia might be dressed as a hoodlum, well yes, nothing is too weird for the inhabitants of the (former) 'Evil Empire.' Hence, the error can continue for a while, partly thanks to American hospitality, which is an inverse version of their arrogance: well, if one is the best, the consequence is that one has to deal with wackos all the time, and the best way to prove one's superiority is by acting polite and controlled.

In turn, the Flodders themselves accept the wonderful welcome matterof-factly since for them it merely illustrates their idea that America is, as Johnnie mentions, the country of unprecedented possibilities, although his brother Kees inadvertently botches the term 'ongekend' (unprecedented) to 'ongewenst' (undesirable'). After the error comes out, they are dismissed from the hotel and have no other option than to spend the upcoming night outside. However, they enjoy the lack of a roof over their heads at least as much as their stay in the Plaza. They are frankly happy to eat sauerkraut with smoked sausage, better than any other meal, and they also appreciate the cosiness of a 
campfire. In short, no fancy stuff for the Flodders, and despite their excessive rudeness, they breathe oxygen into proverbs like 'he who cannot keep a penny shall never have many' and 'if you just behave normally, you are already weird enough.' In this film, this latter saying, which is often said to characterize a Dutch mentality, works to distinguish the Flodders from the Americans. The Flodders may look outrageous and uncivilized, but do not let that fool you, they are content with the simple things in life. Americans, by contrast, are hospitable and civilized in manners, but do not let that fool you, their attitude is a cover-up for their self-absorption, for they like to show off everything as big and beautiful. It is highly significant that the 'family of the year' contest is not won by common American citizens, but by the financially successful Johnson family, an embodiment of true capitalism.

\section{FROM 'JOKES' TO 'HUMOUR'}

The first chapter will offer a more in-depth analysis of the phenomenon of juvenile and low-class comedies like FLODDER, but suffice it to say right now that its overall effect is to advocate a certain amount of authentic roughness as benevolent. This effect ties in with an influential tendency within Dutch mentality, namely the one which presumes that anything is permitted to say because the freedom of expression is an inalienable right. Blunt jokes are an integral part of this right. In her comparative study on American versus Dutch jokes, Kuipers claims that Dutch people with a lowbrow humour style use humour with a 'social, spontaneous intention' in order to create a 'good atmosphere' (231). On these grounds, it is legitimate to make derogatory jokes about anyone, regardless of culture, religion, ethnicity, sex. Kuipers refers to the work of sociologist Johan Goudsblom who claimed in his Dutch Society (1967) that a long-standing tradition of tolerance has caused Dutch humour to be 'decidedly amoral at times' (Kuipers, 241). As a consequence of this typical mixture of individualism and egalitarianism, Kuipers asserts, Dutch people presume that by 'being direct, honest, straightforward you show yourself "as you are", that is: not elevating yourself above others' (241). The popularity of the Flodders among Dutch who adhere to what Kuipers calls a lowbrow humour style is proof of this principle of egalitarianism.

This (Dutch) mentality of refusing to condemn coarse remarks comes explicitly to the fore in the replies to the severe criticisms of the controversial figure of Zwarte Piet [Black Pete]. Those uncomfortable with this black faced servant of Sinterklaas [Saint Nicholas] see this figure as too awkward a reference to the history of slavery and/or to a regrettable tradition of inequality favouring whites over blacks. Due to Zwarte Piet's unfortunate racist connota- 
tions, the critics argue, it would be better if he was replaced. To the supporters of this figure, the critics are simply too sensitive, for he is part of an already ancient celebratory tradition in the Netherlands, aimed at young children, and therefore 'innocent.' To anyone who questions the folkloristic appearance of Zwarte Piet, they say: 'Don't be a squeamish.' From there it is but a small step to those (Dutch) people who lack the antennae to grasp that jokes about foreigners can be a delicate matter. In November 2013, a jury member of the television programme HollaND's GOT TALENT, Gordon, made fun of a Chinese contestant, not because of his singing qualities, for they were excellent, but merely because of his descent. Another jury member, Dan Karaty of American origin, called Gordon's comment awful and said to him that 'you are not supposed to say things like that to people.' When the clip was posted on the social news website Reddit, a general reaction from Americans was that there would be wide hysteria in the country if this had been aired in the US, sometimes 36 followed by the questions whether Dutch people are racist or intolerant. A considerable number of reactions by Dutch people to the accusatory tone ran like this: Gordon makes jokes about everyone, so it is only proof of the acceptance of Chinese that they are turned into the butt of jokes as well. Or to paraphrase Gordon's own reply: We are hospitable to all foreigners and everyone is entitled to express his opinions, but one should not encroach upon 'our tradition' by deciding what I am permitted to say or not (qtd. in Heijmans, 5). My point is that the way Gordon's remarks are defended as not amiss is analogous to the careless modus operandi of the Flodders. The inclination to cover up callousness with the mantle of love is deeply ingrained in some parts of Dutch culture: people should not be too easily offended by jokes. Those who are fond of the humour of FLODDER, I will claim, are more likely to side with the supporters of Zwarte Piet and with Gordon's stance - 'What is all this fuss about?' - than with their critics. For in the end, as chapter 1 will further elaborate, the Flodders can be taken as a backlash against an atmosphere of political correctness which gained momentum in the Netherlands in the 1980s. In this decade, as the tripartite television documentary WONDERLAND (Robert Oey, 2004) suggests, people got caught up in a 'straitjacket of prescribed left-wing opinions. ${ }^{26}$ This backlash manifested itself in a desire, albeit often repressed since one could risk being labelled a 'fascist,' to escape this straitjacket by expressing oneself in terms of political incorrectness. FLODDER offered the advantage that by enjoying this comedy with its outrageous jokes, one could give vent to this desire in a most innocuous form.

Maas' comedy illustrates the double impact of humour. On the one hand, FLODDER can be qualified as critical insofar as it lays bare the hypocrisy of those who take an a priori condescending attitude towards the lower classes. On the other hand, it is reactionary insofar as it is averse to the logic of political 
correctness, advocating a 'live and let live' mantra. This double impact, oscillating between subversive and conservative, will be a red thread throughout the chapters of Humour and Irony in Dutch Post-war Fiction Film. Since the value of humour can only be determined in context, there is no golden rule to decide whether the scales tip in favour of the reactionary or the critical. In many a case, the reactionary pole will speak louder than the critical pole in the end, which will make the exceptions a real treat. In clarifying how a comedy might increase its critical potential, I follow Freud's short essay on humour, which he wrote in 1927, after an interval of more than twenty years, as a concise reconsideration of his studyJokes.

In the essay Freud makes a clear-cut distinction between jokes and the comic on the one hand, and humour on the other hand. He had defined the joke in his 1905 book as the 'contribution made to the comic by the unconscious' (Jokes, 208; 'Humour,' 165). Jokes are often performed to affirm, in passing, the 'invincibility of the ego' by suggesting one's superiority at the expense of others. The comic assumes the role of a grown-up and reduces others to being children (163). Whereas jokes often function to elevate oneself over others - and therefore betray some unconscious aggression - Freud's characterization of humour can be taken as the inverse of the superiority theory. In humour, one treats oneself as a child from an adult perspective, or in Freud's formula: humour 'would be the contribution made to the comic by the agency of the superego' ('Humour,' 165, emphasis in original), in which the superego refers to an imaginary instance 'speaking' with a voice of authority, either as a severe master or, in this case, as a consoling parent. In contrast to jokes, in humour, one laughs at oneself rather than at others, so that one's ego is not aggrandized, but deflated. According to this criterion, FLODDER obviously belongs to the category of jokes, aimed at instant pleasure with low risk for the comic Flodders themselves. Significantly, a character like Johnnie Flodder is always cheerful, just like the teller of a joke often is amused by his own punchline. This study will aim to explore a gradual shift from the Freudian joke to the Freudian kind of humour, perhaps best represented by the films discussed from chapter 7 onwards, such as the ones by Van Warmerdam. In some of his films, servile characters like a waiter, a train conductor or a postman who rebel against their submissive roles in quite pathetic manners become the object of ridicule. They are never the smiley faces themselves, but viewers might consider their sorry fate funny, though not every viewer is sensitive to this type of humour as I will explain in later chapters. To underscore the idea of a deflated ego, it can be noted that Van Warmerdam himself performs these roles of servile characters - and in another film, he even plays a man who has accepted performing as the dog.

My suggestion to consider the pranks pulled by the cheerful Flodders 
as 'jokes' in the Freudian sense, and the deadpan performances in the cinema of Van Warmerdam as 'Freudian humour' is not meant to imply that diegetic laughter necessarily belongs to the category of 'jokes' rather than 'humour.' Let me as a counterexample refer to a film which can be regarded as the polar opposite of FLODDER IN AMERIKA!: DE STILTE ROND CHRISTINE M. [A QUESTION OF SilEnCE] (Marleen Gorris, 1982) was marketed as a kind of 'psychological thriller with particular appeal to female audiences' (Udris, 157). ${ }^{27}$ Housewife Christine, bar worker An and secretary Andrea are arrested in the beginning of the film. Unbeknownst to each other, the three of them are charged with murdering a male boutique owner in his shop, in the presence of, as will turn out later, four female witnesses who remain silent throughout. In a fine contribution to the volume The Cinema of the Low Countries, Jan Udris discusses the formal devices of Gorris' debut feature, like the unstylized 'realist' camerawork in the majority of scenes, the green-blue tint of the prison cor38 ridors, the use of sometimes disorienting electronic music, and the brusque insertion of flashbacks which gradually reveal the killing and the ordinary things the three women do in the aftermath: visiting a funfair, cooking a meal, eating an ice cream. Though Christine is mentioned in the (original Dutch) title, the criminal psychiatrist Janine can be taken as the 'prime identification figure' for viewers (Udris, 159), the more since she undergoes a radical shift in perception. As Udris argues convincingly, the successful career woman regards herself as an emancipated spouse who enjoys an 'egalitarian relationship' with her husband-lawyer (159). Thus, she has reason to think of herself as different from the three suspects who have typical feminine occupations (housewife, secretary) or who, like An, has been divorced from a domineering husband ('so glad the bloke has gone'). In the dream, however, which has no synchronized speech and has many interposed shots of the women of less than one second, Janine becomes aware of her close bond with the three female suspects. She herself has been 'co-opted as a surrogate man' (Udris, 164), intent on producing 'wonderful phrases' about the mental state of mind of the women for the benefit of male authorities. Hence, she starts seeing herself as no more than a pawn in a patriarchal society, just like her 'clients' - whom her husband tends to address as 'patients.' The dream sequence makes her realize that the women did not suffer from a temporary mental disturbance, but were perfectly sane at the moment of their 'bestial manslaughter,' to coin the words of the male prosecutor at the trial. Janine's husband is deeply annoyed by her argument in front of the judge, and since she refuses to step into his car at the end of the film, their different positions seem to foretell a separation.

On two separate occasions in the film, two of the women laugh exuberantly in response to a question posed by Janine, before she has her 'revelatory' dream. When Janine suggests to Andrea that there must have been a motive, 
the latter starts laughing. An is very talkative, driving Janine crazy with her verbiage, but to the question whether An had never wanted to re-marry, she gets a burst of cackling laughter for an answer. It is suggested that when Janine rewinds her tape recording of An's laughter twice, the awareness slowly begins to dawn on the psychiatrist that these women suffer from oppression in a male-chauvinistic environment. The laughter, then, is to be understood as a dismissive reply, as an indication that both Andrea and An consider the psychiatrist too naive - and her 'dream' will reveal this insight to her. Hence, their laughter was a defiant riposte to Janine, who initially failed to grasp the severity of the inherent inequality of men and women.

Near the end when Janine and the male prosecutor are having a discussion in court on the presumed accountability of the women, the latter argues that he sees absolutely no difference between this case and the hypothetical case of three men murdering a female shop owner. Upon hearing this claim, An cannot suppress a laugh. One of the female witnesses joins her, and soon eight women are choking with laughter: the three suspects, the four silent witnesses and Janine. All the men present are flabbergasted, judging from the puzzled looks on their faces. At first glance, the mirth provoked on the part of the women may seem to chime in with the superiority thesis: their laughter has the effect of disqualifying the male professionals as ignorant. Something seems to be hilarious, but the men apparently do not get it. Their silence is only cause for greater hilarity among the women, for it helps to turn the men themselves into the 'butt of the joke.' So far for the logic of the superiority thesis, since the point here is that there is neither a proper joke (or punchline), nor a funny situation like someone acting clumsy or machine-like, nor an (unintended) pun or slip of the tongue. On top of that, the situation is solemn and the prosecutor's tone is deadly earnest, devoid of any irony. Thus, the laughter seems inappropriate for the occasion, which has to do with the fact that the women are not laughing at someone or at some situation, but at a general institutional flaw, deeply rooted in patriarchal society. Because the men in court are blind to this flaw, their response is one of amazement at this convulsive laughter and since the feminine pleasure abides, surprise becomes visible discomfort. The judge demands the dismissal from court of the three suspects and their smiling faces are the last we will see of them in the film. Upon their forced departure, Janine decides to leave as well.

On reflection, the laughter both is and is not an expression of the women's superiority. First, why it is not. If a rational conversation falls on deaf ears, then one can either decide to remain silent (as is Christine's tactic for so long) or one suddenly finds oneself bursting into a hearty laughter at one's own misery. This kind of laughter is far beyond the idea of a prank or a joke in the vein of the Flodders, but it has a provocative and subversive effect, much more 
in the spirit of Freud's idea of 'humour' in his 1927 essay: the spontaneous laughter gives vent to the women's frustration at their structural subordinate position. It is not a reaction to someone stupid or something concrete, but to an abstract structure. The laughter at the end of Gorris' film functions as a gesture of contempt for those who refuse to acknowledge gender inequality. Their laughter puzzles and piques those in power (and that is hilarious), but those in power choose the poorest of options: by getting rid of the 'rebellious' elements, the men hope to 'save' themselves from their laughter, which gives them the creeps. By dismissing them, they in fact return them to 'silence.'

But now let me explain why this laughter can also be termed subversive, and here I refer to one of the most thought-provoking books written on comedy, Alenka Zupancic's The Odd One In (2008), in which she tries to reconsider common notions about humour and laughter from a predominantly Lacanian angle. The point of a comedy, she claims, is not to convince us that we are 'only 40 | human,' endowed with regrettably weak and fallible characteristics. As Lacan has claimed, the laughing stock is not the simpleton who erroneously believes he is a king, but the king who really believes he is a king (Zupancic, 32), which she translates, in different wording, into: The biggest fool is the one who will do anything not to be fooled (84). The men in court do not try to understand the laughter, but they are only concerned to keep up appearances: they pride themselves on their position of authority on account of their togas. The laughter by the women can be taken as a derision technique, as if they are declaring: 'Stop this charade. You are only concerned about the deadly serious letter of the law. You act as representatives of justice, but underneath your togas you are human, too, men who snore, who fart. Thus you are subject to the same physical laws as other mortals.' According to Zupancic, we tend to laugh at a dignity that strives to control any disturbance of order (112), and since the situation in court is becoming uncontrollable for the male high officials, they have to send the female subjects off. In fact, their "embarrassing" pretension to seriousness' makes the dignitaries all the more laughable (Zupancic, 101).

This study oscillates between the cheerfulness of FLODDER IN AMERIKA! and the subversive laughter from DE STILTE ROND CHRISTINE M. It addresses the manifold variants of humour as they manifest themselves in Dutch narrative fiction features, ranging from juvenile jokes and carnivalesque in the first chapters to deadpan comedy and black humour in the later chapters. It also discusses the trope of irony and its related forms, like camp, persiflage and satire, as well as its rhetorical devices, such as hyperbole and understatement. This goal has to be accompanied with one caveat and three disclaimers. To start with the caveat, if this were only a theoretical book on humour, I would have selected fewer examples and focused upon the very best, usually from international sources (scenes from films by Preston Sturges, Billy Wilder, 
Alexander Payne). It is a book in which humour is addressed via analyses of a considerable number of films made in Holland, without any pretence to be complete, for then this study would have been at least four times as voluminous. Ideally, this works as a double-edged sword - a thorough overview of Dutch films to get an understanding of 'typically Dutch' humour - but that is aiming too high. This book is much more provisional than that: an overview to get some understanding of what more or less could be termed 'Dutch' humour and irony.

My first disclaimer is that there are criteria I have set for the selection of titles, but they do not rule out a certain randomness. To start with the obvious ones: a comedy that has proven successful at the box office is likely to be included here. Moreover, favourable reviews and/or much publicity work greatly to a film's advantage. Occasionally, and here I may seem to enter a grey area, a film will be discussed even when it does not fall under either one of these criteria, but because it, like MAN IN DE WAR in this Introduction, happens to serve my argument so excellently. Further, some films address serious subject matter in a not particularly funny manner, and thus would not qualify as 'comedy,' but nevertheless offer some, or at least sufficient, comic relief. Cases in point are DORP AAN DE RIVIER (Fons Rademakers, 1958) in chapter 3, or BORGMAN (Alex van Warmerdam, 2013) in chapter 8, that is to say, insofar one can speak of comic 'relief' in a movie that dark. The status of these titles in the history of Dutch cinema and/or the place these films take in the directors' oeuvre were decisive in incorporating them. A film like WOLF (Jim Taihuttu, 2013) contains some humorous passages as well, particularly thanks to the representation of Adil as a wannabe tough guy, but overall Taihuttu's movie - inspired by among others MEAN STREETS (Martin Scorsese, 1973) and UN PROPHÈTE [A PROPHET] (Jacques Audiard, 2009) - depicts such heavy-laden topics, like criminal behaviour, violence, and cancer, that its tone actually is too 'serious' and pessimistic for consideration in this study. By contrast, Taihuttu's preceding film, RABAT (2011), which he co-directed with Victor Ponten, is examined in chapter 2, especially because the ending is not as gloomy as WoLF's finale but rather parallels the principles of a joke's punchline. Another point of contention could be my inclusion of a film like SPETTERs (Paul Verhoeven, 1980), in chapter 6, for it is neither (meant as) a comedy nor was it received as humorous at its time of release. In the course of time, however, the status of Verhoeven's picture has changed so drastically, that its case has become a cause for humour.

Even though my criteria are fairly flexible, the selection had the unfortunate consequence that some quite good, quite humorous and/or quite wellknown films fell in-between categories and therefore remain undiscussed - like VAN GELUK GeSPROKEn [COUnt Your Blessings] (Pieter Verhoeff, 1987), EEN MAAND LATER [A MONTH LATER] (Nouchka van Brakel, 1987), 
VREEMd BLOED [THE OdD ONE OUT] (Johan Timmers, 2010), to name some - or are relegated to a note - like DE AVONDEN [THE EvENINGS] (Rudolf van den Berg, 1989), Suzy Q (Martin Koolhoven, 1999), Duska (Jos Stelling, 2007), MATTERHORN (Diederik Ebbinge, 2013).

Keep in mind that, as my second disclaimer runs, this study is a firstattempt array to explore the uncharted territory of post-war Dutch narrative fiction film: there is no consistent academic tradition yet to relate to. In order to take humorous and ironic tendencies in Dutch feature films seriously, I will have to preserve discussions of films which offer only (too) little, or even no humorous interludes for another book. Among this list of excluded pictures, there are some of my personal favourites: alas, no DE DANS VAN DE REIGER [THE DANCE OF THE HERON] (Fons Rademakers, 1966); ${ }^{28}$ no EEN OCHTEND VAN ZES WEKEN [A MORNING OF SIX WEEKS] (Nikolai van der Heyde, 1966); no PASTORALE 1943 [PASTORAL 1943] (Wim Verstappen, 1978), despite the clumsy

42 actions by the resistance during the war; no CHARLOTTE (Frans Weisz, 1980); no HeT TEKEN VAN HET BEEST [THE MARK OF THE BEAST] (Pieter Verhoeff, 1980); no DE SCHORPIOEN [THE SCORPION] (Ben Verbong, 1984); no SPOORLOOS, no GUERNSEY (Nanouk Leopold, 2005); no LANGER LICHT [NORTHERN Light] (David Lammers, 2006); no HeT ZWIJGEN [The SilenCE] (André van der Hout and Adri Schrover, 2006); no OORLOGSWINTER [WINTER IN WARTIME] (Martin Koolhoven, 2008); no Nothing PERSONAL (Urzsula Antoniak, 2009); no GluCKaUf [SON OF MINE] (Remy van Heugten, 2015); no THE PARADISE SUITE (Joost van Ginkel, 2015), and, as said, no WOLF. In addition to that, a 'quality' film like Wilde Mossels [WiLd Mussels] (Erik de Bruyn, 2000) is examined, in chapter 6 , but since humour is no more than an undercurrent of this predominantly melancholic film, the interpretation is relatively brief for a film that good.

And finally, my third disclaimer, as Simon Critchley remarks in the beginning of his study On Humour: a theory of humour is itself not humorous. Nevertheless, enjoy reading. 



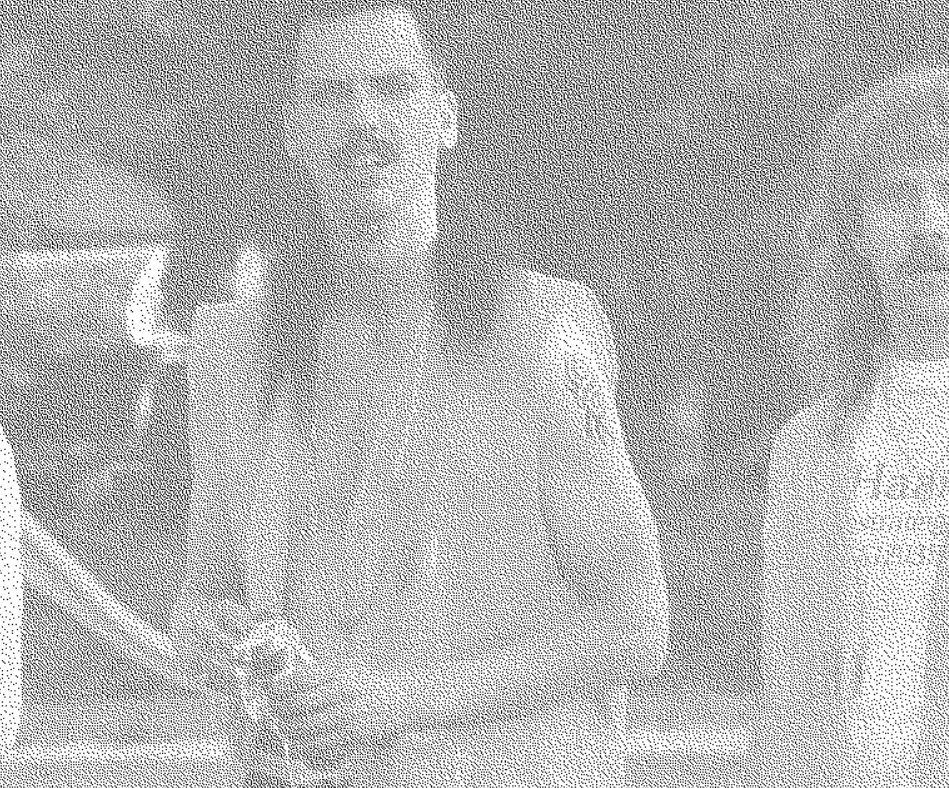

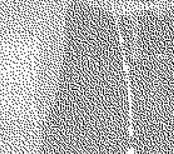

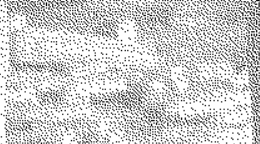
thers $x$ sersine. 20 -2 -

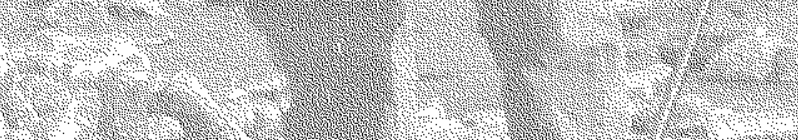

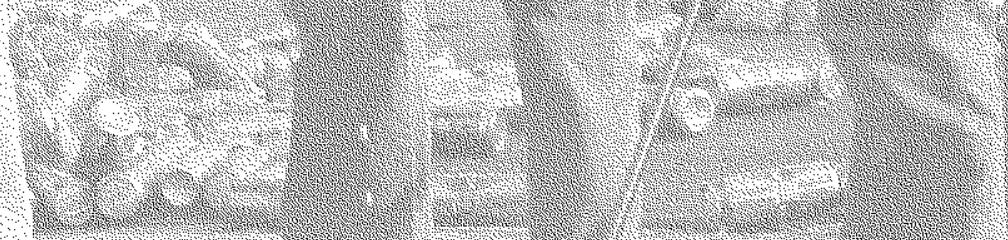

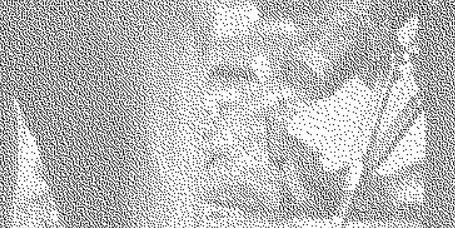
1.1. 列

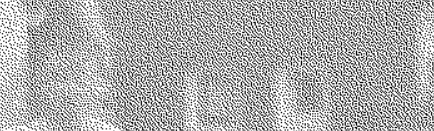
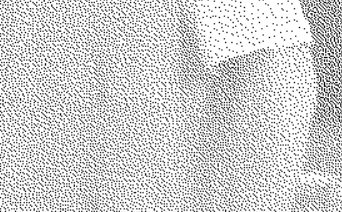
me

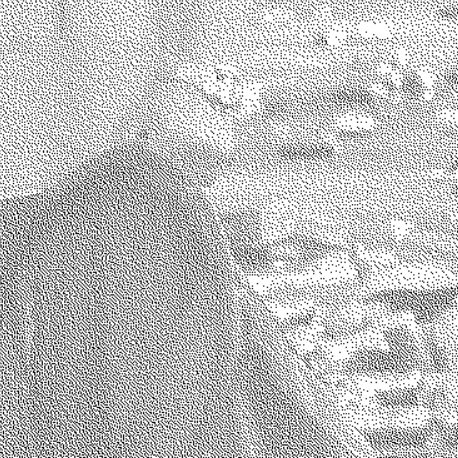
$\frac{-25}{2-3}$ T(2)

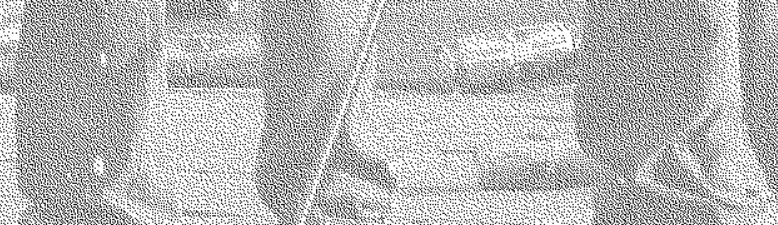
4
4
4

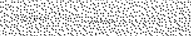




\section{CHAPTER 1}

\section{Low-Class Comedies}

In the Dutch language, the word boodschappen can mean both 'messages' and 'groceries.' When film director Dick Maas was criticized that his film FLODDER (1986) was sheer amusement and consecutively void of (social/political) messages, he retorted: 'Boodschappen doe je maar in de Albert Heijn.' A literal translation of this sentence might run: 'Get your groceries at Albert Heijn [the largest Dutch supermarket chain],' which, of course, slips into the pun: 'Get your messages at the supermarket.' This pun is a variation upon the quote, attributed to, among others, American film directors Frank Capra and John Ford that 'if you want to send a message, go to Western Union' (or 'try Western Union'). ${ }^{1}$

Apart from the fact that it is a witty remark, behind Maas' response is a specific rhetorical question: 'Is there anything wrong with trivial entertainment?' If you disagree with this view, Maas would probably reply along the lines of: 'Laugh and grow fat. Does comic laughter not purge humans from negative emotions and relieve them from their daily sorrows, at least for the duration of the film?' Such a position presumes that a comedy like FLODDER does not offer its viewers food for thought - due to a lack of substance, that is 'messages' - but that it can be mildly beneficial to the mood of the spectators: laughter might help them to forget their troubles for a while. In this chapter I want to argue the superficiality of such a claim by addressing, in addition to FLODDER, films which can be considered to be companion pieces to Maas' successful feature. Maas' shrugging attitude unjustly underestimates (the effect of) such bawdy comedies; they are more meaningful - in both negative and positive terms - than his retort suggests.

If one were to focus on the representation of both the sexy daughter Kees and the womanizing son Johnnie, FLODDER and its sequels bow to the tradition of what can be called 'blue comedy, and for which the Dutch 
have reserved the term 'onderbroekenlol,' translated as 'underpants-fun.' 'Blue humour' involves material that is typically considered more 'adult'; it can include swearing or foul language, sexual or scatological (bathroom) humour. ${ }^{2}$ This tradition is quite modest in terms of numbers, but its boxoffice successes have been considerable. Its main representative in Dutch cinema is WAT ZIEN IK?! [BUSINESS Is Business] (Paul Verhoeven, 1971), which stands uncontested as the prototypical sex farce. Some 'light' versions of this subgenre would be HELP! DE DOKTER VERZUIPT [HELP! THE DOCTOR Is DROWNING] (1974), SHERLOCK JONES (1975), both directed by Nikolai van der Heyde, as well as the two André van Duin vehicles: IK BEN JoEP MELOEN [I Am Joep Meloen] (Guus Verstraete, Jr., 1981) and De Boezemvriend [THE Bosom BudDY] (Dimitri Frenkel Frank, 1982). All these films are, to a lesser or greater extent, marked by a corny kind of fun. In a scene from HELP! DE DOKTER VERZUIPT, there is an enormous rescue operation, after 46 the doctor has accidently driven his car into shallow waters. The nearby gypsies take pity on him and in the kitchen he is about to change his wet clothes. As he stands there naked, he sees the beautiful Katja, who hardly looks at him. Nonetheless, the doctor takes pain to cover his nakedness, first with a feather brush, which he substitutes for a slightly bigger object, a vase. Then he lays eyes on an even more appropriate object, a book which he unfolds to hide his genitals from her sight. We get a close-up of Katja looking in the doctor's direction and she starts to smile. The doctor glances downward, and then we see in close-up the title of the book: What Girls Need to Know. Because of the embarrassing pose of the naked doctor, the content of the book is reduced to sexual knowledge, as if girls only need to know about (male) genitals.

Sexual innuendo is grist for the mill of a popular comedian like Van Duin. ${ }^{3}$ In IK BEN JoeP MELOEN, a nurse has to take the temperature of the protagonist, and while he opens his mouth, she asks him to turn over. He does so reluctantly, and then asks him to help her find the right spot for the thermometer. He says: 'Cold, warm, warmer ... HOT!' Similarly, the title of Van Duin's second (and, due to its lack of success, final) feature also plays on a possibly sexual interpretation of a principally conventional uttering. The term 'boezemvriend' is a Dutch expression meaning 'very best friend.' Set in 1811, Van Duin plays a dentist who is mistakenly identified as a baron and then boasts that he is Napoleon's closest comrade. Since he delivers the emperor from a terrible toothache, Napoleon will at the end of the film confirm, to everyone's surprise, that the dentist is his very best friend, indeed. At the same time, 'boezemvriend' can literally be translated as 'bosom buddy.' The term is then a pun on the physical appearance of the big-breasted woman who crosses the dentist's path on several occasions. Well-educated 
people usually turn up their nose at such 'vulgar' humour and 'risqué' wordplay, at least, in their public statements, but Van Duin's films have particularly catered to the taste of the lower class.

Part of the fun may reside in the tendency of well-educated people to sneer at them, which enables the lovers of these comedies to whole-heartedly articulate their identity as 'anti-intellectual.' Such a reading is too shortsighted, however, for at the same time, several 'intellectuals' have exploited so-called onderbroekenlol, sometimes to a superlative degree, because then this type of amusement could easily transform into a sly provocation at the address of the (petit bourgeois) viewer. This worked well on Dutch public television, e.g., when an 'anarchistic' programme like DE FRED HACHÉ SHOW (1972) featured an act with a nude belly dancer, which raised many angry responses from viewers. Deliberate grossness was also at stake in films by, among others, Wim Verstappen, whose work will be discussed at length in chapters 5 and 8. Together with his close companion Pim de la Parra, Verstappen had presented himself as an outsider to the establishment, even though his success had also made them part of the establishment. In GRIJPSTRA \& DE GIER [FATAL ERROR] (1979), which he made after his split from De la Parra, a detective couple has to visit the place of two men whom they suspect of being drug dealers. No, one of them says, we do not make money with hash, but with the 'nice ass' of my partner. In the presence of both Grijpstra and De Gier, they then start dancing together and when one of them bends over, the other holds a lighter to his buddy's ass, which results into a large flame. 'You were expecting some filth, but no ...,' they say to the flabbergasted guests. 'How did you do that?' De Gier asks, whereupon the gays repeat their act, the large flame in close-up this time. In the next shot, Grijpstra enters his very own bedroom and wants to perform the trick for his wife, but she immediately turns away from him, saying: 'Aaargh, a fart in my face ...,' thus missing the flame. Moreover, in another scene De Gier is in the company of a naked woman in a scene in slow motion with soft focus. As soon as he kisses her nipple, there is a cut to a close-up of De Gier's mouth, sipping. on the tail of his cat, Olivier. ${ }^{4}$

On the one hand, onderbroekenlol derives its humour from the discomforting attitude of dignitaries towards any sexual insinuation. People who have to keep up appearances - or think they have to do that - become the laughing stock in the subgenre of the farce, like the doctor in HeLP! DE DOKTER VERZUIPT who starts to behave nervously when an attractive blonde woman enters his consulting room. ${ }^{5}$ On the other hand, when one pushes this kind of 'underpants humour' a bit further, one can have the effect of annoying those (bourgeois) viewers who presume there are standards of decency which had better not be crossed. These types of viewers are the ideal 
audience for directors who delight in poking fun at everything that reeks of decorum and the establishment. As a popular comedy which adapts to the proverbial 'underbelly of society,' the most important predecessors to Maas' box-office hit would be Verhoeven's WAT ZIEN IK?!, HOGE HAKKEN, ECHTE Liefde [High HeEls, True Love] (Dimitri Frenkel Frank, 1981), Schatjes! [ARMY BRATS] (Ruud van Hemert, 1984) and MAMA IS BOOS! [MAMA Is MAD AS HelL] (Ruud van Hemert, 1986), and its most eye-catching successor is probably New Kids TuRbo (Steffen Haars and Flip van der Kuijl, 2010). Contradicting the position that these 'banal' comedies are devoid of messages, I will set up a 'dialogue' between these films and some theoretical notion of laughter taken from the French philosopher Henri Bergson as well as the tradition of the culture of folk carnival humour, voiced by the Russian literary scholar and philosopher Mikhail Bakhtin.

\section{A PROSTITUTE AND A CHAMBERMAID: WAT ZIEN IK?!}

When offered the chance to shoot a feature-length film in $35 \mathrm{~mm}$ and in colour, Paul Verhoeven was delighted with the opportunity until the moment he heard that producer Rob Houwer wanted to make a 'popular sex comedy' based on the confessions of a prostitute, recorded by Albert Mol. Verhoeven felt he had to make a forced choice as in a hold-up (your money or your life). Naturally, he chose the 'bad' - going along with Houwer's plan and to make the best of it - over the 'worse' option of declining the offer. He feared that he either had to give up directing at all or would be condemned to shoot 'boring, navel-gazing, low-budget art films' like his colleagues did (qtd. in Van Scheers, 126). Together with scriptwriter Gerard Soeteman, Verhoeven decided to balance the sensual story material with the tone of the people's theatre, which had characterized the pre-war successes of DE JANTJES [THE TARS] (Jaap Speyer, 1934) and BleEke Bet [PALE Bet] (Alex Benno and Richard Oswald, 1934). Soeteman gambled that film spectators might then recognize the picture as part of a typically Dutch tradition: 'The more Dutch, the better' (qtd. in Van Scheers, 127).

Even though Verhoeven considers his WAT ZIEN IK?! as a negligible picture in artistic terms, it happened to become a tremendous success financially. The film set the trend for what Hans Schoots termed the 'sex wave' in Dutch cinema in the first half of the 1970s. In most films of this wave (see chapter 5) the dramatic parts (are meant to) preside over the comic parts, but in WAT ZIEN IK?! it is the other way around. Some groups of people in the Netherlands, mainly in Amsterdam, had participated actively in the socalled 'sexual revolution,' facilitated among others by the invention of the 
birth-control pill. 'Free love' became a popular catchphrase and sex was not restricted to only one partner. Many people had no first-hand knowledge of the practices of the sexual revolution, but were acquainted with the rumours. A volume of short stories, compiled by Mol in 1965 under the title Wat zien $i k$...?!, had captured the zeitgeist successfully. The fact that it became a bestseller over the years was an indication that a mass public was willing to read about (and watch) naughty sex adventures, when told in a frolicsome manner. Mol himself admitted that he had heard some gross anecdotes, which he decided not to include in order to keep the tone light-hearted (Van Scheers, 125). Even though tone and approach were not much to Verhoeven's own taste, he understood that the film could only attract an audience if the performances by the actors were relatively down-to-earth, for the material itself was already slightly exaggerated. Hence, he selected actors who had worked in television rather than in theatre, for television actors are more used to keeping emotions in check.

The dramatic plot of Verhoeven's adaptation is very thin: Greet is a redhaired prostitute and her colleague $\mathrm{Nel}$ - also known as 'Haar van boven' [Her from upstairs] - is her dearest friend. Greet gets involved in a relationship with Piet, but he will eventually return to his pregnant wife. Nel, on the contrary, is under the spell of her no-good, pimp annex boyfriend, Sjaak, but Greet encourages her to leave him. After a miserable blind date Nel bumps into a balding but decent merchant by accident, for whom she decides to leave the Red Light District. The pace of the film was deliberately fast to prevent the spectator from noting the absence of a coherent narrative (see Van Scheers, 128), for the plot is little more than a coat hanger for a series of weird encounters between prostitutes and their customers.

In the opening scene, a man returns to Holland after doing three years of development work in Africa. Giving vent to the idea that first things come first, he rushes to Greet by cab, and complains that he has not seen a single gorgeous woman in Africa, except for a nun. Sensing that he is very eager, she charges a high price for her services. In his excitement, the sex is quickly over, to his own deep dissatisfaction. Greet moves over to her cash register and dryly calculates the bill: '2 25 guilders, tax included.' In another scene we see Greet enter a toy shop from a high-angle master shot in order to buy a mask for a 'children's party.' Then we see Greet from behind and we face the salesman. Because the shot is from a slightly low angle, we see the many masks above his head, while he says: 'A children's party, so something cheerful.' He tries on two funny masks himself, but the camera pans to the right as Greet makes a quarter turn and points at a mask off-screen. The camera shows the salesman in close-up who after a few seconds mutters with a puzzled look on his face: 'That one? For a children's party?' 
In the next shot we see a neatly dressed gentleman arrive in an expensive car and enter a building. He walks slowly, while the musical score creates a sinister atmosphere. 'Can I proceed?' the man asks Greet, and a bit later: 'Nothing scary is gonna happen, right?' Greet leaves the room and orders him to get into the bed. Cut to a shot in which we see her from behind while she puts on a wig, lilac in colour. She bangs on the door and yells with an eerie voice: 'Ha ha ha ... I'm coming to get you.' First, we see the man in bed, frightened facial expression, and then the camera tracks behind Greet who enters the room, still yelling and laughing hysterically. In the meantime Nel has come down the stairs to Greet's room, and looks into the open door. Greet turns around in medium close-up, but half-way through the movement, the camera jump-cuts to a close-up and we see the scary witch mask she is wearing. Nel's scream is deafening. In fact, the close-up of the witch mask is the reverse shot of the scene in the toy shop, when Greet made her 50 | choice by pointing at a mask off-screen, one and a half minutes before. The unorthodox jump-cut during Greet's turn can be seen as accentuating the shock that provokes the bloodcurdling scream. The man in bed falls back in the cushions, with a satisfactory smile on his lips. He visibly enjoys the thrill. After Greet has reassured Nel by pulling off her mask, we see the customer leave the place, and he congratulates her on the superb act. He gives her an extra tip because of the fabulous scream.

It will be a red thread in the subsequent scenes between Greet and her customers that she puts on an act, dressed in character, and in retrospect it will turn out to be that the performance is in the service of the erotic satisfaction of a male client. At one point there is a cut to a close-up of Greet who blows a whistle against a white background. She is so close that we can only see that she is wearing something with a high collar. She mentions a variety of children's names, and then singles out 'Jantje' to whom she speaks sternly. Jantje is an adult man, wearing a sailor suit and, as we see a bit later, when he walks to his bench, shorts. In a long shot it becomes clear that Greet is dressed like a schoolmarm with a skirt to her ankles. As soon as she drops her piece of chalk, she bends over and remains in position so that Jantje can come over to put his hand under her skirt. Of course, Jantje has to be 'punished' for this behaviour. With both Greet and Nel, who plays the headmaster, in shallow focus in the background, we see Jantje in sharp focus on the left side of the frame, enjoying the spanking. Each and every time in WAT ZIEN IK?!, a specific setting is created - a horror scene, a school class with a naughty boy, Greet made up as a corpse who is asked for forgiveness by a male client and then comes alive - which is a play-act for sexual pleasure. Sometimes, as in the scene with the man whom they pick up in the park, the act is accompanied by a joyful melody, composed by Julius Steffaro (real 
name: Jan Stoeckart). The tune continues until we see them in three-shot on a bench, from a low angle that centralizes the man's suitcase. As he opens it, white feathers pop up, and in the next shot, Greet and Nel walk and cluck like chickens, whereas the man climbs upon a small table, imitating a rooster. The joyful melody that prepared us for this scene - which takes a twist by the way, when Greet gets angry at the customer - can be taken as a general guideline for all the episodes with the male clients. All the sexual desires in the film are not presented as deviant only, but as comic aberrations. The music is one clue, but Greet's cool attitude is another. Her lack of affection for them clearly shows after they leave. She only tolerates their idiosyncratic wishes because her axiom is, as the English title of the film runs, 'business is business.' Each and every customer is therefore no more than a weird passer-by, of whom we never get to know anything but his eccentric preferences.

Perhaps the strangest bird of them all is the man who chooses the disguise of a chambermaid, dusting Greet's place at her command. His arrival at her place is also announced by a happy tune. Dressed in a white miniskirt, a pair of pumps, and a silly head-cap, he likes the threat of being slapped by Greet's carpet-beater. Greet can play the role of dominatrix. When she checks the cabinet, she says in a loud voice: 'Wat zien ik?! Stof.' [What are I seeing? Dust. The grammatically incorrect language is deliberate, a sign of her lower-class background.] She then starts to hit this 'dirty and filthy girl.' While she continues to hit him, it becomes increasingly unclear whether Greet is merely playing the role of stern mistress or is actually disgusted by the act. When she stops the beating, she apologizes: 'Sorry. Was it too hard?' After some moments of recovery, the 'chambermaid' turns around and says: 'Ah, Madame, it has never been this great before.' While Greet fears that she really has transgressed some boundaries, it turns out that the customer experienced the punishment as the epitome of enjoyment. This illustrates the peculiarity of the male desires in Verhoeven's movie: The most terrible punishment can equal the greatest sexual satisfaction. This conclusion might have been cause for deep reflection, as in a Luis Buñuel film, ${ }^{6}$ but the way the 'chambermaid' behaves and ultimately delivers the line with a happy expression on his face makes the scene fit for comic laughter. The overall impression of the film is that all the male customers seem weird misfits, but though their yearning for role-playing games is a bit bizarre, they treat Greet with respect, minus perhaps the man who has taken on the guise of the rooster. But when she makes clear 'enough is enough,' he runs away as fast as he can, even leaving his clothes behind. ${ }^{7}$ 


\section{(NO) ORDINARY PEOPLE: HOGE HAKKEN, ECHTE LIEFDE AND SCHATJES!}

In fact, the way Greet seems to be in control in almost every scene is part of the vulgar charm of WAT ZIEN IK?! One indication that working as a prostitute is not that bad, is given when Greet visits the newlywed Nel. Her new home in Eindhoven is absolutely spotless. Her husband, Bob, returns home from shopping and announces he has a gift for her: two bottles of Vim, a cleaning product, which he bought on discount. The pettiness of Nel's life in the spickand-span residence (along with Bob) contrasts sharply with the careless conviviality of the lower-class environment to which Greet happily returns after the visit in Eindhoven.

Being direct is a quality that works to a prostitute's advantage in her own world, but such an approach to life leads her into an embarrassing situation when she enters into new, more sophisticated surroundings, as it is shown in

52 the 'classic concert scene.' This episode deserves to be singled out, because it heralds, in a nutshell, the turn that the bawdy comedy will take in the 1980 s. In this scene, Piet takes Greet out for the evening, but where they are going is a surprise for her. When she enters the music hall and sees the pianoforte, she exclaims: 'A concert?' so loudly that people in the audience turn their heads. Piet reminds her that she likes to listen to Schubert and Beethoven, but she counters that she only ever does so when that is what her customers request. For them, she asserts, it is a way to enliven the atmosphere. In every sense, Greet does not fit in with the audience at the concert: she applauds too late and continues clapping after one is supposed to be silent. While everyone is immersed in the aria, contemplating the high-pitched notes, she sits staring at the stage with wide open eyes, flabbergasted. She wants to put her arm over Piet's shoulder, but notices that he is uncomfortable with the gesture and so she starts eating a bar of chocolate instead, doing it noisily, and comments: 'This is certainly not Arbeidsvitaminen,' a radio programme that plays popular music. When Piet tells her this is not a cinema, but a concert, and that he wants her to behave herself, she gets so frustrated that she leaves her seat, causing quite a clamour.

In the concert scene, it becomes clear that Greet is only familiar with an ordinary background and has never been exposed to 'high culture.' She despises that everyone behaves according to some silently agreed upon sense of decorum that she herself is not aware of. She, however, does not just leave the music hall, but she makes a huge spectacle of her departure, which leads to shocked reactions among both the audience and the performers. Her going away is supposed to attract everyone's attention, for it is meant to express her disdain for this sense of decorum. Moreover, the best way to give vent to her anger at Piet is to make him embarrassed of her behaviour in front of all the viewers. 
This scene from WAT ZIEN IK?! can be seen in tandem with the film HoGE HAKKEN, ECHTE LIEFDE, which reverses the pattern, but to a similar effect of privileging the low class. Semijns Roggeveen, managing director of a firm, is bored by his upper-class existence, with a wife talking about yoga and meditation all the time. One day he visits the canteen of his workers, and sees how his employees address each other in a direct manner, like 'Watch out, loaf.' While we see him drinking a mineral water at a table, a subsequent shot shows him amidst the workers, dressed casually and laughing at corny jokes. In another shot, he imagines himself flirting with the assertive and high-heeled sales girl Jenny. While his wife thinks that he is withdrawing into a Buddhist convent, he starts to lead a double life, thanks to a wig and a fake moustache: in his new guise he becomes a truck driver, called Arie Snoek, at his very own company. 'Need a blow?' ('Moet je een knal?') becomes one of his favourite expressions, but when he receives one himself, he enjoys it tremendously. At the same time, he starts setting his new colleagues against the direction, complaining about the poor working conditions. Moreover, Arie starts an affair with Jenny, who one day happens to meet Arie's double, Semijns, in the office. Afterwards she tells Arie that the director told her that her breasts are very shapely, which drives the truck driver mad with anger. ${ }^{8}$ He even challenges the director via a letter to a duel, but this impossible situation of Arie meeting Semijns makes him realize that he has to make up his mind who he wants to be/become. This moment is visualized when he stands in front of a mirror - wearing Arie's clothes, but without the wig and moustache - and with a gun he cracks his own image. While the end credits start running, we see him say farewell to his upper-class friends as an orange-clad Buddhist at the airport, but in a next shot he secretly dons his clothes in a dustbin and continues the relationship with Jenny.

The children of the family Gisberts in the film ScHATJES! can be seen as relatives of both Greet and Remijns in terms of mentality. While the protagonist from WAT ZIEN IK?! displays her contempt for social status predominantly in the concert scene, the disdainful behaviour of Remijns is turned into a structuring principle. The way Remijns expresses his disdain for the upper class, however, is only 'child's play' in comparison to the rude way the four kids in SCHATJES! will behave. The timing of this film by Van Hemert can be considered as striking, for it is released in the wake of successes like ANNIE (John Huston, 1982), E.T. (Steven Spielberg, 1982) and the Dutch CisKE DE RAT (Guido Pieters, 1984). In all three films children suffer from the absence of father figures, but feel-good alternatives are at hand for them. SCHATJES! offers the bleak inverse of such narrative developments and its 'message' can be paraphrased as: 'Well, children, eat your heart out! Parents suck and fathers are even worse than mothers.' On a personal level, this film can be regarded as 
Van Hemert's 'revenge fantasy' upon his own authoritarian father Willy van Hemert, a director himself who became a household name thanks to a few hugely popular television drama series. ${ }^{9}$

From the affluent villa including an enormous lawn as well as from the fancy names they have given their children - the young adolescent Thijs, his slightly younger sister Madelon, and the two young boys, Jan-Julius and Valentijn - we can gather that the parents regard themselves as members of the better social circles. It becomes clear from the start, however, that there is an icy-cold relationship between the parents and the children. The oldest son is driving around on a motorbike on the green lawn, seen via a point-of-view of the father who observes this from his helicopter during office hours, for he happens to work as a pilot at a nearby air base. Father John yells at his son, but to no avail.

This opening scene is merely the overture for a series of violent attacks 54 and demolitions: on the request of Madelon, Thijs executes a bombing via the alarm clock in their parents' bedroom; Thijs floods the house; the two young kids attach a chain to their father's car so that the automobile breaks in half, and Madelon mows the word 'lul' [prick] with huge letters in the lawn as the father flies over the villa once again. One may wonder whether some of these scenes are funny at all, for a bombing is a most serious assault, but the presentation of it is definitely cartoonish. Due to the bombing, a door flies through the air, there is a lot of smoke, one young kid yells 'The Russians!' and the pissed-off father walks outside with one very dark eye and a bandage on his cheek. In another brutal scene, which is nonetheless played for laughs, the mother is thrown of a ladder, off-screen. We hear her scream, and we only see the outcome of the fall: she has landed head-down in a bush. As in animated cartoons, characters have only minor bruises or injuries, ready for other painful incidents in subsequent scenes.

SCHATJES! is a physical comedy which may come across as rude and sarcastic, for it pivots around the total disrespect of a bunch of rogues towards their parents. Since the battle can only harden, and even some soldiers in a jeep (to the dismay of Van Hemert, the budget did not allow for a huge army) eventually arrive to call the young riff-raff to order, the comedy comes to border on horror without ever losing its connection to humour. ${ }^{10}$ The manner in which John starts to chase his children with an axe, while singing 'Who's afraid of the big, bad wolf?,' recalls Jack Nicholson's behaviour from THE SHINING (Stanley Kubrick, 1980), but the overall atmosphere is obviously too humorous to ever become truly as haunting and sinister as Kubrick's classic. The best scene to argue that the horror should not take the upper hand over laughter is the one and only musical interlude. In a scene which is colour-tinted red and pink, Dennis - the handsome blonde tennis coach, both fancied by mother and 
daughter - starts to sing all of a sudden about how much he loves Madelon, if only to prevent the film spectator from getting (too) immersed in the family drama.

Despite the film's insistent emphasis upon comedy over drama and horror, it is worth looking at the nature of the parental crisis in SCHATJES! At the air base, John is senior in age, but he is still lowest in rank, as we gather from his superior, Pete Stewart (played by Rijk de Gooyer, who was Arie and Remijns in HOGE HAKKEN, ECHTE LIEFDE). John had been nominated twice for a promotion, but the behaviour of his children impaired his general esteem among his peers to such an extent that the nomination was withdrawn. Now, he will get a third, and last, chance. From the few scenes at his work, John is shown as a docile pilot who wants to please his superior. He takes his job very seriously, and he works hard to support his family. Actually, he is so preoccupied with the possibility of a promotion that he fails to notice that his house is flooded upon his return, until he lays eyes upon the broken toy helicopter he once received as a trophy.

The basic error John makes is that he projects the hierarchical thinking that works best in a military setting onto the situation at home. In the military a higher-ranked person automatically derives prestige from his symbolic position. In his own family, however, he expects that his children pay him due respect because a father happens to be the head of the family. Symptomatic is the verbal expression he uses when he starts to interrogate the eldest of his offspring after the bombing: 'Your mother has asked me to enquire after the root causes of your behaviour of the last days, last months, yes, you might even say the last few years.' This 'your mother has asked me ...' presumes that a father is supposed to call the kids to account for their deeds: in the opinion of the parents, it is up to a father to speak with a voice of authority. In the eyes of John, his children have been troublesome ever since they could talk. According to him, they are intractable, as if it is in their nature to be nasty brats. To him, his symbolic position is so self-evident that if his command is ineffective, the children are to blame for they probably lack the right mentality and discipline. When they do not listen, he can only impose a penalty, such as withholding their pocket money or (what piques Thijs, as he says later when things go bad at home) threatening to send them to boarding school.

Underlying the apparent sarcasm is the children's attempt to reveal to the father that his power is an empty shell. He always takes a stance of authority, but that does not make him authoritative yet. Since he does not see this discrepancy, John fails to acknowledge that his authority is built on quicksand. Moreover, as the mother makes clear, he overshoots the mark by using rude expressions like 'kut met peren' [literally, 'cunt with pears'] or grandiose words, as when he calls the deeds by the children 'pure genocide.' Such 
efforts are so pathetic that they will ruin any chance of having an impact on the children.

The father not only has a blinkered view of the needs of his children, he is also blind to the licentious behaviour of his wife. She tries to seduce the much younger Dennis and performs some cunning tricks to prevent any encounter between her daughter Madelon and the guy she is infatuated with herself. Mother Danny has told the tennis coach that Madelon is still ill and Dennis asks her whether he can pay her a visit. The mother answers that her daughter is perhaps only pretending to be ill because she does not like playing tennis. While she caresses his neck, we hear the whirring sound of a helicopter. As Dennis walks away from the mother in bad temper, the sound increases in volume. A low-angle shot shows both Danny and the helicopter in one shot. She gets mad at the helicopter, for she realizes that it is probably her husband, who might discover that she fancies Dennis - even when John is actually too 56 | trustful to recognize her behaviour as improper. Her crush on the tennis coach is so extreme that she flies into a fit of rage when the youngest child tells her by phone that Madelon is sleeping with Dennis - actually, he uses the word 'rampetampen.' She even unleashes her anger at a totally innocent child.

SCHATJES! can be qualified as an anti-establishment comedy with children who, while living in relative luxury, rebel against their parents in a manner as if they have never had any form of decent upbringing. The father exclusively relies upon his symbolic position and the mother merely pursues solipsistic desires. She is hardly interested in giving her children a proper upbringing, bribing the two young kids with candy if she wants them to do something. Although SCHATJES! owes its success to the laughter provoked by the bold acts the kids commit, it warrants attention that the children are not just spoiled brats nor are they 'inherently' bad. A great part of their bullying results from frustration with their parents' incompetence and neglect of them. In the absence of their parents, the children turn out to be quite caring among each other most of the time and both Thijs and Madelon take up the parental role, almost matter-of-factly. This implies that their rebellious behaviour is basically aimed at exposing the false pretence of their father. As such, the film can be taken as a critique of the thin veneer of social varnish in a well-to-do family.

Perhaps this (implicit) social critique is the main reason why SCHATJES! was generally more appreciated than its less successful MAMA IS BOOS! [MUMMY Is MAD AS HELL]. (Ruud van Hemert, 1986), which is more like an average drama of adultery. Thijs and Madelon are no longer around and the focus is upon the animosity between the father and the mother, because he has had an affair with a woman, which Danny considers unbearable. She plays the role of the cheated wife to ridiculous effect and he becomes the object of her aggressive fits. In fact, MAMA IS BOos! offers little more than her irrational anger. 
This already shows in the very first, outrageous scene of the film. At the end of SCHATJES! the parents were in pursuit of their children by car, late at night. They deliberately ignore a roadblock and drive their car into a huge gap that is about to be filled with cement. The very final shot of the film shows a little flag, stuck in the highway, apparently locating the spot where the parents are buried. In the opening of MAMA IS Boos!, preceding the starting credits, we get a shot of this particular road. Red, purple and blue filters are used respectively, while the camera zooms in on the little flag still stuck in concrete. The flag flaps vigorously because of the wind caused by busy traffic. The camera moves underneath the road and we hear a radio report about a missing couple. The father, still alive, gets angry when he hears the journalist say that he is 42 years of age: '41, asshole.' The camera tracks back, and then we see the mother lying on the back seat of the car, staring with glazed eyes, as if she is a zombie. Even when a few litres of sewerage floods over her face, she does not move. Initially, the scene seems to be a follow-up to the finale of SCHATJES!, but then father John wakes up, gasping, and it only turns out to be a bad dream.

Nevertheless, there is one elemental feature that distinguishes the bad dream from 'real life': in the dream John's wife was motionless, but in 'real life,' she will burst in a fury, totally unreasoning, time and again. During the party of the $20^{\text {th }}$ anniversary of their marriage, the mere hint of the youngest son, Valentijn, that the tears in his father's eyes are caused by the absence of his mistress, Jane, enrages the mother, Danny. At no point in the film is she open to reason and she grasps every opportunity to wreak physical havoc upon him. When in a later scene John tells his mistress that perhaps some sense will have come into Danny, there is an immediate cut to the mother with a chainsaw.

The difference between SchATJES! and MAMA IS BOOS! can be illustrated by distinguishing the psychoanalytic notion of demand from drive. A demand has some symbolic value. A person can demand something, but, as Slavoj Žižek explains, what he is 'really aiming at through this demand is something else' (Looking, 21). The children demand to terrorize their parents, but what they actually seem to aim at is their affection. Drive, on the contrary, "persists in a certain demand, it is a "mechanical" insistence that cannot be caught up in a dialectic of desire: I demand something and I persist in it to the end' (Looking, 21). This seems applicable to the mother in MAMA Is Boos!, for she seems only bent after the destruction of her husband: terror is her goal.

Of the many subvarieties within the genre of horror, one might say that they are all 'caught up in a dialectic of desire.' Struggling with immature or 'unfinished' masculinity, (young) men in slasher films might give full vent to their frustration by targeting female victims whose behaviour is frivolous, as is hypothesized by Carol Clover; or the sleazy horror can be a reaction to the 
monstrosity of the female body as Barbara Creed suggests, while the vampire, Richard Dyer claims, can be related to a context of (closeted gay) sexuality. ${ }^{11}$ As psychoanalysis teaches us that repressed desires always return, but in a necessarily different form, then the various categories of horror are possibly some of these forms. In such cases, horror can tap into people's unconscious and this can explain the elevation of some well-executed films to the status of classic, from Nosferatu to PSYCHO and from DR. JEKYLL AND MR. HyDE to THE SHINING.

The one subgenre exempted from this logic is the zombie film which may be one of the reasons why the status of its best-known title - NIGHT OF THE LIVING DEAD (George A. Romero, 1968) - is definitely cult, with relatively little appeal to middle-class audiences. The zombie only demands to be fed by someone's flesh and has no further quibbles with (structures of) society. Of course, the zombie can be, and actually has been, read as metaphor for criti-

58 cal tendencies in society (shopaholics are like zombies), but as a character this monster is basically an 'it,' merely programmed to bring death and destruction. The mother in MAMA IS Boos! is, of course, not a real zombie, for she has a clear motive. She is stunned with jealousy and therefore she demands the annihilation of John. But through this demand, she is not really aiming at something else, like the children were in SCHATJES! This may explain why the quite straightforward MAMA IS BoOs! was less successful than its slightly more double-edged predecessor. The superiority of SCHATJES! over its sequel also shows in its intertexts. Whereas SCHATJES! clearly alludes to the classic horror film THE SHINING, MAMA Is Boos! is to be associated with the subgenre of the zombie film, accentuated by the scene in which the characters who are still beholden to the mother move towards the caravan of John's mistress. Shot from within the caravan, they appear as huge threatening shadows outside. This scene is almost like a replay from similar scenes in NIGHT OF THE LIVING DEAD when zombies are trying to invade the house in which the main protagonists of the film are hiding. Whereas the official sequel MAMA IS Boos! could not rival the original SCHATJES!, one might say that FLODDER is its unofficial successor, which brought the anti-establishment comedy to a new level of success.

\section{BE THYSELF (OR ACT LIKE A PERSON): FLODDER}

Since the lower-class family Flodder has been living unwittingly on a dump for toxic waste, the social worker Sjakie van Kooten pleads the case that the council has a responsibility to offer these 'well-meaning people' a proper home. There is no better option than to settle them in a long-vacant house in the well- 
to-do neighbourhood Zonnedael. ${ }^{12}$ According to Sjakie, such a completely new environment has the advantage of forcing the family to adjust themselves to the structured lifestyles of their upper-class neighbours. The basic humour of the film FLODDER consists of laying bare the discrepancy between the gaudily rude behaviour of the new inhabitants and the social conventions of the upper class. This discrepancy is announced in the beginning in two ways - via striking edits as well as via a specific conversation. First, while Sjakie is emphasizing the benevolence as well as the utter sensitivity of the Flodders, we get shot transitions to Mother ('Ma') Flodder which belie his statements. The first time we see her, she is surprised that her oldest son, the 27-year-old Johnnie, digs up a photograph of a man, probably from the attic: 'I have not seen that face for more than ten years,' she says. 'Is that my father?' daughter Kees asks. 'No, his father, not yours.' After the photograph has fallen on the ground, its glass broken, the dog pees over the portrait. This very first scene with the Flodders is meant to suggest the family's laconic un-sentimentality and the matriarch's apparently unforgiving nature, according to the commonplace: 'Out of sight, out of the heart.'

Second, the discrepancy between the family's straightforward stance and the social cohesion among the rich is ambiguously expressed in a dialogue between Johnnie and his half-sister Kees, when they drive with his very old car, exploring the new neighbourhood. Overlooking the villas with their wellkept lawns, Johnnie says: 'Well, don't fancy anything.' Kees: ‘Oh, no, I will just remain my very own self.' Johnnie: 'That is exactly what I am afraid of.' In fact, this conversation goes to the heart of the film's 'message,' if this term can be used at all. The Flodders cannot be but their very own selves, because they live according to their 'instincts.' And in just following their impulses, they wreak havoc in the streets.

A binary opposition is clear from the start: in contrast to the proper and 'good' citizens in Zonnedael, the Flodders are primitive, and hence, (mildly) 'evil,' because it is not in their 'nature' to conform to social conventions. The opening scenes function as illustrations to point out their nastiness and/ or their laconic attitude bordering on moral indifference. When a journalist mentions the nasty odour of their old home, Ma Flodder says: 'What bad smell?' Their obliviousness to dirt is affirmed when the male Kees throws a banana peel out on the impeccably clean streets of Zonnedael. Further, the Flodders address people in either too colloquial a way - 'Hey, Sjakie, old wanker' (Johnnie) - or in sexist terms - 'look, some horny dames' (the male Kees). Their disinterest in a working ethic is illustrated when Ma Flodder tells Sjakie that 11 o'clock is too early to pay them a visit, since everybody will still be sound asleep. Their refusal to recognize authority shows itself in the scene when Johnnie drives away in his car at high speed, almost overrunning two 
policemen. Their utter lack of an intellectual standard is proven in their naming: the mother is simply called by the shorthand 'Ma,' and the old man in a wheelchair is just 'grandpa,' even though as is revealed after his unfortunate death, he probably was not their grandfather at all, but some drifter whom they adopted as their grandfather, another token of a topsy-turvy world. Moreover, this 'grandpa' is not a wise, old man, but seems like a cranky fool, all the time dressed in the attire of a railway guard, and every word he utters is simply inarticulate. The names Johnnie (not spelled as the more common Johnny) and Henkie (not even Henk, but the belittling variant) typically connote a lower-class background; the name Toet for one of the daughters is down-right silly and sounds more like a nickname, whereas the fact that both a boy and a girl are named 'Kees' is the ultimate sign of how little they care about fanciful names.

When Toet meets a neatly clothed girl, called 'Stephanie,' much more fan60 | ciful (like Madelon or Jan-Julius from Schatjes!), the latter's mother is quick to remind her to attend her violin lessons. Stephanie then asks Toet: 'Do you love Paganini as well?' but Toet replies: 'I prefer Chinese,' misunderstanding the fondness for the compositions of a famous musician for a question about types of cuisine. This particular conversation is striking in that it highlights the gap between the typical bourgeois with their cultural taste and the lowerclass family. If the latter hear the name of an unknown artist, they think of food. In the vein of Bakhtin's concept of 'grotesque realism,' the family has the tendency to bring anything abstract, intellectual or cultural to the level of the body. Since they display neither a spiritual nor a sophisticated dimension, they can permit themselves to be frank about basic needs like food, drink, sex and death.

Ma Flodder is brewing her own beverage, while attaching fake labels to the bottles. The point whether she has the capacity to make her own alcohol, is sidestepped by her remark that it is only a 'matter of fermenting.' Quality is not the issue here, but quantity. ${ }^{13}$ The family consumes drink and food in large amounts: they eat fried potatoes with their hands and at an amazing speed. As regards sex, the big-breasted daughter Kees has no problems in showing herself off as an erotic object, on the condition that it offers the family financial profit. She seduces the neighbour in his garage, while her brother Kees takes a photograph of the scene. The seduction is a well-planned act to blackmail the neighbour who works as a car dealer. If the neighbour asks them how they want to pay the expensive sports car they have in mind, Johnnie replies: 'Polaroid.' The scene is exemplary for the overall context of the film: the needs of food, drink, sex and death are absolutely basic in anyone's life - and hence, one might expect a serious treatment - but these are constantly hinted at in a humorous way. For the family, sex is not related to love, affection or excite- 
ment, but it is a commodity value instead. And insofar love and sentimental feelings are at stake, the impression is at hand that it is play-acted or embedded within another aim.

Johnnie has an affair with Yolanda, one of the neighbour ladies who is bored to death with her husband. She is a handsome woman, but part of her attraction may reside for Johnnie in the fact that she is married to a colonel in the army. Such a man tends to believe that he can derive some status from his profession, and moreover, he will definitely think himself superior to an unemployed 'bum.' Cheating with his wife is then a special delight for a guy like Johnnie, the more since the colonel is in fact still only a boy, as can be gathered from the huge toy army he has in the cellar for a hobby. This toy army is used for comic relief in the representation of the sex scene between Johnnie and Yolanda. When they make love for the very first time, their act is off screen, but we see some of the toy soldiers tumble down and, suggestively, we see the 'loop' of several cannons rise.

To summarize, the majority of the comic scenes are rooted in some bodily aspect - be it sex, food, drink - or in an utter disinterest in decorum, and this is the common denominator of all the films in this chapter. For that reason, one might say that their behaviour is not that far removed from the way animals behave themselves. According to a specific theory of humour, the human is to be separated from the animal because of man's capacity for laughter. Humour confirms man's eccentric position in the kingdom of animals. But, as Critchley wagers, the capacity for humour also, 'curiously, marks the limit of the human,' for all too often 'what makes us laugh is the reduction of the human to the animal' (29). If this is the case - and I think it is fairly applicable in the case of FLODDER - the lower-class background is the object of humour. And hence, one might say, in general, that characters who act peculiar, because of bestial instincts, are to be taken as butts of the jokes, that is, we laugh at them, to paraphrase Critchley, because they constantly overstep the limit between the human and the animal (36). The prostitute Greet in WAT ZIEN IK?! is prepared to do anything to satisfy the whimsical demands of her clients, even wear a scary mask or dress and walk like a chicken. ${ }^{14}$

Their ludicrous actions, however, are superseded in silliness by the behaviour of the people who surround them: the male clients of Greet in Verhoeven's film or the decadent neighbours in FLODDER. The Flodders are unconventional, indeed, but in 'being themselves,' their indecent appearance at least corresponds with their indecent 'identity,' not to say, nature. Unlike the Flodders who do not make any attempt to adjust to the well-to-do environment, their neighbours apparently fit in with their surroundings. The presence of the Flodders will actually reveal, however, how their whole lives are exclusively structured according to tight social conventions. All the time, one 
is supposed to act like this, or like that, but this socially accepted behaviour is only the result of the repression of one's impulses. The direct neighbour of the Flodders, Mr. Neuteboom, pretends to be watering the plants and trees, the perfect excuse to his wife for hanging out in the garden, while he is playing peeping Tom at daughter Kees, dressed in a sexy bathing suit. When his wife tells him that his task already takes quite a while, Neuteboom is reminded of the job he is actually supposed to fulfil. Neuteboom's distraction will turn out to be exemplary for the other neighbours as well. They come across as perfectly civilized beings, but as soon as they are sexually aroused or provoked, they give free rein to their desires or aggressive impulses. Hence, it seems no more than logical that at the party at the Flodders' home, near the end of the film, practically everyone starts to indulge in vulgar behaviour.

One might say that FLODDER shows that finally there is hardly any wall separating the lower-class family from their 'civilized' neighbours, and that 62 as soon as one strips the veneer of social conventions, the 'animal within' is released after all. In that sense, ScHATJES! can be seen as a relevant predecessor to FLODDER, for the parents respond to the provocations by their children in a hysterical manner, making the father a match to the father in THE SHINING. Even though this would already come down to a kind of message - which, remember, director Dick Maas would deny his film contains - I guess there is a more intriguing purport to be gathered from FLODDER. If the neighbours, like the parents in SCHATJES!, start to display their particularly uncivilized demeanour, this means, in retrospect, that they have all the time only been pretending to be civilized. Here we can address a specific twist that Critchley mentioned in his study On Humour. A person behaving like an animal (or like a thing) can be a source of pleasure, but at the root of the comic is 'rather - surprise, surprise - a person acting like a person' (59, italics in original). As such, we can point at a displacement taking place. On a superficial level, the lowerclass family is the object of humour, because their conduct deviates from conventional norms in a rather rude way. By contrast, the neighbours conformed to the norms upheld in the villa area, but ultimately it is revealed that they only play-acted this conformity. Whereas the Flodders are 'authentically' rude, the neighbours are in the end 'worse': their polished appearances do not correspond to their identity, deep-down. The best example of this gap between appearance and correspondence is the scene in which Mr. Neuteboom tries out some cocaine and asks the dealer whether it will have a quick effect. 'Oh, yes, it will,' the dealer replies. And at that very moment, Mr. Neuteboom is hit by his wife on his head, for she has discovered in the meantime some compromising pictures of her husband, harassing girl-next-door Kees.

The more the hypocrisy of the rich is being revealed, the more the Flodders are to deserve our sympathy, because it is their attitude of 'just being 
themselves' which is responsible for the revelation of the 'false' appearance of their neighbours. The frequent references to bodily aspects of the Flodder family - food, drink, sex - are ultimately embedded in a satirical portrayal of the so-called civilized environment. We laugh at the all too direct manners of the lower class, but this laugh is relatively benevolent. Despite their unorthodox practices, we at the same time sympathize with the Flodders for their refusal to compromise their desires. They do not undertake any attempt to bend themselves to the norms of their new area. In contrast to this benevolent laugh, the neighbours are ultimately turned into the true objects of derision, if not of scorn, because of their sly ways to respond to the direct manners of the Flodders.

\section{CARNIVALESQUE}

The humour of FLODDER is to be categorized under the section of what Bakhtin qualified as the carnivalesque. The film plays with existing notions of social hierarchies between the upper class and the lower class, and seems to suggest that, on a closer look, these hierarchies are represented topsy-turvy. As in carnival when all hierarchies are temporarily suspended (Bakhtin, 10), the world is portrayed upside-down: the apparently decent people are revealed to be more indecent than the primitives. Moreover, another reversal concerns the fact that the seemingly wild Flodders are ultimately good-natured. Not only are they so hospitable as to invite their hostile neighbours, but if they commit an evil deed, it is because they know no other way how to achieve their goal. The Flodders may have obtained a fancy car with foul means, but they unexpectedly pay Mr. Neuteboom the full sum after all, as soon as they totally unexpectedly inherit a large amount of money. Hence, impressions that they may be sly or greedy are contradicted in the end.

A logical question would now be: Is the effect of this carnivalesque subversive or not? To some extent it always is, as Bakhtin claimed. Carnival laughter is of a complex nature, for it is always ambivalent. On the one hand, one laughs at a specific carnivalesque situation, because one recognizes that it is a reversal of the convention. Hence, the laughter works to affirm the 'original' hierarchy as the norm. On the other hand, however, the 'entire world is seen in its droll aspect, in its gay relativity,' and as such, the mockery is 'also directed at those who laugh' (Bakhtin, 11-12). People who are laughing at the scenery also belong to the crazy world that is being represented. In FLODDER, all social hierarchies are mixed up and hence, undermined, which would underscore Bakhtin's idea of the ambivalence of folk humour.

Nonetheless, several aspects considerably lessen the possible impact of 
the subversion. First, the Flodders at no point effectively resist the existing status quo. They accept the situation as a given, just as they have agreed to be moved to the new area. Their only goal is to continue living as they used to do, regardless of the fact whether their habitat is a dump or a beautiful villa. Being poor themselves, it is no issue for them that the neighbours are wealthy. They are out of step with their environment, but they do not bother and make no attempt to adjust. Their neighbours, however, and that is the basic source of pleasure in this film consider their presence as a nuisance. Even though the Flodders are neither deliberately vicious nor troublesome, their arrival is interpreted by them as an invasion of 'alien elements' and as a violation of their way of life. The careless behaviour of the Flodders has a comic effect, because the neighbours get irritated by any slight disturbance from their regularly coded existence. Being shabbily dressed, as the Flodders are, or ordering the cheapest kind of meat leads to expressions of dismay among their neighbours.

64 In the end, the Flodders owe the audience's sympathy because of their sharp contrast to the self-elected elite in the neighbourhood. The latter are such a stock representation of a bourgeois class who consider sticking to strict etiquettes as more important than personal contacts or emotional ties that viewers are not encouraged to identify with them. The Flodders as a typically maladjusted family, displaying a series of jokes centred around the body - on sex, on eating, on excrement - are to be preferred over the well-to-do citizens who live by rules of decent decorum. As such, the neighbours are exposed as play-acting being aristocrats of 'good taste,' which is 'worse' than behaving like animals. The banality of the Flodders is ultimately a more reasonable alternative than the cold shallowness of their neighbours.

If the social elite is being poked fun at in FLODDER, then there is nonetheless a character who supersedes them in ridicule. Sjakie is a well-meaning social worker with good connections in local politics. His mission is to abolish the borders between different classes. According to him, the differences between people are neither natural nor inherent, but only a result of reigning conventions and habits. People are like chameleons who will automatically adapt themselves to the environment they inhabit. Sjakie aims to mediate between all the parties involved, but in the end he is the true fool of the film because, time and again, something happens which proves the reverse side of his good intentions. His belief that neighbours will behave in a socially cohesive manner and act according to the principle of mutual forbearance is exposed as utterly naive. Hence, his social experiment results into a total failure, illustrated in the particular image of Sjakie waving a flag amidst the ruins after the house has been blown to pieces. Most of the characters have only minor bruises, but Sjakie, as the proverbial unlucky bird, ends up in a hospital with several broken bones and his head bandaged. The Flodders send 
him a postcard thanking him that he has made his holiday resort in the south of France available to them. In the final shot, Sjakie crumbles the card with his one remaining arm.

Three insights can be drawn from FlodDER. First, the Flodders wreak havoc in a well-to-do environment. Their behaviour is a source of vicarious discomfort to the neighbourhood, but becomes a source of humour for the spectators, because the social veneer of the elite gets stripped away. Their intolerant attitude towards the newcomers emphasizes that they only play-act their status as aristocrats. The film is turned into a clash of social classes, with the lower-class family in the role of sympathetic underdog, thanks to the great contrast to the stereotypical bourgeois - or to use that alliterate expression that any Dutch person will know, 'kouwe kak.' Impossible to translate properly, but it would run something like 'cold upper class' or 'fancy airs,' but the expression works so well, because 'kak' is also a lower-class term for poop.

Second, as a necessary mediator and scapegoat, the too truthful Sjakie is time and again put in a position to make a fool of himself. He is mildly, but never severely, punished for his naive belief that there should be tolerance between the classes. He wants to abolish the borders between classes, but its effect is paradoxical. He believes that the Flodders can become 'decent people' when well-bred in a 'solid' environment, but in fact it is the other way around. The two groups can only come together on the condition that the neighbours become a bit like the Flodders.

Third, if there is a depiction of the lower class in a serious manner, it usually has the outlook of a heartfelt art-house drama, shot with a handheld and/or close camera, as in Joy (Mijke de Jong, 2010) or in LenA (Christoph van Rompaey, 2011). The deplorable living conditions should not be taken too lightly, these films imply, with the inevitable consequence that an optimistic tone is only minimal. Maas, however, did not opt for a gloomy, cultural-pessimistic template, but presented his FLODDER as a film about the lower class, in the form of a hilarious comedy, including bright and gay colours instead of a damp atmosphere. Its tremendous success at the box office, proof of its 'entertainment' value, may almost gloss over its ideological message - almost, but not quite. FLODDER may have been produced as sheer amusement without an explicit 'boodschap,' but that does not alter the fact that there is a message underneath: swanky neighbours and the naive social worker are disadvantaged in favour of impulsive simpletons. 


\section{FORREST GONE BERSERK: NEW KIDS TURBO}

Leaving aside its two sequels - FLODDER IN AMERIKA! (Dick Maas, 1992) and FLODDER 3 (Dick Maas, 1993) - and the television series, the best candidate for inheritor of FLODDER in terms of its humour and its popular appeal, might be NEw KIDS Turbo (Steffen Haars and Flip van der Kuil, 2010). This may seem a peculiar claim, since the differences are many and obvious: the New Kids do not constitute a family, but consist of a group of five buddies; unlike the Flodders, they derive their social identity from their home ground (Maaskantje in the region of Brabant) to such a degree that any relocation to another place would be unpopular; they are not being used in a social experiment like the Flodders were, but they initiate a social experiment themselves: What if we do not pay for anything anymore due to the low unemployment benefits? Apart from these obvious differences, there are quite a number of 66 gradual dissimilarities: The language is more coarse, the manners are more rude, the exhibit of sexual desires is more direct, and the homophobic tone is more aggressive. This does not surprise us in a film which post-dates the TV shows of Paul de Leeuw or the late Bart de Graaff, the gross sexual jokes in the films of the Farrelly brothers, the juvenile pranks in the AMERICAN PIE franchise, and the popularity of the violent cinema of Quentin Tarantino. The best token of a general ruthlessness in NEW KIDS TURBO can be illustrated by pointing at the cameo appearances of the popular comedians Hans Teeuwen and Theo Maassen. Teeuwen and Maassen are forerunners in a generation of cabaret performers who are not afraid of provocative jokes, which may anger those who think they violate the conventions of dignity.

Notwithstanding these differences, NEw KIDS TURBO can be regarded as close to FLODDER in terms of its kind of humour as well as its popular appeal. As a common denominator, the five buddies do not compromise and all the time act according to their primitive instincts. So, if one feels like eating fast food, one goes to the snack bar, even during the working day. If one wants to smoke marijuana, one does so from self-grown cannabis. If one wants to drive around very fast, one neither cares about speed limits nor about the safety of pedestrians or cyclists. If one hits a person, one is concerned about a scratch on the car and not about the victim. As a typical feature of their indifferent attitude, they at one point wonder what day of the week it is. Since two of them wrongly assumed it is Sunday instead of Tuesday, they are far too late for work - and both get fired thereupon. Another typical feature concerns their appearance. They are sloppily dressed in clothes which might be qualified by the oxymoron 'camping tuxedo.' All five are wearing a moustache and they have long unkempt hair, covering their neck, except for Rikkert who has a short haircut which is known as the flowerpot style. Because of his haircut, Rikkert recalls 
Forrest Gump, the title character of the successful film, played by Tom Hanks. My point will be that this resemblance is far from accidental, and that the film can be seen as a brutal updating of FORREST GUMP (Robert Zemeckis, 1994). The very first scene, before it is interrupted by a loud and brief title sequence, clearly captures the film's spirit. In the vein of FORREST GUMP which famously starts with a digitally manipulated feather floating in the air until it arrives at the main character's feet, the camera in the opening of NEW KIDS TURBO follows an artificial butterfly, accompanied by the melodic intro of a happy hardcore house song, Paul Elstak's Rainbow in the Sky. As soon as the butterfly comes in the reach of Robbie, he crushes it with a single blow: 'That fucking butterfly.' The song stops abruptly.

The feather in ForRest GuMP was only meant to muse about the idea, effectively articulated at the end of the film, whether each and every person already has a set destiny or that people are 'just floating accidental-like on a breeze.' Although Forrest thinks it may be both, Slavoj Žižek has indicated that the film thereby overlooks a more significant effect: we create our fate but not in conditions of our own choosing (Taylor, 45). It is a tale about an innocent bystander, who just does what he does, without any further ado. All his actions are based upon intuition, not intention, but he happens to set in motion great historical events, like the U.S. rapprochement with China. Forrest's purely accidental deeds, however, serve time and again a conservative mentality. According to Žižek, Forrest 'gives body to the impossible pure subject of Ide$o \log y$, to the ideal of a subject in whom Ideology would function flawlessly' (1996, 200, emphasis in original). He never ever gives the slightest impression of a political orientation, but all of his actions have serious ideological consequences which are constantly in support of the American Dream and are averse to any leftist-liberal tendency of 'free love,' 'allowance of drug use' or 'war protest.' Better be a simpleton like Forrest whose naivety situates him on the right side of history than the idealist and (pseudo-)intellectual stance of the other important character, Jenny. To underscore the conservative tone of Zemeckis' film, Jenny dies of AIDS, which is related to her excessive pursuit of (amoral) freedom. It is excessive in the sense that leftists like Jenny deliberately adopt a political attitude of resistance and presumed commitment: she spends her life involved in the lefty protest movements of the moment, unlike Forrest, who just strolls through the decades, unaffected by the zeitgeist. Jenny is positioned as a rebel for silly causes, time and again opting for the latest fashion or political hype, whereas Forrest remains the very same, stable figure from beginning to end. FORREST GUMP thus suggests that if people follow their natural 'self' or destiny, they are always automatically - and safely - within the domain of a liberal-capitalist society, the secure basis of the American Dream. In order to follow one's natural destiny, and this is the 
basic ideological purport of FORREST GUMP, one should not be hampered by an overabundance of rational thinking, which is the best guarantee to prevent one from siding with political fads. Ultimately, FORREST GuMP seems critical of those who think they are smart, like Jenny who considers herself to be more clued in than a simpleton like Forrest. Unlike his blissful ignorance, her restless intellect is expressed as - literally and figuratively - a fatal variant of political engagement.

FORREST GUMP is a heart-rending film about a sentimental guy who pursues his genuine love for a politically engaged girl whose life is elsewhere and whose wisdom of life can be summed up in the simple tagline: 'Mama always said life was like a box of chocolates. You never know what you're gonna get.' NEW KIDS TURBo can be seen as the conversion of the sentimental FORREST GuMP into a rude comedy. Its hypothesis can be summarized as: what if Forrest had gone wild under the influence of four buddies, with Rikkert - who has 68 a young mother as a girlfriend, but has never had sex with her - in the role of Forrest. If Forrest Gump seems critical of intellectual smartness and political engagement, then NEW KIDS TURBO, as a version of 'Forrest gone berserk,' adds to this a vehement attack on the obstacles created by social rules. So any figure who upholds such rules becomes the butt of a joke. This can be executed in a relatively friendly atmosphere, when Gerrie pokes fun at the local policeman, Adrie, by making him run for his cap. The New Kids, however, get seriously angry when after what they consider a minor offence against a civil servant at the social security office, their unemployment benefits are reduced to zero. First, we see how a bill collector, in a rapidly cross-cut sequence, is persistently ringing the doorbell. Not only is he hit on the nose when Richard finally opens the door, but Adrie also receives a punch in the face when he comes to the assistance of the bill collector. From this moment onwards, it is time for hard and gun-blazing action, for the law enforcement officers have decided that their practice of looting are totally unacceptable.

The trick of the film is similar to FLODDER: how to legitimize the totally unorthodox practices as sufficiently valid so that the New Kids - despite their anti-social stance - can maintain their role as the sympathetic underdog? NEw KIDS TURBo hinges upon a twofold rhetorical strategy. First, Richard who more or less acts as their leader succeeds in sentimentalizing their position, when they are interviewed for the local television station TV Brabant. We hear sentimental music, when Richard tells the story that he was a normal, hard-working guy who got fired because he had brought his bulldog Gradje to his job at the sanitation department. In times of economic crisis, he laments, it is hard to find another job. While we see a shot from the journalist who nods in an understanding way, Richard explains that he could not leave his dog alone at home, because the animal is sick. Due to sensitive intestines, the 
dog needs special food. While he wipes off tears from his eyes, Richard is also shown peeping from under his hands to see whether his story has the wishedfor effect upon the journalist, which emphasizes that he only play-acts his sorrow. Moreover, the television item is intercut with shots from viewers, and the most important of these viewers are two men in a café. One has apparently drunk so much that he has dozed off on the bar, but the other one is still drinking beer and talking, to no one in particular, after we get a close-up of Gradje: 'That is such a sweet dog,' and then again, almost in tears: 'My God, that is a sweet dog.' While the journalist ends his item by stating that the viewers have to decide for themselves whether the five buddies are dangerous swindlers or victims of the economic crisis, the viewers within the diegesis have already decided in their favour. The moment that definitely affirms their status as pitiful victims, is when the beer-drinking man in the café yells to the bartender: 'Hey homo! We won't pay for anything anymore, either. Hand me four more beers, dude,' which is followed by a shot of men sitting on a couch, tearing up letters from the taxman. The media coverage of the New Kids works to encourage sympathy for them and will result into a chain reaction, for many inhabitants of the region of Brabant will imitate their example.

Second, insofar as the New Kids might be 'bad boys,' any civilian alternative is worse. The very worst is probably the Minister of Defence who is called upon by two officials to intervene because of all the uproar in Brabant. Since the five buddies are identified as the root of the problem, the minister decides to bomb Maaskantje, which he constantly mispronounces as Maaskant. (Since he has never heard of the place before, why would anyone else?, he argues.) This cynical attitude is topped by the fact that the army accidently bombs Schijndel, the neighbouring place, of which the minister has probably never heard either, as one of his assistants asks him after the mistake. As the television reports that the bomb - that 'big ass ball of fire,' as the New Kids call it - which has destroyed Schijndel was meant to eliminate Maaskantje, the five buddies become totally determined: 'Nobody touches Maaskantje!' This slogan or battle cry functions as a counterpoint to the cynicism of the minister. Despite all their apparently narcissistic pursuit of pleasure - drinking, smoking, joyriding, insulting people, breaking things - there is something elementary they care about: they have a deep-felt concern for the small community they are part of. Their birthplace is an undeniable core which constitutes their identity, just like the blood running through their veins. Politicians utterly lack such a core. They only cling to symbolic, and therefore shallow, accoutrements signalling power, authority or wealth.

The violence that evolves from the battle with the army and the New Kids will be shown in a humorous context, full of wisecracks and unlikely incidents. Thanks to the sympathy that has befallen them, the Kids get support 
from a variety of inhabitants of Maaskantje, like the pregnant woman Rikkert used to date and the man who delivers Chinese food. The owner of the snack bar, with whom they had many a quarrel, even comes to their aide, although he in turn has to be saved by Gerrie. Thereupon he confesses that Gerrie actually is his son of whom he always was so very ashamed, but only now he has reason to be proud of this 'ugly ass.' Officer Adrie, no longer under the command of a superior, also takes their side, but they nonetheless are still facing a majority. However, when need is highest, the boot is nighest. As a true deus ex machina, a truck runs over a group of soldiers, deciding the fight in favour of the inhabitants of Maaskantje. The driver turns out to be a boy with a Down syndrome. Here, at the end, the boy saves the Kids' skins by citing the stock phrase he uses on each and every occasion: 'Truck driver ... honk ... honk.' By this turn of events, the film ultimately concludes with a ludicrous take on FORREST GUMP, for the kid with the Down syndrome is a hyperbolic version of the title charac70 | ter from Zemeckis' film. Even though the Kids used the term 'mongoloid' as an insult for practically anyone, even their friends, they more than tolerated the guy's presence throughout the film. Ultimately, the boy pays them back for their benevolence, and his intervention ultimately is evidence that the New Kids, despite their brutality, also have a heart of gold.

There is one yet unmentioned difference between FLODDER and NEw KIDS TURBO, and though this distinction is crucial, it is also the main reason why I read the films in tandem. Social worker Sjakie was the butt of many a joke in FLODDER, but was a likeable character. In NEw KIDS TuRbo, this role is performed by the local policeman Adrie. He is a lot like them, except that he is in the ('unfortunate') position of maintaining the law. The true culprit in the film, the one who sets the events in motion, is the official of the social work agency. His inflexible attitude enrages them to such an extent that they behave aggressively and lose their unemployment benefits. The historical gap separating Flodder from New KIDS Turbo is that types like 'Sjakie' have become very strict. The original Sjakie was an optimist, a do-gooder par excellence, though a bit gullible, but NEW KIDS TURBo can be taken to exert a nostalgia for 'Sjakie.' That the New Kids feel themselves left to their own devices is because a mediating figure like Sjakie is missing and has been replaced by a hair-splitting civil servant. FLODDER was a comedy that could be enjoyed by the whole family for Sjakie seemed willing to take all the blows. NEw KIDS TURво is a nihilistic comedy, because the boys feel as if they are taking all the blows themselves, which makes them raving mad. In fact, the attack by the army is a blessing in disguise, for it enables them to project their aggression onto a specific target. 
Films like FLODDER and NEW KIDS TURBo obviously display stereotypes in a superlative fashion. The blond bombshell, the train-loving grandpa, the disorderly mother in FLODDER are hyperbolic figures, whereas the New Kids are offspring of the utterly indifferent daredevil Johnnie. Stereotypes are an 'arrested, fixated form of representation' (Bhabha, 321), which are always in excess of the norm. They can have severely damaging effects in case people do not recognize the image as a deviation from the norm and take them as 'realistic.' The problem then is that they probably will not grasp the humour either, for the basis of this type of comedy is incongruity: one has to acknowledge how obviously the stereotypical representations transgress the norm. One might surmise that this kind of humour can have sanitizing effects: understanding that the image of the sexually promiscuous bombshell, to take Kees from FLODDER as an example, is obviously a fiction can help to understand that women are not like that. A counterargument has it that one might react: well, they are not exactly like that, but only to a certain degree. In that case, one presumes that stereotypes may be exaggerated, but they are apparently not totally unfounded, and hence, they are supposed to contain some grain of truth. If it works like that, the stereotypes will leave some residue after all, albeit as a diluted reproduction of the images. From an ideological perspective, the problem with the type of off-colour humour in films like FLODDER and NEW KIDS TURBO is that they lack explicit signs for reflection. If one just laughs at the ridiculous portrayals of the characters, one obviously acknowledges that they transgress the norm/convention, but this also implies that the norm/convention is implicitly affirmed. Ma Flodder is comical, because she does not do what a mother is supposed to do. She is not disciplined and she does not give her children a decent upbringing. In understanding her shortcomings, one at the same time positions her representation against a conventional idea of motherhood. In the process of seeing divergence, this idea is then turned into an idealized principle - which is the great pitfall of humour based upon stereotypes. In general, one might say that this kind of humour is ambivalent: it offers as much potential relief from conventional imagery as that it affirms stock representations.

Nonetheless, comedies - even such bawdy ones - always have the potential to address issues which can either be too complicated or too controversial. One can act as if the jokes are only innocent and make no sense, as Maas' remark that opened this chapter suggested, but in the meantime they have a social significance, as Bergson stresses in his landmark study, Le rire. Via Bergson I will discuss the two 'vulgar' comedies in order to identify them as two historical stages in the domain of humour, separated from each other by the popular success of 'amoral' humour. 


\section{SOCIAL 'RAGGING'}

In Le rire Bergson is searching for a deeper-rooted meaning of laughter than the obvious claim that we are just smirking at stupid mistakes and trifling matters. For him, earnestness is laughable in particular. In his eyes, man can become comic when he is deadly serious, or rather, when he is overdoing his serious attitude. Any good quality can be regarded as ludicrous as soon as one performs it in a rigid fashion. When a man prides himself on a virtue he possesses - thorough honesty or extreme cleverness, for example - he withdraws from society into himself. And precisely at this point he becomes liable to ridicule (Bergson, 138). Such a man may think he is an utter emblem of a social ideal - of morality, of wisdom, or whatever - but in the eyes of others, his self-righteous attitude is a token of his unsociability. Such a person becomes comic when he falls into a ready-made category. For Bergson, laughter implies what he called an 'anaesthesia of the heart.' It is essential that we temporarily suspend feelings of sympathy, fear or pity for that person, since such feelings might prevent us from epicaricacy. Hence, laughter, and schadenfreude in particular, is incompatible with emotion and requires the indifference of a totally detached observer (138).

Although Bergson associates this working of laughter with 'high-class comedy' such as the plays of Molière or novels like Cervantes' Don Quixote, it seems applicable to FLODDER as well (or would that prove that FLODDER is 'high class' after all?). The well-to-do neighbours all seem to fall in a 'readymade category' of those trying to keep up appearances at all costs. Hence, they only play-act at being sophisticated citizens, and their unrestrained behaviour at the party at the Flodders' residence only serves to prove that in fact there is a discrepancy between their 'inner nature' and their decorum in daily life. The presence of the Flodders has a corrective function insofar as their arrival in the neighbourhood lays bare to what great extent the upper class is not civilized in itself, but only pretends to be civilized. The supreme example of this is the colonel, a well-respected citizen and a member of the fancy tennis club. As the film progresses, he is increasingly estranged from the community up to becoming a 'mad dog,' who defies the authority of the policemen and bombs the Flodders' residence. Thanks to the presence of the presumably anti-social family, his 'true face' as an utterly intolerable man is revealed. All the laughter that is directed at the neighbours is, to adopt a quote from Bergson 'really and truly, a kind of social "ragging"' (135). On the one hand, the Flodders behave in an apparently rude and anti-social way, but on the other hand, in annoying their neighbours their pretence is exposed, which, within the theory of Bergson, can be taken as a service to social conventions. 
While the neighbours are shown to lack social cohesion and to be somewhat narcissistic, Sjakie represents the other side of the spectrum. He can be regarded as overtly tolerant, upholding the social ideal that if people are giving the same opportunities they will adapt their behaviour for the benefit of building a happy community. In order to show the naivety of such an ideal, Sjakie also has to become the butt of the joke, despite his good intentions. By contrast, the Flodders owe their role as instigators of comic scenes to their indifferent attitude towards those conventions. A comic character, Bergson claims, no longer 'tries to be ceaselessly adapting and readapting himself to the society of which he is a member' (196), a description which perfectly fits the behaviour of the Flodders. In not adapting to the rules and regulations of society, however, the family members are ultimately accepted as to who they are: big-mouthed, but not so bad after all.

If FLODDER is to be seen as a comedy of 'social ragging,' then NEw KIDS TURBo adds an element to it because of its particularly coarse tone. Maas' film was released in 1986, but the relatively recent film by Haars and Van der Kuil post-dates, as I already mentioned, the cinema of the Farrelly brothers, of Tarantino. If in the 1980s, PORKY's (Bob Clark, 1981) and its two sequels were eye-catching sex-comedy box-office hits, then AMERICAN PIE (Paul and Chris Weitz, 1999) and its three sequels, can be called its more extreme match for the new millennium. ${ }^{15}$ Whereas FLODDER was still a family film, considered fit for the age of 6 onwards, NEw Kids TURBo has been rated for 16 years, especially due to its violence, its foul language and Rikkert's obsession with getting laid. The havoc wreaked upon citizens, often innocent bystanders, is presented so hyperbolically that its cruel violence recalls the effect of cartoons. The cat can be crushed by a rock or blown to pieces, but in the next scene he is chasing the mouse once again. If one is seriously hit in NEw KIDS TURBo, one either simply disappears from the film, without anyone shedding a tear about the loss, or one continues in the next scene, with only relatively minor injuries. Such cartoonish violence has a repetitive effect, as is commented upon in the film's sequel NEW KIDS NITRO (2011), once again directed by Haars and Van der Kuil. A teenager has an encounter with the five, and tells them that their stuff is entertaining but that they keep doing the same thing over and over again. And when the police officer Adrie is hit by a car, the boy starts applauding cynically: 'Of course, there it is: the car accident. Original.' He continues his condescending tone by saying that if they consider making a sequel, they should not think he will 'spend a dime on another boring movie with a bad storyline and the usual shitty New Kids jokes.' While he adds to this that he will look for a cam version on the Internet, he happens to be shot in the head due to a clumsy act by Adrie. Hence, the kid is criticizing the option of a sequel while he himself happens to be 
an extra in the sequel, until the moment he is killed, to which he definitely would have said: 'Of course, there it is: another innocent bystander dead. Original.'

The crudity of the humour can be seen as an attempt to transgress the norms of what Noël Carroll calls, 'right moral thinking' (80). These norms have been stretched since Tarantino, since the adult animation sitcom SOUTH PARK (which started in 1997), since Sacha Baron Cohen introduced characters like Ali G., Borat, and Brüno. The makers of New KIDs TURBo have jumped onto the bandwagon of these comic shock successes. This type of humour is clearly targeted at those who hold the opinion that humour can act as the 'guardian of relevant norms' (Carroll, 85). Once these norms have been stretched and a new implicit 'limit' has been imposed, another film or series will be introduced to abandon this role of humour as 'guardian.' What was an 'amoral' variant of humour in the 1980 s will look quite tame from a

74 | present-day perspective. 'Amoral' humour is never stable, for it thrives at the grace of exceeding boundaries. For the amoralist, as Carroll postulates, 'it is a category mistake to suppose that indulging in humour is ever immoral. Humour is categorically beyond good and evil.' Humour is to be regarded as a 'verbal carnival': 'What is said in jest stays in jest' (87). Any offensive remark can be justified by saying that one was only joking. ${ }^{16}$

In fact, the object of the humour of NEw KIDS TURBO is someone who believes that humour can be, or perhaps even has to be, morally serious. For such a viewer, the hyperbolic display of violence will be 'too gross' and the banality of the jokes will be 'too coarse.' The possibility of this 'too' enhances the comic effect for those viewers who have no problems with the rudeness of NEW KIDS TuRBo. At the same time, and here I follow Carroll once more, this aggressive and vulgar type of humour has a 'double edge' (101). In laughing at the New Kids, the 'amoral' viewer who has no qualms about transgressive and politically incorrect jokes, already acknowledges his distance from the characters who are 'revealed to be nearly Neanderthal' (Carroll, 101). ${ }^{17}$ The laughter implies that he does not identify with the attitudes displayed in the jokes, 'but it may indicate [his] feelings of superiority to them' (101). Although the humour is aggressive and transgressive, the laughter itself can be regarded as a safety belt, for it signals that the viewer acknowledges that the attitude of the character is too ridiculous to be endorsed. Laughter is then, as Bergson already suggested, a clue that one does not hold an emotional bond with the character. 


\section{OVER THE TOP: VET HARD, MOORDWIJVEN, FILMPJE!}

Why was NEW KIDS TURBo, if it is so banal, a huge box-office success? It attracted more than one million moviegoers in a relatively brief time span. In making a brief comparison to another off-colour comedy a provisional answer might be suggested. VET HARD [TOO FAT TOO FURIOUs] (Tim Oliehoek, 2005) is an over-the-top action comedy in the spirit of a rude comic strip. Mast, an old gangster, is hospitalized because of his bad liver. As a last wish he wants to see his son Koen on whom he has never laid eyes before, but this son is in a Belgian prison, since he, as Mast claims, had not paid his parking fines. Aided by his two sons, the corpulent gangster Bennie, who is Mast's adopted son, will attempt to liberate Koen. One of Bennie's sons has an absolutely crazy master plan, based upon arithmetic and acrobatic tricks. It is impossible to execute, but it works wonderfully. Mast is very happy to see his son, but he is on the verge of dying unless he has a very expensive operation in South America. From then onwards, they try to raise enough money for the operation by way of a variety of (criminal) activities, such as a bank robbery, betting on a fixed kick-boxing match, stealing a container of money at Schiphol airport. In addition to the fact that all these actions develop in a bizarre manner, just as in a cartoon, all the characters are a total caricature. Bennie gets mad when he is called 'Fatso'; the ambition of his two sons is to acquire a delicious quiche recipe while their father only wants a simple snack bar; Koen turns out to be a dangerous psychopath who had not only killed five women in the past, but also two after his jailbreak, excusing his misdemeanours with the words: 'She fell.'

The one woman Koen cannot kill - despite the obvious references to the shower scene in Alfred Hitchcock's PsYCHO - is Katia, who during several crucial moments needs to pee. There is the prototypical dope Vuk who is said to be quite good with electricity, but actually it is the opposite. And I have not even mentioned the many cameo appearances of well-known Dutch celebrities like TV presenter Chazia Mourali as a bitchy nurse; film critics René Mioch and Jac Goderie in a cinema, one eating popcorn, the other asleep; porn star Kim Holland as a pole dancer; or Estelle Gullit, the then wife of an ex-football player, as a stewardess. They all meet a quick and violent death, except for Holland, who is 'only' used as some sort of punching ball. Hilarious is the scene with the stewardess who bows over a wounded man at the airport, trying to reassure him with her one line: 'The ambulance will be here soon,' not knowing that at that very moment an ambulance has been dropped from an aeroplane and is about to land upon them. All the bizarre incidents and striking cameos do not alter the fact that the plot of VET HARD hinges on the deeply felt tenderness of both Bennie and Koen for Mast. They are prepared to do anything for the sick, old man, up to making 
a childish drawing. In a film in which everything is so utterly incredible and over the top, the suggestion of such warm feelings for Mast becomes a travesty itself. These feelings are expressed in such an exaggerated way that they are tainted by an overall context of idiocy.

In principle, New KIDS TURBo is no less idiotic and bizarre than a film like VeT HARD (close to 200,000 viewers) - or FILMPJE! (Paul Ruven, 1995), MoordWijVen [Killer Babes] (Dick Maas, 2007) or Black Out (Arne Toonen, 2012), the latter discussed in chapter 9 - but the film by Haars and Van der Kuil is explicitly set against the background of the economic crisis. Except for Barry, who did not have a job anyway, four of the five protagonists get fired. Even though their work attitude was far from impeccable, they blame it on the crisis. Since the crisis is, rightly or not, associated with the discussion about countries losing their sovereignty in a bigger Europe, there is a counterweight desire among people to cut up the big world in smaller

76 pieces. It has become increasingly popular to derive one's identity from the local area one inhabits. Similarly, for the New Kids, the outside world begins in Schijndel, the rivalling village next to Maaskantje. If a film like VET HARD can be seen as an attempt to make an over-the-top gangster or crime movie in the vein of comic-strip violence, NEw KIDS TURBo happens to have the additional advantage that it can be seen as a response to 'genuine' social problems, no matter how rudimentary such a response might be. It is a matter of reading the tea leaves at the bottom of the cup but I would dare to propose that the timing of NEw Kids TURBo was absolutely right. Perhaps this was no more than a coincidence, the inverse of collateral damage so to speak, but then it was a case of mere luck.

Further, VET HARD could be seen as a typical product of the so-called 'grachtengordel,' a term often used pejoratively to indicate the elitist Canal District in and around Amsterdam, and the parade of (semi-)celebrities, known from television basically, in the film testifies to this association. The 'grachtengordel' is the prototypical 'non-region' in the Netherlands to which countryside areas position themselves as regional. To emphasize that VET HARD lacks a 'regional' aspect and does not respond to local 'problems,' the fact can be mentioned that it is a remake of the Danish film GAMLE MAEND I NYE BILER [OLD MEN IN NEW CARS] [Lasse Spang Olsen, 2002). By contrast, the New Kids could depict themselves as 'grassroots' filmmakers, who were not part of the media establishment. They simply gained the opportunity to make a film because their YouTube clips had attracted attention due to their use of foul language and the aggressive tenor of the actions. Moreover, most of the cameo appearances are by people who have expressed explicit ties to the province of Brabant - Teeuwen, Maassen, actor Frank Lammers. ${ }^{18}$ Perhaps even more than the other films in this chapter, this film is aimed at 
a target audience of young adolescents who dislike big city areas and elite tastes. And they sure responded to the release of the picture, for NEw KIDS TuRBo was a gigantic box-office hit and broke records during its opening week.

The prize of such popularity as 'regional outsiders' among adolescents is that success cannot endure: one loses one's cherished image of fresh newcomers. The only option left for its sequel, NEW KIDS NITRO, was to make an overblown version: bigger, louder, more spectacular. In offering a truly over-the-top comedy, in which, among others, the New Kids have to battle with zombies in the region of Friesland, the sequel lost track of its social thematic. No matter how loose the connection with a social thematic, as soon as it is practically absent, a comedy seems to be void of any urgency, which, influences its (box-office) appeal negatively.

In order to avoid misunderstanding: this aspect of a social urgency is not an iron law, but it is only one of many conditions that can help to make a comedy really successful - apart from the usual stuff, like funny jokes, welltimed performances, solid camera work and editing. For his MOORDWIJVEN Maas was expecting at least a million moviegoers, but it attracted 'only' 400,000. According to the standards of Maas, this is a modest number, but, this relatively disappointing result is due to the absence of a clear conflict between the lower class and the higher class. The story of MOORDWIJVEN is little more than a portrayal of the lives of three spoilt-rotten wealthy women who are mainly preoccupied with plastic surgery. After the famous doctor Bilderberg is shot, one of them says: 'Well, Kit, you were right on time with your nose.' Their lack of empathy comes to the fore on many occasions; when the black gardener from Togo is found dead in the swimming pool, one of them crudely remarks: 'Oh no, now the pool has to be disinfected again.' As their major form of distraction, the three women conspire to have one of their adulterous husbands killed.

In the case of MOORDWIJVEN, the film spectator is left with a view of a greedy, posh culture, but there is no character who mediates this look for us. One could argue that such mediation is not necessary here, and that exactly is the problem with the film. Seeing the overdone acting of female friends with an affluent lifestyle and hearing their decadent comments, it is (much too) obvious that this comedy is to be interpreted as a parody of the upper class throughout. By contrast, the strength of FLODDER was that the viewer started with a prejudicial view of the lower-class family, but as the comedy progresses, the vulgar Flodders garner increasing sympathy at the expense of the high class. The main protagonists in MOORDWIJVEN are so utterly shallow and outrageously silly from start to finish that there is no other option than to laugh at them or, even worse, to cast a cool glance 
at their overblown behaviour. Moreover, unlike FLODDER and NEW KIDS TURBo, MOORDWIJVEn lacks - as does VET HARD - any reference to some deep-rooted social problem, and hence, it risks being a film without a particular trigger, lacking a minimal amount of engagement. No wonder that critics considered it a farcical observation in comic-book style rather than a humorous comment upon a social bias.

My criticism of MOORDWIJVEN is that this comedy lacked a dialectical tension; there was no 'versus,' such as the lower class versus the higher class, for the high-class ladies were already disadvantaged from the start. Such a 'versus' can also be too crude, and then it does not work either. That is to say, Ruven's FilmPJE! did not get great reviews, but it fared quite well at the box office, for the film had the obvious advantage of being an extended version of brief sketches in a TV show hosted by the popular comedian Paul de Leeuw. He always announced these sketches by yelling 'Filmpje!' to clarify 78 that it is recorded and not live. FILMPJE! was the very first film in the Netherlands which was altered based upon the reactions of a test audience. The consistency of the film's plot was sacrificed to have as many scenes as possible with the two characters from the show, Annie and Bob de Rooij, both played by De Leeuw. ${ }^{19}$ Annie is always dressed in the very same chequered ensemble and she is very naive and good-hearted. When asked what she thinks of gambling, she says: 'I am against gambling, but if you want me to be in favour of it, I am in favour of it. I simply do not have an opinion.' She simply does not want to offend anyone. THE WIZARD of Oz is her favourite movie, because, against all odds, she believes that happiness will be 'somewhere over the rainbow.'

Annie is such an exaggerated version of credulousness that she is brusquely exploited all the time by her husband, Bob, who is her polar opposite. In the beginning of FILMPJE!, he files for a divorce because Annie refused to give him a blow job. Bob is an extremely rude and nasty character, who has a whinnying laugh each time he does something nasty or uses foul language - and he laughs a lot. They are such an odd couple that their confrontation lacks tension, for she is always too gentle and he is always too vulgar. Since they are stock characters, each and every confrontation is only a slight variation upon the same theme, and therefore the film never becomes more than a series of sketches. In the end, FILMPJE! is better at being a spoof of James Bond movies and of PULP FICTION than in offering some coherence in plot, let alone a socially urgent plot. ${ }^{20}$ This incoherence is addressed by Bob himself, when he suddenly looks into the camera, in a big close-up and says: 
Yeah boppers, it is turning into a really weird movie, don't you think? I have read the script, and therefore I know how it will end, but I am in a funk right now. Of course, it has a happy end, within less than half an hour, with some fun song from THE WIZARD OF Oz, and a tin man and a scarecrow and the smoked sausage from Oss ${ }^{21}$, but how will it end? Suddenly, everyone is lost. Now, I am about to jerk off. Not because I feel like it right now, but it might give me the idea that I have had an enjoyable day anyway.

\section{LONG LIVE 'SJAKIE'}

The off-colour and vulgar comedies in this chapter are obsessed with the physical joys of drinking, drugs and sex and/or with aggressive impulses and/or, in the case of MoordwiJven, beautifying one's body. These obsessions are so hyperbolic that any viewer may feel superior to the cartoonish characters. Even though their fixations manifest themselves differently, the common denominator is to discredit social conventions. This can happen by legitimizing violence (as in SCHATJES!), by glorifying 'authentic' rudeness (as in FLODDER and NEW KIDS) or in parodying the effects of plastic surgery (in MoordwiJVEn). These comedies testify to Critchley's dictum that worse than the 'animal within' is a person acting like a person. The concert scene in WAT ZIEN IK?! illustrates the disregard of the prostitute for the strict codes of the cultural elite. In SCHATJES! the riotous children hold up a mirror to confront their highfalutin' parents with the shallowness of their authority. The guys in NEW KIDS TURBo cling to their regional identity because they feel themselves victims of a globalized and abstract economy, represented by a civil servant who defends himself by saying he is only doing his job. Actually, FLODDER offers the finest example of the relief theory in this regard: it is a good thing to give way to one's impulses, for those well-to-do inhabitants who become a bit like a Flodder are not as derisive as those who still aim to keep up appearances. Neighbour Neuteboom, who is under the spell of the female Kees and tries a joint, is more likeable than his nagging wife. Better to accept some 'animallike' behaviour than hang on to the restrictive codes of the upper class.

In her study Good Humor, Bad Taste, Giselinde Kuipers has analyzed Dutch humour as a 'social phenomenon.' The building block of her theory is that each and every social group can and probably will appreciate jokes differently. The vulgar humour discussed in this chapter is often derided by intellectuals, but generally positively valued by the lower classes. Kuipers observes that the 'Dutch tend to think of themselves as a classless society, making references to social class slightly taboo' (16). ${ }^{22}$ The utopian nature 
of this thought is undermined as soon as lower-class characters are turned into main protagonists - like the family Flodder, like the New Kids, like the criminals in VET HARD. If these comedies have some merit, it is above all to break the taboo not to refer to class-based distinctions.

It is highly significant that the narrative crisis in NEw KIDS TURBo is the result of a conflict with a civil servant from the social security office and that in FLODDER, the social worker is the ultimate butt of the joke. Sjakie's belief that one is the product of social circumstances is derided as hopelessly naive, and this is basically shown on the basis of incongruity. Each of his statements is contradicted, often via editing. When he mentions that the Flodders are, deep down, sensitive people, we immediately get a shot transition to Ma getting angry, hitting one of her kids and kicking the dog. This can be regarded as no more than cheerful amusement, but at the same time and despite all the vulgarity of the Flodders, Maas' comedy also functions as

8o | a clear thorny signal. The film expresses a certain discontent with the BandAid approach of left-wing politics, represented by well-meaning social workers. Though these latter are the object of (mild) humour in FLODdER, New KIDS TURBO owes its brutal tone to precisely the frustration of the increased inflexibility of a new generation of 'Sjakies.' To couch the aggressive and vulgar humour of the New Kids in positive terms: better well-meaning and naive than nitpicking about rules and details - long live 'Sjakie.' 



\section{Multicultural Comedies}

The more left, the more right-wing the jokes. It's allowed. A must even.

If you make a bad racist joke, you're a racist. But a good joke is too clever to be racist.

- Jos Fransen, main protagonist in Vox POPULI

For Bakhtin, carnival laughter which marks the anti-establishment or folk humour that has been the subject of the first chapter, is ambivalent: it is not only reactionary and toothless, but its mock and derision also have some subversive impact, no matter how minimal. For one, the comedies contradict the utopian assumption that class distinctions are hardly relevant in the Netherlands. Moreover, the laughter could be aimed at some social mischief or situation, as was the case with SCHATJES!, FLODDER or NEW KIDS TURBo. By contrast, the deliberate banality of FILMPJE! and VET HARD seemed to be shown for the sake of banality as such. The primary function of the coarse humour in these films was to test the limits of 'bad taste.' It is perhaps no coincidence that Paul de Leeuw (lead actor in FILMPJE!) and Tim Oliehoek (director of VET HARD) were to unite forces. According to the critical reactions, they went beyond these limits of grossness in the almost unanimously bombed SPION VAN ORANJE [SPY OF ORANGE] (2009).

Since 2004, the farcical comedy has also become a format for ethnic humour, precisely in a period when relations have become quite tense between 'native' Dutch and generations of 'new Dutch' people (because they or their parents or grandparents were born in a non-European country). Since the second half of 2001, Pim Fortuyn entered, after a number of failed attempts with established parties, the political arena, but this time he gained incredible appeal. His success exposed an ideological paradox: The more controversial his statements and the more exalted his public appearances, the more acclaim he received. Declaring the Islam a backward religion, as he did in February 2002, did not diminish his popularity, but only increased it. Fortuyn could become the centre of political debates, because in the years preceding his rise, some critical texts had been published that spoke about the bankruptcy of the so-called 'multicultural society.' In his 1997 study De 
filosofie van mensenrechten [The Philosophy of Human Rights], the legal philosopher Paul Cliteur considered the Dutch tendency to be tolerant towards the customs of non-Western cultures as a regrettable acceptance of 'their' barbaric practices. Whereas Cliteur feared that his 'own' Western values might erode due to the arrival of 'anachronistic' immigrants, the sociologist Paul Scheffer in his essay 'Het multiculturele drama' ['The Multicultural Tragedy'] addressed the subject from an opposite perspective. At the root of this 'tragedy,' Scheffer claimed, was a startling indifference of Dutch people towards the integration of non-Western newcomers. They turned their backs on contact with the new arrivals and moved to well-to-do, white neighbourhoods. They founded their own organizations and brought their children to elitist schools. Partly out of frustration with this 'white flight,' the newcomers cherished their own cultural specificity and continued to practice their own religions. They were too isolated to really participate in Dutch society,

84 but it was their children who came to regard themselves and their parents as victims of this policy of 'coexistence without interacting.' Although the basic assumptions of this 'multicultural tragedy' were widely contested, it became a popular catchphrase to advocate the idea that an unbridgeable gap separates the Dutch from the newcomers.

As regards Dutch film comedies, the response to this 'tragedy' has taken two forms. First, there is the 'political comedy,' best represented by Vox POPULI [Latin for public opinion] (Eddy Terstall, 2008) with its focus upon the opportunistic opinions of a member of parliament. ${ }^{1}$ Second, since the hilarious Shouf Shouf HABibi! [Hush Hush Baby] (Albert ter Heerdt, 2004) and the equally successful HET SCHNITZELPARADIJS [SCHNitzeL PARADISE] (Martin Koolhoven, 2005), a number of 'multi-culti' comedies has been released. Their humour is based upon an exaggeration of this 'tragic' scenario. I will initiate a discussion of this second tendency with the most outrageous of the cycle, ALLEEN MAAR NETTE MENSEN [ONLY DECENT PeOPLE] (Lodewijk Crijns, 2012), which, by the way, can be seen as a 'light' adaptation of a most controversial novel by Robert Vuijsje. Starting with an 'overcooked' case I will work my way back to more subtle treatments of the topic of multiculturalism. Via SHOUF SHOUF HABIBI! and HET SCHNITZELPARADIJS, the chapter will end with a discussion of the road movie RABAT (Jim Taihutti and Victor Ponten, 2010) that counterbalances its comic elements with a dramatic backbone. 


\section{THE JOIE DE VIVRE OF THE RIGHT-WING: VOX POPULI}

VoX POPULI is a lower-class comedy, if there ever was one. At least, so it seems. Terstall's film pits its protagonist, the opportunistic but insincere politician Jos Fransen against its real 'star,' the big-mouthed but much more sincere plebeian Nico de Klerk. They get acquainted with one another, because Jos' daughter Zoë falls in love with Nico's son Sjef. The two fathers are worlds apart. To start with, Nico is the proverbial family guy for whom his relatives, including in-laws, mean everything, but Jos, suffering from a midlife crisis, is unfaithful to his wife. He has an extramarital affair with his naive intern Nina and he has had one with Mira Ornstein, one of his colleagues in parliament, who used to be one of his interns. Jos is the political leader of the Red-Green Party whose 'idealistic' programme is at odds with the ambitions of the rising populist newcomers in the 'Go Holland Go' Party. During one of the first meetings with Nico, Jos boasts that he talks to people from all echelons, but Nico retorts: 'Not to me,' implying that the lower class is unjustly overlooked. Nico is distrustful of Jos, for he holds the idea that the pockets of the elitist politicians in The Hague run deep and that the ordinary guy is always shitted upon. He tends to criticize everything that is not within his scope with remarks which are at times as funny as embarrassing. When he visits a theatrical play from Greek antiquity because Zoë is one of the actresses, he pokes fun at the experimental performance, in which the beautiful Helen is played by a naked guy. He gives comments such as 'A bit a lousy soccer match so far' or 'Is it the heat wave? Or is it Candid Camera?' Nico's son Sjef apologizes for the fact that his father cannot keep his mouth shut, but Jos, who is not a lover of 'high culture' himself, wants to play the diplomat by appeasing Nico. He applauds him for saying 'things we all would like to say, but do not dare to.'

This dialogue exposes their basic dichotomy. As a politician Jos preferably uses veiled language, like when he dictates his intern: 'Must we sacrifice our political morals at the murky altars of misanthropy?' By contrast, Nico does not wear his heart on his sleeve. Indifferent to social conventions, he tends to be pretty clear and unequivocal, as when he complains about official permits. One of the few times when Nico speaks obscurely, is when he discusses the nuisance caused by the 'new Dutch' people. When he mentions that his nephew Rodney is being bullied by brats every single day, he adds to this that 'we are not talking about Swiss here.' Since the naive intern is puzzled, Nico's daughter explains that he means 'the Moroccans,' but that it is more polite to say, 'they weren't Swiss.' This indirect expression functions here as a dig at politicians of Jos' Red-Green Party who claim that the right-wing 'Go Holland Go' Party sidelines many citizens with statements that Islam is a danger to society. Even though Jos had said some time ago to 
Mira, when she was still his mistress, that the people are crazy and dangerous and that a politician should never listen to them, he starts to integrate words used by Nico into his speeches and interviews. When he discusses criminal ratings in a TV show, Jos imitates Nico's euphemistic expression that there is no Swiss among them. Preceding this statement which aroused vehement responses from his fellow-politicians, he had given an interview, a controversial one to say the least. The editing of the interview in Vox POPULI perfectly captures the influence of Nico's cynical opinion on the presence of Islamic people. While sitting on a terrace with Jos, a Muslim man passes in a djelabah - or an 'alibaba' in Nico's words.

Nico: 'Just be honest, such an imbecile who just walked by with his army pants and tent dress, isn't he backward? Or am I crazy?' Jos [shrugs his shoulders]: 'What's backward?'

86 Nico: 'No, he's forward. All right? He's ahead of his times. Next year we'll all wear one. In pastels.'

Jos: 'In a sense someone like him is backward.'

Nico: 'So the truth comes out. Say that in public. Then I might vote for you.'

Jos: 'There is a certain backwardness ...' [While saying this, there is an immediate cut to an interview with a journalist, who reacts surprised]: 'You used the word "backward"?'

Jos: 'In a certain context.'

Mira reacts furiously by saying that a term like 'backward' proves that Jos is pissing on his principles. He defends himself, cowardly claiming that it is a 'quooc,' i.e., a quote out of context, which it is not. The net effect of his statements, however, is that the popularity of the Red-Green Party increases considerably, and this puts its members in the dilemma of standing firm on its political direction or give in to the wishes of the newly won voters. When Jos is accused of behaving like a flip-flopper, he replies: 'No, that is called progressive insight.' He becomes the target of scorn in the public domain, the 'national alpha male,' as comedian Freek de Jonge calls him. He is using Muslims as 'political currency,' a Dutchman from Moroccan descent sneers. Despite favourable polls, Jos' fate is sealed when a hidden camera and microphone register him telling a racist joke about Muslims, which he originally heard from Nico's son-in-law who eagerly feeds him with foul opinions, behaving like a modern-day Rasputin. According to the prime minister, he has gone beyond 'flirting with the underbelly' of society. Ultimately, he needs bodyguards for his safety, and the period of involuntary seclusion makes him conclude during a speech, broadcast on television: 'If you can lead the national lamentations, 
the people reward you with power. As long as you give them what they want. A good politician should say, however: "No, you do not get what you want. You're spoiled."' Realizing that he has not been a very good politician, he steps down as leader of the Red-Green Party, and thus paves the way for Mira as the new prime minister.

While shooting Vox Populi, Terstall told that he had not yet decided whether his film should become a left-wing or a right-wing pamphlet. On the basis of Jos' edifying farewell speech, one might be inclined to presume that the film favours the political left, since moral principles are preferable to instant popularity. Since vanity is one of Jos' weaker traits, he could not resist the short-term success. But while the serious bottom line may favour a left-wing position, the underlying current of the film privileges the characters with the right-wing opinions. ${ }^{2}$ Strictly speaking, Mira is the true 'victor' in this picture, sticking to her principles while taking advantage from Jos' opportunism. She, however, is not as memorable a character as Nico and his lower-class family. On the extra features on the DVD, Ton Kas, who plays Nico, states that, in general, the lower-class fiddlers are more humorous than the righteous people: One cannot reproach them for a lack of joie de vivre. Hence, Vox POPULI is 'left-wing' in terms of content, its 'message,' but it would be forgettable without its 'right-wing' characters. Moreover, Terstall's film is shot without much ado-Vox POPULI has pace, much handheld camerawork, copying the hectic of the work of political (television) journalists. Formally, this makes the (charm of the) film as pretty direct as its lowerclass characters talk.

\section{STRATEGIC AMBIGUITY: ALLEEN MAAR NETTE MENSEN}

To start bluntly, ALLEen MAAR NETTE MENSEN is pervaded with racial prejudices. Each and every character has the habit of talking in terms of 'us vs. them,' and, as the saying goes, never the twain shall meet. Usually, 'they' are met with suspicion, because 'we' presume that 'they' are not as good as 'we.' Evidences of this unshakable barrier are manifold in the film. Significantly, Moroccans are only talked about as a negative point of reference, but in no way are they visualized in the film, except in a strangely distorted fashion. In the beginning of the film, David tells in voice-over that Dutch people cannot tell the difference between a Jew and a Moroccan. This inability is 'illustrated' by a freeze frame in split screen: on the right we see David as a 'Jew' wearing a necklace with a Jew's star; on the left we see David as a 'Moroccan' wearing the same necklace but a black leather jacket as well. For Dutch people, the differences are negligible, for they all are foreigners. Further, as a running gag, prac- 
tically every black character asks main protagonist David Samuels whether he is a 'Mocro,' a disdainful term for Moroccan, because in their eyes he looks like one. No, I am Jewish, David responds calmly at each and every occasion. In the eyes of the Surinam community that David comes to attend, it is clear that being a Moroccan equals being at the lowest level of civilization. In a peculiar speech, one black character named Clifton, argues why David is a 'Moroccan' after all. Moroccans look down upon black people because they consider them monkeys from the jungle, but in the meantime they are the biggest monkeys themselves, for they wear black people's clothes, listen to black music and imitate the movements of blacks. 'If you want to be part of the community of blacks,' Clifton argues, 'that means you are a Moroccan.' Hence, in ALLEEN MAAR NETTE MENSEN, Moroccans are only talked about and referred to in pejorative terms. They are used by the black characters as invisible objects of comparison to mark their superiority over them. The fact that they constantly 88 mistake a Jew for a Moroccan indicates the invisibility of Moroccans. In Crijns' film they are put in the position of an 'unknown other' for whom the blacks feel such a contempt that there is also no craving to know about Moroccans. Likewise, David also makes clear in voice-over that Surinamers like his girlfriend Rowanda hate the Surinam Hindus, the Surinam Javanese and above all the Antillians, abbreviated as 'Antis.'

Nor do the blacks know about Jews, but at least there is some readiness to give David, strictly as an 'individual,' the benefit of the doubt. His Jewishness comes most explicit to the fore in a conversation with the mother of Rowanda, the girl he is infatuated with because he loves her 'big bottom.' As soon as he mentions the charged word 'negro' in the mother's presence, she corrects him by describing herself as a Surinam black woman with African roots. She refers to the history of slavery which has caused such terrible psychic wounds that financial compensation would be most appropriate. It is unfair according to her that the Jewish people have received monetary reparation for the Holocaust, for that was less worse than slavery. Even though the comparison is doubtful, the remark of the mother hints at an angry political edge, at least. Unlike her mother, Rowanda herself is not concerned about David's ethnic-cultural background at all. If he is really serious about dating her, the only thing that interests her is whether David is not a 'lying man' like all her former (black) boyfriends - a question which she asks repetitively. To David, by contrast, his background seems important for he reassures her that both committing adultery and lying are not ingrained in Jewish culture.

The question of ethnicity is for David closely imbricated with the issue of class. He tries to overstep the barrier separating the 'Old South' neighbourhood, where, as his mother says, 'only decent people' live, and the Bijlmer, predominantly populated by lower-class blacks. The film already reveals the 
utopian purport of this endeavour in its opening scene when David walks barefoot and with a bruised face towards the home of his former girlfriend, Naomi. Three months ago, his voice-over tells, he was still happy, but the first shots suggest that he has become a wreck, and ALLEEN MAAR NETTE MENSEN will continue to show how he has gone astray. As for all the adolescents in his upper-class neighbourhood, there is a predictable trajectory ahead for him, but David is at unease with this plotted path. His parents expect him to register at a respectable university, but he does not feel like doing so. The change in behaviour he will undergo in the brief time span of only three months can be interpreted as a juvenal response to his parents' expectations. To underscore his revolt he breaks up with his girlfriend Naomi, whom his parents consider as a most convenient choice as daughter-in-law to be. Her utter decency is best signified by David's description in voice-over of what she considers a nightmare: when she tries on a new dress she always asks him whether she has a big bottom. David's outspoken preference for black women comes about as his imaginary reaction to this nightmare. According to him, they are proud to flaunt their big bottoms and, as his voice-over emphasizes, 'black women would rather die than have a flat ass.'

It is worth emphasizing that the representation of black culture in ALLEEN MAAR NETTE MENSEN is consistently focalized and interpreted by David. As David is telling in a relaxed tone, accompanied by relaxed music on the soundtrack, how blissful he was with Naomi, a black woman passes by. The slow-motion shots of the woman wiggling her hips and of her sparkling golden tooth visibly attract David's attention. These slow-motion shots which are repeated when he takes a bath, clarify from the start that the images will be filtered by his gaze. On top of that, he associates black women with animalistic primitivism, believing that the darker a woman is, the closer she is to nature. According to this logic, the white, upper-class Naomi is corrupted by civilization, and as a resultant, as an early scene shows, he is only able to make love to her in a slow and mechanical way. When he manages to turn on the television with his toes, he can secretly glance at a dark woman who is bending over, revealing her bottom. He accelerates his love-making considerably and even ends with a jungle yell, to the annoyance of Naomi. Talking over the option of a time out with her, he thereupon meets Rowanda at a dance, shaking her bosom and buttocks. This time the slow-motion shots are even more extreme, indicating that this is the one woman for him. Her voluptuous body is a total contrast to Naomi's slim figure. Moreover, in comparison to the black woman from the beginning, Rowanda has not one but two golden teeth, with her name engraved on them.

David truly thinks that his outspoken preference for black culture is 'sincere' and that he can be a perfect match for Rowanda because he, as a Jew, 
cannot be a 'lying man' and will not cheat on her. Soon he discovers that black boys consider it hilarious that David has only one 'chick' and no concubines. The womanizer Ryan takes him for a night out to a night club and encourages him to dance with an Antillian woman whose movements imitate the sexual act. Since this dance happens to be witnessed by Rowanda, she gets angry and now considers him to be just another liar. She calls him a 'speculaas' [a ginger cookie], meaning that he's only pretending to be like a black man, which is 'worse' than actually being a black man. David tries to calm her down, but to no avail. If he likes black women for being 'natural and primitive,' he's getting what he wants: Rowanda is led by 'pure' feelings of revenge and is not forgiving at all.

Rejected by Rowanda as well as by Naomi, David at the end fancies the young black woman Rita for whom he initially felt contempt. She is a student who works as an intern at his father's office, and he despises her for speak90 | ing the very same 'neoliberal social talk' as middle-aged men of his father's generation do, and for wearing neat clothes, so unlike his idea of the code for black women. In his eyes, she is the 'typical bounty,' meaning brown on the outside, white on the inside, who denies her own culture. At the end of the film, he meets her again, when she visits a Kentucky Fried Chicken outlet with two nieces, while he works there as a cleaner, amidst only blacks. Initially, his eyes just fall upon a woman who hits a man in the face for touching her bottom and scolds at him without restraint, to David's delight. Rita has undergone a metamorphosis, for from behind she just looks like Rowanda. David then sees her necklace with her original name Sherida; Rita was only a common Dutch name she had used for getting the internship at his father's work. In some brief inserts we had seen in the film it was already suggested that 'Rita' appreciated the way he stood up against his father, and in the KFC she mentions her former boss in an ironic tone. She is not the 'typical bounty,' keen on integration, David had taken her for, and, in addition to that, it is implied that there is a mutual, mild scorn for his father. As David sees a tattoo on her back, he asks her whether she has children. She bursts out in a way which recalls Rowanda, but it turns out to be a mock answer. When she has left her phone number on the table for the 'cleaner,' he utters a yell with a big smile, exposing a golden tooth. During the end credits we see that both David and Sherida are accepted by his parents.

The film received a mixed response, varying from 'morally questionable' and 'poor story' to an 'enjoyable take on politically correct thinking.' The fact that the reactions are diverse is exemplary for the working of a comedy like ALLEEN MAAR NETTE MENSEN. The film has taken the liberty to put a series of prejudices in the mix, without taking a stance. The film is 'strategically ambiguous in politics,' to paraphrase David Bordwell in his 
characterization of Christopher Nolan's THE DARK KNIGHT RISES (2012). Says Nolan:

We throw a lot of things against the wall to see if it sticks. We put a lot of interesting questions in the air, but that's simply a backdrop for the story.... We're going to get wildly different interpretations of what the film is supporting and not supporting, but it's not doing any of those things. (Qtd. in Bordwell)

In an explanation of this quote by Nolan, Bordwell argues among others that thematic murkiness and confusion have become the norm. Similarly, ALLEEN MAAR NETTE MENSEN brings up a wide range of stereotypes and hence it attempts to create a pick-and-mix with, the makers will hope, something for everyone. To give an example of this, while Rowanda's mother refers to the history of slavery in a serious, almost embittered tone, her son Clifton immediately adds to this that the forced separations during the period of slavery still leave an impact on black men for it is impossible for them to limit themselves to one woman only. It is typical for the tone of the film that an attempt at seriousness is immediately downplayed by a far-fetched remark. Indeed, the filmmakers throw a lot of things against the wall, and the viewer has to figure out himself what sticks. As a consequence, the film had better not have a transparent vision or a particular political stance, but should be open for a variety of interpretations and opinions, at the expense of consistency. Is the violent beating by Rowanda and her two brothers sufficient to cure him of his fondness for the 'purity' of black women? Sherida gives an imitation of Rowanda in the KFC, but is she only a pale version of 'purity'? Has David's desire been compromised, perhaps motivated by his wish to reconcile with his father (not to say, the wish for a 'happy ending')? All these options can be activated, and that makes this film so deliberately ambiguous - viewer, take your pick.

The unevenness of the film can be considered as a wilful strategy, and as a justification for the many ethnic stereotypes of sexually obliging black women, lustful black men, and kids playing PlayStation all day, of upperclass whites who live according to suffocating strict etiquettes and flirt with a Jewish identity steeped in tragedy. The fact that these racially hackneyed representations are presented in the form of a hilarious comedy ideally functions as a disclaimer. As I argued in the previous chapter, a carnivalesque comedy always has the effect of both affirming and undermining stereotypes, but this comes with an important proviso. Comic exaggerations can also be misused as a carte blanche for stereotypes. Whether the subversive force really blots out the 'damaging' reproductions of clichés, depends upon the viewer's willingness to regard them as excessive, but there is always 
the risk that the spectators see the stock images as uncannily close to the assumptions they already hold. This risk is higher the more the represented group is unfamiliar to the viewer. And in such a case, when the evidently excessive nature is not recognized as such, the representations can be counterproductive. Since Crijns' ALLEEN MAAR NETTE MENSEN refrains from offering a coherent guide on how to read the film, it is possible to regard the film as subversive: David becomes a victim of his own naive projections about black culture. But it is as easy, if not much easier, to read the film as an affirmation of ethnic stereotypes, for ALLEEN MAAR NETTE MENSEN does little more than put a comic frame around them.

Moreover, if one were to argue that Rowanda's place is treated in a cliché-ridden fashion, then one might counter such a charge by pointing out that, analogously, the white upper-class culture of the 'Old South' is also portrayed in a stereotypical mode. ${ }^{3}$ Be that as it may, one seminal aside has

92 to be made nonetheless, for if every group is represented according to more or less ethnic and/or class commonplaces, then groups that are missing in the film are favoured implicitly: these groups can 'safely' look at how all the others are shown as quite foolish. Since the white lower class is conspicuously absent from ALLEEN MAAR NETTE MENSEN, Crijns' film can be read in tandem with FLODDER. Whereas the latter comedy is consistently presented from the perspective of the lower class, I would like to qualify ALLEEN MAAR NETTE MENSEN because of its strategic ambiguity as a lower-class comedy in disguise.

\section{0\% HALAL: HET SCHNITZELPARADIJS}

Together with the equally successful HET SCHNITZELPARADIJs, which attracted more than 340,000 moviegoers, Albert ter Heerdt's film SHOuF SHOuF HABIBI! (almost 320,000 viewers) can be seen as the eye-catcher among a cycle of multicultural comedies, like 'N BEETJE VERLIEFD [HAPPY FAMILY] (Martin Koolhoven, 2006), ALibi (Johan Nijenhuis, 2008), GANGSTERBoys (Paul Ruven, 2010), the TV movie COACH (Joram Lürsen, 2010), PIZZA MAFFIA (Tim Oliehoek, 2011), De PREsident [The PRESIDENT] (Erik de Bruyn, 2011), SNACKbar (Meral Uslu, 2012) and De MASTERs (Ruud Schuurman, 2015). They all to a lesser or greater extent play with prejudices surrounding DutchMoroccans and/or Dutch-Turks, but the tone in them is light-hearted, never truly scornful.

HET SCHNITZELPARADIJS comes close to a honey-sweet comedy, with some fairy-tale touches, of Romeo andJuliet and the ending of THE GRADUATE (Mike Nichols, 1967). A voice-over by the 18-year-old Nordip in the beginning 
announces that his Moroccan father has two sons which are incomparable. One is a wastrel called Nadir, but he feels himself blessed with the other, Nordip himself, the 'good son.' He has wonderful grades at secondary school, and his father expects him to do what he himself had never been able to do, that is, take up the study of medicine. Nordip does not want to live up to this expectation, and searches for a place where he will have 'plenty of time to think.' He tells his father that he starts working at the library, but actually he has a job as a dishwasher in the Blue Vulture Hotel. One of his colleagues tells him that here he is 'absolutely nothing,' he only has to do the dishes. To underscore his low status, his name is mispronounced time and again as Nordil. The blonde Agnes, whose entrance is shown in slow motion and with gay musical sounds, is the first who has his name right. She is the niece of the director, Mrs. Meerman, and has to work in the kitchen to prepare herself for her future position as big boss. She is also the one who calls him a 'weakling' because he stoically accepts the bullying practices of his colleagues, who have put a rat in his meal and pushed his head in a pan filled with dirty water. Since he fancies her, he changes his attitude and stands up to one of his bullies, a Dutch guy called Sander. This gains him the respect of Amimoen and his inseparable sidekick, Mo. They introduce themselves as the proverbial back-seat drivers who promise to help him to survive in the 'snake pit.' Their comic performances as Moroccans with a big mouth and big plans, but who never do anything, have received the film many accolades. They pride themselves on their psychological insights and tell Nordip that, since he is not a 'real Mocro with balls,' he will not stand a chance with Agnes. It is just like in nature, Amimoen asserts, 'the biggest beast gets the most chicks.'

Of course, the boasting Amimoen will prove to be wrong and Agnes falls in love with Nordip. They have to keep their love secret, because Agnes' family will not approve of the liaison. At home, however, Nordip gets in trouble, because his brother, Nadir, betrays him to their father by telling him that Nordip is working at the Blue Vulture. The pathetic response by the father goes like this: 'God gave me two sons, a liar and a traitor.' Meanwhile, at work, he is promoted to assistant chef by Mrs. Meerman personally, to the dismay of his 'friends' Amimoen and Mo, who consider him a wolf in sheep's clothing. He got the news of his promotion in a private conversation at Mrs. Meerman's office, whilst this female director tried to utter some Moroccan words she had been practicing: 'You are a very attractive man.' His promotion is replaced with a discharge, however, as soon as Mrs. Meerman finds out that Nordip is dating her niece. In her explanation she refers to Shakespeare's well-known play about a doomed love affair, because the two families are not supposed to mingle: 'Haven't you read Romeo and 
Juliet? Don't, it's all tragedy.' Thinking over the course of events, Nordip is reminded of the words by Goran, a Serbian guy who is cutting large slabs of meat. While Nordip was still a dishwasher, Goran had advised him to leave the workplace, because there is a 'bullet for everyone,' a wisdom that seems derived from a western like THE MAGNIFICENT SEVEN (John Sturges, 1960). Lying on his bed we see an insert of the gesture Goran is making in the restaurant: he imitates the shooting of a gun. This mental focalization apparently motivates him to go back to the restaurant at the very day that the Meerman family have their annual meeting. When Mrs. Meerman sees him by accident, she runs after him, saying, in Moroccan, 'You are such a beautiful man,' but in a homage to the final scene of THE GRADUATE, Nordip shuts the aunt/director behind a door with glass (just as Benjamin leaves a perplexed Mrs. Robinson behind a glass door) and merely by glancing intensely at her, Nordip persuades Agnes, who is amidst her family (like Elaine in THE 94 GRADUATE), to run away with him.

By using the setting of a kitchen in the Blue Vulture Hotel, HET SCHNITZELPARADIJS has created a small microcosm with its own rules and hierarchies. On the one hand, this microcosm with its many bizarre, colourful and sneaky characters from different backgrounds overlaps to a certain extent with irksome structures in society. On the other hand, the film drifts away from these structures. Just as Nordip considers the workplace as an escape from 'real life' with its pressing demands, the film itself constructs a fairytale solution to the story. This (too) utopian dimension is legitimized by its intertextual allusions, to Romeo and Juliet, to THE GRADUATE, and to Goran's oblique reference to a life lesson from the western genre. Moreover, the title sequence is an homage to spaghetti westerns in general, and the rotating words 'the end' to ONCE UPON A TIME IN THE WEST in particular. In turn, the love scene in the hotel is, as Koolhoven told on the commentary track on the DVD, inspired by REVOLVER (1973), directed by Sergio Sollima, who is mentioned at the end credits.

In a cultural climate in which the debates about the multicultural society have become very heated, the more since the killing of filmmaker Theo van Gogh by a radical Muslim of Moroccan descent in November 2004, HET SCHNITZELPARADIJS could have easily become too much of a hot potato. The murder imparted a brutalized tone into the public debate in the Netherlands, opening the way for aggressive views about Islam to be voiced. HET SCHNITZELPARADIJS seems to overcompensate for the rising animosity towards Moroccans and their religion. The film was labelled as a ' $100 \%$ halal comedy' to make absolutely clear that it did not want to perpetuate the negativity regarding Moroccans. Thus, Koolhoven's film is cheerful in every regard, thanks to the likeable characters, the uplifting music by Junkie XL, 
the sweeping camera movements, the swift editing. The tongue-in-cheek references in Koolhoven's film also gave it a cautious tone, as if to ensure that it should not be misapprehended as a too serious or a too pessimistic intervention in the public discussion. One might accuse HET SCHNITZELPARADIJS, based upon a novel by Khalid Boudou from 2001, of being halfhearted, for it is too unpretentious to offer a substantial comment upon the 'multicultural drama.' At the same time, one might reverse the terms of debate here. In a year when the going had gotten tough following upon the death of Van Gogh, the best way to cool off the heated discussion on the role of Islam in Dutch society was to offer the audience unpretentious and delightful comedies as an antidote. Apparently viewers thought so, too, for by the tenth day of its run the movie had become a so-called Golden Film, meaning that it had been seen by more than 100,000 viewers.

\section{PRIMAL DUTCH: SHOUF SHOUF HABIBI!}

While the intertextual references contribute to the playful nature of Koolhoven's ' $100 \%$ halal' comedy, in SHOuF SHOUF HABIBI!, by contrast, intertextuality rather functions to slightly bend the hilarious tone in the direction of a tragicomic drama. Admitting that he perhaps does Ter Heerdt's film a bit too much honour, NRC film critic Bas Blokker proposed that it somehow recalled Luchino Visconti's masterful ROCCO E SUOI FRATELLI [ROCCO AND HIS BROTHERS] (1960), in the way all the (Moroccan) family members struggle with their position in society, like Rocco's family did when they moved from the south of Italy to the north. The sister runs away because she is having an affair with a Dutch boy, the slacker brother suddenly becomes serious in defending the family's name and he goes to Morocco to find himself an acceptable bride. So much for the seriousness of the film, because a comic tone predominates in a film which ironically advertised itself as an 'oerhollandse komedie' [primal Dutch comedy]. Indeed, released in January 2004, Shouf SHOUf HABIBI! [HuSH, HuSH BABY] deserves credit for carrying out the pioneering work of being the first Dutch 'ethnic comedy.' At the time, its light-hearted approach was most welcome as a counterweight to the hardened tone in political debates about the multicultural society. Against this backdrop, SHOUf SHOUf HABIBI! is a priori a more sharp-edged film than ALLEEN MAAR NETTE MENSEN, even when the devices of the two films - presenting racist commonplaces as a cause for laughter - are perhaps not that different from one another. Unlike the deliberate ambiguity of Crijns' film, the strategy in ShOuf SHOUf HABIBI! can be said to consistently put the sharp debate into perspective. 
Ter Heerdt's film pitches a Moroccan life style to an existence sandwiched between Morocco and the Netherlands. The best representative of the Moroccan way of life is Uncle Youssef, who has not migrated to Europe and still lives in the land of, as Abus' voice-over mentions, 'sand and stone.' In this introductory text by the main protagonist, the people of Morocco are marked by a lack of ambition. And if someone has some aspirations, both the circumstances and the people's simplicity are obstacles, as the anecdote of the ice cream man, also told in voice-over, illustrates. He is sufficiently ambitious to sell ice cream, but due to the bloody hot weather all the sticks are floating in his box: 'He can't even keep his ice creams frozen.' In characterizing Morocco as a country of sun, sand and stone, it is put back in medieval times. No better way to express any disability of progress, then to mention that Uncle Youssef has never heard of E.T., and hence does not understand the joke about the five differences between this alien from a 96 | Spielberg movie and a Moroccan, living in Holland: 'ET had his own bike... ET looked good... ET came alone... ET wanted to learn the language... and ET wanted to go back home.'

By contrast, Abus, whose parents have moved to the Netherlands, dreams of a bright future as an actor in Hollywood. He is quite sure he will get rich, but while he talks in voice-over about his plans, we see him lying in bed and after a cut - which evidently suggests the passing of considerable time - he is still in bed. This discrepancy between his voiced ambition and his shown attitude exposes that he misses the discipline to rise to fame. His eagerness for doing little to nothing is underscored when he has troubles in arriving at work at the - from his perspective - impossibly early hour of 8.30. At the very first day at a bank - a job offered to him thanks to the contacts of his older brother who works as a policeman - he is already too late, because he forgot about the 'summer time.' Abus was neatly dressed, all right, but we then get a sequence of jump cuts of him behind his desk, either doing nothing substantial - eating a banana, feet on the table - or employing frenetic, but senseless activities, like putting stamps in a very rapid tempo on one piece of paper or just typing in a totally arbitrary way. The uptempo music is interrupted when the telephone rings, and we see him, in jump cuts, stare at it. Then his boss walks by and says with an irritated voice: 'That was me. On the phone! Should I send a carrier pigeon?'

The plot of the film is structured around some incidents in which a number of typical clichés about Moroccans are activated. Since Abus is too lazy to work, he joins three of his friends to rob a bank, but the plan is not smartly executed. Abus gets caught, but the bank clerk does not recognize him, for all the suspects 'look the same' to her. Another cliché concerns the generation gap, since Abus' parents want a fixed marriage for their daughter Leila. 
This wish is responsible for the introduction of tragic elements within the comedy. Leila runs away to her Dutch boyfriend whose friends make fun of her not consenting to have sex before marriage. When Abus hears of his sister's disappearance, he traces her down and beats her up for violating the cultural custom. It is for Abus the moment to express his intention to his saddened parents to become a good and serious son. He starts working at an Islamic butchery, which again is cause for comic incidents; he goes to Morocco to arrange a grave for his father, and he chooses his bride out of one of the four daughters of Uncle Youssef. Of course, nothing turns out right, since it is a comedy after all. Although he tells his sister Leila that it was love at first sight, he anticipates that the marriage with his too young bride is a silly idea and escapes from his own wedding. Because his father dies immediately after the escape, no one knows about Abus' run to the cafe to play a game of billiards. We then see the family standing at the pompously constructed grave of the father in a far-off spot in Morocco. A bit behind them, is the family of Uncle Youssef, who sums up the benefits of his late brother Ali's decision to go to Holland: 'What did Holland give him? His eldest son is more Dutch than Moroccan. His daughter doesn't wear a headscarf any more. His other son embarrassed him by calling off his wedding. And his youngest son is no good either.' And after a brief pause, another old Moroccan man adds to this: 'But at least he now has the grandest grave.'

This comment by Uncle Youssef captures a general thrust of SHOuF Shouf HABIBI! Practically every scene starts from one cultural perspective be it Moroccan or Dutch - and addresses the peculiar elements of the other culture. The peculiarity gains emphasis to such an extent that the two cultures are shown as totally incompatible. There is no way that the gap between them can be bridged. At the same time, the other culture is not entirely odd, but its strangeness also reveals an unexpected advantage, which is so unexpected that it can provoke laughter. To illustrate this by rephrasing Uncle Youssef's train of thought: going to Holland brought my brother misery, but due to the silly ideas and grand illusions in that country, his son, estranged from our culture, selected an inappropriate grave, but it is very spectacular though. Similarly in structure is the scene in the café when Abus says to his friend 'Mussi' that he is a copycat of Mohammed Atta in appearance. In a climate when Muslims are looked upon with more suspicion than ever before, it is a sheer disadvantage to be identified with a man who was involved with the attacks on the World Trade Center in 2001. Abus, however, gives it a twist by seeing opportunities: Think big, for Hollywood will need lookalikes of Atta in films based upon the 9/11 catastrophe in upcoming productions like SAVING PRIVATE SADDAM.

Significantly, SHOUF SHOUF HABIBI! is advertised as an 'oerhollandse' meaning 'primal Dutch' - comedy, but its focus is upon people of Moroccan 
descent living in Holland, who have not fully integrated into Dutch society. Or rather, they despise those Moroccans who have made Dutch customs their habits. When police officer Sam has to arrest his brother, Abus, for his part in the bank robbery, Sam tells him that he has set a bad example. Actions like these make it hard for other Moroccans, for it confirms the negative opinion of them. Abus replies: 'Are you blind? They do not want us. They hate us! All racists! You have to stand above it. Laugh at them! They only want creeps like you! Cheese head4! Tulips for brains!' In a serious drama, Abus would come across as the angry young Moroccan kid, very hard to handle. In the context of a comedy - of a 'primal Dutch' comedy - he is depicted, however, as a character who uses the image of the angry young kid, sandwiched between two cultures, as a pretext for his misstep. If we take Abus' remark literally, he suggests that Dutch people require 'token Turks' eager to assimilate into Dutch society as a continuation of their racist politics. In that case, all foreign elements become 98 invisible so that Dutch culture becomes an all-encompassing standard. In fact, Abus here pleads to regard his criminal activity as a necessary resistance to the process of assimilation. Moroccans should be identified with 'typically' Moroccan features in order not to be robbed of their specificity, Abus suggests: better to be labelled as 'bad Moroccans' than becoming an indistinct 'Cheese head.' The comic incongruity here concerns that Abus uses this argument as a belated justification of his misdemeanours.

In highlighting the discrepancies between Dutch and Moroccan culture, both cultures are mocked. Some characters are represented as simply rude, such as the jealous girl joking about the sexual unavailability of Leila for her Dutch boyfriend and the bank director who, as a guest in Sam's house, starts to paw Sam's wife in an impertinent manner. Given the context of a comedy, these unfavourable portrayals are so downright embarrassing that they can be taken as 'worse' than the representation of the bank robber who motivates his wrongdoing with a laughable excuse. As such, SHouf SHOUf HABIBI! implies that the gap between cultures cannot be bridged, foreclosing any illusion about a 'happy' merging of them. Instead, by opting for the form of a hilarious comedy, the film turns the encounter of cultures into an enjoyable deadlock.

Entertaining as it is, such a comedy has, in its full display of ethnic stereotypes, some pitfalls. First, as I have put forward several times, even if this display contradicts these images as being in excess of the norm, stereotypes can never be fully exorcized, because by reproducing and/or recalling them, one also risks affirming them. Second, this type of comedy tends to privilege effect over aesthetics and laughter over critical reflection. The pace of the movies leaves no room for contemplation, since one is always keen on another joke or another gag. As such, the stock images are not problematized, but mainly used to exploit them as a basis for humour. In this regard, Maas' pun on the 
slippage from messages to shopping makes sense: the films discussed here predominantly aspire to raise laughter from the audience.

Nonetheless, comedies - even plain ones - always have the potential to address issues which can either be too complicated or too controversial. One can act as if the jokes are only innocent and make no sense, but in the meantime they have a social significance, as Bergson stresses in Le rire. In the previous chapter I discussed both FLODDER and NEW KIDS TURBO as two stages in the domain of 'vulgar' humour. SHOUf SHOuf HABIBI! transcends them and can be identified with a third theoretical stage.

The humour in films like FLODDER and NEw KIDS TURBO is ambivalent, hovering between divergence and confirming a status quo. In the first chapter I argued that they were more successful than other comedies, because they somehow can be seen as a reaction to 'genuine' social issues. SHouf SHouf HАBIBI! complies to this condition as well, for it is a comic intervention to debates on the 'multicultural tragedy,' which were particularly heated at the time. Whereas the derision of the lower class is less harsh than the ridicule inflicted on high-class and/or formal behaviour in FLODDER and NEW KIDS Turbo, SHOuf SHOuF HABIBI! has taken the form of self-mocking display of clichés about and by Moroccan characters.

Since the presumed 'authenticity' of Morocco is taken by Abus as (too) primitive, it is clear Abus has internalized a Western perspective on life. This is also illustrated by his dream of becoming a Hollywood actor and desiring the associated luxuries. For an immigrant acquainted with Dutch culture, SHOUF SHOUF HABIBI! has basically two options on offer. First, one can attempt to assimilate into society, like Sam did by becoming a policeman. Abus describes his brother as a 'Cheese head,' a most contemptible category in his eyes. The 'Cheese head' has agreed to play by the dominant rules and has implicitly elevated Dutch identity to a golden standard, sacrificing his Moroccan background. His brother can only make 'it' on the condition that he becomes (partly) Dutch and he thereby enables the Dutch to hold a policy of ostracism: in principle, Abus says, all Dutch people are 'racists,' but by giving the assimilated Moroccan some opportunity, they can cover up their hostile attitude. Abus himself represents the second option. He himself is living proof of the worst of the stereotypes Dutch hold about Moroccans: he avoids work and he is involved in a bank robbery.

One may blame Abus for affirming these clichés, but the point of SHOUF SHOUF HABIBI! is that Abus' strategy is based upon an overidentification with these stereotypes. He is all too familiar with the hackneyed images about Moroccans by the dominant culture and starts to behave accordingly. Since Ter Heerdt's film is a comedy, his role can be regarded as a humorous imitation of clichés. Thanks to the playful and self-reflexive voice-over by Abus, his imita- 
tion of the 'typical' Moroccan is a token of a self-mocking distance towards this stereotype, precisely by radicalizing the hackneyed imagery. Because of the comic self-reflexivity, it is suggested that this is not how Moroccans are 'by nature,' but that they just perform this way to accord with the imagination the Dutch already have about them. In short, Abus shows himself off as a product of the multicultural drama by deliberately imitating stock images of Moroccans. The flipside of this strategy, however, is that Abus can put all the blame of his lack of success onto the 'racist' thinking of Dutch society. His self-mocking performance of 'being' a 'typical' Moroccan can function in anticipation as the perfect excuse for his failures, which is the ultimate joke of SHouf SHOUf HABIBI! The comic incongruity of the film is that Abus himself is already much more assimilated than he is willing to admit. Any claim that he is so much more 'authentically' Moroccan than his 'Cheese head' brother is opportunistic, meant to explain that his lack of success in society is to be 100 | pinned on others. As soon as he really goes traditional and travels to Morocco to get himself a bride, he becomes particularly laughable. He apparently realizes so himself and escapes his own wedding to play, very 'oerhollands,' a game of billiards in his favourite pub.

Strictly speaking, SHouf SHOuf HABIBI! does not provide a favourable image of its Dutch-Moroccan characters, despite the fact that the film is presented from the perspective of Abus. What saves the film, however, is that the characters humorously flaunt their flaws, but are not inherently bad. And though the film does not have the pretention to offer a clear-cut analysis, SHOUf SHOUF HABIBI! suggests that people like Abus are caught in a deadlock. None of the options they have are very favourable, for indeed, Dutch society is organized so strictly that newcomers and the second generation have little to no space for integration. Instead of whining about this unfortunate situation, SHOUF SHOUF HABIBI! has chosen to comically acknowledge the difficult position of the second generation, of those who are sandwiched in-between cultures. Abus rebels against this impossible situation by radically exposing himself as a comic stereotype so that he can keep on, to paraphrase Zupancic, 'enjoying his symptoms': avoid work, hang out with friends, being late.

My main reason for favouring SHOUF SHOUf HABIBI! over ALLEEN MAAR NETTE MENSEN is that the film does not just ridicule Dutch culture, but that in the case of Ter Heerdt's film, this ridicule is also built into the film's formal structure as well. In ALLEEN MAAR NETTE MENSEN there is some critique of Dutch culture, but it is just part of the package: if anything can be ridiculed, then there is no yardstick for a truly critical perspective. By contrast, SHOUF SHOUf HABIBı! has a particular red thread: the silly Dutch habit of being punctual. The strict attitude towards time shows itself among others in the running gag about summer time, which functions to distinguish a 'seize the day' men- 
tality from the organized, not to say over-organized work ethic of the Dutch. Abus cannot adhere to this mentality, but when he is visiting Morocco he defends the logic of Western customs over the habits of his 'primitive' Uncle Youssef. Discussing the possible gain of putting the clock forward in March and then back in October, Abus says: 'If you put the clock back, people work longer and it saves energy,' and when his uncle does not understand what he is saying, he continues: 'Look, back an hour, means less light in the morning. Then you have more light in the evening. So even at night you can.... ' Since Abus gets entangled in his own reasoning, the Dutch logic to manipulate the artificial invention of time in an attempt to conquer nature makes it appear like a senseless custom. When his uncle then inquires why the Dutch do not put the clock back two hours, Abus gives a preposterous reply: 'The Queen won't let them.'

The Dutch obsession with punctuality finds a counterpoint in the titles of the chapters of SHouf SHouf HABIBI! These chapters are named 'First Quarter,' 'New Moon,' 'Full Moon' and 'Last Quarter,' but these temporal indications refer to the 'natural' phenomena that Moroccans tend to live by. ${ }^{5}$ Hence, on a formal level, the film prioritizes an un-Dutch mentality. This is the more effective, since Ter Heerdt's film was labelled as an 'oerhollandse' comedy, by which SHOUf SHOUF HABIBI! reveals comic exaggeration as its major satirical strategy.

\section{A DUTCH ROAD MOVIE: DUNYA \& DESIE}

Ter Heerdt's film triggered attention for Moroccans in the cinema, and in addition to the comic films mentioned above, there is another remarkable tendency since 2008: the Dutch road movie. This genre had been practically non-existent in the Netherlands until that year, except for a handful of films, but none of them particularly successful, like HEB MEDELIJ, JET! [HAPPY DAYS Are Here AgAin] (Frans Weisz, 1975) about a couple of hustlers travelling around, and EEN STILLE LIEFDE [A QUIET Love] (René van Nie, 1977), about a divorced father who kidnaps his 12-year-old son for a trip through Holland and Belgium, and Boven DE BERGEN [ABOve THE Mountains] (Digna Sinke, 1992), about a group of six friends on a walking tour from the north to the south of the Netherlands. ${ }^{6}$ One can speak of a mini-cycle in the late 1990s, with the very delightful De NIEUWE MOEder [The New Mother] (Paula van der Oest, 1996), THE Delivery (Roel Reiné, 1999), as well as the TV movies Roos EN RANA [Roos AND RANA] (Meral Uslu, 1999) and Monte CARLO (Norbert ter Hall, 2001), in which characters cross borders, physically and, as befits the genre, also mentally. The first concerns a trip from Letland to the Nether- 
lands; in the second the protagonists have to fulfil an assignment for a paranoid gangster, making a first obligatory stop in Wageningen, but subsequent ones abroad; in the third two girls take the train to Turkey; and in the fourth an old widow is driven in a white Mercedes to Monaco by a black chauffeur. Some road movies made for TV which stay entirely within the Netherlands seem to be examples of an anti-variant within the genre. In EN ROUTE (Paul Ruven, 1994), the camera is in the back seat of the car (three in total) for the entire movie, focusing upon an escaped convict and his girlfriend, who seem stuck in Amsterdam and never really get 'en route,' although the open ending promises that they will be able to depart from the city. Significantly, in the mosaic TV movie POLONAISE (Nicole van Kilsdonk, 2002), the main characters are caught in the same lengthy traffic jam.

Distances in the Netherlands are small, and the poor reception of HET WAPEN VAN GELDROP [THE WEAPON OF GELDROP] (Thijs Römer, 2008) may 102 suggest that a road movie entirely set in Holland is not the best idea. Nonetheless, as said, since that year, the road movie has become more popular as a genre format, that is to say, according to Dutch standards. BLACKWATER Fever (Cyrus Frisch, 2008) seems to be a road trip in America, but as soon as the car passes the sign with the names of Los Angeles and Las Vegas, the film takes a bent to Africa all of a sudden. TiRzA (2010) is about a man who tries to find his missing daughter in Namibia, repressing the idea that he has already killed her as well as her boyfriend, before the couple took the plane to Africa. In All Stars 2: Old StARS (Jean van de Velde, 2011), the players of a football team travel to Barcelona for a wedding of one of their mates. JACKIE (Antoinette Beumer, 2012) portrays a trip through America of two sisters with their long-lost mother (at least, they assume it is their mother). The characters in the TV movie HitTe/HARARA [HEAT] (Lodewijk Crijns, 2008), as well as in DUNYA \& DESIE (Dana Nechushtan, 2008) and RABAT (Victor Ponten and Jim Taihutti, 2010) either go to Morocco, via Belgium, France, Spain, and/or they travel within Morocco. The female protagonist in SILENT OnEs (Ricky Rijneke, 2013) travels by cargo ship from Hungary to western Europe in search of a better life, whereas the female protagonist in both Nothing Personal (Urszula Antoniak, 2009) and ZuRICH (Sacha Polak, 2015) wanders abroad, going nowhere in particular, as a reaction to a recent trauma. And in MEET ME IN VeNICE (Eddy Terstall, 2015), an Italian musician takes his daughter, whom he has not seen since she was three, on a musical voyage with the Orient Express from Venice to Istanbul. ${ }^{7}$

In their 'Introduction' to The Road Movie Book, Steven Cohan and Ina Rae Hark claim that the attraction of road movies resides in their promise of an escape from (domestic) confinement. The genre 'owes much to its obvious potential for romanticizing alienation as well as for problematizing the uni- 
form identity of the nation's culture' (1). In other words, being on the road triggers fantasies of becoming an outsider to the existing culture. The trip to Mardi Gras in EASY RIDER (Dennis Hopper, 1969) emphasizes the male characters' identity as non-conformist hippies; the two women in THELMA AND LOUISE (Ridley Scott, 1991) discover during their hyperkinetic ride that they are 'deep down' adventurers rather than subservient housewives. Not all road movies end in a rebellious stance, however. Having experienced the colourful world of Oz, Dorothy in THE WIZARD OF Oz (Victor Fleming, 1939) starts to reappreciate her home which she initially had come to dislike. Similarly, the film director in Sullivan's Travels (Preston Sturges, 1940) gives up his ambition to make a serious film on poverty with a social realist 'message,' provisionally entitled OH, BROTHER WHERE ART THOU? and returns to the comedies he had become fed up with, after he has learned how pleased the lower class is with humorous pictures. Whether one distances oneself from the dominant conventions or whether the journey has made one reconcile oneself to them, the road movie rearticulates the identity of its main characters. Even when the destination looks the same as the point of departure, the trip has brought about a significant change. In a similar vein, DUNYA \& DESIE, which was made after a successful TV series, shows how the two title protagonists undergo a change as a result of the journey they make together in Morocco, by bus, train, cab and hitchhiking in a truck.

Nechushtan's film opens with a voice-over by Dunya El-Beneni, who is of Dutch-Moroccan descent. This device may seem to privilege her over Desie Koppenol, who is the object of her reflections. When summing up a list of what goes without saying in her life, Dunya says that the Dutch weather, breathing and getting older are as automatic as the fact that Desie has a new relationship time and again, which also passes by automatically. The two girls are best friends, but the voice-over and the annoyed look by Dunya when the blonde and flirtatious Desie is toying with her driving instructor clearly indicate that they are very different from one another. The impression that Dunya is a thoughtful character may be determined by her strict upbringing. Her brother Soufian watches her movements and does not flinch from informing their parents. By contrast, Desie acts on impulse. She is working at a barber shop, but when her boss refuses her permission for a day off she not only quits her job right away, but also breaks off the relationship.

Because of her 18th birthday, Dunya receives as a gift a jigsaw puzzle of 1,500 pieces, depicting a castle in the village that her ancestors originated from. Further, some family members have come over from Morocco to arrange a marriage with her nephew, Mounir. Dunya is reluctant to go, but she cannot resist her parents' wish. Just before they go to Morocco, she receives news that Desie is pregnant by her driving instructor, who wants her to have an abor- 
tion. It makes Desie inquire after her own conception - 'You were a mistake,' her mother confesses - and the circumstances of her birth: 'Your father had already left.' This information makes her postpone her decision about whether she will keep the baby or not. She desperately needs to speak to her father first and find out about her own family background: Does her biological father care about her existence at all?

The stakes for the two protagonists are contrasting, as they acknowledge themselves at some point: while Desie searches for her origin, Dunya considers her family background to be a burden. When Dunya is already in Morocco, living in a house that is not yet finished, Desie comes to visit her to get the latest address of her father, Hans, who apparently is somewhere in Casablanca. Dunya's parents are unpleasantly surprised by her arrival, for they consider the 'slut' Desie to be a bad influence on their daughter. For them, Desie represents the lack of moral values in Holland. This lack is signified by the fact that 104 Desie is scantily dressed and even sunbathing in a bikini. She is too naive to understand that a woman needs decent clothing in a predominantly Islamic country. Or she play-acts naivety, and in that case, it is a token of both cultural indifference and rudeness. On behalf of her family, Dunya has to ask her to leave, but at the last minute she takes the bus with Desie (because it is too dangerous for a foreign woman like Desie to travel alone). The trip gives Dunya some relief from the impossible choice she faces. She wants to remain loyal towards her family, but having seen the not too smart and not too handsome Mounir, she is certain she does not want to marry him.

After a few adventures, they meet on their way a reader of tarot cards, like in the opening of the nouvelle vague film CLÉO: DE 5 À 7 [CLÉO FROM 5 TO 7] (Agnès Varda, 1962). The fortune teller then produces a mirror card and on accidently coming across the castle in the jigsaw puzzle some time later, Dunya realizes that while Desie is searching for her self(-image), Dunya herself is fleeing from it. Desie's search is successful insofar as she meets her father, who has a photograph of her as a baby with him. Her mother wanted to keep the child very much, he tells his daughter, and he always thinks of her. This will lead to a feel-good ending: since Desie's mother has arrived in Morocco with her boyfriend there is a happy gathering at the house of Dunya's parents. Not only can Desie wholeheartedly embrace her mother and inform her that she will deliver twins, but Dunya's family is also glad to be reunited with their daughter. They have come to grasp that they have been too harsh on Dunya, for life in Morocco has taught them that they themselves have become 'too Dutch' in the eyes of their neighbours. To indicate the harmony, there is a shot of the finished jigsaw puzzle, hanging on the wall.

DUNYA \& DESIE does not strike one as a comedy. Its humorous moments are in fact restricted to scenes with Desie who is pretty direct and can give 
imprudent responses, to the visible annoyance of her environment. She is careless whether her behaviour is inappropriate or not. If sunbathing in a bikini is acceptable in the lower-class environment she has grown up in, then it should be acceptable anywhere. This leads to scenes in which her attitude is almost as embarrassing and out of context as the Flodders' behaviour was in Zonnedael. From the perspective of Dunya's Dutch-Moroccan family, her uninhibited nature is 'typically Dutch,' and that is the main reason why the mother regrets ever having come to Holland at all. What underlies DUNYA \& DESIE is that Desie has, in the end, such a positive impact upon Dunya's family. Initially, she is a pain in the ass, because she triggered Dunya to follow her own path, but through Desie the family members realize how they have drifted from their 'Moroccan roots.'

Fundamental to the main argument is that Desie could have this impact, because she refused to adapt to her surroundings and never compromised her behaviour. ${ }^{8}$ Since she persists in her 'typically Dutch lower-class' directness, even in Morocco, the Dutch-Moroccan family of Dunya has some point of reference for their position vis-à-vis Holland. She is a nuisance to those who have a strict Moroccan perspective, but her family is no longer able to maintain such a strict perspective. For them, it predominates that she is 'all mouth, no trousers,' clear-cut and distinct, but also benevolent. This character painting of Desie is very similar to the descriptions of the Flodder family members, who remained 'true' to themselves, regardless of circumstances. By not adjusting themselves to their environment, they looked silly, but ultimately the well-to-do neighbours came across as much sillier. FLODDER was an anti-establishment comedy to ridicule the upper-class bourgeoisie. Whereas in FLODDER, the lower-class family is the pivot of the film, in DUNYA \& DESIE, the lower class - Desie, but also her mother and stepfather - rather have a mediating role: they function as a projection screen for the DutchMoroccans. Since Dunya's parents do not think her actions as unseemly as their neighbours do, the presence of Desie makes the latter appear quite obsolete and at the same time it helps to constitute the identity of Dunya's family as 'more Dutch,' or 'more modern,' than they had expected. Thanks to their acquaintance with the Dutch lower class - who tend to behave crudely, but actually are 'generous' - Dunya's family stands at a distance from a traditional culture with its presumed tight restrictions. And thus, (part of) the 'message,' to use this charged term, of the 'multicultural' road movie DUNYA \& DESIE is that it is wholesome for the Moroccans to be tainted by lower-class influences, which can be considered as the 'legacy' of the Flodders in terms of Dutch cinema. The strength of the lower class, from this perspective, is that it tends to take a pragmatic approach over an adherence to strict principles. 


\section{KEBAB SUTRA: RABAT}

In the surprise hit RABAT, the (lack of) taste of the lower class is in the end a most positive force. It helps the Dutch-Moroccan protagonist Nadir to buy himself out of trouble. He is expected to drive his father's old cab from Amsterdam to Rabat, and though his father has told Nadir not to take 'that Tunisian and that clown' with him, Zakaria and Abdel join him on his journey. They leave with high expectations, and at their departure the car radio plays for good reason: 'The grass will always be greener / on the other side of the hills,' a Dutch evergreen sung by Liesbeth List. Whereas Nadir is quite serious and has recently finished an economics degree, his two friends take life very easily. For Zakaria, only the present counts; his basic occupations are, in the accusatory terms of Nadir, 'smoking, drinking, waking up from a hangover.' Rumour has it that Zakaria made a girl pregnant in Tunisia, but he is 'too yel106 | low,' says Nadir, to visit her. Abdel is not much different, although he is always talking about his 'business plan.' Currently, he is still working in what Abdel himself euphemistically calls the 'restaurant' of his uncle, selling kebab, but he claims he has a 'unique concept.' He presumes that his two friends have already agreed to be a part of the project, but it turns out that Nadir has had his doubts all the time. At the film's crucial beach scene, when the three friends put their camaraderie to the test, Nadir reproaches Abdel that his business consists of 'talking for two years' and of designing logos which took about half an hour. 'Your plan is an excuse for doing nothing. All the time we discuss it, we don't have to do anything else. Admit, you're a loser.'

In the first half, Nadir is positioned as the moral anchor of the film and his father's recommendation to travel without friends makes sense. When they are at a beach in Barcelona, however, things take a different turn. So far, Nadir had kept silent to his friends about the true motive for his trip to Rabat, but Abdel guesses that the car is in fact a bridal gift. Since this guess is correct, his reply is a scathing critique of Nadir himself: 'You lack the guts to tell your friends what you were really going to do in Morocco. You're the one who betrayed the trust of his friends the last few days.' There is a brief fight when Zakaria hits Nadir on the mouth, but as it goes with long-time friends, they make up with one another. The confrontation has brought about a change. When they have crossed the sea to Morocco, his two friends wish Nadir all the best with the girl, and encourage him to visit a barber. Nadir himself is not that certain of his 'mission,' set up by his father. His doubt is not just provoked by the reactions of his two fellow-travellers, but the meeting with the French shoplifting girl, Julie, who shows them Barcelona has increased his hesitation. He was thinking that she was bluffing when she said that she knows Nadir's favourite film THE GoDFATHER (Francis Ford Coppola, 1972) 
very well, but he is deeply impressed that she gave the right answer to his question who was Don Corleone's hitman ('That's easy: Luca Brasi'). Later when he is walking around with Yasmine, the bride selected for him, he tells her that the scenery reminds him of a scene from THE GODFATHER, 'when Michael Corleone meets that girl in Sicily. He takes her for a walk, just like we are walking.' When Yasmine replies that she has not seen the movie, he is convinced that this is not meant to be. Like him, she is also doing this only to please her parents, for she prefers studying over a marriage. Back at her place, he tells the father and her brothers about his spectacular business plan. From his pocket he shows him a piece of paper with the logos designed by Abdel: Kebab Sutra. He tells them that all the Dutch are the same and that they want two things: sex and kebab. His plan is to hit two birds with one stone by serving the meals by topless women. The interior will be a combination of Arabian nights and modern design. The menu will consist of modern dishes with names like Kebab 69, Kebab on the Beach, Kebab Happy End.

So far, the film had avoided disclosing any details about Abdel's business plan, but it turns out to be a sleazy plan which could also have been concocted by Johnnie Flodder or Desie Koppenol. Abdel can be seen as a character who has adopted their mentality, and hence, Nadir can pretend that all Dutch are alike. He pictures Holland as a shameless country where immoral values reign, and from the perspective of Yasmine's family, this must really seem like a Sodom and Gomorrah. One might expect that Nadir's suggestion of the Netherlands as a land of doom may offend Dutch people, but probably the effect is rather the opposite. Holland can only be presented as an undisciplined country in the eyes of foreigners who stick to traditional customs. They, the homebred Moroccans, cannot see 'our' achievements as tokens of a progressive liberalism. The fact that 'our' liberal principles come across as lawless is their shortcoming, and only proves that we are more advanced and broadminded than they are. At the same time, the joke on the various kebab dishes implies that Abdel and, by extension, Nadir, are perhaps more Dutch than they had realized. These assimilated Arabs have a touch of Johnnie Flodder, indeed.

From a cinematographic perspective, it is striking that during the trip, perhaps with the exception of the quarrel scene at the beach in Barcelona, the three friends are often shown together in the same shot. To put an emphasis on either Zakaria, Abdel or Nadir, the focus changes within the shot, representing one (or two) in sharp focus and the other or others a bit blurred. This is an effective strategy, for on the one hand, the changes in focus illustrate that they are not alike, characterologically. On the other hand, showing the three together in a great many shots already hints at the mutual influences upon each other. All three make a decisive step forward 
thanks to the fact that the adventures on the road require them to talk honestly with one another, and thus, Zakaria will go to Tunisia eventually, Abdel will start a restaurant finally, and Nadir will choose THE GODFATHER aficionado Julie over the arranged bride.

\section{FLOUTING MORAL RULES}

Much ethnic humour is a case of the comic scapegoating of a minority group: I find you ridiculous because you do not comply with my norms and therefore I laugh at your expense. Such humour, as Critchley remarks, is 'not laughter at power, but the powerful laughing at the powerless' (12). The American TV sitcom ALL IN THE FAMILY (1971-1979) became famous for reversing this effect. The racist slurs by the main character, Archie Bunker, were based upon such 108 an absurd logic that we primarily laughed at his bigotry and thus the joker himself became the object of humour. Analyzing Al Bundy's misogyny in the American sitcom MARRIED WITH CHILDREN, which is structurally similar to the 'humour' of Archie Bunker, Noël Carroll remarks that Bundy's badinage 'provokes laughter by flouting moral rules, but also pokes fun at the character himself' (101). Carroll adds to this that even when we 'recognize something of Al Bundy in ourselves, our laughter may not be affirmative, since we are, in effect, knowingly laughing reflexively at ourselves as well, and in that sense hardly endorsing the hateful, potentially harmful attitudes in question' (101). Carroll suggests that Al Bundy (and Archie Bunker) are so ridiculous that we will not go along with their thinking: such comedies work to deconstruct the silly logic that underlies (sexist or racial) prejudices.

The Dutch counterpart of Archie Bunker was the plebeian grumbler Fred Schuit, played by Rijk de Gooyer, in the comedy series IN VOOR- EN TEGENSPOED [FOR BETTER OR FOR WORSE], broadcast on public television for four seasons, starting in 1991 and ending in $1997 .{ }^{9}$ With the figure of Nico, Terstall's Vox POPULI offers us a diluted version of Archie Bunker and Fred Schuit. He has derogatory jokes about foreigners, but his logic is not as absurd as Bunker's and Schuit's was. Terstall's comedy shows what happens when one does not completely disagree with his opinions and an opportunistic politician integrates them in his public appearances - in an even further diluted form. The initial success in the polls does not pay off in the end and thus Vox POPULI seems to argue against the demagogic tactics of a politician who denounces his moral principles. Since the politician is portrayed as insincere, the plebeian Nico makes, in turn, a more 'authentic' impression. Moreover, unlike the politician who is sleeping around, Nico is more likeable because he is represented as a true family man. Archie Bunker 
and Al Bundy were represented as the 'worst' of characters in their sitcoms to make them function as negative publicity for racist and patriarchal ideas. The portrayal of Nico, on the contrary, is not as 'bad' as the representation of the sly politician. And thus we may still feel (slightly) superior to Nico, as we felt towards Bunker and Bundy, but the more sympathetic Nico becomes, the more Terstall's film hovers between left-wing and right-wing positions.

In the case of the multicultural comedies, the main protagonists are in a position of the 'powerless' themselves, with the exception of the wellto-do David in AlleEn MAAR NETTE MENSEN. I identified Crijns' film as strategically ambiguous due to its inconsistent tone. Ethnic stereotypes are exaggerated, but one could as easily read them as being affirmed. The film threw everything in the mix, so that groups which were spared from derision were implicitly advantaged. Hence, ALLEEN MAAR NETTE MENSEN is a white, lower-class comedy in disguise. In the other films under scrutiny, and in fact SHOUF SHOUF HABIBI! is the most interesting among them, the practice of ethnic scapegoating is often an example of self-mockery. The more Abus embraces his Moroccan roots, to rebel against the notion of a 'Cheese head,' the more he has to acknowledge that 'going traditional' is a dead end for him. At the same time, he blames a prejudiced Dutch society for his lack of success, an excuse which becomes increasingly pathetic as the movie progresses. SHouf SHouf HABIBI! shows that the second generation is caught in the difficult position of being in-between, but instead of whining about this, the film comically acknowledges this, quite mild-mannered. This has, I suppose, to do with the nature of Abus' failures. The habit of being clockwise is considered by Dutch people as part of their work ethic, but as Joke Hermsen argues in her study Stil de tijd at the same time many feel themselves victim of a (too) busy schedule. As a film like MODERN Times (Charles Chaplin, 1936) illustrates, 'clock time' can turn individuals into cogs in the machine. Hermsen makes a plea for the re-appreciation of spare time and boredom and in fact, Abus is already living the dream to the full, and he does so, I claim, in the tradition of the Flodder family. His notion of time has a natural component, and that is why the film is structured according to the tides of the moon: first quarter, new moon, and so on. He fails to conform to time as an artificial system: he is one hour late because he did not know about the Dutch practice of following summer time; if the civil servant at the work agency asks him whether he will call Spielberg for him, Abus gets excited, apparently not noticing that it is a question in jest, but then is told: 'It is about nine hours earlier in America, so he might be having dinner'; when Abus finally has a job as a train conductor, he misses his very own train, for he was too late, once again.

By hopelessly failing in 'being right on time,' Abus can be seen as a 
descendant of the Flodder family. Likewise, the presence of the frivolous lower-class Desie proved 'beneficial' for Dunya's family who became less strict on traditional customs. Nadir in RABAT could save himself from an awkward situation by showing himself off as a heir of typically Dutch lowerclass taste. Thus, it seems that the most successful multicultural comedies either testify to an affinity with the 'bad taste' of the Flodders or they come to discover that there is some 'Flodder within' them. 



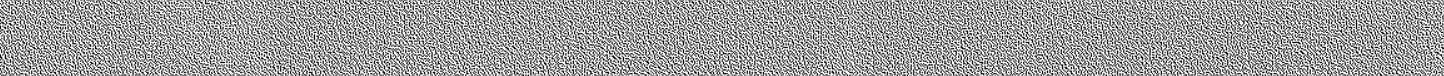
$|c|$
$y$

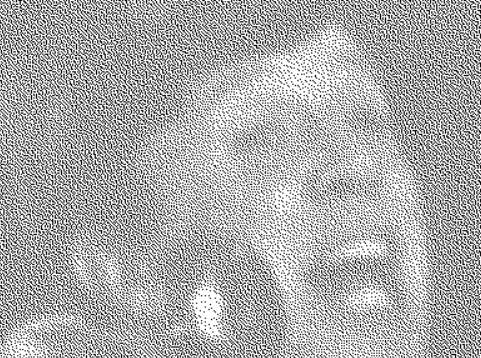

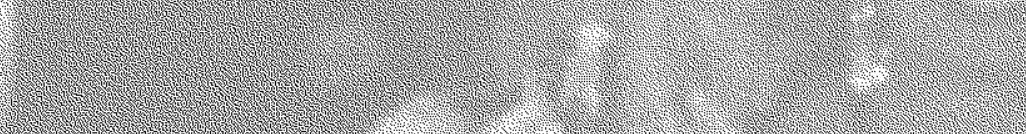

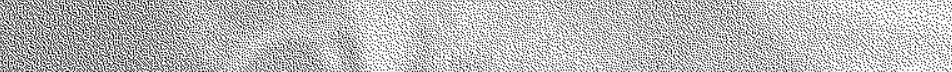

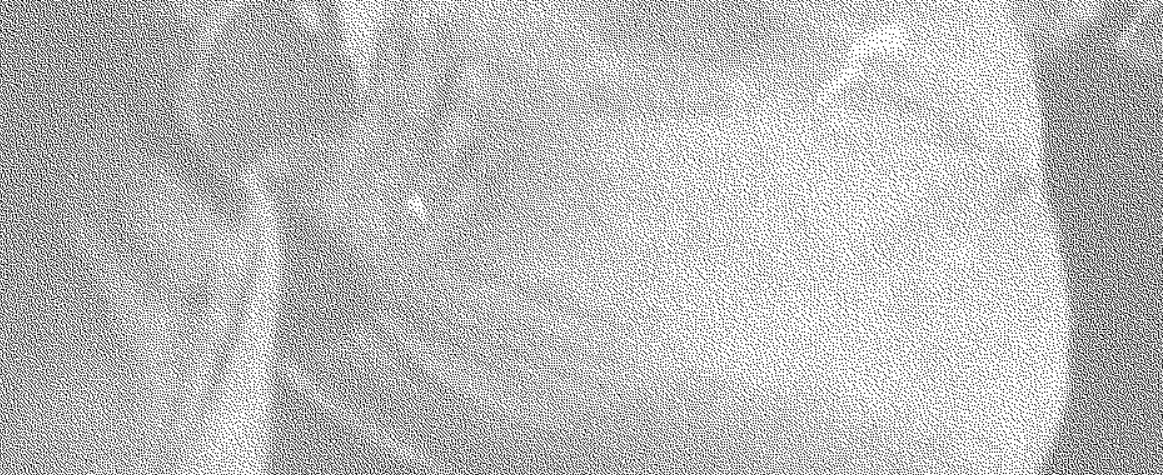

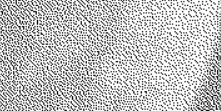

1.

(1) 


\section{From 'Kind-hearted' Comedies to Neurotic Romances}

In a classic essay from 1948, the influential French film theorist André Bazin claims that a theatre visitor comes away with a 'better conscience' than the film spectator. A theatrical play has a 'more uplifting, a nobler ... effect than the satisfaction which follows a good film' ('Theater,' 98). Whereas theatre calls for an 'active individual consciousness,' the film 'requires only a passive adhesion' (99). According to Bazin, a member of a film audience becomes part of a collective. The way the viewer is encouraged to identify with the hero has the effect of rendering 'emotion uniform,... the result of which is to turn the audience into a "mass"' (99). Instead of exciting the spectator, cinema calms its viewer.

This thumbnail sketch of the distinction Bazin makes between theatre and cinema may seem outdated today - after Ingmar Bergman, after Rainer Werner Fassbinder, after the Frans Weisz' pictures LEEDVERMAAK [PERVERSE DELIGHT] (1987) and HoOgSTE TIJD [LAST CALL] (1995), or after a film like TOESTANDEN [CiRCuMSTANCES] (Thijs Chanowski, 1976) - but I bring the essay to memory to highlight that, unlike (serious) drama, most films have conventionally been distributed as amusement for the masses. Obviously, film has been used to artistic ends or political purposes, but if, as Bazin suggests, (a great majority of) film renders emotion uniform, this is mainly due to the entertainment and cheap thrills film has on offer. In a sense, the cinema has never shed its 'birthmark,' when it was hailed as a technological device capable of achieving the marvel of movement as its first special effect. The cinema was in its years of origin not seen on a par with literature, theatre or visual art, but it was considered comparable to vaudeville or fairground attractions. 
It is no coincidence then that, with the exception of the avant-garde documentary REGEN [RAIN] (Joris Ivens, 1929), three out of four pre-war titles on the Canon of Dutch Cinema are geared towards a more popular taste. In addition to a comic short from 1905 and a love tragedy produced by 'film factory' Hollandia from 1919, DE JANTJES [THE TARS] (Jaap Speyer, 1934), in particular, tackles topics and sentiments which have a wide appeal among the common people. The relatively poor circumstances and the ensuing animosity among characters as a result of love intrigues are counterbalanced by gay sing-a-longs and popular tunes. These songs could be enjoyed as the special supplement to an earlier silent version of DE JANTJES (Maurits H. Binger and D.E. Doxat-Pratt, 1922). Speyer's sound film was to initiate a quite successful cycle in the 1930 of of what I would like to term 'sentimental and social drama in a nonetheless happy mood.' Although such a cumbersome label is quite indistinct, the cycle was also known as the so-called 'Jor114 daan-film,' because the drama was often set in De Jordaan, a working-class neighbourhood in Amsterdam.

Sometimes, the not-so-fortunate conditions were supplemented, if not superseded by comic asides in order to create a general feel-good atmosphere, as in BleEke Bet [PALE Bet] (Alex Benno and Richard Oswald, 1934) and Oranje Hein [Orange Hein] (Max Nosseck, 1936). At other times, the characters' attempts to fight both poverty and a sad fate gained emphasis, as in OP HOOP VAN ZEGEN [ON GOOD HOPE] (Alex Benno, 1934). In this type of sentimental and social drama, the scales could tip in favour of laughter, then again in favour of tears. An important sub-category consists of the films based upon youth novels about little rascals. These kids engage in mischief either out of despair or out of clumsiness, but they basically have a heart of gold, like in MeriJNTJE GIJZEN's JEUGd [MERIJNTJE GIJZEN's CHILDHOOd] (Kurt Gerron, 1936), Uit HeT LEVEN VAN DiK Trom [From the LifE OF DiK Trom] (G.B.H. Niestadt, 1937, but released in 1941), and BoefJe [WiLton's Zoo] (Detlef Sierck, 1939). The way these chaps try to come to terms with their troublesome situations results into entertaining movies, fit for all ages.

This type of feel-good tragedy will some 15 years later result into one of the greatest box-office successes in the history of Dutch cinema, CISKE DE RAT [A ChILd NeEDs Love] (Wolfgang Staudte, 1955). I will read this film in tandem with that other big commercial achievement from the 1950s, FANFARE (Bert Haanstra, 1958), for, as I aim to claim, both films can be regarded as two sides of the same coin. My point is that if one removes the poverty from CISKE DE RAT - set in a lower-class urban environment - the film is not quite unlike FANFARE, located in a provincial town. Because of a few humorous asides and the optimistic mood at the end, Staudte's heart-rending drama is closely aligned with Haanstra's film, which can be called, for want of 
a better term, a 'kind-hearted comedy of/for the common people.' Leading relatively prosperous lives in the countryside, the characters in FANFARE can permit themselves to get involved in petty conflicts which were caused when one of the protagonists laughs too loudly at a false note, blown by a horn player in a brass band. In this chapter I will discuss CISKE DE RAT, FANFARE and several of their unofficial predecessors and successors in an attempt to elucidate some of the ingredients of the combination of sentimental/social (family) drama and mild comedy. My main argument will be that this combination could survive because this type of cinema converted itself over the decades from 'worn out' to a range of three contemporary variants, provisionally called 'formalistic,' 'tongue-in-cheek,' and 'neurotic.'

\section{FEEL-GOOD TRAGEDIES: KOMEDIE OM GELD AND CISKE DE RAT}

In attracting more than 2.43 million and more than 2.63 million paying viewers, both CISKE DE RAT (Wolfgang Staudte, 1955) and FANFARE (Bert Haanstra, 1958) became unprecedented box-office successes in Dutch cinemas. These numbers are not to be underestimated, because they exceed the results of even the most popular blockbuster films of today in Dutch cinemas by far. There had been some occasional commercial success in Dutch post-war cinema preceding these two titles, like STERREN STRALEN OVERAL [STARS SHINE EVERYWHERE] (Gerard Rutten, 1953), ${ }^{1}$ but it is hardly disputed that with CISKE DE RAT and, in particular, FANFARE the Dutch feature film finally grew to maturity. While the popular appeal of both films is more or less comparable, there is nonetheless a watershed that separates them. In the period between 1930 and 1958 the majority of the more than 50 films had been directed by foreign filmmakers. Until FANFARE, made by Haanstra, the majority of film directors working in the Netherlands had been foreigners. Like Staudte, who had directed CISKE DE RAT, most of them came from Germany.

Two of these directors became internationally acclaimed filmmakers. Detlef Sierck made BoEFJE but he never got to see the end result, because he was already on his way to America where he had, under his new name Douglas Sirk, a booming career as the king of colourful melodramas. The other one was Max Ophüls, who made with Komedie om GELD [THE Trouble WITH MONEY] (1936) perhaps the most refined film in the Netherlands of the decade, according to Kathinka Dittrich in her article 'De speelfilm in de jaren dertig,' although its commercial success pales in comparison to other comedies from the 1930 s. $^{2}$ Due to a flaccid scenario, a popular film like BLEEKE BET is no more than a 'theatrical picture book' consisting of static tableaux, Dittrich claims (123), but KOMEDIE OM GELD, by contrast, displays 
an inventive alternation of images full of ironic effects. The film opens with a ringmaster in an imaginary circus telling us that the game is about to begin and singing about money 'which covers up what is evil.' Ophüls uses some of the cinematographic devices which will turn into his trademark, like lowand high-angle shots, (slow) lap dissolves, rapidly cut dream sequences with superimpositions, and the camera circling around in the space of the bank office, even making 360-degree pans later in the film. These devices function to accentuate the situation of main protagonist Karel Brand, who is fired as a money runner at a bank after 25 years of loyal service. The reason for his discharge is the accidental loss of a huge amount of money. When he is crossexamined by the police inspector, the latter is shot from a low angle, making him (morally) superior, whereas Brand is shown from a high angle, which has the effect of miniaturizing him. Back at the office, the porter hands him a letter. Initially, the camera zooms in out of curiosity, but as soon as the 116 | camera tracks backward, it is already clear that this must be the fatal letter of resignation. The one job he gets is as an employee at a bowling alley and to suggest his humiliation one of the balls goes straight at the camera.

Then there is a remarkable sequence of parallel editing: the board of a huge building company discusses the sudden death of its director. When the word 'catastrophe' is uttered, the term resonates over shots of Brand. Another alternation between the board and Brand has the expression 'no possible way out' resonate a couple of time. Instead of an upcoming suicide, there is an unexpected turn of the tide: since the company claims to work in the service of the proverbial 'little man,' it wants a typical 'little man' as its director and they consider Brand fit for the function. ${ }^{3}$ The ringmaster intervenes to tell about the importance of saying 'yes' at the right moment, for then the only way is 'up.' The next shot shows Brand from his nicely polished shoes up to his decent smoking. The camera tends to show him from a low angle rather than from a high angle, since he really has become somebody. Brand in fact is too conscientious for his job. He resists the plan to build houses with the cheapest of bricks, and he gets the feeling that he is exploited as a straw man. When he decides to resign, the company's cunning trick becomes apparent. While the camera zooms in on the face of the chairman of the board to an extreme close-up, it turns out that the company had hoped they could get a hold of the lost money, presuming that Brand had secretly hidden it somewhere. Brand is determined to withdraw from his job and he literally goes down, by elevator, and later, after heavy drinking with his brother-in-law, he ends up in a cellar after his mate has stumbled into it. This downfall introduces yet another twist, for here he finds the money he had lost before by accident. Brand is sentenced to a year of detention, but then the ringmaster shows up for a happy ending to this tale of the 'irony of 
fate.' Thanks to a confession by a young boy, Brand's name can be cleared finally.

The irony of KOMEDIE OM GELD is partly created by the camera perspectives. Brand is looked down upon from a relatively high angle in those cases when he is just a modest money runner suspected of deceit, and hence an object of contempt, but Brand turns out to be morally upright. In turn, the camera emphasizes his high status as a neatly dressed director, but despite his favourable appearance, Brand himself comes to realize that he has become part of a cynical and money-hungry world.

The reference to the specifically filmic means of KOMEDIE OM GELD, which were so dearly appreciated by Dittrich, is meant to suggest that I will read both CISKE DE RAT and FANFARE in more or less the same vein, with a focus on formal devices. Even though the film opens with a kid near one of the canals in Amsterdam who starts running away as soon as a female voice shouts his name 'Ciske,' we hear after the opening credits the voiceover of schoolteacher Bruis, telling about his daily routine at school. Then he is addressed by the school principle and two of his colleagues who tell about a new rascal in Bruis' class. This creature - 'heerschap' - has gotten into trouble with the police a couple of times, he has been fighting with all of his teachers, and on top of that, he had spilled red ink on a school mistress. The school principle says that the kid's nickname, 'The Rat' is supposed to remind Bruis he can only be taught manners by giving him a punch now and then. Since Bruis reacts laconically at the cautionary remarks, the three start talking over each other. This cacophony of voices has the contrary effect that it prepossesses the kid in Bruis' favour. While the camera zooms in on the teacher's face, we hear him say in voice-over: 'Whatever he may have done, he is only a kid after all,' implying that he cannot believe his new pupil to be that bad. While the principle and the two colleague teachers continue to convince Bruis, their voices die down as mere background noise the moment the camera captures a kid at the other end of the corridor in a long shot. Then we hear the principle say: 'There he is,' and he walks in a frontally staged reverse shot directly towards the camera, urging the boy to take off his cap as a token of decency. Obviously, this is a point-of-view shot from Ciske's perspective, but since the effect of such a direct address at the camera is generally experienced as quite aggressive by the viewer, it immediately suggests that the boy is unfairly treated, without any reason. When the kid does not give in to the command to take off his cap, the principle hits the cap from his head and orders him to pick it up. The principle threatens to slap his face if the boy does not do so, but the latter does not even blink. Just before the principle is about to strike, Bruis calmly puts the cap back on Ciske's head. 
Bruis' act proves that his decision, uttered in voice-over, were no vain words and that he is inclined to adopt a benevolent attitude towards the new kid he had never set eyes upon before. The more one had tried to convince him of the evil nature of Ciske, the more he felt obliged not to condemn the kid on the basis of only hearsay. The impression that the boy is unfairly judged due to a bad reputation is confirmed in a subsequent point-of-view shot. The principle walks towards the kid in a frenetic way, but by shooting the shot as the kid's point of view, his demeanour comes across as an assault. Hence, the combination of Bruis' voice-over and the kid's point of view shot are the filmic means that provide ground for an immediate bond between the two as well as gaining the sympathy of the spectator. Bruis then takes Ciske along with him, but the boy suddenly turns around and tries to run away. The camera zooms in on Ciske's face and then we get a technically advanced reverse shot: in a point-of-view shot we see how the camera/Ciske 118 is swiftly moving from left to right to left through the corridor in order to escape the stretched out arms of the teachers and the principle. This mobile shot, which could only be made by putting the heavy camera on a bike, once again emphasizes that the boy seems a hunted kid, no matter whether he has done any mischief or not.

In fact, the whole film will come to pivot around the bond between Ciske and Bruis who feels some responsibility for the kid after he gets to know that the boy has been raised in the most poor and unfortunate of circumstances. His father is about to divorce his mother, for they live in an atmosphere of assault and battery. The father has the habit of spoiling the kid, whereas Ciske's mother lacks any maternal feelings. Since the family guardian is not up to the task required of him, Bruis goes to great pains to become the kid's tutor. Nonetheless there are some moments which even supersede the close tie between Ciske and Bruis, and they involve detective Muysken for youth affairs. When one kid in Bruis' class, Jantje Verkerk, accuses Ciske of being cut with a knife, Muysken arrives at school to interview Jantje about this 'bloodbath.' He asks whether the kid needs a cushion, for he may probably feel a bit weak after all the loss of blood. Thereupon, the detective deliberately takes the wrong arm to inspect the wound and then only gives Jantje a tiny Band-Aid, which, as Bruis remarks in voice-over, makes that the boy has definitely fallen from the 'highest heaven of martyrdom.' After this sarcastic examination, Ciske is supposed to enter the room. We see Bruis and Muysken in a two-shot, but as soon as the detective greets the kid, Ciske is shown via a swift pan. This swiftness of the camera movement suggests that one has to be really on guard for this brat, but it is already clear that the camera here only play-acts that he is a truly dangerous kid, just as Muysken will only describe Ciske's deeds in terms of mockery: 'Why not use anything 
heavier next time, a hand grenade maybe?' At the same time, the pan had the effect of putting Bruis off-screen, and this accords with the teacher's experience upon hearing the interview between Muysken and Ciske: he envies the tone of conviviality with which the detective treats the kid. This downplay of Ciske's presumed deeds by way of an ironic exaggeration is qualified by Bruis as the ultimate attitude.

This attitude frames Ciske's subsequent crime, which is brought to us in ellipsis. There is an outdoor shot of a barrel organ while in the background we see Ciske running and hear him scream. It turns out that he has killed his heartless mother. The precise circumstances are only clarified in court by the housekeeper, Marie. Ciske's mother is pestering him all the time according to Marie's account. She has locked him in the coal shed, she forces him to eat against his will, and on top of that, she threatens to tear the pages of a book Ciske has received from his closest friend, a handicapped boy. We see a close-up from the torn pages, then a close-up from a bread knife on the table, and Ciske throws the knife in a split second, whereupon we see his frightened face for a brief moment. Next shot is a repetition from the earlier shot with the barrel organ. The ellipsis is significant in the sense that it works to downplay the actual crime of matricide. All the formal means have prepared us for putting Ciske's situation into perspective. Bruis' voiceover created sympathy for the kid with the troublesome background; the point-of-view shots made us aware of the aggressive treatment that befell the boy; the swift pan was a visual example of the ironic detachment, playacting that he was a dangerous kid, and the ellipsis was meant to repress the horror of the actual crime, because the shot of his frightened face, followed by his screams in the outdoor shot are evidence that the matricide is not only unrepresentable but also strictly accidental. Although he has committed the worst of possible crimes, it is fully acceptable that Ciske does not receive a more severe punishment than borstal. It gives him the opportunity to reform, and during his stay he gets interested in the pious lessons a parson teaches him. Robbed of the bad influence of his mother, the boy can change for the better and open up his good heart, as the convention of such a feel-good tragedy commands. My point in juxtaposing CISKE DE RAT with FANFARE is related to a similar emphasis on cinematographic devices. The charm of Haanstra's film, I will claim, resides in its ludic framing of shots as well as its playful parallel editing. 


\section{PLAYFUL PARALLEL EDITING: FANFARE}

FANFARE is set in Lagerwiede, the fictional variant of Giethoorn, a village without streets so that one can only travel by boat. The composer, Mr. Altena, functions as an internal narrator. He is an outsider who introduces the viewers to this 'unusual village' whose peacefulness is only disrupted by its many noisy tourists. As an extra-local inhabitant from Lagerwiede, he will be the mediator who intervenes in the story a few times and act as someone who can take an unbiased view of the conflict that will arise in the small community. Two rival innkeepers are members of the same band, and as long as they can bury their differences, the brass band is entitled to receive a grant and also has a good chance to win an important upcoming competition. The moment the mayor utters to a representative of cultural affairs that all is well now, a new quarrel ensues, just because Geursen laughs out loud at a false note, blown

120 | by Krijns on his horn. Geursen excuses himself by saying he cannot help it, and he decides to offer apologies. The cow Clara that Geursen brings with him, happens to break loose, because it is frightened by Krijns' dog. Due to the consternation, all the 30 customers at Krijns' terrace are chased away, much to the latter's anger. The enmity has become so serious by now that they both attempt to create their own brass band, and Krijns has a new conductor come over from Amsterdam. The mayor tells the two rivals that the grant will be offered to the largest band. Since the one group has thirteen members and the other group twelve, it is just a matter of persuading only one person to go over to the other side. No one is more susceptible to taking a bribe than the grocer, Koendering, and both parties try to outbid each other. To illustrate the futility of the whole dispute, this spineless Koendering plays the triangle, the most insignificant of all instruments. In the meantime, one group has stolen all the instruments, including the banner of the band, and this deed results into a hilarious game of hide-and-seek. There is a whole mishmash of mutual cheating on each other, and finally each of the two groups has collected enough instruments by some cunning tricks to believe that they are entitled to perform at the contest. While one is on its way by boat, the other goes in a truck, meanwhile practicing their own musical numbers which are composed by the internal narrator, Altena. When it is Lagerwiede's turn to perform, the two groups both take their seats, but while they start playing their own melodies, they sound in perfect unison. To everybody's joy, it is worth the first prize.

In addition to the various moments of comic relief with the new director from Amsterdam falling into the water, stumbling from a stage, or being attacked by a flying chicken, the cinematography of FANFARE keeps up with the film's light-hearted tone. Exemplary is a pan to the right at the very beginning of the film. A cow seems to move magically amidst the grass. Another 
pan, this time to the left, shows a cow moving backwards. A closer camera shot to the left and from a higher angle, however, reveals that the cow is being transported on a boat. Further, there is the shot in which Geursen's daughter tells her father that she thinks Krijns is not capable of any mischief, but the moment she utters these words, the images illustrate the contrary: we see Krijns and his son stealing the band's banner. One of the best examples of the charming cinematographic tricks is the scene when the police officer, Douwe, sees his girlfriend, Marije, with the conductor from the big city. A large white sheet is in front of the couple, so that Douwe sees only a shadow play. While the conductor makes wild gestures in order to illustrate to Marije how he tried to hold on to a pole before he fell into the water, it looks from Douwe's perspective as if the two are embracing each other. Another such moment of apparent misperception takes place in a cross-cutting scene. We see Krijns' group practicing in a barn and we see Geursen and Douwe search for the instrument. The two only have to proceed towards the sound of music, but when they enter the space of the presumed rehearsal, they only see an old man listening to a tape recorder.

Perhaps most significant as regards the playful tone of FANFARE are the many inserts with ducks which live in the canals of Lagerwiede. When someone announces that the whole village will be amazed, the ducks stretch their necks as if in surprise. When the policeman says that Krijns has hidden all the instruments, we see the ducks dive as if looking for the instruments under the water surface. When at one point the mayor of Lagerwiede has fallen into the water while waving his arms, we get a series of shots of ducks clapping their wings. When two people are in front of mirrors dressing up for their wedding, we see several ducks washing themselves. The several brief inserts from the ducks, unrelated to the story whatsoever, can be regarded as functioning as a light-hearted reference to the chorus in a Greek classical tragedy. This chorus intervenes at regular intervals and can either comment on the proceedings in the play, express a moral voice or garner sympathy for the protagonists. On the level of the plot, FANFARE showcases a dramatic conflict of full-blooded rivalry, but at the same time, the inserts of the ducks work to put the earnestness of the conflict into perspective. Hence, Haanstra's film invites the spectator to a double reading. One can enjoy the film as a serious drama, but one can also consider this quarrel as an example of 'much ado about nothing,' because of the suggested analogies with the behaviour of ducks, including their quacking. Indeed, the viewer is willing to accept to identify with the petit bourgeois affairs in Lagerwiede thanks to the in-built relativization of the gravity of the dramatic plot situations. To add humour to this relativization, there is the scene when Geursen and some of his men think that Krijns' group has hidden the instruments on boats in 
the rushes. In an attempt to misguide Geursen, Krijns asks his assistants to imitate the sounds of ducks. The quacking creates some sort of a feedback loop: there are not only some parallels in the actions of the people in Lagerwiede and the behaviour of ducks, but these people are really like ducks. ${ }^{4}$

The great success FANFARE enjoyed needs a two-fold qualification. First, as screen writer Jan Blokker recalls in an interview from 2006, Haanstra's film had a cold reception abroad with the exception of Russia. When FANFARE was selected for the main competition at the film festival in Cannes, no one among the audience was laughing; only some sighs were heaved (Blokker, qtd. in Hendriks, 85). ${ }^{5}$ One reason for this lack of enthusiasm among the foreign public could reside in the fact that FANFARE was unprecedented in Dutch history - and therefore had great appeal among the Dutch public - but that this type of comedy had already been practiced elsewhere, most evidently in Great Britain. FANFARE bore quite some resemblance, in its 122 mild comical tone, to Ealing Studios productions, which should not be surprising, since prolific film director Alexander Mackendrick who was affiliated to this company, had been hired as advisor. ${ }^{6}$ Second, FANFARE has a paradoxical status in Dutch film history, for it also happened to bring the combination of (social) drama and kind-hearted comedy to a temporary standstill. In the eye of the public, Haanstra's film may have brought this type, almost single-handedly, to high acclaim, but for a young generation of aspiring directors, FANFARE became the eye-catching example not to follow. The youngsters who attended the Film Academy which had opened its doors in 1958 regarded the film as way too jocular for a medium that deserved serious attention - of course, one did not attend an Academy to make 'stale entertainment' oneself. As a consequence, these youngsters cut the ties with both popular film comedy and sentimental social drama (as well as the combination thereof). This does not mean that these types died down, but they were eagerly adopted by the new medium of television in favourably rated series like STIEFBEEN EN ZoON (1963-1966), based upon the British sitcom STEPTOE AND SON, or SWIEBERTJE (1955-1975). The (combination of) heartrending drama and kind-hearted comedy later got revived in cinema in, roughly speaking, three different fashions.

First, this type of cinema got 'spiced' up, because more (sexually) exciting material was inserted in it. The representation of Ciske's mother had been based upon the trope of the 'lady is a tramp,' but in films from the 1970 s the tragic stories of prostitutes could be shown in a more favourable light, such as in Keetje Tippel (Paul Verhoeven, 1975) and Rooie Sien [ReD SIEN] (Frans Weisz, 1975) with the memorable song 'Telkens Weer' ['Again and Again'] by Willeke Alberti. Second, in the 1980s, a decade often associated with a mood of nostalgia, there was a remake of CISKE DE RAT (Guido 
Pieters, 1984), with an important deviation from the original. Staudte's film shows how the schoolteacher gains sympathy for the rascal, whereas in Pieters' remake the kid is the focus of attention throughout. This time, the film opens with a song performed by the main actor in which he gives voice to his misery: 'Had ik maar iemand om van te houden' ['I Wish I Had Somebody to Love']. Since the song became a massive hit, the kid is the one the audience can identify with as soon as the music sets in during the opening credits. For his next picture, Pieters opted for another nostalgically tinted remake, OP HOOP VAN ZEGEN (1986), which was already the fourth adaptation of the play by Herman Heijermans.

Third, if CISKE DE RAT and particularly FANFARE can be seen as examples of Dutch folklore, some films can be seen to take a slightly ironic attitude towards typically national sentiments. The festivity of Saint Nicholas offers the best example of all, and in the upcoming paragraph I will discuss a film by Fons Rademakers featuring this saint with his long, white beard and his red mitre.

\section{BERGMAN 'LIGHT': DORP AAN DE RIVIER AND MAKKERS STAAKT UW WILD GERAAS}

Before Rademakers was to make MAKKERS, STAAKT UW WILD GERAAS [THAT JoYous EvE] (1960), he shot that other eye-catching film of 1958, next to FANFARE, which was DORP AAN DE RIVIER [VILLAGE ON THE RIVER]. The plot of his debut feature, based upon a so-called regional novel by popular writer Antoon Coolen, was steeped in folklore like FANFARE. The stubborn and unconventional Van Taeke from high up north works as a doctor in a rural community in the south of Holland. The internal narrator, the regular jailbird Deaf Cis, speaks in voice-over with reverence about the Frisian doctor, 'that peculiar and odd character.' For Van Taeke can give the impression that reading his newspaper and smoking a cigar are more important than the well-being of his patients, but if the tide is high, he always performs his duty and proves, as one villager says, to possess 'nerves of steel.' When the doctor undertakes a reckless journey during a dangerously icy night in order to save the life of a pregnant patient, many villagers are dumbfounded in their admiration for his bravery. Nevertheless, Van Taeke will be given a 'honourable discharge' by the mayor who has been offended by the doctor's frank refusal to play along with the highfalutin' upper class. The mayor is flabbergasted when the doctor says bluntly: 'I don't see how we could have any joint interests.' During the celebration of Van Taeke's 25 years as a practicing doctor, the mayor delivers a speech and hands over an envelope containing 1,000 guilders, which is no less than 
a kiss of death. Without opening the envelop, Van Taeke burns the gift in the presence of all guests and then goes back to his native ground.

However, Rademakers did not opt for a light-hearted adaptation of this 'culture clash,' in the vein of FANFARE. He could have turned the adventures of a village doctor into a comedy, as Nikolai van der Heyde would do some 16 years later with HELP! DE DOKTER VERZUIPT. Although DORP AAN DE RIVIER is not without its humorous moments - as when Deaf Cis hides from the police underneath a toilet basin, but meets an unfortunate fate when one officer has to use the bathroom - the mood in Rademakers' film is quite dark, with superb black-and-white photography, especially in the candlelit scene in which four drinking men are gathered at the coffin of a man who has hanged himself. Other striking devices are the frequent use of almost frontally staged close-ups of distinct faces, a few well-timed extreme close-ups - e.g., when the doctor talks to one of his sons about his deceased wife - and the wonderful 124 180-degree pan to the left during the hypocritical speech, starting from the mayor alongside the guests and coming to a halt in a medium close-up of a coldly gazing doctor. Stylistically, the film can be seen as a companion piece to films by Ingmar Bergman. Before making his film, Rademakers had carefully studied two of the films by the Swedish director, GYCKLARNAS AFTON [SAWDUST AND TINSEL] (1953) and SOMMARNATTENS LEENDE [SMiles of A SUMMER NIGHT] (1955) (Bernink, 15). Since Rademakers originally had a background in theatre - also as an actor - it was not illogical that he wanted to draw inspiration from a director like Bergman who had a close affinity with the theatre as well. Rademakers also asked Bergman to be a consultant on his picture, not because he needed help, but in order to reassure his financiers that although he was a novice filmmaker he would seek out the help of an experienced director. Though not supposed to get truly involved with the film, Bergman persuaded Rademakers to omit the scene in which the doctor shows himself from a particularly unsympathetic side. When a farmer has spread rumours about the doctor's crude behaviour towards his own wife, Van Taeke threatens the farmer with a gun three times, driving him crazy. To the dismay of scriptwriter Hugo Claus, a well-known Belgian novelist and playwright, who considered the moral complexity of the doctor fundamental, Rademakers followed Bergman's advice to kill this darling (Bernink, 18).

In the light of later Bergman films, like DET SJUNDE INSEGLET [THE SEVENTH SEAL] (1957), not to mention NATTVARDGÄSTERNA [WINTER LIGHT] (1963), DORP AAN DE RIVIER, the very first Dutch feature ever to be nominated for an Academy Award in the category of Best Foreign Language Film, can be qualified as 'Ingmar Bergman light.' ${ }^{7}$ It is a slimmed-down version in the sense that the existential and/or religious themes that often pervade Bergman's film from DET SJUNDE INSEGLET onwards, are lacking in DORP AAN DE RIVIER. By 
contrast, Rademakers' film pays tribute to its 'regional' source text by putting an emphasis upon the doctor's outright contempt for the upper class. As such, this seminal film, in which the dramatic supersedes over the comic, is symptomatic of a tradition of privileging the perspective of the 'common citizen,' which is continued in quite a number of comedies discussed so far. ${ }^{8}$

If DORP AAN DE RIVIER is Bergman 'light,' Rademakers' subsequent feature, MAKKERS STAAKT UW WILD GERAAS, seems an even 'lighter' picture, but what it lacks on the side of tragedy, it gains in irony. If this film walks the middle ground in tone between FANFARE and DORP AAN DE RIVIER, it is perhaps due to the fact that this time the script was not written by Hugo Claus, but by Jan Blokker, who had co-authored the screenplay of FANFARE. ${ }^{9}$ The (untranslatable) title is revelatory in indicating the shift to mild irony. According to a traditional notion, irony is a rhetorical trope which exhibits a contradiction between the said and the non-said. Irony is then an antiphrasis and the message is to be decoded as the inversion of the literal meaning of the expression. If someone says 'splendid weather' when it is raining cats and dogs, he probably means to communicate that he thinks the weather is terrible and hence the opposite of splendid. In such a case, irony is a trope that reveals the hidden meaning of the message via a detour. Several critics have pointed at the narrowness of such a conception. Despite attempts by scholars such as Wayne Booth in his well-known study $A$ Rhetoric of Irony in which he aimed to figure out which clues enable a reader to stabilize irony and to cross out ambiguities, irony is particularly difficult to pin down. According to Linda Hutcheon, irony is neither only the said nor only the unsaid, but it is both at the same time. Or in her phrasing, irony 'happens' in 'the space between (and including) the said and the unsaid' (Irony's, 12). Rademakers' title MAKKERS STAAKT UW WILD GERAAS offers this double-coded process in a nutshell. Every Dutchman will recognize the title as the second line in the song 'See the Moon Shines through the Treetops,' originally written in 1843 . The widely known rhyme is sung by children in the hope of receiving presents from Saint Nicholas. For Dutch viewers the association with this nostalgic tradition, aimed at kids, will be particularly strong since 'Makkers, staakt uw wild geraas' is an uncommon expression, which no one will ever use outside the context of Saint Nicholas. In plain terms, it means something like 'friends, be quiet,' but in such a translation, the ring of the archaic terms is lost. 'Mates, Cease Your Wild Roaring' might be more appropriate, but still misses the true peculiarity of the expression. ${ }^{10}$

The reference to Saint Nicholas is visually confirmed in the first minutes of MAKKERS STAAKT UW WILD GERAAS which show the happy event of the yearly arrival of the 'Spanish bishop,' greeted by a huge crowd of young children and the inevitable brass band. If only the association with the tradition of Sinterklaas were relevant, the film might also have been named 'See the 
Moon Shines ..., or it might bear the title of any other famous line from any other famous Saint Nicholas rhyme. However, as soon as Mr. Leegher closes the curtains so that his young son, Eduard is cut off from the festivities, the screen turns completely dark for a moment and the film shifts gear. The idea of 'mates, cease your wild roaring' is from now onwards to be taken literally as well. As the narrative will make clear, the 'wild roaring' does not so much refer to the noise produced by young children, but to the behaviour of the adults portrayed in the film. At the heart of each of the three families portrayed is some internal dispute. Hence, one can read the archaic title also as a call for stopping the conflicts. At the same time, the title should also not be applied too literally to the events in the film. An odd and solemn expression like 'mates, cease your wild roaring' will only befit those formal people who tend to regard any minor disturbance of the peace as 'wild roaring.' In that sense, the title is a form of free indirect speech. In such a case, one quotes the manner of speak126 | ing of those formal people, without using quotation marks, but one does so in order to stand at a distance from them. In fact, the conflicts in the film are not that deeply rooted, but from the perspective of decent civilians who are used to an orderly lifestyle - like, e.g., the Keizer family - they can be quite alarming. The film itself however does not adopt their perspective, but rather adopts a perspective on them, in fact not only mocking the petit bourgeois, but all of its characters. Hence, by way of archaism, the title is a wilful exaggeration of the actual situation, and therefore a perfect example of how irony channels both the said and the unsaid. It is just a reference to a children's rhyme; it can function as a call to stop the quarrelsome atmosphere among the adults, but if one takes the archaic terms to their letter, they also become too heavy-handed and as a rebound effect, it works as an indication to take the conflicts not too seriously.

Since the stories of the loosely connected families are intercut with one another, MAKKERS STAAKT UW WILD GERAAS is an early example of the mosaic film: Mr. Leegher is a colleague of Mr. Keizer; Emma is a friend of Mrs. Keizer and also the babysitter for the Lomijn family; the young Eduard Leegher is playing with his schoolmate Rolf Lomijn, at the latter's home. The Leeghers are separated from bed and board, although Mr. Leegher hopes his wife will accept him returning to his former home. The Keizers have only one child, the troublesome teenager Henk, who rebels against his parents, to the sorrow of his mother. During the opening credits she is present at the arrival of Saint Nicholas and, seeing a child sitting on his father's shoulders, she nostalgically recalls the time when 'our Henk was that small.' In turn, Mrs. Lomijn has increasing suspicions that her husband is having affairs with other women (which he has, indeed, been doing).

Although the characters experience their respective problems as seri- 
ous issues - a separation, the generation gap and adultery - the way they are handled is benevolent. Henk's father, Mr. Keizer, is everything but a strict patriarch. At the request of his wife, he asks his son, amidst all of the latter's friends, whether he wants to celebrate Sinterklaas at home, but the teenage Henk naturally refuses to participate. Mr. Keizer accepts his son's refusal, for he fully understands that young people like his son do not always accede to their parents' wishes. The scene when Mrs. Keizer, in the company of her friend Emma, wants to buy a record for Henk is both endearing and funny, but she only vaguely remembers the melody. She is humming the tune in music stores ('pom, pom, pom'), but to no avail. Then there is a shift to Henk who is enjoying himself in the café with some of his friends, while a record is playing diegetically. Back to Mrs. Keizer who now, as if she has been present in the previous scene in the café, all of a sudden has the melody right. At the end of the film, when Henk is brought back home totally drunk, his mother is worried sick, but his father puts on the record as both a surprise and as an attempt to comfort him. Henk, however, is too intoxicated to appreciate the gesture. Even Mr. Lomijn who is perhaps the least likeable character because he is cheating on his wife, is depicted relatively gently. He is represented as a bon vivant, flirting with women and stealing kisses, but in the end, when he is on his way to yet another meeting with a mistress, he all of a sudden returns home and makes up with his wife. He confesses his love to her and she says she believes him. It is not an 'all's well that ends well' for them, because whether Mr. Lomijn will behave like a Don Juan no more is doubtful.

Most interesting of the three narratives is the story concerning the Leeghers. When he comes to see her at her photo studio, she tells him she wants to be left alone: 'We're probably not the kind of people to be married.' She tries to keep aloof from him, but when she has invited many guests in her house to celebrate the joyous Saint Nicholas eve, Mr. Leegher arrives at her place dressed up as Saint Nicholas. Their son, Eduard, is still awake, so the father in disguise cannot be sent away, even though Mrs. Leegher is embarrassed, since she had asked a colleague to perform the role of Saint Nicholas. Disguised as the socalled friend of all children, Mr. Leegher sits in the best of chairs and says: 'It's great to be back here.' The effect of his trick is postponed, because the story is interrupted in order to show the developments at the Keizers (with the drunken son) and the Lomijns (the suggestion of a reaffirmation of love). We return to the Leeghers when, Eduard probably asleep, the booked Saint Nicholas has arrived as well and is dancing a tango with Mr. Leegher in his disguise. ${ }^{11}$ Because there is also an exchange of a rose from mouth to mouth, the scene is a deliberate imitation of the dance act between 'Daphne' - a man dressed up as a woman - and an old millionaire from SOME LIKE IT HOT (Billy Wilder, 1959). Mrs. Leegher is clearly enjoying the spectacle and has a tender look on 
her face. Then we get a sudden close-up of Mr. Leegher, contemplating. When she embraces him after all the guests have left, he says ultimately: 'Difficult, isn't it? ... Maybe we are not the kind of people to be married,' in a repetition of her earlier phrase. He announces his departure, still partly dressed as Saint Nicholas. Now there is a close-up of her face, contemplating. In an extreme long shot we see the sloppily disguised Saint Nicholas from behind, as he goes into the dark night, a jazz score on the soundtrack.

Joop Landré, the producer of the film, was not amused by the sour ending of the film, but Rademakers and the scenarist, Blokker, refused to comply to his wish for a happy outcome. Blokker explained that characters like the Leeghers suffer from a loneliness that cannot be 'remedied' by marriage. Their reconciliation would have been a stopgap, at odds with the actual disposition of the characters, he claimed (Bernink, 33). For Blokker, MAKKERS STAAKT UW WILD GERAAS should have a documentary appeal. In sticking to its original

128 | ending, the film preserves its status as a 'document humain' (Bernink, 33). The film represents a conveniently arranged world in which upright people are suddenly confronted with (minor) dramas, Blokker said in an interview. 'If I were to show my grandchild what the Netherlands looked like around 1960, I would not take him to a documentary by Bert Haanstra, but to MAKKERS STAAKT UW WILD GERAAS' (qtd. in Hendriks, 87).

As a mildly comical moral drama, Rademakers' film has had some offspring in the history of Dutch cinema, which I will tentatively divide into three subcategories: a 'theatrical' and 'formalistic' approach to the pitfalls of modern relationships; a tongue-in-cheek recycling of the comedy of remarriage; and a neurotic and/or decadent comedy of manners.

\section{STICKS OF SATAY IN THE THEATRE: EEN ZWOELE ZOMERAVOND AND TUSSENSTAND}

Rademakers had never shed his close ties with the domain of the theatre. For him, cinema is a performance art basically, with good acting at its core. As theatre was the ancillary medium to cinema for Rademakers, the films made by the theatrical company Het Werkteater, which existed between 1970 and 1985 , can be seen as one of his heirs, despite some divergences. Rademakers was a classically schooled man of the theatre, whereas Het Werkteater bore fruit as a company to overturn theatrical conventions. It was fashionable in the days of the early 1970 s to emphasize socialist ideals by deliberately misspelling words, and so the group's name was intentionally written without the letter ' $h$ ': Werkteater instead of Werktheater. In line with those ideals, there was no real leader of the company, there was much improvisation and roles were 
played interchangeably: one evening someone played the mother, the next evening they were the father. Above all, the group owed its rebellious reputation to the fact that its members performed their shows in unorthodox places. In their eyes, a show about mortally ill patients had best be put on in a hospital. Moreover, such a setting had the advantage of enticing a discussion with the public, which could break the daily grind of the regular theatre where the audience always went home after the last round of applause. Preferably, the performances were aimed at actual and social wrongs, e.g., the treatment of psychiatric patients, and for that reason acting out one's emotions was more valued than a technically superb acting style. Of all the shows which were eventually adapted into films, EEN ZWOELE ZOMERAVOND [A HOT SUMMER NIGHT] (Shireen Strooker and Frans Weisz, 1982) based on a show that was presented in 1978, can be seen as the closest successor to Rademakers' MAKKERS STAAKT UW WILD GERAAS.

EEN ZWOELE ZOMERAVOND could as well have been titled, with a wink to Ingmar Bergman, 'scenes from a modern relationship.' The film is set amidst a group of entertainers who will give a show in some sort of circus tent which is full to overflowing. Foremost among the artists are the De Nellicos, which consists of the couple Nel and Koos, parents of two children, one of them still a baby. Amidst all the excitement, the pair are discussing their marital problems. ${ }^{12}$ While they are doing their make-up in the caravan, Koos confesses that he is having an affair, just before they have to enter the ring. He adds: 'Nel, if you would like me to end it, you only have to tell me.' The situation is comic, because Nel remains calm on the surface ('Oh, you mean you want to continue it. Of course you do'), whereas there is chaos around them: her father walking in and out of the caravan; their children making noise; an old woman knocking at the window asking for the main entrance. Moreover, the scene is intercut with the audience going inside the tent, accompanied with the gay sounds of a fanfare. Before they enter the arena, Koos asks Nel for a kiss, since he reassures her that the affair does not mean anything, but she does not grant him his wish. The lyrics of the song they have to perform are blatantly at odds with their situation: 'I have never been so much in love. / I mentioned your name a thousand times. (Nel, Nel, Nel) / There has never been someone else. / You were my ideal. ${ }^{, 13}$

The film is predominantly structured around such ironic contrasts. On the one hand, there is excitement and stress, because incidents prevent the show from running smoothly: the small orchestra is late; there is a power failure in the tent because someone uses the coffee machine; the baby, played by then 45-year-old actor Joop Admiraal, crawls into the ring. On the other hand, Koos and Nel continue their conversation during all this, with ever-changing moods. Initially, Nel reacts deceptively calm: 'Is she only 28 ? Oh, then she 
still wants children one day,' or during an acrobatic act: 'What was her name again? Patricia? Oh no, it was Pamela. That's even worse.' During one of the unplanned breaks, however, she locks herself in the caravan, crying out loud, with Koos asking through the door whether there is anything wrong. At the same time, his young son and a friend are nagging him for money to buy chips, and he gives them a hundred guilders to get some. While sobbing, Nel wants to know what Koos' mistress looks like, her hair colour, her size. When he says that she is quite robust, Nel first is a bit puzzled 'Is she fat?' and then she repeats with a slight mock in her tone, 'Is she fat?' During a subsequent act, Koos is singing in front of the audience, while Nel is showing the leader of the orchestra, who happens to be his brother, Flip, that her black stockings have a ladder. From Koos' position it looks as if she is making advances to his brother, and from then onwards he reinforces his attempts to win her back, albeit in an ill-thought-out way. He tells Nel that Pamela fatigues him, because she 130 is sexually insatiable and wants to do it everywhere - in the bedroom, in the kitchen, on the staircase. Later during an act, he carelessly makes a comparison that is supposed to favour Nel: 'I behave like a fool. When I go to her, I have to perform three times in a row, while with you I can have sex whenever I want,' with an emphasis on the last I. Nel pulls the toupee from Koos' head, which causes another interruption in the show, giving room to an intermezzo, which is perhaps the best known part of the film. A Surinamese woman, played by the white male actor Gerard Thoolen, who was erroneously called to bring $15^{\circ}$ sticks of satay, uses the break to sing and dance, to the delight of the audience. Nel's father is in dismay, however, and he takes up the microphone to tell the public that their joy proves that 2,000 years of civilization has not amounted to anything substantial.

Made by an unorthodox theatre company, EEN ZWOELE ZOMERAVOND is a comedy about a man who expects to be able to get away with having an affair, since he believes his wife is so broad-minded as to accept this non-monogamous form of a 'modern relationship.' He hopes she will agree to his affair with a woman, based entirely, as can be gathered from bits of information, on sex. It is unclear whether he brings up the topic just before the show out of naivety or out of strategic reasons, perhaps counting on the chaos of the moment to increase the chance that she will accede to the arrangement. It turns out to be wishful thinking on his part, and Koos' bad timing only works to create commotion, which ironically contrasts with his attempts to win her back. He tells Nel that he has broken up the affair, because Pamela wanted him to come over more often, which he considered as 'too bourgeois.' Moreover, he warns Nel that she should not fancy his brother, for a relationship produces much fuss. In the final shot, with the camera at quite a distance, we see that Nel sits on the roof of the caravan, smoking a cigarette, whereas Koos is searching for her all around. 
The humorous ingredients are easy to detect: a man thinks that his wife should be 'modern' enough so as to accept his mistress, but the bad timing of his confession creates an awkward situation. Seeing trouble ahead, he tries to avoid it in a clumsy way. Moreover, he (mistakenly) suspects his wife of flirting with his brother, and the fact that he cannot conceal his jealousy, makes him comically hypocritical.

On the surface, EEN ZWOELE ZOMERAVOND may seem to come remarkably close to the type of coarse humour (discussed in chapter 1) as it is delivered by André van Duin in IK BEN Joep Meloen. Indeed, it is set in the environment of revue artists, ushering in banality, but it stands out nonetheless from Van Duin movies. First, the films by Van Duin have not the value of actuality, whereas the film by Strooker and Weisz ties in with the contemporary subject of the 'supposed liberty of modern relationships.' Second, the main actors do not exaggerate their behaviour or their facial expressions, like Van Duin who is, among others, explicitly pulling madcap faces for the sake of laughter. Third, and perhaps most crucial, EEN ZWOELE ZOMERAVOND adds a reflexive dimension to the silly jokes, which is missing in any film discussed in chapter 1. As an intermezzo Koos tells jokes about the utter stupidity of the Belgians. One of the spectators rises from his seat to protest the insulting nature of the jokes. Thanks to the discussion, the jokes might still make one laugh, but mediated by the protest, it is made clear that jokes like these also, if not more so, can make one squirm. Because of this duality - making jokes and at the same time qualifying them as improper - EEN ZWOELE ZOMERAVOND is on the side of irony rather than straightforward comedy. One might say that FLODDER or NEW KIDS TURBO are too hilarious to be taken seriously, but they are comedies nonetheless, which in practice cater to lower-class audiences in particular. EEN ZWOELE ZOMERAVOND has a built-in irony to distinguish itself from this type of comedy, and perhaps for that very reason a company like Het Werkteater was relatively popular among (left-wing) intellectuals, just like the mildly ironic and theatrical MAKKERS STAAKT UW WILD GERAAS was.

Although EEN ZWOELE ZOMERAVOND is scripted, its acting nonetheless gives the impression as if it is being improvised on the spot, which is enhanced by all the backstage chaos. ${ }^{14}$ Whereas this theatrical spontaneity accords with the guidelines of the company, there is a cinematic dimension as well, since the film creates its ironic contrasts via the principle of crosscutting between the gaiety of the audience and the repressed emotions of the couple. Taking a cue from this principle, Tussenstand [Stages] (Mijke de Jong, 2007) can be seen as a relatively recent companion piece to this type of theatrical cinema. On the one hand, the teenager Isaac is predominantly represented in lengthy and meticulously framed static shots, which usually show him isolated from his environment: he can be in sharp focus, but the background is not; the 
shot shows his body, but not his head; we listen to music via his earphones. In apparent contrast to this sterility, the shots with Isaac are consistently juxtaposed with scenes in public spaces like restaurants, frequented by his parents who have divorced but meet to discuss their son's upbringing. There is background noise, music, and the frenetically moving camera depicts faces, very John Cassavetes-like, in (extreme) close-ups, so close that it times disorients us. If we see the mother up close and the father bends forward, his head is out of focus. The two of them are having dinner together because the mother is worried since Isaac is so tight-lipped lately and even bought himself a samurai sword. The mother's sketch of a totally self-absorbed and socially dysfunctional teenager seems correct if we consider the scenes with Isaac, but the irony of TUSSENSTAND is that the manners in which the two adults cope with one another is hardly any better. They have conversations, but they either exchange small talk - about shared memories of a 'Mrs. Pussybeard' - or they

132 tend to address their partner using reproachful terms. He seems to take positions which are wilfully contradictory to her ideas: if she says she distrusts their son's reclusive attitude, he replies that one has to let teenagers explore things at that age. A samurai sword is not a token of aggression, as the mother might presume, but of discipline and control, the father 'corrects' her. So, the adults are talking but as they do so the situation turns into one of 'psychological warfare.' Indeed, the father seems bent on belittling his ex, as when he says: 'If you have so little personality, it is a good thing if you can imitate people.' Fed up with his bantering remarks, she finally calls him a 'fat, gluttonous, selfish non-father.'

TUSSENSTAND, a collaborative effort by De Jong and with actors who have won their spurs in the field of theatre (Elsie de Brauw, Marcel Musters, Jeroen Willems), uses cinematic means - handheld, close-up shots versus cold, static ones - to articulate a huge gap between talkative adults and their quiet teenage son. Since the conversations do not lead up to any understanding, but to frustration, their result is in fact 'worse' than Isaac's taciturnity. Due to its ironic contrasts, which might elicit a smile or a grimace from the audience, De Jong's film can be seen as a disclosure of modern divorce. Its final shot, when mother and son are watching some programme on television on the same bench, is as good as it gets. ${ }^{15}$

\section{PURSUITS OF HAPPINESS: ALLES IS LIEFDE AND ALLES IS FAMILIE}

In addition to these 'theatrical' films which usually do not end on a very optimistic note, but are stuck in ambiguity, there is a particularly successful category of feel-good films, redefining modern relationships. Joram Lürsen's 
Alles is liefde [Love Is All] (2007) and Alles is familie [FAmily Way] (2012) both draw on the subgenre of the comedy of remarriage that was particularly popular in American film history in the years between 1934 and 1941. The central drive of the plot in a comedy of remarriage, as Stanley Cavell claimed in his seminal study Pursuits of Happiness (1981), is not to get the central pair together, but to get them back together, together again (2). ${ }^{16}$ Of the six seminal titles in the Depression period, three of the films start with a divorce. In The Awful Truth (Leo McCarey, 1937), The Philadelphia Story (George Cukor, 1940) and HIS GIRL FRIDAY (Howard Hawks, 1941), Cary Grant plays the part of the overbearing male whom the woman has become fed up with during marriage. She has experienced too many disappointing foibles. In THE AWFUL TRUTH, Jerry is self-conceited, suspicious, foolish and boasts about his 'continental mind.' The quite independent and assertive woman Lucy (Irene Dunne) is a successful singer who becomes engaged to an impeccable man from Oklahoma, while Jerry has insubstantial affairs with an empty-headed nightclub dancer and a woman who appears in gossip magazines. They gradually come to realize the 'awful truth' that they cannot live without one another. The purport of this type of comedy is that one does not love a partner for all of their ideal and decent characteristics - honesty, wealth, upper-class appearance - but one loves the other because of his or her typical idiosyncrasies. As a woman one has to re-appreciate the oddities of the man, and vice versa. Love can only bloom after putting aside the prejudices against one's partner. The genre has to be understood within the context of the Freudian wisdom that an object is never discovered but it can only be valued upon its rediscovery. A second marriage is therefore never identical to the first, or as Jerry remarks at the end of The Awful Truth: 'As long as I'm different, don't you think, maybe things could be the same again, only a little different.' In short, the comedy of remarriage suggests that a remarriage is an improved repetition of the first phase of matrimony.

In the other three seminal films in the subgenre - IT HAPPENED ONE Night (Frank Capra, 1934), BRINGING UP BABY (Howard Hawks, 1938), and THE LADY Eve (Preston Sturges, 1941) - man and woman have not been married to one another, but they position themselves in situations as if they are husband and wife, or are seen by others as a wedded couple. In IT HAPPENED ONE NIGHT, the upper-class daughter Ellen Andrews tells her rich and influential father that she has married a pilot. This angers her father, because he feels utmost disdain for the man and he warns his daughter that he will see to it that 'you're never going to live under the same roof with him.' Ellen escapes from her father's ship and decides to travel on a night bus in order to prevent being spotted by the detectives hired by her father. She meets a poor journalist, Peter Warne, and because she has been robbed of her luggage and money, they can 
only afford to stay at a boot camp on condition they share a room. In addition to the fact that they live under the same roof, they are strategically registered as 'Mr. and Mrs. Warne,' so as to avoid problems. When detectives arrive in the boot camp the next morning looking for Ellen, the two succeed in fooling them because the journalist play-acts such a serious quarrel with his wife, a 'plumber's daughter,' that the detectives truly believe they are a married couple. The running gag in comedies of remarriage is that the constant bickering of the man and the woman convinces suspicious observers that they are a seasoned couple, thereby suggesting that 'a willingness for marriage entails a certain willingness for bickering' (Cavell, 86). One of the effects of films like IT HAPPENED ONE NighT and the hilarious BRINGING UP BABY is that the pair enjoys doing things together, no matter how trivial. They can have quarrels together, they can sing silly songs or waste time, but the point is that no one else can keep up with their pace of talking or bickering. Once the language 134 they speak has become a private one, because they are the only people to fathom the inside jokes, they come to realize that they are meant to be together.

The mosaic film ALLES IS LIEFDE follows up on both of these variants of the comedy of remarriage. Lürsen's film has five major narrative trajectories, which not only have a happy ending during that joyous eve of Saint Nicholas, but also conform to some conventions of the classical comedy of remarriage. In one case, the marital problems of a family were based on a misunderstanding: when she finds out that he has kept silent about losing his job, she presumes that his pretence is a cover-up for a secret affair. The ensuing conflicts turn out to be a stepping stone for a reaffirmation of their love. In another case, a man runs away during his own wedding ceremony, possibly out of 'fear of commitment,' as one of the characters guesses. After he discovers his biological father who had abandoned him at a young age, he decides to marry his gay friend after all, so that the wedding party over the end credits is only the postponement of an earlier event: the repetition is an improved version of the original. In a third case, a woman has left her husband who has committed adultery, and starts an affair with a handsome, 16-year-old boy. His total adoration for her, however, encourages her to return to her fallible husband, choosing the latter's idiosyncrasies over the charming but overwhelming naivety of the adolescent. As befits the conventions of the comedy of remarriage, the brief encounter with the boy is here like the necessary detour to reappreciate the man one has left behind.

The fourth case concerns a woman who is dressed up as a huge box with a bow on her head on the occasion of the arrival of Saint Nicholas. By accident, she ends up in the arms of the country's most popular bachelor, Prince Valentijn. Her replies to his teasing words are dismissive for three reasons. First, she feels embarrassed that he meets her in the ridiculous guise of a huge present. 
Second, she thinks she is out of the league of the highborn celebrities he usually dates. Third, she is waiting for Mr. Right, the proverbial prince on a white horse, and does not want to be dumped after a 'night of wild pleasure.' In spite of, or rather thanks to her dismissive tone, the prince makes efforts to renew the contact and chooses the disguise of Black Pete. When she finally sleeps with him, it is telling that he still has all the grease paint on his face, as if one can only win someone's heart under a mask (as a life-size present, as Black Pete), not as oneself, which fully accords with films like IT HAPPENED ONE NigHT or BRINGING Up BABY. In the end, the prince shows up with a white horse in order to convince her that he seriously thinks that he can be her Mr. Right, which in her words means that he will continue to love her, even when milk is leaking from her breasts and when they are still laughing together at the age of eighty.

These stories are intermingled with one another, first because the characters of the separate stories have some relationship to each other (brothersister; their kids are classmates; or they meet each other by fate, in a café or during a funeral). Second, the stories are woven together by way of constant cross-cuttings from one story to another. Third, the narrative lines are positioned against the background of the fifth one, about a middle-aged man who is a last-minute substitute to play the role of Saint Nicholas for the live television coverage of his arrival from Spain. Actually, this man has returned from Spain to Holland to look for both his ex-wife, who died a couple of years earlier, and the son he had left behind. When he tells his story on television in his role as Saint Nicholas, the gay man who had run away from his own wedding recognizes himself as the abandoned boy, and thus finds his father. Remarkably, they had met each other before, by pure coincidence, on a bench in a park. Without any disguises, they met as strangers, and the older man gave the younger one some advice, which with hindsight can be termed as a truly fatherly advice.

My point in comparing the two mosaic films MAKKERS STAAKT UW WILD GERAAS with ALLES IS LIEFDE is that the first uses the festivities of Saint Nicholas for a contemporary comedy of morals and the second for an updated variant of the comedy of remarriage. The difference in genre determines the possible outcome. As a comedy of morals, Rademakers' film acknowledges that any solution is no more than a veneer for each and every crisis at hand. A woman cannot continue to treat her adolescent son as 'mommy's dearest' or people who are really attached to their personal freedom have better not be married. The 'joyous eve' of Saint Nicholas may suggest an overall atmosphere of camaraderie, but that is only a matter of outward appearance. Any happy ending would undermine this conclusion. For that reason, it is appropriate that Rademakers opted for a 'theatrical' approach to his film: showing the 
states of affair in long shots and only using a close-up for crucial shots, usually when a character is silently contemplating his situation. Mieke Bernink notes that Rademakers is often called a director of scenes rather than of films, meaning that he is more interested in what happens in front of the camera than in what one can do with a camera. At several times his scenes last longer than the screenplay had prescribed (Bernink, 29). Rademakers himself added to this: 'I love long shots. I want to see the whole situation. A long shot enables the viewer to look around himself' (qtd. in Bernink, 30). ${ }^{17}$ It is small wonder then that most actors in a Rademakers' film were originally performers in the theatre, like Ellen Vogel, Guus Hermus, Guus Oster, Yoka Berretty, Ank van der Moer.

By contrast, the comedy of remarriage is known as a talkative genre, in which characters speak out what they expect of life or what frustrates them, at least the female characters in ALLES IS LIEFDE tend to do that. Their wordiness 136 is underscored by a relatively rapid kind of editing and a more frequent use of close-ups. Instead of a theatrical approach, a film like ALLES IS LIEFDE is rather measured to the format of the television soap, albeit a perfectly executed one, with a script that is at least as solid as the screenplay of LOVE ACTUALLY (Richard Curtis, 2003), which had functioned as a source of inspiration. Except for the fact that a soap postpones closure, for that would mean the end of the story, both a comedy of remarriage and a soap have a cyclical pattern as a common denominator. Each and every attempt to achieve one's aim makes one wiser - not necessarily sadder - so that each new try can bring about a (slightly) improved repetition. Hence, to paraphrase Jerry in THE AWFUL TRUTH, things can be the same, only a little different, meaning a little better. Yes, the gay man can go to his own wedding ceremony for the second time, after he has found his father, the presumed missing link who had to be traced to overcome his 'fear of commitment.' Yes, the premature speculations during the television coverage about the prince and the 'surprise' woman in his arms, followed by her scepticism, can only be affirmed after she has defined her ideas about love and Mr. Right on a white horse. In fact, the happy ending of each narrative line is prepared by the external voice-over in the beginning. In telling about the tradition of Saint Nicholas, he draws a comparison between the children's belief in the Holy Man and the necessity to believe in love, despite all its trappings: 'What would happen if we all agreed that Saint Nicholas exists? We'd still have to buy the presents ourselves, but it's the idea that counts. The belief that we will prevail in the end, that love will prevail in the end. Because love is like Saint Nicholas. You have to believe in it or it doesn't work.' In a comedy of morals like MAKKERS STAAKT UW WILD GERAAS we know that love is based upon a void called marriage, but in a comedy of remarriage like ALLES IS LIEFDE, the well-known formula of fetishism is applicable: we know that love is unattain- 
able, but we act as if it is possible after all. In such a case, knowledge is inferior to belief, which is the prerequisite for the happy endings in Lürsen's film. ${ }^{18}$

As an unofficial successor to ALLES IS LIEFDE, Lürsen's film ALLES IS FAMILIE is another mosaic film about new discoveries of reaffirmations of love. Although in familial terms, the most important one is the temporary separation, followed by their reunion, of the father and mother right before the $40^{\text {th }}$ anniversary of their marriage, the most intriguing one, plot-wise, is the developing relationship between their son, Charlie, and his wife's brother, Winnie. She has been married to Rutmer, but their wish for children is thwarted because he turns out to be infertile. Since he does not want her to be inseminated by some hunk, whose genes may carry on some character flaw, he wants his brother Charlie as a sperm donor. Since Winnie dislikes him for his phlegmatic approach to life and career, this has to be executed as a secret plan with the help of a doctor, to whom Rutmer is befriended. During Winnie's pregnancy there are two striking scenes. First, since no one else is around, Charlie has to bring her to the hospital because of some emergency, and, of course, he is addressed as the 'father' all the time, which he soon stops denying. Second, at one point, Charlie is the babysitter of two kids, while Winnie happens to come by to fetch some things, and is surprised to see him. Since one of the kids has started to cry, which he heard over the baby alarm, he goes to the child's bed, and as instructed by the father, he sings a children's song. We see Winnie in the room, while she listens to him singing the child asleep. Her facial expression communicates that this spineless fellow at least has one great talent: he would be a wonderful father, not knowing that he is the biological father of her yet unborn baby. This talent perplexes her so much that she starts to see him afresh, in a much more positive light. If in the comedy of remarriage the accidental pose as a married couple precedes the realization that the man and woman love each other, then ALLES IS FAMILIE has scenes in which the man and woman are seen as 'father and mother' before she even knows that she carries his child. The order that a man becomes a lover first and a father second, is here reversed.

In contrast to Rademakers' theatrical document humain with its stage actors, the two films by Lürsen, measured to the format of a soap opera, feature quite a number of actors who had built a reputation on Dutch television. Restricting myself to ALLES IS LIEFDE, one can mention Paul de Leeuw, Wendy van Dijk, Valerio Zeno, Chantal Janzen, Marc-Marie Huijbregts and one can also count Michiel Romeyn, Thomas Acda and Viggo Waas among them. Most of these names are known as comedians and casting these familiar faces contributes to the tongue-in-cheek humour of the film. Even if De Leeuw plays a relatively serious part - far removed from his outrageous roles as Bob de Rooij in FILMPJE! (see chapter 1) or as terrorist/would-be-couturier in the spoof of 
spy films, SPION VAN ORANJE [SPY OF ORANGE] (Tim Oliehoek, 2009) - his share in a film automatically tends to be taken with a grain of salt.

\section{FREE-FLOATING IRONY: DE GELUKKIGE HUISVROUW AND GOOISCHE VROUWEN}

Some of the main characters in the ALLES IS ... films are fairly laid back, but others are quite affected, not to say neurotic. It is therefore but a small step to the third tendency of post-MAKKERS STAAKT UW WILD GERAAS films, in which the neurotic behaviour comes to take the upper-hand. For want of a better term and with a wink to the next chapter I will call this last category, 'neurotic' comedies about modern relationships from the $21^{\text {st }}$ century. It has to be noted that this category is on a sliding scale from 'slightly berserk' - GoOISCHE VROUWEN, JACKIE, DE GELUKKIGE HUISVROUW - to over-the-top productions 138 | like Amazones, MoOrdwijven, Phileine zegt sorry. In general, these films fared quite well at the box office, although AMAZONES is the negative exception $(26,563)$ and GoOISCHE VROUWEN overshadows them by far with $1,919,982$ viewers, and part 2, released in 2014, even surpassed this number, being the first Dutch film since 1986 to attract more than 2 million moviegoers, becoming the all-time number 7. A common link between the ALLES IS ... films and both JACKIE and DE GELUKKIGE HUISVROUW is that Carice van Houten is the scene-stealer in all four.

Hearing the plot summary of DE GELUKKIGE HUISVROUW people would not assume the film as a comedy, but this drama has its moments of comic relief. The stewardess Lea Meyer, about 30 years old, lives in a huge villa with her rich husband, Harry. She gets pregnant, but after the arduous delivery of a healthy boy, swapping 'canapés for nappies, ${ }^{19}$ she starts to suffer from psychotic hallucinations. Recovering in a mental institution she is being told that she has to mourn the death of her father who drowned himself in a lake when she was nine years old. As a drama the film is schematic, as if derived from a book on psychoanalysis for dummies. Lea's mother has incessantly taught her to despise her father, who was, in her opinion, unfit to raise children. As a child, Lea was therefore encouraged to repress all memories of her father, but now, 20 years later, she feels the urge to dig up the past, for, as she is told in the institution, a dead father is a father, too. ('How profound,' she utters, and judging from her tone she is serious about it.) Initially, she only had some dim memories of him, but after she has been given a picture so that she at least knows what he looked like, her notion of him becomes clearer. Moreover, she comes across a notebook with a rhyme dedicated to her, and this will be one of the set-ups for a belated encounter with the ghost of her father. Following a quarrel with her mother, she hallucinates that she sees him in the rear 
seat of a car via her driving mirror. She even hears him speak, telling her she slept so peacefully while he stood by her bed for 15 minutes before he went to drown himself. Reassured that he really loved her after all, she imagines that he walked into the lake. At the end of the film, she faces the camera, with her baby in her arms, suggesting that now she has come to terms with the past, she is finally ready for her role as mother.

This overtly conventional drama - for a psychoanalytic scenario is at odds with such a feel-good ending - is mixed with comic scenes whose nature can be divided in two. First, there are the incongruous situations, like in the beginning of the film. One of the passengers follows the stewardess behind the curtain for some champagne, and then into the bathroom. A colleague stewardess, who has witnessed them, advises the passengers to fasten their seatbelts, for some 'turbulence' is to be expected. After the brief sexual encounter, the man tells the woman that 'it was a real pleasure again, Mrs. Meyer,' and only then it becomes clear that they are a married couple who only play-acted that they were 'strangers' for the sake of erotic titillation. This 'joke' repeats itself in a next scene when she pretends to be the cleaning woman who, when she turns around, exposes her naked buttocks. At the end of the film, when she has successfully come to terms with the history of her father, her husband, Harry, plays the role of cleaner, who asks 'Mrs. Meyer' to follow him upstairs, exposing his naked buttocks. Actually, Lea and Harry as a modern couple are equals, but for their sexual satisfaction, or 'turbulence' as the bawdy wordplay in the beginning has it, they apparently have to create deliberate hierarchies in class status, not unlike the situations between the prostitute Greet and her subservient male customers in WAT ZIEN IK!? (discussed in chapter 1 ).

Second, the film owes its humour above all to the way Carice van Houten performs her comic-angry lines in the most awkward of situations. Her husband has a compliant character and finds it difficult to handle any drawback. When he thinks his pregnant wife has an orgasm, she retorts: 'No moron, it is a contraction.' While he is eating Asian food with the midwife, Lea complains about the smell of the meal. Are you okay?, he asks, and she scolds at him: 'My pelvic floor is being torn asunder and you're chatting with a dyke about crackers!' Suffering from post-natal depression, she puts the child, Harry Junior, into a box during the night. Harry is shocked by this behaviour and calls for a doctor, who asks her why she put the baby in a box. She yells at him: 'No, not in a box. He came out of my box. I have to explain that to you? He calls himself a doctor!'

Her frustration about the fact that she had to carry all the burden, while 'Harry did not do a thing,' unleashes some angry energy on her part which translates itself into wisecracking replies. The film does not suggest that it is in her nature to be a 'post-feminist bitch.' Her job, for one, requires her 
to behave as a friendly host to all the passengers aboard. And the end scene suggests that she can be happy in the role of mother. The slightly kinky sex, which is hinted at both in the beginning and at the end, may be one of her few dissipations left. So, her funny-aggressive retorts, aimed at her husband, her mother or medical personnel, only came about as a reaction to a situation that frustrated her. At the end of the film, having mourned her father's death, it is suggested that she can finally 'act her age,' as Harry has requested her several times during her depression. Hence, her hysterical-comic days seem to be over.

One of the charms of GoOIsche VROUWEN, exploiting the huge success of the homonymous television series, for its target audience is that the four female protagonists do not give in to the demand to 'act their age.' ${ }^{20}$ Their refusal is not hysterical, however, for they are hardly traumatized like Lea in DE GELUKKIGE HUISVROUW, but the main and painstaking thrust of their 140 | relatively luxurious lives is to remain 'forever young,' or as Cheryl asks herself, 'how to grow older with style.' ${ }^{21}$ Each of the four girlfriends has her own problems, like Anouk, who is called a 'slut' by her daughter because of her series of (young) male lovers, but those of Cheryl are the most decadent. She thinks she has lost her sex appeal, so her gay male 'fashionista' friend Yari advises her to wear a push-up bra, but, oops, she has already got one on. When Yari thereupon meets Cheryl's husband, the popular torch song vocalist Martin Morero, the latter complains that he does not know what present to give his wife for her upcoming birthday. Yari suggests that he buy her 'new boobies,' not realizing that Martin will misunderstand the joke. So, when Cheryl has the laugh on her side when she guesses in the company of the party guests that it is a 'book gift certificate,' Martin says in all vapidity: 'You're close, it is a booby certificate. The thing does not even exist. I had to design it myself. There's a gap in the market.' Martin adds vulgarity to embarrassment when he says: 'A breast enlargement. Of course, I mean: breasts enlargement. Get them both done, otherwise you'll be off balance. And so will I.' Displeased with the cold reception of what he considered as a highly original gift, he mumbles a bit later: 'Next year, I am giving another watch again.'

The depiction of Cheryl and Martin is of interest, because it shows what happens when a type like Johnnie Flodder catapults himself, thanks to just one talent - his vocal qualities - to the level of the nouveau riche, with a mortgage of 2.9 million euro on his residence. Whereas in Maas' comedy, FLODDER, a social experiment put the lower class into a position to flaunt their 'true selves' in order to mock the upper class, in GooIsCHE VROUWEN, the upper class are shown to have a lower-class mentality. ${ }^{22}$ Cheryl's joke on the 'book gift certificate' shows that they do not buy books. Martin has a poor taste in clothing and wants to appear in a 'flashy costume' because he thinks that 
would make a 'grand entrance.' He not only speaks in a sophisticated manner, which reveals that he originates from a well-off neighbourhood, but he also uses curse words without being aware how inappropriate that is in public settings. Further, when the teacher at primary school tells him and his wife that their son has the habit of doing 'deferred imitation' - copying actions he has seen others perform - Martin says: 'How is that possible? He does not even know what that is. Neither do we.'

In FLODDER, the presentation of the upper class as stiff was mediated for us from the perspective of the lower class. In GoOISCHE VROUWEN, this mediation is missing, since the lower class itself has become bourgeois, and it is up to the viewer to recognize the hilarious incongruity of their social rise to an upper-class position. The depiction of Cheryl and Martin equals the Flodders becoming decadent: they show off a luxurious lifestyle, but 'deep down' they are quite trite. This discrepancy has been turned into the source of mocking the upper class. Both Johnnie Flodder and Martin Morero have a huge libido, but whereas Johnnie gets away with anything, Cheryl, as an upper-class woman, cannot accept her husband getting a blow job from one of the neighbouring mothers, primarily because it might affect her social position. Problems arise because there is a position to be upheld, and, ironically, as an antidote to this pressure, Cheryl attends a workshop on 'Becoming Who You Are' in a castle in sunny France. Whereas the Flodders caused problems to others, because they never bothered about their social status (they were just 'being themselves'), the upper-class women are in search of their inner selves. Since they are subjected to New Age jargon about exploring the vibrant shell of their bodies, they give up the workshop. After their failed attempt at self-actualization, they go shopping in Paris with their friend, Yari, the ultimate activity to show off one's social class. Their 'core business' is aptly summed up by one of the lines of Cheryl in the extremely successful sequel, Gooische VRouwen 2 (Will Koopman, 2014), who tells Claire after the latter's return from a three years' stay in Burkina Faso: 'You can take the girl out of Het Gooi, but you cannot take Het Gooi out of the girl.'

Placing Gooische VROUWEN under the banner of the 'neurotic comedy' perhaps does injustice to the film (and the TV series). I presented KoMEDIE OM GELD, MAKKERS STAAKT UW WILD GERAAS and EEN ZWOELE ZOMERAVOND quite favourably as mildly ironic films, so why then deny this honorary label to GoOISCHE VROUWEn? Well, Koopman's film can be termed mildly ironic, like its predecessors, except that irony has come to mean something different since the 1990 s. Perhaps the television programme GLAMOURLAND is a watershed in this. Presenter Gert-Jan Dröge went to visit parties attended by the rich and famous and poked fun at the affected behaviour of the guests. Instead of being embarrassed by their portrayal, a number of these guests - Jan des 
Bouvrie, Harry Mens - used their appearance in the programme to become (second-rate) national celebrities, which greatly benefited their career. They were being laughed at, but at the same time they themselves laughed with the people who watched the programme. The train of thought runs like this: 'You smirk at me because of my posh lifestyle and my attendance at shallow parties, but do not underestimate me. I know it is silly, but I happen to have a sense of self-mockery.' For that very reason, Christy Wampole has described irony as 'the ethos of our age' on The Stone, a commentary page of the New York Times. For the relatively well-educated and financially secure, as she puts it succinctly, 'irony functions as a kind of credit card you never have to pay back.' Irony has become the perfect excuse for not committing ourselves to any cause or lifestyle, but meanwhile we continue to support that very cause or lifestyle. People might consider the programmes of a commercial TV station stupid, and watch them out of a sense of perverse delight, but the station itself 142 is only interested in statistics: for their business model the only thing they care about is how many people are watching and how much can they charge the advertisers. They do not really care whether the programme was enjoyed by the viewers or not. This discrepancy between ratings as such and the (lack of) appreciation on the part of viewers is at the very heart of the liberal-capitalist ideology. A TV station, or a social medium like Facebook, does not bother about ironic viewers/participants as long as they are watching or do not give up membership. Similarly, it leaves a torch song artist like Martin Morero indifferent whether he appears to be a laughing stock to people, as long as they buy his records or attend his concerts: 'Of course, his songs are kind of banal, but it is sheer fun to sing along with them.' This logic is the basis for kitsch: yes, I know that this is an unpretentious and sentimental song/object, but because I know I can enjoy it, or rather, enjoy it differently than those who simply consider this sentimental song/object beautiful. In such a case, the knowledge becomes the excuse for enjoying the song/object. In short, under the banner of kitsch, mediated by an ironic perspective, people derive pleasure of songs/ objects which they 'officially' regard as beneath their taste.

Since this kind of free-floating irony has become the sign of the times, as was Wampole's point, it should not surprise us that GOOISCHE VROUWEN has struck a chord among audiences. Even though it hardly carries any subversive edge, the film has no more pretence than ridiculing the affected behaviour of the financially secure for commercial entertainment. To put it bluntly, the rich might be thinking: 'We think it is fine when you laugh at us, as long as you do not consider our decadent lifestyle as a reason to bring up the subject of a class struggle.' In that sense, GooIsche VROUWEN is in the context in which 'irony is the ethos of our age,' a harmless film, since this type of laughter will guarantee the status quo. Koopman's relatively unpretentious film is ultimately in 
the same league as those films which display an eagerness to show themselves off as very hip, but which despite their bravado, remain stuck in the very same kind of free-floating irony.

\section{POST-FEMINISM: PHILEINE ZEGT SORRY}

Phileine zegt SORRY [Phileine SAYS SoRry] (Robert Jan Westdijk, 2003) is shot as a fast-paced film with frenetic camera movements which accords with the energy of the main character, the 'powerbabe' Phileine. She can be called a typical representative of post-feminism. She has benefited from the emancipatory struggles of the feminist movements in the 1970s and 1980s, but instead of continuing these struggles, the post-feminist creates the image of the assertive and independent woman instead. Phileine is a true she-devil, at times parading like a female James Bond. The film owes its humour to the fact that Phileine is foul-mouthed - 'My aberration, dear Kitty, is that I love discussing sex with girlfriends, preferably vulgar ${ }^{23}$ - and excels in wisecracking, which is contrary to how an adolescent girl is supposed to behave.

On the one hand, Phileine suggests a state of independence, so far so good, but on the other hand she ultimately is dependent on the whims of her laconic lovers. Since her boyfriends cheat on her - like the 'cute and toe-curling' Max with the excuse that he has to rehearse an erotic scene for a modern Shakespeare interpretation - she vents air at randomly selected victims, like a 'hideously ugly' guy. She thinks it great when she has a 'poor boy's soul dashed.' Her intimidating behaviour is born out of frustration. Her incapacity to control her lovers throws her off balance. Granted, Phileine herself notes the inconsistency that she is, or rather pretends to be, a 'cynical, insensitive bitch' but who starts 'wagging her tail as soon as her boss comes in.' The problem of the film is that such reflexive remarks seem to legitimize her behaviour. She radiates toughness, but in the end she only wants to have a relationship with a boy she can call 'my everything.' The image of Phileine as a funny example of Girl Power with all her smart retorts is therefore embedded within a conservative and narcissistic desire of having a steady relationship with the one and only. Phileine hates making apologies, but in the end, she can only win Max back by saying 'sorry,' a couple of times. And as such, Phileine is a typically male fantasy, or 'every boy's wet dream. ${ }^{24}$ She is a cat on a hot tin roof on the outside, but at the core she is fairly tame. During the end credits Phileine can show up dressed as a female 007 and hit the 'sorry'-saying Phileine on the nose in an attempt to restore her 'girl power' image, but it is too little too late.

Because the tame Phileine wins over the wild post-feminist Phileine which is more a posture than her actual identity - the humour of the film falls 
flat. All the wisecracks are no more than window dressing. And as a consequence, all the filmic devices in PHILEINE ZEGT SORRY fall flat as well: Phileine gives comments either in voice-over or by talking directly into the camera; the dream sequences of Phileine floating in space on the Richard Strauss music from Stanley Kubrick's 2001: A SPACE ODYSSEY (1968); the insertion of a pseudo-documentary on Phileine with talking heads (Max, her girlfriend Lala, her mother); the commercial break from the sponsor when writer Ronald Giphart says that the film adaptation is much better than his own book (oh, my God, really?); the play with shallow focus or with freeze frames, and above all the many frenetic camera movements. All these devices are meant to underscore the unconventional representation of Phileine, but they lose their function because, deep at heart, she is a romantic soul. In short, her post-feminist stance is a charade, and so are the filmic devices that go along with them.

The spectator may laugh because he recognizes that her behaviour is the 144 opposite of the convention of the average girl. At the surface the film may seem to turn conventions inside out, but on closer inspection the comedy is more conservative than one might have expected, since her tough posture is no more than a disguise for an average identity and concomitant desires. At the outset, the film seems to offer humorous pleasure because of Phileine's attitude, but on closer inspection the laughter risks, notwithstanding its apparent hipness, reaffirming mediocrity. In defence of Westdijk's post-feminist comedy, it could be said that my comments are too harsh and too serious. For the tone of the film is so mocking throughout that my critical point about the disappointingly conventional ending should be put into perspective. So, I reconsider my 'verdict': PHILEINE ZEGT SORRY has a tame ending, but because of its overall ironic mode, it can also be seen as a parodic mimicry of tame endings. May be, may be not, but that precisely is the point of this type of free-floating irony: in the vein of the idea of strategic ambiguity, discussed in chapter 2 , the viewer is offered here a vision upon 'female power' which is strikingly directionless.

\section{WOMEN WHO KNOW TOO MUCH}

So far I discussed the mixture of social drama and comedy 'light' according to a sliding scale: from the lower-class melodrama of CISKE DE RAT (Wolfgang Staudte, 1955) and the narrow-minded affairs in FANFARE (Bert Haanstra, 1958) to the theatrical irony of MAKKERS STAAKT UW WILD GERAAS and the screwball humour of ALLES IS LIEFDE (Joram Lürsen, 2006). Seen from another angle one could say that this chapter addressed typically Dutch phenomena with comical overtones: the boyish pranks of a little rascal, the 'much ado about nothing' conflicts in a brass band, the love perils triggered by the 
upcoming celebration of Saint Nicholas. In both MAKKERS STAAKT UW WILD GERAAS and ALLES IS LIEFDE, the festivities were a backdrop for all kinds of family matters: adolescent rebellion, reunions, romantic encounters and marital conflicts. And though these conflicts were not always solved on that joyous eve, there was at least some form of reconciliation, if only the awareness that marriage is not apt for anyone. The films suggest that Saint Nicholas can bring about some advance among people, and often this advance is of a comic nature. In Rademakers' film, Mr. Leegher unexpectedly arrives in the disguise of Saint Nicholas in the hope of making up with his wife; in Lürsen's film, Prince Valentijn is dressed as Black Pete to seduce Kiki.

A film such as ALLES IS LIEFDE firmly stands in the tradition of the idea that disguises might work in winning someone's heart, which in cinema history was executed to perfection in the aforementioned SOME LIKE IT HOT. ${ }^{25}$ First the saxophone player Joe disguises himself as Josephine to escape the Mafia. He then meets Sugar Cane, who confides in him, thinking he is a girl, that tenor sax players are unreliable, for the only things they leave behind are 'a pair of old socks and a tube of toothpaste, all squeezed out.' She tells him she prefers 'helpless' men with weak eyes as a result of reading 'all those long columns of tiny figures in the Wall Street Journal.' Joe/Josephine then takes on the guise of Shell Junior, a bespectacled and impotent millionaire with the voice of Cary Grant. Impersonating this immensely rich offspring she falls in love with him, unbothered by his eventual revelation that he is just a tenor saxophone player. Both SOME LIKE IT HOT and ALLES IS LIEFDE can only work on the condition that the film spectator is prepared to accept the naivety of characters who do not see through disguises. In ALLES IS LIEFDE, this naive position is not only represented by Kiki, but above all by the lone drifter, Eppie, with his childish imagination. He cannot see through a disguise, which makes him such an endearing character: a bearded man with a red cloak and a mitre is for him Sinterklaas, or as he calls him 'Sniklaas.'

Films like Phileine zegt Sorry and GoOISCHe VROUWEN seem a bit more mature than the quite naive ALLES IS LIEFDE, but let me clarify the surplus value of the latter by making a brief detour via superhero comics/films like BATMAN, SPIDERMAN and SUPERMAN. The charm of these films resides in the split identity of the male character. The protagonist is 'divided into the weak everyday fellow with whom sexual relation is possible and the bearer of the symbolic mandate, the public hero' (Žižek Enjoy, 24). Clark Kent is in love with Lois Lane, but she has a crush on Superman, not knowing that he is Clark's alter ego. As soon as his identity would be exposed, Žižek argues, 'we are bound to lose him' (24). The makers of the television series LOIS \& CLARK: THE NEW ADVENTURES OF SUPERMAN, originally broadcast between 1993 and 1997, nonetheless took the risk to make Superman's identity known to Lois 
at the beginning of the third season. ${ }^{26}$ They argued that Lois simply was too smart and intelligent a woman to remain ignorant of what seemed so obvious after all those episodes. The revelation made sense from a 'realistic' as well as a feminist perspective, but it spoiled the charm of the 'original' fantasy to such an extent that all kind of bizarre script interventions had to be made to keep the series going (Lois temporarily acquires Clark's power; they get married, but then she turns out to be a clone; she suffers a bout of amnesia; Clark's wife from the planet Krypton comes to Earth). A film like ALLES IS LIEFDE made its viewers accept the route of naivety by setting the film up as some kind of suspension of disbelief: you, viewer, you have to believe in love, in Saint Nicholas, or it simply does not work. The biggest joke of the film is that Kiki (acts as if she) does not recognize Prince Valentijn as Black Pete, which is comparable to Lois Lane in the first two seasons of LOIS \& CLARK.

Phileine, the 'happy housewife,' the 'desperate housewives' from GooI146 | SCHE VROUWEN and the 'killer babes' from MOORDWIJVEN are all women who 'know too much.' Just as the plot twists in LOIS \& CLARK became increasingly bizarre after Lois had shed her naive stance, the humour in these films with assertive and wisecracking women became more and more 'hysterical,' which is a true title with pride seen from the angle of 'deliberate camp,' the subject of the next chapter.

\section{EPILOGUE: A NOTE ON TOLERANCE}

I would like to pause here briefly for some 'helicopter view' of the chapters so far. It may be a caricature, but in the $20^{\text {th }}$ century people in the Netherlands were usually described as phlegmatic and forbearing - by 'lazy foreign journalists,' as Ian Buruma is quick to add (10). The Dutch, however, were not naturally born to be tolerant, but their tolerance was rather a consequence of the peculiar phenomenon of verzuiling, i.e., pillarization. Specific religious groups (Catholics, Protestants) and secular groups (the Social Democrats being the most important one) had their own institutions: political parties, trade unions, schools, newspapers, broadcasting organizations. Life was relatively uncluttered: one knew how to vote, what magazines to read, what clubs to frequent, and so on. As Buruma observes, 'all the real or potential conflicts between the pillars were negotiated by the gentlemen who stood at their pinnacles' (48). There was a mutual understanding among these 'gentlemen' not to intensify the debates but to settle for watery compromises. For the ordinary citizen, membership of a pillar worked as a wall of protection; in fact, one was pampered, as Marcel ten Hooven notes, from the cradle to the grave (11). According to the adage 'good fences make good neighbours, ${ }^{27}$ the idea of 'liv- 
ing apart together' was a most pragmatic solution. The attitude of tolerance helped the Netherlands to develop into a prosperous country and even when the pillars started to totter in the 1960s, tolerance truly became a catch-all term for the upcoming decades: it was not illegal to use recreational drugs, free love was advocated, prostitution is pardonable, gay rights should be supported, euthanasia should be possible, albeit still under strict conditions, and so on. Buruma is right when he notes that this led to 'an air of satisfaction, even smugness, a self-congratulatory notion of living in the finest, freest, most progressive, most decent, most perfectly evolved playground of multicultural utopianism' (11).

What most of the comedies in these first three chapters have shown - and in that sense they can be regarded as 'typically' Dutch - is what happens when a pragmatic tolerance is challenged. FANFARE shows a mild version: the burst of laughter by Geursen is too much to bear for his fellow musician Krijns. A conflict ensues, but apparently insurmountable differences among sworn opponents dissolve in perfect unison as soon as the two groups enter the musical stage, illustrating how silly the dispute was in the first place. The films made after FANFARE are more outrageous, since they reply to the atmosphere of tolerance since the 1960s. These comedies exploit what the freedom regarding $\mathrm{X}$ leads to, and $\mathrm{X}$ is to be read as prostitution (WAT ZIEN IK?!), extramarital affairs (EEN ZWOELE ZOMERAVOND), disregard for authorities (SCHATJES!, New KIDs TuRbo). Most of these films tend to highlight the berserk effects resulting from an 'excess' of tolerance. In some cases, the purport can be quite conservative. Emancipation in general may meet support as a good cause, but the struggle for equal rights for women has also produced the "cold and selfish bitches' from MOORDWIJvEN and PHILEINE ZEGT SORRY.

Pace Dick Maas' reply that FlODDER has no 'message,' this lower-class comedy teaches its viewers that if we are to take 'typically Dutch' tolerance seriously, we have to accept the Flodder family for what they are. A lenient attitude, as promoted by types like Sjakie, gives them ample room to show off their rudeness. In the film, the Flodders are presented as the 'odd one in,' to paraphrase Zupancic, but the required tolerance of the well-to-do neighbours soon evaporates into thin air. On a closer look, Maas' comedy is a foretelling of the 'multicultural tragedy' Scheffer was talking about when one substitutes the lower-class white family for the new Dutch with a religious, often Islamic, background, albeit with a crucial difference. The Flodders are an anomaly who are distinguished by their coarse manners. Their arrival disturbs the quietness in Zonnedael, but their presence is mainly a practical nuisance. One may dislike the Flodders due to their rudeness, but one could trust them instinctively: the party is the definite proof they have nothing behind their sleeves. In a changed political environment since the new millennium, Mus- 
lims, however, are regarded as invaders, in principal opposition to the liberal values of the West. The readiness to tolerate their presence has its limits, even for Dutch progressives like Scheffer, as Buruma has argued: It is easy to be tolerant of those who are quite like ourselves, but what if the other seems to denounce our values? (127-28). It is the fear that the newcomers aim to rob us of our hard-earned luxuries; tolerance being one of our main achievements. The fact that many women wear headscarves and that they endorse the practice of female circumcision are taken as visible tokens of their presumed intolerance. A typical reply by Dutch people to this discrepancy is the sour mood of verongelijktheid, 'to be wronged, not by an individual so much as by the world at large' (Buruma, 15-16). We start wondering: What did we do to deserve such intolerant people coming to join our little paradise of tolerance? From this perspective, the Muslims are, in the words of Buruma, regarded as 'the spoilsports, unwelcome crashers at the party' (127).

148 The multicultural comedies from chapter 2 aim to belie the idea that being a Turk or a Moroccan equals taking a fundamental stance. Abus and his friends from SHouf, SHOuf HABIBI! want to enjoy the privileges from the West, but the source of comedy is that they find it so hard to cope with this freedom. For one, Abus is never ever punctual. In DE MASTERs (Ruud Schuurman, 2015), Aziz, also played by Mimoun Oaïssa, succeeds in reuniting his former rap crew, and guess what? For their performance at a sweet sixteen party in a small village with, says Aziz, a 'rich tradition of hip-hop,' they arrive three hours late, but Aziz responds that if they want to go to bed in time, they had better ask Frans Bauer. Well, probably the kids should have done that, for the performance goes completely out of control.

The comedies so far have basically addressed the excesses that come with the lack of sexual mores and disrespect for authority. Thus, they present material which is quite hot to handle. This could have resulted into provocative films, but by couching these excesses in the form of 'plain' comedies, the 'transgressive' effects were minimized though not yet fully neutralized. In case of controversial content, it is a relatively safe bet to do this under the banner of humour, for the laughter might drown out reflection - almost, but not quite. In the analyses of films discussed in subsequent chapters, the balance will gradually shift towards the reflexive part.

To mark this transition, let me refer to Mike van Diem's DE SURPRISE [THE SURPRISE] (2015), which indeed was a surprise, coming from a filmmaker who had not directed a film, since the Oscar-winning KARAKTER (1997). ${ }^{28}$ DE SURPRISE was advertised as a romantic comedy, featuring two actors who were television celebrities. The actual marketing of the film as if it were another ALLES IS LIEFDE or HARTENSTRAAT was a bit of decoy to attract a huge audience. The film is a romantic comedy, for sure, about a wealthy but impassive 
esquire whose attempts at suicide after his mother's demise are time and again interrupted. He then goes to the mysterious 'travel' agency, Elysium, which promises him, in the euphemistic terms of its manager, a 'once-in- $a$ lifetime journey to the ultimate destination.' And, yes, then he finds the love of his life, who introduces herself as a fellow-traveller. Since, alas, the contract is irreversible, the question becomes: How to escape fate? A similar plot is also used in I Hired A CONTRACT Killer (1990) by the Finnish director Aki Kaurismäki, but Van Diem wanted to avoid being put in the category of deadpan absurdism. The 'surprise' of DE SURPRISE is that it walks the middle ground between the snappy style of the regular romantic comedy and the dry-comic surrealism of a Kaurismäki film, giving the film a classic allure. Van Diem's picture is littered with a great number of stylistic quotes, from GIANT (George Stevens, 1956), Charade (Stanley Donen, 1963), MARNIE (Alfred Hitchcock, 1964) and Le SAmourai (Jean-Pierre Melville, 1967), so that the film comes to border on 'theatrical abstraction' (Van Diem, qtd. in Van der Burg, 13). Thanks to this stylistic concern, DE SURPRISE becomes a rom-com, wrapped up as a thoughtful ode to classic cinema. It thus adds a reflexive extra to the entertaining love story it offers at the same time. In the upcoming chapters I will aim to trace variants of such reflexive extras in comedies which are to be categorized as camp, ludic, ironic, absurd or grotesque. Owing to a more unconventional approach of these films, the chances of subversive effects will increase accordingly. 


\section{CHAPTER 4}

\section{Deliberate Camp}

Each and every episode of the television series KREATIEF MET KURK [CREATIVE WITH CORK], directed by Pieter Kramer and broadcast on Dutch public television in the years 1993 and 1994, contained a remake of some fragment from a well-known film. The two performers Arjan Ederveen and Tosca Niterink imitated segments from a huge variety of titles: the silent film THE SHEIK with Rudolph Valentino; the Julie Andrews vehicle MARY POPPINS; Höstsonaten [AUTUMN SONATA] by Ingmar Bergman; BLUE VELVET by David Lynch. Though the majority of remakes was no more than mere mimicry of a fragment (albeit displaying a keen eye for the smallest of details), the humour resided in the fact that Ederveen performed as Rudolph Valentino in a movie scene with flicker effects in one week, as Ingrid Bergman with a phoney Swedish accent the next week and as an hysterical Dennis Hopper in the week thereafter. The outlandish effect of such persiflages is that there seems to be an Ederveen - or a Niterink - behind every great performance in film history. You happen to be watching Michael Douglas and Sharon Stone in Verhoeven's BASIC INSTINCT (1992), but suddenly, a thought crosses your mind: Could this be Ederveen and Niterink in another disguise? Such an anti-immersive hypothesis, if perhaps only for a brief moment, is the potential short circuit produced by their remakes.

At other times Ederveen and Niterink deliberately added a comic element to the remade scene, as when the melancholic mouth harmonica sounds in ONCE UPON A TIME IN THE WEST (Sergio Leone, 1968) give way to the happy tune of De Vogeltjesdans [Little Bird Dance] by the Dutch band De Electronica's. They could also mildly overdo some aspect, like the acting, or, as was the case with their version of FANFARE, they could slightly exaggerate the spoken accent and the intonation of words. The team of KREATIEF MET KURK made some adjustments to the story in their 5-minute remake 
of Haanstra's classic, but the makers carefully reproduced both the 'original' black-and-white visuals and the style of filming. A character named Van Punteren had fallen into the water while playing the tuba. Because of this unfortunate fall he is a bit late for rehearsal. When he takes his position in the band and starts to blow, his tuba produces water rather than notes, to everybody's amusement. Finally, Van Punteren laughs so heartily that his chair tumbles over, which once again provokes an outburst of laughter.

Since KREATIEF MET KURK was a television programme with humorous sketches bordering on parody, the context of such a fragment like the one from FANFARE turns the remake into a persiflage. In the case of a persiflage, irony is used to emphasize a specific feature, usually via mimicry: the vain is exposed in its vanity; the trivial in its pettiness; the ugly in its ugliness. Though the difference from the original may seem minimal or even negligible, the imitation has the aim of mocking. As a consequence, the viewing 152 attitude towards such a scene has shifted considerably: even though one can still watch it as just a remake, a (great) number of viewers will recognize the fragment as deliberately silly. This effect in KREATIEF MET KuRK's version of FANFARE is also achieved thanks to aural means because the diction of the characters is even more archaic than in the original film and the sound is slightly more tinny. The deviation from the (style of the) original is only minimal, but the way the fragment is embedded into a programme like KREATIEF MET KURK, broadcast by the VPRO which, in general, has a leftist 'intellectual' audience, creates an ironic detachment, for roaring with laughter at such an incident, as Van Punteren does, is an uncommon reaction for a VPRO public. If a detached attitude was optional in the case of Haanstra's FANFARE, this attitude has become the most viable one in the remake of it. Moreover, the effect, if not the amusing surplus value of such a persiflage is that if one reviews Haanstra's film, one can only see it through the lens of the remake by Ederveen and Niterink. To paraphrase the purport of the well-known short story by Jorge Luis Borges, 'Pierre Menard, Author of the Quixote,' which takes the form of a literary critical piece about a fictional $2 \mathrm{O}^{\text {th }}$-century French writer who rewrote Cervantes' Don Quixote: after KREATIEF MET KURK, one starts to see FANFARE as if it were a film made by Pieter Kramer. If this effect is brought about, the spectator will come to regard Haanstra's source text as dated, or, if he already did consider the film as outmoded, the persiflage will further emphasize this. Since the tone of Kramer's remake is not bickering, the viewer can still garner sympathy towards the source text, but the type of humour is definitely presented as corny and hilarious.

The working of the imitations in KREATIEF MET KURK ties in with the principles of so-called 'camp,' which conforms to a protocol based upon 
reading between the lines. If we return to the key text on the term, the wellknown 'Notes on "Camp"' by Susan Sontag, we can see that she mentions a series of conditions to qualify a text as possibly camp. According to her, camp is 'something of a private code' (275). The viewer should be able to recognize in the text/film a 'love of the unnatural: of artifice and exaggeration' (275). ${ }^{1}$ By just imitating (the style of) an old classic in the context of a television programme which is known by its target audience of (left-wing) intellectuals for its ironic stance, the 'original' carefree nature of the film is reread as excessively silly. It should not be overlooked that not every viewer is equipped with an antenna for camp, and in their eyes, the remake will be much more stupid than the source. Or a viewer can disqualify the ironic imitation, because he is still 'genuinely' fond of the humour of FANFARE - and of André van Duin, FlODDER, FILMPJE! A text/film is never inherently camp, but it requires a willing reader/viewer to interpret it as such. In this chapter I will indicate to what extent camp has evolved into a familiar strategy in Dutch cinema.

\section{A FAGGOT'S FAIRY TALE: THEO \& THEA EN DE ONTMASKERING VAN HET TENENKAASIMPERIUM}

It is a common mistake to conflate the terms camp and cult, but in his article “"Trashing” the Academy,' Jeffrey Sconce made a valuable distinction. He identified cult (or paracinema, as he prefers to call it, for good reasons), with an 'aesthetic of vocal confrontation' (374). Those who love exploitation movies have a tendency to express their preferences out loud. Wilfully disregarding the existing film canon (featuring Orson Welles, Ingmar Bergman, Andrei

Tarkovsky, and the like), they want to be acknowledged as the guardians of neglected films that despite their ludicrous content and style should be valued as masterpieces. ${ }^{2}$ The best examples are the film events, presented by the Belgian Jan Verheyen (aka Max Rockatansky) and the Dutch Jan Doense (aka Mr. Horror), under the name DE NACHT VAN DE WANSMAAK [THE NighT OF BAD TASTE]. The aim of such events is to present the spectators with the dredges from the bottom of the cesspool of cinema. They consider the Dutch horror film INTENSIVE CARE (Dorna van Rouveroy, 1991) as one of the 'pearls,' which has been selected for the so-called 'Hall of Shame.' In particular, the question posed by Amy, a role played by Nada van Nie, who only featured in two films, to her boyfriend Peter, played by the then-popular Flemish singer Koen Wauters, whether he wants a Band-Aid when he is bleeding like a stuck pig has become a classic line of cluelessness.

Film Institute EYE in Amsterdam organizes once a month on a Friday 
evening a so-called Cinema Egzotik. The double bill is dedicated to films whose quality, according to film aficionados Martin Koolhoven and Ronald Simons, is too little recognized by critics and scholars. This is often the case with genre films - (spaghetti) westerns, crime films, horror, science fiction are particularly popular. In Cinema Egzotik, action movie director Walter Hill, horror filmmaker John Carpenter, and giallo specialist Mario Bava are put upon a pedestal, for the simple reason that they are unduly neglected. The aim is to balance the score with those directors whose names are already secured within film history (Alfred Hitchcock, Stanley Kubrick, Yasujiro Ozu). To underscore the cult cinephilia, which accords with the idea of 'vocal confrontation,' for each and every screening film posters are being designed. Cinema Egzotik often takes an auteurist perspective: frequently a film is selected based upon the director's (or scriptwriter's) entire body of work. An advantageous criterion for selection can be that the film at hand 154 is an 'anomaly' within the filmmaker's oeuvre. If I were to propose some Dutch 'egzotik' films, I would settle for DE INBREKER [THE BuRGLAR] (Frans Weisz, 1972), BECAUSE OF THE CATS (Fons Rademakers, 1973), NAAKT OVER DE SCHUTTING [NAKED OVER THE FENCE] (Frans Weisz, 1973) - for the mere reason that it features a very young Sylvia Kristel as a ravishing pop singer and Adèle Bloemendaal - ANDY, BLOED EN BLOND HAAR [ANDY, BLOOD AND BLOND HAIR] (Frank Wiering, 1979), about an obnoxious adolescent from Hengelo who maltreats several people in Amsterdam, ${ }^{3}$ the occult horror of DE JOHNSONS [THE JOHNSON's] (Rudolf van den Berg, 1992), and my personal favourite, WiLDSCHUT [STRONGHOLD] (Bobby Eerhart, 1985), an underrated tough gangster thriller with a chilling performance by Hidde Maas. A comic note is provided by the bulky local policeman, a not too smart 'cowboy,' who seems to have stepped right out of the American television series THE DUKES OF HAZZARD, broadcast between 1979 and 1985.

Whereas cult adopts the strategy to loudly advertise one's preferences, camp follows a completely different agenda. Camp is an 'aesthetic of ironic colonization and cohabitation' (Sconce 'Trashing,' 374). The pleasures and benefits of camp are not proclaimed oppositionally, but adjacent to the mainstream and to the established film canon. According to Richard Dyer in his article 'It's Being So Camp as Keeps Us Going,' originally published in 1977 , homosexuals have developed the quality to read secret codes between the lines due to their position within society. In contrast to the cult lovers who want to distinguish themselves as cinephiles with a deliberately odd taste, homosexuals prefer to adapt themselves to all kinds of social circles. They like to be part of the crowd in order not to reveal their sexual identity. In the words of Dyer who speaks about homosexuals in the form of 'we': 
Because we had to hide what we really felt (gayness) for so much of the time, we had to master the façade of whatever social set-up we found ourselves in - we couldn't afford to stand out in any way, for it might give the game away about our gayness. So we have developed an eye and an ear for surfaces, appearances, forms: style. (Dyer 'It's Being,' 59)

Dyer indicates that homosexuals usually opt for run-of-the-mill storylines than for utterly extravagant material as a tactic. However, in the way the style of a book or film is excessive, the homosexual reader/viewer recognizes something of a private code that he shares with a minority of fellow homosexuals. Writing her pioneering 'Notes on "Camp"' in 1964, Sontag had noted no more than a 'peculiar affinity' between camp and homosexual taste. Moreover, she had a definite preference for what she called 'naïve' camp, for '[p]robably, intending to be campy is always harmful' (282). She uses the qualification naive for texts which despite their earnestness, fail by mistake. This failure is usually only acknowledged in the course of time and should not be pursued as an effect in advance. It is unpredictable what or who becomes campy. Merely aging does not suffice, but becoming outmoded 'provides the necessary detachment - or arouses the necessary sympathy' (285). It helps, she says, when an important theme is presented in a too trivial work of art. This might have given rise to shaking one's head or, worse, indignation at the time, but years or decades later, 'when we become less involved' in it, we can 'enjoy, instead of be frustrated by, the failure of the attempt' (285). The label of naive camp can practically be applied to almost any text or any behaviour, as long as it is not too conscious of its own nature. For Sontag, Trouble IN PARADISE (Ernst Lubitsch, 1932) and The MALtese FAlCON (John Huston, 1941) are 'effortless' in tone, whereas All About Eve (Joseph L. Mankiewicz, 1950) wants so badly to be campy that it is constantly 'losing the beat' (282).

Encouraged by scholars like Dyer and Jack Babuscio, camp has been increasingly appropriated from the 1970 s onwards as a means of expression for homosexuality. Camp has evolved in a reflexive tactics of homosexuals who take the liberty to present themselves as aristocrats of dubious taste, with a prerogative to be fond of musicals choreographed by Busby Berkeley, films featuring Judy Garland, and a tendency to adore royal families. Homosexuals, albeit not all homosexuals, are supposed to have a special sensibility for double entendres. ${ }^{4}$

Due to the appropriation of the term camp for a gay audience, the nature of camp has shifted from naive to deliberate. In the context of Dutch cinema, the situation is somewhat different, for it does not have a version of naive camp - but if it did, it would be seen in JENNY (Willy van Hemert, 1958), the first Dutch film in colour. JENNY is about an 18-year-old girl who is a mem- 
ber of a women's eight rowing team and who is made pregnant by a handsome art dealer, Ed. Though a bit stale, the film has, probably unwittingly, some visual undertones from a Douglas Sirk melodrama, with its inserts of colourful flowers, deep red (Jenny's coat), the mirror shots in the dressing room of Jenny's father playing the role of Henry IV from Pirandello's play, and above all the ravishing Teddy Schaank in her role as Mrs. Gonzalez, who seems to have stepped out of Sirk's All That Heaven Allows (1955). The way she delivers a line to Ed, the man she fancies, is worthy of a (naive) camp etiquette: 'You could be Mexican ... so dark-skinned, exotic ... that wonderful line around your mouth.'

An early example of deliberate camp (one that nearly dates to the first use of the term and predates the writings of Dyer and Babuscio), a film not even en vogue to indicate a homosexual sensibility, might be the third in a series of four SAD MOVIES, entitled SUMMER IN THE FIELDS (Wim T. Schippers and 156 Wim van der Linden, 1967). We see rather lavish shots in CinemaScope of cows, of a farmer on his tractor, shown in fetishizing close-ups, digging up potatoes. While the farmer removes sweat from his face with a huge, red handkerchief, we get an imaginary balloon, clarifying that he longs for a cup of coffee. Meanwhile his wife is in the kitchen, in a setting which seems straight from THE SOUND OF MUSIC (Robert Wise, 1965), putting his meal into a basket. We follow her on her trip to the fields, whereas her husband is awaiting her arrival. A bit abrasive, he asks her why it took so long, but then he drinks his coffee, and the couple, proudly standing next to the tractor, start singing an overtly gay song about their mutual love, wondering whether people can be more happy than they are now that it is 'summer in the fields.' At the same time, some inserts show cows peeing and pooping, actions that are emphasized by the sounds of huge farts on the soundtrack that accompany the song. As the man finishes his coffee, the song stops right away, and he says to his wife: 'Well, that was mighty good.' It is not without a certain irony that a voice-over at the end of this short, which seems the polar opposite of the series of SAD Movies it belongs to, announces that the farmer continues with 'faith, hope, and charity, contributing his share to the happiness and welfare of his family, his country and all mankind.'5

If there are, apart from these exceptions, hardly any candidates for the label of camp before the late 1980s, one could say that Dutch cinema went overboard since then. Starting with THEO \& THEA EN DE ONTMASKERING VAN HET TENENKAASIMPERIUM (Pieter Kramer, 1989), there are some cases which can best be termed as 'deliberate camp to a superlative degree.' Actually, the film's title is too silly to translate, but it would run something like: Theo \& Thea AND THE UnVeiling of The Toe Cheese Empire. The film had the advantage that it could capitalize on the popularity of a television 
series, named after the two main characters Theo and Thea. This series ran from 1985 to 1989 and while it was officially aimed at children, it became particularly successful among students. THEO \& THEA owed this effect to some extent to the indefinable age of the two protagonists. On the one hand, the pair introduced themselves as young children with fake gigantic front teeth and thick glasses. On the other hand, they were played by grown-up actors who addressed in their programme adult themes like emancipation, homosexuality or sexual harassment. They could permit themselves to discuss these themes in a frank manner, full of sexual innuendo, since they could always pretend to be just children, curious to know about the birds and the bees. Their guise as kids worked as the perfect pretext to present controversial subjects as if one is ignorant. To any joke with connotations of sex or smut they started to laugh out loud in a childlike manner. The humour of THEO \& THEA can only be described in terms of contradiction: both sharp-witted and extremely cheesy. Moreover, while postmodernism was a buzz word at the time in academic circles, thanks to seminal works by Brian McHale, Linda Hutcheon and Fredric Jameson, their 1989 film extensively practices eclecticism, the most prominent of postmodern devices, constantly (visually) quoting from a range of sources.

In the beginning of the film, the camera goes inside a fake woman's body, passes some clumsily constructed intestines, and ends up at the uterus. We can recognize Theo and Thea in their 'embryo suits,' glasses on their noses and a crown upon their heads. While the camera floats inside the artificial body, they announce that they are about to play all the parts in the fairy-tale Snow White, but a famous Dutchman is cast as the handsome Prince. 'We will not yet reveal his name,' Thea says, 'but it is Gerard Joling.' There is a transition to Theo and Thea, this time in the guise of a royal couple, woken up by the alarm clock. The camera pans to the left, showing the interior of the bedroom. As the door to the balcony opens to a dazzling white screen, we read the beginning credits: indeed, Theo and Thea play all the parts ('except the one of the handsome Prince'). Queen Marianne has balloons for boobs, and her wig is made of huge piles of toilet paper. The king's wig is made of an enormous series of toilet rolls. While the scenes are sepia-coloured, his face appears white because of an abundant use of powder. He speaks a very affected kind of Dutch laced with French terms, introducing himself as 'Edouard van Oranje-Nasi' - a mangling of the official name Nassau to 'nasi,' which is an Indonesian fried rice dish. He says that he is a keen amateur archaeologist, who digs up old pots ( $p o t t e n$ ) from prehistory. The queen retorts in a jovial tone: 'But I am not an old pot, or am I?,' which is a verbal pun on the fact that the Dutch word pot can also mean 'dyke.'

When the sketch of the king and the queen is soon hereafter interrupted 
because a female usher at the museum thinks they have no permission to 'finger' the Venetian glass, the film turns into a sheer hodgepodge of styles, genres, and formats. We get 'behind the scenes' material with museum personnel who are eager to look straight into the camera; a black-and-white report including corny voice-over commentary is inserted as a persiflage of the bygone tradition of cinema news items (here called Polykroon Journaal instead of Polygoon Journaal); we see the deliberately clumsy shooting of the childbirth scene in the room containing 'modern art,' because that one offers the most 'sterile' environment, which is a funny way to recommend the presumed 'lifelessness' of modern art as hygienic. Immediately, thereafter the scene turns into a sex farce, when the doctor (Theo) shows up to give Queen Marianne a 'relaxing massage' as a remedy against the loudly exclaimed contractions. When he touches her balloons (or 'bombanellas,' as he calls them) and kisses the queen, she says in a mock excited fashion: 'Oh, 158 doctor, you always turn something medical into something so intimate.'

And this is only a prelude to the actual story of the film, which concerns an attempt to adapt Snow White. Before they can make a head start, they have to find a new actor for the role of the 'handsome prince,' for Gerard Joling - a popular gay crooner, a bit Liberace-style - has called off his participation. To illustrate the disappointment of Theo and Thea, they have pushed the camera away. While it is lying on the ground, it shows the scenery from a skewed angle. One of the ushers then suggests approaching the well-known operetta star Marco Bakker. Dressed as the two female musicians Bea (Theo) and Ans (Thea), who improvise a jazz version of the famous lullaby 'Slaap, kindje, slaap' [Sleep, Child, Sleep], they immediately attract Marco's attention, for he is completely under the spell of Bea. While Ans/Thea is in love with him, Marco says he can only kiss a big woman who stands firm on her feet, which is then followed by a close-up of Theo's shoes with no high heels. It has become obvious by now that the film has become a parody of Billy Wilder's SOME LIKE Iт Нот (1959). Since Marco has to sing in Austria, he asks them to shoot the film over there, and seven extras, among whom are the museum personnel, join them, singing the silly singalong 'ik heb mijn potje met vet al op de tafel gezet' [I've already put my pot of fat on the table]. The song ends in a visual ripoff of Robert Wise's THE SoUND OF MUSIC (1965) - the characters on the green hills, while the camera is moving higher and higher into the air.

At some point in the film, Ans/Thea has hidden herself on a toilet out of despair, because Marco neglects her entirely. She is shown with a wide-angle lens turning the toilet into a claustrophobic space. At the same time, Bea/Theo flees into the very same ladies' bathroom, to escape Marco, who persists in his attempts to seduce her. We see their feet from under the toilet door, and Ans is so disgusted by it that we then see her face framed through the toilet 
seat, before she starts vomiting. In a subsequent scene, Marco is driving a car and proposes to Bea. He/she thereupon says: 'Marco, do you like surprises?' In the next shot we see the car stopping on the road and Bea being kicked out of it. Bea/Theo then returns to the ladies' bathroom, and takes Ans' head out of the toilet, which is once again framed through the upstanding toilet seat. Bea tells her that the fairy tale is over, but as soon as he says this he realizes that Marco has taken the dog Trudy to the castle of the power-crazy Brigitta Berger. Going after him to get Trudy brings them straight back into a dark fairy tale, about a wicked witch who asks a fluorescent screen: 'Computy, computy, who is the greatest beauty?' She plans to create so-called Empire Cheese - containing, among others, her toenails - that will enable her to rule the world. After they both ruin Brigitta's experiment and free Trudy, they continue the shooting of Snow White. The wicked witch takes her revenge, by showing up on set in the guise of an old woman who does not sell apples, but cheese. Theo and Thea actually seem dead, but because the coffin accidently falls on the ground, they cough up the piece of poisoned cheese they had swallowed by accident. Alive again, they remember that Brigitta told them that she was about to go to a place in which all the shit in the world gathers. Reading in a newspaper about a meeting of world leaders in Geneva, they head off for Switzerland. Their guess proves to be right: while Brigitta is delivering a speech to the hypnotized world leaders present, they catapult a piece of cheese that was originally stuck in one of their throats in her open mouth. They take over the microphone and Theo shouts: 'Childish innocence always conquers!' They then ask the leaders to pull down their trousers, and the latter do so obediently. If they want to punish the wicked Brigitta, Marco intervenes and warns them not to misuse power. They turn her into a good person, and transformed on the spot, Marco kisses Brigitta as his wife to be. Theo and Thea are invited for a cup of tea at Queen Beatrix' residence to thank them for their rescue operation.

As can be derived from this description, the film is downright outrageous, which is acknowledged by the characters themselves. 'We are now in the midst of it.' 'In the midst of what?' 'In the story with a bizarre twist.' Such silliness divides the audience between those who find it exhilarating and those who detest it. Though the only three IMDb user reviews cannot be considered representative, there is a striking common denominator: the two Dutch reviewers already point out that if you are not Dutch and if you are too young to know about the television series, this film will probably not be your cup of tea. The American reviewer confirms that he indeed was completely baffled by this film and even the subtitles did not help him get the joke. Being Dutch, however, is no guarantee that one will appreciate this film, as can be concluded from a glance at the responses at moviemeter.nl. There are perhaps as many fans as there are people who disqualify the film as 'infantile' or as 'faggot's humour.' 
The film can be termed 'faggot's stuff' insofar as one characteristic of camp is that it does not take anything seriously. This attitude has a drawback, because life is, as Dyer contends, not 'a bed of roses for gay men,' but many homosexuals do not (always want to) adhere to a political agenda, because they think politics is too dull and heavy-handed. Hence, they develop the tendency to react in an inversely proportional manner to serious issues by turning everything into 'a witticism or a joke' (Dyer 'It's Being,' 50). Theo and Thea do so by showing themselves to be obsessed with bodily functions to a superlative degree in a cheesy manner that tends to foreground artifice. There is not even an attempt made to create convincing costumes or believable decor. The dressing-up of Theo in the role of Bea is far removed from seductive femininity: it is a sheer parody of the idea of womanliness as a masquerade. Moreover, it is very obvious that Brigitta's castle is a cardboard set piece. Even though there might be sloppy art direction in cult films, it is often a matter of technical 160 | incapacity and/or low budget; here it is being flaunted as a deliberate choice.

After they ended their Theo and Thea characters, the two actors Arjan Ederveen and Tosca Niterink cooperated for the aforementioned KREATIEF MET KURK. As a running thread, there was each and every week an episode in which they made a persiflage of a so-called Teleac course about 'how to make things from cardboard.' Ederveen and Niterink were overdoing the silliness of this craft course by using cork as a 'basic material,' clichéd expressions like 'always cut away from yourself' when working with a box cutter and many sexually insinuating remarks by anchor woman Ellen which were time and again misunderstood by the clumsy handyman Peter.

In addition to this persiflage of a craft course, there was a variety of sketches. Most famous, or rather notorious, was the sketch in which a female doctor presented, in an apparently serious tone, a new method to remove intestinal polyps. Then a very small and bearded dwarf is shown who, his pointed cap forward, tries to enter the patient's anus. While we get close-ups of very hairy buttocks, the dwarf tells the man to relax. Once inside, the dwarf starts singing, on his way to cut down the polyp with an axe. At least as hilarious as this sketch was the infamous item on the preparations for the 'Gay Games in Twello.' Instead of the official Olympic sport pole-vaulting, there will be a competition of men throwing their wrist bags in three categories - which is in Dutch a pun: instead of polsstokhoogspringen, it is now called polstashoogwerpen. A stereotypical leather queen with a horseshoe moustache and fashionable spectacles explains that he chooses to compete in the middle-weight class, for, as he says, he has no affinity with the effeminate types who participate in the light-weight category. There are also the heavy-weight contestants, who happen to throw beauty cases, but since that is more fun to watch, he does not like to compete at that level, either. We see him practice and with some gracious moves, he 
throws his bag high in the air. Then his female co-organizer wants to give it a try. She has some of the stereotypical characteristics of a dyke, with her short haircut, thick glasses and an angry look, but, most importantly, she has an abundant bunch of (artificial) hair, actually made of wool, under her armpits, and she is apparently not wearing a bra, because her huge breasts wiggle while she runs up and throws the bag. Her cast is totally out of control and the bag has vanished. 'Go look for it,' the man says, to which she retorts in a snappy tone: 'Do it yourself. You are wearing a pair of leather trousers.' In a later scene the man comes out of some thorny bushes with a bag in his hand: 'All well and good, but this happens to be my bag for the competition.'

The representation of the gay man and the lesbian in this sketch could reek of homophobic sentiment. The woman, in particular, is depicted as a diehard and old skool feminist who refuses to give in to any demand from the fashion industry: as we can gather from the man's facial expression, she is not even using underarm deodorant. Owing to the context of the television programme, however, it is better to regard the sketch under the banner of 'deliberate camp.' Ederveen and Niterink, homosexuals themselves, are so bent on turning everything into a witticism that they do not shy away from poking fun at the agenda of politically oriented gays.

In order to emphasize the importance of context in cases like these, Dyer claims that camp can only possess a subversive potential on condition that it is enjoyed by homosexuals. The cutting edge of camp, Dyer argues, depends upon its identification with the gay experience. If homosexual men sing the praise of John Wayne's virility, a tone of parody is immediately built into the tough performance. The enthusiasm for the masculine image of Wayne goes hand in hand with a certain mocking distance, with the awareness that this image is deliberately manufactured. Well-known is the example of the Village People, a disco group from New York City that had its heyday in the late 1970s. The group consisted of six members in the guise of a police officer, a construction worker, an Indian, a cowboy, a biker, and a soldier. Instead of just wearing regular costumes that befitted their roles, they ironically exaggerated certain signifiers that characterized their clothes. The way they dressed up in their fancy, often leather attire, was a clear showcase of masculinity. And as Jacques Lacan stated in 1958, virile display always seems a bit feminine (85). As soon as marks of masculinity gain too much emphasis, the man's attitude provokes the effects of femininity.

The subversive effect of this paradox gets lost the moment straight men take over the enjoyment of virile display, Dyer argues. The ironic outlook still indicates a distance from an image of machismo, but at the same time it allows straight men with a 'certain wishful affection' for the macho type to linger on it (Dyer 'It's Being,' 6o). Apparently rejecting the style of virility, 
straights appropriating camp parasite upon a secret pleasure that this style may endure, after all. Whereas homosexuals predominantly play at being a man, the straight version of camp risks holding on to an implicit desire to be such a tough guy.

Despite Dyer's attempt to draw a line between the homosexual enjoyment of camp and its straight appropriation, it is fairly difficult to make a valid distinction between them. Is it more common for heterosexual guys to enjoy blood-spattered movies, kung-fu pictures or films in which the enormously big breasts of a woman are literally used as 'deadly weapons'? And is it more common for homosexual men to enjoy Audrey Hepburn vehicles, Douglas Sirk melodramas or a film like Paul Verhoeven's SHOWGIRLS (1995)? Gay males are, as I.Q. Hunter notes, especially delighted by the imitation of Busby Berkeley dance routines in SHOWGIRLS, hilarious lines like 'I've a problem with pussy' and 'You ARE a whore, darlin'!,' and on top of all that, the female protagonist

162 | mispronounces fashion designer Versace as 'Ver-saze' (477-78). It is perhaps understandable that homosexual men have appropriated a film like SHowGIRLS, but at the same time, there is not something inherently gay about these pictures, but it is rather a matter of address and reading protocol. ${ }^{6}$ The fans of cult movies derive pleasure from sheer amazement about their poor quality and ask themselves: What kind of debased creature could possibly be the right audience for this terribly bad spectacle? Camp, as Eve Kosofsky Sedgwick has observed in her Epistemology of the Closet, involves a gayer angle of view and the key question to be posed is a 'what if': 'What if the right audience for this were exactly me?' (Sedgwick, 156) In case that a gay person considers him- or herself the appropriate addressee of a specific film, one can, says Sedgwick, truly speak of camp.

\section{DEMY REVISITED: DE TRANEN VAN MARIA MACHITA}

Is De tranen VAn Maria Machita [The Tears of MARIA MaChita] (1991), the 43-minute-long film Paul Ruven made for his graduation at the Film Academy, such a typical case of camp? There are many striking ingredients: practically every line in the film is sung, as was also the case in LES PARAPLUIES De Cherbourg [The Umbrellas of Cherbourg] (Jacques Demy, 1964); its narrative core is also partly inspired by this film: a woman is sad that her boyfriend has to fight a war in his native country, in this case Turkey, but, despite its short time span, DE TRANEN VAN MARIA MACHITA has much more melodramatic moments than Demy's film. After Maria has quit her job, she hears that her pilot father's plane has crashed. While her mother is singing about the devastating news on a stage, she all of a sudden collapses and dies as well. 
As the eldest child, Maria becomes head of the household, gets a new job at a shoe store and falls in love with one of the customers, a lookalike of her father, actually played by the same actor, Jacques Herb. He is so fully absorbed in writing a song that he neglects Maria. Then, we learn, why he did not pay attention to her - he sneaks away from the marital bed, back to the gay bar where he is greeted in a mock-enthusiastic manner: 'What's it like? A lady in the stack?' When his old lover neglects him, the film immediately shifts its tone with a depressing song. In a corridor with Francis Bacon reproductions, Elbert, 'sad and abandoned by all,' shows up in one of them, singing: 'Paintings of my whole life pass by in frames.' He pours gasoline over himself, but when a female child approaches him, he seems to make up his mind and sings to her: 'Never play with fire,' but at the very moment someone throws his cigar away, and Elbert catches fire. After Elbert's cremation, Maria's Turkish lover returns, but only for a while, since duty calls once again. She is so desperate that their love will bleed to death that she puts a mixing machine into his stomach. After she has been sentenced to prison, Maria's final song is in church, asking God for forgiveness to soften the pain she feels. Nonetheless, the film ends on an optimistic note, for surrounded by white-clad monks she sings she is 'on the brink of starting afresh.'

In her article 'Film Bodies: Gender, Genre, and Excess,' Linda Williams claims that, in addition to horror (fear-jerker) and pornography (the jerk-off), melodrama (tearjerker) is a body genre marked by excess. Since it is inappropriate in a melodrama to settle conflicts by means of direct, forceful action, the story is often embellished with syrupy stylistic features. The characters operate within kitschy decor and are carefully framed behind windows or among mirrors in order to signify mental obstacles. Both the extradiegetic music, often slightly sentimental, and the theatrical way of acting function to compensate for the repression of (female) desires (Verstraten, 192-93). If colours are used, they are usually bright and extravagant, to draw attention to the role of outward display in the provincial environment the characters inhabit. Though (forceful) action is minimal and an explicit manifestation of desires is held back, Williams observes that melodramas are caught in the grip of intense sensation and a form of ecstasy. Visually, the body can show signs of 'uncontrollable convulsion or spasm,' whereas an aural excess expresses itself in 'sobs of anguish' (Williams 'Film Bodies,' 4).

In DE TRANEN VAN MARIA MACHITA, all the elements of a melodrama are presented in such a compressed manner that intense sensation or emotions cannot evolve. The film is, so to speak, overdoing its usual 'excess': the story goes from one heartbreaking scene to a merry one, to and fro, without any preambles. The too quick pace of emotional scenes wilfully prevents identification with the fate of the characters. Though Ruven's film uses melodrama as a 
model, the usual effect of this genre is hollowed out. By downplaying any emotional attachment as an effect, the viewer will consider the excessive series of tragic and joyful events with ironic detachment, which offers an ideal pretext for all kinds of jokes, both aurally and visually. To start with, the fact that practically all lines are sung enables the scriptwriters to include clichéd phrases, which happen to be inherent about torch songs, but would sound awkward if spoken in dialogue. When the Turkish soldier says that he fights for patriotic reasons, Maria sings: 'I love you, Love / I iron your shirts, love your flirts / Don't go away / Don't seek death, embrace me, sit on my lap.'

In an early scene when they are worried about Maria's mother, she all of a sudden rings her daughter - a dedicated connection, no mobile phone. She sings about her husband who, while performing his duty as a pilot, has died. The mother still holds the phone against her ear as Maria enters the room. When the mother turns around and sees her daughter, she drops the earphone with 164 | a surprised look. Simultaneously, she sings: 'Long live communication / long live the telephone,' which at first seems ironic because she had not noticed that her daughter was no longer on the receiving end: communication had already dropped dead, since no one was listening to her words any more. The song then continues: 'Since Dad's cremation that bloody thing makes me cringe and groan.' The phrase 'long live the telephone' then takes another meaning, of dramatic irony, for a subsequent scene shows that the air base called her husband for a test ride which proved fatal to him in the end. Had he not taken up the phone during his leave, the accident might not have befallen him.

One other great joke concerns Elbert's furious attempt to compose a song on the piano for Maria. Surrounded by Maria and her younger siblings, he succeeds in producing only two words: 'Turbulent waves ...,' which Elbert repeats multiple times. He is so absorbed in his work that he disregards Maria's ways to draw his attention with a heart-shaped cake and with sexy lingerie. When in bed, he finally bends over Maria, who is waiting for a tender kiss, but just before their lips meet, he sings: 'Turbulent waves / clouds and winds.' It soon becomes clear why he prefers music over love-making, for, to cite the lines which are sung in the gay bar, being with 'a lady in the stack' is odd for someone who used to be the 'biggest member' in the gay community. When Elbert is to be cremated in a later scene, suddenly his coffin opens up, and both melody and lyrics are complete now, with lines like: 'Storm on the coast / Seas so grim / Nothing worries me / I trust in Him ... If I ever strand / He'll throw me a rod / I am in his Hands / Skipper with God.' As long as he was alive Elbert was struggling with the composition, but upon death, this morbid joke teaches us, he can finish his song, with references to Him/God, fluently. In the final shot of the film, we get a glimpse of the 'hereafter.' His coffin is like a rowboat at sea without any speed, but suddenly the Turkish soldier turns up who was killed 
with the mixer. He puts the mixer into the water, pushes the button and off the two men go, full speed ahead. This way an ordinary object from the kitchen is first used as a deadly weapon, and second as a very practical tool: the mixer is transformed into an outboard motor.

DE TRANEN VAN MARIA MACHITA can be labelled as deliberate camp insofar as it is inspired by melodramatic and musical elements. Its song about the gay bar only reinforces the deliberate nature. At the same time, the film has some 'gory' scenes, like a factory boss, a Hitler lookalike who squeezes a cute little chicken with a bare hand, and the Turkish soldier who starts to puke blood when a rotating mixer is pushed into his stomach. Since such scenes rather belong to a cultish 'bad taste,' Ruven's graduation film is not easy to classify: deliberate camp in the vein of Kramer's film, but also with some touches of cult taste. Similarly, the output of Ruven could be considered as unclassifiable, if not erratic. He made minimal movies and experimental films, like How to Survive A Broken HeArt (1991), SAHARA SANDWICH (1991), or Sur PLACE (1996), with Katerina Golubeva as the main actress, shot in the vein of a Chantal Akerman film. He also made films aimed at a large audience, such as FILMPJE! (discussed in chapter 1), the crime comedy GANGSTERBOYS (2010), or the derided Wendy van Dijk vehicle UsHI MUST MARRY (2013) as well as the bombed DE OVERGAVE [THE SURRENDER] (2014).

\section{DOUBLE ENTENDRES: JA ZUSTER, NEE ZUSTER}

Ruven has made a huge variety of types of films and his DE TRANEN VAN MARIA MACHITA was a one-time attempt to be 'creative with camp.' By contrast, a Pieter Kramer film is much more consistent in outlook and his signature is easily recognizable. LANG \& GELUKKIG [HAPPILY EVER AFTER] (2010) is vintage Kramer: cardboard sets, a number of drag queens, such as the two 'ugly' stepsisters Paris and Hilton, a homosexual prince and a bad wolf in the guise of a tough rock star. It is delivered in an excessively amateurish fashion in order to avoid any misunderstanding that this is a parodic take on fairy tales. Less hysterical, and therefore more of a family film, is his JA ZUSTER, NEE ZUSTER [YES NuRSE, No NuRSE] (2002). The film is inspired by a popular and so-called 'legendary' television series, made between 1966 and 1968, which consisted of 20 episodes in total. Many of them are no longer available in archives, only a single episode as well as 15 of the 59 songs have been preserved, since these songs were shot on celluloid. At the time, television was a relatively new medium that was supposed to offer amusement for the entire family, for there were only two channels. Since viewers should not take offence at programmes, their content is in general quite mild, fit for all ages. 
JA ZUSTER, NEE ZUSTER was centred around a so-called resthouse, in which sister Klivia lived together with Jet, Bertus, Bobbie, and the Engineer. Soon Gerrit, after a failed attempt at burglary, also becomes one of the inhabitants. Gerrit's grandpa joins them from episode 5 onwards. Their landlord is living next door and calls the residence a 'resthouse full of hoo-ha.' This neighbour, Barend Boordevol, is a grumpy old man who time and again invades their home to complain about insignificant matters. The series was written by Annie M.G. Schmidt, who had a huge reputation as an author of children's books, with a distinct preference for self-willed and idiosyncratic kids. Her work is slightly rebellious, but seldom if ever venomous. It is a bit teasing, but never scorching, which is clear from the songs. Some of the texts were just witty and nonsensical, like 'Uncle Willem's cat has gone travelling, gone travelling, gone travelling.' Other song texts suggest burlesque puns, like in the case when only the first syllable is given before the name of the plant 166 is mentioned in its entirety, 'fuch, fuch, fuchsia' (in Dutch to be pronounced as 'fuck, fuck, fucksia'). Most important perhaps is that Schmidt's texts are interwoven with controversial subjects, albeit in a most implicit way. She does not recoil from ridiculing a small-minded moral. In her children's books she presents the perspective of a maladjusted character, like the constantly filthy girl Floddertje. She attempts to create sympathy for the kid who deviates from the norm, so that the oddball comes across as kind-hearted. A good example is the song sung by sister Klivia, 'I Change,' in the very first episode. It is about the sister's desire to transform herself with a wig into one of the Beatles as soon as everybody is off to bed. 'Yeah yeah / I feel different / completely different / yeah yeah! ... Different than normal / Yeah, I feel different than normal.' Initially, it seems to be an ode to a group of long-haired trash, but it is quickly replaced by different roles, such as a pretty school mistress and a wicked fairy. The 'yeah yeah's' vanish from the number in favour of a 'yes yes' and an 'ay ay.' Being 'different than normal' would have been a firm political statement in the tumultuous decade of the 196os, but it remains toothless because in the end, it is no more than a free-floating dress-up game.

In case the lyrics are too burlesque or too flippant, its potentially controversial nature is neutralized by the insertion of a few corny lines or overwhelmed by polished arrangements. This nature cannot always be contained entirely, as is best illustrated by the song 'The boys of the travel association,' from the very last episode. The lyrics address the holiday trips in bygone days of Barend Boordevol with an old acquaintance from the association. 'The whole bunch on a trip to the Lorelei. With Marinus and Matthijs to the Lorelei. With Evert and with Vic. With Robbie and with Dick. We had so much fun with Johan and Boudewijn.' Apparently Albert Mol, who sang the number with Dick Swidde, seems to have said that it is wonderfully impossible what Mrs. Schmidt had 
come up with (Visser, 9). On the one hand, it was just a song about boys on a trip together, but on the other hand the openly gay Mol recognized its subtle double meaning and its allusion to cruising as well as homosexual bonds.

The film version of JA ZUSTER, NEE ZUSTER is not a gay picture, but offers ample signs to support a homosexual viewing attitude. Like in his other productions, director Kramer displays a taste for extravagance. The gaudy art direction, which shows among others in the excessively colourful setting of a carefree village, elevates JA ZUSTER, NEE ZUSTER to the level of deliberate camp. At the start of the film, Jet and Gerrit have a duet, singing 'Together with you under the umbrella' in a choreography reminiscent of Demy's aforementioned LES PARAPLUIES DE CHERbOURG while men in suits with fancy briefcases perform a graceful dance act in the background. If the song about the Travel Association is already double-edged, in the film the number is preceded by a scene in which neighbour Boordevol proudly shows a valuable clock, which he keeps in a safe, to the burglar Gerrit. Sister Klivia interrupts their encounter because she knows how sensitive Gerrit is to all that glitters. Thereupon the neighbour says he regrets her intervention, since he meets 'so few young men who know how to appreciate a great carillon.' The original Dutch term 'klokkenspel' for carillon is a euphemism for the male sexual organ, and thus this term, specifically added in the film, is meant to reinforce the homosexual allusions. ${ }^{7}$ The 'legacy' of such camp interventions shows itself in the difference between the television series FLORIS and its cinematic adaptation 35 years later.

\section{THE DETOUR OF POSTMODERN IRONY: FLORIS}

According to those viewers who adhere to the idea of camp as a strategy of 'aesthetic colonization,' the charm of camp gets spoiled as soon as the irony becomes too obvious. Subtlety is recommended because then only the minority among the audience which has a gay sensibility will consider it as camp. My point is not to make a plea for such subtle irony for this subtlety is hardly present in Dutch cinema. Rather, I aim to articulate via the case of FLORIS that deliberate camp was used as a mediating strategy: its makers realized that a film adaptation in the $21^{\text {st }}$ century had to be 'reloaded' to prevent the risk of naivety. As a television series, broadcast in 1969, FLORIS consisted of the adventures of a medieval knight, assisted by a fakir. Rutger Hauer played the knight, Paul Verhoeven directed and Gerard Soeteman wrote the screenplay of the action-packed episodes, targeted at a youth audience. When the format was adapted into a film in 2004, Soeteman, who this time was involved as coscenarist, opted for an entirely different tone. 
In the opening scene of FLORIS (Jean van de Velde, 2004), the title hero is dressed up as a nun in a theatrical play. His father is among the audience, but has fallen asleep. He wakes up in time to see the 'nun' deliver an attacker a death blow with a sword. After the performance, Floris' parents are looking for their son backstage. Someone recognizes the father as the well-known knight Floris van Rozemond, which visibly pleases him. Then the parents see their son with a blonde-haired wig and while the mother emphasizes the delighted response of the audience, the father tells him that the fight looked awful. In a laughing tone he says that the cutting off of the head was faked. 'You wield such a sword differently! You slant it, or it'd take three blows.' Annoyed, the son replies that they fight without killing, for his generation, he explains while removing his silicon breasts, prefers the hippie catchphrase 'make love, not war' over actual battle. ${ }^{8}$ Hurt in his pride, the father then refers to the late grandfather who 'was the first to bear the name Floris.' We then see some 168 | black-and-white excerpts from the original television series from 1969 with the title hero riding horseback. 'A defender of freedom, a knight to a tee,' the father calls his forebear, while we see the black-and-white Floris enter a castle. The grandfather's last words were addressed at his son: 'Now, you are Floris ... Floris!' The young Floris, however, dismisses the references to his wellknown grandfather as no more than a trip down memory lane. In a paraphrase of a Bob Dylan song from the sixties, the young actor says that 'the times are a-changin',' which is followed by the son's statement: 'Things were black and white, then.' While the original series was in black and white, indeed, this statement has to be associated with 'black and white' as used in figurative speech: the past world was divided in overtly simplistic oppositions, but now things have become much more complex. This laconic reaction angers the father who finally takes up one of the silicon breasts, and says that the one thing he regrets is to have named his only child Floris instead of Tit-us.

This opening scene suggests that the youngest Floris is not a "natural-born killer' despite his descent and that comedy will preside over serious action. The grandson's oblique references to phrases used by the protest generation of the 1960 s turn him into a youngster with pacifist sympathies. Moreover, he plays the role of a transvestite as if to emphasize the distance from the male posturing of his forebears who derive their identity from authentic battles. In the 1960s, early years in the history of television, it was still possible to make a straightforward adventure story about a medieval knight, but in the $21^{\text {st }}$ century such a story has become outdated, even for a family film. In order to avoid the pitfall of naivety in an era of post-Quentin Tarantino cinema, it has become a mark of hipness to dwell in postmodern irony. The only way to present a Robin Hood-like adventure, is to do it on the condition that one first has acknowledged that one knows how silly such a type of story actually 
has become. Mediated by such an 'ironic' warning, one can continue to show a series of spectacular fights after all, although we have to take these action scenes with a grain of salt.

Averse to violence, the young Floris, the grandson, will get caught up in violent conflicts by accident. He becomes a valiant knight, but willy-nilly. To emphasize the irony of an 'accidental hero,' the action is presented everything but seriously, as a brief summary of the bizarre plot of FLORIS will illuminate. Two rivalling parties compete over the possession of a so-called Holy Nail, for this relic is supposed to be a harbinger of luck. This Nail is first hidden in the ass of a horse and later in cheese by father Floris. Since this cheese is part of the enemy's Christmas bonus packets, Floris wants to win his father's respect by getting the Nail in return. As befits the peculiar plot, the film consists of slapstick action and fights which are played for laughter. Just consider the moment when father Floris is about to be slain, but the movement of his opponent is arrested because the sword is too big for his aching back. Or the moment when Floris escapes from the castle tower by having the Nail transform the long yellow dress of his sidekick Pi into a parachute. By such means, the original adventure tale is transformed into a not too serious action movie, injected with a campy tone.

FLORIS was not greeted by critics as a great film, and that is perfectly understandable. If the film has some merit nonetheless, it is that it illustrates how an ironic prologue is required as a frame in order to make an adventure story in a time when adventure stories were considered to be practically impossible. ${ }^{9}$ To the detriment of the film, one might say, however, that this necessary detour of irony has been too obvious. The original adventure tale has been transformed into a not too serious action movie, injected with a tone of (too) deliberate camp. An important feature of the old-fashioned adventure film is that the spectator can be naively immersed in its story. In FLORIs, the tone is so campy-comical that this possibility is entirely lost. At best, it might provoke laughter; at worst, it leads to a reaction of indifference.

JA ZUSTER, NEE ZUSTER worked much better than FLORIS in this regard, because Kramer's film both pays homage to the 'original' television series and simultaneously takes an ironic distance from it. The film achieves this two-sidedness because it takes the nostalgic reverence in earnest while nonetheless the tongue-in-cheek irony is not to be missed for any viewer with a sensitivity for camp. Whereas JA ZUSTER, NEE ZUSTER walks the tightrope between nostalgia and camp, in most subsequent pictures the scales tip in favour of the latter. Even in Kramer's later films, the irony has become (too) obvious: ElLIS IN GLAMOURLAND (2004), with, among others, Joan Collins teaching a course ('How to Marry a Millionaire') and LANG \& GELuKKIG, featuring the ugly sisters Paris and Hilton. If there is a film which can match the achievement of JA 
ZUSTER, NEE ZUSTER, then DiK Trom [CHUbBy Drums] (Arne Toonen, 2010) comes closest. The film is inspired by the famous classic book series, written by C. Joh. Kieviet, from the late $19^{\text {th }}$ century, but in Toonen's modern interpretation the boy's (innocent) pranks and the jokes on his name - 'I am Chubby,' 'So I see' - have been embedded in a satire on an obsession with healthy food and slim bodies. Dik originally comes from a town which holds as a motto: 'A healthy mind in a round body!,' but moves to a place where people consume only vegetables, soup and juice. At the end of the film, however, each inhabitant of Dunhoven starts eating his father's delicious hotdogs with all the trimmings. The ultimate 'lesson' of Toonen's DiK Trom that enjoying life equals eating calorie-rich food has as its subtext: 'it is better to be a happy outsider than an unhappy conformist.' This lesson is brought with extravagant gusto in the common visual language of camp with artificial sets, colourful characters and overdone acting. The strategy of camp works in this film, because it

170 | chimes with the nostalgic sentiments associated with the Dik Trom character, which simply beg for an ironic perspective. Unlike the adventure tale to whose 'essence' camp is in fact alien, camp can be made congruent to the nostalgia of DIк TROM, whose titular hero is regularly described in the books with the words 'he is an exceptional boy, sure he is,' which from the perspective of camp can be used to various purposes.

\section{GAY PRIDE: CHEZ NOUS}

Under the influence of this tendency of deliberate camp in Dutch cinema to update classic books and television series, a second strategy can be detected. Characters with a clear camp sensibility seem to have become a staple feature in recent romantic comedies and feel-good movies. They feature openly gay male actors as over-the-top characters in minor roles. In ALLES IS LIEFDE, Marc-Marie Huijbregts is cast in the 'over the top' role of a male salesman, Rudolf van Hoogstraten Bosch, which caters to an audience well-versed in the codes of camp. In a high-pitched voice he tells Prince Valentijn that he considers him the 'best sack runner' of the royal family during Queen's Day and that his Black Pete stockings are 'marvellous.' When the prince in his guise as Black Pete is asked to skip, he does so, but Rudolf would consider it wonderful if he could show a 'bit more joie de vivre.' In GoOISCHE VROUWEN, as I explained in chapter 3, the well-to-do characters themselves are so exaggerated - like the vulgar singer Martin Morero or the New Age-type Roelien Grootheeze - that an ironic perspective upon them is already quite self-evident. For those viewers who might possibly miss the irony, the outrageous character of the gay fashion stylist Yari hammers the point home: actor Alex Klaasen has the most ravish- 
ing clothes, the most wondrous haircuts and wigs, and colourful hats. Being fashionable is his second nature, as becomes clear when he advises - in the television series - his girlfriend Cheryl to sell a kidney rather than give up her Hermès bag. In MATTERHORN (Diederik Ebbinge, 2013), Klaasen sings the 'gay classic' par excellence, Shirley Bassey's 'This Is My Life.' HaRTEnSTRAat (Sanne Vogel, 2014) also has a number of gay male characters, but these are played by actors who are cast against type. Egbert-Jan Weeber and Jan Kooijman usually play heterosexual leads who are popular among (young) women, but in this film Weeber is Rein, who runs a coffee bar with his boyfriend Jacob. After he has seen the handsome Wesley pass by, he proposes to his friend that they should spice up their relationship. After a lengthy introduction, Rein says 'Let's go on Grindr ...,' while Jacob speaks aloud at the very same moment, to indicate that he got Rein's point: 'Let's get a puppy.' But Grindr, an app designed to help gays (or bi or curious guys) to find hook-ups, it will be.

In these Dutch films, male homosexual characters are immediately recognizable as gay. ${ }^{10}$ They are stereotypically feminized, suggesting that a homosexual man is 'a woman's soul enclosed in a man's body.' As Ernst van Alphen hypothesizes, this means that 'first we have a gendered identity, next, in its wake, a sexual orientation' ('Introduction,' 3). Because the man is actually a woman (in terms of gender), 'she,' logically, desires a man. Considering that the object-choice of the feminized gay is in fact conventional, a drag queen - a man dolled up as a woman - is not an anomaly. Against that background, the tagline of CHEZ Nous [AT OUR PLACE] (Tim Oliehoek, 2013), featuring Klaasen as drag queen, makes sense: 'Normal friends, abnormal plan.' In order to prevent the gay bar Chez Nous from being sold at a bankruptcy auction, a group of regular visitors concocts a complicated plan to steal a very expensive necklace, property of the Sultan of Mongul, from a museum during the annual Gay Parade, early August, in Amsterdam. Locomotion of the action is Bertie, a drag queen who excels in performing numbers originally sung by Anita Meyer, and who cherishes the fantasy that he, abandoned by his parents, but adopted by the owner of the bar, is actually her child. In a voice-over we hear him say that when he was little he clung to the idea that Meyer would come to get him when her career was finished. After a silence, while we see his face reflected in the dressing room mirror: 'Right. She's still singing.' The heist is the central action of the film, executed with references to such blockbusters as SPEED (Jan de Bont, 1994) by running surveillance images in a loop, and above all to MIsSION IMPOSSIBLE (Brian de Palma, 1996), but, as Bertie already says preceding the opening credits, while he is hanging from the ceiling on a cable, he is 'not Tom fucking Cruise.' A gay film like CHEz Nous has, of course, the usual jokes such as 'let's put our shoulder pads to the wheel' (Bertie), 'the only thing [in life] I need is you guys ... okay, may be a wig and an old piano' (Bertie), or to 
illustrate the lesson that life has its misfortunes: 'Even a pink cloud sheds rain sometimes' (Rachid).

From a camp perspective, the biggest asset of the film, however, is the fact that the two most important male heterosexuals are put in a position - to ensure that the heist will succeed - to act as if they are gay. Gijs is an artist, a bit over the hill by now, who participates at the Gay Parade in a small boat, dressed up as a leather queen. When his wife Hettie sees him totally by accident, he shouts that 'it's not what you think.... I love you and everything about you. Your boobs, your bum.' He cannot convince his wife, who yells at him, surrounded by a huge audience: 'Just admit your gay. Don't deny it,' to which a woman next to her adds: 'Well, seems quite obvious to me.' In a later scene, after Hettie has hit her husband's presumed boyfriend in the face, she understands that she was mistaken and that he in fact was involved in a crime - for charity, that is.

172 The other heterosexual character who is forced to play a gay role is Bertie's long-lost biological father Helmer, who has been sentenced to prison for a couple of years for burglary. Upon seeing him for the first time, but ignorant of the fact that he is his father, Bertie sits on Helmer's lap while performing an Anita Meyer song in drag. Initially, the son is reluctant to make up with his father, who has never been around, but the impending closure of the bar makes him change his mind. Helmer helps him to enter the museum from the roof, but when the father gets impatient, he says, in a slip of the tongue: 'Hurry, stupid fag.' Bertie demands that he be pulled up, which causes a serious delay of the whole heist. Back on the roof, he gives his father a lecture on this slip, which actually is quite serious, but given the situation quite hilarious: 'Do you know how hurtful that is? And it just slips out? What do you think Gay Pride is all about? ... About the things that just "slip out."” The father thereupon decides to go down himself, hoping that his son will have the strength to hold his weight. Since there is a risk that Helmer has been seen by a surveillance guard, he escapes in the possession of the necklace. Some think that he has disappeared for good, leaving them penniless, but Bertie is about the only one who has confidence that his father will not abandon him a second time. Helmer returns indeed, in the guise of a lady to fool possible observers, after having sold the necklace for cash. Bertie greets him matter-of-factly, and after Helmer has donned his hat, glasses and wig, he makes a remark, characteristic of a pansy: 'Oh, your taste is so gauche.' To celebrate the re-opening of Chez Nous, Bertie performs once more, while the real Anita Meyer comes on stage to sing 'Idaho' in duet. He is dressed most extravagantly, in a dress with shoulders as huge colourful balloons, as if to suggest the lesson of 'deliberate camp' that a true gay man 'naturally' outdoes any heterosexual man when it comes to masquerades. 


\section{THE RISK OF MERE WITTICISM}

According to Fredric Jameson, the aesthetics of postmodernism is characterized by pastiche, a term he uses to refer to a patchwork of motifs, elements and styles. In the vein of postmodern pastiche, the deliberate camp films that have been analyzed here are steeped in the practice of eclecticism, for they borrow influences from a variety of sources. Jameson is critical of pastiche, because he considers it little more than a 'neutral practice of mimicry' and a recycling of 'dead styles' (17-18). The films discussed in this chapter have a surplus value nonetheless. The many tongue-in-cheek references to gender bending, political slogans, and television programmes in the updated version of FLORIS served the purpose of hammering home the point that one cannot make a good old-fashioned adventure story these days, except by flaunting its anachronism. All these references illustrate that 'yes, we makers, we know it is quite outdated to make a knight's story, but since we have amply clarified the silliness of the enterprise, we think it justified to present you an adventure after all, though, dear viewer, you do not have to take it very seriously.' And thus Van der Velde's FLORIs is not about a 'natural-born' hero - that was once - but about a guy who initially masqueraded as a woman in a theatrical play and suddenly finds himself in the position that he has to perform the role of hero. On the one hand, one might say that a film which painstakingly excuses its existence, cannot be a very strong film and FLORIS is not a great picture, indeed, because the fun predominates over the serious battle throughout. On the other hand, the production of FLORIS is of great interest, because it is clear proof that deliberate camp abounds in Dutch cinema.

In his influential study on postmodernism Jameson is annoyed by pastiche, because this practice is 'deprived of any satirical impulse.' Postmodernists texts are devoid of any historical sense, because history gets lost within the aesthetics of quotations. Jameson's succinct formulation runs like this: pastiche is blank parody, a statue with blind eyeballs (17). Well this is true of these deliberately camp Dutch pictures. The hodgepodge of stylistic references in the films in this chapter is so bright and colourful that the issue of homosexuality is presented as 'unbearably light.' Sets are artificial, the acting is overdone, the emotions are at best a mimicry of deep-felt emotions. Let me refer to a brief sketch from the television programme THEO \& THEA from 1988, which, I repeat, was aimed at children originally. In the sketch they played prehistorical troglodytes, waiting for their 'spontaneous and photogenic' son to arrive home. Upon Huubje's return, he confesses that he is homosexual. The parents react with excessive grief: 'What did we do wrong?' Huubje - played by, of all people, Huub Stapel, the 'original' Johnnie Flodder - responds to their dismay that he is glad to be a homo- 
sexual, and the mother immediately realizes her son's courage: 'He is right, because by coming out of the closet, he can be himself.' The father then also understands that the son's confession is a reason for joy: 'I wish all my children were homosexual,' and the three of them start dancing. First, the parents are in deep grief, because they blame themselves; the next moment they are exhilarated because they see the 'problem' from the son's perspective, and the 'problem' has in a split second evaporated into thin air.

Such a swift shift in moods is symptomatic of the deliberate camp in Dutch cinema: attitudes are easily donned or replaced, just as easy as one puts on a new jacket or changes a pair of trousers. To paraphrase Dyer once more, everything in these deliberate camp films is turned into a 'witticism or a joke.' In favour of these films, it should be mentioned that they simply benefit from the relative luxury that it is possible in a Dutch context to make such cheerful, gay-friendly pictures for a general public, which is (or was?) a

174 sign of a relative tolerance towards homosexuality. The choice can be paraphrased as: 'All too often homosexuality is presented in an atmosphere of doom and misery - see AMERICAN BEAUTY (Sam Mendes, 1999) and BROKEBACK MOUnTAIN (Ang Lee, 2005) - so let us grab the chance to celebrate it abundantly while it can. ${ }^{11}$

In the case of camp, reading protocols are of paramount importance for the viewer has to recognize subtexts. In distinction from naive camp, deliberate camp is, as Sontag postulated, very conscious of its own nature (282-83). The next chapter will highlight some films which are not really covered by the labels of cult or camp, but their humorous effects are adjacent to them. I will examine films which were highly conscious of their nature when they were made, but this nature has changed considerably, due to the progress of time: once provocative and vanguard, now comically anachronistic and rearguard. 



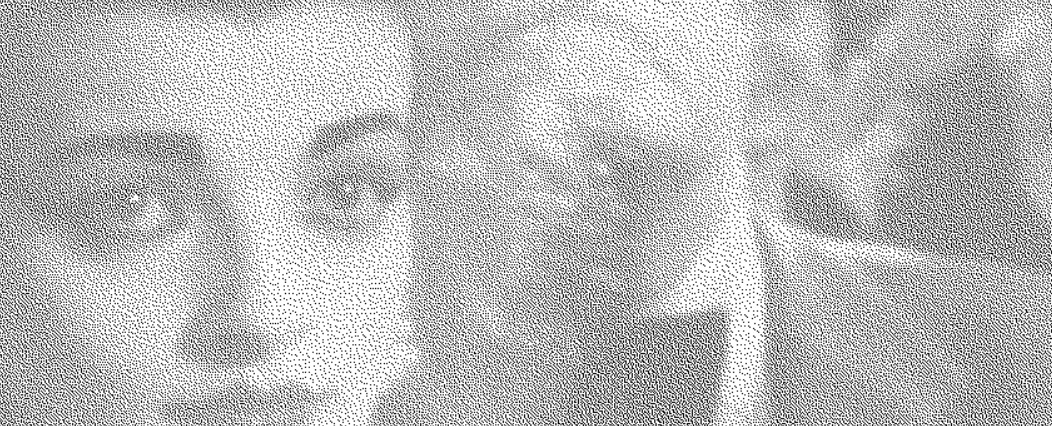

3) 


\section{CHAPTER 5}

\section{Humour as an Aftermath Effect}

In her study Screening Sex, which traces the historical development from the very first film kiss in THE KISS (Thomas Edison, 1896) to the online possibilities offered by cam.whore experiences and Virtual Sex Simulators, Linda Williams introduces the concept of 'on/scenity.' According to her, the obscenity of the public display loses its scandalous impact the more that display becomes familiar (Screening, 260). At the time, THE KISS caused quite a stir when the short film, initially made for the small format of the Kinetoscope with its peephole device, was projected on the much bigger film screen. Williams suggests that it probably gave offence that the intimacy of a kiss was 'monstrously enlarged' (Screening, 30), but for a present-day audience THE KISS is no more than an innocent 'attraction.' Over the decades, the (adolescent) kiss has shifted to presumably more adult displays of what happens between the sheets in mainstream movies, as in the controlled interlude of the spectacle of sex in The Graduate (Mike Nichols, 1967) (Screening, 21, 84), leading up to the 'erotic modern art' of LAST TANGO IN PARIS (Bernardo Bertolucci, 1972) and the 'crass hard-core pornography' of DEEP THROAT (Gerard Damiano, 1972), in which the ejaculation of the male performer functions as visual evidence of 'the orgasmic bliss of the female' (Williams Hard Core, 101). ${ }^{1}$ Whereas the latter film, as befits conventional pornography, had the overt intention to arouse viewers, Williams uses the term 'hard-core art' for those films which merge visibility of genitals with the (narrative) conditions of art cinema, considering the Japanese film AI NO KORÎDA [IN THE REALM OF THE SENSES] (1976) as one of the early 'benchmark' films. Though a great number of hard-core art pictures foreground that sex can have humiliating and alienating effects or even induce boredom, like INTIMACY (Patrice Chéreau, 2001), SHAME (Steve McQueen, 2011), or the second part of NYMPH()MANIAC (Lars von Trier, 2014), hard-core scenes in some other art films with explicit sexual content, can 
be loving, playful or joyous - as in 9 SoNGs (Michael Winterbottom, 2004), Shortbus (John Cameron Mitchell, 2006), LA VIE D'AdÈle [Blue IS THE WARMEST COLOR] (Abdellatif Kechiche, 2013), L'INCONNU DU LAC [STRANGER BY THE LAKE] (Alain Guiraudie, 2013), and in several episodes from part one of NYMPH()MANIAC (Lars von Trier, 2013).

No matter whether these hard-core art titles emphasize the bleakness or the euphoria of sexual experiences, film audiences have grown acquainted over the years with a certain explicitness of sexual imagery, 'through repeated and magnified anatomization' (Williams Screening, 30). The two lengthy lesbian sex scenes in LA VIE D'ADÈLE might have raised some scandal in previous decades because of the explicit display, but in 2013 it was only controversial because it was reported that the male director had subjected his two leading actresses to fatiguing shooting sessions and not because of the display as such. ${ }^{2}$ An even better indication that the 'scandalous' impact

178 of explicit eroticism on the white screen seems to have gradually faded away is the release of the art-house suspense thriller L'INCONNU DU LAC, which hardly stirred a debate, despite its frontal nudity and 'gay male sex on/near the beach' scenes. Many an older film with a graphic display of sex was greeted as too provocative by a contemporary audience, but is in fact quite 'innocent' in comparison to Guiraudie's thriller. This implies that the original provocative impact of a film can get lost as time progresses, which results in a remarkable paradox. It is often the fate of those daring films which try very hard to capture or even to anticipate the zeitgeist that as soon as the historical conditions change, they suddenly find themselves lagging behind - unlike movies with a more classic allure, like LAWRENCE OF ARABIA (David Lean, 1962) or TySTNADEN [THE SiLENCE] (Ingmar Bergman, 1963), which remain solid as a rock. In this chapter I will focus on films which have undergone a thorough shift in reception: at the time of production they held a vanguard position, but they have gained, willy-nilly, a comical effect in the aftermath. Originally, these expressions are token of a provocative, often anti-bourgeois mentality, not necessarily of a sexual nature, for the films at hand will also concern 'drugs and/or rock ' $n$ ' roll' and the horrification of a national symbol.

\section{A DISCREPANCY BETWEEN STORY AND NUMBER: BLUE MOVIE}

Let me give a brief synopsis of a Dutch movie from the early 1970 . Michael is free on parole after serving five years in prison. He was sent to the penitentiary for sleeping with the 15 -year-old daughter of a notary, and while he was a jailbird he beat up a fellow-prisoner. Guided by the probation officer Eddie, 
who advises him not to rush things, he will start living in an apartment on the eighth floor in the so-called Bijlmerflat, trying to build a new life. The film follows his reintegration process and portrays his attempts to get acquainted with other inhabitants. After becoming familiar with the locale, he starts a profitable business.

This may read like the synopsis of an art-house production or of a social document about readjustment, until it is revealed that the majority of encounters with the inhabitants are of a sexual nature. As soon as a commercially released film contains explicit eroticism, the story tends to become of minor importance. In his The Plague of Fantasies, Slavoj Žižek claims that a (film) story and graphic sexual numbers are mutually exclusive: '... if we choose one, we necessarily lose the other' (177). From the perspective of mainstream cinema this exclusivity can be illustrated via the hypothetical example of an extra inserted sequence in OUT OF AFRICA (Sydney Pollack, 1985). Since every spectator suspects that the main characters will sleep with one another, is it not realistic then to actually show how they make love, if only for a few minutes? Had Pollack opted for this, then the romantic bearing of the film would have been completely disjointed. OUT OF AFRICA would have become notorious as a scandal picture and would basically be remembered because of the steamy sex scene.

In fact, this is what befell BLUE Movie (Wim Verstappen, 1971), a Scorpio Films production whose synopsis was mentioned above. ${ }^{3}$ Because of the inclusion of erotic scenes the official film censorship board did not give permission for the release of BLUE MOVIE in regular theatres. Director Verstappen was dissatisfied with this decision and in a quite lengthy counter-plea he pointed out the scientific and religious purport of the film. BLUE MOVIE, he bluffed, should be seen as a loose adaptation of De toekomst der religie [The Future of Religion] (1947), a volume consisting of nine essays by the respectable writer Simon Vestdijk. Verstappen also attached an official American scientific research document, called The Report of the Commission on Obscenity and Pornography, to his apology, for he claimed that this was crucial source material. By explaining in his apology that such extra-textual aspects had been influential, which of course was hard to deny, Verstappen provoked the Film Commission. Moreover, a psychologist was consulted who thought the film made sense from the perspective of his profession. One minor character, called Newman, is known for his stories about sexual debaucheries, but after he is exposed as an impotent man he commits suicide. Further, the presence of a zoologist in the film, played by the renowned actor Kees Brusse, also added some weight to BLuE MoviE. This professor, Bernard Kohn, is among the inhabitants of the Bijlmerflat, but lives six months a year in Africa studying the behaviour of monkeys in order to better understand 
the human biotope. The zoologist not only teaches Michael that the female monkeys yearn after the males with the highest (social) positions, but he also tells him that apes are not interested in sex, but once you put them in cages, they turn into sex maniacs, as happens to humans in huge apartment buildings. This hypothesis is then proven in the film by the conduct of practically all inhabitants who are in for a quickie time and again. The professor is so obsessed by apes that he neglects his young wife, who therefore has every reason to be adulterous. On top of that, BLUE MOvIE strategically capitalized on a shift in the 1960s mentality regarding sexual mores in Amsterdam, and as such it could be seen as a film with social value. Michael was sent to prison in a period preceding the so-called 'Summer of Love' in 1967, which led to less strict ideas on sexual behaviour. The inclusion of sex scenes was a not illogical consequence to illustrate this changed mentality. Finally, in his counter-plea Verstappen also argued that the visibility of the protagonist's 180 | erection proved Hugo Metsers' commitment to the whole project. To top it all, the visibility of Michael's erect penis earlier in the film was required, because in the final scene with Julia, who seems to become his love interest, a shot of a non-erect penis suggests he is unable to perform (Den Drijver, 131). Thus, the erection had the narrative function of suggesting the tragic irony of Michael's impotence. The Commission gave Verstappen the benefit of the doubt and approved of the film without demanding any cuts. From that moment onwards people, including moviegoers in Belgium and Germany, were anxious to see the much-discussed picture.

After the film censorship board had shot itself in the foot with the final approval, Verstappen claimed that it had been his goal to undermine the functionality of the board. A few years before, in 1967, he had co-signed a petition to protest that the Centrale Commissie voor de Filmkeuring had disapproved of Jef van der Heyden's ONGEWIJDE AARDE [UNCONSECRATED EARTH]. ${ }^{4}$ According to the Commission, its makers disrespected dead bodies, for corpses were 'dragged around' in the film and it had been crude to shoot the funeral of a priest with a candid camera (Van Gelder, 107-8). Let us take Verstappen at his word, that his intention was to put the efficacy of the Commission into doubt. If so, then his BLuE Movie had lived up to its aim. ${ }^{5}$ In short, judged by its effect, the film was a success, for the Commission was reduced to paralysis and in 1977 film censorship for viewers aged over 16 years ceased to exist.

Given that the effect was of greater importance than its actual content, it does not really matter whether BLuE Movie was a 'good' film or not. In fact, it is not, and measured by present-day criteria, BLUE Movie is an uneven film. It can only be enjoyed as the sheer oddity it has turned into in the course of time. It can be said in defence of Verstappen's film that DEEP 
THROAT (Gerald Damiano, 1972) still had to be released, so there was no key reference point for erotic or hard-core cinema yet. Despite its differences to this porn classic to be, BLUE MOVIE shares with DEEP THROAT the idea that having sex is wholesome. Analogous to the structure of American musicals like the ones by Vincente Minnelli (MEET ME IN ST. Louis, 1944; AN AMERICAN IN PARIS, 1951), in which any problem at the level of the story finds a (miraculous) solution as soon as characters start to sing and dance, the performance of sex is the utopian remedy for any ailment in an erotic/porn film. Whereas the one guy who talks only about sex, but is incapable of practising it, dies tragically in BLuE MOVIE, Michael's reintegration into society is so successful because he understands that screwing his female flatmates is beneficial. It helps him to develop his social skills and it gives him the much needed confidence to start his own sex-based business. Blue MoviE can be regarded as comic because Michael's probation officer Eddie - who is supposed to teach his client about social values - is utterly ignorant about the beneficial role of free love. Eddie wants to encourage him to enter into a steady relationship, but Michael retorts that he already knows two of the single women on the list: the first one is lesbian, and a second one is a member of a Maoist organization, cunningly adding to this that it is probably not a very good idea to engage with her. In response to Michael's bluff, Eddie has no other reply than some stumbling words. Ultimately, the probation officer is a nice chap with good intentions, but because of his naivety, he is the sitting target in Verstappen's film. As such, the portrayal of Michael and Eddie foreshadows the later representation of Johnnie Flodder and Sjakie.

A second reason why BLUE MOVIE can be read as a comic, if not hilarious picture, is because its main story, about an ex-convict's return into society, has the air of seriousness, but obviously should be taken with a grain of salt. In his brief essay 'How to Recognize a Porn Movie' Umberto Eco claims that some story is indispensable for the porn flick. A plot, no matter how rudimentary, is required to justify the staging of sexual acts. Eco's argument from his 1985 article is based upon a comparison between art cinema, like Michelangelo Antonioni's L'AVVENTURA (1960), and porn. In L'AVVENTURA, hardly anything happens for more than two hours, but boredom and the 'waste' of time are essential to the aesthetic experience of the film. A porn movie also consists of many wasted moments, but viewers regard them as annoying delay: characters drive cars, wait at elevators, sip various drinks, or a plumber comes by to fix the sink. Those apparently irrelevant scenes are advantageous nonetheless, because they create a 'background of normality.' The insertion of ordinary scenes may seem superfluous, but psychologically a porn flick would be unbearable for its viewers if there was only sex without any narrative framing, according to Eco. The viewer can only appreciate a 
'healthy screw' on the condition that everyday scenes prevent the film from becoming an abnormal showcase of permanent saturation. Regardless of the ridiculous nature of those storylines, the regular porn movie depends upon a necessary interaction between narrative and number.

For Eco the difference between an art film and porn seems only gradual, a matter of a different emphasis. The art film can permit itself to ignore a story, whereas the porn movie has to offer a narrative, although the plot by definition lacks substance, for it merely functions as a stepping stone for the sexual number. Since present-day viewers have become much more familiar with what has grown over the years into a staple feature of regular porn, they will recognize the preludes to the sex scenes as the obligatory imposition to construct a frame of 'normality.' Living on the eighth floor, Michael has to take the elevator. The only other person in the elevator is a woman who challenges him - sign of the changed mentality - to make it stop and have a

182 quickie. Michael takes up the challenge while downstairs a growing crowd is becoming more and more impatient. A mechanic is called in, but before he has been able to repair the breakdown, the two have reached ground level, fully dressed again. In another scene, Michael spies on the neighbours who have left their curtains open while love-making. Michael recognizes that the wife is horny, so he plucks up courage and approaches her the subsequent day by asking whether she can spare a cup of sugar. In both cases, there is a prelude, albeit minimal, not to say that it is hilariously minimal.

In the 4-minute-long persiflage by KREATIEF MET KURK, broadcast in 1993, the minimalism of the preludes is even further reduced. When the man rings the doorbell, the woman immediately asks, before he can even utter a word: 'You come to borrow a cup of sugar or you want to fuck?' The persiflage by KREATIEF MET KURK reveals the wonderful paradox of BLUE MOVIE. Once it was a daring project pervaded with an anti-bourgeois sensibility and a provocation at film censorship to great effect, but these days it can only make an obsolete impression as if the whole film was just a joke.

\section{A BOHEMIAN DISPLAY OF SEX AND DECAY: TURKS FRUIT}

TURKS FRUIT [TURKISH DELIGHT] is not so much a scandalous picture because of its depiction of sexual acts, but because it insistently links 'desire, death and decay,' Xavier Mendik claims in his analysis of Verhoeven's 1973 film (109). It is one of the key titles in the blossoming period of 'porn-chic' in this decade, but instead of equating sexuality with a joyful bliss, the film is quite macabre in tone, as seems to befit the tradition of European (art) cinema. ${ }^{6}$ Mendik underscores this claim by selecting some scenes that have an 
'uncanny effect' (113). When the blonde bohemian artist Erik Vonk is about to have sexual intercourse with his beloved Olga Stapels in his studio, she falls asleep amid an elaborate array of candles. Since an overhead shot with reflective mirrors is used to show the naked Olga, she 'appears corpse-like, part of some bizarre funeral display' (113). In another scene, also described by Mendik, her inanimate body, covered with flowers by Erik, gives 'the appearance of death.' As soon as he removes the flowers, Olga's breasts and stomach are covered with maggots and insects, once again an image of decay. And due to the tragic ending, whereby Olga dies from a brain tumour, all these scenes can be interpreted as signs of a death foretold. Despite the morbid moments and sad ending, the film is above all appreciated for its overall vibrant atmosphere and the bohemian lifestyle of the main protagonist.

Most of the time Erik's acts seem prompted by an impulse to show himself off as wilfully contrarian. Sometimes his behaviour is only a boyish prank. At one point he takes an ice cream from the hands of a pedestrian when he passes him on a bike and he cycles right into a liquor store, with Olga on the bearer. At other times he just expresses his annoyance. The newly-weds Erik and Olga are about to have sex with one another, but time and again the bell rings which interrupts the consumption of sex. Fed up with all the ringing he throws the water in a flower vase to the man at the door, who happens to be Olga's father. Luckily for Erik, he is about the only person from an older generation who can appreciate a prank. Most of Erik's practical jokes are directed at characters for whom he feels a certain contempt. For an official assignment, he makes a sculpture of Jesus, but ornaments it with maggots and worms. He calmly explains that this is the awful truth, because Jesus was dead for a couple of days according to the Bible, but the representative of the tourist town Valkenburg is disgusted and demands removal of the nasty details. Immediately thereafter Erik turns a festive meal attended by this very same representative into a total mess when he starts spoiling and throwing food. Olga's mother is also a target of ridicule for him, because she undertakes efforts to keep Erik at a distance from her daughter. When he finds a balloon in the bathroom that is meant to cover-up for one of her removed breasts, he first says to Olga that her mother's charms are made of air and he then writes 'greetings, Erik' upon it with lipstick. In the scene when the queen arrives to inaugurate a sculpture he has made on commission, he encourages Olga to take off some clothes because it is so warm. The comic provocation falls flat, however, because a civil servant and his obsequious assistant make sure that the brass band passes in front of him and the scantily dressed Olga so that they are hidden from the queen's sight.

Erik behaves in a contrarian way, partly because he does not want to submit to rules of commonly accepted conduct, but above all to annoy figures 
who lay some claim to authority - the representative of Valkenburg, Olga's mother who thinks she can have a say in her daughter's love affairs, the store manager with whom he has a quarrel first and a physical fight second when he tries to prevent Erik from seeing Olga. The notable exception is Olga's father who does not disapprove of the relationship of his daughter with Erik, has the habit of telling jokes, albeit stale ones, and on top of it all, sings to the rhythm of the 'Radetzky March,' by repetitively adding the words 'tits 'n' ass' [tieten-kont]. Unlike Erik whose rebellion is overt, the father's is concealed so as not to irritate his own wife too much. When Olga's mother accidently breaks the heel of her pump, he starts laughing, but stops immediately as she expresses her dismay at his fun. Erik's affinity for the father is most evident during a scene at the old man's funeral, when Erik dilates his eyes which works to emphasize his focalization. We then get a hallucinatory shot: the father rises from his coffin, singing 'tits 'n' ass' to the Radetzky

184 March once more. This scene is on the one hand a friendly salute, imagined by Erik, and on the other hand, we can consider the scene, discussed in chapter 4 , from DE TRANEN VAN MARIA MACHITA when Elbert finally has the right lyrics to his song as a homage to this hallucinatory resurrection from TURKS FRUIT.

All these comic scenes notwithstanding, TURKS FRUIT is of course best remembered for the frankness with which it displays scenes of sex, right from the start. The film opens in medias res, after Olga has left him for Henny. Lying on his bed in his untidy apartment Erik has some dark fantasies, strangling the new couple among others. After cleaning his place, he puts on a black leather jacket and says to himself in the mirror, 'Scoundrel,' which is the start of an extensive episodic sequence on 'making a pass at every woman.' The scenes are all brief: he goes into the city and starts to bother a girl in a phone booth. She reacts annoyed initially, but she starts to smile, however, when he draws a heart with his thumb on the glass. In a subsequent shot he is already on top of her in his bed. He frankly announces that he will fuck her, followed by a quick transition to Erik smoking a cigarette, while the girl is sobbing that he is sending her away and, moreover, without a 'souvenir.' With his back to her, he quickly draws a huge cock and signs it. Handing it to her, he says, 'Frame this.' The structure of this scene is repeated for his next 'conquest.' In town again, he jumps into the back seat of a cabriolet which has stopped at a traffic light. The woman yells at him to get out, but he kisses her. Cars start to honk, so she has to drive on. In the next shot she is already undressing in Erik's apartment, although he tells her she can leave her shirt on, since he will only use her bottom half. A next shot shows her bare buttocks, while his hand takes a pair of scissors, with which he then cuts some of her pubic hair. He puts it under his nose as if he 
has a moustache and then glues the hair in a book, asking her name: Josje is his 'number 50.' The tempo of the episodic sequence accelerates from here onwards, for this is followed by a post-coital shot with another woman, who tells him that she missed God in their encounter, to which Erik responds: 'I fuck better than God.' Shocked, she turns away, and he then tries to smash a peeled banana into her mouth. Immediately there is a transition to a closeup of a crying baby in a pram, and then a high angle shot, showing Erik making love to another woman. In a closer shot we see that her right hand takes the pram and the rhythm of the sex comes to correspond to the movement of the baby carriage, which immediately silences the kid. The moment Erik and the woman stop, the child starts to cry again. A transition to another post-coital scene when a woman complains that she feels like a cow, for he considers her buttocks too soft and her tits too small. Then she takes up a black-and-white photograph of the ground, asking whether this is her. The melancholic theme music, played on a harmonica by Toots Thielemans, starts as Erik pensively touches the photograph. When the woman then remarks that she has left him for some shithead, he throws her out of his apartment while she is still naked. Then we see, as the last in the series of this episodic sequence, that Erik takes a girl with him on a bike to his house, shown in a long shot. Initially we might think it is Olga, the photographed woman, and that this is already a flashback. She also has the same, slightly hoarse laugh that Olga has. While Erik embraces her, he suddenly stares offscreen at something, accompanied by some sinister sounds. We see a sculpture, difficult to discern in the dark. Thanks to some light from outside, a closer shot reveals it is Olga. Erik seems paralyzed, then walks towards her. The girl, in the background, turns on the light, and it becomes evident that it is only a dark sculpture, representing Olga. The girl wraps her arms around Erik and asks: 'Fancy a fuck?' but Erik shakes his head. She looks over her shoulder towards the sculpture, and as if she considers herself an unworthy rival to the image, she leaves. The episodic sequence ends with Erik caressing the sculpture, before we go two years back in time when Erik is about to meet Olga.

I have described this sequence of about five and a half minutes at length, because of its fundamentally double-edged nature. On the one hand, the sequence is vulgar, presenting Erik as a lout who treats women disrespectfully. He seems uninterested in knowing their names or engaging them in conversation, and passed nasty comments about their body and even cuts a woman's pubic hair without asking permission. It is suggested he just wants to have sex with as many women as possible in a limited time span - as we can gather from his album in which he collects souvenirs from all his 'conquests.' On the other hand, as we can read from the last two encounters, his 
rude behaviour is determined, to some extent at least, by his melancholia which apparently arose after he lost the love of his life to another guy. The last part of the sequence is so very efficient, since, covered in the darkness, she seems to bear some resemblance to Olga. At home, Olga really seems present, until the spell is broken when the lights are switched on. The hallucination confirms that, meeting other women for casual sex is perhaps a way for him to vent emotions, but none of them will meet the required standard.

Strictly speaking, one might say that TURKS FRUIT keeps us guessing what is pretext and what is goal or 'message.' Are the erotic scenes subsidiary to illustrate Erik's deep affection for Olga? Yes, that is possible. One might also see this the other way around. The romantic aspects are basically a smart excuse to legitimize the insertion of the series of brief sexual encounters. In practice, however, the scales definitely tip in favour of the latter option, since 'romance' and 'sex' are not of equal weight. As soon as sex is 186 involved in mainstream film, any balance gets disturbed. That happens with TURKS FRUIT also, but at the same time the film partly compensates for this imbalance in two ways. Sex scenes can bewilder a mainstream movie when its main effect is to evoke excitement and arousal; in short, when the scene is 'hot.' TURKS FRUIT tones down this effect by associating sex with death and decay on the one hand and with humour on the other hand. Only think of the scene when Erik is having sex for the very first time with Olga, in her car at a parking lot. Their quite uncomfortable, but apparently very needy lovemaking in a cramped space is suggested by the fact that his buttocks make the car horn blow and his boots put a lever that turns on the water spray and the windshield wipers. When Erik then quickly wants to zip up his pants, he catches his penis in the zipper. They have to go to the nearest house so Olga can borrow a pair of pliers, at the same time keeping the curious farmer and his wife at a distance. Such comic appeal worked to ensure that TURKS FRUIT was not received as a truly provocative film, but as only mildly so, leading to both an Academy Award nomination for Best Foreign Language Film and an unprecedented success in Dutch cinema with more than 3.6 million paying viewers at the box office.

A landmark film such as TURKs FRUIT has of course functioned as a source of inspiration for other filmmakers. The results belong to the poorest of what Dutch cinema has on offer - BRANDENDE LIEFDE [BURNING LOVE] (Ate de Jong, 1983), IK OOK VAN JOU [I LOVE You Too] (Ruud van Hemert, 2001), ZOMERHITTE [SUMmer HEAT] (Monique van de Ven, 2008) - and, to put it in positive terms, each failure further accentuates the remarkable achievement TURKS FRUIT is, illustrating that it is an inimitable film. One of the lessons of the most ambitious of these failed imitations, KOMT EEN VROUW BIJ DE DOKTER [STRICKEN] (Reinout Oerlemans, 2009), is that this 
specific kind of genre requires a male protagonist who deserves our sympathy. Erik was an artist with an anti-bourgeois mentality who preferred his love for Olga over money. By contrast, Stijn in Oerlemans' film is an egotistic yuppie working at an advertising agency, or in his own voice-over, 'I was a major-league hedonist and I lived like a God in Amsterdam,' until he moves to the suburban Amstelveen with his wife, Carmen. He thinks that she has to tolerate his 'cheating as a bad habit,' just like another guy picks his nose as a habit. No problem for him and her, for his heart belongs to Carmen until he loses his heart to Roos. What is wrong with KOMT EEN VROUW BIJ DE DOKTER is, paradoxically, that the photography is too stunning, the editing too fluid, and the musical score too conventional. Since the film is too glossy and not a bit 'gritty,' there is neither a built-in option for the spectator to dis-identify with a spineless protagonist like Stijn nor to feel uncomfortable about his 'amoral' choices.

\section{ONCE PROVOCATIVE, NOW OBSOLETE: PIM \& WIM MOVIES}

In comparison to the bohemian Erik, the car salesman Frank van Eeden from Pim de la Parra's Frank \& Eva: Living APART TOgETHER, also from 1973, is a good-for-nothing. Whereas Erik's pranks are not disrespectful to Olga and can be regarded as an inverted expression of love, Frank's jokes are often at the cost of his wife, making her blood boil. At the very start of the film, Frank is lying in bed, a gun in his hand and his head covered with blood. Eva has to use a key to open the locked door, but whereas the sight of Frank terrifies the maid, Eva hits him in the groin, which makes him cower in pain: 'Drop dead, prick,' is her verdict. During the opening scenes we see Frank having fun by flirting and drinking alcohol while driving. When he hits another car, he runs away because the police will find 'too much blood in his alcohol.' Frank is a typical slacker and playboy, about whom one of his best friends, the elderly Max, will say that every time he hears Frank talk about 'freedom,' this has to be interpreted as 'making a pass at women.' Not surprisingly, then, the most serious crisis in their relationship occurs when he considers the news that she is pregnant a very bad joke, because this would require him to take up fatherly responsibilities, which would limit his freedom. Eva is so mad that she leaves the house, in which they are 'living apart together,' each on a different floor. When she returns after a while, she finds him looking through binoculars at a sexy woman who lives on the other side of the canal. She warns him she will leave him once he shows himself at that bombshell's place. Frank immediately challenges her by ringing the woman's doorbell. Once inside, he tells her he has a bet with the woman at the window, carrying binoculars. He requests 
her to close the curtains for 15 minutes. We see her do so via Eva's binoculars. Upon his return, she has his back towards him, while we see a displeased look on her face, but she coolly asks: 'Back so soon?'

While this scene is staged for her eyes to annoy her, there is a structurally similar scene in which the roles are actually reversed. After Frank has gone out with two women, Eva picks up a stranger in a restaurant. Frank enters the house by smashing a window and then sneaks into the closet of her bedroom. He looks on when Eva and the stranger undress and as they are about to have sex, he mimics the sound of a cat. It does not bother the stranger, but Eva is puzzled since there is no cat around. Hearing 'meow' once again, Eva is convinced there is a cat in the closet. When the guy decides to size up the situation, Frank jumps out wearing a cloth over his head. The stranger is so aghast that he takes his clothes and runs downstairs as quickly as he can. Eva laughs out loud at Frank's practical joke. Whereas in the previous scene, the observer 188 - Eva with binoculars - was the fooled party, in this scene, the observer - Frank in the closet - turns the situation to his benefit. Frank keeps on pretending, and the end scene shows him once again in bed, door locked, gun in his hand and blood on his face. Tired of the joke, Eva takes the gun and accidently pulls the trigger. This time, the gun was loaded and the sudden shot startles them both. She starts hitting the 'idiot,' saying that she will leave him and while they both fall into the bathtub, her blows transform into caresses, suggesting that a definite goodbye will, once more, be postponed.

In terms of their identity as a bon vivant, Frank is more or less in the same league as Erik in TURKS FRUIT, but with a huge difference nonetheless. The latter really cared for his girlfriend Olga, and many of his pranks can be taken as either a sign of melancholia over losing her or as a salute to her. By contrast, Frank is a solipsistic guy who is lucky to get away with his incorrigible behaviour. The only one who gives him a note of warning is the old and deadly Max. He tells his young friend that 30 years ago he himself was making the same stupid mistakes as Frank is making right now. The senior calls him a juvenile, egotistic and stubborn idiot, but Frank takes the advice light-heartedly. Even Max' death has not really reformed him, as the final prank illustrates. In the beginning of TURKS FRUIT, Erik was using a series of women as sex toys, but this could at least be seen as a reaction to his grief. Even though Erik's behaviour can also be seen as a token of narcissism, since her departure had insulted his masculine pride, Olga was nonetheless one of a kind for him. For Frank, on the contrary, every woman, including Eva, is an object of his bohemian lifestyle.

Eva is a good-hearted woman who has to endure his boyish pranks as if he is constantly putting her loyalty to him to the test. At one point, when he has driven her mad again, he curls up next to her in a foetal position and 
thumb in his mouth, and what else can a 'mother' do than forgive her foolish 'baby'? Thus, he permits himself to act disrespectfully, which in FrANK \& Eva is cause for comic amusement, or rather, it is meant to be comic, a deliberate attempt to transgress bourgeois norms. Some might consider Frank's chutzpah funny, but others will regard his incessant rowdiness annoying, and thus very unfunny.

The title of De la Parra's next feature film, Mijn naChten met Susan, Olga, Albert, Julie, Piet \& SANDra [My Nights With Susan, Olga, Albert, JULIE, PIET \& SANDRA] (1975) also provokes a male fantasy, since the 'My' refers to a man named Anton. The story is quite simple: this Anton wants Susan to go on a trip, but she is not sure whether she really feels like it, so he stays a couple of days. Via this newcomer we get to know the particularities of the residents. Susan came to live in the house amidst meadows near the seaside some three years ago. Albert joined her, but ever since the arrival of Olga and Sandra, he has hid himself in a dark sheltering place. Susan brings him food and Julie visits him secretly. Olga and Sandra have never set an eye upon him, but through a small peephole Albert spies on the two promiscuous women.

In the beginning of De la Parra's picture, we see a couple of swans in a lake, which can be taken as an allusion to the ducks in Haanstra's FANFARE. Shots in which the ducks submerge their heads under water function as a comment upon the ostracism of the inhabitants in Lagerwiede, but in MIJN NACHTEN MET SusAn, Olga, ALbert, Julie, Piet \& SANDRA, the swans dive because Olga and Sandra throw little rocks into the lake. Scantily dressed, they walk into the open landscape and along a small road, where they block a car driven by an elderly American. He yells at them to get into the car, which they do. While Sandra whispers something in the man's ear, she hands a whisky bottle to Olga in the back seat. Then we get a high-angle shot of the camera, panning the surroundings, until it captures the car from above. Sandra is having sex with the American in the car. In a close-up, Olga raises the bottle and hits the American on the head with it. In the next shot, the two women are driving the car, with the dead man's body on board and the Stevie Wonder song 'Don't You Worry 'bout a Thing' playing on the soundtrack; in a close-up we see the man's cigar still smouldering in the ashtray. The women hide the corpse in a ditch, but their action is witnessed by Piet, a woman living as a hermit in a shed nearby.

Advertised as a 'sex-psycho, suspense mystery thriller,' De la Parra's film represents the two girlfriends as blown-up versions of femme fatales, even more brutal than Catherine Trammell in Verhoeven's BASIC INSTINCT (1992), some 17 years later, will turn out to be. When they see Piet, they start yelling at her: 'Piet, Piet, crazy Piet, do you see my cunt, do you see my tit ['tit' is tiet and thus rhymes on Piet].' The very first evening the handsome Anton is around, 
Olga says to him: 'Sandra's nipples are hard, her cunt is all wet. She has never had a man, however. She has been waiting for you, Anton. Oh, you are a real man. I feel it. Oh, Sandra, I am so jealous of you.' Once again, Olga is about to hit the guy who is having sex with Sandra, but we get a cut to the next day: Anton is still alive and kicking. And at this point we are only a quarter into a film with a weird plot, weird characters, and an outrageous ending: Olga and Sandra are locked into a small shed, and Piet sets fire to it. Finally, the camera zooms in onto an extreme close-up of Piet's iridescent eyes.

In the previous chapter I paraphrased Sontag's argument that we can get irritated when an important theme is brought up in a commonplace work of art, but once we become less involved in it, a few years later, we can derive pleasure from it. According to her, 'time contracts the sphere of banality. ... What was banal can, with the passage of time, become fantastic' (285). In the case of the Pim \& Wim films from the early 1970s, there is a reverse effect. They

190 | profiled themselves as vanguard filmmakers, who address the theme of sex in a time when its insertion in mainstream cinema could still be considered a bold move. This connotation of boldness evaporated, the moment sex lost its provocative appeal and became commodified. The soft-erotic film series of EMmanuelle, which started in 1974 with Sylvia Kristel in the titular role, accelerated this process. And thus what was anti-bourgeois initially became, with the passage of time, quite banal and (slightly) humorous.

The label of cult and/or naïve camp is usually applied as soon as a serious work of failed art meets appreciation in its aftermath. The work is then cut loose from its original context. In the cases of the films in this chapter, it is contrariwise. If we enjoy the films by Pim \& Wim nowadays it is in the full awareness that these sex-crazed pictures once were (meant to be as) vehicles of provocation. We understand all too well that they are signs of their uproarious times. The fact that these progressive texts have become so rapidly obsolete is cause for comic amusement. Their change in status from anti-bourgeois to banal is definitely a comic and ironic turn, worth a (big) smile at least. Likewise, a film centred around the best-known 'rock 'n' roll junkie' in the Netherlands, the singer Herman Brood, known for his consumption of drugs and his capricious behaviour, also became more quickly outdated than its makers probably had bet on. Posing as a rebel does not automatically stand the test of time. 


\section{BAND OF OUTSIDERS: CHA CHA}

In its first ten minutes, CHA CHA (Herbert Curiël, 1979) promises to be a film with politically subversive undertones. ${ }^{7}$ Intercut with photographs, the film opens with a lengthy text in English by the German Intelligence Bureau warning the Dutch police about the arrival of Nina Hagen, Lene (misspelled as Lena) Lovich and Les Chappell (misspelled as Less Chapell), 'three suspects of anarcho provocations' who have to be put 'under constant surveillance.' After the opening credits, we see some archive material about both the inflammatory power of pop music performances and the social unrest in Amsterdam when a police force confronts young squatters. The sequence is concluded with a gig by Dutch pop singer Herman Brood in open air. Then suddenly the camera tracks the three 'suspects,' who take a stroll through Amsterdam. We hear a voice-over dialogue between Nina and Lene, and then we hear them sing together, on screen, a Russian song. Thereupon Lene suggests that they might rob a bank, but that, if caught, it will cost you four or five years in prison, unless it is discovered 'there are political motives,' for then 'there is the chance that you might be locked up for a longer time.' Nina responds in a thick German accent, while giggling: 'I do not want to go to prison, but I do like to make a bank robbery, haha,' as if it is no more than an enjoyable pastime. We then get a close-up of handcuffs, and hear Nina's voice: 'Put your hands just in front of it, tchak, tchak.' The camera zooms out and two employees are being handcuffed. Herman has a gun and Nina has her huge gun pointed at the employees. Lene walks outside with a bag, followed by Nina and Herman, and that is about it. We hear Lene's voice-over, which could have come from a Jean-Luc Godard movie like BANDE À PART [BAND OF OUTSIDERS] (1964): 'In this picture I play the part of a political activist. As you can see, we havejust robbed a bank. And now that I have the documents, I have the power to make some certain changes.' They step into a runaway car, and so the robbery takes less than 30 seconds of screen time. Nina adds to this, once again in voice-over: 'Future is now, 1968 is over, 1979 ist Wahnsinn, the future is mine.'

While a police car is chasing them and Nina has taken some money for a washing machine and video recorder, we get the most important cross-cutting scene from the film. All of a sudden, we see a blue-tinted shot of a man and a young kid walking in the street. The kid says to his father that he wants to become a singer. The father acts surprised: 'What are you saying? You want to become a singer?' Brief insert from inside the car, where Herman suddenly says: 'I'm gonna go back in rock 'n' roll ladies.' Immediately back to the bluetinted scene, where the father gives the advice to his kid: 'You have to make a career in crime, because only crime pays.' Back to the car, where Herman repeats his statement: 'Leave me alone. I want to go back to rock 'n' roll.' 
The brusquely blue-tinted inserts might be Herman's reminiscence of his childhood. The cross-cutting is a case of comic incongruity, a father advising his boy to become a criminal instead of a singer, strictly out of financial gain. And to add some more humour to this incongruity: this father is played by Dolf Brouwers, a gesture of ironic casting, since Brouwers dearly had wanted to become a celebrated singer all his life, and only became famous after he was already 60 years old. ${ }^{8}$ In case it is a flashback indeed, the adult version of the kid remembers he has acted according to his father's advice, but he immediately has second thoughts. All of a sudden he is very sure he wants to be a (rock 'n' roll) singer, suggesting it is better to pursue one's vocation than to get rich. At this point, the film takes a different turn, centred around Herman's preoccupations, often told in mumbling voice-over reflections, and many lowkey performances. CHA CHA still breathes an anti-bourgeois sensibility, for Herman is an unconventional and maladjusted musician as there ever was in

192 the Netherlands, and both Nina and Lene add a dose of capriciousness to the overall wayward atmosphere, but the film no longer lives up to the promise of subversion. The first ten minutes mixed a number of incompatibles - people strolling the city, committing a crime, a political backdrop - as alienating as a Godard movie, but this potential is sacrificed, alas, to Herman's determination to become a singer after all. ${ }^{9}$

\section{AGENT PROVOCATEUR: 06 AND BLIND DATE}

If Herman Brood was to pursue a career as a 'rock 'n' roll junkie' and as visual artist, then Theo van Gogh more or less took over the role as 'agent provocateur' in the domain of cinema. This is not meant to suggest that Van Gogh is a successor to Brood, for the two are worlds apart in many regards, including their personalities. My reason for including Van Gogh is that the way this 'misguided missile' would build himself a reputation is marked by ironies.

A first irony, a tragic one. Until his untimely death on 2 November 2004, Theo van Gogh was a jack-of-all-trades: besides being a filmmaker, he also was a (script)writer, a television creator, a columnist, and a blogger on his website De Gezonde Roker [The Healthy Smoker]. He usually played the role of a 'pain in the ass.' In many of his public appearances he was notoriously rude and he not only had feuds with sworn enemies but also with former friends. As Ian Buruma argues, he considered Thom Hoffman an 'early comrade-inarms against the commercial film industry,' but once Hoffman's acting career started to prosper, he was no longer a 'fellow outsider' in the eyes of Van Gogh and thus a coward who deserved contempt (94). Van Gogh 'placed himself squarely in the tradition of abusive criticism' (Buruma, 98) and voiced extreme 
opinions on Jews, on Islam, on left-wing politics; he spoke favourably of the Muslim-bashing politician Pim Fortuyn, the 'Divine Baldy.' His 06/05 (2004) suggests that the killing of Fortuyn was not a one-man's action, as the official investigation has concluded, but the main protagonist uncovers a conspiracy behind the murder. During the post-production of this film, Van Gogh himself was murdered by a Muslim extremist who took revenge for him directing the anti-Islam short SUBMISSION (2004), scripted by Ayaan Hirsi Ali, the actual target of Mohammed B. This film was supposed to reveal that many Koranic verses, which were written on semi-naked female bodies, are unfavourable to women. Like Hirsi Ali, Van Gogh had received death threats, but he had declined an offer of personal security. He himself suggested that he was no more than a 'village idiot,' for, he asked himself rhetorically, who would really take his unorthodox opinions seriously? Making provocative statements was part of his DNA; his many edgy and pestering statements could perhaps better be seen as a form of playing ding dong ditch to keep policymakers alert. Well, Mohammed B. did not consider him just a joker.

A second irony, an amusing one. Some of Van Gogh's early films are wilfully provocative, as if he wanted to be noticed as a bad boy. In his debut feature, LUGER (1982), a gangster shoved his gun in a woman's vagina, and two kittens were spun in a washing machine. His third film, CHARLEY (1986), was about a female serial killer who seduces men and ultimately eats her victims. Albeit notorious as a troublemaker, Van Gogh only became acknowledged as a film director to be reckoned with when he started to make more reserved and sober films. His seventh feature, 06 [1-900] (1994), was based upon a theatrical play and it was shot in no more than five days. The camera was either in the apartment of architect 'Thomas' or in the house of the bourgeois Sara, a former art history student in Leiden. He left his number on a telephone sex line, and she rings him every Thursday. They chit-chat on a variety of subjects: his work, the song 'Telkens Weer' by Willeke Alberti from RooIE SIEN (see chapter 3), or a horny encounter she has had with another woman. During one of their conversations, he pretends to be a sociologist who has to do a questionnaire on masturbation. And, of course, they also practise masturbation. A line is crossed, however, when he finds out her last name, thanks to an accidental meeting with one of her former fellow-students: 'Keep out of my life,' she warns him. When she rings him next time, 'his father' takes up the phone, informing her that Wilbert, whom she knows as Thomas, is dead by suicide. She is quite taken aback by the father's story, and then commits the error by giving the 'father' her phone number. He then says 'just kidding.' She calls him back, telling him he is insane and sadistic, and the film ends with her staring off-screen. The reverse shot shows the phone huge in the foreground and a vague silhouette against a brightly lit window in the background. 
The film 06 is extremely simple in structure: it is chronological, and the observing camera mainly punctuates the emotions: at moments of excitement it is relatively close, at other moments it is distant from the characters, with an occasional high-angle shot from behind, and fairly often it slowly circles around them. The camera work and the editing are strictly subservient to the dialogue which was, to some extent, improvised by the actors. ${ }^{10}$

Like 06, Van Gogh's BLIND DATE (1996) is theatrical, small-scale in design and dialogue-driven, and hence, another two-hander domestic drama, according to Kate Connolly in The Guardian, 'reminiscent in [its] intensity of Pinter, Ibsen or Mamet.' A man who performs magical tricks as clumsy as Tommy Cooper, and a wife, a former dancer, have regular meetings on the basis of contact advertisements. It will turn out that these dates are re-enacted in order to cope with the death of their three-year-old daughter, Annabel. We hear this girl in posthumous voice-overs, that persistently demand that her parents join 194 | her: 'They have to do what they promised each other. I have been on my own long enough.' After their suicide at the end, the voice-over says: 'Dear diary. It is now the three of us again.' It is an instance of wry sarcasm that BLIND DATE mentions at the end: 'This film was made possible with the support of the Elco Brinkman Foundation to promote the family as the cornerstone of society.' This acknowledgement is fictive, because there is no such a foundation. This word of thanks is a banter at Elco Brinkman who was the former leader of the Christian Democratic Party (CDA), focused upon a policy to discourage divorce and to make euthanasia impossible. In BLIND DATE, the child's voice-over suggests that the family is back together again, but the way this is solved is in total contrast to what CDA has in mind.

A third irony, a fateful one, is best summed up by quoting a few lines from Connolly's article in The Guardian on the release of Steve Buscemi's INTERVIEW (2007), a remake of Van Gogh's film of the same title from 2003 ${ }^{11}$ : 'Theo van Gogh was no one in America - until his murder made the director a cause célèbre. Now Hollywood is queueing up to remake his films. ... [T] he irony is by no means lost on [his] friends and colleagues that it is only because of his death that his films are being remade in America.' Moreover, his INTERVIEW, almost entirely shot within one room, was remade according to his 'doctrine' of the three-camera set-up, born out of necessity. Since one camera focused on each actor and another provided a master shot, single takes could be recorded that lasted as long as 20 minutes. ${ }^{12}$ To add irony to irony, his friends like Emile Fallaux and Doesjka van Hoogdalem guessed that even though Van Gogh had dearly wanted to make films in America, it probably would have been impossible for him to work in a country that is so staunchly politically correct, has very strict time schedules for crew imposed by the union, and, perhaps worst, 'has no sense of irony' (Fallaux, qtd. in Connolly). And thus the fateful irony 
entails that his films could only be produced in a 'land without irony' because he himself was no longer around. ${ }^{13}$

\section{THE HUMOUR OF HORROR: SINT}

When 06 was released in 1994, two complainants asked for a ban on the 'pornographic' poster of the film, made by photographer Erwin Olaf. It showed a naked woman, straddle-legged on a toilet pot with one hand on her vagina and another hand on a telephone horn. The Advertisement Code Commission judged that the poster contravened common decency, the more since it was visible on billboards near the public highway. The controversy surrounding the placard for 06 paled in comparison to the brouhaha about the poster for the film SINT (Dick Maas, 2010). Hundreds of agitated parents, among them filmmaker Johan Nijenhuis, lodged a complaint addressed to the Advertisement Code Commission, even before the poster was hanging in the street. The advertisement would have attracted no attention at all, if not for the fact that, of all people, Saint Nicholas was depicted as the Grim Reaper. In dark silhouette and on a hollow horse, but nonetheless clearly recognizable because of his mitre and his staff. Being confronted with a zombie version of a figure known as a friend to children, disturbed the rose-tinted idyll of the festivities and could be traumatic for young kids, according to the accusers. Despite a lawsuit and an appeal process mounted by Nijenhuis, it was decided that the poster was not damaging to morals. To make matters even worse for him, the poster won the TV Krant Filmposter Award, an Audience Award for best poster of the year. Maas himself was delighted by all the discussion, betting that it would benefit the box-office sales favourably.

Whereas the film poster gave the impression of horror, SINT definitely is a mixture of horror and comedy. This should not surprise us, since humour seems part and parcel of Maas' signature. His best-known attempt at horror, DE LIFT [GoIN' UP] (1983), later remade less successfully in America as DowN (2001), is suspenseful but at the same time it is not short of comic moments. Most of these moments are red herrings, attempts to fool the viewer via editing. In a restaurant named Icarus, pun intended, ${ }^{14}$ situated on the upper floor of a huge building, we get a close-up of a wide open mouth at the start of DE LIFT. It seems a terrifying scream at first, but when the camera zooms out it turns that one of the guests has burst out in roaring laughter. In a later scene when four guests have fainted in the elevator, we get a reverse shot in low-angle from some personnel in the building staring in a state of shock. The next shot is not an eyeline match, but shows an ambulance with sirens. Then suddenly the ambulance is halted by a shoe: it turns out it is only a child's toy 
and when the camera tilts up, the main protagonist is introduced to whom the shoe belongs. At one point a hilarious visual analogy is created when a night guard is stuck with his head between the doors of the elevator. After the question by his not so bright colleague whether he should get some 'green soap,' the guard's head is cut off. We then get an immediate transition to a close-up of a cigar whose top part is being chopped off. When the camera zooms out the police inspector who will investigate the case is introduced.

For a number of viewers the scene with the guard's cut-off head is the most humorous fragment. Many aficionados of horror hold the rule that the more a film (scene) scares the shit out of people, the better and the funnier. For those spectators, the scene in Maas' subsequent horror (or rather slasher) film, AMSTERDAMNED (1988) which will be met with delight is perhaps the one with the dead woman hanging upside down from a bridge, whose body slides over the glass roof of a tourist boat on the canals. The scenery causes huge 196 | uproar among the unsuspecting passengers, the more since the body leaves a trail of blood on the glass and eventually ends as a dreadful spectacle inside the boat. ${ }^{15}$ From this stance, good horror is already humorous, albeit with a caveat. Good in this context does not concern the psychological suspenseful variant, for that too subtly uses sounds and off-screen space as sources for eerie events. Symptomatic of this is the user review on IMDb by Quentin Zwerenzino of ZWART WATER [TwO EYES STARING] (Elbert van Strien, 2010): the movie's 'biggest flaw' is that it starts really creepy, but then, halfway, the horror develops into 'some sort of drama.' In other words, ZWART WATER is in fact too sophisticated a film and it fails to explore its potential for grossness. More or less the same can be said about DE POEL [The POND] (Chris W. Mitchell, 2014), which Jan Pieter Ekker on cinema.nl describes as, more of a classical, psychological drama with a fraternal discord and a 'neat portion of rancidity' than scary horror. Good horror is considered (comically) delightful when it has some gory special effects - spelled 'SFX' in the jargon of the film buff. The gritty SL8N8 [SLAUGHTER Night] (Frank van Geloven and Edwin Visser, 2006) is not a great movie, a user on IMDb says, but he recommends the film nonetheless because 'gore hounds and horror freaks will have fun.' Some will prefer it when a film really becomes gross, although the risk is that if a movie is too obviously made to shock, it becomes interpreted as just a 'sick joke.' Significantly, one user on IMDb describes THE Human CENTIPEDE (First SEQUENCE) (Tom Six, 2009) not as a gruesome, mad scientist horror, but, how fitting, as a 'misguided comedy.'

Upon making The Human Centipede II (Full Sequence) (2011), which supersedes the 'first sequence' in grossness, the Alkmaar-born director Tom Six remarked that it is 'like I made a comedy and they take out all the good jokes.' On the one hand, the quote suggests the proximity between horror 
and humour, as effect: creating SFX that make the viewer scream, shiver, or nauseate is 'fun,' like watching them can provide comic pleasure - especially because one knows that other viewers will be nauseated or shocked by them. On the other hand, the quote also implies that horror and comedy, as a genre, almost seem antithetical: good jokes and comic relief risk spoiling the terrifying effects. The matching of horror and comedy requires a delicate equilibrium to prevent being characterized as just 'weird': if the filmmaker is too heavy with the comedy, he might be too light with the horror, and vice versa. ${ }^{16}$ ZoMBIBI (Erwin van den Elshof and Martijn Smits) consists of a series of comic-strip violence, with giant guns and a lot of death-stabbing. One character cannot use guns, because his fingers are stuck in bowling balls, which also turn out to be very effective weapons against the zombies. Moreover, the scene with the Barachi brothers is shot like a video game, with terms like 'final round, 'rip-off,' 'jawbreaker' in big letters over the screen. ZOMBIBI is too cartoonish to be a shocker, and opinion is divided whether it is funny at all.

Maas' SINT is not so much a horror-comedy, but a horror film within an overall comic frame, which is a consequence of using the legend of Saint Nicholas as a backbone. In telling about a 'good holy man' who delivers presents on his birthday, young children in the Netherlands are turned into naive believers, until the age of nine. By exploiting this tradition, SINT commits both a comic and an ironic reversal, I will claim. Instead of a light-hearted mock of a ritual which offers a backbone to several storylines, as in MAKKERS STAAKT UW WILD GERAAS and ALLES IS LIEFDE in chapter 3, Maas rewrites the legend of Saint Nicholas to create a shocker. In Maas' horror film, the saint is a living dead creature who returns to Holland according to a specific schedule. Each and every year when there is a full moon on 5 December he and his Black Petes randomly wreak havoc among Dutch citizens, adults and children alike. He did so in 1492, as is shown in the prologue of the film. He also did in 1968 when Goert Hoekstra sees the dark shadow of the horse-riding saint on a rooftop before he discovers that his father, mother and siblings have been massacred. He later joined the police force because he considers it his duty to warn the citizens for the upcoming disaster in 2010 when it will be full moon again on 5 December.

Maas uses all the devices which have become a trademark for horror pictures: things or characters which suddenly pop up from off-screen, punctuated by heavy sounds; fast tracking shots; the juxtaposition of idyllic moments (such as kids singing Saint Nicholas songs) and gruesome suggestions (blood spatters on the television screen). At the heart of his film, however, is the discrepancy between the common convention of Saint Nicholas as the 'good holy man' and his actual nature as the 'bad holy man.' The discrepancy between the benevolent fantasy and the little known existence of a murderous bish- 
op is used to comic ends, as when Goert calls himself one of the few people who really believe in Saint Nicholas, or 'Niklas' as his name is spelled in the policeman's report. Against this background, the comic reversal of SINT can be described as: whereas in real life those who believe are considered innocent and naive, in the film, those who do not believe, are likely to be duped. It is perhaps no coincidence that the very first victim of Niklas in the film is Sophie, a teenager who refuses to celebrate 5 December because she disdains the festivities as a commercial excess of the welfare society. ${ }^{17}$ The fact that she is a victim can be termed a streak of irony, because in Maas' film the tradition of Sinterklaas, as we know it in Holland, is put to ridicule and de-sanctified. Hence, the ironic reversal runs like this: since SINT is a travesty of the yearly celebration, the film presents itself from the vantage point of a viewer who is an unbeliever, but in the film, those characters become victims who are as incredulous as the average film spectator.

$198 \mid$

Films which are made to provoke - and thus pretend to take a vanguard position - can become hopelessly obsolete in the course of time. This change in status from a bold enterprise to an outdated impression has been treated as a source for humour in this chapter. The films with an anti-bourgeois sensibility like the Pim and Wim productions or Curiël's CHA CHA have become marginal oddities, if not anachronistic relics that produce a smile once we realize their 'original' ambitions. TURKS FRUIT is the notable exception, for this film is still considered as a Dutch milestone, but this probably has to do with an unprecedented vivacity of Verhoeven's box-office hit. It is to the credit of director of photography Jan de Bont that he convinced Verhoeven to shoot with mobile and 'gritty' camerawork, in the vein of William Friedkin's THE FRENCH CONNECTION (1971)..$^{18}$

The career of Van Gogh is criss-crossed with a number of ironies, of which the most relevant here is that he tended to shout down himself when trying too hard to be provocative, whilst his simply structured films turned out to be much more effective in being acknowledged as the rebellious jester of Dutch cinema. The fundamental irony of Maas' horror-comedy SINT, on the contrary, was that there were huge protests against the poster by parents of believing children, whereas in the film itself, only non-believers become the victim of the saint's dreadful campaign. The only strategy for survival in the film is to take the existence of a horror saint seriously, which is ironic for the film is targeted at a $16+$ audience of sceptics. 

T.

(1)

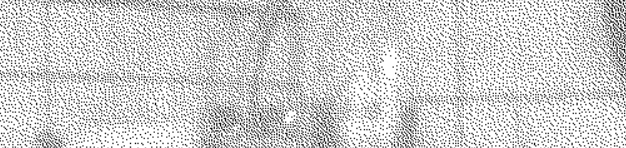

(1)
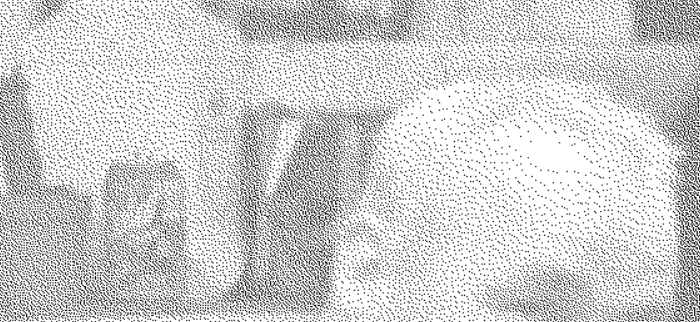

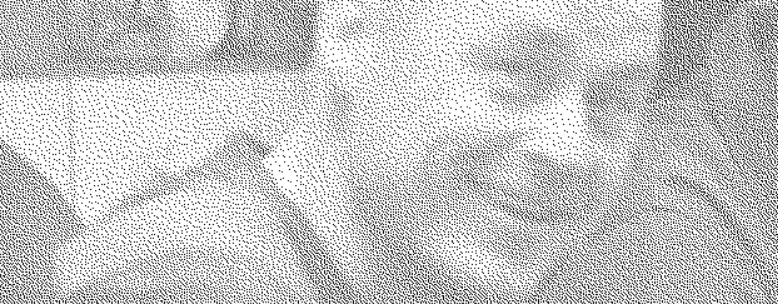

\begin{tabular}{l}
\hline \\
\hline
\end{tabular}

(1)

(2) 312

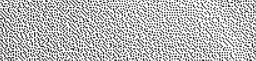

P

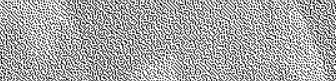

2.

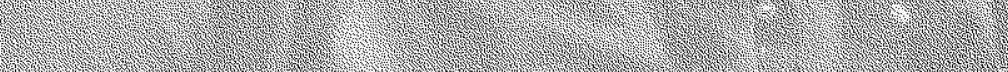

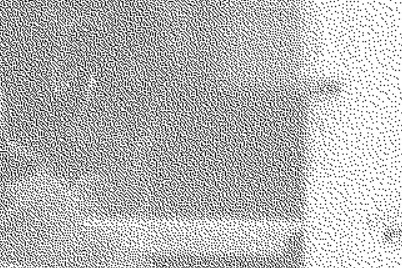

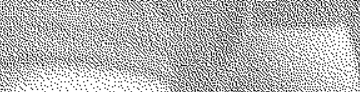

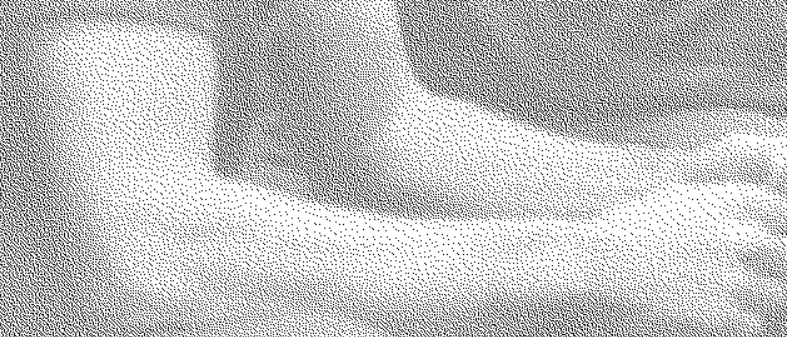

P

?. 


\section{Homosocial Jokes}

In a memorable scene from The LAST PiCTURE SHOw (Peter Bogdanovich, 1971), set in a small Texan town in the early 1950s, the teenager, Duane Jackson, is about to have sex for the very first time with his girlfriend, Jacy Farrow, in a shady local motel. She encourages him to undress quickly, because she is excited about losing her virginity. Lying naked on the bed, she closes her eyes while he mounts her. The camera shows his face in close-up, but his look is puzzled. 'I don't know what's wrong,' he mutters. 'How can anything be wrong? Just go on and do it,' she says and once again closes her eyes. To his repetitive phrase 'I don't know what happened,' she has some denigrating retorts like: 'Put your clothes on. You think I want to look at you naked?' And Jacy ends on a dramatic note: 'I knew you couldn't do it. I'll always be a virgin! What do we tell everybody? The whole class knows.' When Duane is dressed and once again says: 'I don't know what happened,' she stops him from leaving: 'Don't go out there! We haven't had time to do it. I don't want anyone to know. You'd better not tell one soul. You just pretend it was wonderful!' As Duane leaves, the camera shows a car with two girls in it and pans to the right. A close-up of Duane with a happy smile on his face, looking in the direction of the car. A next shot is also a pan, and brings the car of his best friend, Sonny Crawford, in view, who opens the door. Then the two girls enter the motel room, and ask in an excited way what it was like. Jacy sits on the bed with a dreamy expression and talks slowly, with a faint smile: 'I just can't describe it. I just can't describe it in words.'

In a scene from SPETTERS (Paul Verhoeven, 1980), reminiscent of this one from the American film THE LAST PICTURE SHOw, the two friends Hans and Eef have taken two girls whom they have just met to a construction site at night. They enter one of the partly built apartments, and each chooses a separate room. One girl, Truus, is undressing herself, but Eef does not get 
aroused, because, as he says, he has been drinking too much. The camera pans to the right and while Hans is about to penetrate the other girl Annette, she finds out that she has started her period. He checks it out, and indeed, his two fingers are covered in blood. Back to Eef who is trying the missionary position, but fails. She attempts to excite him with her hand, but then sighs that her arm is getting tired, while his penis still looks like a shrimp. Then they hear moaning sounds from the adjacent room, and she says she will not embarrass herself in front of her girlfriend, who will know they did not have sex. Eef answers that they just have to pretend and advises her to wheeze, just like they do in TuRKs FruIT. And so they do, gradually increasing the volume. Then the camera pans to the right once again and shows Hans and his girlfriend almost fully dressed, imitating sounds that suggest sex. Hans commands her to make louder noise, and since she does not do so to his satisfaction, he bites her in her arm. She screams and slaps him in the face, which leads to a yell on his part. He immediately calls to his buddy, Eef, to check whether he is ready to leave: 'I only need to remove a spot.' The two guys walk away from the girls, and Eef says upon leaving, 'Not bad, right?' to which Hans retorts: 'Well, I got her hard.' Then the two girlfriends meet one another, and the scene concludes with one of them saying: 'Great, right?'

Both scenes comically undermine the idea that the goal of love-making is to experience private pleasure. They merely fake the enjoyment of sex in order to impress their (male and female) friends, albeit there is a difference in response qua gender and historical period. Set in the 1950s, Jacy in THE LAST PICTURE SHOw is yearning after sexual knowledge, and her two girlfriends want to hear about her experience in order to gain knowledge as well. Duane first walks past their car with an attitude which radiates that thanks to him she 'knows.' The fact that he is pretending to have achieved a successful performance seems more aimed at them than at his buddy, Sonny. There is no need for Duane to show himself off as a true hunk to Sonny, since he already dates Jacy, the most gorgeous girl in town. It would only hurt his pal, as is confirmed later when Sonny starts dating Jacy in Duane's absence.

By contrast, in SPETTERs, the two girls Truus and Annette are not interested in gaining knowledge. They are simply flirtatious - it is clear they have done this before and just want to have some fun. For Jacy, it was experienced as sheer drama that Duane could not perform, but Truus takes Eef's failed performance light-heartedly, illustrated by the joke about the shrimp-like shape of his penis. If there is something at stake for anyone, then it is for the boys. Both Eef and Hans encourage the girls to fake and to pump up the volume of their panting. The sighs and moans are clearly staged for the ears of the beholder, so that they can boast upon leaving the girls behind that they 'got them hard.' This scene humorously suggests that a (hetero) 
sexual encounter is not just between a boy and a girl, but that a male friend is a required third, who can bear witness to his buddy's masculinity. It illustrates that male bonding is characterized by an oscillation between competition and friendship, rather than by the exclusion of the one by the other. Such inter-male relations can be cherished to such an extent that they are privileged over heterosexual love affairs, and as the scene from SPETTERS illustrates, this can lead to comic effects, showing that masculinity often stands on feet of clay.

\section{IRONIC DISTANCE: SPETTERS}

Like Blue Movie, discussed in the previous chapter, SpeTters can only be considered by taking its reception history into account. And once again, the reception history increases the pleasure of watching the film. Being a most versatile director in the 1970 and a guarantee for box office success, Verhoeven was both surprised and frustrated that he met only resistance with this project. To start with, the Productiefonds voor de Nederlandse Film refused to give him money for SPETTERS, because its members considered the screenplay shallow and commercial. ${ }^{1}$ Ultimately, the Productiefonds gave a subsidy after the original screenplay had been rewritten into a bowdlerized version. During shooting, however, Verhoeven worked with the first draft, the rejected one, which, of course, angered the Productiefonds. When SPETTERs reached the screen, the film got a hostile reception from the press: after the suspenseful World War II film SOLDAAT VAN ORANJE (1977), the majority of the critics felt that a film about some adolescents on motorbikes was a waste of Verhoeven's talent. On top of that, the film raised an unprecedented degree of protest as shown by the founding of Nederlandse Anti Spetters Actie (NASA) to fight the 'disgusting' and stereotypical representations of women and homosexuals in the film.

Feminists were particularly angered with the portrayal of Fientje, a young woman who runs a travelling fish-and-chips stand with her brother, Jaap. ${ }^{2}$ When a policeman tells them they need a permit for parking their stand in the built-up area, she asks him in for 'a cup of coffee,' which of course is a euphemism for sex, and which of course settles the problem. Because of her alacrity Fientje can turn on all the young men in town. She is after the one whom she thinks can offer her a better future than working herself to the bone making fish and chips. Or as she tells her brother: 'I do not know what love is. I am searching for a bit of security, then love will come itself.' Leaving in the middle whether her assessment skills are limited or whether, as

she herself believes, she has bad luck all the time, each and every boyfriend 
has a drawback. Since the boys follow one another in quick succession, one jealous girl, who has lost her own partner to Fientje, describes the snack-bar girl as a 'cashbox with a cunt.' Though Fientje has made some economic improvements (for in the end she exchanges the stand for a shop in a fixed location), she offered, as reviews emphasized, a pretty bleak prospect for young women, as if the only way to improve one's situation was to offer sex in exchange for the necessary help or resources.

Even more prominent as a target of critique were the outbursts of homophobic violence in SPETTERs. The three male friends, Eef, Hans and Rien, step out of their car in the company of three girls to chase after a man who is walking with his boyfriend. While they call him a 'dirty ass-fucker who has to keep his hands off little boys,' they stain lipstick on his face, to give him a 'great mouth for a blow job.' Later in the movie, Eef makes a habit of following men to underground places and after the sexual act, he either blackmails

204 the client or robs the male prostitute. At one point he is being chased by a group of gay men, who pull down his trousers and rape him anally. Among them is Jaap, whom we have seen reading a bodybuilder's magazine in an earlier scene while Fientje was offering the policeman a 'cup of coffee.' The men leave Eef behind, but Jaap returns saying that they did it just for fun since they considered him a gorgeous guy. Since Eef is also seeing Fientje, he adds to this: 'Don't mess with my sister. She is too good for a queer. You have to be honest with yourself.' In a subsequent scene Eef goes to his pious father, and confesses to him he is a queer, a sissy, a faggot, but since these terms do not mean anything to his father, Eef cites Leviticus 20, verse 13: 'If a man also lie with mankind, as he lieth with a woman, both of them have committed an abomination.' The furious father thereupon tries to put into practice what is foretold in the Bible: their blood shall be upon them.

According to a NASA pamphlet which was distributed to paying viewers at the cinema, SPETTERS gave rise to the beating and mistreatment of homosexuals as a pastime. Verhoeven defended his pre-FLODDER film that it merely offered a portrayal of rural male teenagers, a seriously neglected group in Dutch cinema, which according to him, has the habit of privileging elitist social circles. He only had in mind to give a 'realistic' representation and in his eyes, this happens to include the homosexual panic that has stricken such rural fellows. In reply the pamphlet mentions that Verhoeven's reality is 'in all respects negative.' Moreover, the director is accused of being driven by 'pure egotism (only his own success is leading).'

The words of NASA's pamphlet left little to be desired in terms of clarity. SPETTERs was a deleterious product and had better be banned from screens. The press was also quite unanimous in its verdict, summed up in the judgement that the film offered no more than 'indecent amusement.' 
Verhoeven's film was not an isolated case, however. In 1979, the year preceding the release of SPETTERS, vehement protests had already been charged at films with so-called emancipatory objectives. Both EEN VROUW ALS EvA [A WOMAN LiKe Eve] (Nouchka van Brakel, 1979) and TwEe VRouwen [TwiCE A WOMAN] (George Sluizer, 1979) were about a lesbian relationship, but they were criticized by feminists for not being radical enough. It had been unacceptable for them that Eva was played by Monique van de Ven, who was not a lesbian herself. No, Van de Ven riposted, that is right, but as she said with a streak of irony, in TURKS FRUIT, she had played a woman with cancer while she did not suffer from the illness herself. Further, the avant-garde filmmaker Frans Zwartjes was vilified for his low-budget Pentimento (1979), because its violent images of humiliation were not interpreted as a reflection upon the repression of women, but simply as a misogynist encouragement to sustain the power structure. ${ }^{3}$ These protests, however, paled in comparison with the wave of revulsion SPETTERS met. The uproar is a clear token of the politicized climate in the late 1970s, which left hardly any space for nuanced positions, let alone for touches of irony.

This sketch of the protests is not meant to argue that irony was non-existent in films in the 1970 os and early 1980 s, but my point is that it was hardly appreciated as such, as the poor fate of Adriaan Ditvoorst's DE MANTEL DER LIEFDE [THE CLOAK OF CHARITY] (1978), described in chapter 9, will also illustrate. If irony is not appreciated or acknowledged, it falls flat. Today, the reverse seems the case. Irony is attributed even when it is unlikely that it was intended. A film can be so poorly executed with technical failures and terrible performances that viewers may, as a rebound effect, start to enjoy it as a great work of alienation. Bad taste is then ironically converted into an unorthodox play on conventional devices. This happened with INTENSIVE CARE, discussed in chapter 4 , as one of the 'highlights' in DE NACHT VAN DE WANSMAAK. SPETTERS belongs to a different category, because it became a cause for huge disputes due to its 'immoral' purport. Nowadays, Verhoeven's film has a different status, which is already proven by the mere fact that Film Institute EYE restored SPETTERS in 2012 as an acknowledgement of its film-historical value.

Today's reception of the film is marked by an ironic distance for two reasons. First, we have seen other representations of contemporary (youth) culture since 1980, which were at least as cynical and pessimistic, like CrUISING (William Friedkin, 1980), NAKED (Mike Leigh, 1993), AMERICAN HISTORY X (Tony Scott, 1998), IrRÉversible (Gaspar Noé, 2002), or the Belgian Ex DRUMMER (Koen Mortier, 2007). A film which originally is considered as too gross loses its sharp edges, once other films supersede it in brutal directness. Writing on occasion of the re-release of SPETTERS in 2012, critic Gawie 
Keyser noted that the protests at the presumed vulgarity had hidden from his sight that the film is actually very bleak: the 'moral chaos' of the characters is embedded in a sour sense of unease, for the most talented guy on a motorbike ultimately commits suicide and the boy who comes out of the closet is abandoned by his father. Because of all the fuss back in 1980, Keyser was, more than 30 years later, not really prepared to be confronted with such gloomy and dark undertones. Against such a backdrop, the vehement protests against SPETTERs become, in retrospect, quite hysterical, which is an important reason to give Verhoeven's film a belated benefit of the doubt. This can be summed up in the stance of 'SPETTERs is not as morally bad as I thought it had been.' Such an attitude is a crucial condition under which to reconsider the film, including the whole brouhaha, from an ironic distance. A proviso has to be made, nonetheless. This distance can give rise to comic amusement: Ha, look at those sensitive souls in 1980; what was too 206 | hot to handle for 'them' is acceptable for 'us' right now. This amusement would tie in with the superiority theory and risks giving present-day viewers the faulty idea that they are more tolerant than the NASA protesters in 1980. At the same time, this historical gap can be a sign of regret about what has been lost: look at those people, they still knew what political engagement was about.

Second, SPETTERs partly owes its present-day ironic celebration to Verhoeven's successful period in America, which has affected, with hindsight, the reception of his Dutch films. After his first international film FLESH + BLOOD (1985) was recorded in Spain, he went on to direct in Hollywood, making RoboCop (1987), Total ReCALl (1990), BASIC InStinCt (1992), SHOWGirls (1995), StARSHIP TroOpERS (1997), and Hollow MAN (2000). In an article, written as a 'fanboy,' the British film scholar I.Q. Hunter claims that a number of critics dislike Verhoeven's work, because he 'frolics among the clichés of Hollywood blockbusters.' It is easy to disqualify SHOwgIRLS (1995) for its cheap sensationalism and STARSHIP TROOPERs (1997) for its noisy militarism. Yes, Hunter contends, these critics are right for Verhoeven's cinema is 'flash-trash,' and no, they are not right, for his cinema is also a mimicry of 'flash-trash.' On closer look, Verhoeven's work excels in double coding, and because so many reviewers misread him as a bombastic filmmaker, it offers Hunter extra pleasure to recognize him as an ambivalent director who voices his critique in a style that seems a copycat of the type of cinema he criticizes. If SHOWGIRLS is a sarcastic comment upon the commodification of sex in Hollywood, then this is presented to us via "quantities of choreographed flesh' and obscene dialogue (475). The key is that Hunter does not reproach Verhoeven for inconsistency, but that he considers his approach as hyperbolic, as over-the-top. In comparison to a 'bad' exploita- 
tion movie, SHOWGIRLS is better at being 'bad.' In beating the 'bad' film on its own terms, Verhoeven's film is a vehicle for Hunter's 'own (European?) ambivalence towards disreputable material which I both love and am culturally obliged to rise above' (479).

In my own Film Narratology, I wrote that STARSHIP TROOPERS has been criticized for its featherweight protagonists. That argument was reason enough to discard the film in its entirety: empty characters means empty film. The fact that the characters appear to be nitwits is consistent, however, for their cartoonish representation legitimizes that we read STARSHIP TROOPERS as a satire of American foreign policy and its 'silly' propaganda. In short, if we take Verhoeven's film seriously, it is a nasty picture with hints of glorifying America. If we, however, read the adoption of fascist iconography as ironic, then we foreground the film's satiric impulses (Verstraten, 58-59).

If we consider Verhoeven's approach not as a repetition of clichéd codes but as an over-identification with them, then the spectator is inclined to read his previous work also from the angle of irony. And thus, the representation of the life of the youngsters in SPETTERS is deliberately exaggerated as to offer comic amusement. The over-the-top depiction of their preoccupations is then not seen as affirmative and conservative, but on the contrary, as 'too much' and slightly subversive.

It could be argued that such a 'boys among boys' atmosphere is already a bit overdone, which has to do with the intricacies of so-called homosocial bonding. As the already quoted scene of the fake orgasm from SPETTERs suggests, real experiences count less than bragging about experiences towards one's best friends. In her study Between Men, Eve Kosofsky Sedgwick has argued that male camaraderie oscillates between the twin poles of mutual affection and rivalry. It is constitutive of homosocial relations that there is a constant movement between the two. One way to treasure the friendship is to have a good laugh by making a girl or woman the butt of a joke. Eef is working as a motorcycle mechanic, and while his two best friends are around, a girl who seems big-breasted asks him to fix her moped. Eef thinks she makes a pass at him, and while he pretends to approach her he pulls tennis balls from under her shirt. Since he saw through her trick, all three guys can laugh at her. Eef tells his buddies that she is 'two peas on a shelf,' and he then yells after her to aggravate her humiliation: 'Take your big sister with you next time,' which implies that they are big boys themselves.

In the scene at the nightclub, however, one of the friends becomes the butt of a joke. Hans wants to pick up a black girl who is seated on a bar stool. After he has had eye contact with his friends to indicate that he has had suc- 
cess and even yells that this girl is easy to get off with, he puts his right hand between her legs, despite her warning not to do that. He then withdraws his hand, and discovers to his astonishment that his fingers are covered with mustard, which she used to ward off intrusive guys. Hans' two buddies do not feel pity for him, but of course greet this scene with great hilarity. One of them jokes: 'Now you know where Abraham gets the mustard,' which is a proverb to indicate that someone knows all the answers - but Hans apparently does not.

Hans wants to be on an equal footing with his buddies Eef and Rien, which is a crucial condition for 'mutual affection,' but he is underperforming most of the time. He wants to date a girl like they do, but he produces a misfire. He wants to be as great a motorcyclist as Rien, but he is not as talented as his friend. Moreover, his material is not as good as Rien's, which is driven home by one of the girls who refuses to sit on Hans' motorcycle, 208 for she guesses they will stand still in a minute. Hans' role as a klutz within the group of buddies is important, since he has similar aspirations as his friends, but his failures enable them to laugh at him. At the same time, this laughter is not meant to truly ridicule him, but to encourage him to try harder so that he might be as good as they are. In a group of friends, the theory of homosocial relations presumes, there is always some competition underneath: there is a leader of the pack, but his position is also potentially vacant. In principle, anyone among the buddies is entitled to this position, but foul play is not accepted, for that would ruin the friendship. So, a guy like Hans who plays by the rules, but to no avail, is seminal for determining the implicit hierarchy among friends.

Nonetheless, there is one crucial scene in which Hans is acknowledged as the winner, and once again it is a scene in which a girl is used as an object of exchange among the boys. All three fancy Fientje, and each of them believes that she will pick him. Since they cannot decide who can go after her, they agree to solve the matter by measuring the length of their penises: the one who has the largest prick is to 'have' Fien, which is 'fair' to her. This time, Hans deserves the admiration of his friends, but in practice, Fien chooses to date Rien first, because she thinks he has the most prosperous future ahead, Eef second, and Hans only last. Rien's accident ends his affair with Fien and it ruins his career as a professional motorcyclist, but, at least as important, it affects his implicit leadership within the group of buddies. Now, he suddenly finds himself in the position that seemed reserved for Hans, as the 'typical loser.' If people still treat him in a very friendly way, such as when a brass band celebrates his homecoming from hospital, they do so, he guesses, because they feel pity for him, a thought he cannot bear.

A certain dose of rivalry is wholesome to keep male camaraderie intact, 
according to the theory of homosocial bonding. This competitive element often manifests itself in caustic remarks towards each other in an altogether playful and humorous tone, like in 'Now you know where Abraham gets the mustard,' directed at Hans. A supplementary advantage of competition is that it prevents the friendship from becoming 'too friendly.' As soon as affection comes to overrule the urge for rivalry, the 'spectre' of male homosexual desires erupts. The basic problem with same-sex desires is that they threaten to disrupt the required oscillation of affection and rivalry. In the case of a man-loving-man, the intimacy of friendship can become too strong as a result of which competition, the twin-opposite of camaraderie, fades away. As a consequence, not all friends play by the same rules any more. For that very reason, male homosexuality has always been such an encumbered subject for soldiers. The army is an institution which derives its strength from a fixed hierarchy: every man is given a specific role and has to discharge this role absolutely seriously. A gay soldier may withdraw from this competition, if only because using women as an object of exchange does not work for him. Bragging about female conquests, as soldiers yearning for popularity might do, is suddenly a game without cards.

As Sedgwick has hypothesized, there is a sliding scale between social companionship and male homosexuality. This male continuum is far from continuous, however, for there is a slippage. Homosociality presupposes that men are prepared to serve each other's interests - at the expense of women usually - but on the condition that one is not 'interested in men' on an intimate or sexual level. There is a tendency among men to articulate a rupture within their friendly bonds in order to prevent them from becoming too friendly: you can be my best buddy, but there is no way that you can be my lover - a position Sedgwick labels as 'homosexual panic.' It seems to be mandatory within homosocial relations to mark a profound schism in order to ward off any suggestion of same-sex intimacies.

The guys in SPETTERS run after a gay man and when they catch up with him, they smear lipstick on his mouth against his will. Their response is a mixture of fascination ('great mouth for a blow job') and contempt ('this way we'll recognize you better, dirty faggot'). The latter statement gains extra weight within the context of 'homosexual panic.' The red lips function as a visible sign to distinguish him from them: the more he is recognizable as a gay man, the more they ensure their heterosexual identity. At the same time, as SPETTERS will spell out, the necessity to differentiate homosexuality from heterosexuality is usually stronger when a man is insecure about his identity, as if an aggressive act is required to convince oneself that one does not have homosexual affinities. The maltreatment of the gay man is completed by a blatant joke. In the presence of his friends and in a laughing atmos- 
phere Eef tells them: 'I would have liked to fuck him.' Within this context, this remark is interpreted by his friends as an inverted message. By saying ' $I$ would have liked to ...' Eef indicates the opposite within this context: it just articulates how much he does not want to fuck this guy, who they humiliated a minute ago. No one at this point, perhaps not even Eef, realizes that his statement should be taken more literally than anyone within the group does. In SPETTERs, it is thus suggested that gay-bashing can be a cover-up of a man's fascination with homosexuality; for Eef beating up homosexuals is a means to postpone that he has to come out of the closet.

In addition to the aggression as a particularly nasty and concrete effect of 'homosexual panic,' a more light-hearted but no less effective strategy to avert the threat of homosexuality is by way of humour. Preceding the scene when the three friends start measuring the length of their penises, they discuss the possibility of a threesome with Fientje. Eef has an immediate objec-

210 | tion to this proposal: 'Mine will not get erect when you are looking on.' ${ }^{4} \mathrm{We}$ have seen Eef fail to perform sexually in an earlier scene, but nonetheless he boasted about his qualities as a lover afterwards. In case such an embarrassing situation might arise again, Eef already covers himself in advance: if I fail, it is not due to a lack in male potency, but because I get nervous when I am aware that you are watching (or directly involved as in a threesome). The remark can also be taken as a thorny remark that boys make to poke fun at each other, hinting at the 'ugliness' of Hans and Rien: you guys are so unattractive that your presence will deflate my penis; even a beautiful woman will not be able to compensate for your disenchanting impact. Such a remark is not meant to offend the tight companionship, on the contrary, it is an example of homophobic irony that strengthens male camaraderie, and can be paraphrased as: 'I like you as my friends, but I am so very nonhomosexual that even the presence of my very best buddies will rob me of any sexual excitement.' It is symptomatic that Eef will start to realize and to explore his desires for other men, after the friendship with Hans and Rien has practically dissolved, so that it will not become a dodgy subject as it is in All StARs (Jean van de Velde, 1997).

\section{HOMOSEXUAL PANIC AS BALONEY: ALL STARS}

Each and every week Bram tries to make sure that his football teammates from Swift Boys show up for the weekly match on Sunday morning. In the beginning of ALL STARs, he calls them on his way back from China. Everyone asks him whether he knows at what time he is calling, whereupon Bram calmly replies: 'Almost half past two at night, but that is about the only moment that each of 
you is at home and still awake.' (As the film was shot in 1997, Bram is the only one who has a mobile phone.) This comic retort rightly suggests that the players do not have a professional mentality, to put it mildly. They are already a team since they were seven, except for Peter who joined them a year later, which matter-of-factly makes him the outsider within the group. In a voice-over Bram explains that the actual result is secondary to the experience of being part of a team: 'Lying on the wet grass with an injury while your friends keep up the honour of the team, is the highest conceivable form of happiness. ${ }^{5}$

This voice-over text rightly suggests that male bonding is at the heart of Van de Velde's film, including a series of stereotypical notions about women. One running gag is that a woman is a creature who will never understand offside, no matter how clear the explanation offered. ${ }^{6}$ At the same time, women can be an obstacle to the joyful gathering on the football field, demanding that the men spend time with them. Goalkeeper Willem has a strict wife who reminds him of his fatherly duties regularly so that he is not allowed to watch sport on television on Sunday evenings like all his friends do. When Hero tells Willem that he is lucky to have his own business, wife and kids - for the always hesitant Hero would be happy to have some stability in life -Willem responds: 'You are lucky. You study, have leisure time, are single, have rich parents.' Hero, a philosophy student, sums it up in an aphorism: 'Wind behind you is wind in front of you if you want to go in the other direction.'

Since everyone is getting busier and busier lately, they have to decide whether their upcoming match, which happens to be their $5 \mathrm{Oo}^{\text {th }}$ game together, will be their last one or not. For old time's sake, they will organize - which in practice means that Bram will organize - a training's camp like they used to have in the past. During the camp they meet three women from a speed ice skating team. Of all people, Mark ends up with one of the girls. He is about to get married to the pregnant Roos, but he had to win back her trust after he had cheated on her. This time he is making the same 'mistake,' and his teammates know about it very soon, because the woman is yelling ecstatically in the car where he is having sex with her. To prevent detection, Mark had to put his hand in her mouth to muffle the noise she was making, but to no avail - she bites in his hand. We then get a shot from inside the car: three laughing faces of his friends peep through a rainy window. On the one hand, they are smiling because they have caught Mark in the act, and this explains that we see a closeup of an annoyed Mark in reverse shot. On the other hand, their laughter turns Mark's 'mistake' into a 'triumph,' suggesting they envy him for his conquest. Not everyone thinks so, however. Johnny gets mad because Mark apparently does not understand that at this phase in his life dating other women is a sign of immature behaviour: 'Asshole, you are about to get married. You become a father. Do you know what that means?' 
The consequences seem severe for Mark, for soon the news is out that the marriage is off. Mark tells Bram that she kicked him out, 'even though I said to her that she is absolutely the only one whom I make love to when sport is broadcast on television.' Since Bram has been a close friend of Roos since childhood, Mark requests him to talk the break-up over with her. During dinner, Roos immediately guesses that the invitation was Mark's idea, which Bram denies. 'It does not matter,' she says, 'for it is over for good. And the worst thing, he is becoming a father and he has ... what, are you nodding?' A close-up of Bram: 'Committed adultery.' While Bram is describing the atmosphere of booze, fun, and the presence of ladies during the training's camp, Roos asks who he is talking about. Bram mentions the girl's name, and while Roos is close to tears, he asks: 'Who are you talking about?' 'The midwife.' When Mark enters the bar, hoping that Bram has convinced Roos, she starts kissing Bram on the mouth to scare him off.

212 This kiss is quite poignant, because we viewers already know by now why Bram is still single. It is not as Mark supposes, that is, that Bram is secretly in love with Roos, for during the training's camp one of the other girls wondered why Bram was not able to kiss her passionately. She tries to guess what might be wrong: Is he married? Am I too ugly? Until it suddenly dawns on her - he does not like girls. 'But your friends do they know ...?' And before she can mention the love that 'dare not speak its name,' Bram says: 'No, I could not tell them, for then I would have been lying to them all those years.' In one of the very few flashbacks in the film, in an overtly lit scene Bram discloses in voiceover a joyful memory. At a very young age, they were about to win a tournament but Bram missed a crucial penalty kick. All of the boys started consoling him, and then Bram reveals to us that he did not cry because of the missed penalty, but 'because they were so very kind to me, because all these various boys considered me worthy of their consolation. I cried because I was certain I would never be happier than that day in the dressing room.' A team sport like soccer is a homosocial event par excellence, because competition is at its core and it should be played in a manner that is sportsmanlike. Bram, however, is not so keen on winning the game, as a true sportsman is supposed to do, but, and this is an apt expression for his utter falsity, he experiences the mutual intimacies as more valuable. Physical contact in soccer is permitted for either the benefit of competition (such as touching someone to prevent him from scoring a goal) or to be a good sport (shaking hands after a foul play), but one is not supposed to derive pleasure from bodily contact. To make it clear that this thin line between touching someone as part of the game or for one's enjoyment, any term connoting 'homosexuality' is used as a pejorative or a curse word. If you are called a homosexual it means that you are unfit to be on the pitch, for then the rules of the game become secondary to one's fondness of 
bodily intimacies. Against this background, it always offers such a great relief to call the referee a 'blind homo,' which Johnny describes as his particular Sunday morning pleasure. And no one ever denies him this pleasure.

After two matches have been cancelled for various reasons, Willem announces to his wife for the third time that the upcoming game is not to be missed because it is their $\mathbf{5 0 0}^{\text {th }}$ one. 'You look like a bunch of women who've turned 40,' Willem's wife sneers at him. This time they have to play an away game against a physically tough team, called the Poldervogels, that is to say, if enough players from the Swift Boys show up. Johnny has to bring his seriously ill father, who happened to be their former coach, to the hospital; Hero is not in the mood since the woman he is in love with will become his stepmother. And goalkeeper Willem has not arrived yet. During the warming-up Mark gets furious at Bram, and we then see a series of point-of-view shots, from either Mark's perspective or Bram's. Mark gives Bram a push, and the latter defends himself by saying: 'I have not slept with Roos.' Mark: 'So, you kiss, but do not fuck,' and he then pushes him onto the grass. Thereupon the captain of the Poldervogels gives him an elbow: 'But he is a homo. Take a good look. Don't you see. He is a homo.' At that moment Willem arrives, yelling from afar: 'Is it alright for me to get dressed?' The players from the Poldervogels shout in unison: 'But we don't play against homos.' Willem: 'Get lost, you're a bunch of homos.' In slow motion they start running towards Willem, while we hear threatening music on the soundtrack. In one of the subsequent scenes we see that Willem has a great number of bruises.

Mark's response to Bram coming out of the closet is two-faced. On the one hand, he asks Bram why did he not tell them before, for 'We don't live in a backward country.' All the homophobic phrases in the cloakroom are no more than baloney, he reassures Bram. On the other hand, when Bram confesses to him that in fact Mark himself is his 'big love,' the latter is all of a sudden less obliging, and even threatens to hit him in the face. Bram is angry and in a later scene Mark visits him, in the company of Roos, to make up with him. The verbal confrontation between the two guys is completely couched in terms of a soccer match: I stick to your heels; you lose against an agile forward; your defence has a gap; I make a step forward and you are offside. When Roos then intervenes that she is puzzled by this talk, Bram and Mark then start explaining offside to her, but as the movie has made evident so far, that is to no avail. Ultimately, witnessed by Roos, Mark kisses Bram on the mouth and says: 'This is the way to solve it. Queers among one another.'

It would be too optimistic to consider this kiss as a sign that Mark's 'homosexual panic' is cured. First, the kiss is a gesture of opportunism, because he wants Bram to organize the $5 \mathbf{0 0}^{\text {th }}$ game, this time for real. Second, homosexuality will remain a vehicle of humorous disdain throughout, albeit differently, 
as is clear from Willem's peculiar logic: 'Bram is not gay, not really I mean. Homosexuals always are feminine-like. And what is characteristic of females? They do not know what offside is, and moreover, it is pointless to explain it to them. Well, Bram knows what offside is.' This quote illustrates that a hackneyed idea of male homosexuality is activated so that their very own team mate can be exempted from it. This seems not so much meant to spare Bram, but to reassure their own state of mind: one of our mates is gay, well almost, but not quite, and therefore we keep on using homophobic irony as a structuring principle in our cloakroom.7 Eddy Terstall's SIMON (2004) goes one step beyond, for in this film homophobic irony becomes the paradoxical foundation of a dear companionship between two seemingly unlikely male characters.

\section{BONDING BETWEEN A GAY YUPPIE AND A HE-MAN: SIMON}

In the beginning of SIMON, the picture with the highest IMDb score (8.0) of all Dutch films, Camiel is almost overrun by a SUV. Irritated by the wild manoeuvre, he is about to obtain redress. The driver who seems an obnoxious macho upon first impression, gets out of his car and says straight away: 'Just lost ten points. Queers count double.' Camiel can take the insult, because it is clear that the two are acquainted, but have not seen each other for quite a while. Simon informs: 'You're still with us?' Camiel: 'Yes, you too?' Simon's reply is blunt: 'Barely. I have cancer. That's life.' Camiel introduces Simon to Bram, his partner, 'in the private sense.' Simon: 'I am Camiel's ex-partner. In business. So don't get any ideas.'

Two minutes into the film we go back from October 2002 to June 3, 1988, the day Simon 'entered my life with a bang,' Camiel recounts in voice-over, but actually he is telling the story later that October day to Bram who has just met Simon for the very first time. What happened in the afternoon was almost a repetition of what had happened 14 years ago. This time an accident was only just prevented, but in 1988, Camiel was actually hit by a car, driven by Simon, who brings him as quickly as possible to hospital. Camiel can only think: 'Anyone who drives this fast must be crazy.' When they return from hospital, Simon tells him that he fancied the nurse, a 'straight-up horny blonde.' Camiel then reveals without any hesitation that he is not interested in her, because he is gay. 'Better you than me, buddy,' Simon replies.

The two will meet regularly, because Camiel will buy his supply of weed at Simon's place. They are worlds apart, but become close friends nonetheless. Camiel himself is a decent student in dentistry whereas Simon, of Jewish descent, is the proverbial 'rough diamond,' who fully believes that life is discovered through play. Though he is a dealer in soft drugs, he also claims 
unemployment benefits, according to the peculiar logic that if 'I wasn't on the dole, they would question my income and I would be screwed.' At the same time, he also gives some of his average wage to animal organizations. Calling someone 'whacko' or 'nutjob,' Camiel explains in voice-over (but diegetically to Bram), means in Simon's vocabulary 'I like you.' When a policeman gives him a ticket, he asks him: 'Aren't you in the Village People? Where are the Indian and the Leather Boy?' Simon also has regular fights with 'that ugly albino' and 'that Bogus Brother,' whom he also calls 'Sjors and Sjimmie,' two characters from a Dutch comic strip. ${ }^{8}$ His reason for disliking this couple is his assumption that 'Sjors and Sjimmie' desire his girl, Sharon. Simon considers them rivals for he is paranoid that Sharon is sleeping around with other men. His main reason for accepting Camiel as a friend is that he can be quite sure that a 'guacamole fag' will not vie for Sharon. In turn, Camiel confesses that he had become 'addicted to Simon's weird world; I put up with his political incorrectness and comments about my gayness.' When Camiel asks whether Simon's parrot is a boy or a girl, Simon answers: 'Funny you ask, for he asked the same about you,' a remark that plays upon the stereotype of the male homosexual as feminized. ${ }^{9}$ Camiel has to take into the bargain that Simon makes a series of jokes but he understands that Simon does not do so to humiliate him. On the contrary, the jokes are a constant reminder that they are so utterly different. That is to say, they are so different that the option of an aggressive rivalry is irrelevant. This absent option is the basis of their seemingly uncommon friendship. The unexpected happens, however. At one moment, when both Camiel and Sharon are 'as drunk as a Mekong monkey,' Sharon 'started her "I can't control myself" act.' Afterwards, when Camiel gets a grip on himself again, he considers himself a worthless friend and a worthless fag. The incident will result into an abrupt ending of their friendship, until they meet again after 14 years.

The scenario jumps back and forth in time, because several characters start telling what has happened over the years: Sharon recounts memories of Simon; Joy does so as well - she is Simon's daughter born in Thailand who came to Amsterdam with her younger brother after their mother died. Simon tells how Sharon became the girlfriend of 'Sjimmie,' of all people: 'At least she is politically correct: first a Jew, then gay, then a brother. Just a Turk and a dyke, and she will get the Nobel Prize.'

Let's first take this phrase literally: Simon calls Sharon politically correct because of her variety of lovers, in terms of ethnicity and sexuality. This is not meant as a recommendation, for Simon is very sore about this achievement, since his worst nightmare has come true. Hence, his prediction that she will get the Nobel Prize is to be taken ironically and meant to indicate how much she does not deserve such a prize. By sneering at her presumed politically cor- 
rectness Simon makes a politically incorrect remark. He will consider himself excused to make such a blunt joke, first, because she has hurt him in his pride as a He-Man. As a self-acclaimed macho, it was his privilege to sleep with other girls, while she was only privileged to be his 'prima donna.' Second, Simon shows himself a representative, in the aftermath of the Flodders, of a position which has become dominant in Dutch (political) culture, the more since the short-lived rise of Pim Fortuyn: if we really take the freedom of speech seriously, then I am permitted to say anything. In principle, everyone can become the target of comic scorn - policemen, gays, (ex) girlfriends, or, as cited in the Introduction, Gordon poking fun at a Chinese candidate in HoLland's GoT TALENT - so to treat others as equals, one precisely should not spare them. In short, being politically incorrect is from this perspective an emancipatory tool.

Simon may be a nephew of happy slacker Johnnie Flodder, but Terstall's 216 | film is not a rip-off of Maas' comedy - far from it. In many a film from chapter 1 , the humorous incidents are often quite cartoonish. In the world of the cartoon, characters always seem to have more than one life; the bodies of 'positive' heroes are practically indestructible. If they have a serious accident, they have only some minor bruises, like a black eye. After their house has exploded, the Flodder family cheerfully writes a postcard from their holiday address, as if nothing outrageous has happened. Simon, however, is confronted with an illness that devastates his body from within, and hence, his chutzpah is mixed with 'terms of endearment.' In between his chemo treatments, he still wants to keep up his spirit high by making jokes. When Camiel asks Simon to be best man - which in Dutch means 'witness' - at his wedding with Bram, he puns: 'Witness? Like "It was them, your honour, I saw them behind the bushes. Committing unnatural acts."' The joke covers up that he is 'touched' by the request (Sharon's interpretation), although he himself proposes to water down the term 'touched' to 'honoured.'

When Simon was still alive and kicking, his jokes on homosexuality were meant to articulate their mutual differences, as if to say: 'You are not like me, and therefore I do not have to fear you as a potential rival.' In the period of Simon's illness, his jokes function as a defence mechanism and are rather meant to keep his emotions at bay, for that may spoil his image of the He-Man he always was. The fact that this imago of machismo was not as solid as is the case with Johnnie Flodder probably contributed to the popularity of SIMON. When Simon receives his fatal injection, his friends are gathered at his bedside. It is followed by a close-up of Camiel, who then reminisces about the one moment that he had seen Simon scared. Working as a stuntman double on a Vietnam movie in 1988, he stood above a waterfall and had to jump into the water. Camiel had talked about this moment to Joy, Simon's daughter, but it 
had not been visualized to us. Simon is standing there in an army uniform and looks over his shoulder to Camiel. 'Kinda high, isn't it?' A transition to Camiel in the present, watching intensely off-screen, probably at Simon, at the verge of dying, and at the same time thinking back to this remarkable event. The final shot shows the object of Camiel's memory: we see Simon's jump in slow motion, but before he hits the water, the film has faded to black. How appropriate to end Simon like this, for, first, it accentuates that the figure of Simon is consistently focalized by other characters, Camiel in particular, and as I have argued in Film Narratology, at the level of focalization interpretation takes place: someone never just 'is' a 'real man' objectively, but someone is seen by others as a hero, a macho, a weakling, etc. Second, rather than being a natural-born daredevil, the ambiguous ending suggests that the title hero was very good at playing he was one. ${ }^{10}$

\section{DEAD MAN 'WALKING' AS A COMEDY: DE MARATHON}

On the poster for SIMON we see eight characters walk on the beach on Simon's very last day alive. Marco, one of his friends, is pushing an empty wheelchair, for Simon is still walking all by himself. ${ }^{11}$ On the poster for DE MARATHON (Diederick Koopal, 2012), there is also a wheelchair, but this time a man in sportswear is seated in it, with his head on his chest, while two of the four people, in the same sportswear, behind him hold his arms in the air. One has to see the movie in order to understand the quite morbid context of this poster.

The five male characters all work at the car service station Groteboer, owned by Gerard. He often plays a game of cards with three of his colleagues. Kees is under the thumb of his devout wife, but every time he vehemently contradicts this assumption, the others laugh. Nico lives all by himself since the recent death of his mother, but his answering machine still starts with: 'You've reached Mrs. Witteveld and Nico.' While a date leaves the message that she cannot make the appointment and is not sure whether he had counted on her, the camera pans across a copious takeaway meal. The most boisterous of them all is Leo, who does not want to face the fact that his young girlfriend Anita is working as a prostitute. ${ }^{12}$ Leo usually talks loudest, always having a wisecrack at his disposal. To his Egyptian colleague Youssoef he says while playing cards himself: 'Keep working. At your pace, the pyramids wouldn't have been finished yet,' or he calls him 'Tutankhamun.' Such remarks to which Youssoef shakes his head with a smile, is symptomatic of the atmosphere at work. The jokes Leo makes usually contain cultural prejudices, both positive and negative: he refers to a pharaoh from the rich ancient history of Egypt, but to Youssoef's presumed laziness as well. More important is the homosocial 
dimension of the jokes: it affirms the hierarchical order in the work place, which already was clear from the fact that Youssoef is excluded from playing cards.

All Leo's wisecracks are meant to keep everyone else in their places, to ensure him a fixed world view. His surroundings are structured according to stereotypes. When an attractive woman drives her car to the service station, she asks: 'All of a sudden a red light came on. I have no idea what it means,' Leo answers: 'Time to go to work?,' which is a hint that a woman's most important function is to offer sexual pleasure to men. When Kees advices him that banana liquor will keep his partly Cape Verdean stepson satisfied - 'for all blacks love bananas' - Leo indeed puts the crybaby's soother into Pisang Ambon. For types like Leo, ignorance is considered bliss. He tells the Muslim neighbours during the barbecue that the hot satay is 'halal pork,' which is a contradiction in terms.

218 Drinking beer is one favourite pastime for the workers and helps them to confirm their identity as regular guys without much ado, who, since they are Rotterdam-based adore Feyenoord and hate Ajax/Amsterdam, or in their phrasing '020,' so they do not have to pollute their mouths with 'dirty words.' When Gerard invites them for his birthday on Sunday, he says, coffee and cake at 11:00 am, beer at 11:30. At one point, when Leo is in the pit repairing a car, he looks intensely at the underside, while his right hand tries to grab something behind him: an aerosol, a screwdriver, a bolt perhaps, but when the camera pans slightly to the left, it reveals a bottle of beer. No need to add that any hint at homosexuality is taken as an insult. They collect 50 euros to send Nico to a prostitute, but he declines the offer until they suggest he might be gay. Judging from the sounds, the sex is intense, but in long shot we see that the prostitute is only massaging his calves.

The characters are shaken out of their habits after it has become known that Gerard is having financial problems. When Youssoef is reading Runner's World during a break, his colleagues think that the Muslim is coming out of the closet, for he apparently likes men's legs. Youssoef then tells them that he used to earn money running marathons, until an accident injured his foot. This sounds like a great way to cover the almost 40,00o euro deficit, but as Youssoef guesses, no one is prepared to sponsor 'four badly-wrapped mummies.' After some rejections, Youssoef might be able to arrange a meeting with his uncle, Hussein, who sells 'class vehicles.' Suddenly, Youssoef is treated like a prince: You want sugar in your coffee? You want a Twinkie? During the conversation they are surprised that Gerard puts his whole business at stake. He tells the uncle that they will receive 40,00o euro if all four of them reach the finish; if not, the service station is Hussein's.

During their first training we see them leave and in the very same take, 
without any editing, we already see them return, exhausted and one of them puking. They guess it must be the 'thin air': 'How high up is Rotterdam?' Youssoef explains they have to train their 'metabolism' and to 'watch their nutrition.' The greatest part of the film is dedicated to showing how this 'mission impossible' requires that their mentality be changed. Youssoef is prepared to act as their coach, but when he is about to quit the ungrateful job, Gerard persuades him to return by confiding in him that he has oesophageal cancer and only has a few months to live. Youssoef gives in and thereafter they definitely make progress, despite a few occasional relapses. Near the end, it seems a failure when Kees might drop out, for his wife forbids him to run on a Sunday, but he shows up after all. They reach the start in the nick of time, dressed in canary shirts and pink pants, which was met with the predictable sarcasm by Leo: 'Do we want to finish as an egg yolk?'

They do finish together, except for Gerard, who was having severe difficulties. Youssoef, knowing about the cancer, says he had better quit, but Gerard refuses to give up. At one point, he is on the big screen as the very last participant in the marathon. Broadcast on television, both Uncle Hussein and Gerard's rebellious teenage son are fascinated by his struggle. We get shots in slow motion, but then Gerard falls down, close to the finish, and will be brought to hospital. He dies and when Youssoef tells that he had kept silent about his illness because he did not want anyone to worry, his fellow-workers realize that their boss was an 'incredible hotshot.' With a brief 'We can make it, guys,' they secretly sneak Gerard out of the hospital, in a wheelchair. While the streets of the race are being cleaned, they walk the last couple of hundred meters in slow motion and pass the finish line with his arms in the air until the image freezes. The poster, which more or less equals the freeze frame, has a suggestion of an ultimate triumph, but as soon as we know the narrative context, this triumph is overshadowed by tragedy. It is a heroic death, nonetheless, for service station Groteboer has been prevented from bankruptcy. Youssoef has been promoted to the fourth card player, though he still has some stuff to learn at the game of cards. Meanwhile Gerard's son, who seemed to go astray, has now taken Youssoef's position. And thus, even though it may seem quite morbid to have a dead man on the film poster, Gerard's passing away has a positive outcome, as befits a feel-good film. ${ }^{13}$

\section{A WANNABE TARANTINO BROMANCE: BROS BEFORE HOS}

In DE MARATHON, homophobic irony and ethnic skits abound, but since they are not really malicious, they basically function to keep the world uncluttered for the working-class characters. It is inherent to friendship among men 
that one accepts jokes about one's 'weak spot,' for camaraderie is never free from mutual rivalry, as I explained before. Youssoef can take the ribbing about pyramids, Tutankhamun and camels, because he understands that their possibly racist undertones are embedded in homosocial relations. The remarks are not intrinsically hostile, and he apparently acknowledges that they are made to affirm male bonding. Even when Youssoef has definitely won their respect, he will remain a Tutankhamun or a camel. Part of the relative benevolence of the jokes by Leo or Kees is that they include their own class and gender, albeit in a light-hearted manner. They make fun of their own unsportsmanlike nature, as when Leo says that the distance of a marathon is already far by car. They also make bantering remarks about each other's physical appearance - read: unattractiveness - like the running gag that 'your wife would not mind if you had a new V-belt,' for replacing a V-belt is a common repair in their line of business. Because of its mild-mannered tone, the rock solid comedy DE MARATHON is 220 | the 'diet version' of the unpolished and raunchy BROS BEFORE HOS (Steffen Haars and Flip van der Kuil, 2013), a homosocial title if there ever was one. ${ }^{14}$ In terms of purport, they are comparable: jokes work to channel friendship/ brotherhood. The tone of the latter is much more comically violent, however.

The expression 'bros before hos' is an abbreviation of 'brothers before whores,' meaning that one's best friend is always to be privileged over one's girl - and 'ho' is a most pejorative term, suggesting that women tend to sleep around with other men. This lesson is already hammered home by the father of the 'white' kid Max and his adopted brother, the 'brown peanut' Jules, when they are both 5 years old. After their mother has left the house after a serious quarrel, their father advises them: 'Never ever, I mean never ever, have a relationship,' and the two guys swear to it.

After this prologue, Max introduces himself and his brother while they are about to turn 30. Jules is assistant branch manager of the Stipmarket, 'free snacking all day, phoning and slacking.' Max lives very close to the video store he is working at, 'hoping that I do not get any customers.' When they go out, they frequently pick up girls with an elaborate ruse. When they meet some girls they like, Max pretends to be upset that his girlfriend has just broken up with him, while Jules confides to the girls that it happened 'on our birthday, of all things.' The act of seduction practically always works, but Max has to admit that Jules ends up with the prettier girls, 'perhaps because of his colour.' They are shown in rapidly cut sequences coming on to different girls. One time Max says that Jules is from Turkey, another time from Botswana, or Djibouti, and once he even claims that his brother is an aboriginal. The two always have onenight stands, until they meet Anna.

BROS BEHORE HOS can be labelled as a 'bromance' (or a 'brom-com'), inspired by a cycle of American films in which boyish slackers postpone a 
'healthy' relationship with a girl/woman and wallow in inter-male closeness. This cycle came to prominence with the release of such titles as Judd Apatow's THE 40-YeAR-Old Virgin (2005) and his KNOCKED Up (2007), SuPERBAD (Greg Mottola, 2007), I LOVE YOU, MAN (John Hamburg, 2009) and HuMPDAY (Lynn Shelton, 2009). The narrative conflict this cycle has to overcome is, as Jenna Weinman argues, between 'funny boys "who don't give a shit" and the serious women who "care," and desperately want, albeit hardly need, men to "care more"' (44). One of the historical roots of this cycle is, as Michael DeAngelis asserts, the 'buddy film' from the late 1960s and early 1970s - MIDNIGHT CowBOY (John Schlesingen, 1969), EASY RIDER (Dennis Hopper, 1969), THUNDERBOLT AND LIGHTFOOT (Michael Cimino, 1974) - in which female characters are marginalized, any identifiable 'home' is absent, and 'the death of at least one of the protagonists is required in order to preclude any possibility that the relationship will be "consummated"' (Robin Wood, qtd. in DeAngelis, 8). In a period of 'a noticeable lessening of social stigmata attached to homosexuality,' some distinctions manifest themselves. In addition to the fact that no one has to die anymore, the main difference between the 'buddy film' and the bromance is that the buddies are allowed to remain silent about the larger purpose of their intimacy, whereas the male characters in a bromance are 'required to talk' about it (DeAngelis, 13). Navigating the possibilities of the male-male relationships helps them to mature and fosters their manliness, which prepares them for the (heterosexual) marriage contract. Hence, the bromance is marked by a wonderful curiosity, as DeAngelis observes: something must happen - boys demonstrating their mutual friendship - on the condition that other things not happen - no consumption of sexual desire between straight males (1). If all the adventures lead up to a marital end, it should not amaze us, as Weinman remarks, that 'despite their raunchy content,' proponents of the conservative right have praised brom-coms 'for their family values' (44).

Although steeped in a tradition of the countercultural buddy film, the bromance comes, at its core, close to the conventions of the usual stuff from romantic comedies, and (the plot of) BROS BEFORE Hos is no exception. Max saw Anna first at the video store, but Jules starts to date her and the ensuing relationship is the end of their pact, much to the chagrin of Max, since Anna is the first girl he knows who is hot without being annoying. Predictably, the film by Haars and Van der Kuil will bring the sympathetic 'loser' Max and dream girl Anna together, in three stages. First, when Anna goes steady with Jules, Max is so depressed that he goes to his father's place, and after watching a game of Lingo on a lousy television set with his Dad, he locks himself up in his former room, with all kinds of 1980 s paraphernalia, like a RAMBO poster and a Playboy magazine with Viola Holt as Playmate, its pages stuck 
together. One day his father bangs at the door, bringing him a birthday cake which he finally throws on the ground. With a silly party hat on his head, the father explains that he had made a terrible mistake sending Max's mother, who really was 'the nicest woman in the world,' away. Max should not make the same error, and the fatherly advice is like a command, delivered in a comic deadpan vein: 'You turned 30 today, goddammit. Better go and fight for her. You won't get a second chance that easily. Look at me. Even better: talk to your brother first. No, even better: shave off that gnome beard first.'

The second one who, after his Dad, comes to Max' assistance is his brother, Jules. Due to a misunderstanding made by Max, Anna has lost her job as an attendant to mentally retarded patients, or in the belittling terms of Max, 'sexually frustrated authentic freaks.' The patients are duped as well, because without Anna they are no longer able to perform the fairy-tale play Goldilocks and the Three Bears at a festival. With René, Jules, and the institu222 tion guard Bart, Max secretly kidnaps them to teach them how to put FIRST BLOOD (Ted Kotcheff, 1982), aka the first RAMBo movie, on stage. Anna is present at the festival, but she is not amused. Bathing in backlight, she tells him in public that it is indecent to misuse those 'sexually frustrated authentic freaks.' Jules then gives a brief speech, admitting that he himself is not made for 'eternal faithfulness' and tries to persuade Anna that his brother is the perfect match for her. She is not convinced, and to make matters worse, Max and his companions end up in prison for kidnapping. When they are released after six weeks, Jordy who played Rambo, comes to greet them: 'Bros before hos.' In fact, Jordy turns out to be the third, and most important, mediator, for we then hear Anna's voice: 'Those dudes did nothing but talk about you,' a conclusion which is sealed with the obligatory kiss. Initially, his 'gift' to her in the form of the performance was not appreciated by Anna, until later when she finds out how much Jordy, a most intractable patient, has enjoyed his role as Rambo. So, the 'brotherly' pact between Max and Jordy makes her accept him as her love interest.

On the one hand, BROS BEFORE HOS is filled with the requirements of a romantic comedy to the brim. After Jules has confessed in public that he is not made for 'eternal faithfulness,' a woman he had earlier seen as a striptease dancer tells him: 'I love open relationships.' René's utterly decent girlfriend Suzanne who had left him because she thinks that he prefers porn actress Sasha Grey over her, comes to the prison and sitting on her horse Misty she starts singing Volumia's 'Hou me vast' [Hold Me Tight]. While her jangling version transforms into the original song on the soundtrack, we see René slowly ride away from his friends on horseback. On the other hand, BROS BEFORE HOS is a spoof of romantic comedies. We hear Volumia sing, but the song is interrupted brusquely for one of the question games 
the brothers are playing regularly. They constantly invent 'difficult' dilemmas for each other, that are impossible to answer, for the choice is always between 'bad' and 'worse,' like: 'Who would you bang? Doutzen Kroes with full-blown AIDS, without a condom, or Viola Holt (Playboy, 1984), overrun by a truck dragged along for a mile, but down there she's still perfect?' Seeing René on horseback with Suzanne, Jules has another dilemma for Max: 'Suppose you have to choose. Either those mud flaps of Suzanne in your face, or ...' but before Jules can finish, Max already says: 'The horse, definitely,' and Jules joins him: 'Me, too,' to emphasize how much they do not want a girlfriend like Suzanne.

Suzanne is utterly disliked by the brothers because she is the typically controlling girlfriend who does not understand the fun of male bonding. She is very much like Melissa, the woman with whom the dentist Stu from The HANgover (Todd Phillips, 2009) is about to get married. Stu lied to her about the stag party in Las Vegas he is having with his three friends and has told her he is on a wine tasting tour. One of the humorous lessons in a homosocial comedy like THE HANGOVER is that a man should never choose a woman who disapproves of her hubby hanging out with friends. Thus, Stu's girlfriend, Melissa, is represented here as a total misfit. By contrast, the bride, Tracy, has consented to the trip which the friends make on occasion of her wedding to Phil. Of course she was nervous about the fact that the four only arrived in the nick of time, but she did not make a scene. This response makes Tracy a woman in the same league of Anna, one worth fighting for.

The main reason why Anna stands out, is because she understands boyish behaviour. She gives evidence of such understanding when she is playing the same video game which we saw Max play at the age of five. On top of that, she tells him, after she has belched loudly by the way, that FIRST BLOOD is the 'best movie ever, so fucking bad.' And imitating a heavy voice: 'He just wanted something to eat.' Max continues, imitating Sylvester Stallone: 'They drew first blood, not me. Are you telling me that 200 of our men against your boy is a no-win situation for us? You send that many, don't forget one thing,' and then Max and Anna together: 'A good supply of body bags.' The shared preference for FIRST BLOOD not only makes Anna his object of desire, but it was also Max' reason for choosing this film to have it performed on stage by her (former) patients - his 'gift' to her.

Strictly speaking, the romantic ending of the film does not cross out the continuation of homosocial relations. Anna falls in love with Max, predominantly because one of her male patients starts considering him as a 'brother.' Moreover, she expresses his love with a 'boyish' prank. 'While you were in prison I fell in love. With Rick. Rick Brandsteder,' she tells a baffled Max, and after a few seconds, she adds: 'No, of course not.' Since a girl like 
Anna proves herself more of a 'bro' than a 'ho,' the romantic plot does not really violate the reigning principle of male bonding.

Throughout the film, the two brothers and their housemate, René, address each other as 'niggaaaah.' The nerdy René, whose acts provide hilarity time and again, mimics 'nigga' talk, in particular: 'Control your bitch is what I am saying.' He is big-mouthed in the company of his friends, but his actual behaviour in the presence of his girlfriend is in flagrant contrast to his words. As soon as Suzanne requests something, he sits up like a puppy. This already clearly indicates that their conventionalized use of the N-word is no more than a fetishization of black culture. Their boyish desire to be associated with the position of an outsider is expressed without ever giving up the privileges of the Western slacker who lives in relatively luxury. The more they talk 'niggaaaah' speech, the more it becomes manifest how shallow their words are and how much of an 'outsider' they are instead of a black 224 insider (see Willis, 210-13).

Just as the characters can be described as 'wannabe white Negros,' BROs BEFORE Hos can be described as a 'wannabe Tarantino movie.' This is not meant as a disqualification, for his films are themselves an amalgam of many other titles, ‘wannabe' versions of a variety of films. A film like Tarantino's PUlP FiCTION (1994), as Sharon Willis observes, 'recycles them as a kind of nostalgia to the second degree' (197). It is not a nostalgia for the 1950 s to the 1970 s as such, she argues, but for the way the films from these decades have circulated in television, radio, and particularly relevant, on VHS. Tarantino was simply too young to know the spaghetti westerns by Sergio Leone or the blaxpoitation films from their original theatre release, but his nostalgic longing for them is a belated appreciation as a consequence of watching them on television or video. By recycling them into his own homage to these films, Tarantino makes them contemporaneous. Diverse pictures such as KISS ME DEADLY (Robert Aldrich, 1955), FOXY BROWN (Jack Hill, 1974) and The DeEr Hunter (Michael Cimino, 1978) thus become part of 'a kind of utopian eternal present' (Willis, 197).

The main points of reference in BROS BEFORE HOS are from later decades, and via these references the identity of the characters gains definition. The fact that Max works at a video store, where we see posters of PLAN C, DE MARATHON, TUSSENSTAND, SNACKBAR, MATTERHORN, is already a nostalgic reference. A 'nice job,' Max says in voice-over, but the job is no longer as nice as it used to be in the time when Tarantino himself was working at a video store. At one point, two boys ask whether Max can advise them some great pictures. He mentions DJANGO (Sergio Corbucci, 1966) - the film that inspired Tarantino's DJANGo UNCHAINED (2012) - some 'Will Ferrell shit,' and the 'awesome' TED (2012) by Seth McFarlane. The boys respond to his 
list by saying: 'OK, thanks, then we will download them from the Internet. Loser. Who the fuck still rents movies at the video store?'15 Early in the film, a boy and a girl bring back the DVD of THE BIG LEBOwSKI (Joel and Ethan Coen, 1998), which they considered a piece of crap. Max then throws CosTA! (Johan Nijenhuis, 2001) onto the counter for them. The girl asks whether that is the one in the snow with all the skiing. Max does not try to contradict her - for that is SNOWFEVER (Pim van Hoeve, 2004) - and coolly replies: 'Definitely. Best Dutch film ever made.' Whereas 'Will Ferrell shit' and TED are definitely liked by the people who make BROS BEFORE HOs, because they are more or less in the same league, Max' recommendation of CoSTA! is to be interpreted as an ironic reversal: if you think THE BIG LEBOWSKI is a piece of crap, your taste is perhaps so rottenly bourgeois, that you will probably like Costa! better.

BROS BEFORE HOS is a dustbin of references to popular cinema, above all in the category of FIRST BLOOD and ESCAPE FROM ALCATRAZ (Don Siegel, 1979). The latter is referenced to 'free' the patients from the institution where Anna used to work as an attendant. The guard who assists Max in the 'rescue operation' actually mentions Siegel's film as his favourite movie, the one with 'Whoopi Goldberg' (almost right, it is Clint Eastwood). Moreover, in the end credits, the patients copycat scenes from a variety of films. The director of the institution has permitted them to do so, since their enjoyment of the stage performance has proven to her that violent movies actually work therapeutically. Although the acting performances are wooden and the delivery of lines is blunt, they enthusiastically imitate scenes from such films as JaWs, ROCKY, SCARFACE, PUlP Fiction, BRAVEHEART, AMERICAN History X, and New Kids Turbo, which all are, significantly, highly popular among adolescents and young film aficionados.

But perhaps more than anything, BROS BEFORE HOS has affinity with the quirky comedy CLERKS (Kevin Smith, 1994), about two guys working at a video store. ${ }^{16}$ 'This job would be great if it wasn't for the fucking customers,' Randal says in CLERKS, which recalls a line from Max' voice-over. The most striking parallel, however, is with the scene when Randal is on the phone and wants to place an order with the distribution house. While a mother and her young child ask him where to find HAPPY SCRAPPY HERO PUP, Randal continues the phone conversation and mentions no less than 19 titles from porn movies. There is a slightly comparable scene in BROS BEFORE Hos, when the mentally retarded Jordy has been permitted to hire porn DVDs from Max' video store to keep his sexual lust under control. By coincidence, Max' boss is desperately searching for precisely these porn movies which have been reserved by a customer. He loudly names all the titles in the presence of a grandmother and her granddaughter who are at the counter 
with a DVD. Max then has to call Anna straight away to request the return of the films. He also starts mentioning all the titles, while the grandmother and the granddaughter are still waiting patiently: RAPING MIDGETS II, THIS WHORE SEES A Doctor, SCHINDLER'S Fist. Thus, Bros BEFORE Hos can be said to be a romantic comedy which dearly wants to be a bad-ass bromance, portraying the intimate bonds between Max, Jules, and, to a lesser extent, the quite weird René. These bonds are channelled by picking up girls for one-night stands, as we saw in a series of episodic sequence shots, and by visiting striptease joints. These bonds are put at risk when the brothers vie for the same woman, but they become particularly strong again when Jules helps Max to conquer Anna. But above all, these bonds are secured by liking the very same movies which date back to their childhood and adolescent years, First BloOd, Pulp Fiction, CleRKs, The Big LEBowsKi.

Max and Jules' enjoyment of films from the 1980 os and 1990 is basically 226 nostalgic, reminiscent of their juvenile tastes and years of unconditional brotherhood without the responsibilities and desires that come with age. Significantly, Jordy's enjoyment of (imitating) these movies is still 'authentic,' since as a mentally retarded person he is more or less still the young boy they once were. When Jordy greets them at the end with a 'bros before hos,' he becomes a part of the brotherly pact. His inclusion of this pact, which, as I state at the risk of repetition, is mediated by popular films predominantly from the 1980 s and 1990s, makes Anna realize that Max definitely is okay. At the same time, their kiss may result into a gradual dissolution of the homosocial bonding, for as Max says in voice-over: 'Shit, 30, this is the beginning of the end. Probably I will change into a yes-nodding, stay-at-home daddy. I'll have two kids, a minivan and a gay-looking Golden Retriever. But fuck it. With Anna, I don't give a shit.'

\section{POETIC HOMOSOCIALITY: WILDE MOSSELS}

Verhoeven's SPETTERS was neither a comedy nor an ironic work, but in retrospect, it can be regarded as such because of its remarkable reception history. And thus it makes sense to discuss, as I did in this chapter, the comic offspring of Verhoeven's controversial 1980 film. Strictly speaking, BROS BEFORE HOS is much more vulgar, but it did not get the vicious reception of its predecessor. Unlike the quite 'realistic' SPETTERs, the film by Haars and Van der Kuil did not claim to capture the zeitgeist. The homosocial pattern in BROS BEFORE Hos functioned as a skeleton for 'cool' jokes in an attempt to catch up with comedies like CLERKS or comically violent films like PULP FICTION.

To prove the impact of SPETTERS, Hans Schoots mentions in his 2004 
study Van FANFARE tot SPETTERS, that Verhoeven's film influenced pictures like the gritty VAN GOD LOS [GODFORSAKEN!] (Pieter Kuijpers, 2003) and the 'poetic' WILDE MOSSELS [WILD MUSSELS] (Erik de Bruyn, 2000), about three rural fellows in Zeeland. To reinforce the kinship: Hans Veerman who was cast as Eef's father in SPETTERs, played the stepfather of male protagonist Leen, who happens to be a motorbike enthusiast. In addition to funny oneliners, WILDE MOSSELS has its comic moments, as when one of the friends clumsily shoots himself in his leg during the robbery of a small local bank where only one female employee is working. The three buddies in WILDE MOSSELS are as much descendants of the pals in SPETTERS as Max, Jules and René in BROS BEFORE HOS are. What separates De Bruyn's film from the one by Haars and Van der Kuil is the editing and cinematography. Stylistically, BROS BEFORE HOS uses many hip techniques we know from music videos, which were at the peak of their popularity in the 1980s and 1990s: use of split screen, swish pans, slow motion, fast motion, high-angle shots, time-lapse photography. Thus, the film by Haars and Van der Kuil is a homage to (the era of) the music video in terms of both style and efficient storytelling. By contrast, the overall tone in WILDE MOSSELS is melancholic. Even though De Bruyn's film has some quickly cut scenes and extreme slow motion as well, it frequently uses wide lenses for long, lengthy shots to convey that the characters are situated within bare acres and close to the seaside. The distant landscapes work to propel the teenager's vague desire to disappear behind the horizon for a more vivacious existence, in the vein of the poems by Slauerhoff, who made many sea voyages during his brief life. De Bruyn's film, which has a preference for the colours green and blue, also uses very slow dolly movements which contribute to the general poetic indeterminacy: while the viewer can barely perceive that the camera moves, the perspective slightly changes nonetheless.

In terms of content, WILDE MOSSELS, aptly described by Jan Pieter Ekker as a 'potato western about a lost generation,' ties in with the homosocial pattern of the comedies in this chapter: boys hanging out with one another, making plans together, while the longing for a girl (or girls) may be an obstacle to the friendship. In WILDE MOSSELS the rivalry that ensues from this longing results into a deadly incident, and for that reason the melancholy, accentuated by the cinematography, definitely presides over the humour. ${ }^{17}$ In the comic descendants of SPETTERS, on the contrary, the friendship will be regained precisely when death has foretold its arrival, as in SIMON, or when, as in DE MARATHON, death incites the friends to an illicit ode. 
४

४ै।

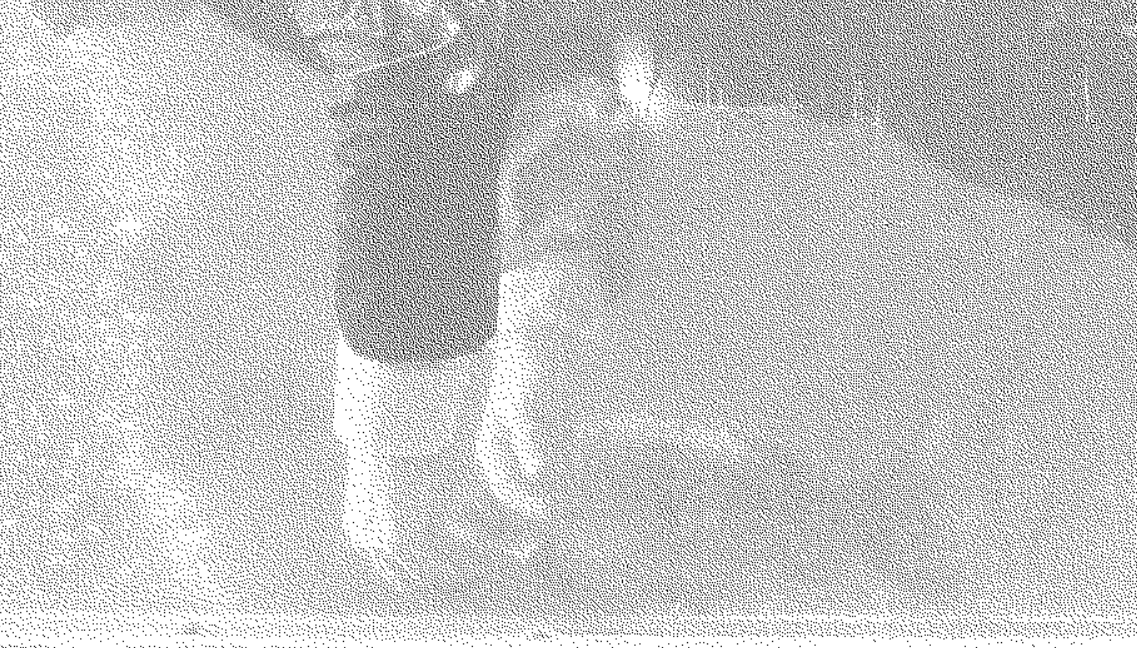




\section{CHAPTER 7}

\section{From Ludic Humour to Cosmic Irony}

In his groundbreaking study Homo Ludens (1938), the famous Dutch historian Johan Huizinga gives a 'notoriously elusive' (Rodriguez) reflection on the play element of culture. On the one hand, he asserts that in play, we move below the level of the serious. There are (primitive) forms of play, like children pretending to be someone else, a game of cards or a sporting contest, which are 'largely devoid of purpose' (49). Despite the fact that children or grown-ups can play 'in the most perfect seriousness' (18), such (primitive) play, 'senseless and irrational' (17) as it is, has 'that irreducible quality of pure playfulness' (7). Huizinga uses the Dutch term 'aardigheid' to describe this quality, but admits that no word better sums up the essence of this kind of play than the English word 'fun,' adding to this that the 'fun of playing, resists all analysis, all logical interpretation' (3). Hence, play has a strictly ludic function that goes beyond full comprehension.

On the other hand, and this is a main thrust of Huizinga's study, play has a 'significant function - that is to say that there is some sense to it' (1). In play, people can also move above the level of the serious, 'in the realm of the beautiful and the sacred' (19). Play, Huizinga points out, is innate in aesthetic categories like music and poetry, which in classical antiquity had an ethical and educational value (162). Even more important, every ritual of either a political, legal or religious nature, which is 'seriousness at its highest and holiest,' grafts itself upon play (18-19). A ritual event and play both take place at a so-called 'consecrated spot'; they step out of 'real' life into a temporary sphere and the acts can be performed 'with an absorption, a devotion that passes into rapture' (8). Since such examples illustrate that play can 'very well include seriousness' (45), the concept of play oscillates between the 'highest regions of the spirit' and futility. According to Huizinga, there is a 'substantial similarity' between the ritu- 
al forms of play, often performed in a social and cultural context, and the ludic forms (19).

I refer to the work of Huizinga, because this canonical study, written by a Dutch scholar of international fame, seems to have left quite an imprint on Dutch culture, albeit its precise marks are difficult to detect. Perhaps this imprint shows itself best in the Netherlands in the particularly vivid tradition of cabaret performers, from Toon Hermans and Wim Sonneveld to Freek de Jonge and Youp van 't Hek, to Hans Teeuwen and Brigitte Kaandorp, to Claudia de Breij and Ronald Goedemondt. They take a ludic approach to their subjects, but such an approach can, to quote Huizinga, "very well include seriousness. ${ }^{1}$ This option of earnestness is clear in the politically engaged shows of Freek de Jonge, but it is also applicable to the more absurdist performances of Hans Teeuwen, like the silly song about the $16^{\text {th }}$-century French seer Nostradamus in his tight green pants. The surplus value of the

230 | ludic can reside in a disordering potential, catching the viewer by surprise. The number one requirement for a successful cabaret performance seems to be that the comedian acts against conventions: he might sing the praise of something totally idiotic, be annoyed about something absolutely trivial or advocate a nonsensical opinion. This can offer the spectator pleasure and fun as much as have an alienating effect upon him. In this chapter I will focus upon films made by, among others, Jos Stelling, Orlow Seunke, Robert Jan Westdijk, Lodewijk Crijns, Eddy Terstall and Alex van Warmerdam, which are all rooted in the ludic, but nonetheless can slightly estrange the viewer because of an uncommon angle presented.

\section{A STILLED FORM OF CATHOLIC SLAPSTICK: DE ILLUSIONIST AND DE WISSELWACHTER}

One usually visits a camping site to enjoy a holiday. The theatrical company Het Werkteater, already discussed in chapter 3 , went to such a camping site and improvised some characters as well as a couple of scenes on the spot, according to the company's aim to perform in the midst of 'real life.' Normally, the films of Het Werkteater were based upon theatrical plays, but CAMPING (Thijs Chanowski, 1978) was the exception. In one of the first scenes of the film, Guus tries to park his caravan while driving backwards. First, he gets annoyed because he cannot see his wife, Trix, who is supposed to give him directions. She is standing behind the caravan, not next to it. Second, he gets irritated because a child kicks a ball towards his car. When he wants to spank the kid, a man intervenes by saying: 'Quiet, quiet, this is a camping site not a housing estate.' 'Neither is it a football field,' Guus retorts. Third, it gets on 
his nerves that as soon as the caravan is in the right spot, his wife immediately starts offering him a plethora of 'cosy' options - Shall we have a drink on the terrace? Shall I unpack the chairs? Would you like to refresh yourself? He can only respond by gradually raising his voice: 'Quiet, quiet, holiday, holiday ... holidayyyyyy!' In short, Guus takes offence at his wife's forced attempts to create a free and easy atmosphere that will guarantee a good time at the camping site. This scene is exemplary of the general tendency of CAMPING to poke fun at the apparent paradox that holidays impose a 'duty' to enjoy one's leisure time. Instead of moments of relaxation, the film comically illustrates that one's holiday can go with the stress to perform this 'duty,' which is best expressed in Guus' peevish 'holidayyyyyy.' Another fine moment of Guus' nuisance is the scene when he can judge by the shoes under the door that there is a man occupying the ladies' toilet. He puts a girl on guard so that he can get the camping steward, but the man has vanished upon his return. He makes a scene, frustrated by the man's escape, but, once again, it is much ado about nothing. Only during the evening of the hilarious 'Miss' and the slightly more hilarious 'Mister' election, one of the film's final scenes, is Guus able to set his mind at rest, to sing along with other guests about 'fine lads who always show up everywhere.'

Though CAMPING was to become quite popular when it was later broadcast on Dutch television, film critics were less enthusiast this time than with other projects by Het Werkteater. Perhaps the fact that this film was not an adaptation of one of their own socially engaged theatrical pieces worked to its disadvantage. CAMPING was considered as no more than a loose array of sketches, and Margot van Schayk suggests that Het Werkteater required a well-tried theatre performance as a necessary 'foreplay' for a film. CAMPING more or less proved that their projects were to remain stuck in a ludic atmosphere and that the direct and critical testing for a live audience helped the company to combine their work with social engagement (Van Schayk, 131). Thus, the exception of CAMPING underscores the hypothesis that for Het Werkteater the transition from theatre to film can result into a favourable cross-fertilization. Likewise, the Swedish director Ingmar Bergman once remarked that even in cases that it proved to be incompatible, the crossover from theatre to film felt like a small step. DE ILLUSIONIST [THE ILLUSIONIST] (Jos Stelling, 1984) is an example of such a small step which has an incompatibility at its core: a talkative theatre show was adapted into a film without spoken text. ${ }^{2}$ The film consists of a series of sketches, which are framed as remembrances by the protagonist - or perhaps figments of his imagination - when he peeps his head around the door of his drawing room to look at the auditorium preceding his performance.

One of these remembrances concerns a memorable 3-minute sequence 
from the beginning of DE ILLUSIONIST. A father, a mother and two children, played by grown-ups, are seated around the dinner table, their hands folded and eyes closed in prayer. Only the table is lit thanks to the one lamp hanging above it; the rest is in darkness. The camera then shows the mother in profile, and we see a weak light bulb at a small distance behind her. When she turns her face to the left, the focus shifts to the grandfather in a chair near the bulb in the corner, playing cards all by himself. When he notices that the mother is looking at him, the old man quickly folds his hands and closes his eyes. He then stops, but when he observes that the mother is still looking at him, he quickly pretends to be praying. The only sound we hear in the scene is some murmur that accompanies the prayers, but soon the sound of a buzzing bluebottle is heard as well and attracts everyone's attention, as we can gather from their eyes. When the kids perceive that their mother sees they are distracted, they continue their prayers, eyes closed. A bluebot-

232 the is seated at a spoon, and one son moves his hand slowly in its direction, but he quickly withdraws when he notices he is being watched. The father thereupon increases the volume of his murmur. We then get a long shot of the dinner table, the camera positioned so that we see the grandfather in the background, in the middle of the shot. We see him playing cards, but he is also constantly peering in the direction of the dinner table. After a few seconds, the son cannot resist hitting the bluebottle on the spoon - we see his hand in close-up - but some porridge flies through the air, landing on grandfather's right cheek. We then get a shot in which the mother and son are out of focus, continuing their prayers, while the grandfather is in sharp focus, cleaning his face.

A shot then of the other son who takes the dead bluebottle from the dinner table. In a close-up we see that he has the insect between thumb and finger and starts cleaning it carefully, removing some porridge. His mother looks at it, but he is too focused upon his work to be disturbed by her glance. He then puts the bluebottle in a drawer of the table and starts counting the 20-something number of them, in a whispered voice. The mother has closed her eyes, apparently pensive. A bluebottle lands on her cheek, and she wants to get rid of it by slightly moving her facial muscles, but while the one son is still counting, the other son hits her on the cheek. The latter quickly closes his eyes, but his brother looks up and moves his hand to his mother's face, to which the bluebottle is still glued. When he takes the insect from her cheek to make it part of his collection, his mother hits him on his cheek, apparently thinking that she is paying him back. While the sneaky brother starts suppressing his laughter, his pair of thick spectacles falls into his porridge. Since he cannot see anything without them, he starts groping with his hands. Thereby his head gets affixed to one of the many sticky fly strips 
hanging over the dinner table. His brother comes to his assistance, but since he is clumsy, he only makes things worse, which is, as we see in a medium close-up, secretly enjoyed by the father. End of sequence.

In this sequence, the only sounds we hear are the murmurs of prayer, the buzzing of bluebottles, the silent counting of insects, some furtive laughter and two blows. There is no dialogue, and actually there is none in the entire movie. This absence of spoken text is in notable contrast to the fact that De Jonge's theatrical performances are known for verbal fireworks. Initially, De Jonge's monologue was meant to be part of the film, but during shooting, it was decided that the combination of his lines and the scenes in the open air was awkward. Thus, in the case of DE ILLUSIONIST, theatre and film could only be spliced insofar as Stelling and De Jonge realized that the verbal performance had better be made as a wordless tragedy with slapstick effects.

Shooting a film without dialogue offered a considerable advantage for Stelling, for it perfectly suited his vision of cinema. Since Dutch culture is, as he claims, essentially Calvinist Protestant, cinema is relatively poorly appreciated in the Netherlands. For the Calvinist tradition regards literacy and erudition highly and favours text definitely over images. This preference is based upon the idea that the meaning of texts is, or at least can be made, quite straightforward. With words one can be pretty clear about one's intentions, and it is the task of clergymen associated with a rigorous doctrine like Calvinism to reduce biblical texts to only one unambiguous message. In contrast to the (enforced) clarity and unequivocality of texts, Stelling believes that images are not to be limited to just one meaning. Because of their essential indeterminacy they open up space for ambiguity and leave room for interpretation by the viewer. A good image always represents more than meets the eye, inviting the viewer to add extra meaning to it. Unlike Calvinist Protestants, Stelling puts forward, Catholics do not have a problem with ambiguity; on the contrary, they have no quibbles with simulation and lies. In an interview with Theodoor Steen for Salon Indien, Stelling quotes a statement by Wim Verstappen: 'Film is a Catholic medium, because only Catholics know what heaven looks like,' meaning that Catholics even dare to represent the un-representable. Because a vivid imagination is more challenging than (some contestable version of) the 'truth,' austere textual accuracy is for them inferior to the indeterminacy of visual representations. In the spirit of his self-chosen dictum that film is basically a Catholic medium, Stelling asserts that dialogue in film is only of interest on condition that it reinforces lies and leads the spectator astray. Too often it has an explanatory function, which for Stelling is un-cinematic, for dialogue risks being an obstacle to one's visual attention.

Believing that his films are much better tailored to Catholic than to Cal- 
vinist cultures, it does not surprise Stelling that his films are usually more successful in countries like Portugal, Italy and Russia than in his home country. A film like his ambitious project DE VLIEGENDE Hollander [THE FlYiNg DUtChMAN] (1995) - and the more modest No Trains, No Planes (1999) - received only a cold to lukewarm response in the Netherlands, but were much better appreciated abroad. DE VLIEGENDE HOLLANDER even made it to the top 100 of the best pictures of European cinematography in the $20^{\text {th }}$ century according to IMAGO, which is a considerable contrast to Jos van der Burg's review in De Filmkrant that this fantasy of the legend is 'without wings,' an opinion shared by many Dutch. The fact that DE ILLUSIONIST had fared much better in the Netherlands and even was voted as best film of the year by the readers of the (leftist) newspaper de Volkskrant was, Stelling hypothesizes, due to a misreading. Dutch viewers tended to see the film as humorous, mediated by the aforementioned slapstick scene, but above all 234 by the participation of main actor De Jonge, a comedian especially popular among (leftist) intellectuals. For many, DE ILLUSIONIST was De Jonge's film and this was decisive for seeing the film as a ludic comedy with absurdist incidents. ${ }^{3}$ In fact, Stelling says, DE ILLUSIONIST is a bitter and bleak picture about a boy paying a visit to his brother in a mental institution, and the humour is added to make the film bearable. ${ }^{4}$ For viewers from Eastern Europe, the director had noticed, DE ILLUSIONIST is indeed a 'tragedy,' which corresponds to the title of the original theatrical show, and De Jonge, unbeknownst to them, was interpreted as a melancholic character, whereas in the Netherlands the label of comedy prevailed.

Leaving his films set in historical periods out of consideration, like his medieval debut feature MARIKEN VAN NIEUMEGHEN (1974), the aforementioned DE VLIEGENDE Hollander, and Het MEISJE EN DE DOOD [THE GIRL AND THE DEATH] (2012), Stelling's signature is a tragic starting point supplemented with comic interludes. This comes best to the fore in his perhaps finest achievement, De wisselwachter [The Pointsman] (1986). ${ }^{5}$ The plot is only ancillary: a French lady, dressed in a fancy red winter coat, gets off a train by mistake and is stuck in the middle of nowhere, because it is no longer a regular station. She can take shelter at the little place of the pointsman, a most peculiar hermit who does not really know how to approach her. The film depicts how they gradually grow closer together, among others by the fact that he shoots the intrusive postman. After having shared an intimate sexual moment together, a train stops to take them away, but he stays behind in his place which he has filled with moss. He will be fully covered by cobwebs at the end.

DE WISSELWACHTER is very sparse with text. The lady says a few words, but the pointsman does not understand French, nor do the three guests who 
come along. Hence, she never has an actual dialogue with anyone. The only time the pointsman gives in to a request by her is when she yells 'tire' (shoot), but probably he would have shot the postman anyway. About the only word the pointsman himself speaks in the movie is a funny example of miscommunication. When the machinist asks him for her name, he answers after some moments of silence: 'Dégoûtant,' a term he has heard her utter, thinking she had introduced herself, while she was actually describing his living conditions with the French word for 'disgusting.' The machinist tells the pointsman a story but the latter only listens and does not give a verbal reply. When the postman comes along, the pointsman just stands by, the lady does not understand him, the assistant machinist is still recovering from being frozen and the machinist only answers by way of petulant gestures, which express his antipathy to the postman. Hence, the few spoken texts in Stelling's film take the form of monologues, even though - and that makes it humorous - the speaker is waiting or hoping for a verbal response.

Because there are so few incidents, so little words and no music except for a few diegetic fragments, DE WISSELWACHTER stands out for its attention to details: the sound of a dripping tap or of a rattling chain; the visual presence of insects. Most remarkable, however, is that while the film itself never uses slow motion as an effect, all the movements of the main characters, and the pointsman in particular, are very slow paced and sometimes also repetitive: if he takes a look at something, he then takes another look, and then perhaps once again. Any simple action, such as eating a meal by the pointsman, watched by the lady upon her arrival, is protracted. If in much slapstick, the actions can be very energetic, and even seem speeded up, DE WISSELWACHTER offers its spectators a stilled form of slapstick. As a consequence, it is already slightly absurdist when the pointsman does something quite normal like a little dance, or when the woman caresses his face amidst red currants which either are already bottled or still have to be pickled. A scene in which the pointsman hides himself behind some bush and moves closer at intervals to spy on the postman is even more absurd, all the more so when he puts the bush on the railroad, as if it was growing there. Not to mention the bizarre scene in which the pointsman puts the dead postman on his motorcycle and starts the machine so that the deceased drives away into the wide open. ${ }^{6}$ So, the humour in DE WISSELWACHTER resides in the actor's performance at slowed-down actions without ever becoming slow motion. 


\section{A BUSTER KEATON LOOKALIKE ON AND OFF THE SET: OH BOY!}

The world of the classic slapstick comedian 'defies common logic and physical laws' (Desser, 34). No matter how extreme the pratfall, the slapstick character is never seriously hurt. He seems impervious to bodily pain and in that regard he is not quite human. Noël Carroll describes clowns as 'creatures who can take a hit on the head with a sledgehammer and who then, after a brief swoon, are back in the game almost immediately' (30). The clownish protagonist in slapstick inhabits a universe in which he does not fit in, but thanks to his 'indomitable will' (Desser, 56) he can bend all the forces that seem to conspire against him to his advantage. He is constantly put to the test, but his imagination is so vivid that when things go wrong, as they invariably do, he transforms the regular use of objects to surprisingly new ways; 'necessity is the mother of invention' (Desser, 62) and because of his clever mind, the outsider

236 | can prevail. In situations where slapstick comedians like Harold Lloyd and Buster Keaton end up with their beloved girl besides them, 'it is a matter of their proving themselves through physical challenges and not of their innate romantic qualities' (Desser, 57 ).

In Orlow Seunke's OH Boy! (1991), Pim (Seunke himself) is a young and inexperienced actor who plays the role of Boy, a Buster Keaton lookalike. As befits a Keaton character, he is interested in 'mechanical and electrical engineering' (Desser, 42). When the alarm goes off or when he pulls a rope, all kinds of objects are set in motion: tea is made, a shirt comes down from the ceiling, an electric train throws the dirty dishes into water, and so on. In this movie-within-a-movie, Boy owns a gas station in the middle of nowhere in a studio-made desert. According to the director within the film, the more desolate the setting the purer the drama. Business is far from thriving, and in the beginning of the film, a man pays him a visit who is tied to a wheelchair with a little bit of modern propulsion. He needs to have some petrol in his small tank and also one drop in his lighter. One of the gags is that the man - played by Jim van der Woude from DE WISSELWACHTER - utters sounds, but his speech is unintelligible, except for the one time he speaks a line as an actor on the set.

The story of the movie-within-the-movie is set in motion when Boy all of a sudden gets a neighbour who also runs a gas station, albeit slightly more modern. The two start competing for the few customers, trying to outbid each other. ${ }^{7}$ Moreover, this neighbour, Bozz, has in addition to a brutal little son a handsome daughter, Gal, with whom Boy falls in love. He tries to win her heart in his own clumsy manner, but the father is fiercely against their meetings. Bozz' attempts to scare off Boy result in a series of him pulling breakneck stunts - although, to be honest, not as skilful as the actual Buster Keaton. Boy turns a lengthy ladder in some sort of air bridge but while walking over 
the steps, Bozz uses a gun. The ladder turns over, but miraculously Boy succeeds in clinging to the underside of the stairs. To cap it all, it starts raining at that very moment. In another scene Bozz lights a fire that makes Boy run so hard that he bumps into the front of his own house. The wall comes tumbling down, but he is not hurt at all, because the open window falls over him, just as happens to the Buster Keaton character in StEAmboAT BILL, JR. (Charles Reisner and Buster Keaton, 1928).

Actually, this is one of the very few scenes that is met with great enthusiasm on the set, because this difficult shot required precise timing. During the viewing of the daily rushes, director Otto Waaijer is still delighted until it is remarked that the man in the wheelchair is seen in the background taking a shower, which is impossible because he is an invalid in the movie. They are moving the scene forward and backward, but since it is shot in one long take they cannot re-edit it: the only option is to shoot it once more. Actually, this is one of the minor problems of the production. To mention others: no one speaks highly of the acting skills of Pim, who plays Boy. With a guy like him, it becomes 'HELLZAPOPPIN',' the producer remarks, a reference to an anarchic comedy full of sight gags and slapstick by H.C. Potter from 1941. Another one: Pim is in love with Chloe, who plays Gal in the film, but is too shy to approach her. He spies on her by looking through the peephole in a toilet which is no more than a prop for the film. He is so nervous he has to defecate, but he has apparently forgotten that a toilet on a set is not real and accidently ruins the rinsing tub. When Boy runs away in great hurry, the whole toilet falls apart. The director sighs: 'I guess I have to omit the entire toilet scene.' Another one: Since the shooting of Otto's picture is a few days behind schedule, the crew of a subsequent production is already preparing for their own film. As a consequence, there is snow in the desert.

Worst of all, and a main reason for the delay, is the pedantic attitude of the self-declared big star of the movie-in-the-movie, Gert Schouwen, who plays the neighbour, Bozz. It is beneath his dignity to have Pim as his opposite number, someone whom he considers to be a 'prick, with capital P.' He has invited the society press for a tour and introduces Chloe, the actress playing Gal, as the 'new Sylvia Kristel.' He contradicts director Otto whenever he can, to everyone's annoyance. He is mad that he has to wear a cap all the time, to which Otto responds that he is fed up with the vanity of actors. Gert is displeased with his line 'Is the grass greener over there?' because he thinks it silly to use proverbs in the desert and he refuses to throw two ice creams in the direction of Boy, since it does not 'feel' right to do so. He speaks in disdainful terms about the director, even in a news report on the making of the film. According to him, the director is great at collecting beautiful shots and visual gags, but the script lacks consistent motivation. 'Give an actor a motive and he does everything 
for you,' he tells Otto, who retorts: 'You read the script? It is all motive.' Gert: 'But you are not directing, you are just editing, accumulating shots.' Whereas Hitchcock, Gert tells to a journalist, considered his actors as cattle, for Otto an actor seems no more than a prop. Moreover, the 'star' shouts that he wants to have his name removed from the credits when a video compilation of scenes from Buster Keaton 'prove' to him that Otto has committed plagiarism. He does not follow through with his threat, but he decides to deviate from the script single-handedly when a surreal romantic encounter between Boy and Gal is about to take place: 'I am not acting in a Tiroler sex movie,' he says to justify his outburst.

OH Boy! was Seunke's third feature and can be considered as a humorous reworking of some frustrating experiences with both DE SMAAK VAN WATER [The TASTE of WATER] (1982) and PERVOla, SPOREN IN DE SNEEUW [PERVOLA, TRACKS IN THE SNOW] (1985). DE SMAAK VAN WATER seemed to launch a 238 promising career, and won among others the prize for Best First Work at the Venice Film Festival, but the success was slightly overshadowed by a controversy. The film was inspired by György Konrád's novel A látogáto [The Case Worker] (1969), but Seunke claimed he simply had forgotten to mention Konrád's name on the credits. In $\mathrm{OH}$ BoY!, the most despicable character in the film is blathering about a theft of ideas. Since Bozz is the one who gets on his high horse regarding presumed plagiarism, the accusations are uttered so hysterically that they become 'all spin and no delivery.' Bozz' inability to distinguish homage from unoriginal mimicry can be taken as a belated riposte by Seunke: the whole controversy at the time was much ado about nothing. Moreover, the portrayal of the obnoxious actor Gert functions as a satiric revenge upon the actor Gerard Thoolen, who played main parts in Seunke's two previous films. In PERvolA, Thoolen had especially shown himself to be a busybody who got on Seunke's nerves quite regularly. As a clear sign of Thoolen's highhandedness it can be mentioned that he, schooled in theatre, had protested against the choice for Bram van der Vlugt in the role of his brother, because the latter was mainly known for his television work. If Seunke's OH BoY! consists of a chain of brief anecdotes and is short of a true curve in development, as Gerdin Linthorst claims, this is due to Seunke's split aim (568). He not only wanted to pay homage to Buster Keaton, but he wanted to use the form of a comedy to settle a score with his meddlesome leading actor from a previous film.

The critics' response to Seunke's OH BOY! was only lukewarm, for which probably the complexity of the double aim is to blame. SHERLOCK JR. (Buster Keaton, 1924) is such a wonderful comedy, because the two layers are perfectly intermingled. Accused of a theft in 'real life,' a film projectionist dreams himself as a detective onto the big screen and solves the mystery. When he wakes up from his reverie, he is absolved from blame to the joy of the girl with whom 
he is in love. Inept at kissing her, he peeps at the film that is still being projected and copies the romanticism on screen. In $\mathrm{OH}$ Boy! a similar situation ensues, but this time the cumbersome Boy glances at the crew and sees that the producer is play-acting a kiss. When Boy is still hesitant, the producer kisses the director directly on the mouth. Boy does likewise with Gal, but such a mimicry of Buster Keaton is less well integrated than in the case of SHERLOCK JR. The homage seems too much embedded in paying Gerard Thoolen his due via highlighting the tense relations between the director and his overbearing 'star.' Ironically, this also proves Gert right, for he said at one point: 'I am irritated at the two layers in this production.' $\mathrm{OH}$ Boy! tried so hard to be a vicious satire, ridiculing Gert, that it failed to be the apt and light-hearted comedy it also wanted to be.

I bring this critical note into the debate, precisely because I am sympathetic to Seunke's work in general, which regrettably seems to have fallen by the wayside. ${ }^{8}$ But $\mathrm{OH}$ Boy! also deserves this sympathy, because its ending is exemplary of postmodern irony 'light,' something that will be brought to greater perfection in a film such as Alex van Warmerdam's OBER, discussed later in this chapter. At the very end of $\mathrm{OH}$ Boy! Boy's gas station is totally ruined, and he takes a scooter from under the debris. With Gal at the back he takes a gun, loaded with real bullets, and shoots the lock of the studio door to pieces. The scooter drives into the wide open, while the producer encourages the camera man to do a crane shot. Otto says this is really great for the end credits, but Gert disagrees: 'Stop, is the camera still rolling? What a waste of material.' Gert steps into the shot, facing the director: 'What a nonsense. We will do another take, don't we? Those two will return, right?' But the end credits are already visible over the perplexed Gert.

This final scene shows in a nutshell some aspects of the working of representations. The shot that shows Boy and Gal driving away is an integral part of the film; the reverse shot in which the camera is moving higher and higher is part of the making of the movie. When we then see the scooter ride towards the horizon, it is once again, the movie-within-the-movie, whereas the directions by Otto to the cameraman we hear over the shot is one diegetic level up: the sound belongs to the shooting itself. At the same time, when Gert enters the frame, his status is unclear. He is supposed to react as Bozz, the character he is playing, but he reacts as Gert, flabbergasted because this narrative turn was apparently not included in the script - for Otto still was thinking how to end the movie. Now the finale has been handed him on a silver platter, director Otto wants the camera to stop running, for the intervention of Gert spoils the shot since he is not playing Bozz. For director Seunke, however, the perplexity of Gert finishes off his pique at Thoolen, for whom Gert is more or less a stand-in. 


\section{THE BROTHER WITH A MOVIE CAMERA: ZUSJE}

In $\mathrm{OH}$ BoY!, the camera itself was used as a prop, but this was done to even greater effect in the successful low-budget film ZUSJE [LITTLE SISTER] (Robert Jan Westdijk, 1995). Its reputation as a true landmark film was strengthened after the publication of the study De broertjes van Zusje [The Brothers of Little Sister]. The beginning of the film says that it is a film by 'Martijn Zuidewind.' This Martijn takes his camera upon his shoulder and we see what he films while he is about to visit his little sister, Daantje. At her place he is clear about his aim from the start: 'I want to record the way you react to me.' Something has happened in the past which has affected Martijn seriously, and though we have some hints, we only get a picture of the events near the end. 'I have to know what I did,' but Daantje is not willing to be of any assistance: 'Why? We're happy like this.' But Martijn is not, and Daantje is the only one who can 240 | help him to put an 'end to his misery' which he briefly sums up as: 'loneliness, boarding schools.' Filming her day and night is his way to put her under pressure. The hints we get in the course of Westdijk's film consist of some homemovie-style inserts: the $8 \mathrm{~mm}$ scenes suggest a close bond between brother and sister, as when they play a mock wedding couple. Most crucial, however, is the fragment that their mother opens the bedroom door with a candle-lit cake for Daantje's ninth birthday and a naked Martijn sneaks out of the bed. As this home movie footage from the past might suggest, Martijn acts contrite, and apparently his mother draws the conclusion that he, as the older one, is to blame. At the end of the film, at the moment of the ultimate revelation, they are re-enacting their childhood. Daantje puts the camera in the corner and in a static shot we see that she was inquisitive about sexual knowledge, asking her older brother about his then girlfriend, Claudia. She takes the initiative, for she wants to know whether they kiss, how they kiss, how he lies on top of her. He is hesitant, but she is persistent: 'I'm the boss. I want to know. It is my birthday.' Though no penetration took place, the intimacy has marred Martijn's existence, for their mother caught them by surprise. Apparently, the reenactment has been healing for Martijn, for at the end credits we see that all his 'Zusje' tapes are for sale at a flea market.

The innovative gimmick of Westdijk's ZusJE is that Martijn is filming Daantje relentlessly in order to force her to an exposition of past events. She wants to get him off her back, but he simply will not let go. So the footage we get of Daantje's daily occupations is what Martijn has been shooting with his handheld camera. The sloppy cinematography, including out-of-focus shots and abrupt transitions, therefore is not a nuisance, but makes sense, just as it makes sense that we hardly ever see Martijn, but hear his voice often. The film which in essence is a drama comes across as a comedy because of the broth- 
er's cynicism. He can afford to piss off her friends, like Ingeborg or Daantje's lover Ramon, because he is only interested in his sister. A few examples to prove ZuSJE's comic nature: Martijn challenges Ramon to show that he is a cute kisser. In a direct address to the camera, Ramon explains in a boastful manner that kissing is not a technical thing, but it is all a matter of feeling. 'I have big lips, that helps, too.' Upon Martijn's request to show him, Ramon says, in extreme close-up: 'You wet your lips, open your mouth, like this ... and stick out your tongue.' He then wets the camera with his tongue. In another, early scene, we get some random impressions from a party Daantje has organized at her place. At one point, Ingeborg asks Martijn: 'Why don't you rewind your tape?' While he does rewind the tape, we see that Martijn has passed out for some time, and that Ingeborg tells the occasional camera man to 'zoom in on that drunk's head.'

Most crucial, and most funny as well, is how Martijn uses his camera as a tool to drive a wedge between Daantje and Ramon. Secretly he goes up the stairs and sees the lovers doggy-style, with a copy of the Kama Sutra in Ramon's hands. As they change positions, Daantje looks straight at the camera, but instead of yelling, she says: 'Ramon, don't stop.' A few moments hereafter, Ramon notices the presence of Martijn and he is frightened out of his wits: 'Jesus Christ. Your brother is a real nutcase.' Martijn makes the situation even worse when he says: 'Do you want to see how she looked at the camera, saying "Ramon, don't stop?"' Ramon is so mad he sends them out of the house, throwing the Kama Sutra after them. The pause in the relationship enables Martijn to spy on Ramon. He then proudly presents his 'masterpiece' to Daantje. We see a woman ring at the door, we see Ramon close the curtains. When the woman leaves, there is a shot of Ramon at the balcony, waving. Though Ramon plays presumed innocence, Daantje cannot forgive him for cheating on her. Later, as she watches the raw footage, she sees that the woman was one of the prostitutes, ordered by the neighbour living above Ramon, and that the idea that Daantje's boyfriend was having an affair was merely a result of Martijn's manipulative editing.

Ramon, not knowing about Martijn's role, asks him to record a video message. When Ramon starts to express his emotions, Martijn interrupts him sardonically by saying: 'This is bullshit. Maybe you have to write it down?' Ramon acts according to this advice, but as soon as they start recording, it sounds way too formal, with a line that starts with 'Under the circumstances ...' Ramon crumbles his piece of paper and then gives an improvised speech, full of passion: 'I love you, baby, I am not seeing someone else, you wretched little thing. Please call me, Daan.' He begs Martijn to show the material to her, but we hear the brother only murmur: 'You bet, sucker.' A true bully, Martijn does not show his sister the tape, for that might convince her of Ramon's sincerity, but 
gives her the crumbled piece of paper. Her response is: 'What a load of crap is this? "What did I do, Daan, to deserve this cruel fate?"' All Martijn's comic abuses are a result of his manipulative use of the camera - editing, withholding footage, shooting at inappropriate moments - and they are all aimed at one specific goal: to give an unfavourable picture of her friends so that she will confide in him and re-enact the event from 11 years ago. The mission to be accomplished is highly dramatic, for sure, but the means to Martijn's goal are comic, for he knows how to use the film camera itself to both sly and humorous purposes. ${ }^{9}$

\section{PLAY WITH ONTOLOGICAL LEVELS: HET ECHTE LEVEN AND MOCKUMENTARIES}

The riddle in ZuSJE is a matter of psychological motivation: Why is this 'young

242 man with a movie camera' stalking his sister? The answer is suggested near the end in a re-enacted scene. In his fourth feature film, HET ECHTE LEVEN [REAL LIFE RE-EDITED], Westdijk offers the viewer a riddle of a different nature: is it possible to determine the status of all the shots ${ }^{10}$ It seems so simple from the start. After the starting credits, which read that it is a 'Martin Zomer' film, we watch a young man, Milan, fall off his bicycle, and see him follow after Simone, who was responsible for the accident. He enters her house and climbs up the stairs. Suddenly, they are kissing and then end up in bed. When she leaves the next morning, she kisses him while he is still asleep, saying, 'Goodbye, stranger.' Upon her return, she is surprised to find him still at her place. From the subsequent conversation, the viewer realizes that they had play-acted the seduction scene. They pretended to be strangers, but Simone and Milan are actually lovers. Milan seems to be an overly sensitive type when he says in an angry tone: 'You cheated on me before my very own eyes. You gave yourself so easily to him. As if it didn't cost you any effort.' Simone replies: 'That's because I knew it was you.' Milan: 'That's not true. I was a complete stranger.' Since Milan concludes that 'everything could be fake' with Simone despite her claim that he is her 'one and only true love,' he starts an experiment: he will be away for a while and leaves her a letter with the assignment for her to 'find someone and fall in love.' He has the idea that only a relationship with another guy can help her to determine what they both mean to each other.

Some 13 minutes into the film, 'Milan' suddenly enters the scene, and says 'beautiful, thanks' and 'cut.' Milan is now Martin, the director of the film. From that moment onwards, the spectator knows he has to be on his guard all the time, for a scene can turn out to be a rehearsal for a scene, an actual film scene, or a slice from 'real life,' e.g., when Simone and Martin spend some time together in-between takes. ${ }^{11}$ To complicate matters, a scene can also be 
a bad take that has to be redone: either because a crew member is visible in a mirror, or when a hired actor has troubles reciting the scripted lines and in the next take is permitted to improvise. The failed takes contribute to the comic charm of HET ECHTE LEVEN. The inexperienced actor, Dirk, originally a crew member, is cast to play Simone's love interest as a substitute for the guy who kissed her too passionately during rehearsals, according to Martin ('It is not a porn movie'). Dirk has difficulty in distinguishing the acting performances from 'real life and real emotions.' He is really startled when he wakes up and finds a naked Simone besides him. He starts to excuse himself, thus spoiling the scene. Dirk thereupon reproaches Martin that he is sick to treat his own girlfriend like this, as if she is a prostitute.

When Milan returns in a subsequent scene, Simone tells him that she is fed up with playing games. She chooses 'the honest and authentic' Dirk, who starts behaving like a jealous boyfriend. Then Dirk's wife catches the two lovers by surprise in the bar, but Dirk does not recognize her, for she is only an actress, pretending to be his wife. Because Dirk has started to mix up fiction and 'real life,' Martin takes a more drastic measure: he secretly has Dirk's real children come over. We now get a clapboard which does not mention the title Het ECHTE LEVEN, but SLECHTE LEVER [bad liver], as if to announce some transition. The actress who played Dirk's wife says, while Dirk is kissing Simone: 'Dirkie boy, do you recognize these two?' His children ask: 'Were you really kissing her?' to which Dirk replies: 'That was just for the film.' After he has taken his children outside, Dirk is mad at Martin for not asking permission to bring the kids to this scene. According to the script, Simone is to break up with Dirk the next day in the bar in the presence of Milan, but Dirk comes over to her work and declares his love to her. This conversation is intercut with (lines from) rehearsal scenes by the actor who was originally cast as her love interest. She abruptly breaks the spell for Dirk, by yelling at him to stop, for it was only a job to act as if she loved him: 'I did it for the film.... We're not a good fit. Don't you see that?' Devastated, Dirk leaves the workplace.

Up till now, it has seemed that Dirk was not very bright to confuse fiction and real life, but from this point onwards, with a few scenes remaining, it becomes increasingly difficult for the viewer to distinguish the primary from the secondary diegesis. We now get an exact repetition from one of the earliest scenes in HET ECHTE LEVEN (or perhaps SLECHTE LEVER by now), the one in which Milan tells Simone: 'You cheated on me before my very own eyes. You gave yourself so easily to him. As if it didn't cost you any effort,' except that there are a few additional lines. When Simone says, as in the earlier scene 'That's because I knew it was you,' Milan says in dismay: 'Oh, yes, Dirk and I really resemble each other.' At the same time, while the scene runs, Milan switches to Martin, when he gives some directions to his cameraman. When 
Milan - or has he become Martin by now? - accuses her, once again, that she is a great faker, she tries to convince him by saying she loves him and kisses him. Then there is a sudden transition to the scene where Dirk leaves Simone's workplace, after she has chucked him. Initially, it seemed as if this was part of the film-in-the-film, because the scene was intercut with rehearsal scenes with the original actor from the past. Apparently, the scene was always already scripted. This time, however, it seems as if Dirk is not leaving the workplace, but the actual set. Simone starts crying and asks Martin to come to her, but the director is too flabbergasted: 'What did you do? I still had some scenes with him.' Simone's facial expression is one of disbelief; she regards Martin's reaction as heartless. Then the preceding scene which had abruptly been interrupted is taken up again. ${ }^{12}$ Milan and Simone have been kissing, and then she asks: 'You've got all you need now?' Milan - or is she addressing Martin right now? - does not respond, and she gives the answer herself: 'I think so.'

244 She gives him one more kiss, stands up and walks away from the set, leaving Milan/Martin behind in total confusion.

The ending suggests that Simone is not only done with Milan's weird games (on the secondary diegetic level), but she also accuses filmmaker Martin of being too fond of playing games. It is quite ironic that this very same reproach launched by Simone can also be applied to Westdijk as the actual director of HET ECHTE LEVEN. The entire film is set up as a game and invites its viewer to attempt to solve the puzzle, for each and every scene: is it part of the film-within-the-film, the rehearsal, or of 'real life'? Near the end, it gets more difficult to distinguish 'Milan' from Martin. The drawback of this emphasis upon a play with ontological levels is that it, inevitably perhaps, goes at the expense of the (romantic) drama of the film. As a consequence, this film lacks the poignancy of ZUSJE, which was a balanced blend of comedy and drama.

HET ECHTE LEVEN also lacks the acuity of the early video shorts made by Lodewijk Crijns, KuTzOoI [FUCKING SHIT] (1995) and his graduation project at the Film Academy, LAP ROUGE (1997). KuTzOOI is a grainy black-and-white video about three young adolescents who meet each morning and then decide on the spot whether they will go to school or not. Frequently, they play truant, and the camera follows them closely, e.g., when they find the porn magazine Big Mamas in the bushes or when they are invited into the canalside house of a middle-aged woman and suddenly close the door on the crew, until the moment the woman has had a mysterious fit. In a later scene, the boys ride on a bike with their eyes closed, but one of them, Leto, falls into the dirt among broken glass. The director himself comes to the boy's assistance and asks Hans to stop, but the camera keeps on rolling. Despite the sincere impression of the video, the documentary turned out to be a mockumentary, since all incidents were staged. The spectator of Westdijk's HET ECHTE LEVEN knows he 
is watching an enigmatic puzzle and has to concentrate to discern the status of the shots. In the case of KuTzoor, however, the viewer himself might be puzzled: Is this supposed to be real, or is it perhaps fake after all? Since Crijns plays by all the codes of a documentary, the viewer has no clues to decide whether the depiction is fictional. He may be suspicious, the more because Leto loses both arms at a really weird game, but he cannot know, unless extratextual information is provided. Whereas the effect of HET ECHTE LEVEN is predominantly ludic and playful, the ludic strategy of a mockumentary can sharpen the viewer's critical attitude: do not take for granted what you see.

Crijns' like-minded LAP ROUGE is about two bearded, middle-aged, native Dutch brothers who live with their elderly and dominant mother in a deserted village in France. Like KuTzooI, it is a bit strange perhaps, but it could have been a real documentary, for as the saying goes, sometimes the truth is stranger than fiction. The title of his first video, KuTzoor, has a deliberate ick factor. The term is used by the boys themselves to characterize their school, and it explains their reason for playing truant. Hence, the rancid title is a quote by the teenagers without the use of quotation marks. This is known as free indirect discourse, when a narrator's text is cross-cut with the specific wording of a character. This device increases an impression of 'authenticity,' for the film's title suggests that the makers have conformed themselves to the vision of the three boys. The title KuTzoor helps to set a trap for the spectator. Similarly, the title LAP ROUGE is another instance of free indirect discourse, for it is a corruption of a saying expressed by one of the brothers. Talking about his mother, he wants to say that 'she is like a red rag to a bull,' but he erroneously mixes the Dutch word lap [rag] and the French word rouge [red]. Moreover, his slip of the tongue gives the illusion of spontaneity, as if their depicted lives are for real. Hence, the titles of his video shorts are deceptive signposts, leading the viewer astray.

Several other films by Crijns have titles that are replete with irony. He made a film about male teenagers who suffer from cancer, but the Dutch title of this picture KANKERLIJERS [SICKOS] (2014) not only literally means 'cancer sufferers,' but also connotes a strong insult, comparable to 'motherfuckers.' For the boys, the term 'kankerlijers' is embraced as a streak of black humour, for they like to cause uproar in the hospital and behave like pains in the ass. At least as ironic is the title of his first TV movie MET GROTE BLIJDSCHAP [WITH GREAT JOY] (2001), an expression one uses, among others, to announce the news of a childbirth. In Crijns' film, it turns out that a man and wife have hidden their severely mentally disabled son in a dark, isolated room adjacent to their remote house. Instead of making news about the birth public, they have withheld all information about the kid, even to their family. Considering that Crijns had started his career with two mockumentaries, it almost goes without 
saying that he had wanted to work with an actual mentally challenged boy in the role of the hidden son. Since one usually works with actors in such parts - Dustin Hoffman in RAIN MAN (Barry Levinson, 1988), Leonardo DiCaprio in WHAT'S EATING GILBERT GRAPE (Lasse Hallstrom, 1993) - it would have been another option for Crijns to go against the grain. For the sole reason that practical obstacles could not be overcome, he cast a 'normal' boy for the part after all, but the performance is so utterly convincing that many a viewer kept believing that the (totally unknown) actor must be severely disabled, indeed. ${ }^{13}$

\section{BAUDELAIRE'S IRONIC DOUBLING: RENT A FRIEND}

In Terstall's underrated and dryly comic RENT A FRIEND (2000), there is no overstepping of ontological boundaries in the strict sense, but the world of 246 fiction is used to mirror the relationship between protagonist Alfred and Moniek. Alfred is a failed painter who hardly sells any work, while Moniek provides the income ever since she started as a copywriter at the soap factory of Wiert Fokker. With this background information, the opening scene makes sense. We see an episode from the soap Het kan vriezen, het kan dooien [Rain or Shine], and when the character Roy says 'Darn it,' Alfred, who is watching television, asks 'Darn it?' Moniek responds: 'That is "soap speak." "Darn it” is one of the recommended expletives.' Then Alfred asks: 'And why am I played by a black actor?' Moniek: 'Every soap needs a racial mix. And we felt that this character's colour was not so important so we gave him a colour.' Or when the soap character Roy says: 'I hate people who flash their wallet around,' Alfred comments that he has never said that, to which Moniek replies in turn: 'Soap characters are always direct.'

When in another episode Roy says that he suspects his girlfriend, Myrthe, of having an affair with her boss, and we actually see her kiss this man who prides himself on his 'sea legs,' Alfred becomes convinced of Moniek's adultery in real life. Thus, Alfred packs his suitcase and starts living at his sister's place. ${ }^{14}$ Despite Moniek's claim during her first encounter with Alfred that 'money is unimportant,' he thinks that she has fallen for her boss because the latter likes to show off his great wealth. According to Alfred, anyone with a brain can get rich, so he starts his own business - 'Rent a Friend.' ${ }^{15}$ This business turns out to fill a gap in the market and becomes hugely profitable. He is hired by a great variety of people, and many of the visits he has to pay to them are very amusing. He sits next to a lonely man on a bench in public, who tells he is often made fun of because he is too fat. 'But when you're with a friend, people don't laugh. And even if they do, it doesn't matter, because you're not alone.' He is also rented by a Dutchman to watch the German soccer team play 
a match. Since the man knows no one with whom he can celebrate a German victory, the only assignment Alfred has to fulfil is to shout 'Tor, Tor, Tor!' out loud when the team scores a goal. A husband and wife pay him to visit them, for they quarrel all the time, except when they have a guest. His presence, they tell him, saves them a lot of broken china.

Because of the success, 'Rent a Friend' has to hire new employees and he has to screen them during job interviews. A girl named Françoise who describes herself as opportunistic and ruthless becomes his business manager and introduces new categories like 'vague acquaintances,' 'good friends' and 'close friends.' So, while his business is booming, Alfred sees on the television that Myrthe, who is modelled after Moniek, is celebrating the holidays with her new lover, but she also catches him in the act while he is cheating on her. Alfred knows about this affair, because since he is living at his sister's place, his sister shows him a taped episode from Het kan vriezen, het kan dooien. He then is rented by Moniek, but he sticks to the house rule of his own firm that sex with clients is not permitted. We then get a transition to the soap, in which Myrthe has an encounter with Roy, Alfred's stand-in: 'I want to come back to you. Shall we go to Mexico and give it another try?' Alfred's sister switches off the television, saying, 'I already know the answer.' In the final scene we see Alfred having good times with Françoise, who is fascinated by Japanese culture.

The hugely enjoyable RENT A FRIEND presents the world of soap as almost a one-to-one pattern card for real-life characters; almost, because so-called 'soap talk' slightly differs from everyday expressions and a soap, as Alfred says at one point to the actress who plays Myrthe, offers 'emotions in bite-sized chunks.' In creating some parallel between the soap and real life, RENT A FRIEND comically suggests that modern-day life lacks psychological depth and 'authentic' emotions. No wonder then that people are in need of 'friendship,' and are so desperate to rent a friend: the married couple which is having a fight all the time, except when a guest is around, is the caricatural epitome of this despair. This does not yet mean that Terstall's film is desperate, on the contrary, for the film's tone is mild overall, thanks to Alfred's detached attitude and his deadpan comments. To add irony to this mildness, Alfred's dry comic remarks are so flatly spoken that they come to resemble the non-expressive manner of speaking of the soap character Roy, who functions as his stand-in. In the case of Roy, this flatness is due to both tight shooting schedules and a lack of talent that soap characters tend to suffer from. By contrast, in the case of Alfred, his deadpan tone seems to result from a desire to keep aloof. It looks as if his position coincides with the characters in what Jeffrey Sconce called the tendency of the 'new American "smart” cinema,' like SAFE (Todd Haynes, 1995), EleCtion (Alexander Payne, 1999), HAPPINESS (Todd Solondz, 1999), Being John Malkovich (Spike Jonze, 1999) or The Royal Tenenbaums 
(Wes Anderson, 2001). Characters in these films adopt an attitude of ironic detachment, not out of disinterest or general apathy, but because they simply do not know what (political) position to take. These films (the ones by Haynes and Solondz are the clearest examples) are marked by a 'blank style,' for they frequently use 'long-shots, static composition and sparse cutting' (Sconce 'Irony,' 359). In smart cinema, the spectator clinically observes a phenomenon and there are no a priori moral judgements. To politically engaged critics, this is sometimes taken as a form of nihilism, but Sconce claims that it is a refusal to identify with prefabricated positions; it is a 'strategic disengagement from a certain terrain of belief, politics and commitment' (369).

RENT A FRIEND can be said to endorse the 'blank style' of this smart cinema, marked by seemingly dispassionate framing and static tableaux. In fact, Alfred's current painting style, his 'Mexican period,' is symptomatic of this film mode of 'clinical observation.' He usually paints Mexicans from high above so 248 that we only see the top of their sombreros. ${ }^{16}$ No one buys these paintings, but he will sell the picture half price to the person who can guess what the image represents. He adds in voice-over that so far no one has come close. ${ }^{17}$ One of the canvases depicts four sombreros against a colourful background and an object between them. To his sister, Alfred explains that they are Mexicans playing poker and the object is a bottle of tequila. 'Where are the cards?' his sister asks. Pointing at one sombrero, Alfred explains: 'He's shuffling them,' and therefore the cards are invisible, hidden underneath the sombrero. Usually, a poker game is based upon psychology, since reading the faces of one's opponents can help one to make an educated guess as to what cards they hold in their hands. Alfred's painting, however, is an absurd representation of a poker game, devoid of all psychology. This painting can be seen as a synecdoche of the film's refusal to psychologize: we never get a clear notion of what goes on in Alfred's mind. He packs his suitcases and leaves, without making a scene. The emotional range of his soap alter ego seems greater, for Roy at least asks Myrthe: 'What does that show-off have that I do not have, Myrthe?' When Alfred sets up his business, it is not because of a burning ambition to be successful. He just wants to test his claim that making money is easy. In fact, Alfred is fit for the job as a 'friend,' because his work requires him to set aside all emotions. In one scene, he is even hired to play the third man, the fall guy. Says the man who ordered both Alfred and one of his colleagues: 'When I go out with my two best friends, one always is the fall guy, two always pick on the third. And the third is always me. I want to be one of the other two for a change.' So while the other two 'friends' are fishing, third man Alfred is bombarded with denigrating commands: 'Hey four eyes! Hurry up with those worms. We've almost run out. How are we supposed to catch fish?' Or: 'The worms were scared stiff when they saw your ugly face.' 
Alfred is the better fit for a job as a 'friend' as he is a psychologically 'blank' character. The required malleability shows in the scene when someone who has hired him, asks Alfred: 'Can I even call you Bram?' Alfred: 'Sure, whatever you like.' Man: 'That's a good name for a friend - Bram. Got a friendly ring to it.' Alfred: 'Yes, my name is Abraham. But Bram for friends.' And thus, Alfred comes across as an emotionally 'empty' character who talks (almost) as flat as the soap characters. Because he is a character, lacking any personality and ambition (in the opinion of scriptwriter Moniek), he might as well be played by a black actor. Nonetheless, Alfred differs from his soap stand-in Roy in a crucial respect. He is capable of taking an ironic distance from situations and of making deadpan comments, even when they are at his own cost. Commenting upon the choice for a black guy as his stand-in, Alfred says: 'Well, idiots come in all colours.' Similarly, when Françoise asks him why he broke up with Moniek, he refers to what he has seen on television: 'She met someone with sea legs.' The implication of this answer is: Like me, Roy is such a loser that he apparently has no compensation to offer for the fact that another man has the trivial quality of sailing on a boat.

Alfred is all too aware that by poking fun at the pathetic Roy, represented as his double, he is actually committing self-mockery. By watching his alter ego in the soap series, he observes himself, to paraphrase Charles Baudelaire in his essay 'De l'essence du rire' ['On the Essence of Laughter'], 'with the detachment of a disinterested spectator' (qtd. in Lang, 51). In this essay, Baudelaire complicates the so-called superiority theory, discussed in the Introduction. According to this theory, laughter is an expression of one's feeling of preponderance over another person - 'a satanic idea if ever there was one!' according to Baudelaire (145-46). When I see someone fall in a clumsy way, the standard example goes, I start laughing, because he is the bungler, not me. This kind of laughter, Baudelaire claims, refers to a pure and childlike joy, and is unaware of itself, resembling the 'happy tail-wagging of a dog' (Hannoosh, 39). It signals a weakness, for as he asks himself: 'Is there anything more deplorable than weakness delighting in weakness?' ${ }^{18}$ (qtd. in Hannoosh, 29). As a supplement to the superiority stance, Baudelaire introduces the ability to laugh at oneself. The reflexive type, which I use as a more common denominator for Baudelaire's specific mentions of the poet-philosopher and the comic artist, understands that it is not someone else who is falling, but that he himself is susceptible to falling as well. The misfortunate of another is coupled with knowledge of one's own vulnerability, or rather, one's potential inferiority. This self-consciousness can be considered as an ironic doubling, or dédoublement: he who falls could be me ${ }^{19}$ It is crucial for Baudelaire that one does not flaunt this knowledge, but that one pretends ignorance, for one's silliness makes others laugh: the essence of the comic, Michele Hannoosh surmises, 
resides in 'the power to step back from oneself and survey the phenomena of the self, the power to be at once oneself and another' (Hannoosh, 70), for only on that condition laughter as a sign of pride, out of superiority over others, is matched by laughter as a sign of one's own imperfection and/or misery.

In the case of Alfred, his confrontation with Roy as his screen persona enables him to 'step back' from himself, which may explain why many of Alfred's remarks have a self-deprecatory ring to them. One remark is particularly selfironic, and even though it does not directly concern Roy, its irony is a consequence of the mirroring function the soap has on Alfred. On one occasion, Alfred walks out on a client because he is uttering ethnic insults, which in fact is the one and only moment where he is more than just a blank character. Françoise justifies his act, because as she says: 'Ethical business principles are important.' Alfred: 'There goes my unblemished record. And for an idiot like that.' Françoise: 'You can't be everyone's friend.' Alfred: 'But I'm a perfection250 | ist. May be we should have a new range of "dodgy friends." Alfred's claim that he is a perfectionist is ironic for two reasons. First, the whole business was for him only a side issue. His true passion is making paintings, even when no one wants to buy them. 'Making stupid paintings, that's difficult!' Moniek at one point complains ironically, to which Alfred dryly responds: 'Not for me. I make lots of them.' Second, businesswise it is smart to be everyone's friend if your business happens to be 'Rent a Friend,' but in general, it is considered as an indication of a strong personality to be selective in choosing one's friends. Alfred's claim at perfectionism is here ironically converted into an admission of weakness: I have the talent of being everyone's friend (almost), precisely because I am a spineless figure.

\section{A METAFICTIONAL JOKE PLAYED ON A SERIOUS MAN: OBER}

RENT A FRIEND is the most 'Alex van Warmerdam' film Terstall has made to date. This picture, his sixth feature, was the first film Terstall shot on Super 35 CinemaScope instead of Super $16 \mathrm{~mm}$ thanks to a bigger budget. This enabled him among others to practice a 'blank style' with carefully framed compositions, also a trademark of Van Warmerdam. Moreover, the excessively down to earth attitude of Alfred recalls the sobriety of several Van Warmerdam characters. Further, many of them are 'split' into a different person as well, albeit differently than Alfred. The protagonist in RENT A FRIEND sees himself 'split' because of his (ex-)girlfriend's script, but in the case of Van Warmerdam, characters either choose to play another role - the farmer and his wife in KLEINE TEUn [LiTTLE TONY] (1998) decide to introduce themselves as brother and sister out of strategic reasons - or they are themselves condemned to role-play- 
ing, puppets in the hands of a screenwriter, as happens to the waiters Edgar and Walter in OBER [WAITER] (2006).

The two men in OBER are working in a restaurant, which is not very successful. In the beginning of the film, Walter is not feeling well, but since most seats are vacant, Edgar can serve the customers all by himself. One of them is his mistress, Victoria, who is hoping for some nice conversation, but Edgar treats her coldly, pretending he has no time for cheerfulness. When she whispers in his ear that she is very horny, he looks up and asks with a blank expression on his face: 'Salad?' In a later scene we understand why Edgar has a mistress, for he has an ill and bedridden wife at home, whom he treats brutally: he deliberately turns up the volume of the music so loud that her bed starts shaking. When we see in a subsequent scene that Edgar is having sex with Victoria, trying different positions, we suddenly get a scene with the scriptwriter Herman, complaining to his girlfriend Suzie about the unoriginality of the scene we have just witnessed: 'Always the sex. No need to show that,' until he has the brainwave to turn it into role-playing. The scene then continues with Edgar, dressed as a hunter, followed by four bare-chested blacks with spears, chasing after Victoria. When Edgar finds her in the shower, Herman is satisfied with the scene, but Suzie is not, for she wants to see what comes after. Herman does not give it, explaining it will become a cheap effect, if he were to turn this into an 'orgy with four Negroes.'

With the introduction of Herman, the status of scenes has shifted. Edgar is not a character in the primary diegesis, but in an embedded one, for he is written by Herman. At the same time, the scene in which we saw him perform sexually with Victoria is apparently deleted in favour of the scene with Edgar dressed as a hunter. Things take another turn, when Suzie sits behind the computer, while Herman is taking a bath. She writes that Edgar drags his wife out of bed and makes her confess that she is having an affair with her doctor. When Herman returns, he is mad and we actually see him delete the text Suzie has written: 'It is bullshit, for Edgar cannot know his wife is having an affair.' Hence, the scenes with Edgar are either fragments from a script or instantly deleted scenes.

So far, so good, but this scheme is further complicated after Edgar has been bullied by three male guests in the restaurant. His taking of their order was not enthusiastic enough according to them, and while using violence, they make him say that he sincerely recommends the deliciously soft German sausage. It is a true stroke of genius that this scene is followed by Edgar entering Herman's apartment, complaining that he has not been given a proper retort. Herman is flabbergasted with the entrance of the 'fictive' Edgar who also wants to know what the function of his 'chronically ill' wife is, for 'she ruins my life.' Herman: 'That is exactly the idea.' Edgar: 'But she also ruins 
your story. A sick wife is boring.' Suzie's revelation that Edgar's wife has had an affair with the doctor, elicits from Edgar such negativity - 'that filthy bitch' - that Herman immediately says that the secret affair will be deleted. It turns out that the writer has no clue where his story is heading towards, except that Edgar has to suffer: 'You have to be exasperated.' Edgar continues negotiations by asking whether in exchange for all the punishment that will befall him he wants to get rid of his present mistress and start an affair with a new girlfriend, 'a brief moment of happiness.' Herman is prepared to give him one, temporarily, on the condition that he will no longer bother him. Edgar will violate this condition, for he madly bangs at the writer's bedroom door after the brutal guests have returned and the only reply he was given was a 'lousy term of abuse' - namely, asshole. Thereupon he was beaten up and thrown into an aquarium. Herman, woken up in the middle of the night, then explains to him that he is a modern character without purpose, to which the distressed Edgar 252 | replies: 'A modern character, that is totally outdated.'

OBER explores the overstepping of diegetic boundaries by on the one hand having Edgar say scripted lines in his role as waiter. The things Herman writes on his computer are immediately visualized for us. When Edgar says 'eeeeeeee' for some time, this is a consequence of the fact that the writer had fallen asleep on the keyboard. Keeping in mind that Edgar has no text of his own, it is ironic that his former mistress tells him she wanted a friend who says something original now and then. On the other hand, there is the 'independent' Edgar engaged in a dispute with his spiritual father about the (lack of) ambitions of the main protagonist, the waiter Edgar. Humour resides in the writer's helplessness in the presence of Edgar and of other characters who also come to visit him. As soon as they leave his place, he can regain control, although to a limited extent. Since he lacks the creativity to offer Edgar an escape route, Suzie prompts solutions. When he then blames her for the outof-control screenplay, she decides to leave him, but not after she has inserted some terrible events as a sort of revenge upon Herman.

The major achievement of Van Warmerdam's cinema - and he shares this quality with someone like the Finnish director Aki Kaurismäki - is that the more deplorable the fate of the character, the more hilarious it gets. Near the end of OBER, after another of Edgar's complaints, Herman promises him salvation and a happy ending back in the arms of his girlfriend Stella. And indeed, she shows up in the restaurant, but when he runs after her, Edgar is suddenly run over by a truck. This accident is cruel, but also hilarious, since it is an actualization of one of the writer's earlier threats: 'If you come to my place once more, I will have you run over by a truck.' Hence, the writer's promise of salvation was only a pretext to get Edgar out of his apartment, but he was already keen on revenge. Moreover, during his last visit, Edgar accused Her- 
man of flaccid, sloppy script writing. Having his protagonist killed all of a sudden in fact proves Edgar's point. Indeed, Herman is a third-rate screenwriter, but also, it is an instance of irony that Edgar becomes the victim of his own accusation about the screenwriter's poor talent: you think I am a lousy writer, well, I will show you by having you killed. When thereupon minor characters like a Japanese gangster and Stella also pay Herman a visit, the bloody limit has been reached for the writer. He quickly types 'The End,' so that the last of the visitors dissolves into thin air. The final image is a long shot of the writer, all alone, staring at his computer screen.

In an article on cosmic irony in the cinema of the Coen brothers, Svetlana Rukhelman argues that several of its protagonists 'arrogantly attempt to "play god," scheming against the other characters' but because the scheme 'invariably goes awry,' we can take delight in 'wickedly laughing at the schemer's ironic downfall' (103). She uses A SERIOUS MAN (2009) as an example of the wicked game played by the Coen brothers. Larry Gopnik regards himself as a righteous man, who starts to wonder why he is suddenly beset by a string of terrible events. According to Ethan Coen, the 'fun of the story for us was inventing new ways to torture Larry. His life just progressively gets worse' (qtd. in Rukhelman, 106). Despite Larry's belief that he will be given an explanation, thinking that he is entitled to one, because he is 'a serious man,' he receives no response at all. Rukhelman argues that the Coen brothers are enacting in A SERIOUS MAN, the ultimate malicious cosmic joke by masterminding Larry's downfall, purely for their own aesthetic sport and 'plainly announcing this fact to their audience' (110). While Larry presupposes that he is being toyed with by the Jewish God and 'seeks a genuine theological explanation for his suffering' (Gallagher 'Introduction,' 8), the film explores the metafictional role of the filmmakers as deity, for it is they, who are toying with Larry with sadistic glee.

In OBER, screenwriter Herman is the spiritual father of Edgar, and of Walter, Stella, and several others. He is in a godlike position, but at the same time he is bombarded with questions, not only by his own characters, also by his girlfriend, Suzie: What are you up to with the script? Edgar, in particular, wants to know what is the purpose of the story, that is, what is the meaning of his life? Herman is unable to come up with answers, except that he tells Edgar: You have to suffer first, redemption will be later. Like in A SERIOUS MAN, the promise will not be fulfilled. In the film by the Coen brothers this is due to the fact that they themselves play the protagonist a cruel joke; in Van Warmerdam's film, the writer punishes the protagonists for his accusatory interventions by not giving him redemption, but an instant death. This punishment also backfires, for in using his power as a 'deity' to kill his annoying 'darlings' at will, Herman is bereft of all his characters, while no proper solution has 
been reached. At 'the end,' everyone has gone, including his own girlfriend Suzie. Initially, Herman plays a cosmic joke on his characters: 'You want to know about the purpose of your life? First you will be subjected to misfortunes before anything can come of it.' In the end, however, by getting rid of everyone who starts complaining at his door, he is left with a script that seems to lack coherence and meaning. Zooming out, as we see Herman all alone in the apartment in a long shot, the viewer can now wickedly laugh at the scriptwriter's own ironic downfall. Like Edgar and the others are toyed with by Herman, the scriptwriter in turn is toyed with by the external narrator of OBER. ${ }^{20}$

\section{A ROM-COM WITH PETER PAN: AANMODDERFAKKER}

As a reverence to Huizinga's Homo Ludens, this chapter on the ludic was meant

254 to suggest on the basis of various examples that playful humour can also have a serious edge: the enjoyment of one's holiday is not without stress and minor nuisances (CAMPING); the visual nature of the humour in the films by Stelling has to be taken as a most welcome antidote to a Calvinist tradition in the Netherlands; via the figure of the annoying smart aleck Gert, Seunke tried to settle the score with an actor he himself had worked with on two previous films $\mathrm{COH}$ Boy!); and all the other films indicated that images can be deceptive and therefore require scrutinizing attention.

Another concern, perhaps even an overriding one, was to examine a number of films which court confusion between primary and secondary worlds. Remember that in the vulgar comedy FILMPJE!, discussed in chapter 1, there was a scene in which the rude character Bob interrupted the progress of the story to comment upon the incoherence of the plot. In a rare moment of selfawareness, he called it a 'really weird movie,' but this moment might also be qualified as an admission of weakness: the script of this film is such a mess that it is better not to wait for the critics to say so. The films under scrutiny here are arguably more subtle than this and the order in which they are presented in this chapter lays bare an ever-tightening loop between levels. Seunke's $\mathrm{OH}$ Boy! is a ludic film about the shooting of a film, in which primary and secondary diegetic levels are to be distinguished, except for the last shot: Pim's departure with Chloe from the set is also turned into the ending of the filmwithin-the-film. ZusJE was about the use of a camera to intrude upon someone else's life in an unscrupulous attempt to clarify muddled affairs from the cameraman's past. The re-enactment scene at the end, in which the brother no longer holds the camera but is in front of the apparatus, belies the $8 \mathrm{~mm}$ home-movie footage that has been inserted throughout ZusJE and which has clouded the brother's life. In retrospect, the fragmented footage is revealed 
to lead to a biased interpretation of events. HET ECHTE LEVEN employed the postmodernist device of misleading its spectator in presenting an embedded, secondary world as the primary, diegetic world. In postmodernist texts, as McHale claims, such deliberate 'mystification' is frequently followed by 'demystification,' in which the true ontological status of the supposed 'reality' is revealed (116), but at the end of HET ECHTE LEVEN, which is constructed like a puzzle, the viewer is left to doubt the exact status of shots which are a near repetition of earlier shots in the film. In the case of Crijns' early films, the status of the 'documentaries' as such is unclear: KUTZOOI and LAP ROUGE trigger the viewer to search for clues whether the images are truthful or staged.

In RENT A FRIEND it is very clear how to distinguish the world of the soap from the 'real' world, although Alfred speaks almost as blandly as the soap character Roy, but this film owes its subtlety to the protagonist's self-mockery. Alfred is a character who stands at a distance from situations and his Mexican 'landscape' paintings are the ultimate proof of this: the perspective is so distant that we only see the huge sombreros from above. Since he watches the soap featuring his stand-in Roy, he himself also becomes the object of his deadpan irony, recalling Baudelaire's complication of the superiority theory: in laughing I also become the one who is being laughed at. The uncrowned master of this deadpan irony in Dutch cinema is Van Warmerdam, whom I will also discuss in the next chapter.

His OBER abounds in supreme ironies thanks to the ongoing breaching of ontological boundaries. At the primary level, there is a scriptwriter who has no clue where his screenplay is heading towards. His excuse for the lack of structure and direction is that Edgar is a 'modern character without purpose.' In the embedded world, Edgar can only perform poor lines, and he gives vent to this frustration when he visits the scriptwriter, not in the guise of an actor playing Edgar, but as the character Edgar. Since he has to depend upon the whims of the scriptwriter, he requests better lines, suggests deletions as well as more creative twists, and offers meta-commentary. As a result of his efforts, Edgar is, in the secondary world, overrun by a truck, since the scriptwriter was fed up with his interventions. To add irony to this malicious joke, the screenplay lacks all that the characters were begging for (substance, coherence, meaning). This lack is visualized in the final shot of the solitary Herman, a shot which ironically summarizes that he is inept as a scriptwriter.

The irony in the cinema of Van Warmerdam - but also in RENT A FRIEND and DE WISSELWACHTER - works so well, because of a deadpan approach, which is totally at odds with many films from earlier chapters: in the majority of comedies the neurotic behaviour of characters is underscored by frenetic camera movements, hectic music on the soundtrack, exuberant colours and/ or emotional outbursts, from laughter to sobbing. By contrast, the films by 
Stelling, Terstall and Van Warmerdam refrain from using any comic markers, and since the characters themselves do not laugh, it is really up to the spectator whether he finds the situation hilarious or not. There is no better example in the oeuvre of Van Warmerdam than the scene in which Edgar - suggested by Suzie to Herman - walks into an obscure alley and passes a shop window, which displays a bow and arrow. Upon his entrance an old woman with a head scarf and a bent back very slowly descends the stairs. The buying of the bow and arrow will last five and a half minutes of screen time, during which the woman - a magnificent role by the male actor René van 't Hof - does not utter a word. It takes that long, because her movements are very protracted. The woman takes the objects out of the shop window and starts to pack the arrow. She has to search for a pair of scissors, she cannot find the beginning of the adhesive tape, she accidently tears a part of the wrapping paper, and the pair of scissors remains stuck between her fingers. When she is about to wrap the 256 bow, Edgar decides he had better not wait any longer and takes it unpacked, out into the street, for everyone to see. Packing the arrow, which has the air of slapstick, was so slow-paced that it could cause irritation among viewers if not for the perfect timing by the actor. As such, the scene is not funny, but it can elicit laughter from the audience, precisely because the woman patiently continues her 'duty' in such an incredibly slow pace. The duration of the action turns it into a comic scene, at least for the viewer who has affinity with such deadpan humour.

Released in early November 2014, Michiel ten Horn's second feature AANMODDERFAKKER [HOW TO AVOID EVERYTHING] proves to be a perfect elaboration of the deadpan style of the last couple of films discussed in this chapter. ${ }^{21}$ Its title even goes beyond a Crijns' title, 'Aanmodderfakker' being a pun that is as cheesy as smart. 'Modderfakker' can be taken as a literal transcription of a Dutchman pronouncing 'motherfucker' poorly. 'Modder' sounds like 'mother' (which is 'moeder' in Dutch), but actually means 'mud.' More crucial is the additional prefix 'aan,' for 'aanmodderen' is a verb one uses to say that someone is just muddling through. In the end that is just what the main protagonist Thijs, a 32-year-old slacker, is doing, although an active verb like 'doing' is probably too big a term, for Thijs is, in the vein of Alfred from RENT A FRIEND, an emblem of passivity, time and again avoiding doing something substantial. At one point in the film, he is reading a bedtime story to a child, and the few lines about Wendy and Peter suffice to make us realize that it is from J.M. Barrie's Peter Pan. This can be taken as a clue to associate Thijs with the so-called 'Peter Pan syndrome,' a pop-psychology term to refer to a (male) adult who has remained an eternal boy and is socially immature. ${ }^{22}$ Thijs spends some occasional shifts at the information stand in an electronics store, but at no point do we see him helping a costumer, whereas the smoke breaks with col- 
league Tommy are frequent. ${ }^{23}$ To a young employee who passes by, he says, in the company of both Tommy and Dirk, the latter a hippie-styled guy who is reading a novel all the time: 'I understand you are new here, but could you please move a bit less? It gets on our nerves.' He eats some vitamin-rich food because his meddlesome mother has given him some leftovers in Tupperware containers. ${ }^{24}$ Time and again, she requests, apparently hoping to keep the contact going, whether he will bring them back. He never does, of course, until the moment that he is so fed up with his mother that he throws his entire collection of containers on the floor in the living of the parental home. One of the running gags is that he spills beverage on the keyboard of his computer. After cleaning the keyboard he hangs it on a clothesline. For his regular laundry, however, he visits his sister's place, where he meets one evening the 16-yearold babysitter Lisa, the half-sister of his brother-in-law.

Since Thijs has made laziness into an 'art' and refuses to take any initiative, he cannot change, as Mariska Graveland wrote in her review of Ten Horn's film, thanks to an inner urge, but only because someone else makes him act much like Alfred came up with the idea to rent himself as a friend as a reaction to his girlfriend's adultery (and also much like the two friends in SHAUN OF THE DEAD (Edgar Wright, 2004), who turn their moribund lives around with the arrival of the zombies). In AANMODDERFAKKER, it is Lisa, precocious for her age, who pulls Thijs out of his purposeless existence. She wants to have high grades at her secondary school in the hope of being accepted to Oxford University and she is also concerned about environmental issues. From the moment of the encounter between these two opposites, Ten Horn's film is clearly modelled after a typical romantic comedy - of the kind of NotTING HILL (Roger Michell, 1999) - except that Thijs is too 'fearful' (Lisa's reproach) to really engage himself. Thus, he has the very same excuse for being late every time - a problem with his bicycle chain - and when she really says that she loves him, he insults her by saying that she is too childish. When he is about to walk out on her, he meets Lisa's much older half-brother, who gives him a good punch on the eye. The one time Thijs is on time, to his mother's performance in a church choir, he realizes he has to run for love after all, but Lisa is already about to take the plane for a stay abroad. Since she is on her way to the gate, they only have a brief form of communication, separated by a glass wall, with Lisa writing some text, and drawing a picture of a sea turtle to indicate that she is going to help this species.

Even though AANMODDERFAKKER takes the guise of a romantic comedy qua structure, including the ups and downs in the encounters between prospective lovers, the film never really becomes one because Thijs is too cynical to believe in love. A passion for Lisa only awakens when it is already too late, but while he rushes after her, he also remarks: 'What a fucking cliché,' as if 
he is fully aware that, because he runs for his love, he is trapped, as a fictional character, in a romantic comedy, much like many characters in this chapter have been struggling with ontological boundaries. The curious case of AANMODDERFAKKER is that all the ingredients of a romantic comedy are there, but the inactivity of the protagonist works against it. On the one hand, Thijs' passivity is underscored by carefully composed long-take shot compositions, a stylistic characteristic AANMODDERFAKKER shares with RENT A FRIEND and the work of Van Warmerdam (as well as with the 'quirky' films of Wes Anderson and Todd Solondz). The art direction in Ten Horn's film is excellent and often we can detect striking and funny details in the background: Dirk moving on a Segway through the store, still reading his book; during a film party, one character is disguised as Chewbacca from STAR WARS, but because he is reading a book, we know that it must be Dirk; adults jumping in an idiosyncratic style on a trampoline during a party in a garden; an employee replacing the 258 | sign 'comedy and romance' in the DVD section for 'drama,' just when Thijs' brother-in-law comes to tell about his marital problems; often such details are conspicuously absent as well, for Thijs, who occasionally says he is 'too busy' and has 'things on his mind,' is regularly shown in the right part of the frame, with the left part significantly blank, no more than just an empty wall.

On the other hand, the camera is hardly very static, as if its role is like Lisa's attempt to change Thijs' sleepwalking existence. The camera is particularly mobile when Thijs is most passive: lying in bed the camera slowly circles in overhead shots around him; when Thijs' roommate has announced his departure, Thijs is passive, while the camera tracks backwards in the direction of the living room, where his mother is already waiting, as if to encourage him to face her. When the camera pans to the left with Thijs, he suddenly goes to the right when he sees Uncle Dick, and the camera then follows this uncle who catches up with Thijs to tell him a cheap pun about his nephew who had gone to India to visit the 'Touch my Hole' (Taj Mahal). On a few occasions, the camera has already moved a bit advance of Thijs, who then enters the frame from an off-screen position, e.g., in the scene when the camera tries to locate the mice on the basis of the sounds they make. Moreover, AANMODDERFAKKER has some quirky sequences, when the stop-motion technique is used to make characters, including Thijs, to move fast, and there is a quick succession of overhead shots in which Thijs gets angry at losing games against children (chess, draughts), while a number of significant objects fly across the screen, like toy dinosaurs, Lego bricks, Jew's harps, mousetraps. In addition to the fact that Thijs realizes being caught in a clichéd romantic comedy, such ludic sequences emphasize the fictional nature of AANMODDERFAKKER. ${ }^{25}$

Thijs, like Alfred, can be considered, in the words of Herman, the scriptwriter in OBER, as a 'modern character' without a clear aim. Nonetheless, he 
- and Alfred as well - awaits a relatively good fate: Thijs' new roommate keeps the place tidy; Thijs is listening to an audio version of Allen Carr's Easy Way to Stop Smoking; and he has his own washing machine. In the very final shot, the camera zooms in on the rotating machine, while Thijs' face becomes gradually visible in its glass door. This visibility may still be a token of his narcissism, for people do not change overnight, but at least there are clues that Thijs has made a start to break out of his cyclical life pattern. ${ }^{26}$ At the same time, there is reason to doubt the optimism of the ending, for the tracking zoom shot on the washing machine, which seems to rotate every second faster and faster, suggests that impending doom is at hand, but before anything bad can happen, the end credits set in. Therefore, in AANMODDERFAKKER, the comic tone can still be said to preside over the tragic part. By contrast, Edgar in OBER, who constantly rebelled against the aimlessness imposed on him by Herman, meets a tragic death as if to emphasize that the struggle between scriptwriter and character is unequal by definition because they belong to different ontological levels. Accusing Herman of flaccid screenwriting, a malicious joke is played upon Edgar as a sheer instance of cosmic irony. 


\section{From Insubordinate Playfulness to Subversive Irony}

The so-called '1,2,3 Group' was a ludic group, if there ever was one in Dutch cinema. The group united five young filmmakers, described on René Daalder's webpage as 'future architect Rem Koolhaas, director Jan de Bont, TV personality Frans Bromet, software tycoon Samuel Meyering and multimedia pioneer Rene Daalder.' ${ }^{1}$ In 1965 , they made the 15-minute-long short DE 1,2,3 RHAPSODIE [1, 2, 3 RHAPSODY], consisting of five brief segments, which have a totally unpretentious appeal. In the segment 'Hoe stoer Jan kan zijn' [How Tough Jan Can Be], De Bont poses in front of the camera as an aviator and a fisherman among others and he is prancing around in a meadow, wearing only white underwear. In another segment, Koolhaas plays a lackey who crawls under the skirts of the English queen. Further, Daalder is portrayed as a maternity nurse who is extensively being praised in voice-over by a young mother: 'She's one in a million,' but 'My husband was constantly hanging around her. I have no idea why.... She's not that pretty, is she? But she didn't encourage him at all.' Because it was a sloppily shot short, the black-and-white DE 1,2,3 RHAPSODIE had an improvised feel.

The seemingly playful short was a follow-up to a manifesto the five had written to distance themselves from François Truffaut's famous dictum that the director should be attributed the honorary label of auteur when he has full responsibility for the film, from the first words written in the script to the final cut. The Group explicitly resisted this requirement: for its five members a film was the result of a cooperative effort of cast and crew, in which no one, not even the director, had pride of place. To underscore their criticism of the concept of the auteur, which had created such a buzz in circles among French cinephiles, the five constantly switched roles. In the one segment De Bont (or Daalder or Bromet, etc.) was the director, in a second the actor, in a third the scriptwriter, in a fourth the cameraman, in a fifth the sound record- 
er. Since DE 1,2,3 RHAPSODIE was made to downplay the snobbish attitude of film lovers, the short had to avoid any suggestion of pomposity. In order to live up to their pretence, they paradoxically had to make a film which necessarily gave a ludic and matter-of-fact impression. Because the aim to subvert a dominant vision on the practice of filmmaking lurks behind the unpretentious stance, DE 1,2,3 RHAPSODIE belongs to this chapter, which differs from the previous one in displaying a (slightly) stronger inclination to subversive forces.

This short illustrates the fact that Dutch films in the 1960s had the advantage of being made amidst a whirlwind of tendencies, which could be termed 'rebellious' because the cinematic tradition in the Netherlands was still young and above all quite tame (see chapter 3 on Staudte's CISKE DE RAT and Haanstra's FANFARE). There was much to explore for the new film school generation, and they did so either by resisting international trends (as the 262 1,2,3 Group) or by adopting influences: Adriaan Ditvoorst and the nouvelle vague, Frans Weisz and the baroque cinema of Fellini. In his Van FANFARE tot SPETTERS, Hans Schoots gauges the claim that the rebellious stance of the filmmakers is in fact a belated aping of the mentality of an artistic avant-garde from the 1950s, represented by the writer-poets Simon Vinkenoog, Gerrit Kouwenaar, and Remco Campert, painters like Karel Appel and Corneille, as well as the painter-poet Lucebert. The influence of these artists came literally to the fore in several short documentaries dedicated to their work (Jan Vrijman on Karel Appel; Johan van der Keuken on Lucebert) and Campert wrote several scripts for the screen, directed by either Van der Keuken or Weisz. ${ }^{2}$ Hence, Dutch films in the 1950 s had been overall complacent, but in the 1960 s some filmmakers incorporated the insubordinate undercurrent of the 1950s, then voiced by a scene of writers and visual artists. In this chapter I will examine how such an insurgence is laced with humour and wit.

\section{LUDIC PARANOIA: DE MINDER GELUKKIGE TERUGKEER VAN JOSZEF KATÚS NAAR HET LAND VAN REMBRANDT}

DE MINDER GELUKKIGE TERUGKEER VAN JOSZEF KATÚS NAAR HET LAND VAN REMBRANDT [The Not SO FortunAte RETURN OF JoszeF KATÚs TO THE COUNTRY OF REMBRANDT] (Wim Verstappen, 1966) was made with limited means: Verstappen had some unused film stock available totally by accident; his former fellow student Wim van der Linden had an Éclair camera; Rudolf Lucieer offered himself to play the main role. ${ }^{3}$ So they simply decided to make a film. The film was made according to the idea of contiguity as it was prac- 
ticed by neo-realists such as Roberto Rossellini. The French critic André Bazin praised Rossellini's RoMA CITTÀ APERTA [ROME, OPEN CITY] (1945) and PAISÀ [PAISAN] (1946) among others because of their 'adherence to actuality' and their strong concern for day-to-day events. He described these films as 'reconstituted reportages,' without ever becoming pamphlets for specific ideological positions. Rossellini's 'revolutionary humanism' is particularly notable in ROMA CITTÀ APERTA in which a Catholic priest comes to the assistance of a communist resistance fighter. They could have been used as paeans for or against Catholicism, or for or against Communism, but, Bazin claims, Rossellini walks the tightrope between these two positions. The neo-realists, he argued, focused upon the 'concrete social realities' such as the black market, poverty, prostitution, unemployment and thus they downplayed 'the a priori values of politics' (Bazin 'Cinematic Realism,' 34).

Verstappen's film about Joszef Katús has an even stronger concern for day-to-day events than Rossellini's films and covers the days from 29 April to 5 May 1966. The main actor was present during an actual procession near Palace Soestdijk to celebrate the queen's birthday and improvised on the spot. He also spontaneously joined in with an actual demonstration, shouting for the release of a Provo member, ${ }^{4}$ although the character later says he has no clue who this Hans Tuynman was. ${ }^{5}$ At the same time, politics is trivialized to an extent that the neo-realists would never do. In Italian cinema, politics is perhaps only temporarily side-tracked, Bazin suggested. Because of an emphasis upon urgent social problems, political discord does not come to the fore in their cinema, but, as Bazin states, it 'could happen that tomorrow [the priest and the Communist] might not get on so well' ('Cinematic Realism,' 34). Verstappen's film constitutes an ironic contrast to Bazin's characterization of neo-realism. DE MINDER GELUKKIGE TERUGKEER is set amidst an atmosphere of explicitly political and anti-bourgeois provocations, but its main protagonist keeps aloof. Interviewed by a documentary maker who wants to capture the revolutionary spirit of the so-called Provos, Joszef explains that he is just a hanger-on, an opportunist who is neither in favour nor against ideals. Since Joszef refuses to side with the Provos, the documentary maker calls him a fiasco and a commonplace type. Joszef, however, does not want to assert ideas, he just wants to 'be.'

Instead of advocating political engagement, Verstappen's film ties in with the cinematic avant-garde, although its makers once again opt for a light-hearted variant, up to the point of irony. Michel, protagonist of Godard's breathtaking debut feature À BOUT DE SOUFFLE [BREATHLESS] (1960), was a model for the character of Joszef, but the latter was only a small-time crook. Whereas Michel had shot a policeman, Joszef only sold sugar cubes with eye drops as if it were LSD. Moreover, Michel is shot by the 
police in the streets after his girlfriend has betrayed him. In an imitation of the staggering walk of a character from the western MAN OF THE WEST (Anthony Mann, 1958), Michel dies. In DE MINDER GELUKKIGE TERUGKEER Joszef is severely hit in the stomach by someone, perhaps a secret agent, on the street in Amsterdam. We see this scene at the very beginning of the film, but it is repeated at its very end, where it fits chronologically, for this incident takes place on 5 May. We know by now that this figure has been stalking him since his arrival in the Netherlands. Joszef is suffering from serious stomach pain so probably the blow is deadly. The other clue that he does not survive the assault, is derived from an ambiguous voice-over, spoken by actress Shireen Strooker, in the beginning of the film: 'Joszef Katús came back to Amsterdam (in order) to die.' Since the film also starts with the end scene, it is tempting to consider this text as a comment upon the beginning couched in terms of a foretelling.

264 Despite the aggression in this repeated scene, the overall tone of Verstappen's film is droll and whimsical. There are frequent references in voice-over to cola: 'When he came back from Paris, the cola was not as good as when he had left.' Or: 'In East Germany, Coca-Cola was synonymous with capitalism, murder and rape.' Or: 'In Morocco, they had the best cola.' None of these voice-over texts have anything to do with the images we see or with the actual story; they are spoken in isolation. Another indication of the droll tone: cheesy music is being played when Joszef is about to be examined for his stomach pain. Or Joszef has the strange habit to make duplicate keys to open station lockers. He does not do so in order to get rich, but to mull over the odd objects he finds in them, as the voice-over explains: 'Old clothes, mouldy bread, orange peels, a rickety umbrella, hardly anything of value.' To top all drollness, we get a comical close-up of this 'secret agent' at one point, who addresses the camera and utters this paradoxical line: 'Such a pity that I am not permitted to say anything in this movie.'

DE MINDER GELUKKIGE TERUGKEER never fulfils its suggestion that this might be a politically engaged film, because of its focus upon banal details, its isolated references to cola which become no more than a gimmick, and its alienating devices (like the frontal staging of the 'secret agent'). Or rather, Verstappen's film so provocatively refuses to be a political film that it becomes humorous and comic in rebound - a mere ludic film. At the same time, there is an edge to this apparent playfulness when we consider the extra-textual information that director Verstappen had the idea he himself was being watched by Dutch secret agents, since his visit to East Germany with Pim de la Parra. From this perspective his ludic film, with the ludic title, is an ironic lure. Because Verstappen presumed he was prosecuted himself for political reasons, he made a film about a guy who may seem politically 
active, but is no more than an idler. And thus Verstappen's paranoia translates itself into a mild satire of Dutch security services, for the stalker, taken for an agent, keeps on following the 'wrong man,' who has nothing on his sleeve. In the guise of a ludic film, Verstappen seems to plead the case that he is absolutely an innocent man and that the security services are overcautious, for if they are really watching him, they are wasting their time on him - and, worse, wasting their aggressive energy on the film's protagonist, who is senselessly beaten up in the street.

\section{A TONGUE-IN-CHEEK SHORT: BODY AND SOUL}

Verstappen's tongue-in-cheek tone is perhaps only matched by a short film, also from 1966, made by the aforementioned Daalder. The 12-minute BoDY AND SouL, has, as the title may suggest, all the ingredients to become of iconic value for the upcoming 'soul-searching' hippies. Instead of becoming a 'sign of its times,' BODY AND Soul is best to be seen as a parody of hippies even before the Flower Power era has really taken off, which makes it an historically odd picture, but also, in retrospect, an amazing achievement.

BODY AND Soul is beautifully photographed, by Jan de Bont, in black and white and in widescreen, and it consists of a few daily episodes out of a strong man's life. This bodybuilder, named John, does not speak in the film, but a voice-over, in English, speaks for him all the time in a fairly flat tone. John is trying on new clothes in a men's shop, but he actually is fearing 'that he is nearly too big for ready-made clothing.' After the opening credits, we see him working out at the gym by lifting weights. The voice-over mentions that his muscles had pumped up so much that he was thinking that 'his body might grow over his head if he didn't take care.' At that point John gets distracted, and after hanging around a bit, goes home. Meanwhile, the voice-over mentions that he supposes that 'the mind is superior to the body,' but in his case the mind apparently does not keep up pace with his body, for thinking always puts him 'in a bad mood.' He is trying on a white shirt for a party that night, but 'his clothes had conspired to make him conscious that his body had outgrown him.' He does not succeed in fastening the top button, and when he expands his chest in front of a mirror, a button pops off the shirt. He then reads an article in the magazine Mr. America which states that one has to tell oneself, a thousand times: 'I will become a real man like the Creator has intended me to be,' but his mother tells him she wanted him to be the way he was.

When John then passes a mirror, he 'couldn't resist the temptation' to look into it and starts admiring himself. The voice-over and the music 
remain silent for about one minute while we see him doing some bodybuilder's poses either from a frontally staged low angle or from behind his back displaying his torso via the mirror. 'The feeling grew stronger and stronger that his body didn't belong to him anymore and would live its own life one day.' $\mathrm{He}$ then continues the poses once again, until we see his mother who has been climbing the stairs appear via the mirror under his right armpit. John stops immediately, disenchanted by her arrival, because, as the voice-over says, she gives him the impression that his posturing is indecent.

At the party, John is alone, not knowing anybody and he is not sure whether he wants to know anybody. Once again, the voice-over is expressing John's concerns with his appearance: 'He didn't like eyes on his back. Funny, he thought, nobody knows how one looks from behind. He should have taken some pictures from behind.' Another rumination by the narrator: 'His presence didn't change the party a bit. Everyone was too much occupied with themselves 266 | to think about him.' We then see some partygoers throw wood into the open hearth, commented upon in a deadpan voice-over: 'When the mood goes down everyone tries some acts of despair.' After someone challenges him to a game of arm wrestling, we see John from behind, blocking our view of his opponent, until the moment when the latter loses the contest. This piques the curiosity of the guests, who suddenly realize 'that there was a bodybuilder in their midst.' The girls present want to know what a bodybuilder looks like. 'John didn't know what happened to him; they began to undress him, that he noticed.... Most people would be embarrassed if their body was exposed like this, but what kind of bodybuilder does not want to show his body?' Standing there, 'lifeless as a statue,' suddenly a student with knowledge of classical mythology has a great idea of how to make a spectacle of John: 'Let's make him an Atlas, he suggested.' The student puts a globe on John's shoulder. 'For once, John was allowed to bear the whole world.' When the globe falls from his shoulder, the camera tilts down slowly and follows the globe between the legs of the partygoers, who use it like a football.

Oh God, John realized, the globe will be destroyed. Why is everything always to be destroyed? The party was now quite degenerated. For the first time that day, he knew exactly what he was going to do. He took the globe away to put it back where it belonged - in the holder. There are still some things around you didn't play with, and John was the only one around here who was conscious of it. He was certainly annoyed by the destructive inclination. And what a waste of money, John thought. Such an expensive globe. 
Daalder's short can be seen as a particularly tongue-in-cheek film, once we start considering its title in combination with the period in which it was made. Around 1966, soul-searching hippies were en vogue, but this film was about a huge and strong man who is all body. He seems out of step with his times, for he is not pursuing mind-blowing experiences. On the contrary, John is as blank a character as imaginable, without facial expressions throughout the 12 minutes the short lasts. He has several thoughts, but they are quite pathetic: he has the silly anxiety that his body growth will affect his mind negatively, as if the bigger the body, the less well his brain will function. Nonetheless, his own body fascinates him tremendously, for he cannot resist the narcissistic desire to show it off, and the camera cannot resist registering John's admiration of his own body. Moreover, the fact that the narrator speaks on behalf of the protagonist has an ironic effect, because of a striking contrast: he paraphrases the thoughts of the bodybuilder in a very reflexive and precisely verbalized manner without ever commenting upon John's naive ideas. Because the bodybuilder himself does not speak a single line, the protagonist is really made into a spectacle. This reaches a climax at the party, where he is not offered a drink or a sandwich and does not speak to anyone, but he is undressed for the enjoyment of all the guests, who are anxious to see what a bodybuilder looks like. He swallows this treatment, which makes him a very passive character throughout. The voice-over describes him as 'lifeless as a statue' for good reason. The one action he undertakes, except for the exercises at the gym and the expanding of his chest, is to put the globe in the holder as he sees the guests playing with the object as if it is a football. The voice-over is, on behalf of John, talking about his awareness of their 'destructive inclination.' The narrator uses pathetic phrasing to describe the emotional turmoil of the character in the final shots ('Oh God ... why is everything always to be destroyed?'), whilst still speaking in the very same detached tone. The flat tone is visually underscored by the meticulous mise-en-scène and the relatively lengthy widescreen shots. The narrator's description becomes the more ironic since hippies, unlike John, consider the mind superior to the sanity of the body. For them, a body is a mere vehicle to mind-blowing experiences, and one of the ways such an experience can manifest itself is in getting in touch with 'mother Nature,' figuratively speaking. The final words of the narrator are an ultimate ironic twist, because he takes his task to 'save Mother Earth' in the most literal sense possible: if in the eyes of John, the world might be coming to an end, this has nothing to do with political matters as hippies would claim, but with the way the guests treat an expensive globe. This strong man, who is all body, is only concerned about Mother Earth in the form of a precious object, which can be taken as ultimate ironic proof of the fact that a gigantic physical appearance perhaps affects one's mind, indeed. 


\section{ANTI-BOURGEOIS SATIRE: DE VERLOEDERING VAN DE SWIEPS}

If both DE MINDER GELUKKIGE TERUGKEER and the short BODY AND SOUL tended to comically trivialize the typical 1960s engagement of the Provo movement and the soul-searching hippies, then DE VERLOEDERING VAN DE SWIEPS [The Whipping Cream Hero] (Erik Terpstra, 1967) portrays a bohemian about whom can be said that 'he's the man for his time and place. He fits right in there. ${ }^{6}$ This bohemian is Manuel, played by Ramses Shaffy, who by that time had already become known as a maverick and larger-than-life artist/singer. He is introduced as a hitchhiker on the road, and when he is picked up by the civil servant, Jan-Hein Swiep, he says: 'You are going in the right direction.' 'Where do you have to go then?' 'Your way.' From that point onwards, Manuel will suggest proposals which are increasingly more impertinent. And Jan-Hein simply is too compliant and polite to say 'no' to any one of them: his natural attitude

268 is the obedient mode. In the very first scene we have already seen that he lets everyone pass ahead of him into the elevator so that he ultimately has to take the escalator. Once Jan-Hein has introduced Manuel as his 'guest' to his wife, Ans, and his little son, Heere - 'a name chosen for sentimental reasons of a familial nature,' Jan-Hein says - the intruder starts to adopt a strategy of interchangeably pleasing and stupefying the couple. Initially, Jan-Hein is inclined to defend Manuel, if perhaps only out of hospitality. When Ans asks Manuel, who calls himself a poet by profession, after his surname, Jan-Hein answers that their guest has become an orphan at a very young age. Thus, Manuel is kept from revealing his surname.

After Manuel has been allowed to sleep over, he starts to charm Ans, while Jan-Hein is at work. They go shopping together, they buy records and clothes. Jan-Hein starts complaining about Manuel's presence to a colleague at the office, for the guest drinks all the booze and the television has been moved to his bedroom. When Manuel unexpectedly visits Jan-Hein at work, he pokes fun at him in the presence of his colleague. Jan-Hein is fed up with the intruder, but Ans tells her husband: 'You invited him into the house, and wanted to show off your hospitality. Now you want to throw him out.' Ans points out a presumed inconsistency in her husband's behaviour because it is in her own interest to keep Manuel around: she is involved in a romantic liaison with the guest, or at least, so she thinks. ${ }^{7}$ Jan-Hein is fighting a losing battle, and the more the guest is taking liberties of luxury - demanding an egg for breakfast, inviting guests for a dance party - the more Jan-Hein collapses. He has become so deranged by the end that he joins the guests in their acts of destruction. They tie him on a chair, and the next day, after Jan-Hein has freed himself, he finds himself amidst a total mess. The film ends with a freeze frame of his contorted face. 
One might postulate that DE VERLOEDERING VAN DE SWIEPs is, in terms of content, a tragedy, since it shows how an honest citizen is driven to despair for being too well-disposed. Nonetheless, it makes more sense to call Terpstra's film a comedy insofar one highlights Manuel's jovial behaviour: he is the proverbial bon vivant who really knows how to charm a woman and he watches Jan-Hein's decline with malicious delight. A main reason to consider the film as a comedy rather than a tragedy resides in the way the film is shot. DE VERLOEDERING VAN DE SWIEPS uses fairly unorthodox devices, like near frontal close-ups in some moments; a relatively fast forward tracking shot now and then; a few unconventionally framed shots that cut off a head half or in its entirety; a few freeze frames. One might argue that these formal devices underscore Manuel's position, since the brusque close-ups, the zoom shots, the raw editing are sufficiently unconventional to favour the perspective of the maladjusted debauchee instead of the proper employee. Thus, in pitting Manuel against Jan-Hein, DE VERLOEDERING VAN DE SWIEPS formally sides with the former.

A main reason why Terpstra's film has always remained beneath the radar, I would surmise, is that Jan-Hein's downfall is presented in an easy-going fashion: let us watch how a citizen goes to the dogs. ${ }^{8}$ And Manuel is too eagerly presented as the embodiment of the hippie fantasy that one can live as a cheerful rake, unhampered by any conventions. Hutcheon defines satire as 'the art of diminishing a subject by ridiculing (with intent to discourage) its vice or folly by the use of irony, sarcasm, humour' ('Introduction,' 36). According to this standard, DE VERLOEDERING VAN DE SWIEPS can be called an anti-bourgeois satire, indeed, but one which uses unholy glee as its main instrument. Thus, it lacks the ambivalence and the complex subtlety - and hence, the poignancy - of those quintessential anti-bourgeois satires by Luis Buñuel, like BELLE DE Jour (1967) and LE CHARME DISCRET DE LA BOURGEOISIE [THE DISCREET CHARM OF THE BOURGEOISIE] (1972). ${ }^{9}$ In DE VERLOEDERING VAN DE SWIEPS, the independent drifter was represented in opposition to the compliant citizen, ${ }^{10}$ but the surreal satires of Buñuel expose how such positions are inextricably entangled: the bourgeoisie itself is already perverted (Trevitte, 218). Whereas the degeneration of Jan-Hein Swiep has a clear cause and is therefore not shown as innate to people as such, no work in Dutch film history comes closer to suggesting a Buñuelian imbrication between bourgeois decorum and perversity than the cinema of Alex van Warmerdam. ${ }^{11}$ 


\section{BUÑUELIAN DESIRES: DE NOORDERLINGEN}

Of his 32 films, only Buñuel's first two can be called 'die hard' surrealist films, since they were made under the direct influence of the surrealist movement and outside the commercial film industry (Williams Figures, 151). Buñuel's short UN CHIEN ANDALOU [AN ANDALUSIAN DOG] (1928) and his L'AGE D'OR [AGE OF GOLD] (1930) are no exceptions to the convention that surrealist artists always tended to respect the grammar of a medium. If the viewer of a surrealist photograph has difficulty in deciphering the depicted object, it is because the photographer has chosen an uncommon angle or taken the picture of a small object at very close range, not because they have manipulated the image. The meticulous framing has defamiliarized the object, made it surreal, often by adding overtones of eroticism to the picture (Van Alphen, 'Geschreven realiteit,' 167). Likewise, Buñuel's first two radically formal films

270 are enigmatic in terms of plot, but he did not violate conventional principles of editing. If a character looks outside a window onto the street in UN CHIEN ANDALOU, the next shot is a high-angle shot from that position, thus attributing the focalization to that character. If the scenery is bizarre, this is due to the surrealist adage that characters see with 'eyes of imagination': their observation is criss-crossed with desires and phobias, which explains why we see a deformed object. If a woman's dress dissolves into a torn piece and we get to see her naked buttocks, it is unmistakably the man's wishful thinking, as we can gather from his dreamy facial expression. If a man stares at his hand and we then see, in close-up, how insects crawl out of a gaping wound in this hand, this is the consequence of his slumbering disgust. In UN CHIEN ANDALOU, the desires and fears of the gazing characters distort the perception of a scene to such an extent that the armpit hair of a woman can suddenly appear as the goat on a man's chin. In short, a shot shows a character looking at something off-screen, a subsequent shot shows the 'obscure object' of the character's desire or anxiety.

According to Linda Williams, subsequent films by Buñuel tended toward coherent narratives, but from EL ÁNGEL EXTERMINADOR [THE EXTERMINATING ANGEL] (1962) onwards he returned to surrealism proper (Figures, 151). The films of his late period, however, are no longer the works of an anarchistic iconoclast, but of a 'mellowing surrealist master' (152). These films have a 'slick prettiness, a sunny glamour' but the 'slicker and sunnier the films appear on the surface, the more complex and troubling they can often be underneath' (153). Like in the old days, Buñuel persistently explored the analogy between the structure of film and the discourse of the unconscious, which has, as Williams argues, 'the paradoxical effect of making the spectator more conscious of the processes that produce desire' (217). One of the concerns of 
psychoanalysis, to which the surrealist movement felt affiliated, is to suggest that desire cannot be fulfilled, and its object will be a mirage, permanently out of reach. Buñuel's films are structured according to postponements: two couples want to dine together in LE CHARME DISCRET DE LA BOURGEOISIE, but time and again something intervenes that prevents fulfilment of this simple wish. Thus, his films shift away from a conventional narrative to an 'elusive elsewhere, an other scene constructed out of mechanisms analogous to those in dream work' (Williams Figures, 214).

While exploring the structures of desire, his late period films show that, as Roger Ebert says, bourgeoisie manners are 'the flimsiest façade for our animalistic natures.' Citizens perform social rituals to hide the dark desires that lurk beneath their appearances. Freedom is only a 'phantom of liberty,' a false illusion that one is liberated from rituals, while civil compliance is an attitude to cover up repressed wishes. Specifically talking about BELLE DE JOUR (1967), Matt Lau claims that Buñuel's scathing satirical critique is 'subversive in its orthodox realism': camera work is usually done without flourishes or special effects; there are long takes with stilted dialogue; no musical score.

This characterization of late Buñuel almost reads like a formal description of a Van Warmerdam film. He tends to shoot relatively straightforward and prefers the use of hard cuts, deep focus and elliptical editing. The majority of shots in his films are static, and when the camera does move it is to follow a character or observe a situation, hardly ever to accentuate a mood. There is some musical accompaniment to scenes, but it is never intrusive, for that might affect the general mood too much. The main reason for this sober approach is to acknowledge, as already mentioned in the Introduction of this study, that Dutch culture is rooted in a Calvinist tradition of austerity. Van Warmerdam does not revere this tradition, but uses Calvinism - that is to say, his notion of Calvinism - as a background for a story in which bourgeois characters are either obstructed in their impulses or seem to rebel against the strict coding of their environment. ${ }^{12}$

Symptomatic of the Calvinist sobriety is the setting of DE NOORDERLINGEN [THE NORTHERNERS] (1992), his second feature. After an opening in which a man and his wife with a toddler on her arm are instructed in a photo studio to look 'with hope ... to the future,' the subsequent scene shows that the photograph of the happily smiling family is used on a billboard accompanying the text '2,000 houses will be finished by 1958.' While a text over the shot mentions that it is 'summer 1960' already, we see that only one street happens to be built so far, surrounded by barren land and deteriorating building materials, which are covered by weeds. ${ }^{13}$ The uniform and austere houses in this one street are adjacent to the sidewalk and have huge, almost square windows, so that passers-by can easily look inside, a 'typically Dutch habit,' according 
to Van Warmerdam. Not only the man-made settings excel in uniformity, but also the natural environment. Frequently we get a shot of a deserted landscape on the left side and a forested area on the right, with the trees positioned in a straight line as if a ruler has been used to demarcate an absolute distinction between emptiness and density. ${ }^{14}$

Events in DE NOORDERLINGEN are set in motion because Jacob and Martha have marital problems. We know from a letter, read by the postman, Plagge, who secretly opens the mail he has to deliver, that Martha has asked one of her girlfriends for advice about how to cope with a sex-crazed husband. The answer: do not dress attractively, do not use make-up. And thus the corpulent butcher Jacob seeks his pleasure elsewhere. While he is preparing sausages, he observes the cleavage of his shop assistant. Sight leads to touch, but once she has freed herself from his embrace, she runs into the street of this microcosm. In a long shot we see his female neighbours standing at their 272 door, all lined up, watching in the direction of Jacob, as if they all know what a 'brute' he is.

It is not only that (sexual) desires are restricted in the small (Calvinist) community, but DE NOORDERLINGEN suggests above all that such scrutinizing looks contribute to a repressive climate. In this bourgeois environment, one cannot escape being observed. This is consistently underscored in Van Warmerdam's film by the way windows repeatedly function as a frame within the frame of the film. Plagge stands right in front of the huge window of Martha's house, gesticulating at her not to wear any lipstick. One of the quarrels Martha has with her husband is played out in the street, for everyone to see behind their windows, and she does this deliberately to prevent him from acting too aggressively. When the camera is on the street we see the neighbours in the background, peeping through their windows; or the camera is positioned inside a house, making the quarrel look like an odd and hardly audible spectacle. The analogy between the huge window and the frame of the film is emphasized once again, when Martha's self-imposed abstinence from sex turns her into some sort of a holy Madonna. ${ }^{15}$ Lying in her bed near the huge, square window, her female neighbours come to kneel at the pavement, taking a look at her, with their hands folded. Jacob chases the onlookers away, but in a subsequent shot the small group has become a crowd, and still more people are arriving by bus. At one point their son, Thomas, closes the curtains for he and his father are about to eat, but the noise of tapping fingers makes him pull the curtains away, revealing the window as a screen, even though the spectacle on display is no more than a woman lying in bed.

It is perhaps no coincidence that of all the thirty-eight videos uploaded by Alex van Warmerdam on YouTube - accessed on 12 October 2015 - there is only one from a (foreign) feature film. He has selected two wordless excerpts 
from DU LEVANDE [YOU THE LIVING] (Roy Andersson, 2007), and one is about a window. We see a cleaning man on his back before the window of an art gallery in a static long shot. Inside the building there is a man and later also a woman, who are carefully scrutinizing the pane. Now and then they point their finger at what apparently seems a dirty spot, which the cleaner then goes to wipe with a cloth. The scene shows a quite common situation, registered by an immobile camera at some distance from the scenery, but its display is nonetheless slightly peculiar. Of course, the people of the art gallery have every right to a perfectly clean window, and of course, the cleaner has to polish the glass as brightly as possible, but the impression arises that the man and woman in the gallery want to have any tiny, practically imperceptible, stain removed. Seen from a distance, which is a result of the choice of a long shot, we as film spectators are not able to discern any dirty spot and hence, the scenery suggests that the couple carps at every minor detail. The cleaner follows their instructions, but it is impossible to guess whether he really cleans a stain which he happens to have overlooked or whether he just sheepishly gives in to their commands in order to satisfy his clients. Because of this ambiguity, the scene might add silliness to their possible hair-splitting attitude. I write 'might add,' since the scene is (fairly) normal, but thanks to the particular framing, one is invited to interpret the scene in an ironic way. The specificity of a Roy Andersson film resides in the option that both readings can be activated simultaneously: there is an everyday - or middle-of-the-road - situation, but it can be looked upon from a slightly awry perspective, and if one does so, it turns into an absurd scene.

One of the characteristics of this type of what I will call 'middle-of-the-road absurdism' is its deadpan quality, accentuated by the immobile camera at quite some distance from the scene. ${ }^{16}$ Every character acts as if it is a perfectly normal situation, and in fact it is. Nonetheless, in the midst of this normality, there are always some details in excess, which give the scene its specific acumen, for a principle conditional of the absurd is to confuse logic and the order of sense. Zupancic makes the important point that the absurd can only have an (intense) comic effect when the apparent 'nonsense' nevertheless 'makes sense' (58). In order to 'make sense,' the scenery should not be distorted by cinematic techniques and hence, as the example of the window pane suggests, the function of the camera preferably restricts itself to registering a situation. Thanks to the strategy of offering a seemingly neutral stance, the camera guarantees the endurance of the double option. Odd details are displayed in everyday situations, but these details are not overemphasized and are only shown as part of the overall picture. ${ }^{17}$

Likewise, Van Warmerdam's cinema restricts itself to presenting weird details. The conflict between Jacob and Martha may suggest otherwise, since 
their marital problems are conventional, almost too schematic, but the roles of other characters are murky ones. There is Silent Willie, a fat boy in short pants (played by the then 34-year-old Theo van Gogh) who is all eyes, but does not say a single word. His only pleasure is driving on his moped to scare off other people. If one were to cut the scenes with Silent Willie from the film, it would not hamper the story at all, which in turn is an argument for appreciating his odd presence. The most enigmatic character is Plagge, who is played by Van Warmerdam himself: why does the postman secretly open the mail near a small lake in the woods at the risk of being caught in the act by the bespectacled forest ranger? Thanks to his spying activities, he knows about the latter's infertility and teases him repeatedly. When the forest ranger asks Plagge what he was doing in the forest, the postman calmly responds he had a letter for William the rabbit. His dirty finger nails, he explains, are a result of helping William to dig his burrow. When the forest ranger wonders whether this rab274 | bit has a lot of offspring, Plagge dryly replies: 'No, William is infertile.' One of Plagge's other nasty jokes is to hide himself in the woods and to call to the forest ranger, with a high-pitched voice: 'Sweet little hunter, make me a child.' We can only guess whether Plagge has been bullying the forest ranger for quite some time now, since Van Warmerdam's cinema is shorn of explanatory flashbacks. Conventionally, a flashback is inserted to offer psychological motivation: by digging into the past the logic behind a character's acts can become clear. None of that, in DE NOORDERLINGEN, or in any of Van Warmerdam's other films. ${ }^{18}$ We have no clue whether the animosity is due to some past incident. Or is Plagge simply taunting him as some sort of resistance to his own obliging role as a postman? In that case, being confined to a civic function has made him into a 'pervert.'

\section{PERVADED WITH ROLE-PLAYING: KLEINE TEUN AND DE LAATSTE DAGEN VAN EMMA BLANK}

The impossibility to understand Plagge's motivations for his behaviour is to be related to Van Warmerdam's ‘confession' on the extras on the DVD of ALLEMAAL FILM, ${ }^{19}$ that he has a 'fear of meaning': he shies back from imposing a meaning upon the viewer. He will waive the use of a crow in his films, because this animal too easily connotes death. As soon as a character, an animal or an object evokes too obvious an association, Van Warmerdam will avoid his or its inclusion. He prefers an animal without a fixed connotation, like a goat, to encourage the spectator to unsuspected interpretations. This reluctance is totally at odds with the tradition of Calvinism, which takes hermeneutics as its core practice. In his account of 'iconophobia,' Christopher Collins explains 
that a hermeneutic profession tends to display a distrust of images and a suspicion of the visual potential of verbal texts, for they can unleash an 'uncontrollable imagination' (1). In a similar vein, it is the purpose of Calvinism to suppress the possible ambiguity of images/texts to only one, preferably very rational meaning, or, in the words of Collins, to an 'abstract-propositional function' (1). In contrast to the strict Dutch Calvinist tradition of unilateral meanings, Van Warmerdam's films should evoke 'accidental' meanings which he himself never has had in mind.

These 'accidental' meanings are far removed from the principle of the 'chance encounter' embraced by surrealists. They were interested in chance in every possible manner - like found objects, discovered at flea markets, for instance - because for them, chance is a structuring device for the unconscious; chance is antithetical to rational deliberations. For surrealists, significance is a by-product of coincidences. Buñuel had the tendency to emphasize the element of chance by interspersing his story of 'interruptions' with shots which have the status, often in retrospect, of fantasies, of dreams, of dreamswithin-dreams. By contrast, the 'accidental' meanings by Van Warmerdam are meticulously staged: information is provided, but never the obvious and never too much. At the end of KLEINE TEUn [LITTLE TONY] (1998), his fourth feature, which was screened in the Un Certain Regard section at the Cannes Film Festival, the husband murders his wife, but the act of killing is only shown obliquely. From inside the house through the window we see him raise an axe, but the woman is slain off-screen. An establishing shot had been made, showing her in a flower field with a wound in her back, but no matter how great the shot, Van Warmerdam cut it, because upon reflection he considered it excessive. ${ }^{20}$

Typical of his long-take style are an almost complete neglect of optical effects, such as superimpositions, and a minimal use of close-ups, which in conventional cinema is often used for emphasizing a crucial detail. If an optical effect is used, it is done so conventionally that it seems inserted as a joke. To underscore that the father of the title protagonist in Van Warmerdam's debut feature ABEL [VOYEUR] (1986) is at a loss, all the ashtrays start to move in the café he uses to frequent in a shot focalized by him. Since such a shot is an obvious exception to the rule, it comes to border on irony. ${ }^{21}$ In general, the viewer is manipulated only to a minor extent and is encouraged to actively distil his own interpretation from the shot or to attribute qualities to characters or objects. Deep focus can be considered a form of 'montage within the frame': the viewer can divide the space however he deems fit. He can decide to focus upon something in the upper-left corner of the shot, because the length of the take enables him to scrutinize the image carefully. Since for directors like Van Warmerdam - or Andersson, or Aki Kaurismäki, or Bent Hamer - the manner in which characters are positioned in space is seminal, the décor has 
a determining function. For his De LAATSTE DAGEN VAN EMMA BLANK [THE LAST DAYS OF EMMA BLANK] (2009) as well as for his subsequent film BORGMAN (2013), Van Warmerdam had a whole house built, simply because he could not find what he was looking for. The house for DE LAATSTE DAGEN VAN EMMA BLANK was constructed with an eye to the Cinemascope frame, which enabled him to show a room in the background in each and every shot. On the one hand, this choice is an invitation to the viewer to discover details within the shot, on the other hand, a tragicomic effect can ensue because the framing of characters can anticipate the oppressing situation they are about to meet.

To downplay the importance of (too much) information, a scene from KLEINE TEUN is striking. A countrywoman is fed up with the daily habit of reading aloud the subtitles on television for her illiterate husband. She hires a female teacher who at one point is invited for dinner. When the guest starts crying, she walks to the toilet, whereupon the host tells his wife that as a city 276 | girl, she tends to weep easily. Upon her return in the living room, the wife asks what is up, but the man answers that as his teacher he is not supposed to know anything about her background, one can only speak small talk. And thus her feelings remain undisclosed.

The humour of this type of middle-of-the-road absurdism - to stick to that label - is based upon subtle incongruities. Everything seems perfectly normal, almost, but not quite. There usually is some detail out of joint - not very awry, but slightly awry, as I already mentioned above. ${ }^{22}$ Let us take the very first shot in ABEL, the film about a 31-year-old guy who, still living with his parents, has not been outside for years. He spends his time trying to cut bluebottles in half with a pair of scissors and keeping watch on the neighbourhood with a pair of binoculars. In the opening shot, we see him play Peeping Tom at his neighbour, a fairly old man exercising on a home trainer. Since his right leg is in a cast, he only uses one pedal. The shot is displayed without any further emphasis. The second shot, once again seen through Abel's pair of binoculars, shows us the image of a living room with a black-and-white television, playing a western. A cowboy is on the verge of dying, since his body has been riddled with arrows. Later, about half an hour into ABEL, the genre of the western is referenced in a dialogue between Abel's father, Victor, and his mother, Duifje, which is the diminutive of 'dove.' The mother suggests they buy a television set so that their reclusive son can at least see some of the outside world. The father is fiercely opposed to television and argues that it only broadcasts a load of rubbish, like cowboy films: 'This cowboy, hasn't he got any parents to visit from time to time? Or have those parents died? Is this cowboy a foundling? Has he got brothers and sisters? Has he had an education? Not a word about that, no.'

The father condemns westerns for being totally unrealistic, since the cow- 
boy is a character without any personal background. The brief fragment of the dying cowboy on television which we witnessed through Abel's pair of binoculars, underscores this opinion to a superlative degree. We only see an image of a cowboy apparently breathing his last, nothing else. The screen shot shows only a stock image, even lacking any narrative context: Was he the 'good guy'? Did he 'deserve' to die? Who shot him? Strictly speaking, these questions are more fundamental than the questions raised by the father about siblings, parents and education, in fact, reducing his words to drivel. Although this might be a possible way of reading the silliness of the father's criticism of westerns, the actual object of derision of a (or perhaps of any) Van Warmerdam film lies somewhere else. If the father faults westerns for a lack of psychological consistency, ABEL as well as other films by Van Warmerdam work contrariwise to this criticism. His cinema reveals an affinity with cowboys and seems to distance itself from 'deeply felt' psychological scenarios with so-called 'round' characters. ${ }^{23}$

If psychology is alluded to in the cinema of Van Warmerdam, it is usually done so by negation or in a too obvious fashion, as in ABEL. The son does not seem to have a particular ambition at all; he is unmotivated in every regard. If his parents propose to go for a walk in the dunes, he has a range of arguments to stay at home: gin traps, stray bullets, raving mad poachers, the risk of getting lost. In fact, his goals are twofold. First, he wants to be cuddled by his mother. He even stages an accident so that his body is fully covered by a pile of boxes to attract his mother's attention. Second, his main purpose seems to annoy his father, who works as an administrator, a profession deliberately mispronounced by Abel. Perhaps his reason for staying inside is that his father wants him to go outside. When the father wishes the family a Merry Christmas and adds to this: 'And let us for once try to have a dinner without any arguments,' the son calmly replies that by accentuating it, there will be an argument. And indeed, a quarrel ensues. When a psychiatrist visits Abel's home, on the request of the father, the son acts like a mentally challenged person. The psychiatrist quickly makes a diagnosis, an indication of the too obvious nature of the Oedipal conflict: the boy is trapped by his overprotective mother. The psychiatrist further suggests that another part of the problem is that the father is ashamed of his son, to which the father retorts: 'Wouldn't you be ashamed of a son like that?' Apparently the son rebels against the father by giving him all the more reason to be embarrassed by him. This leads to a series of scenes which are as straitened as they are hilarious. When the father invites a girl at their place for Abel to meet, the father prepares Abel for the visit, for he himself is an expert on how to treat a lady. The son ignores all instructions or he explicitly recalls one of its lessons, thus embarrassing his father once again. Hence, Abel ruins the date on purpose, sometimes by keeping lengthy 
silences, sometimes by blathering about his favourite subject, the Iron Curtain and the poor working conditions in Russia. Or he asks the amateur actress a silly question like: 'Could you also climb into the skin of ... a potato?' After her puzzled reaction, he says: 'I think you'd make a very good potato.'

In the second half of the film, Abel is thrown outside the house by the father, but he happens to be offered a home by the woman Zus - or Sis, an abbreviation of sister - who, as only the spectator knows, is his father's mistress. Zus, who works at a peep show, breaks off the affair with the father, while the mother finds her son's hiding place thanks to Abel's unique fish pullover, worn by the female model. From now onwards, ABEL turns into an inter-male competition over a young woman who for both father and son has taken the mother's place. The tone has changed, but the film still seems to be overdoing its Oedipal scenario. Due to the overtly clear outline of the positions of father, mother, son and the girl both father and son vie for, the viewer is not invited to 278 really identify with the characters. Since ABEL so obviously alludes to an Oedipal scenario, the film is to be taken as a caricature of a psychological drama. And although the father is called Victor, the son is the actual 'victor,' which is proven by the fact that while Zus is sweeping up the splinters of a broken wine bottle at the very end of the film, Abel cuts a bluebottle in half with his pair of scissors. ${ }^{24}$ Hence, Abel's 'victory' lacks any grand gestures whatsoever, no wedding, no kiss, but is condensed in the most trivial of triumphs. For once Abel is successful in a habit which constantly functioned as an indication of his dysfunctionality. Though his final success at cutting a fly is a sign of his development into maturity - he is no longer a virgin, he has surpassed his father - this preoccupation remains an empty gesture, because of its utter silliness. The ending of ABEL, which is his only film not to end on a wry note, is like a timpani stroke without any resonance.

It is a recurring feature that Van Warmerdam's films start as apparently uncluttered psychological dramas. Opening scenes frequently show a fairly ordinary scenery, or so it seems. A family having Christmas dinner in ABEL; a waiter is serving the guests in a restaurant in OBER while one of the guests is his mistress; the household is watching while a woman is eating her meal, as in DE LAATSTE DAGEN VAN EMMA BLANK. Soon the identifiable setting takes a slightly bizarre turn, and as the story progresses, slightly bizarre twists start to accumulate. In several of his films, such a twist concerns an element of deliberate role-playing, as in OBER, discussed in chapter 7, already illustrated. The starting premise of KLEINE TEUN is that Keet hires a woman who can teach her husband, Brand, how to read. After a few lessons, this relatively familiar overture takes a slightly bizarre turn. When some affection arises between Brand and the female instructor, Lena (the familiar element), Keet does not get angry, but encourages them to have a sexual relationship (the slightly 
bizarre element). She provokes her husband by telling him he is not bold enough to sleep with her: every other man would have done already by now. She also suggests they tell Lena that they only play-acted being married, but that they really are brother and sister. This charade leads to a complicated love triangle, which is a springboard to another bizarre twist. Keet instructs Brand that she wants him to act in a dominating way towards her, so that Lena will be overwhelmed by his power and will desire to be fertilized by him: infertile herself, Keet plans to take the baby. Her plan fails finally, because Brand in the end no longer sides with his 'sister,' who wants to reclaim her position as his wife, and therefore he kills her.

DE LAATSTE DAGEN VAN EMMA BLANK is pervaded with role-playing from the very start, although the viewer realizes this only in retrospect. Bella is the cook, Gonnie is the maid, Haneveld is the butler, Meier is the handyman and Theo is the dog. Initially, it seems peculiar that Theo is not an animal, but a human, wearing clothes and, when outside, sunglasses. Despite his human appearance, he behaves like a dog, e.g., by enthusiastically jumping towards the Madame while she is eating, and he is treated like one: he is punished like a dog for misbehaviour and he is taken outside when he has to use the bathroom. An hour into the movie, it turns out that everyone is just playing a role the butler is in fact Emma's husband; Gonnie her daughter - in order to please the 'Madame,' who claims she is on the verge of dying. 'Madame' behaves like a true dominatrix, and everyone seems prepared to swallow her vagaries. Their willingness evaporates the moment Emma explains that there is no wealth to be inherited. Lacking the care of her former household, Emma will soon die; it were her last days, indeed.

On the basis of the opening scenes of films like ABEL, KLEINE TEUN and DE LAATSTE DAGEN VAN EMMA BLANK spectators may suppose that these films with their bourgeois settings can be interpreted according to the conventions of psychological realism, a favourite mode of reading. In fact, every bizarre turn in a Van Warmerdam film is a more or less polite request to give up this mode. If viewers get frustrated with his pictures this is due to their continued adherence to the principles of psychological realism: for them, the film no longer makes sense; its logic is thwarted. Since films like KLEINE TEUN and DE LAATSTE DAGEN VAN EMMA BLANK are best seen as a mimicry of a psychological drama, tending towards absurdism, a more fruitful mode of reading is to adopt an ironic distance towards the narrative, which is facilitated by the deadpan tone of his cinema. Expanding upon Van Warmerdam's aforementioned 'fear of meaning,' it makes sense that viewers (should) have difficulty in making sense of his pictures. His films problematize the spectator's desire to attribute meaning to the film, and this 'quality,' I will claim, makes them so 'ironic.' 


\section{MIDDLE-OF-THE-ROAD ABSURDISM: DE JURK AND GRIMM}

Van Warmerdam's third feature, DE JURK [THE DRESS] (1995), is a delightful exercise which because of its deceptively simple structure sets a trap for the viewer. To start with, the film does not have a character as a main protagonist, but an object. This object, a dress, has a strange genesis, for a designer has been asked to propose a particular motif for a summer frock. All the designs have been declared unfit for use, for in the eyes of the advising committee, they are too 'avant-garde' and not 'sunny' enough. When Van Tilt continues to doubt the willingness of the designer to think commercially, director Loohman is so annoyed that he quite randomly picks a 'timeless leaf motif.' This motif, as the viewers know, is no more than a copycat from a dress worn by one of the designer's neighbours, an Indian woman. Van Tilt and Loohman get embroiled in a physical fight, whereupon the latter not only fires his employee, 280 but also yells at him that he hopes that Van Tilt will become very unhappy.

As soon as the dress is taken in production, the film follows one particular item, bought by a woman in her early sixties. While wearing it, she gets ill and spoils coffee on the frock. Her husband washes the dress, but at the very moment of her death, the heavy wind takes the dress from the clothesline. This is the beginning of the journey of the dress, with one constant factor: each and every woman who wears the item, experiences something dreadful, like being harassed by a horny train ticket inspector, and gets rid of it thereupon, by giving the item away for charity, for example. At the end, the dress is stolen by a female vagabond, who starts wearing it in combination with other clothes. Bearing in mind that the piece of cloth was officially made as a summer dress, it is a streak of black comedy that she will only some time later freeze to death. As darkly comic is the fate of Van Tilt who pops up at intervals in DE JURK, but time and again in a different guise. After his discharge, we see him selling coffee and snacks in a train, and as an ultimate sign of his downfall, we see him as a tramp befriended to the female vagabond. After her death, he tears a part of the dress and uses it as a shawl. With some of his very last money, he pays a woman to French kiss him in the park and after that he throws away the improvised shawl which is immediately torn to pieces by an electric lawnmower.

DE JURK invites the spectator to draw an analogy between the sorry fate of Van Tilt and the diminishment of value of the dress, for this object starts as an attractive window shop item but in the end, it is partly being buried and partly torn to pieces. The editing of DE JURK suggests causality, for Van Tilt is made to cross paths with this particular frock regularly. Therefore, it seems as if director Loohman's angry discharge of Van Tilt has, in retrospect, the status of a godlike prophecy when he bade him farewell by wishing him bad 
luck. If there is anything godlike about Loohman, however, it is his authority to take arbitrary decisions. No matter how obvious the analogy between the whereabouts of both Van Tilt and the dress, drawing such a parallel seems a trap set for the viewer. It is tempting to suggest that Van Tilt is punished for trying to prevent the manufacture of the dress and that the dress can cast a bad spell on practically anyone, since most characters appear to be affected by it somehow. Van Warmerdam's film seems to satisfy the viewer's desire for meaningful connections, but this is so deceptively logical that it, in case of a Van Warmerdam film, had better be distrusted. Is the striking discrepancy between the utter simplicity of the item and the severe impact it seems to have on several characters, not played primarily for laughs? Originally, the dress was produced as an object designed to radiate joy, but it has become a token of despair for the majority of characters. And at the same time, there is no clue at all that it is anything more than a strictly random item, and all the events that befall the characters are purely happenstance. The simple frock is to be interpreted as much as a highly significant garment and as a banal object, and as such it is a sign of unstable irony.

Irony requires that the reader/viewer can take the text/film literally, but a figurative interpretation is at least as plausible. In most cases, a line can be drawn between seriousness and irony, for the balance seems to tip into the favour of one of two poles, but in the case of Van Warmerdam, it is fairly difficult to decide how to read his films. Can DE NoORDERLINGen be read as a reflection upon the impact of religion, or is it too absurd for that? Can DE LAATSTE DAGEN VAN EMMA BLANK be read as a reflection upon the greed of bourgeois citizens, or is it too absurd for a serious analysis? The final scene of DE JURK can be taken as a lead, for the dress is depicted on a painting in a museum, made by the partner of one of the women who wore the garment. A teacher points out to a group of pupils that the cheerful colours contrast with the dark mood of the painting, but he also mentions that the characters have no eye for this antidote to gloominess: 'For them, the dress does not exist.' At that very moment, his interpretation is interrupted when the train conductor who has had some unfortunate experiences with women wearing such a dress, mutilates the painting with a Stanley knife. On the one hand, this aggressive act makes the teacher's explanation instantly insignificant, for without the dress, the effect of the contrast is lost. On the other hand, while the teacher said that the characters ignore the cheerful print, they now, ironically, have reason to neglect it, for the dress is cut out. This final scene oscillates between two moods - a serious one and a trivializing one - allowing the film spectator to choose either one. The violent act by the train conductor has strokes of absurdism, no doubt, but the act is also committed out of frustration, and thus can be said to have some serious purport. It is a recurrent feature in his 
films that the tone keeps oscillating between seriousness and absurdism, and the resulting undecidability can be called 'ironic.'

If GRIMM is considered as his least successful film, then this is due to the impression that Van Warmerdam is overdoing attempts to escape any categorization. In terms of genre, the film constantly shifts gears. GRIMM starts as a fairy tale about children left behind in the freezing cold woods out of poverty, but unlike characters in a tale by the Brothers Grimm, they have to perform sexual acts - Jacob is forced to satisfy a farmer's wife, that 'witch,' and Marie prostitutes herself for money. After the clumsily executed death of her client, the film becomes a road movie. They travel on a moped and all of a sudden, when going through a tunnel, they find themselves in warm Spain. Their trip seems to come to an end when a Spanish surgeon lodges them in his affluent residence, and marries Marie. It will soon turn out to be horror in bright sunlight, for the surgeon removes one of Jacob's kidneys. ${ }^{25}$ More dead than alive, 282 Jacob finally arrives on a deserted film set used to make spaghetti westerns, together with his sister. There is the conventional shoot-out amidst a sand storm, but the victor, Jacob, uses a bow and arrow instead of a gun, before the film concludes with a biblical reference when he takes off in the company of both Marie and a donkey. Even more indistinct than genre classifications in GRIMM is the nature of the relationship between Jacob and Marie. Significantly, the script opens with a kind of instruction leaflet that the brother and sister may come across as 12-year-old children, but that their age is 'abstract.' The actors playing them are over 20 , but they radiate a 'visual youth,' according to the script. The close intimacy between the two is striking: when Marie complains that she is cold in the opening scene, her mother tells her to sleep in her brother's bed; they take a bath together in a Spanish hostel, caressing each other; Jacob is jealous of Marie's status as the surgeon's wife. Though GRIMM is about the tight bond between a brother and sister, Van Warmerdam told that the term 'incest' should not cross the viewer's mind, 'for that is a social term, and I do not want any social or so-called contemporary message.' A social reading risks restricting the preferred plurality of meanings, and such plurality is better served by indistinct genre classifications, abstract ages and an enigmatic relationship between brother and sister.

To guarantee such plurality, main characters often have common, even archaic names, such as Jacob, Anton, Marie, particularly popular in the 1950 s. Such names, as Van Warmerdam has said, refer to a period of class differences and paternal authority, implying a hierarchically ordered neighbourhood where one still lived according to strict social roles. Though the option that this bygone era still can exert some nostalgic fascination is not crossed out, this period is presented in a laughable manner, thanks to its relatively detached depiction. ${ }^{26}$ This duality between fascination and absurdism is 
never truly solved in his films, which is most evident in the representation of blacks. About halfway through DE NOORDERLINGEN, two white priests arrive to showcase an African man, labelled as a 'negro,' as an educational exhibition. In its portrayal of the black man as a caged animal, this image reproduces the worst of stereotypes, but it can also be regarded as a parodic mimicry of a cringing, patronizing attitude on the part of white people. To underscore this latter option, we see that the priests are busy hanging a wooden board, announcing the exhibition, but it breaks in two halves. The function of the 'negro' becomes even more complex when we consider the preoccupation the young teenager Thomas, the butcher's son, has with news flashes about the figure of Patrice Lumumba, a resistance fighter in Congo who contributed to the country's independence from Belgium. Thomas even paints his face black and dresses like Lumumba, identifying with a man totally foreign to his own petit bourgeois environment. Seeing how the priests do not permit the 'negro' to smoke, Thomas aids him in escaping from his cage. He also helps him to take shelter by sitting on his shoulders in the guise of Lumumba, while wearing a long coat. Thomas gets away with the trick, because the forest ranger Anton presumes that the postman Plagge, who is pestering him all the time, is hidden underneath. Strictly speaking, Thomas' attitude is marked by exoticism, but since the teenager is presented as a down-to-earth boy, shorn of any pathetic gesture, it is at the same time a particularly dry-comic variant of exoticism. Later the black man is once again shown as stereotypically wild. Thomas has brought him to a subterranean place of refuge in the woods. He then witnesses an accidental killing of a young girl by the forest ranger, who submerges her body in a small pond. The negro takes revenge in a primitive fashion: only dressed in a skirt, he jumps from a tree upon the forest ranger and lances the latter's eyes with a handmade spear. After the hunter has been blinded, the black man hides in the postman's house, dressed in his uniform. Thus, the black man's role in DE NOORDERLINGEN constantly oscillates. On the one hand, he is depicted according to old-fashioned notions about black men, still current in the 1950s: he is either a primitive brute or a token of exoticism. On the other hand, the blank and deadpan presentation is so wilfully odd that the option of ridicule keeps resonating throughout. As said, the impression that his films remain caught between seriousness and ludicrousness makes his work so thoroughly ironic. 


\section{A BLACK HORROR-PASTICHE: BORGMAN}

In comparison to its immediate successors OBER and DE LAATSTE DAGEN VAN EMMA BLANK, BORGMAN is a bit more macabre, without losing its comic tone entirely. After its premiere at the main competition of Cannes, reviewers made connections to films like Pier Paolo Pasolini's TEOREMA [THEOREM] (1968), Kim Ki-duk's BIN-JIP [3 IRON] (2004), Dominik Moll's LEMMING (2005), and Ben Wheatley's KILL LIST (2011) as well as to the cinema of Buñuel and David Lynch. Foremost among the comparisons, however, was Michael Haneke's FUNNY GAMES (1997), except that Van Warmerdam's home invasion film was called 'actually funny' by critic Robbie Collin in the Daily Telegraph. In Haneke's film, two decently dressed and seemingly polite boys have a small request - one of them only asks for eggs to bake a pie - but the pair develops into manipulating intruders. The couple starts tormenting the three resi284 dents - father, mother and boy-child - but as they tell in frontally staged shots, they merely commit their violent acts to entertain the audience, presuming that film spectators are delighted by watching torture scenes on the screen. In suggesting that they have some contract with the public, on whose behalf they perform their evil, the two boys perversely make the viewers complicit to their atrocious deeds. After a series of brutalities, most of them committed off-screen or at some distance from the camera, the woman succeeds in killing one of the boys with a gun, shown in plain view of us. This scene which sometimes is greeted with a sense of relief by the audience, is 'neutralized' by a notoriously cruel joke, played upon the film spectator. The other guy takes the remote control and rewinds the film, until the moment when the woman got hold of the gun and then grabs the weapon himself, hence reducing the chance for catharsis. In the end, the woman, the last of the family surviving, is casually thrown overboard of a boat, as if the guys have become bored by their 'funny games,' which in fact have proven not to be funny at all.

Like the boy in Haneke's film who asks for eggs, Borgman also has a small request at the beginning: the vagrant Camiel Borgman, who introduces himself as Anton Breskens, just wants to take a bath, because 'I am dirty.' This request is refused him by the middle-class businessman Richard who even beats up the stranger after the latter insinuates that he has been on intimate terms with Richard's wife, Marina. Apparently, the woman feels guilty about the violent treatment and she offers the bearded stranger a shed with a bed on the condition that he does not show himself in the house. Time and again, Borgman asks for little favours - one more night, a breakfast, another bath and the woman gives in to each request. He sneaks into the house at will, but he is for some reason never perceived by her husband, Richard, only by the three children and the Danish au pair who are all immediately under the spell 
of Borgman. They behave compliant and obedient and never betray his presence to Richard. The hobo exercises a hypnotic power upon Marina as well, and this is affirmed in the scenes in which he sits, naked and squatting, over her. These shots can be taken as a clear reference to Henry Fuseli's 1781 oil painting The Nightmare, which depicts a sleeping woman with her head hanging down, surmounted by an incubus. ${ }^{27}$ Just as in the painting, it seems as if the demon is capable of injecting her with nightmares. In BorgMAN, the content of her dreadful dreams is time and again a revelation of her husband's aggressive nature, which Borgman himself had experienced physically. The one true, albeit very brief, horror and blood-spilling moment of the film is also one of Marina's nightmares: her husband sexually assaults her and as soon as he cuts her flesh with a Stanley knife, she wakes up. As a consequence of the nightmares, Marina develops a growing suspicion towards Richard up to the point that she tells Borgman that her husband has to die. But not only he will be poisoned, Marina herself will also die after drinking a glass of wine offered to her by Borgman. The corpses are buried into the garden, which is being strewn with artificial fertilizer. Meanwhile, their children as well as their nanny have been drugged and have each undergone a small operation. The resulting scar on their backs is a sign that they have definitely joined the gang of conspirators.

The purport of Haneke's FunNy Games was unashamedly didactic. The film was made as a provocative reflection upon the too alluring depiction of violence in much contemporary cinema. By way of its coolly detached and minimalist style, FUNNY GAMES was deliberately made as a nauseating antidote to films like NATURAL Born Killers (Oliver Stone, 1994) and PUlP FiCTION (Quentin Tarantino, 1994), which (too) eagerly show graphic violence for the viewer's entertainment. As said, BORGMAN refrains from graphic violence, except for a very brief shot, only a few frames, and as such it recalls FUNNY GAMES, but it lacks the didacticism that Haneke's film is pervaded with. Since Van Warmerdam usually shies away from offering social criticism, it is only consistent that the motivations of his villains are 'blurry,' and that his horror pastiche is without a true 'killer punch' (Shoard) ${ }^{28}$ In the first half of the film, BORGMAN creates the expectation of being a spellbound horror thriller. At one point, Marina tells her husband that something surrounds them, 'an agreeable warmth that both intoxicates and confuses one; a sheath of something that wants to do evil.' All the ingredients for a vicious criticism of middle-class values in the form of an occult horror film are there, including a no-nonsense husband who downplays Marina's intuition as a hallucination. Instead, BorGMAN starts to shift gear from here, as if Van Warmerdam wants to 'eschew standard genre trappings,' just as he did in his other films. One might have expected that Borgman would take revenge upon the bigoted and decadent 
lifestyle of Richard, but that would have been at odds with Van Warmerdam's reluctance to inject his films with social messages. In fact Borgman, as he tells Marina, who halts him as he is about to depart, has no bigger ambition than to 'play': 'I am bored. I want to play. I do not feel like hiding. I want to eat at the big dinner table.' If he is so bent on playing, could he then not, Marina proposes, return in a different guise?

By foregrounding the element of play, the promise of an occult horror film is twisted to scenes of absurdist and black comedy. Black humour, as it is characterized by André Breton who coined the term in his Anthologie de l'humour noir, is the opposite of joviality, for it is the 'mortal enemy of sentimentality' (25). We witness something horrific, but because of a too detached representation of the scenery, we are not encouraged to sympathize with the misfortune of the victims. Their fate is depicted in such a trivializing manner that a laugh is closer at hand than a shocked response. This is the case in BORGMAN, when

286 | Borgman's eagerness for play becomes the preamble to a series of calmly executed and elaborate plans, devoid of any emotion or passion. Aided by his offbeat accomplices, Borgman disposes of the gardener and his wife by encasing their heads in buckets of concrete and then sinking the bodies, upside down, to the bottom of a greenish lake 'like a submarine sculpture' (Calhoun). Since the job of gardener has become vacant by now, Richard will select a new employee from among five applicants. Unbeknownst to him, Borgman and his co-conspirators have selected a number of prospectless candidates whom they pay to ring at the doorbell: non-Western foreigners without diplomas, 'even a Negro,' Richard exclaims in despair. When Borgman then offers his services, Richard immediately takes the bait. The fact that he does not recognize the shorn and scrubbed applicant as the bedraggled tramp he has mistreated before is a token of his self-absorption. By contrast, Marina sees immediately through his appearance. Having Borgman around the house gives her the idea that she might become close with the gardener, but he discourages any advance as 'too early.' He insists that he plays the gardener, and that as such Richard is his superior, and one is not supposed to mess with the boss' wife. Only after Richard's demise does he get intimate with her, but it is a kiss of death.

Upon the question why Van Warmerdam made BORGMAN, he responded in an interview with cinema.nl: 'I felt like making a horror film. Or rather something along that line.' BORGMAN is a typical Van Warmerdam film in the sense that as soon as you believe you are watching a genre film with social purport, it frustrates that expectation. Out of his 'fear of meaning,' he bends generic conventions to such an extent that it either becomes a pastiche (as in BORGMAN) or a different genre (as in GRIMM, going from fairy tale to road movie to horror to western). Moreover, in each and every film, the scales tip in favour of playful elements over social and/or ideological aspects. On the 
one hand, this playfulness expresses itself in dry-comic scenes, ranging from the son's attempt at cutting flies with a pair of scissors in ABEL to the sinking of bodies with their heads in buckets of concrete in BORGMAN. On the other hand, deliberate role-playing is used to humorous effect in especially his last films. The husband and wife in KLEINE TEUN pretending to be brother and sister; the waiter aiming to obtain redress from his very own scriptwriter in OBER; Emma's family members, who play an utterly servile household in DE LAATSTE DAGEN VAN EMMA BLANK; and the idler Borgman, playing the role of gardener in such a serious manner that it becomes slightly absurd.

Moreover, Van Warmerdam's ninth feature, SCHNEIDER VS. BAX (2015), as such can be regarded as a form of 'play.' In this film, the family man Schneider is given the assignment to kill the writer Bax. Schneider is reluctant to do so, because it is his birthday, but the job cannot be postponed, the contractor Mertens tells him. He is not impressed by Mertens' arguments, such as 'Tuesday is a perfect day for a good kill, because that is the lucky day of the week.' Schneider will only start preparations after Mertens has told him that Bax is a 'child killer.' When Schneider is on his way, the very same contractor instructs Bax how to await the arrival of the assassin. Thus, the whole scheme is an intricate trap set for Schneider who is, Mertens assures Bax, a 'child killer.' SCHNEIDER VS. BAX is set in the present; we do not get background information about any of the two titular heroes, except for the questionable statement that they both are child killers. Nor do we get to know anything substantial about the minor characters. Thus, the film is structured like an extended shoot-out of a cowboy movie, set in the midst of the polder. Unlike a classical western, however, it lacks the conventional distinction between 'good' and 'bad.' Should we sympathize with Schneider, father of two young daughters? But he behaves mercilessly to a woman 'from Culemborg' who crosses his path, and lies to his wife each time she phones him to inquire after his job. Initially, he has set the strict condition that he will only kill Bax when there are no visitors, but later he is adamant to kill Bax's daughter as well. Should we then rather identify with Bax, who uses drugs and alcohol and detests the presumed healthy food his depressed daughter consumes ('muesli is meant for goats'). He is unfriendly to her even though she pays him a visit after they have not seen each other for a year. He grumpily tells her: 'I want a daughter who is well off, not a sad one.' And he has apparently good reasons to behave extremely rudely towards his father, 'that bastard.' Since the protagonists are not endowed with a clear history, we are not manipulated in regard to with whom to identify, and this lack of guidance can be taken as a form of 'play.' As Van Warmerdam suggested, perhaps one should not identify with characters here but with props, landscape and actions: guns, water, sky, horizon, people shooting and wading through swamps (qtd. in Beekman, V4). ${ }^{29}$ 
Van Warmerdam's ludic approach to cinema can be taken as a response to the strict Calvinist-Catholic tradition that Dutch culture still was steeped in during his childhood and adolescence. His films allude to this tradition of firm hierarchies and unilateral meanings, but also drift away from these conventions up to a point where meanings cannot be fixed at all. Averse to explicit (social) messages and conventional psychological motivations, his films are, despite their common starting points, difficult to read, since they are not easy to categorize, neither in terms of genre nor in tone. They oscillate between tragedy and humour, between horror and hilarity, between irony and seriousness. If the tone tends to incline towards one pole, one can be sure that it will soon be tilted to the other pole. The more this might confuse spectators, the better.

\section{DEADPAN IRONY}

The way irony has been discussed in this study has made it into a curiously indefinable trope. Traditionally, as I already mentioned in chapter 3, irony is taken in terms of an antiphrasis, meaning that one thing is said, but the opposite implied. Or irony was associated with a notion of 'excess,' as in the examples of deliberate camp in chapter 4: conventions are blown up to such an extent that viewers no longer take them seriously. Gerrit Komrij once wrote a review of Een romance [A Romance] (1973) by Dutch novelist Dirk Ayelt Kooiman in which he praised the book in the most exuberant manner, as the Ultimate Masterpiece. It is such a rave review that Kooiman's friends suspected that the article was meant to be ironic. Komrij was capable of making such a joke and the article itself contained quite a number of stock phrases of the sort used by publishing houses to advertise their novels. ${ }^{30}$ Komrij's review shows that an ironic text - let us assume that it is, for the moment - can be read perfectly non-ironic, which provokes the question: If readers regard an ironic text as non-ironic, does it thereby become non-ironic (and vice versa)?

For those who are attached to irony as inherently textual, the answer is 'no.' The reader/viewer is supposed to reconstruct the 'intended' meaning of the text/film, and not pursue anachronistic readings. In his A Rhetoric of Irony, Wayne Booth goes to great pains to 'stabilize' irony: what clues can help a reader/viewer to decide whether a text/film is ironic or not? Booth is not satisfied until he can narrow down a text to a specific meaning. If he comes across a truly impenetrable text, like a work by Samuel Beckett, e.g., he uses an escape route and terms it a form of 'infinitely unstable irony.' Booth would have great problems with irony as a mode of reading, i.e., with those who answer the question above with a 'yes.' In the words of Linda Hutcheon, how- 
ever, irony has to 'happen'; whether a text 'is' ironic or not is an interpretive act. The crucial condition is that readers/viewers decide to attribute irony to a text. Blue Movie and SPETTERs were such curious cases, because there is little reason to regard the films themselves as ironic, but as soon as spectators make the controversial production history of both films part of their reading of the film, irony can be attributed after all. I side here with the astute remarks made by Sontag in her essay on camp, in note 30: Time 'contracts the sphere of banality,' because time 'liberates the work of art from moral relevance.' Over the years, Sontag postulates, we have become less involved in the work, and 'can enjoy, instead of be frustrated by, the failure of the attempt.' Since we are no longer as shocked by the brutality of SPETTERS as viewers in 1980 and no longer tend to see the film according to a yardstick of realism, there is room to appreciate the film as an ironic comment upon the 'immoral' behaviour of the male youngsters.

The irony in a Van Warmerdam film is even of a slightly more complicated nature, and would definitely be too subtle for one of Booth's 'stable' categories. As regards the cosmic irony, discussed in chapter 7, a God-like entity, embodied by scriptwriter Herman in OBER, is, in the formula of M.H. Abrams, 'deliberately manipulating events so as to lead to false hopes, but then to frustrate and mock the protagonist' (92). Despite promises for a more fortunate course of events, Edgar becomes the victim of his reproach to Herman that he has no creative solutions on offer, for the scriptwriter promptly misuses his powerful position.

The overall, unstable, irony of Van Warmerdam is one of unreadability, thwarting (generic) expectations in order to confuse the viewer. Moreover, the presentation of 'negroes' in his films leaves the viewer in doubt whether they reproduce hackneyed imagery or satirize Western paternalistic attitudes towards blacks. For, if the purport 'risks' becoming too critical, playful elements are inserted to counterbalance the seriousness. On the one hand, this playfulness expresses itself in drily comic scenes, like the one with the old woman slowly packing an arrow in OBER. On the other hand, deliberate roleplaying is used to humorous effect in especially his last films. Keet in KLEINE Teun, takes up the role of 'sister' to her husband; Haneveld behaves like the proverbial obedient butler to his wife; Borgman is very serious in his role as gardener. All three look like everyday types of characters, but they become comically absurd since they develop into or have already developed into villainous schemers. The more polite and obliging their appearance, the darker the energies which ultimately are unleashed as soon as play time is over.

Initially, every family member in DE LAATSTE DAGEN VAN EMMA BLANK seems to feel compassion for Emma and gives in to her capricious wishes. One of her most hilarious demands is that she orders the 'butler' Haneveld - 
who is her husband, actually - to wear a moustache, so that he will gain a certain allure. Haneveld tells her he is hardly able to grow a beard, so she makes him buy a fake moustache. When he has one under his nose, she starts, in the presence of everyone else, criticizing its size: it is too big. It seemed a bit childish to have a small moustache, Haneveld replies. 'There is quite a gap between this moustache and a small one,' Emma snaps, 'I had asked for a moustache that suits you.' Since he had bought several items, he is asked to try them on in an adjacent room and to enter as if he has been wearing a moustache all his life. And when another day Haneveld is wearing a different fake item than the one Emma had chosen originally, he obediently starts changing the moustache.

When it turns out that there is nothing of any value to be inherited, however, the charade is immediately over. From that moment onwards, they all let Emma waste away, only offering her a wet sponge for her face to prevent 290 | her from dying of dehydration. Gonnie wants to give her mother a glass of water, but Haneveld takes it away after she has had a few sips, saying: 'She did not have milk to breastfeed you. Is that a mother?' And when Emma dies thereupon, Haneveld mentions that they did give her water, and while bending over the corpse, says: 'It was out of goodness, you hear? Out of goodness.' The most benevolent of characters turns out to have repressed the darkest of impulses. Owing to such darkness in Van Warmerdam's cinema, the more ludic approach of HeT ECHTE LEVEN or RENT A FRIEND, both discussed in chapter 7 , is supplemented with the perverse impulses from Buñuel, which comes close to grotesque effects, as is the subject of the next chapter. ${ }^{31}$ 




\section{From Grotesque Caricature to Grotesque Satire}

In an interview, he gave at the beginning of his career, Quentin Tarantino said that the only people in America who tend not to take violence seriously and laugh at it are 'black people. They don't let violence affect them at all' (qtd. in Willis, 212). What Tarantino had in mind was to make movies in which violence is represented as ridiculous as the violence in his beloved Sergio Leone spaghetti westerns, but aimed at a white (middle-class) public. And indeed, his films, which feature not only extreme violence, but also cheap jokes about shit and drugs and have a lot of talk about 'niggers,' became a tremendous success. The horrific scenes in his pictures provoke laughter, ${ }^{1}$ as the infamous 'ear cut' scene from his debut feature RESERVOIR DoGs (1992) illustrates - a film about a well-prepared heist that fails miserably. In an attempt to find out the identity of the 'rat,' psychopath Vic Vega, whose codename is Mr. Blonde, threatens to cut off the ear of a police officer. Preceding this torture scene, he praises the radio station 'Supersound of the Seventies.' When he switches the radio on, we hear the middle-of-the-road track 'Stuck in the Middle with You' by Stealers Wheel. Then, Mr. Blonde takes a sharp razor to the officer's ear; while the camera turns away and shows the hangar's blank wall, we hear the officer screaming through the Stealers Wheel song. Conventionally, a viewer may be inclined to identify with a victim who meets a sorry fate, but here the combination of a horrific scene with the carefree music is so ludicrous that the viewer may not only react appalled, but cannot suppress a giggle or a smile. The deliberately chosen soundtrack, to which Mr. Blonde starts to make ultrarelaxed dance movements, is incompatible with his upcoming deed. ${ }^{2}$

According to Sharon Willis, an internal social censorship mechanism is activated, since we experience fun rather than shock. This produces a mismatch between our affective state (laughter) and our awareness that we are witnessing something horrific. The mixed emotion of shock and laughter 
this scene unleashes serves to exacerbate the gruesomeness of the torture scene. Tormenting the officer was already bad enough, but the fact that the light-hearted song keeps playing, 'indifferent' to his suffering, possibly makes it even worse. In case the cheerful 'Stuck in the Middle with You' makes the spectator smile or creates only a slightly happy mood, the song starts to function as a sign of a lack of consideration for the police officer. The easy-going tune in RESERVOIR DOGS becomes 'complicit' with the malicious actions of Mr. Blonde.

The mismatch between the scene (relaxed music/horrific deed) and response (hovering between disgust and laughter) may produce a feeling of shame, since as socially disciplined beings the spectators know they should not have laughed. Those viewers who have a habit of watching gory movies and therefore already tend to laugh at violence in cinema, may not experience this mismatch, but those viewers who realize that it was fairly inappropriate to 294 burst into laughter, precisely these spectators may feel as if, to borrow men's 'worst fear' in a Tarantino film, 'they are caught with their pants down' (Willis, 190).

This characterization of Tarantino's nouvelle violence cinema accords with the definition of what has come to be known as the 'grotesque,' whose effect, as Philip Thomson has it, is 'at least as strongly emotional as it is intellectual' (5). The incongruous co-presence of some laughable and disgusting things is the seminal building block of the grotesque. It derives its impact from the intrusion of comic elements in a 'spine-chillingly uncanny' setting (5). In trying to specify the conditions of the concept, Thomson mentions as an extra ingredient that a grotesque scene is preferably presented in a 'matter-of-fact fashion,' that is, within a relatively realistic framework. Moreover, some physical aspect is usually foregrounded, in this case the severe mutilation of someone's face. We abhor such cruel abnormal physical treatment, but add only some dose of humour to it, and the 'civilized and sane response' of disgust risks being mixed with 'unholy glee and barbaric delight' (9). And here is the astonishing paradoxical effect of the grotesque: one may expect that the comic makes it less harmful, for a laugh is presumed to release the tension, but it can also work the other way around, as I argued on the basis of the scene from RESERVOIR DOgs. When something repulsive is juxtaposed with something comic, it can generate a strong affect response, for the laughing spectator may feel ashamed for not having had a 'proper' reaction. In this chapter I will examine a number of films according to a sliding scale of variants of the 'grotesque,' from cartoonish versions to satires with a vengeance. ${ }^{3}$ 


\section{THE GROTESQUE AS A CONCEPT}

As a concept, the grotesque dates back to the end of the $15^{\text {th }}$ century, when ancient Roman decorative art was rediscovered consisting of fantastic mixtures of humans and animals with plants. Over the centuries, the grotesque has often been linked to a monstrous exaggeration of physical idiosyncrasies, and as such it has been seen, often in a pejorative manner, as overstepping a classical ideal of symmetry. The grotesque tended to be treated as a 'vulgar species of the comic' (Thomson, 13). In his De boekenpoeper, Maarten van Burren argues that, until the $20^{\text {th }}$ century, a grotesque breach of classical prescriptions was only appreciated in a few periods, like the era of Baroque style and the Romantic era. In those periods, some of Shakespeare's plays which mingled traditional stories about kings with down-to-earth elements like the pranks of jesters or matter-of-fact statements by grave diggers, were received more favourably than during other times. Van Buuren also mentions that Madame Bovary (1857) by Gustave Flaubert, written at the peak of the realist movement, was considered as a polemical novel, because Emma's tragic agony is brusquely interrupted by a banal melody, sung by a blind man in the street. According to him, this crude cross-cutting from the sublime to the vulgar was regarded as the true scandal of the novel at the time of its publication (60-62).

In the $20^{\text {th }}$ century, the concept of the grotesque has gained a fresh impetus, because it got elevated to an aesthetic category in itself. It does not only owe this raise in prestige to the enthusiasm among surrealists, but above all to two important studies, which, quite remarkably, happen to take totally divergent positions. In chapter 1, I referred to Mikhail Bakhtin, who dedicated a study to the $16^{\text {th }}$-century French writer Rabelais, for Bakhtin the uncontested master of what he called 'grotesque realism.' Rabelais had the guts to submit anything sublime and exalted to free and easy folk humour, time and again concerning bodily transgressions. According to Bakhtin, it had a positive and liberating force when something lofty and grandiose was converted into physical representations of a laughable nature, which, as I argued in chapter 1, was the case with FLODDER. Apart from being jolly, such a grotesque effect had a vitalizing function, since it worked to downplay pomposity.

Whereas Bakhtin proposed the grotesque as a sub-form of folk humour, the German art historian Wolfgang Kayser connected the concept to the idea of the 'metaphysically terrible' (15). The grotesque artist 'plays, half laughingly, half horrified, with the deep absurdities of existence' in an attempt to 'exorcise the demonic elements in the world' (Thomson, 18). According to Kayser, the grotesque arouses contradictory feelings; 'we smile at the deformations but are appalled by the horrible and monstrous elements as such' (31). He describes Kafka's works like the story Die Verwandlung [The Metamorphosis] 
as 'cold grotesques' for we never know when we 'are supposed to smile ... and when we are supposed to shudder' (148-49). For Kayser, the grotesque 'instills fear of life,' since it confronts us with an 'estranged world': 'we are strongly affected and terrified because it is our world which ceases to be reliable' (185).

Kayser's position is indebted to the realm of the irrational and the mysterious rather than the comic, due to his 'somewhat melodramatic over-emphasis on the "demonic",' as Thomson claims (18). Studies on the grotesque have been versatile since Bakhtin and Kayser, because their opposing perspectives have inspired scholars to come towards a definition which usually walks the middle ground between the two spectrums. At the core of the grotesque is, as Thomson argues, an 'unresolved clash of incompatibles in work and response,' which is only a fairly abstract description of its formal pattern. Secondary to the definition is that the grotesque concerns the 'ambivalently abnormal' (27). Abnormal is the outlandish juxtaposition of elements which do not logically 296 fit together (like the solemnity of a royal court and the buffoonery of the jester). The adverb 'ambivalently' is applicable to the people's response: for the one the work (of art) will be nauseating, for another funny, and a third will consider it both horrifying and comic. Thomson presumes that the latter group will be the largest one, not really knowing whether to shiver or to laugh. ${ }^{4}$ The grotesque has a 'harder message' than tragicomedy, according to him, for the latter points out that 'life is alternately comic and tragic, the world is now a vale of tears, now a circus.' In the case of the grotesque, 'the vale of tears and the circus are one,' implying that 'tragedy is in some ways comic and all comedy is in some way tragic and pathetic' (63).

Thomson has set himself the task to draw dividing lines between the grotesque and other modes and categories, like the absurd, the bizarre, the macabre, and so on, in order to come to a better understanding of the functions and the purposes of the grotesque. According to him, these functions vary from purely ornamental to showing off one's eccentricity to aggressive bewilderment, when 'the guffaw becomes a grimace' (59). My overview will not be as exhaustive as Thomson's, for I will restrict myself to three interconnections: the grotesque-caricature; the grotesque-irony; and the grotesque-satire.

\section{A WANNABE TARANTINO CAPER MOVIE: BLACK OUT}

If, strictly speaking, NEW KIDS TURBo and VET HARD are too absurd and cartoonish to be considered under the umbrella term of the grotesque, then both NAAR DE KLOTE! [WASTED!] (Ian Kerkhof, 1996) ${ }^{5}$ and BLACK OUT (Arne Toonen, 2012) are borderline cases. They are hyperbolic as well, but they revere the cinema of Tarantino in a way that NEW KIDS TURBO and VET HARD 
do not or only to a lesser extent. ${ }^{6}$ BLACK OUT not only looks like a Tarantinostyle caper movie, but Toonen's film also has some explicit references to his work. To start with, the two 'power babes' Petra and Charity have to collect some money from people who owe the old gangster boss 'Granddad' a debt. At one point in the film, Petra mentions that gangster films do not offer female criminals the prospect of a true career. The guys watch SCARFACE (Brian de Palma, 1984) a thousand times, but Michelle Pfeiffer is a poor model for women, she claims. Charity then suggests FOXY BROWN (Jack Hill, 1974), a role played by Pam Grier who is briefly mentioned in a discussion among the gangsters in RESERVOIR DOGS, and who performed the role of the title heroine in Tarantino's JACKIE BROWN (1997). Petra disagrees, because Foxy Brown is not a professional by choice, but she is motivated by revenge. After the two women smash the window of a car with a cricket bat and an axe, Charity refers to Uma Thurman in Tarantino's double-feature KILL BILL (2003-4), but Petra briefly replies: 'That is revenge, too.'

A more oblique reference to Tarantino's cinema concerns the controversial use of the term 'nigger.' In BLACK OUT, this word is only used during the scene when main protagonist Jos Vreeswijk is interrogated by the cynical police commissioner André; in Tarantino's films, the so-called N-word is uttered frequently. It is obvious from his pictures that Tarantino perceives black culture as the embodiment of cool. He considered it a compliment when someone told him that he had 'given white boys the kind of movies black kids get' (qtd. in Willis, 211). It is one thing, however, to be infatuated with black masculinity as a model for 'looking like a badass,' but the frequent mention of the so-called N-word is another thing. If Tarantino believes that African-Americans think that term is 'trendy or slick,' then he is mistaken, black filmmaker Spike Lee once criticized him. ${ }^{7}$ Lee refuses to use the term because it is too much burdened by the dark history of slavery, but Tarantino's notion of history is entirely different. For him, history does not so much refer to actual events from the past, but it is basically a quotable text. Writes Willis: 'For the world of Tarantino's films is a world without history - a world where all culture is simultaneous, where movies only really watch other movies' (213). And thus, one can fantasize and stage any event, like Hitler dying in a fire in a French film theatre in INGLOURIOUS BASTERDS (2009), even when such an event clashes with historical data. Debunking official documents Tarantino builds a 'privatized public sphere' based upon the principle of recycling. He can appropriate anything from television, music, popular films and put it in the blender of a new, contemporaneous text. Expanding this logic, Tarantino's films offer a 'screen beyond history' (213), in which images and words can circulate without their usual connotations. The frequent use of the term 'nigger' may hint at Tarantino's (utopian) desire to sanitize the word and to lift it 'out of its web of social meanings' (Willis, 209). 
Bearing this utopian goal in mind, the interrogation scene in BLACK OUT adds an additional layer to the use of the word 'nigger' (neger in Dutch). In the presence of his young assistant, Youssef, the experienced detective, André, tells an old anecdote about Jos, who is about to be interrogated for the first time since he has quit the criminal circuit ten years ago (which is one of the running gags every character says to Jos: 'Thought you had quit the business?'). The story is about some coke party when Jos was trying to seduce a girl, who happened to date a 'big nigger.' Youssef asks whether there is no different way of expressing this; André does not get the point. 'Well, nigger is a slave term.' André defends the use of the word: 'But it was a nigger all right. Niggers address each other like that all day. Nigger this, nigger that.' Youssef keeps silent, and André continues: 'You are the very first Arab who makes a fuss about this.' Youssef corrects him: 'I am a Berber' [an ethnic group indigenous to North Africa]. While there is a shift from the interrogation room to 298 the flashback at the coke party, André's off-screen voice continues the story: 'So our Jos stands in front of a Harry Belafonte who is two heads taller.' 'Who's that?' Youssef informs. 'A nigger,' the black guard who had been silent so far, dryly replies.

This dialogue is to be seen as a comic wink at the criticism targeted at Tarantino. Initially, the conversation references the controversy surrounding the N-word, a 'slave term,' but the troublesome nature of the term is neutralized as soon as the black guard uses the word 'nigger' to clarify a euphemistic expression. One might consider this punchline - the black man using the term 'nigger' - as an attempt to give some backing to Tarantino against the charges of an immoral use of the N-word.

Whereas, as I said, Tarantino recycles images, sounds and texts from other cultural objects, BLACK OUT in turn replays the privatized universe of Tarantino's cinema. And thus it is only consistent that Toonen amply borrows from other sources as well, just like Tarantino. As regards the particular story element of a protagonist whose mind has gone blank just preceding an upcoming wedding, BLACK OUT resembles THE HANGOVER. There is, in a mob drama like BLACK OUT, the inevitable quote from THE GODFATHER. And a detective who prides himself on his 'intuition' like André does, is liable to become scapegoated: he got it entirely wrong and in the end he suffers the flop from degradation to a policeman carrying out alcohol checks.

The main reason for inclusion of BLACK OUT in this chapter on the grotesque is not due to the intertextual references to gangster movies, but because Toonen is overdoing the representations of its characters, in a fast-paced style, which reminds one of the Guy Ritchie films, even more than of Tarantino movies. Several of the directors, the British Ritchie among them, who followed in Tarantino's footsteps had the tendency to escape the label of 'copycat' by 
accenting the oddities of its story and its characters, as well as to highlight sweeping cinematic devices, like fast zooms. Toonen's film is shot as edgy as the Ritchie's crime-thrillers LOCK, STOCK AND TwO SMOKING BARRELS (1998) and SNATCH (2000) with freeze frames, extreme low angles, frontal stagings, hectic camera movements, sound effects and smart-ass voice-overs, like the one about Inez who is nicknamed Cocaïnez, because she can perfectly determine the degree of purity of this white powder. Hence, as in a Ritchie film, the frenetic style of Toonen's BLACK OUT underscores the slightly overdrawn plot with its innumerable situations and the slightly overdrawn representation of the characters. A gangster boss like Don Corleone arouses fear because he hides his cruelty and authority behind a veneer of calmness, giving him an aura of impenetrability, but the two gangster bosses in Toonen's film border on the caricaturesque. Like the ruthless mafia boss tied to a wheelchair in Things to Do In Denver When You'Re DeAd (Gary Fleder, 1995), 'Granddad' sits in a wheelchair and has a personal nurse who looks after his condition. He uses foul language and can burst into anger, but his fits can suddenly switch into serious coughs or make him run out of breath. The other gangster boss is at least as uncommon, named Vlad the Gay Basher, a former dancer in the Russian ballet, who realized that his agile body came in handy in violent settings which are reminiscent of FIGHT CLUB (David Fincher, 1999). That was the start of his career as a criminal. Vlad is a smooth-talking character, who can take it in his stride to blackmail a person on the phone and to correct one of the customers in his bowling centre: 'No walking on the lanes, please.' Or while he is suffocating his failing assistant with a pillow, he says to a bowler who orders a coke: 'I will be with you in a minute,' which happens to be a running line uttered by Cary Grant in BRINGING UP BABY (Howard Hawks, 1938).

The representations of these gangster bosses are abnormal, and definitely based upon a clash of incompatible elements. ${ }^{8}$ The terminally ill and incredibly avaricious 'Granddad' behaves in an authoritarian way, also towards his two sexy dames, whom he advises to adopt more creative - that is, ruthless - methods in collecting money. Vlad gracefully dances to the music of Swan Lake when he has planned to kill protagonist Jos on a bowling alley, to no avail by the way. But this clash of incompatibilities is not as unresolved as the concept of the grotesque requires, since the two bosses are ludicrous rather than threatening. They are downright criminals but of such an oddball nature that laughter at their exaggerated portrayal is more obvious than any uncanny feelings among spectators. The identities of both 'Granddad' and Vlad lack the mysteriousness to bring about a divided reaction from the viewer, and therefore they are not so much grotesque, but a sub-form: a grotesque caricature. And ultimately, the scales in this Dutch nouvelle violence film tip in favour of comedy, no matter how serious the setting seems to be, as some brief exam- 
ples imply. 'Opium is the people's religion,' Inez says, and she uses a crucifix to snort her coke. At one point, Jos is fighting in a car, while the Tom Tom says: 'Turn around if possible.' Or what to think of the scene in which the gangster Gianni - who gets mad when someone calls him 'Jan' - has his two companions point a gun at two black guys. When Gianni describes their business as a service for walking dogs, the guys start to explain in detail during this tense moment that their speciality is to cut the dogs' hair.

\section{(NOT) A TARANTINO DANCE MOVIE: NAAR DE KLOTE!}

BLACK OUT is a grotesque caricature, in which the chill down the spine is drowned out by comic exaggeration. Ian Kerkhof's NAAR DE KLOTE! offers the other side of this coin. The film is not set up as a comedy nor as a mob thriller, 300 | but gradually evolves into a gangster film with caricatural undertones. The film focuses upon the young couple Jacqueline and Martijn who move from Tilburg to Amsterdam, and get involved in the house scene of the mid-199os. Popular drugs like magic mushrooms and ecstasy are crucial ingredients of their lifestyle. The first ten minutes of the film are shot like a trip: fluorescent colours, bright lightning, unorthodox angles, out-of-focus and jerky camera movements, so that the opening has many moments of an abstract quality. Although NAAR DE KLOTE!, which is primarily aimed at a public of adolescents and young adults, is unlike Kerkhof's previous films, the abstract quality of many shots can be seen to close the gap to his earlier work. In the early 1990s, Kerkhof had earned a reputation as an avant-garde and experimental director in the tradition of Frans Zwartjes ${ }^{9}$ with his Kyodai MAKES THE Big Time, winner of the Netherlands Film Festival's Golden Calf for Best Feature Film in 1992, a film with sex scenes shot in a minimal, long-take style. ${ }^{10} \mathrm{~A}$ film on rapists and one inspired by monologues of serial killers had further gained him notoriety, but hardly an audience. NAAR DE KLOTE! offered him the opportunity for a functional embedding of experimental devices within the format of a popular film. The colours are at times very intense: sharp white, deep red, or a sex scene tinted in blue; some shots have black edgings as if to suggest that the sight of characters is constricted; jump cuts underline the idea of life in the fast lane; when characters eat in a Japanese restaurant the camera is as low as the tatami perspective in a Yasujiro Ozu film; superimpositions suggest that Jacqueline still longs for a time when her relationship with the unpretentious Martijn was stable. Martijn is a guy who just wants to hang around in a coffee shop and when Jacqueline takes him to a Japanese restaurant he says that he prefers McDonald's. His lack of ambition is best summed up by the ironic slogan, with which they arrive in Amsterdam: Let's get 'wasted.' 
In their new home, Jacqueline outgrows Martijn and this process is accelerated after she meets the dealer JP, who has a red sports car, like the posh American producer in Jean-Luc Godard's LE MÉPRIS [CONTEMPT] (1963). Initially she only works for him, but JP soon gets more demanding. After a miserable threesome at his place, she gets home while Martijn is leaving. She throws away some pills out of frustration, which is the beginning of her financial problems. Later she takes 4,00o guilders from the cashbox of a shop to finance the record release of two girlfriends. Jacqueline promises to give the money back that very night to Winston, a black man who has a business conflict with JP. From the moment JP goes, accompanied by a buddy, to Winston's office to settle the dispute, events go quick and are cross-cut. The record release is successful, but Jacqueline is angry that her name is missing on the single and during a quarrel that ensues she is hit; Martijn has spotted JP's car and will start to demolish it with some friends; meanwhile JP is forcing Winston to call him, that is, JP. We get a quick series of shots of which the extreme close-up of the right side of JP's face, shot with a wide-angle lens for a distorting effect, is the most remarkable. Since not only the buddy, but also JP has pointed a gun at Winston's head, the latter wants to talk sense into his opponents by saying: 'This is the real world, man' and while we look over the gun into Winston's left eye in a shaky, hand-held close-up, he continues: 'Not a Tarantino movie.' Shot of JP with the gun he holds in the foreground: 'Tarantino?' He turns around, and while the camera makes a 180-degree turn as well, JP repeats: 'Tarantino? I will give you Tarantino, motherfucker.' And while we see JP aim, the shot is interrupted by the smashing of the windows from inside JP's car, then back to JP who strikes a pose as a shooter, and this goes back and forth in a fast crosscut rhythm: a few frames of Mandela's portrait hanging in Winston's office, a high-angle shot of the demolition of the car, the bleeding face of Winston, JP's shocked buddy, JP's hysterical laughter in close-up. Immediately after JP and the buddy leave the office, Jacqueline enters to bring back the money in a highangle shot. She starts to call the police, while we see Mandela's portrait, immediately followed by 'directed by Ian Kerkhof.' Cross-cut with the end credits, JP becomes the target of some cartoonish violence, and Martijn and Jacqueline decide to go home, back to Tilburg.

NAAR DE KLOTE! is not a comedy, like BLACK OUT is, unequivocally, an action comedy. Kerkhof's film might even be said to show 'the real world,' at least the world according to those people who attend house parties and experience an occasional ecstasy trip. It is a scenery in which conceited and narcissistic types as JP or the blonde-haired DJ 'Cowboy' are as much drawn to life as they are silly caricatures. The way they consider themselves to be at the 'top of the world' makes them quite ridiculous, but the irony of NAAR DE KLOTE! is that if this particular youth culture is so hyperbolic, well, then Winston's 
'this is the real world, man' is not an unfounded claim. The film shifts gear, however, the moment JP says, 'I will give you a Tarantino movie, motherfucker,' for this heralds a swiftly cut finale of over-the-top violence, during which the most excessive and self-assured characters are turned into pathetic victims. Winston is bleeding to death in his impeccably white suit; JP is humiliated by Martijn and his friends; and Cowboy is lying completely wrecked on the side of the road during the end credits after his ego has been very badly shaken when a female DJ has surpassed him in popularity. This finale is so excessive in terms of cartoonish events, fast (cross-)cutting and jerky camera movements that it is a Tarantino movie, but to a second, if not third degree. Or to put it in terms of this chapter: near the end, NAAR DE KLOTE! is turned into a grotesque caricatural version of a Tarantino movie. There are no particularly comic scenes or jokes in Kerkhof's film, but, if you consider Kerkhof's reputation as an experimental art-house director as well as the ironic title NAAR DE KLOTE!, one may

302 be inclined to consider the film as a hilarious enterprise.

\section{COMIC STRIP MEETS TARANTINO AND TARKOVSKY: DE WEDEROPSTANDING VAN EEN KLOOTZAK}

Guido van Driel described his DE WEDEROPSTANDING VAN EEN KLOOTZAK [THE RESURRECTION OF A BASTARD], which was the opening film of the International Film Festival in Rotterdam 2013, as a mix between 'Tarantino and Tarkovsky.' Such a characterization is already a hint at the grotesque, for if the American irony of Tarantino's grindhouse meets the meditative long-take cinema of the Russian Andrei Tarkovsky, then we must be definitely dealing with a clash of incompatibilities. This clash is resolved, but only to a certain extent. Main protagonist Ronnie has had, as becomes clear later in the film, a neardeath experience, when someone, with a tattoo of the Weapon of Dokkum on his wrists, shoots at him in the men's toilet of a huge dance party. The camera makes wobbling movements, then ascends, without a cut, one floor up to the dancing crowd, and even higher and higher into an overhead shot with a circling camera, that ultimately dissolves into a white screen. In this bravura shot which recalls the visual style of films by Gaspar Noé, known for IRRÉVERSIBLE [IRREVERSIBLE] (2002) and ENTER THE VOID (2009) with cinematographer Benoit Debie, Ronnie seems to float high in the air over the dance audience. Ronnie survives the attack, but from that moment onwards, he has undergone a mental change. Or, as his faithful buddy Janus tells someone on the phone, 'I'm telling you - he has completely changed. Like Bruce Willis in THE SIXTH SENSE is completely different from Bruce Willis in DIE HARD. Something inside him has snapped. He is no longer the old Ronnie.' 
We then get, 18 minutes into the film, white letters on a black screen announcing the portrayal of the 'old Ronnie.' This old Ronnie is a ruthless criminal in the vein of the psychopath Mr. Blonde. ${ }^{11}$ He did not shy away from mutilating a guy's eye with a vacuum cleaner. 'No more $3 \mathrm{D}$ movies for Stanley,' one of Ronnie's assistants will comment later with a smile. The scene is as morbid and as suggestive (for it takes place off-screen and we only hear the sound effect) as the torture scene from RESERVOIR DOGS. It is also very Tarantinesque that Ronnie and his buddies discuss films, like THE Boston STRANGLER, and television series. Watching THE PERSUADERs together, Janus observes that exciting events befall both Roger Moore and Tony Curtis: 'Car chases, fights, hot chicks. You'd think they have plenty to catch up on when they meet. But they never do. They are funny kind of friends.' 'They are no friends,' Ronnie corrects him, 'they are colleagues.' In addition to such a Tarantinesque dialogue, there is also the gangster boss whose moustache is as peculiar as his name, James Joyce. The visit Ronnie and his companion Jaap have to pay him, makes them nervous, so this James Joyce is acknowledged as an authoritarian figure before we have set eyes on him. He is absolutely calm on the surface and before he even looks at Ronnie, he is first finishing an anecdote about a bird that had burned its legs on a stove, recorded by a camera. Only then does he ask Ronnie to step forward and to smell his breath. 'What do you smell?' 'Maagzuur,' Ronnie says, which is translated by the cameraman into 'heartburn.' James Joyce then calmly says: 'Ronnie, you give me heartburn.' On the one hand, this gangster boss is terrifying because of his composure, on the other hand such a tranquil criminal has also been a stock image of the genre, and therefore the recycling of such a cliché risks becoming a bit ridiculous.

Hence, as regards the flashback episodes, DE WEDEROPSTANDING VAN EEN KLOOTZAK stands in the tradition of Tarantino's nouvelle violence, and in the near-death experience, it is influenced by Noé. In the scenes in Dokkum, which is the present in the film, Van Driel's picture is split. Janus is still his old self, blathering about practically anything and hence, as talkative as Vincent Vega from PUlP FiCTION. He has a series of outrageous theories, about food: 'Hogweed can bring you blisters on your dick,' or about female models in commercials. He regrets that these women do not have full hips and big breasts, but are always skinny daddy longlegs, because the gay men in the fashion world 'give us girls who look like boys.'

By contrast, the 'new' Ronnie, wearing a neck brace as a consequence of the attack, has become a more contemplative character with an extremely strong sensory perception. He takes ample time to smell the food that is being served. He asks Janus to stop the car, walks into a meadow and can save a man from burning alive, because he was already there before the fire actually caught him, suggesting that he has the gift of clairvoyance. To emphasize 
Ronnie's inner change the rhythm in the scenes in Dokkum is less hectic, although the average shot length is still way too brief to be really compared to a Tarkovsky film. Tarkovsky regarded film as 'sculpting in time,' meaning that its editing should conform to a consistent and precise rhythm, but Van Driel's debut feature feels, as one reviewer at IMDb put it, 'a little arrhythmic,' meaning that its storytelling is uneven: sometimes disclosing too much information, sometimes too less. Instead of considering this as a flaw, the charm of this arrhythmia is that it betrays that the film is an adaptation of a graphic novel, one written by Van Driel himself, Om mekaar in Dokkum (2004). Bearing in mind that this graphic novel was praised for its painterly style, the background of the film shots originated from a meticulous framing. In his review for cinema.nl, Gerhard Busch even refers to the Dutch $17^{\text {th }}$-century painter Vermeer in the high-angle shot of the picturesque streets of Dokkum on the left while on the right we see protagonist Ronnie through a window enjoying 304 his meal of trout and pomegranates.

A too painterly style can be at the expense of a narrative logic: why does the 'new' Ronnie decide to go cycling in the empty Frisian landscape at night? Why does he go into the water and remove his brace (for, given his exceptional sensory perception, we can presume that he knows his avengers are following him in the dark)? The logical answer to these questions is that narrative logic seems suspended, just as in a Tarkovsky film conventional causality is short-circuited. The film seems to work towards its remarkable final shot, for it is only then that the story about Ronnie is merged with another one, about Eduardo, an asylum seeker from Angola in Dokkum who has had such traumatic experiences that we only have been offered some snapshots from his past, but not an actual account. Someone tells Eduardo that Frisians used to believe in holy trees, but that Saint Boniface had come to convert them by chopping down trees. Seeing the empty landscape, Eduardo on the one hand remarks that the Frisians have become very orthodox these days, but on the other hand he mentions that he believes that the ghosts of the dead are hiding in the trees. At the moment, the trigger is pulled for the final shot at Ronnie, Eduardo suddenly falls from a tree, interrupting the execution of the gangster. At the end of the film, both Eduardo and Ronnie are sitting next to each other in the top of the tree, the wind through its branches. The status of the last shot offers food for thought: has the attempt to execute Ronnie been called off and resulted in the shots fired at him during his escape into another near-death experience, with him once again high above the ground? Or has he perhaps become a ghost of the dead, hiding in the branches according to Eduardo's belief in black magic? This latter option would give body to Van Driel's reference to Tarkovsky. In the metaphysical science-fiction film SoLARIS (1972), the main protagonist Kris Kelvin is on an expedition in a space station, where he 
learns that people can materialize as memory remnants due to the bio-energy coming from the ocean of the planet Solaris. Since he still thinks of his wife, Hari, who had committed suicide, he encounters her once again, and despite her lifelike appearance, she is no more than a ghost.

In order to characterize DE WEDEROPSTANDING VAN EEN KLOOTZAK as a film inspired by both Tarantino and Tarkovsky, it has to be understood that there is no true meeting of influences. That would have made Van Driel's work an extraordinary grotesque. Now the adaptation of his own graphic novel foremost shows a dual face: on the one hand, it is a sketch of the grotesque gangster scene, slightly caricatural, and on the other hand, it has the allure of metaphysical cinema which closes with the suggestion of some magical realistic bond between Eduardo and a hypersensitive Ronnie.

\section{IRONY OF FATE: PLANC}

The type of irony which is most likely to become grotesque, Thomson observes, is the cosmic irony (49). Although I discussed OBER in chapter 7 as a variant of cosmic irony, I would not consider Van Warmerdam's film here, for the imagery of his strikingly 'unsentimental' cinema is not particularly grotesque: bodies are hardly ever depicted as disfigured. We see Edgar floating in an aquarium after he has insulted the three macho guests, or we see, in Borgman, three bodies head-down in a bucket with concrete at the bottom of a lake, but the shots are represented from such a 'markedly detached perspective' that they are closer to black humour - that 'mortal enemy of sentimentality' (Breton, 25) - than to the grotesque, which elicits a more 'emotionally charged' reaction from its audience, as Vanessa M. Merhi concluded. Both black humour and irony achieve their greatest effect by tinkering with codes and traditions that are being inverted in a work, Phil Wagner claims, whereas the grotesque relies more on the 'audience's gut-instincts and the strange, invigorating appeal of the monstrous and the vulgar' (n.p.).

In her textbook on irony, Claire Colebrook classifies cosmic irony, together with irony of fate, and the more literary concept of dramatic or tragic irony, in the category of situational irony. ${ }^{12}$ This latter category refers to, in the words of Hutcheon, a 'state of affairs in which events or circumstances, desirable in themselves, are either perversely ill-timed or turn out in a contradictory manner to what might be expected' ('Introduction,' 34). The Dutch boxer André van den Oetelaar used to be a talented fighter, but he never became national champion. Then he had a serious accident after which he had to have surgery. Due to the pins placed in his body he had gained so many kilos that he had to compete in another division, of the heav- 
yweight class: this time, in 1981, he became champion after all - ironically, thanks to the misfortune. In such a case, the outcome is so contrary to logic that our 'understanding of the world is undercut by some other meaning or design beyond our powers' (Colebrook, 14 ). ${ }^{13}$ With cosmic irony this 'design beyond our powers' is represented by some godlike instance manipulating events - the more Edgar starts to interfere with the scenario, demanding adjustments, the more the scriptwriter in OBER starts to act as a deity punishing his protagonist. Irony of fate can be called its plain and down-to-earth version: it simply concerns 'the contrast between the individual's conscious aspirations and what fate ... eventually makes of him' (Hutcheon 'Introduction,' 34). Such an irony of fate is already implied in the title of PLAN C (Max Porcelijn, 2012). It is usually a bad omen when the original plan does not work, and even worse when the backup plan fails as well. Porcelijn's film shows its viewers what happens when even another plan has to be impro306 | vised 'as a bit of jazz,' as one of the character says. Everything goes downhill for protagonist Ronald, but as a brief recapture of the plot of PLAN C will illustrate, thanks to a bizarre and miraculous twist near the end he gets away with the 'bad things' he was about to confess.

The divorced policeman Ronald Plasmeyer has only one week to pay his debts to a Chinese crime boss. His habit to participate in poker matches in Amsterdam North does not offer him benefits, but makes his financial sorrows worse. He asks his friend, Gerrit, to rob the poorly guarded office. Ronald bets on it that the organizers will not alarm the police since their tournament is illegal. When Ronald wants to finalize the deal in the lobby of some roadside hotel, Gerrit has brought his ex-brother-in-law Bram with him, to Ronald's dissatisfaction. While the couple is on the way to rob the place, Ronald phones them from the toilet to abort the mission, because this very evening he is winning practically every game, but Bram insists they see the original plan through: 'The machine is already set in motion. It's not a school trip. Easy peasy.' Despite Ronald's command not to use any violence, not even as a last resort, Bram turns out to be trigger-happy and kills two people in a grotesquely violent scene. When they meet again in a diner, Ronald is mad because of the dead, but Bram reacts laconically. Moreover, Bram refuses to split three ways fair and square, for Ronald was no more than 'Prince Charming,' acting all high and mighty, while he and Gerrit had been sweating like work horses. From here onwards, the action develops in quick succession: Bram runs off with the money in the company with Gerrit; they check in at a small hotel; the money gets blood-stained; Bram shoots Gerrit when the latter tries to phone Ronald; Ronald tracks down Bram's hiding place; he almost stumbles over a rip in the carpet; Bram catches him by surprise but his gun malfunctions; Bram runs away, but he really stum- 
bles over the rip in the carpet; Ronald shoots him and makes it look like an accident; he pays off his debt to the crime boss who accepts the bag with money without deigning a look at it. For the police, it is case closed: the two dead guys are the perpetrators.

Ronald's fate is the opposite of the misadventures of Jerry Lundegaard, the protagonist of FARGO (Joel and Ethan Coen, 1996), with whom he shares quite some parallels. Both Jerry and Ronald concoct some minor crime in order to solve their financial sorrows, and in both cases, they are saddled with not so very adequate associates: the one a bit clumsy, the other - and that will turn out to be worse - unfathomable. In FARGO as well as PLAN C the protagonist does not really have confidence in the unfathomable type, but the ball has been set rolling and there is no way of stopping the plan, which leads to a number of disfigured bodies on the way. In PLAN C, as in a film by the Coen brothers, the violence edges into slapstick, the horror into comicstrip farce and vice versa (Bergan, 27). FARGO will confirm the scenario of what came to be called Murphy's Law: Anything that can possibly go wrong, does. Hence, the outcome for Jerry will be a total disaster; in PLAN C it is the same, except for the miraculous twist.

The ending of Plan C is counterintuitive, for film conventions have it that sly characters do not get away with their wicked deeds. Woody Allen's CRIMES AND MisdemeANORS (1989) can be considered as a metaphysical reflection upon this convention. The widely respected Judah Rosenthal is raised according to the dictum that the 'righteous will be rewarded and the wicked will be punished for eternity.' When he kills his mistress, who had said she would reveal their affair, he expects that a morally just God will make sure he gets caught. Since he is not punished at all, he starts to believe that our lives are not determined by some heavenly force, but by the arbitrary moral choices we impose upon ourselves in an indifferent universe. ${ }^{14}$ When Judah tells his own experience in the form of a pitch for a murder mystery to a filmmaker, the latter says that the character will be so much burdened by his moral conscience that he will eventually give himself in. 'That's fiction,' Judah replies. Whereas the filmmaker in CRIMES AND MISDEMEANORS presumes that according to dramatic conventions characters have to suffer for their immoral decisions, no matter how hard they try to escape their fate, Judah knows better. Plan C gives credence to Judah's position, for Porcelijn's film is an example of an 'irony of fate' which privileges the instigator of a crime. ${ }^{15}$

A main reason why the wheel of fortune is on Ronald's side, is because his chief, Peter, who is about to retire, does not have the ambition to get to the bottom of the situation. ${ }^{16}$ He has his intuitions about Ronald's share: Peter has found Ronald's lighter at the scene of the crime; he guesses that 
Ronald is in deep trouble, but only tells him that he himself knows 'the darker side of life'; Peter does not contradict the colleague inspector who says that it would unnecessarily complicate the case if they were to take seriously that an eye-witness has reported a third person, a 'bald' one; and when Ronald is about to confess, Peter interrupts him and ultimately tells his minion a story, whose short version goes like this: A guy is stuck in a hole, and asks passers-by for help. The doctor gives him a prescription, the priest sends him a prayer, but the friend who comes along, jumps into the hole, so that they are stuck together. Since Peter has forgotten the punchline, he sums up the moral of this clueless anecdote with a brief 'you need friends, Ronald.' This story, devoid of an object, brings the opening voice-over by Peter into memory:

In India I once spoke a wise ... well ... man who told me that a plan can change you and if you are strong, you might also change the plan. The rest is sheer luck. That's how he saw it. I never really understood what it means. My father always said that if you let it come down to luck there's only one certainty: Whichever way it goes, it will always swing back the other way in the end. But these are just theories, but in practice, it is ... [And here the sentence is cut short, because Peter's extradiegetic voiceover is overwhelmed by the interdiegetic curses by Ronald who, in the background of the shot, is complaining about his bad luck at the poker game.]

As the voice-over illustrates, Peter's ruminations are amusingly shallow throughout; his thoughts remain stuck in trivial phrases. The first part of the quote is mystic, because he himself admits that he does not understand it. The second part is superficial, kind of proverbial rather than philosophical: this time one is unfortunate, next time one may have luck, but actually he doubts whether this theory is right. On account of his seniority, Peter functions like a counsellor to his employees, lending them an ear to problems of whatever nature. He is a 'good listener,' at least he claims so himself in a conversation with Ronald, but despite his work experience his advice is never very sound. It is particularly ironic that Peter debunks his father's theory about the fluctuation of luck and bad luck as too flimsy, whereas the film PLAN C - which can be called the 'practice' - proves the opposite: all the odds seemed against the typical schlimazel, or buffoon, Ronald, but it is more by hit than by wit that suddenly luck turns his way.

PLAN C is unmistakably inspired by the bleakly comic tone of the films by the Coen brothers, like FARGo in terms of plot, and as is also confirmed by the oblique visual quotation of having a Chinese man put out a cigarette 
on the protagonist's rug versus a Chinese man peeing on 'The Dude's' rug in THE BIG LEBOWSKI (1998). In a study, in which he regards the Coen brothers as 'masters of the grotesque,' Schuy R. Weishaar argues that their films depict characters in 'moments of extremis': they are caught in moments of catastrophic rifts which demand actions and decisions. They either engage in short-sighted actions 'without much reflection, or alternatively, they get lost in their ruminations - or both' (115). Once they set the wheel turning by a first decision, a trajectory is set out before them, with the tragic and comic result that the crisis expands. In L'Étranger [The Stranger] (1942) by the French writer Albert Camus, Weishaar asserts, 'moments of extremis' finally lead to some self-discovery on the part of protagonist, but in the films of the Coen brothers the characters' leap to 'know thyself' is at best partial: 'they finally glimpse who they are, and they fail to recognize the image, or the weight of the knowledge is more than they can bear' (116). Moments of enlightenment, Weishaar continues, are 'more likely to be signalled with a bout of nausea or a vacant stare than they are with a look of intellectual satisfaction' (118). Either the films fall short of offering a satisfactory explanation to the characters or if there is some kind of closure or 'answer,' it is usually 'obviously false, overly simple, or utterly ludicrous' (118). At the end of PLAN $\mathrm{C}$, after Ronald has promised Peter to make a report on a simple snack-bar case, the protagonist is sitting in a café. He sees there is some blood spilt on the sleeve of his jacket, and at that very moment, someone hails at him to play a game of poker. We see him hesitate, but before we get his answer, the end credits start, as if the 'overly simple' lesson is, following the superficial dictum of Peter's father, that one should not try one's luck again after such a narrow escape. ${ }^{17}$

If PLAN C does not offer a more profound lesson to its protagonist (or its audience) than a commonplace, one can add to this that with a mentor like Peter it is no surprise that Ronald will not make a true leap into self-discovery. This disability to 'know oneself' is humorously expressed by one of the running gags about a going-away present for Peter. Agent Henk repeatedly reminds Ronald that he is the last one to pay his share of 25 euro, excluding a colleague suffering from a nervous breakdown. At the end of PLAN C, Peter thanks Ronald in a private conversation for the present. We see a bronze sculpture, and Peter explains: 'It is abstract, they told me.' By saying 'it is abstract' Peter clarifies to Ronald it is a vain attempt to search for meaning, since it is a non-figurative artwork. This can be called a humorous miseen-abyme for the whole film, in which the logic of a plan or dramatic conventions do not really make sense. Further, Peter's addition 'they told me' disqualifies his status as an expert on art. He apparently did not understand what it represents, so someone explained to him that it does not represent 
anything. As such, his words 'it is abstract, they told me' indicate that art, like so many other things, are beyond his understanding. At this time, the sculpture is a very appropriate present, for by labelling it 'abstract' it is no longer required to comprehend it. Thus, the present can also be taken as a very ironic gesture by his minions.

In his fine analysis of the cinema of the Coen brothers, Weishaar argues that all the confusion and disorientation on the part of characters 'has to be represented physically - through the body, by or in actions or inaction, by or in expressions or moments when characters look expressionless' (126). In order to exorcize their internal tensions, they 'fall into physically performed rituals' (126). In the case of Ronald, his internal tensions find an outlet in weirdly funny tantrums, at his ex-wife and her new boyfriend, when he loses a game of poker, as usual, or, the most memorable one, when his friend Gerrit has arrived later than promised: 'You see that piece of paper? First I 310 walked all the way over there, then I went in and ordered a sandwich. I ate it walking back here. Then I arrived and you still were not here. Then I leaned against the car and threw that piece of paper away out of anger.' He then continues to give an account of a cup of coffee he drank. Such a fit of anger is comical, because of the elaborate descriptions of his actions. Ronald gives the impression that his fits are not a character flaw as such, but are simply born from the feeling that the world has come to conspire against him. He shows his frustration every time a character refers to his baldness, which leads to a particularly humorous scene when he is being registered for the poker tournament as 'Ron (bald).' Why bald? Ronald informs. The man at the table drily answers: 'Handsome Ron is playing, too. I have to know who's who ....' Ronald: 'Why not moustache?

In PLAN C, the gimmick about a physical 'flaw' like baldness works to signify the inner turmoil of the character, and that makes it so quirky. Similarly, Ronald has nervous tics, like skittishly looking around and putting his hands in his coat during conversations. His gaze is agitated and tired, and frequently a character asks him whether he has had a long night. Upon his 'No, why?' they either say 'Never mind' or they explicitly mention his 'eye bags.' At one point he is reading an article in a magazine titled '10 Tips to Cure Eye Bags.' Most important, however, is that his inward restlessness is at the root of a comic-strip like display of dead bodies. He is not directly responsible for the corpses, except for the last one, but others - like the inspector and his chief - deny him his responsibility, so that fate intervenes ironically in his favour. In addition to that, Porcelijn's film has a number of remarks concerning bodily waste, almost obligatory in a post-PULP FICTION film which treats violence in such a slapstick manner. As in VET HARD (chapter 1), characters either spend some time in the toilets or announce they 
have to go to the bathroom. Ronald frequents the toilet regularly in order to find moments of relaxation, as if it is his safe haven. Just preceding the robbery, Bram addresses in a deadpan tone the filthiness of toilets, in much the same vein as the contract killers in PULP FiCTION talk about foot massage: 'Never piss in a urinal. Your piss spatters back at you, you know, back at your penis. ... Your piss mixes with the piss of thousands of other dudes.' This quote is as nasty as hilarious, and as such it captures in a nutshell the ironic grotesquery of PLAN C.

\section{METAFILM AS A VENGEFUL SATIRE: DE MANTEL DER LIEFDE}

According to Hutcheon, satire is 'the art of diminishing a subject by ridiculing (with intent to discourage) its vice or folly by the use of irony, sarcasm, humour,' or, as Thomson would add, by the calculating employment of the grotesque. De MANTEl DER LIEFDE [THE ClOAK OF CHARITY] (Adriaan Ditvoorst, 1978) has a 'definite purpose' (Thomson, 4 ) to ridicule and discourage, as befits a satire. To appreciate this absolutely outrageous film with its star-studded cast as a grotesque satire, the curious career of its director Adriaan Ditvoorst has to be taken into account. He was one of the students at the Film Academy in the early 196os, and his fellow peers regarded him as very talented. His first film, the 22-minute IK KOM WAT LATER NAAR MADRA [THAT WAY TO MADRA] (1965) was an experimental short, inspired by the French nouvelle vague. It was shot in black and white with brusque transitions, violations of conventional principles like the 180-degree rule and match on action, and a remarkable soundtrack, including scenes in total silence. The short got a favourable reception at film festivals, and directors like Bernardo Bertolucci and JeanLuc Godard expressed their enthusiasm. Two years later, Ditvoorst made the feature PARANOIA, an adaptation of a novel by W.F. Hermans. The story of this beautifully shot, black-and-white film is bleak. After seeing a photograph in a newspaper, the main protagonist starts to believe, erroneously, that he is a wanted war criminal, and his paranoia makes him increasingly aggressive. His suicide only comes as a logical conclusion. The film consolidated Ditvoorst's reputation as a promising filmmaker, and after a few shorts, ${ }^{18}$ a film of medium length was released in 1973, DE BLINDE FOTOGRAAF [THE BLIND PHOTOGRAPHER], based upon a short story of, once again, Hermans.

DE BLINDE FOTOGRAAF, albeit in black and white, could be qualified as a Van Warmerdam picture avant la lettre. The film announces itself as 'a day in the life of a reporter,' as if the day is selected at random. The starting point is very simple: the journalist of a local newspaper has the assignment to write an item on a blind photographer. The journalist is met with suspicion by the 
parents who live in a small alley, in-between two houses. This isn't fair, the father tells the 'parasite from the press': you can see him, but he cannot see you. Upon the reporter's suggestion that he will conduct the interview wearing a blindfold, the mother answers that monetary compensation is a better idea. The father only allows the journalist in on the condition that he use a black light lantern only. When he returns with a lantern, the photographer's mother says, while the father is out of earshot, that her son wore special glasses and always had a pair of binoculars hanging around his neck, even though it caused welts in his skin. Later she bought a lot of Sunlight soap for the saving stamps, which she used to get him a camera. ${ }^{19}$ When the journalist finally meets the photographer, he says that all his mother's stories are nonsense. The journalist replies that he enjoyed her accounts, adding that a mother is a holy figure: 'I only write what my public wants to read,' he says. The photographer then explains that his father always pretended to take out 312 his roll of film once it was used up and put in a new roll, but he always put the very same roll of film back into the camera, time and again, out of cheapness. When the son became known as a 'blind photographer,' his father had the film with the many superimposed images developed. But he was afraid that his son would ask for another roll of film, so he kept his son in the dark room. How did you know that your parents lied to you?, the reporter asks. 'The point is not that I cannot see. You think I do not know that you are a fraud and an asshole? You have a lantern with real light, so that you can see me. How did you get it?' the photographer says, while he shines it into the reporter's face. For some time the screen is totally white, and then we see and hear the journalist laugh hysterically. The reverse shot shows that the photographer has his eyes wide open and they are without pupils, 'as white as ping-pong balls,' as Hermans' story has it.

Whereas the story progresses like a Van Warmerdam film, DE BLINDE FOTOGRAAF is shot in the vein of Orson Welles' THE TrIAL (1962), an adaptation of Franz Kafka's Der Prozess. Ditvoorst's film is shot in highly contrasting black and white, the more contrasting near the end because of the use of the lantern's sharp flashlight in a dark setting. Like Welles' film, which in an opening voice-over says that the logic of Kafka's story is 'the logic of a dream, or ... a nightmare,' DE BLINDE FOTOGRAAF explores a visual style that is quite like surrealist cinema. In the case of a surrealist film, Linda Williams argues, the representation of 'reality' is distorted but not via 'camera or laboratory effects such as slow-motion or superimpositions' (Figures, 215).$^{20}$ If the world is perceived as bizarre, this is usually the result of a play with the composition and the framing of the shots. In fact, the camera records the scene without distortions but from such an angle that it might take some time to get the picture. In DE BLINDE FOTOGRAAF, there are many uncommon angles, 
either high or low, and at some point the reporter seems dwarfed in a dark alley. In short, at times the shots are wilfully unbalanced.

Strictly speaking, one might have expected that DE BLINDE FOTOGRAAF consolidated Ditvoorst's reputation as a filmmaker with a signature style. Unfortunately this film, though praised by critics, had only a very limited release in film theatres in a double bill with DE ANTIKRIST [THE ANTICHRIST] (Roeland Kerbosch) and thus it can be said that Ditvoorst missed the moment. It was a film that recalled the art-house fare from the mid-1960s like his critically acclaimed PARANOIA, like DE MINDER GELUKKIGE TERUGKEER ..., like Het GANGSTERMEISJe, but 1973 was the year that brought TURKS FRUIT to the screen. To emphasize the turn to more sensational amusement in this period, one can point at the films by Frans Weisz, DE INBREKER (1972) and NAAKT OVER DE SCHUTTING (1973), which were quite unlike his earlier Het GANGSTERMEISJE. In interviews, Ditvoorst said that he detested those colleagues of his generation who had sacrificed their artistic standards for commercial success (Verdaasdonk 'Marginality,' 47). Upon the suggestion of the producer Matthijs van Heijningen, who then was at the very beginning of his career, Ditvoorst agreed to shoot the crime revenge thriller FLANAGAN (1975), based upon a book by Tim Krabbé. There was conflict between the producer and the director about the script and the cast, and though Ditvoorst made concessions to please a more popular taste, this film was box-office poison again, to his deep frustration (Verdaasdonk, 47). After this flop, the only person who was willing to finance another one of his films, was the quite shadowy café owner Luc Bijkerk, about whom it was rumoured that he had earned his money by distributing soft pornographic films (Verdaasdonk, 48). DE MANTEL DER LIEFDE would remain Bijkerk's only attempt to make a name in the film business.

The first shot of DE MANTEL DER LIEFDE shows two bare feet walking in sand. Then an extreme close-up of a mouth, moustache and a beard. The mouth produces an enormous yell: 'Moses.' Then a close-up of eyes and nose; then a close-up of wild, black hair. We see some smoke in the distance and hear a voice, asking: 'Who are you?' 'Who do you think?' We get a close-up of a right hand with a wound in its palm. The camera swiftly pans to the other hand, also shown in close-up with a similar wound. Jesus passes a woman, but completely neglects her; she goes after him on all fours. While Moses is about to slaughter a little goat, Jesus announces that he has come to get Moses' soul, for the laws are not being obeyed by the people: 'It is a total mess everywhere.' Jesus explains that his father has sent him because Moses has failed. Moses is about to protest, but Jesus lifts his hand, which we see in close-up, and Moses falls silent immediately. 'You are finished; you have had your chance,' Jesus says, and when Moses indicates that he has a problem 
with an itchy foot, Jesus advises him to cut it off. Instead of slaughtering the goat, Moses raises the axe and does just that. No attempt is made to disguise the fact that the remaining part of the leg and the streaming blood are fake; this special effect is deliberately poor. Moses is screaming like a pig, just like the woman. She wants to seduce Jesus, but he throws her into the sand. She lifts up her dress, but Jesus says disdainfully: 'You stink,' and walks away, while Moses' cries are mixed with relatively cheerful classical music on the soundtrack, 'Grand Potpourri for Cello and Orchestra,' composed by Carl Maria von Weber.

This 3-minute-long scene is a prelude to a number of sketches, which, as the starting credits announce, are inspired by the Ten Commandments. At best, these sketches can be called a travesty of these commandments. In one of them, which is cut up and interwoven as a red thread through the film, a boy on a bicycle is halted by two men on a motorbike who, for no reason, 314 slowly start demolishing his two-wheeler, and then ride on calmly. When the boy complains about the incident to two policemen, they tell him that it is not allowed to cycle on this dike, whereupon the boy throws the remainder of the bike into the water. In another sketch, a woman, Lies, is irritated by the impassivity of her husband, Cor, but he is so annoyed by her irritation that he picks up the television set and throws it through the window. The apparatus falls down several floors and produces a great ball of fire when it hits the ground. A neighbour, Toos, tries to console Lies, and then picks up an axe. Cor, who has just been singing 'The Internationale,' does not see her coming and a few seconds later she has imbedded the axe into his skull. In a subsequent scene we see a blood-spattered kitchen, while Toos is frying an enormous amount of meat. Lies is perplexed and, glassy-eyed, she just mumbles, 'Cor, Cor, Cornelisje, what are they doing to you?'

Not all of the sketches are this morbid, but they practically all are this absurd. Since no one attends church any more, a bishop advises a priest to go where the people are and so he ends up in a local café where his presence causes an uproar. In another sketch, a secretary insinuates to the chief tax inspector that the high supplementary income of Miss Split is perhaps related to her beauty. Maybe he should check on her, she suggests. When he pays this Miss Split a visit, she tries to soften him up by a striptease. Then he wakes up from his daydream and he leers at his secretary: 'Now I grab you, monster.' At that very moment, all people at the office start to indulge in degenerate behaviour: touching each other in their intimate places, and one woman even starts to photocopy her breasts before making love. Another sketch is centred around the hypocrisy of a cardinal, who has invited two former youth friends - a minister and a doctor - for a copious dinner. The cardinal is vehemently opposed to abortion, while the doctor wants to recommend this as a viable 
option to the minister. When the cardinal goes to the toilet, he can eavesdrop on them via a bug. As he thereupon confronts the minister with bribery, the latter asks him how he knows. 'God hears and sees everything,' is his hypocritical answer before he forces the minister to resign his job. Another sketch concerns a quarrel among siblings about the cost of the upcoming funeral of their dying father who had been strongly advised to quit smoking. When they all go outside because an attempt is made to steal the car of one of the daughters, grandson Henkie is the only one to enter the room of the deadly sick old man who asks him for one last cigarette. Henkie gives in to the request, and while smoking, his granddad dies.

The most absurdist sketch is, however, the one with a corpulent baker and his equally corpulent wife. We see them sell bread and pastry, among other things, to the minister from a previous sketch who is dead drunk and busted by now. As soon as it is six o'clock, they immediately close the shop and remove all the furniture and put a black, plastic canvas on the floor. They both undress and while they are whinnying like a horse and shout ecstatically - 'Jetje Kadetje,' the baker cries out repeatedly - they throw cream pies and other baked goods at one another. This sketch is interrupted with shots from an impeccably dressed secretary sitting next to a film projector, watching the film. We also see a shot of a producer with a big cigar, before we return to the baker and his wife, who now throws a box of eggs against her husband's naked body. The producer, who is played by the very same actor who played Moses in the opening scene, is rubbing the goat's head. When the baker throws a pan of chocolate sauce over his wife's head, 'Moses' exclaims: 'Jesus Christ, what is this? Did I ask for this? Schlemiel, what kind of a director are you? Here, you were supposed to make this; that was the deal,' and he shows a script with the working title 'The Ten Commandments.' 'What the fuck did you do with my money? You stole from me. By the way, where is the commandment “Thou shalt not steal”?' The director, who was 'Jesus' from the opening scene, calmly answers: 'We are showing it to you now, Mr. Meyer [Rudolf Meyer was a producer, responsible for FANFARE]. You do not understand.' 'As producer, I gave you the assignment to make a classical film. What do I care for this shitty baker? Turn the projector off!' 'But the credits are still due. Your name,' but the producer's mind cannot be set at rest. When he then reaches towards the projector to switch it off, we get a close-up of an adjusted shoe, which brings into the memory the shot that Moses chopped off his itchy foot. He then stumbles over some cans with film and because his shawl gets attached to the projector, the producer is being strangled. Aghast, the secretary runs away and pushes a button. We then return to the baker's wife, who places a cream pie on her husband's erect penis, before the film burns itself, and the projector sinks into the ground, together with the producer. The film closes with the 
cyclist without his bike on the Afsluitdijk. He tries to hitchhike, but since no one stops, he cries out 'god dammit' twice, and starts rolling on the cycling path hysterically.

DE MANTEL DER LIEFDE has its grotesque, if not gross moments: the cutting of Moses' foot, the axe in Cor's skull, the debaucheries of the baker and his wife. More significant than these vulgar effects is the explicit polemical tone of the film, mocking the legacy of Christianity. The meeting between Moses and Jesus during the opening of the film functions as a frame for all the subsequent sketches which have a contemporary setting. According to Jesus, speaking on behalf of his Father, humanity has drifted from the Commandments. He accuses Moses of having been too passive to resist the corruption of mankind and having excused many objectionable things. Or, to refer to the film's title, Moses is to blame for covering all vulgarity under the 'cloak of charity.' The film we are about to see after the starting credits, shows the per316 versity of people: needless aggression, egotism, disrespect of one's parents, illicit sexual pleasure. Hence, the fact that the world of today embraces ethical principles that are the inverse of those found in the Bible seems to be the irrefutable purport of the film. There is a double twist, however. First, just like Jonathan Swift's argument in his landmark satirical piece 'A Modest Proposal' (1729) that eating the children of the poor would be a clever solution to the problems of widespread hunger and poverty was too outrageous to be taken in earnest, all sketches are simply too outrageous to consider DE MANTEL DER LIEFDE as a morally serious wake-up call. Ditvoorst's film is anything but a plea to return to the firm ethical principles of the Old Testament, for it is too ironic. At times he combines vulgar scenes with solemn classical music; religious characters are represented as caricatures, such as the bishop who gets a manicure from his assistant and splashes his bare feet in the water of his footbath, enjoying the fact that the naive priest takes his silly advice seriously; and most ironic perhaps is the sudden intertitle after Henkie's granddad has died of cancer, for it not only reads 'intermission,' but it also contains the text: 'You now have time to smoke a cigarette.' The fact that this intertitle lasts for about three minutes, halfway DE MANTEL DER LIEFDE, can only be taken as a darkly humorous 'service' to the viewer to have a smoke indeed.

Second, all the sketches we have seen turn out to be the work of 'Jesus' in his role as director-in-the-film. This revelation recalls the opening scene in which Jesus holds Moses responsible for the fact that the world has become corrupted. The film-within-the-film holds up a mirror to the producer/Moses, but the latter can no longer bear to watch it. Apparently expecting to see a morally just world living according to the principles of the Ten Commandments, Moses is only confronted with the world's ugliness. DE MANTEL DER LIEFDE can be called a grotesque satire, because this Moses figure is positioned as the 
true target. As for Moses, he is blind to reality; in the role of producer-of-thefilm he is trying to rewrite reality according to his own wishes and commands. Moses the producer is a meddler who demands that the director compromise his artistic vision, and the analogy to Ditvoorst's own situation is not to be missed. Those times he had given in to the wishes of a producer, as in his then latest project FLANAGAN, had not gained him any success at all. It is only a small step to consider the penultimate scene from DE MANTEL DER LIEFDE as his revenge upon cigar-smoking producers who behave like dictators. Ironically, Jesus tries to play the card of the producer's vanity - 'your name' on the credits - but Moses is beyond reason. It is a streak of sarcasm that he has his comeuppance when he is killed because his shawl, another sign of vanity, is winded into the apparatus. And thus irony and sarcasm are called upon to articulate the grotesque death of this miserable figure who was an ignorant and vain busybody. When his corpse has sunk into the ground, we get a 'mortal' point-of-view shot, from a very low angle, looking up to Jesus who stands at his 'grave,' making the cross sign as a mock salute. The secretary pulls at his arm, but he only says, recalling the opening scene: 'You still stink,' and walks away, whilst she crawls after him. Thus, DE MANTEL DER LIEFDE which Ditvoorst made with a first-time producer, seems meant to settle old scores with meddlesome producers. The most influential critics remained favourable to his work, but the general public did not get enthusiastic. Alas, for it would have been a perfect joke and a great example of an irony of fate if precisely this film - a vengeful satire on commercialization - would have marked a first commercial success for Ditvoorst. ${ }^{21}$

There is nonetheless an irony to be noted, which came true after all. If Ditvoorst was 'the golden boy of art-house cinema' in the late 1960s, Verhoeven superseded him in the early 1970 s as the 'golden boy of the box office.' Just as DE MANTEL DER LIEFDE was a grotesque satire, made out of deep frustration, Verhoeven was to make DE VIERDE MAN [THE FOURTH MAN] (1983), because he felt deeply dissatisfied with the Dutch film climate. As a 'text' DE VIERDE MAN is an ironic film with grotesque elements, but when put in context, this last film Verhoeven made before he left the Netherlands can be regarded as a satire. $^{22}$

\section{FANTASTIC IRONY: DE VIERDE MAN}

After an opening shot of a spider building a web, Verhoeven's film adaptation continues with a scene in which Gerard's boyfriend is playing the violin, while Gerard creeps up on him and strangles him. After the strangling, we see Gerard walk through a corridor, while we still hear the violin play. He enters 
a room and there is his boyfriend, still playing. Gerard just tells him he will be on his way to Vlissingen by train. The sequence of strangling, which obviously only proved to be a morbid fantasy, sets the tone for the film: a seemingly daily situation slips into a surreal scene and suddenly it goes back to 'normal.' Gerard will be seeing things throughout the film, and although the status of his observations is sometimes easy to determine, often it is not. Travelling by train, initially his perceptions are not extraordinary: he sees a drawing of Samson and Delilah; he sees a poster with the text 'Jesus is everywhere,' the apple peels around the head of a toddler are like a halo. When he focuses on another portrait in the train, however, he has a vision of the Hotel Bellevue, room number 4, and of blood dripping from a mutilated eye, a grotesque shot which obliquely references Buñuel's surrealist film UN CHIEN ANDALOU, already mentioned in chapter 8 . The crying toddler marks his return from this unpleasant daydream to 'reality,' whereupon a blonde female passenger in a 318 blue coat realizes with a shock that tomato juice is oozing from a bag above her head. The scene in the hotel is unmistakably a nightmarish vision, but it is uncertain whether this vision has been triggered by the juice or has anticipated it: cause and effect are unclear. This scene also indicates that Gerard seems to be a character whose imagination can run wild. This is emphasized in a subsequent scene when on the platform at the station he sees a coffin and thinks that the ribbon has his name written on it, for he distinguishes the letters G-E-R-A. When the ribbon is unfolded it reads 'Guido Hermans.'

These scenes basically suggest Gerard's inclination to sinister hallucinations, but the film owes its deeply ironic effect, I will argue below, to the overall framing of his perception of a blurred distinction between fantasy and reality. This framing is determined by the representation of the main protagonist as someone who excels at comments which are as sardonic as amusing. His fondness of such comments becomes clear during Gerard's lecture, of which a few excerpts, absent in the book, are included in the film. He tells the story of a gigantic coffin at the station, carried by 30 dwarfs. He then admits that he invented the story on the spot, but that if he were to continue it at length, it could start to sound like a true story. He then summarizes the essence of his authorship in the paradoxical claim: 'I lie the truth ... just as long as I start to believe it myself.' He presents his idea in a serious manner, but as equally optional, if not more so, is that he makes this assertion in jest. Similarly, all the other answers he gives during the Q \& A are playful without ruling out that they can also be interpreted as serious, such as: 'Being Catholic means opening up to the domain of the fantastic' or 'The only time I suffer from madness is when reading the newspaper, for I read lamp as ramp [lamp as disaster], gloed as bloed [glow as blood], and rood as dood [red as dead]. Is that crazy? No, not really, just some trouble with my eyes.' 
There are two other essential scenes in which Gerard defines himself as an ironic jester, while preserving a serious stance. These scenes take place after Gerard has spent the night in the bed of the seductive Christine, who is the treasurer of the association which had invited the writer. Christine also runs a beauty parlour named 'sphinx,' although when Gerard arrives at her place the neon letters only show the word 'spin,' meaning spider. When the next morning a female customer in the beauty parlour - hardly recognizable as the blonde woman in the train - recounts a spooky dream, she considers this as a sign of impending danger and adds to it: 'When you are being warned, you have to listen.' Gerard retorts sarcastically: 'Well, the people who listen, are they still around?' The second scene concerns his attempt to fool Christine by play-acting that he has occult gifts. On his way to Vlissingen, he saw an incredibly handsome boy, taking the train to Köln. At Christine's place, he sees a love letter, which conceals the photograph of this very same boy, named Herman, only dressed in swimming trunks. As the back reveals, the photo was taken in Köln. Without telling Christine of his discovery, Gerard starts to boast that he can read signs with the ultimate hope of meeting Herman. He takes Christine's hand and tells her that there is another lover, besides himself, that he sees the letters $\mathrm{K}$ and an $\mathrm{O}$ with two dots. Yes, he is from Köln, she confirms, in a tone of mock impression, for it seemed in an earlier scene that Christine had left the letter deliberately on her desk for Gerard to find. Gerard will only continue on condition that she takes a personal object of this man. Returning with the love letter, Gerard guesses correctly, obviously, that there is a photo hidden between the pages, that the lover is hardly wearing any clothes, and that the name starts with an $\mathrm{H}$ and an E. Before mentioning these letters, however, Gerard has a vision which shocks him: Herman walks out of the sea, and his eye is severely mutilated, like in his earlier dream.

The three examples are structured in a similar way. Whilst keeping up an earnest appearance, Gerard seems to delight in ironic remarks and playful acts. It befits a character like him who boasts about his high intelligence, to consider all visual clues from daydreams as unfounded and superstitious. However, after pretending that he possesses occult gifts, for erotic purposes, the sudden visions, just as the one of a bleeding Herman, will come to grow on him as if he really did have occult gifts. He gradually realizes that he had better lend credence to his bizarre observations and his seemingly surreal visions. The turning point of DE VIERDE MAN is that Gerard himself, this ironic jester, has to take all signs as deadly serious warning signals: the light at Christine's place which accidentally spells the word 'spin' (spider); the seagull which drops dead at Gerard's feet; the frequent appearances of the blonde woman; the number four in his dream - Gerard begins to arrange all these signs into a causally logical pattern. His mind, which has become frenetic by now, turns 
Christine into a femme fatale who like a spider has webbed her three husbands till death did them part.

Now convinced of her deceptive identity, Gerard becomes afraid that a terrible accident is awaiting him. He himself, however, is not the fourth man to die, but Herman is. At the very same spot where Christine was driving excessively fast earlier in the film, Herman ignores the speed limit and hits the iron tubes on a truck, which pierce his eye. After the fatal crash leading to Herman's death, Gerard is hospitalized, in a state of shock. He is nursed by the blonde woman who already crossed his path several times. Gerard becomes convinced that this woman is his guardian angel and he calls her 'Maria.' Excitedly, he tells the doctor that 'Maria' has protected him against the evil witch Christine. As further proof of his belief in her cunning tricks, Gerard mentions that she has an insensitive spot at her back. The doctor contradicts Gerard's words and diagnoses that the writer is suffering from delusions. To 320 him, Christine is the epitome of a tragic woman, marred by ill fate and who one can only pity. While Gerard is shivering in his hospital bed, through a window we see Christine outside, meeting a wind surfer. Then we see the close-up of a spider in its web, with which the film also began.

There are two ways to read the ending, but neither one gets the upper hand. The first option is the doctor's analysis that Gerard suffers from hallucinations as a consequence of having witnessed Herman's atrocious death. For the doctor, Gerard is, partly due to his fondness of alcohol, a pathological liar and it is a token of disrespect to speak ill of the poor widow. Whereas the doctor believes that Gerard is suffering from delusions, the writer himself has to think that he is truly gifted with second sight. For him, the frequent appearances of the blonde woman in a blue coat are no longer coincidental, but meaningful and life-saving. The film's strength is that not only both options make sense, but that the two conflicting interpretations of delusions versus conspiracy are framed by Gerard's stance, which can be explained as both serious and ironic. As the doctor tells him, the option that Gerard might have (erroneously) made up Christine's guilty role is strengthened by his confession during the Q \& A that 'I lie the truth ... just as long as I start to believe it myself.' The doctor takes this potentially ironic credo seriously and puts the emphasis on the lies as well as the vivid imagination. The other option presumes that Gerard has made this remark tongue-in-cheek, implying that he knows how to separate truth from lies. In that case, the irony is that Gerard dearly believes that his scepticism has led him to see the true state of affairs.

The main reason why this ambiguity cannot be resolved is a consequence of the cinematic devices employed by Verhoeven. A filmmaker conventionally uses dissolves, superimpositions or soft focus in order to mark the transition from 'reality' to a character's mental world. By contrast, Verhoeven uses hard 
cuts practically all the time, with the result that, formally, a daydream or hallucinatory sequence is cinematically presented in the same way as any scene from the 'normal' world. However, the spectator can still distinguish a dream or hallucination from an everyday practice because of the bizarre content of many sequences: obviously Gerard did not strangle his boyfriend nor did Christine castrate him with a pair of scissors; it is obvious that the sequence in the hotel with the injured eye is a weird fantasy, and when he sees Herman, hanging at the cross in the church and only wearing swimming trunks, everyone will interpret this as a hallucination. The irony is that the viewer has the illusion throughout the film that he understands the status of each and every shot - this is a dream and this is not - and that he knows how to separate lies from truth but due to the final episode, the status of the visions becomes undetermined after all. What seemed to be too strange to be true, may not be that strange after all. In the eyes of the doctor Gerard's scenario that Christine is a cunning woman is too bizarre for words, but since the viewer has been confronted with the very same signs as Gerard, the story of a dark conspiracy is not that outlandish any more.

Remember that Gerard defined a Catholic as someone who has opened up to the fantastic. This could be regarded as an ironic and playful remark, but the irony of the film is that Gerard owes his life - or, at least, he thinks so - to the fact that he becomes one of those people whose very existence he had ironically doubted: he is one of those rare types who happens to listen when he is being warned. To turn Gerard's train of thought into a legitimate option, scriptwriter Soeteman decided to introduce 'Maria,' a new character not in the novel, for without her the scales might have tipped in the favour of the down-to-earth vision of the doctor. In Soeteman's words, the blonde woman is the femme céleste, the mirror image of the femme fatale. The presence of the woman in the blue coat is required to bring about a shift in Gerard's attitude. As soon as he interprets her frequent appearances as warning signs of impending danger, he starts to act in congruence with those remarks he initially made in jest.

Since the film does not resolve the status of the fantastic visions as either outrageous or as meaningful flash-forwards, the spectator gets caught in the deadlock of how to interpret the protagonist: either Gerard is paranoid, as the doctor believes, or he is a visionary who is truly open to the fantastic - which was his ironic definition of the essence of Catholicism. On these grounds, one might claim that with DE VIERDE MAN, Verhoeven has performed a particularly unstable kind of irony. Seminal for this effect is that Verhoeven's film consistently problematized the status of the dreams and hallucinations. As I indicated earlier, Verhoeven refrained from employing formal means to help the viewer by using hard cuts throughout. In an attempt to explain that the film 
becomes a balancing act between the conventions of realism and surrealism, Verhoeven, as he told Van Scheers, decided to shoot in deep focus. According to the director, the foreground and background should be equally sharp; a shallow focus may 'exclude reality.' At the same time, Verhoeven adopted the idea to use special filters in order to obtain extremely bright colours one sees when watching surrealist paintings: blue should be deep blue and red deep red. And of course, these hyper-real colours were not only used during hallucinatory scenes but throughout the whole film. Verhoeven's choice to represent the dreams and visions via deep focus and bright colours was an eminently functional one to underscore the effect of the incessant oscillation between irony and seriousness.

Throughout my interpretation I have emphasized the ironic potential of Verhoeven's DE VIERDE MAN, in the sense that it is frankly impossible to draw a line between seriousness and irony, which recalls the undecidability of Van

322 Warmerdam's cinema. At the same time, the film owes its grotesquery to a combination of surreal humour and horror: because of the dark hallucinations (or 'warnings'), it contains aspects of 'eeriness, of the spine-chillingly uncanny,' which Thomson considers as seminal to the grotesque (5). In addition to these textual features, the film can be seen as satiric if we consider DE VIERDE MAN against the background of Verhoeven's career. Remember that Verhoeven felt really sore about the hostile reception of his SPETTERs, which had raised an unprecedented level of sharp protest (see chapter 6). It may read like kitchen sink psychology but according to his biographer Rob van Scheers, it amused Verhoeven that after all the accusations of banality he turned to a novella by Gerard Reve, a highly respected writer who belonged to intellectual circles: 'All right then, let's make an art film!' Verhoeven is supposed to have said (qtd. in Van Scheers, 234-35). Associating himself with Reve could offer Verhoeven 'collateral advantage,' but not only because of the writer's renown. Reve had also built himself a reputation as a provocateur because of racist statements in his work, but he got away with it because there was a tendency among readers to consider Reve's quotes and performances as an act of ironic provocation. In a letter to 'fellow artist' Simon C. in his De taal der liefde [The Language of Love] (1972), Reve advocated, in apparently disdainful terms, the return of black people on a 'tjoeki tjoeki' steamboat to the 'Takki Takki' Jungle. At a poetry festival in Kortrijk in 1975, he recited, dressed in a dark shirt with a silver cross, the poem 'Voor eigen erf' ['For One's Own Backyard'] about black scum and white power. Text and performance do not give guidance on how to interpret them. A critic like colleague-writer Harry Mulisch presumed that Reve had betrayed the two-faced nature of irony. Racist opinions are disguised as tongue-in-cheek phrases, but one should not be fooled, Mulisch warns: Reve may really hold these opinions (Mulisch, 52). Hence, he misuses 
the trope of irony as a playground for abject ideas. According to this position, irony functions as a poor excuse for a serious support of racist ideas. A reverse stance could be defended with equal gusto. Reve uses irony to expose and condemn the silly logic of racist thinking, and in such a case irony functions as a critical gesture. Both Reve and Verhoeven had caused quite a stir with controversial work, but whereas Verhoeven had been offended by all the negativity surrounding his SpetTERs, Reve had been given the benefit of the doubt and thus the racist slur had not deteriorated his success. So, the choice to adapt one of Reve's books into a film was to be seen as an implicit strategy: if you, critics, misread my films as banal, let me then make an 'art film' on the basis of a writer who despite controversial statements can have his cake and eat it, too. And thus his DE VIERDE MAN is to be interpreted as a satirical comment, aimed at those critics, including the people from the Netherlands Film Fund, who took him for a director who prefers to work 'below the belt.'

One final irony in all this is not to be missed: Ditvoorst's 'revenge' film elaborated upon a kind of vulgarity that had been introduced by Verhoeven with his WAT ZIEN IK!?, discussed in chapter 1, albeit it did not have the success of the latter. Verhoeven's 'revenge' film, by contrast, was a surrealist grotesque and as such it had much closer affinities with Ditvoorst's blackand-white DE BLINDE FOTOGRAAF than to his previous work, albeit that the very colourful DE VIERDE MAN was quite successful, perhaps thanks to the insertion of erotically charged elements. Ditvoorst was only to make one more film, released a year after DE VIERDE MAN. His DE WITTE WAAN [WHITE MADNESS] (1984) was a slightly surreal and pessimistic picture about the drug-addicted visual artist Lazlo who comes to live with his mother, a former theatre actress, after she has returned from the hospital. Initially, her halfsister acts as a nurse. This half-sister suggests that Lazlo should arrange a television set to offer his mother some distraction, but the latter prefers to stick to Anton Chekhov's The Cherry Orchard. The half-sister replies: 'All that sorrow, why don't you want some comedy?,' a remark which only raises eyebrows from both mother and son. Eventually she leaves, after she has come to realize that she is out of place, an obstacle to the strong bond between mother and son. The film is intercut with shots from animals like snakes and eagles, both living, made of marble, or drawn by Lazlo, but also with close-ups from a lemon cut in half or blossoming trees, and the general pompous style is the overture to a theatrical finale. In a beautiful bed, surrounded by red and pink flowers as well as many candles Lazlo gives her champagne and a pill to commit suicide, while Mozart is playing, just as she had requested in a letter, as we can see in the final shot. This bleak film was, in spite of the main role for Thom Hoffman who had played the handsome boy in DE VIERDE MAN, way too idiosyncratic and it attracted no more than 1,700 viewers. In 1987 
Ditvoorst committed suicide; that very same year Verhoeven made RoBoCoP, which was his ticket to fame in America.

\section{ALMOST FULL CIRCLE}

In the case of the grotesque, gruesome elements can be presented in such a comic manner that the grimace can become a guffaw, and vice versa. In this chapter three variants of the grotesque have been addressed. First, the caricature, which was clearly inspired by the cinema of Tarantino (BLACK OUT, NAAR DE KLOTE!) as well as by the odd combination of Tarantino and Tarkovsky (DE WEDEROPSTANDING VAN EEN KLOOTZAK). Second, the grotesque irony of fate of PLAN C in which a happy ending is handed to the clumsy protagonist on a silver platter. Third, both Ditvoorst and Verhoeven produced grotesque satires

324 either to ridicule the Dutch film climate (DE MANTEL DER LIEFDE) or as a farewell project out of acerbity with this climate (DE VIERDE MAN). Ditvoorst's film seemed modelled after the vulgarity of WAT ZIEN IK!?, replacing the latter's erotic humour for hilarious violent scenes. Verhoeven's film resembled in its eerie surrealism a Ditvoorst picture, with colourful eroticism and perverse desires as extra ingredients.

With this discussion of the grotesque, this study has almost come full circle, for some of the films discussed contain the vulgar aspects that were central in chapter 1 . Nonetheless, the vulgarity in the films from chapter 1 , like FLODDER, NEW KIDS TURBO, VET HARD were too clearly played for laughs, whereas the vulgarity in films like BLACK OUT, NAAR DE KLOTE!, DE MANTEL DER LIEFDE had the effect to (slightly) confuse the spectator, and to create shifting moods, from shocked reactions to giggles. As such, the grotesque has to be distinguished from the deadpan (black) humour by Van Warmerdam. In his films dreadful scenes are hardly ever visualized, but only suggested. In BORGMAN, there is only one horror scene in which human flesh is cut with a knife for about a second only, because then the female character wakes up from her nightmare. In the cinema of Van Warmerdam, the performance of the characters is relatively blank so that the emotional register of the viewer is not pushed in a certain direction. The characters in his film do not gesticulate wildly and their facial expression is often demure, so that we do not get a clue as to their mood and state of mind. They do not laugh, no matter how hilarious the situation. And if they start laughing, as some characters do in GRIMM, it is fairly inappropriate. When gazpacho is being served by the butler, Luis, the Spanish host, Diego, wittily remarks, in Spanish: 'In Holland, the weather is cold and the soup is hot. In Spain, the weather is hot and the soup is cold.' Diego starts laughing at his own cleverness, whereupon the utterly obedient 
Luis follows Diego's example, but in an exaggerated manner as if to please his master. The two Dutch guests, Jacob and Marie, then decide to participate in this social game, although their laughter is much less heartily. In fact, laughter in a Van Warmerdam film has to be met with suspicion, for Diego and Luis are later revealed to have a diabolical nature.

If the characters in his cinema have an emotional outburst, the effect upon the viewers is usually the opposite: when they laugh, we do not laugh; when they have an angry fit or use a snappy timbre, it comes across as laughable. When Marie and Jacob are on a deserted spaghetti western set in GRIMM, Marie wants to cure her brother's belly wound with alcohol. She then returns with a bottle of eggnog, because the label says it contains 14 per cent alcohol, and pours the yellow substance over the enormous scar. Jacob then starts to scream, telling her that the terrible pain is probably caused by the fact that the use-by date of the eggnog had expired many years earlier. Similarly, it is laughable the way Emma Blank is giving ridiculous commands with a stiff voice all the time, which allows no contradiction. At the same time, dark impulses can be unleashed, precisely by those characters who have behaved benevolently throughout, or seem innocent by appearance, like Jacob and Marie, who start as a kind of Hansel and Gretel, but are responsible for many deaths, while she also robs a Spanish woman, who is on her way to a funeral, of her clothes. Van Warmerdam tends to suggest these impulses in dry-comic fashion, whilst the grotesque displays them - either as caricature, as irony, or as satire. 


\section{Conclusion}

In Dutch there is the saying 'wie zijn hoofd boven het maaiveld uitsteekt, die wordt zijn kop afgehakt.' This saying is equivalent to what the Anglo-Saxon world knows as the 'tall poppy syndrome,' which is defined as the 'tendency to disparage any person who has achieved great prominence or wealth.' Humour is often used as an instrument to belittle people, or to say it in slightly more friendly terms, to save the other from unseemly feelings of superiority. ${ }^{1}$ It is often considered very effective to confront the other with physical aberrations, like a plump body - Ma Flodder, Bennie in VET HARD, Dik Trom - or a comically injured body, as in the grotesqueries from chapter 9. In case we laugh at remarkable facial expressions - Jim van der Woude in the films by Jos Stelling, André van Duin - or at an extremely agile body, however, the person is often lacking in another regard, e.g., because he is a naive underdog as is Pim in $\mathrm{OH}$ Boy!, who is visibly surprised at his own elasticity. ${ }^{2}$

Laughter, as Bergson has postulated, is a social phenomenon, and we tend to laugh collectively, as a group, at another group. Poking fun at people, even with the cruel aim to humiliate them, has a useful social function, according to Bergson, for the effect may be to correct the rigid and inelastic behaviour of others. Even though Freud hardly referred to Bergson, this idea can be made congruent with his theory of jokes. In his Jokes from 1905, Freud claimed that jokes are predominantly tendentious, often with the intention to discredit someone. Most jokes are not without hostile and/or obscene subtexts in an attempt to aggrandize one's ego at the expense of others. Since the comic is hardly ever innocent, a comedy always has some message as an effect, pace Maas' pun on the term 'boodschappen.' We do not so much appreciate a joke or a comedy because of its clever technique, but 'we laugh at the tendentious thought behind the joke' or the comedy (Billig, 159). To give FLODDER as an example: the butt of many a joke is Sjakie who is portrayed as a leftist ideal- 
ist who believes in the possibility of a classless society. His utopian aim is to elevate the lower class to the level of the upper class, which seems a noble gesture, but the tendentious thought of FLODDER is that the lower class would be foolish to sacrifice its 'uninhibited instincts' to the strict conventions the upper class live by. Sjakie's assumption is that the Flodders will be delighted with this opportunity, but the comic incongruity is that the low-class family kindly refuses the offer: we prefer being rude oddballs to becoming posh people, for we are at least still 'authentic' in our rudeness.

In her attempt to bring out the specificity of the comical, Zupancic has pointed out that comedy 'involves a strange coincidence of realism ... and utter unrealism' (217). Sjakie tries to boost the boorish family out of idealistic motives: their concrete habits of drinking, eating and cursing have to be transformed into more abstract - that is to say, 'decent' - behaviour. Comedy, Zupancic observes, is supposed to be 'more realistic and down-to-earth than, say, 328 tragedy' (217). A tragedy progresses from a concrete 'individual' to an abstract lesson about the hero's 'infinite passion,' but in a comedy, the abstract and the concrete change places. A comedy is about a relatively abstract type - the Happy Slacker, the Cigar-Smoking Woman, the Busty Babe, the Well-Meaning Social Worker - which, as the film progresses, becomes a concrete character. Moreover, it is characteristic of a tragedy that there is nothing behind the veil, to paraphrase Zupancic. In Alfred Hitchcock's VerTigo (1958), Scottie is obsessed by the ravishing Madeleine, but there never was a Madeleine in the first place: she was just a masquerade, impersonated by the quite ordinary Judy. In a comedy, Zupancic claims, there is always something behind the veil, but this something is of a trivial nature 3 : Ma Flodder brewing alcohol, Kees selling her body, Johnnie transgressing the speed limit. In addition to this down-to-earth concreteness, a comedy is at the same time utterly unrealistic, because the characters are always kind of 'undead': as a rule, comic characters inhabit the 'universe of the indestructible' (Zupancic, 28). Whatever accident befalls the unfortunate Sjakie, or the 'new kids' or the characters from VET HARD, they 'rise from the chaos perfectly intact, and relentlessly go on pursuing their goals, chasing their dreams, or simply being themselves' (28).

In practically all films from the first half of this study, some 'constructive' tendentious thought is to be detected: the lower class does not give up its 'authenticity'; in the multicultural comedies stereotypes are exaggerated in the hope of undermining them from within; in the romantic comedies characters separate knowledge from belief in order not to give up the hope of finding Prince Charming; in the case of deliberate camp the option of double-coded reading is activated to entertain a gay audience with the advantage of an emancipatory potential, for camp, says Richard Dyer, is 'just about the only style, language and culture which is distinctively and unambiguously gay male' ('It's Being,' 49). 
Whilst such variants of humour often seem rebellious in content, they nonetheless all too often fulfil conservative functions, as Anton Zijderveld already suggested in his Reality in a Looking-Glass (qtd. in Billig, 213). The attitude of the Flodders and the New Kids is too outrageous and vulgar to provide a viable alternative to the conventions. In trying to expose the sheer silliness and the absurd logic of stereotypes, as in Shouf Shouf HABIBI!, one also risks reiterating the clichéd images and hackneyed phrases which unduly disadvantage the minority groups. At worst, the multicultural comedies throw a plethora of commonplaces into the air, as in ALLEEN MAAR NETTE MENSEN, with the result that many viewers are being served: those who yearn for a political reading will find what they are looking for, but at the same time political themes are trivialized to such an extent that one can neglect them at will - a rhetoric which I qualified, following Bordwell, as strategic ambiguity.

The comedies in the first chapters can be taken as such an ambiguous comment upon the proverbial Dutch tolerance. On the one hand, the films seem to teach us to be tolerant towards 'our neighbours.' The protagonists may be rude, foul-mouthed, lazy or stubborn, but do not be too harsh on them, for they are good-hearted after all. On the other hand, the comedies play upon the effects of an overtly tolerant attitude. Sjakie's naive belief is that one should avoid pigeonholing entirely: 'living apart together' should become 'living together.' His utopian project illustrates that when the practice of pillarization is actually put under fire, the presumed Dutch tolerance easily converts into envy and gossiping. Dick Maas told he only had in mind to offer entertainment, but in passing, this lesson was the meaningful effect of his canonical comedy. Paul Scheffer's scenario of a 'multicultural tragedy' in the year 2000 showed that tolerance can be a disguise for indifference. Those new fellowcitizens who are grounded in non-Western traditions are tolerated as long as they do not interfere with 'us.' They are left to their own devices, while they are estranged because living in a tolerant country means for them that they are thrown into an environment that lacks morals. This estrangement was exploited in the multicultural comedies in chapter 2, mainly by pitting hackneyed images against each other.

The irony in the romantic or neurotic comedies is 'risky business,' because the effect can be counterproductive. Irony can be misused to legitimize one's actions: 'I know that wearing Prada is a silly obsession, but nonetheless I do not like to wear anything else,' or 'Look at me, I like to show myself off as an unruly girl, but deep down my wishes are quite bourgeois.' Such a gap between knowledge or posture and doing is 'ideology at its purest' according to Žižek, and I have labelled this, at the end of chapter 3 , as free-floating irony. The plus of camp that it creates a 'tight togetherness' among gays also has a drawback, for not all gay men have an affinity with camp and its hilariously overblown ver- 
sions of either femininity or masculinity. Moreover, camp can come to equal the apolitical tendency to turn everything into a witticism or a joke, which in the long run can be quite wearying (Dyer, 'It's Being,' 50).

In the case of camp, viewers are in the position to decide about the status of the film: 'Does the subtext give rise to recognizing double-entendres?' Likewise, (self-declared) cinephiles are, led by a relatively capricious taste, in a position to enjoy a film as a cult movie, despite or rather thanks to the poor quality. This study is structured as to make such relatively 'user-friendly' versions of viewer address slowly slide into more uncanny variants. Films which play with (postmodern) ontology, like OH Boy!, HET ECHTE LEVEN, RENT A FRIEND and OBER, are textually constructed as going from one diegetic level to another level, to-and-fro, and they thus require the spectator to be attentive. The cinema of Jos Stelling is still predominantly ludic, but his protracted form of visual humour, close to slapstick, is aimed at opening up a plurality 330 of meanings as an antidote to the textual urgency of Calvinists for unequivocality. With his DE ILlusionisT and DE WISSELWACHTER, Stelling prepared the way for the middle-of-the-road absurdism of Van Warmerdam. Thanks to a consistent deadpan approach, it is difficult to decide whether his films are to be taken as serious or as ironic. When his films toy with the charged representations of 'negroes,' such indecidability can create discomfort on the part of viewers.

Freud has argued that a joke requires three subjects: the joker, who is the 'first person' in the role of perpetrator, a victim, who functions as the doormat of the joke, and an accomplice, the third person laughing. ${ }^{4}$ According to Freud, a joke is a 'double-dealing rascal who serves two masters at once': since the first person is unable to laugh at it himself, he is 'compelled to tell [the] joke to someone else' (Freud Jokes, 155). And Freud adds to this that when 'I make the other person laugh by telling him my joke, I am actually making use of him to arouse my own laughter' $(156) .{ }^{5} \mathrm{~A}$ third person is thus required, because the first person is unsure whether or not his joke is funny and therefore he seeks confirmation from an external party. When the third person then starts retelling the joke, as Naomi Beeman has argued in an illuminating essay on 'uncanny laughter,' he is trading places and he himself becomes a first person and is likewise 'contaminated by its uncertain status.' In a regular comedy, such uncertainty is overcome by incorporating signs - such as canned laughter in a television sitcom or the contagious laughter of the characters in the French box-office hit INTOUCHABLES [ThE INTOUCHABLES] (Olivier Nakache and Eric Toledano, 2011). The cinema of Van Warmerdam can be taken as the inverse of this principle: this time the viewer in the role of the 'third person' is unsure whether it is funny, because the reactions of the characters are usually so demure. Rather, the viewer is provoked to laugh involuntarily, at seemingly 
inappropriate moments, e.g., when the characters act cruelly or when they get angry. ${ }^{6}$

In laughter, as Bergson has famously asserted, 'we must, for the moment, put our affection out of court and impose silence upon our pity' (4). According to him, the comic 'demands something like a momentary anaesthesia of the heart' (5). If there is, following Bergson, a 'cold cruelty at the core of the comic,' then a dividing line can be said to run through this study, which corresponds with the difference between Freud's joke book and his short paper on humour, 22 years later, in 1927. As Freud's position was in 1905, in acting. as if a joke is harmless, we repress the idea that we like a joke because it makes us believe the best of ourselves, often at the expense of others (see Billig, 15960). The New Kids are a case in point, for they ridicule others all the time, out of their conviction that they themselves are not to blame for their problems, but always someone else. Often this someone holds an official function and deserves to be turned into a comic object of derision. Jokes usually yield pleasure 'in the service of aggression' (Freud Jokes, 163), meant to inflate the subject's ego: the idea that one is not as stupid as one's neighbour can be 'stuff of mirth' (Polizzotti, 11).

In Freud's much later essay 'Humour,' however, he suggests that a humourist does not just take up the role of the superior adult who treats the object of his gag like a child, but he also puts himself into the position of a child. This much more 'dynamic explanation of the humorous attitude' holds that the 'ego can appear tiny and all its interests trivial' (164). The deliberate role-playing in the cinema of Van Warmerdam is a good example of this kind of humour, for it requires the characters to adopt a distance from their selves: Edgar has discussions with his spiritual father in an attempt to improve the script, but after each encounter he cannot but return to the role of the unfortunate waiter, delivering poor scripted lines. In a reversal of the superiority thesis, this kind of Freudian humour is 'essentially self-mocking ridicule' (Critchley, 94) whereby the comedian/character looks at his own 'childlike, diminutive ego' (95). As soon as the ego is subordinated, Mark Polizzotti mentions in his Introduction to Breton's Anthology of Black Humour, everything that seemed all-important is reduced 'to a pretty scale' (12).

Writes Polizzotti: '.. black humour is the opposite of joviality, wit, or sarcasm. Rather, it is a partly macabre, partly ironic, often absurd turn of spirit that constitutes the "mortal enemy of sentimentality" and beyond that a "superior revolt of the mind"' (10). In the anti-jovial cinema of Van Warmerdam, characters display a discrepancy between an unsentimental decorum like Haneveld playing the role as butler - and their perverse impulses. When they perform their dark compulsions, however, they usually stay 'in character,' calmly keeping up appearances. Thus, in black humour, as Critchley men- 
tions in reference to FARGO, there is often a 'disjunction of action and affect' (88). Evil deeds are executed so clinically that they become 'partly macabre, partly ironic, often absurd,' as when the obedient family members of Emma Blank abandon their submissiveness and nail the Madame to the floor in her very best clothes.

Macabre events are presented in a deadpan style, whereas the grotesque exploits the tension between the comic and the gruesome. Whereas the grotesque-caricature can be said to be close to the effect of the joke, the grotesqueirony of PLAN C and the grotesque-satire of both DE MANTEL DER LIEFDE and DE VIERDE MAN are closer to the effect of (Freudian) humour. Ditvoorst's DE MANTEL DER LIEFDE in particular can be said to be 'sublime' in its 'ambition' to adapt the Ten Commandments while none other than 'Jesus' in the role of film director produces a banal version of the biblical instructions and prohibitions. At the same time, Ditvoorst performs a 'self-mocking ridicule,' as if he,

332 | known as an 'art' filmmaker, had in mind to outdo the vulgarity of a film like Verhoeven's WAT ZIEN IK!? (chapter 1), which is to be regarded as a gesture of humour par excellence. In turn, Verhoeven, accused of ushering in banality after the release of SPETTERS, started making an 'art film,' a gesture which can be understood as a 'sublime satire.' 


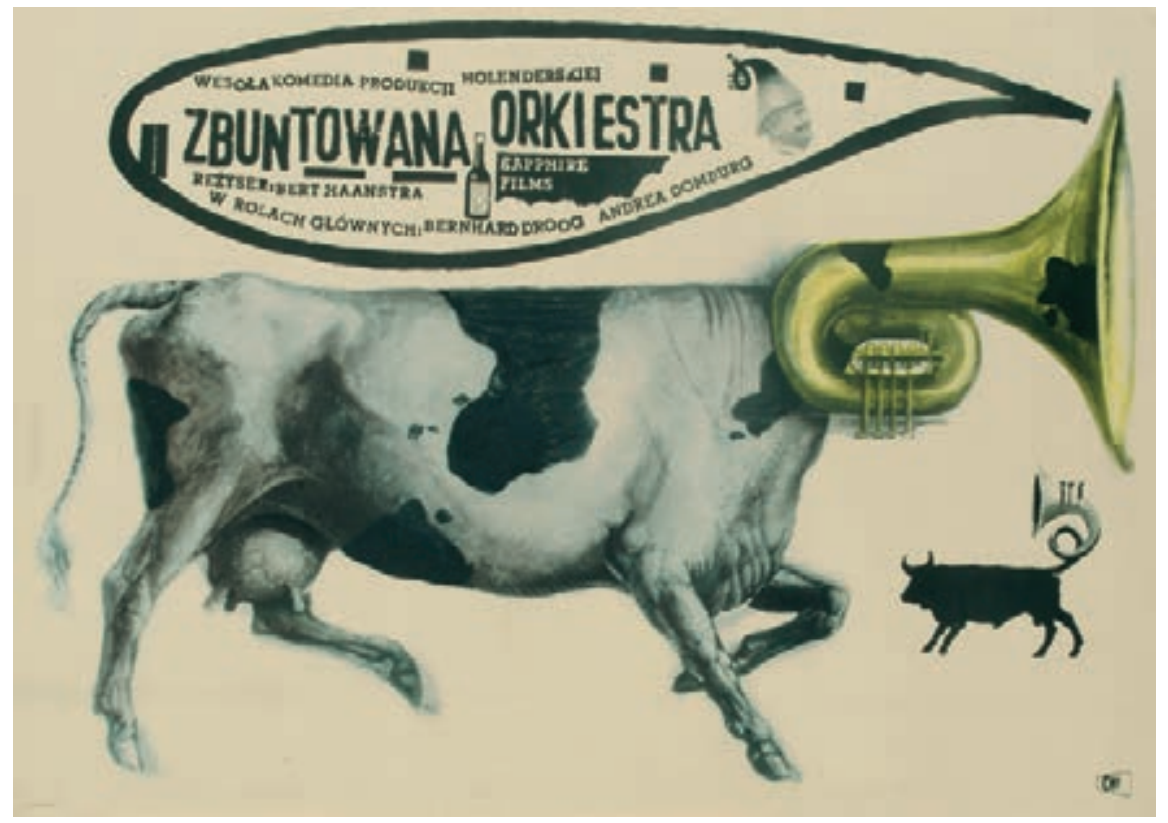

Plate 1. FANFARE 


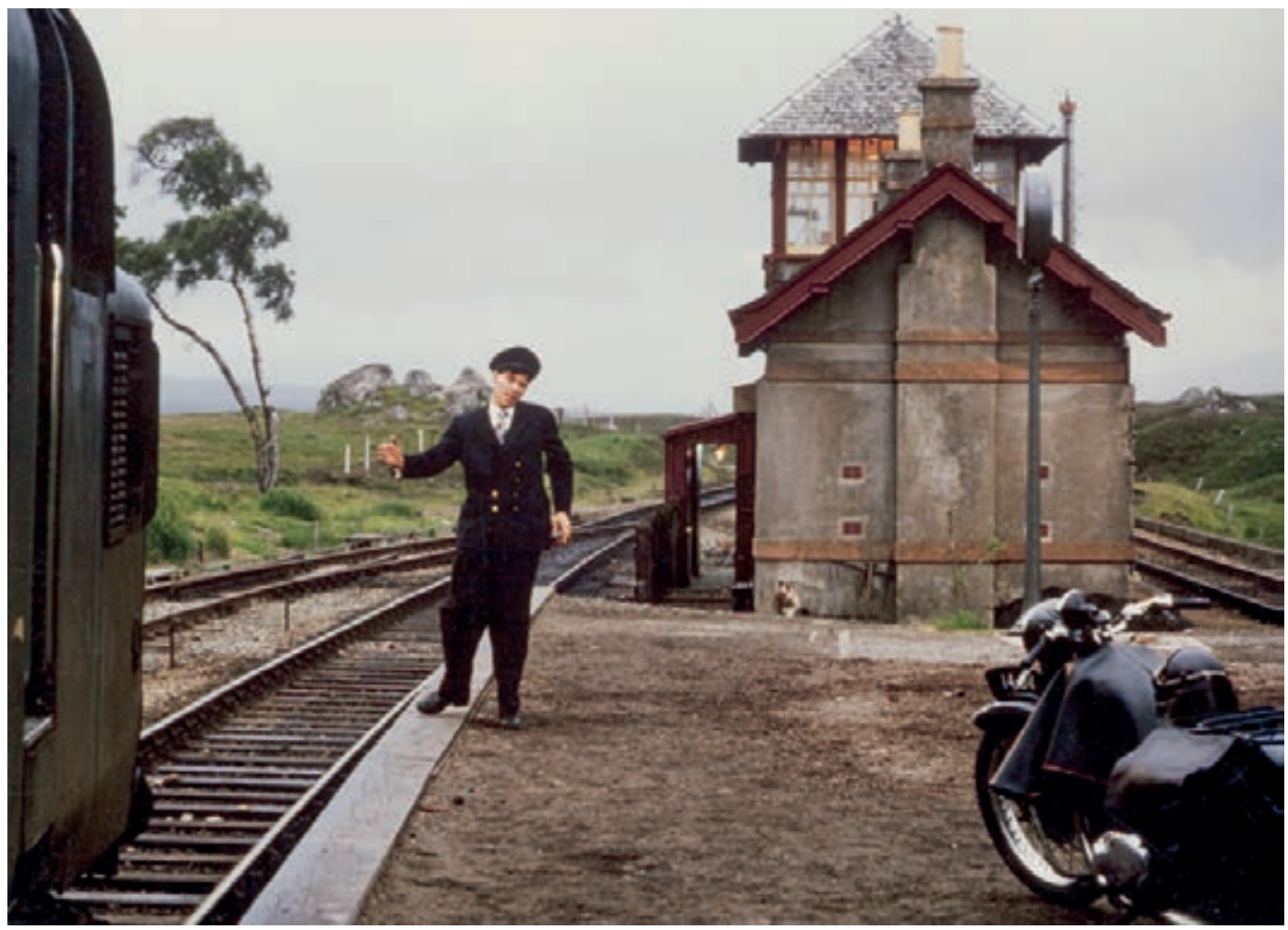

Plate 2. DE WISSELWACHTER

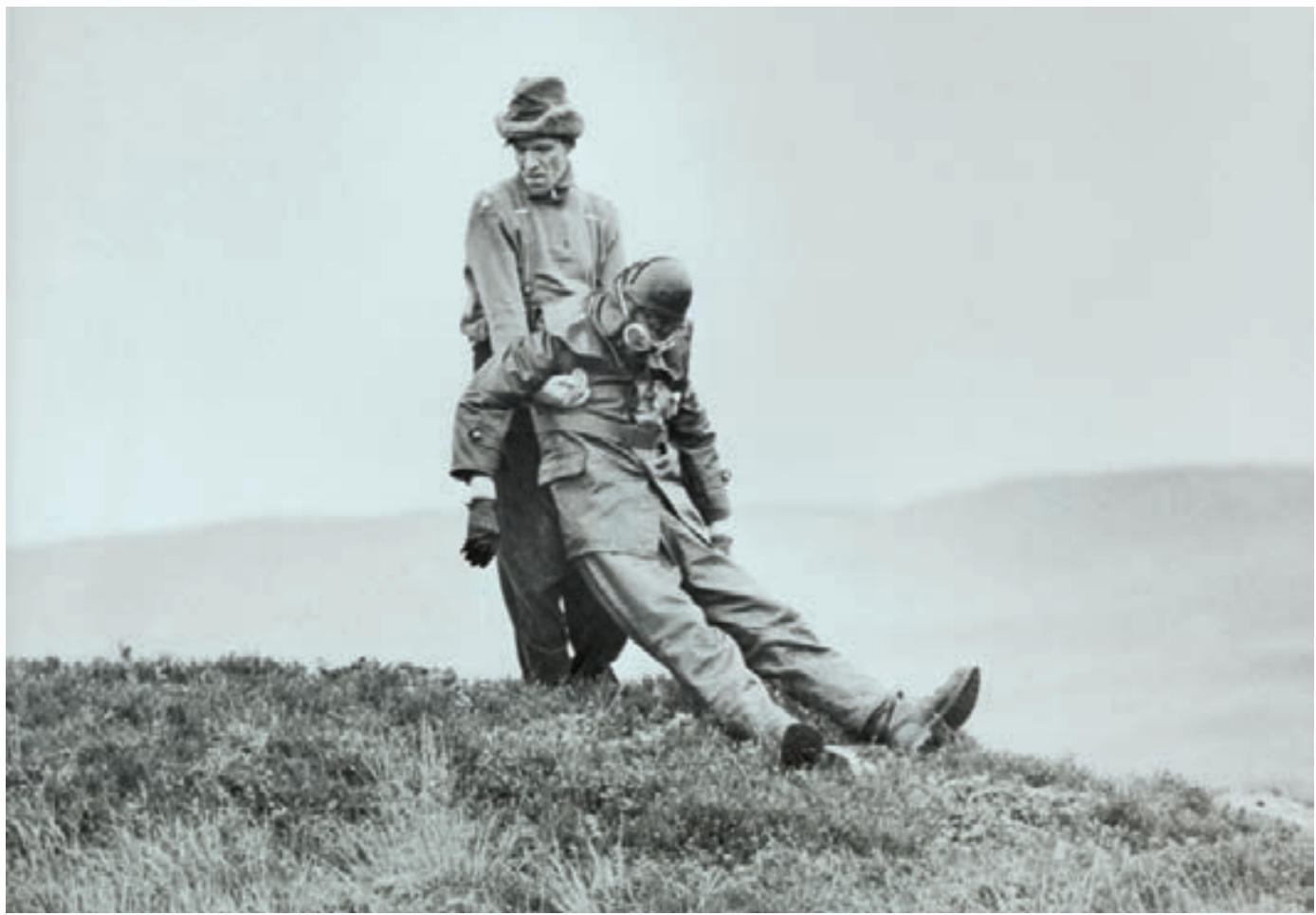




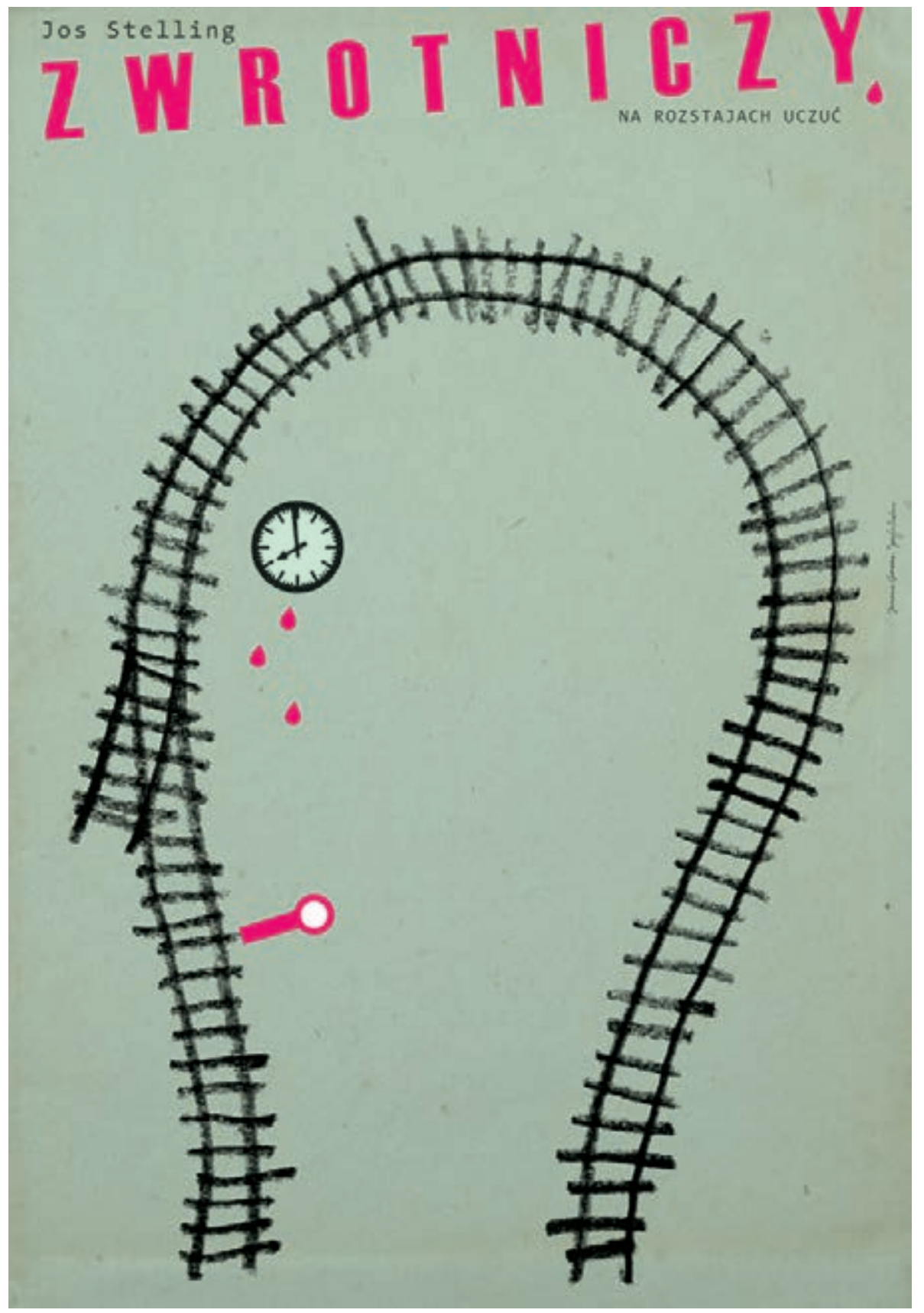

Plate 4. DE WISSELWACHTER 


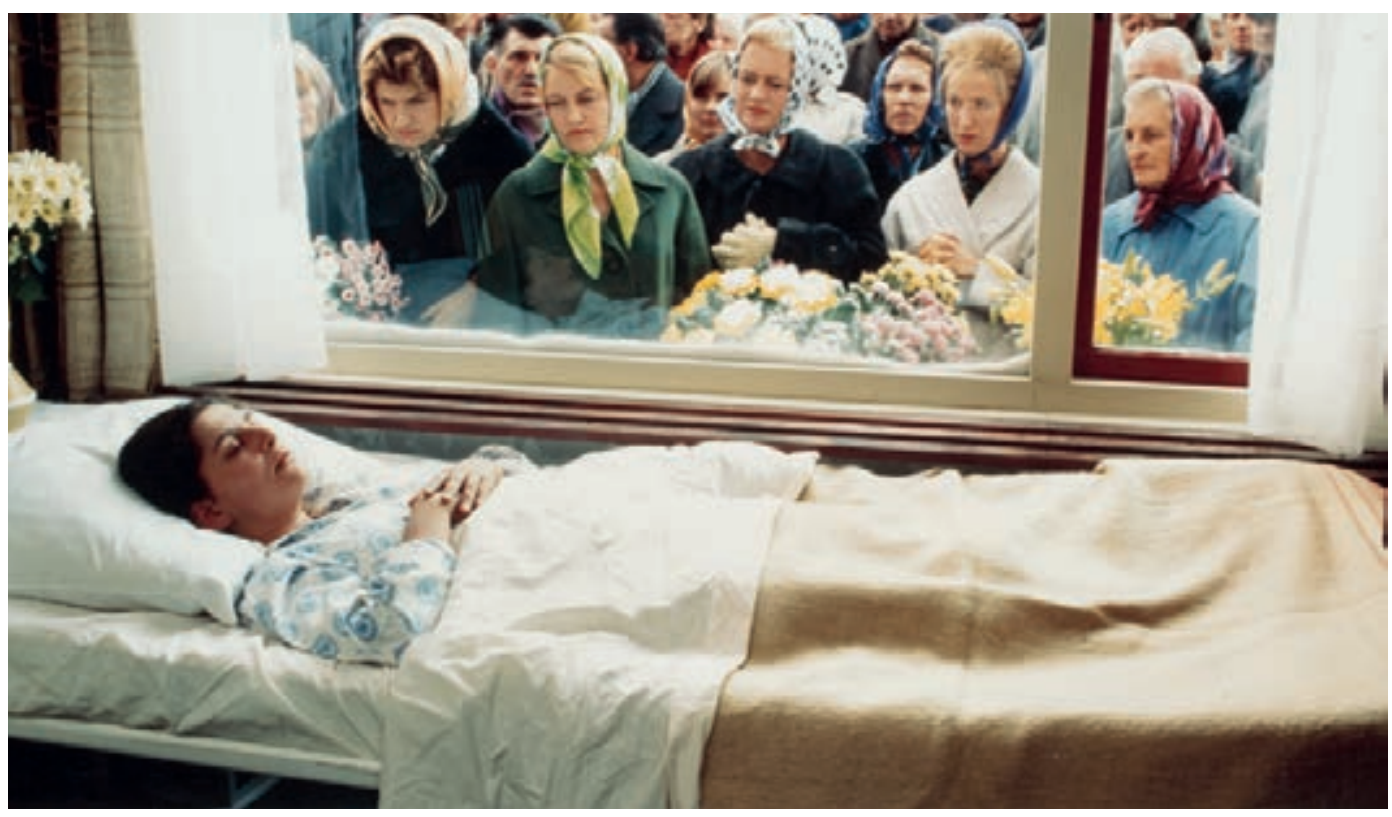

Plate 5. DE NOORDERLINGEN

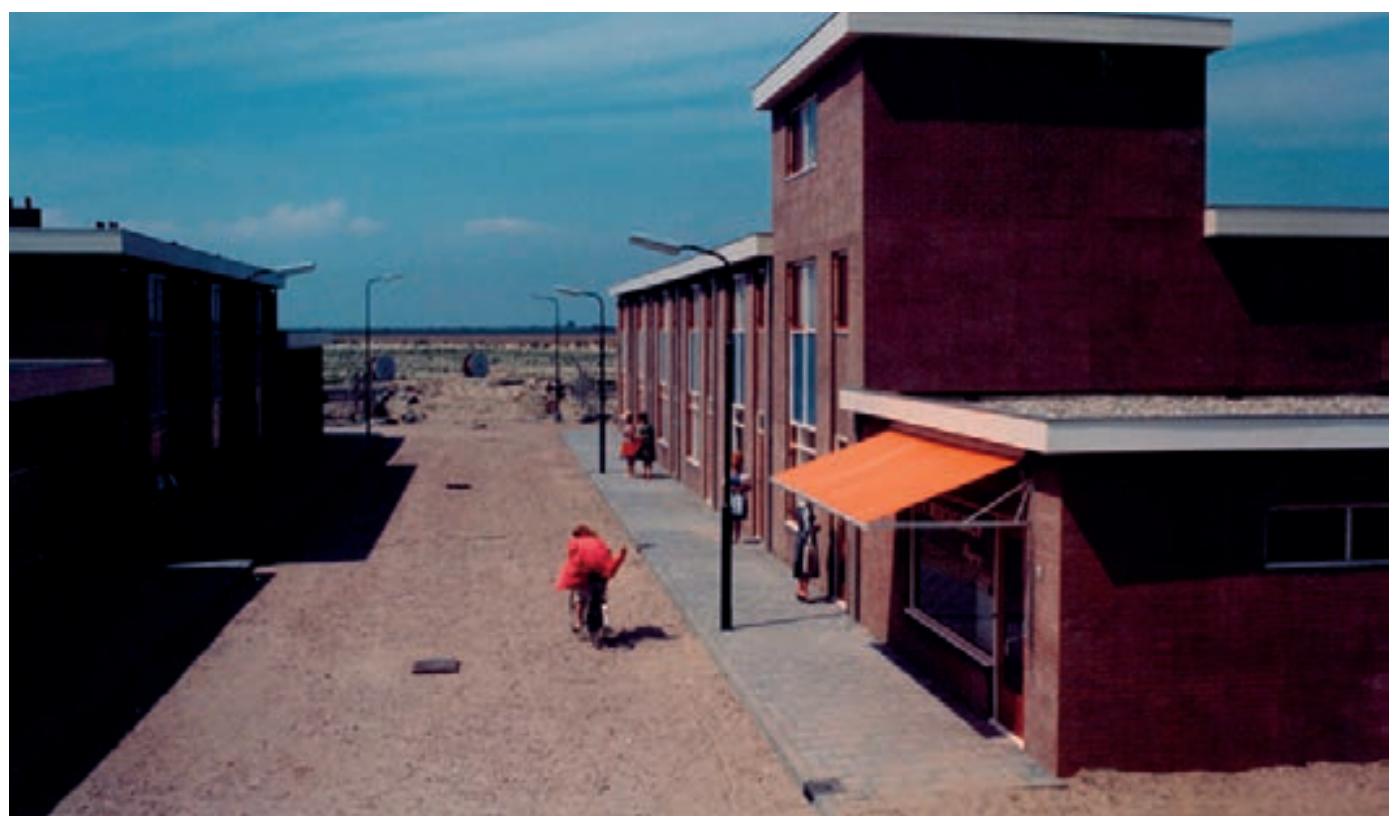

Plate 6. DE NOORDERLINGEN 


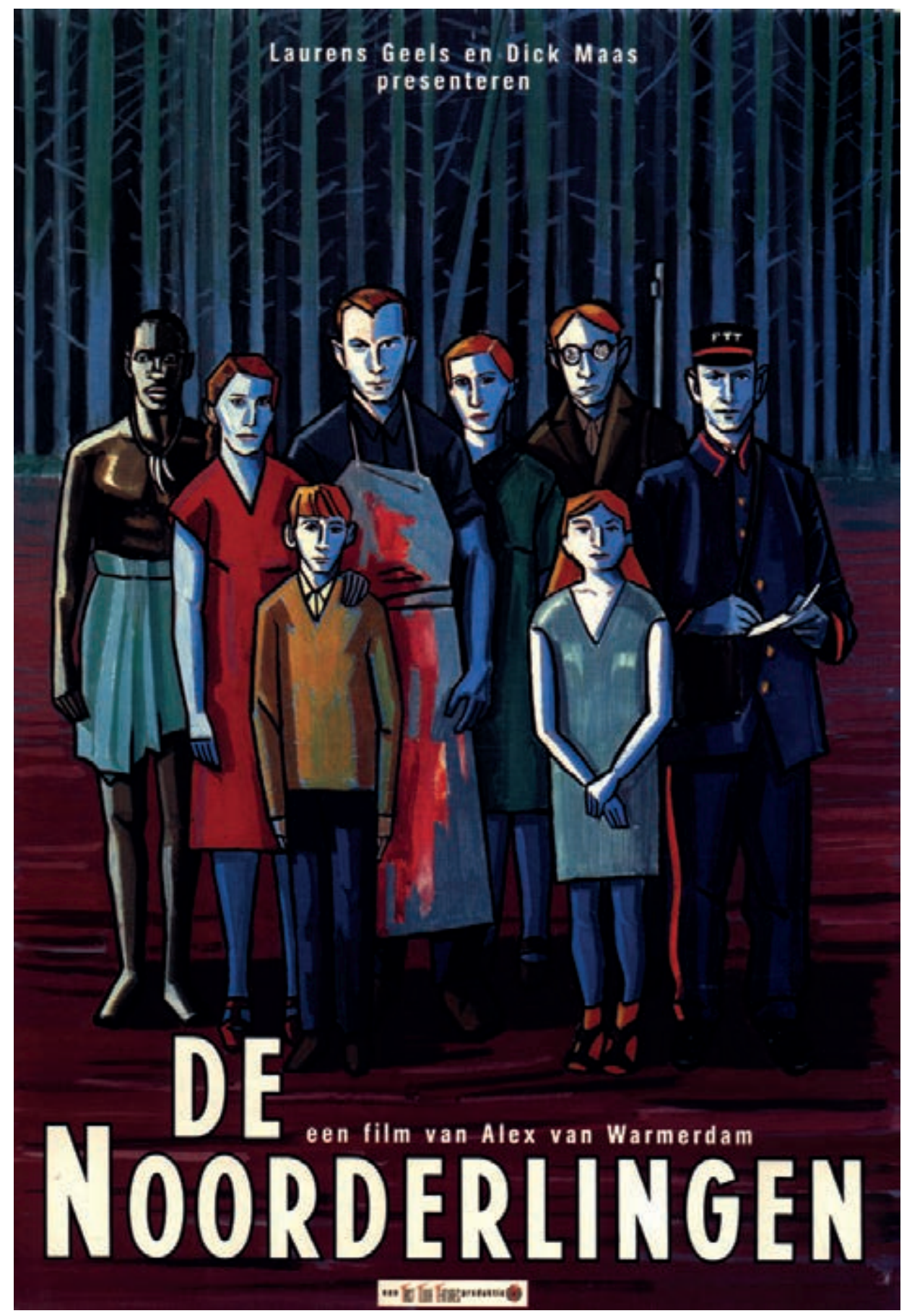

Plate 7. DE NOORDERLINGEN 


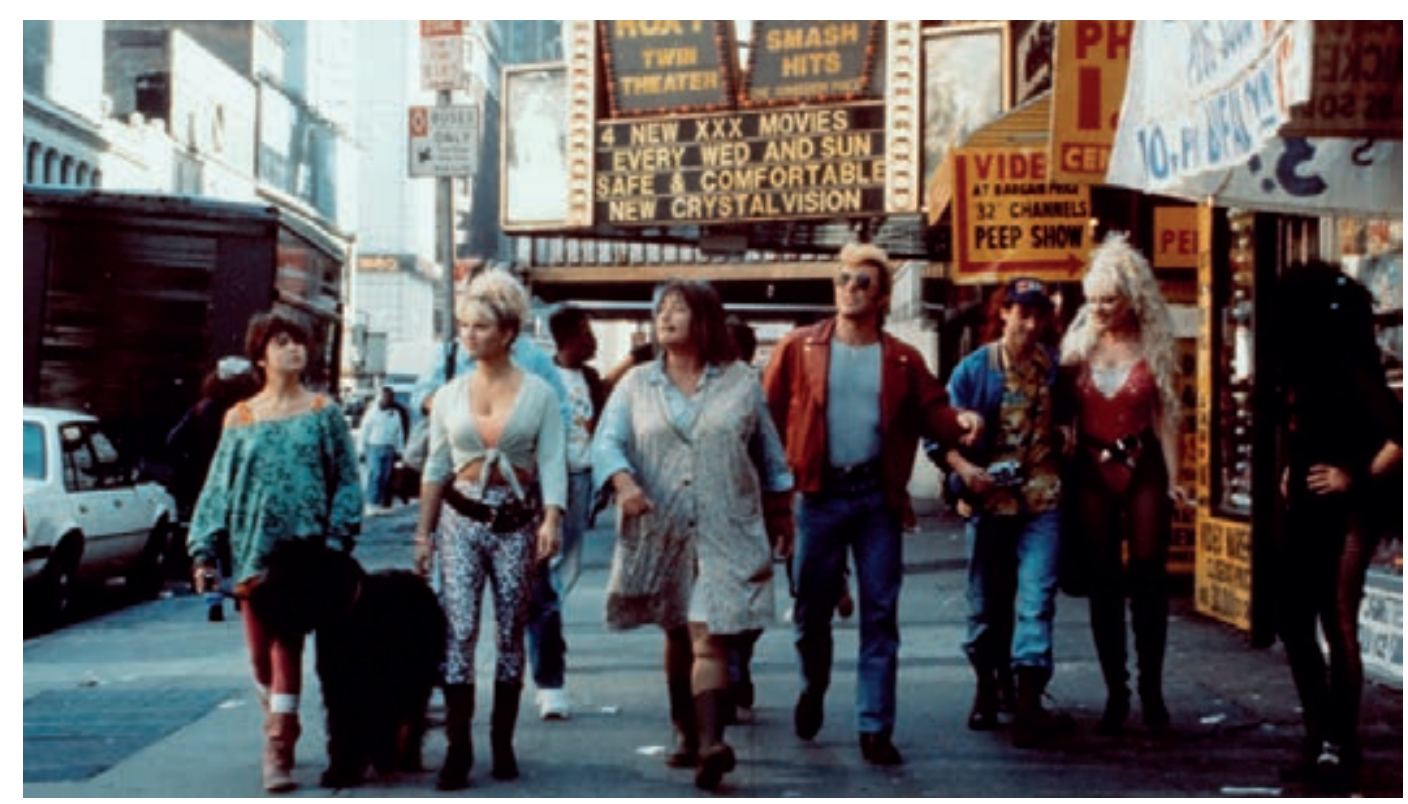

Plate 8. FLODDER IN AMERIKA!

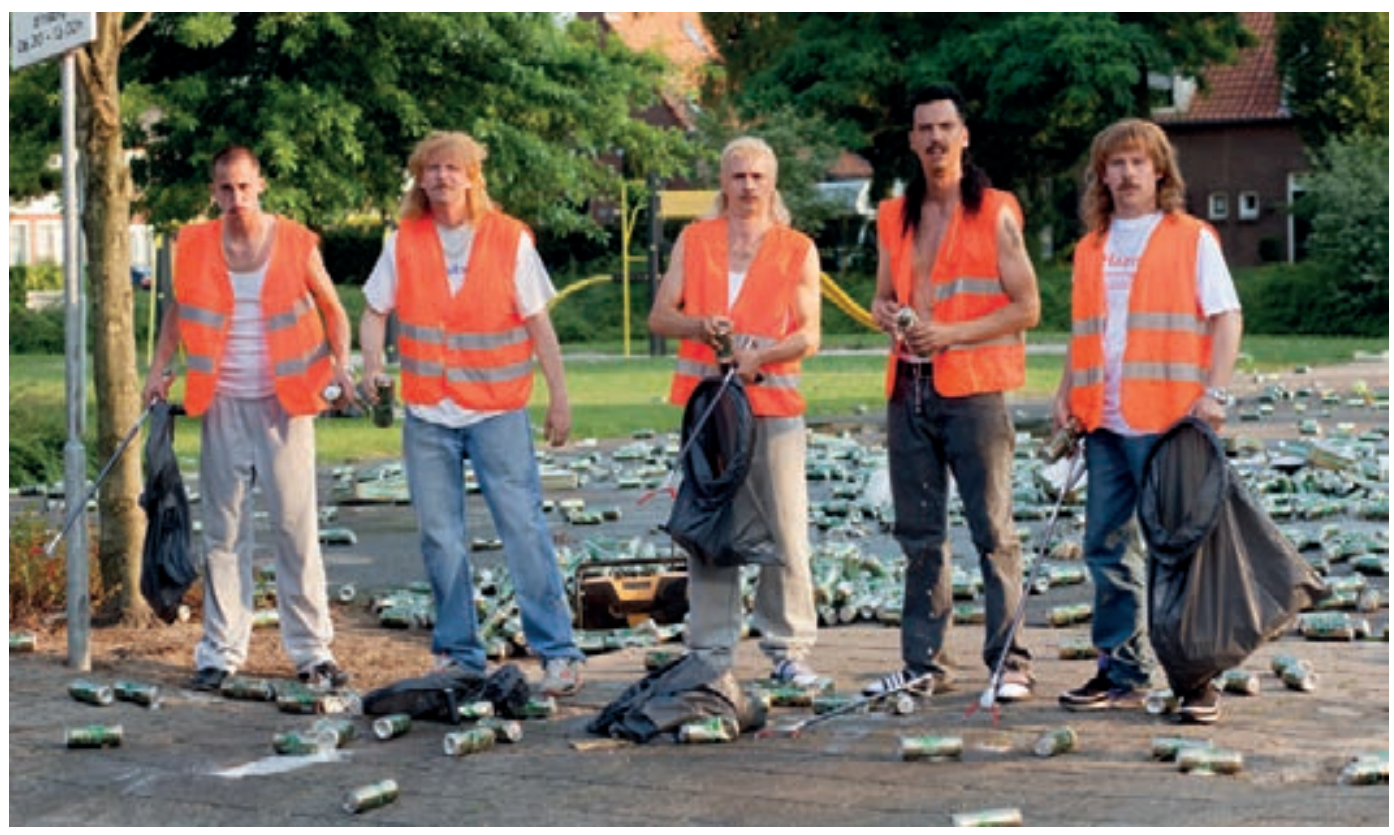




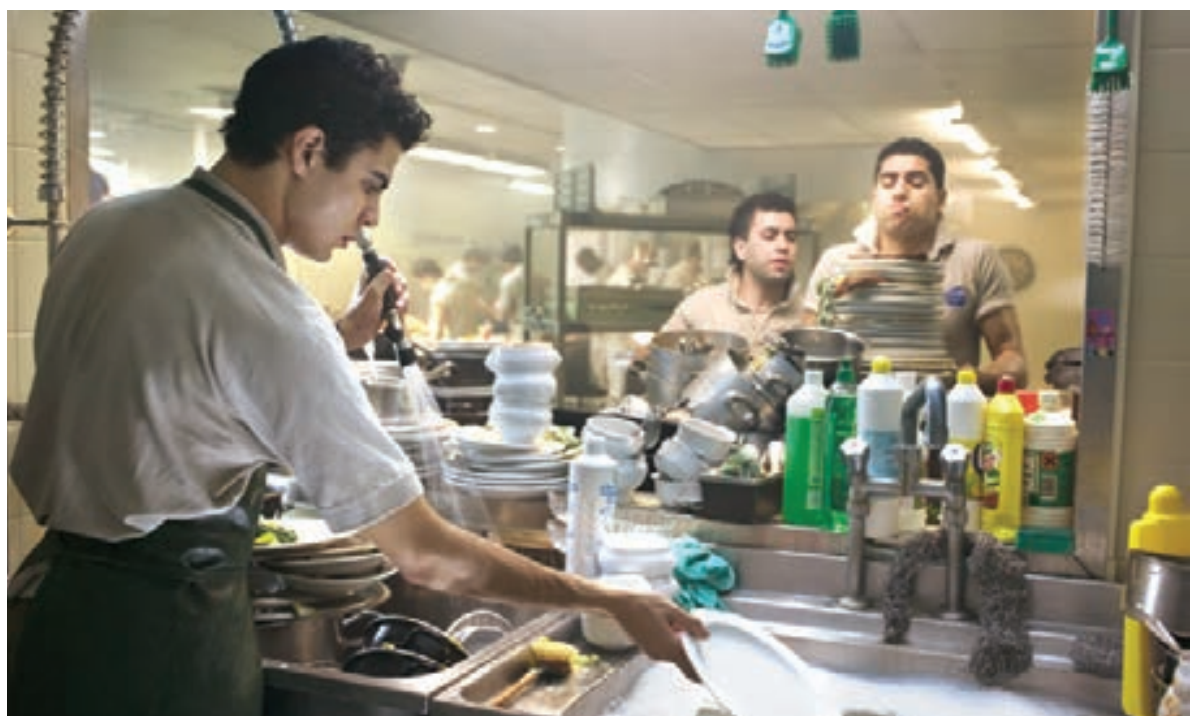

Plate 10. Het SCHNitzelPARAdIJS

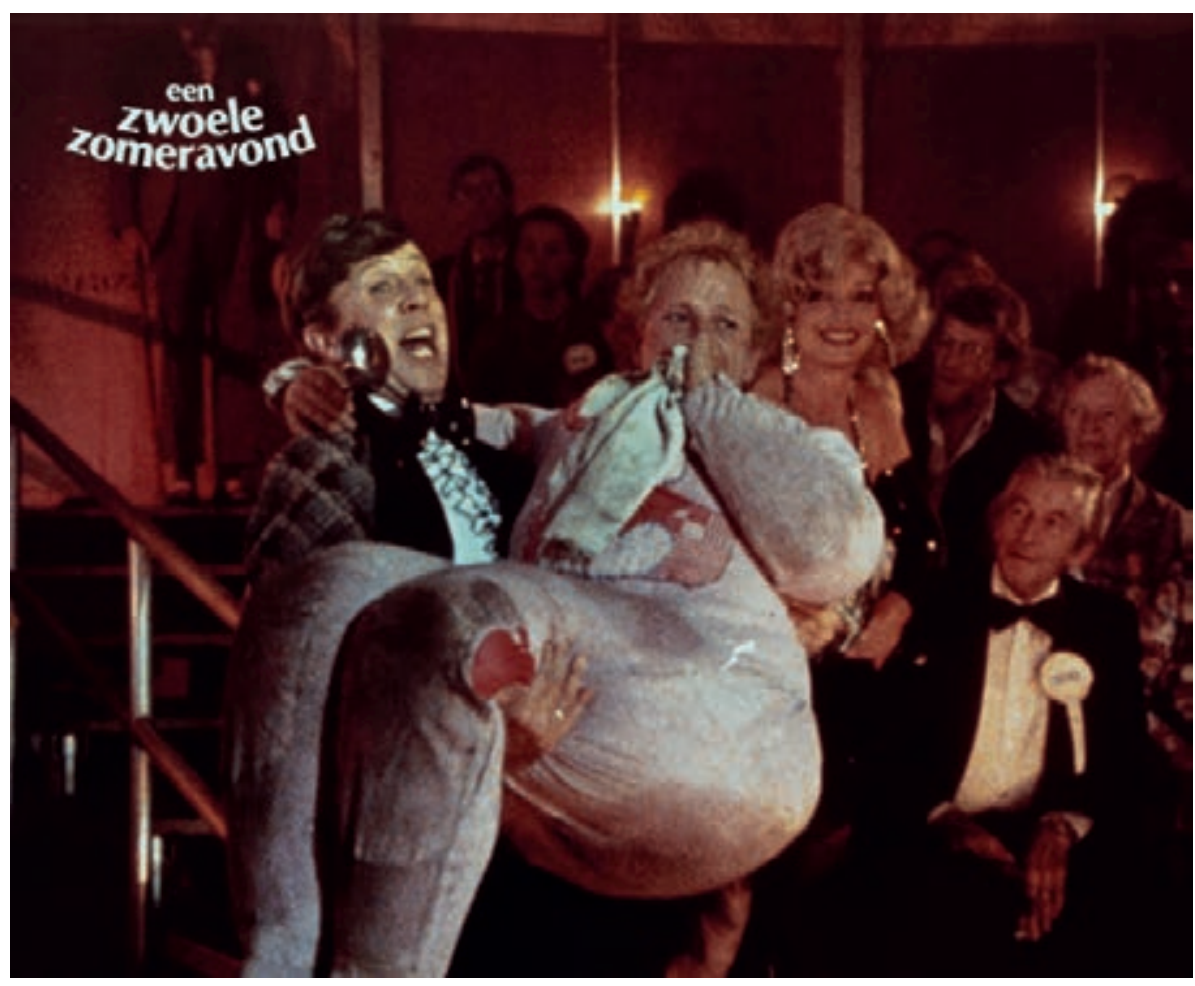

Plate 11. EEN ZWOELE ZOMERAVOND 


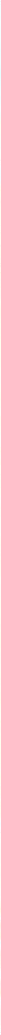

Plate 12. JA ZUSTER, NEE ZUSTER

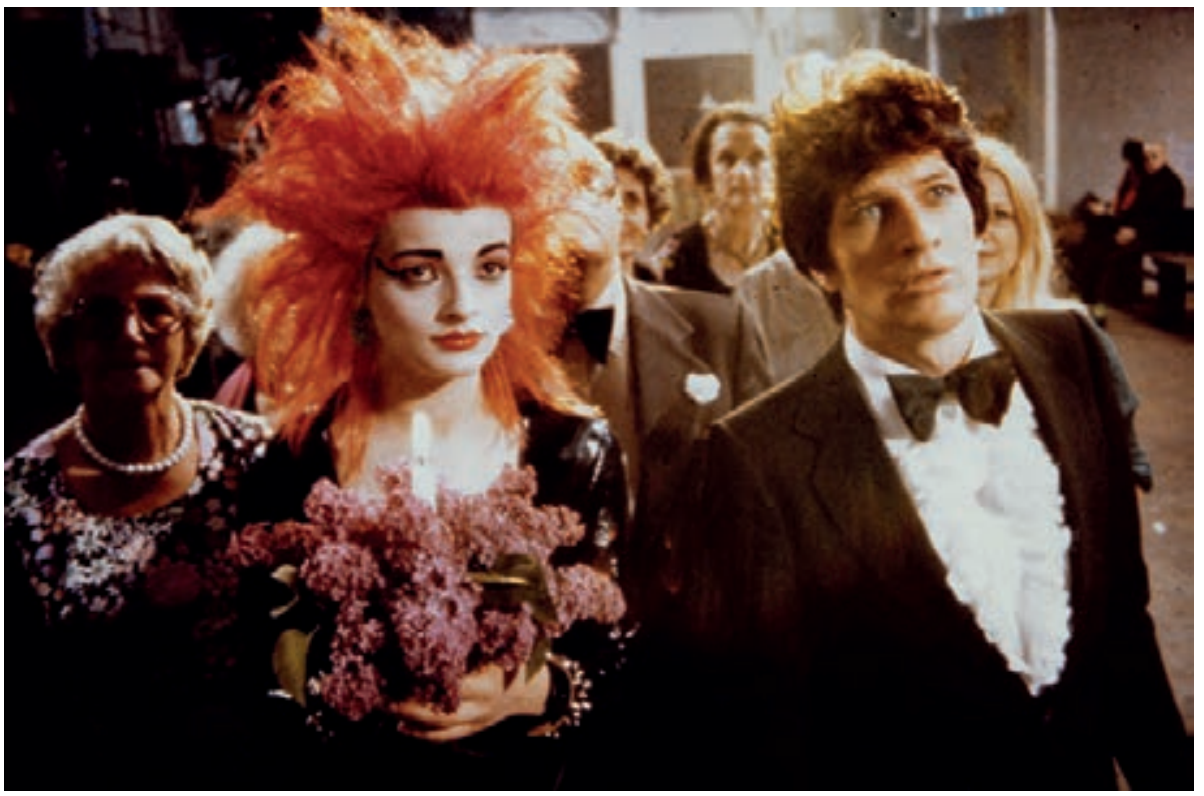

Plate 13. CHA CHA 


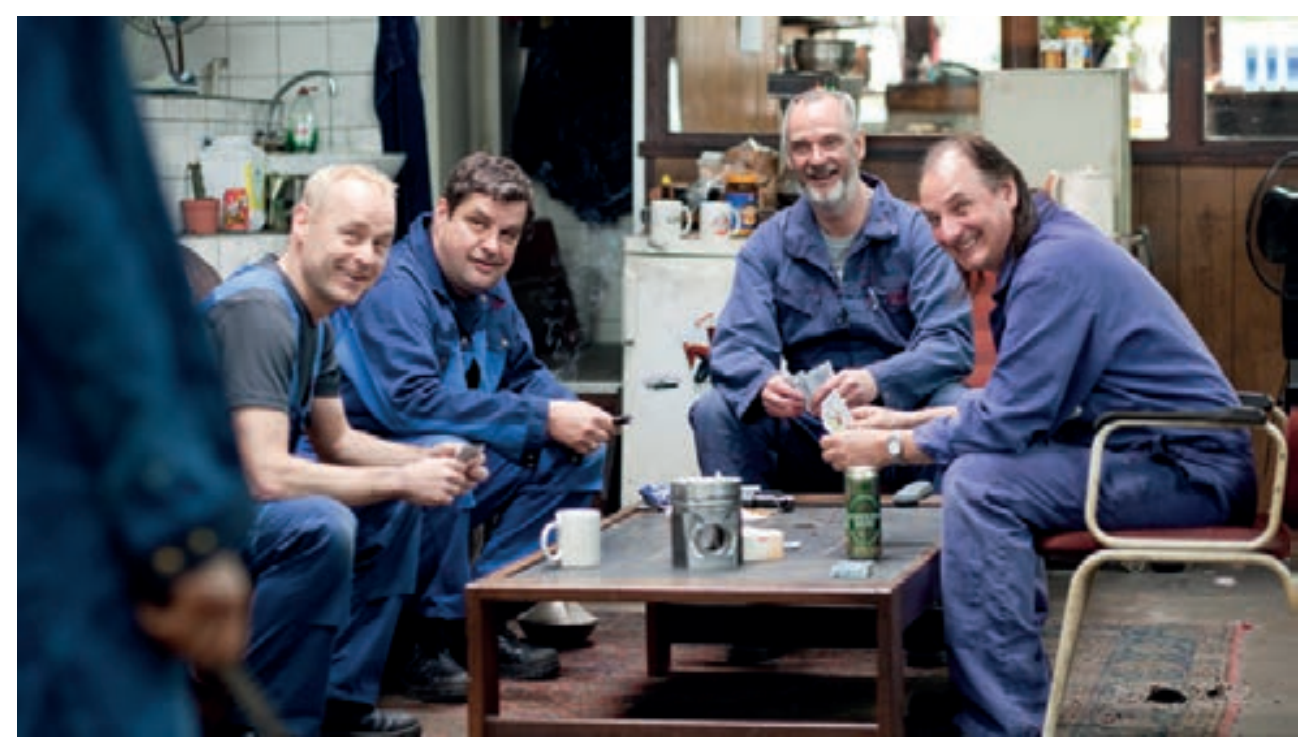

Plate 14. DE MARATHON

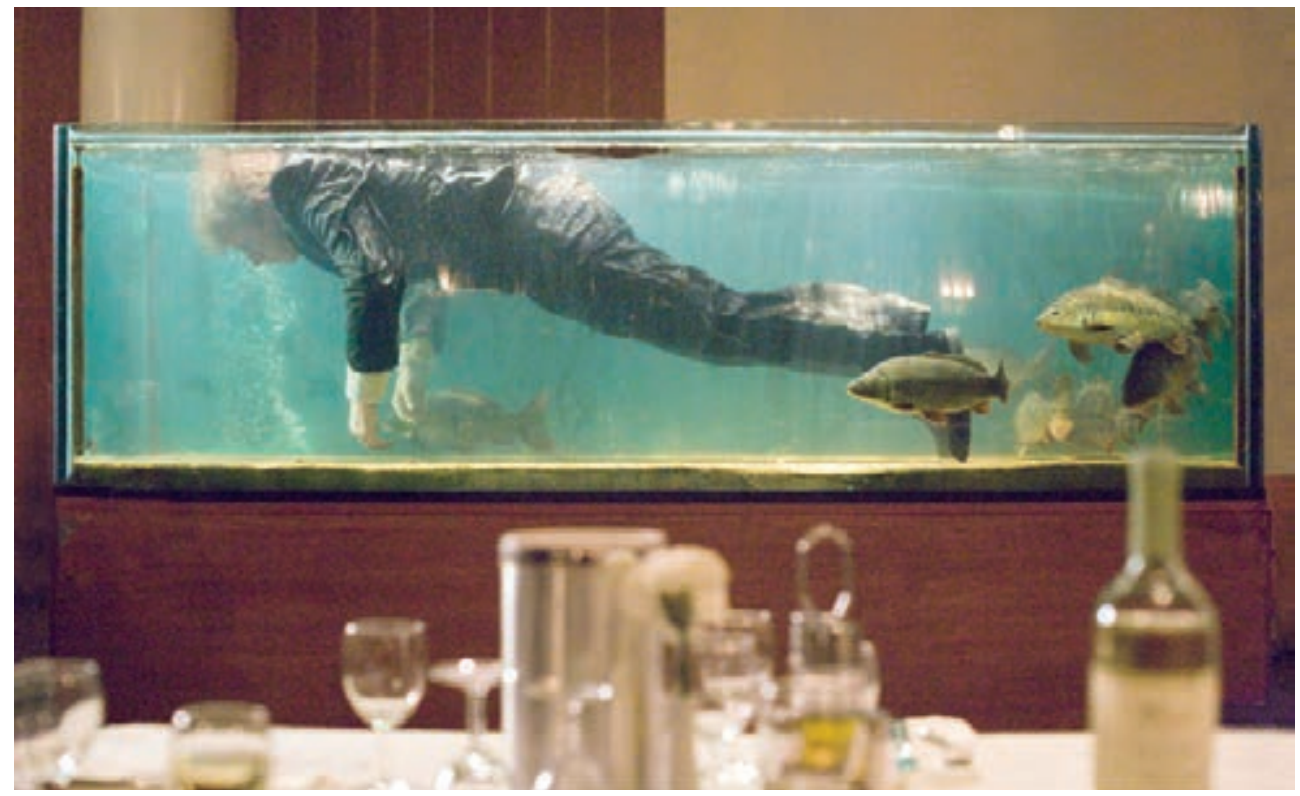

Plate 15. OBER 


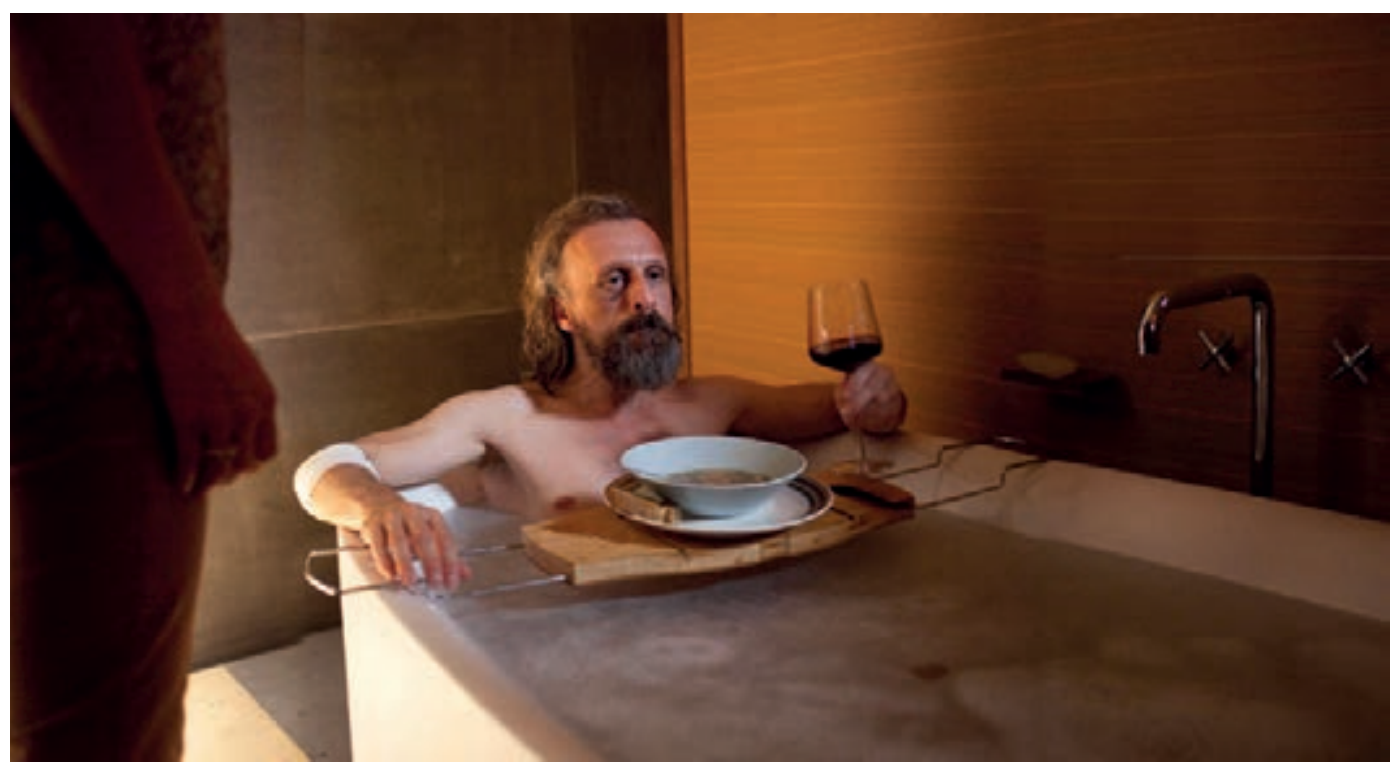

Plate 16. BORGMAN

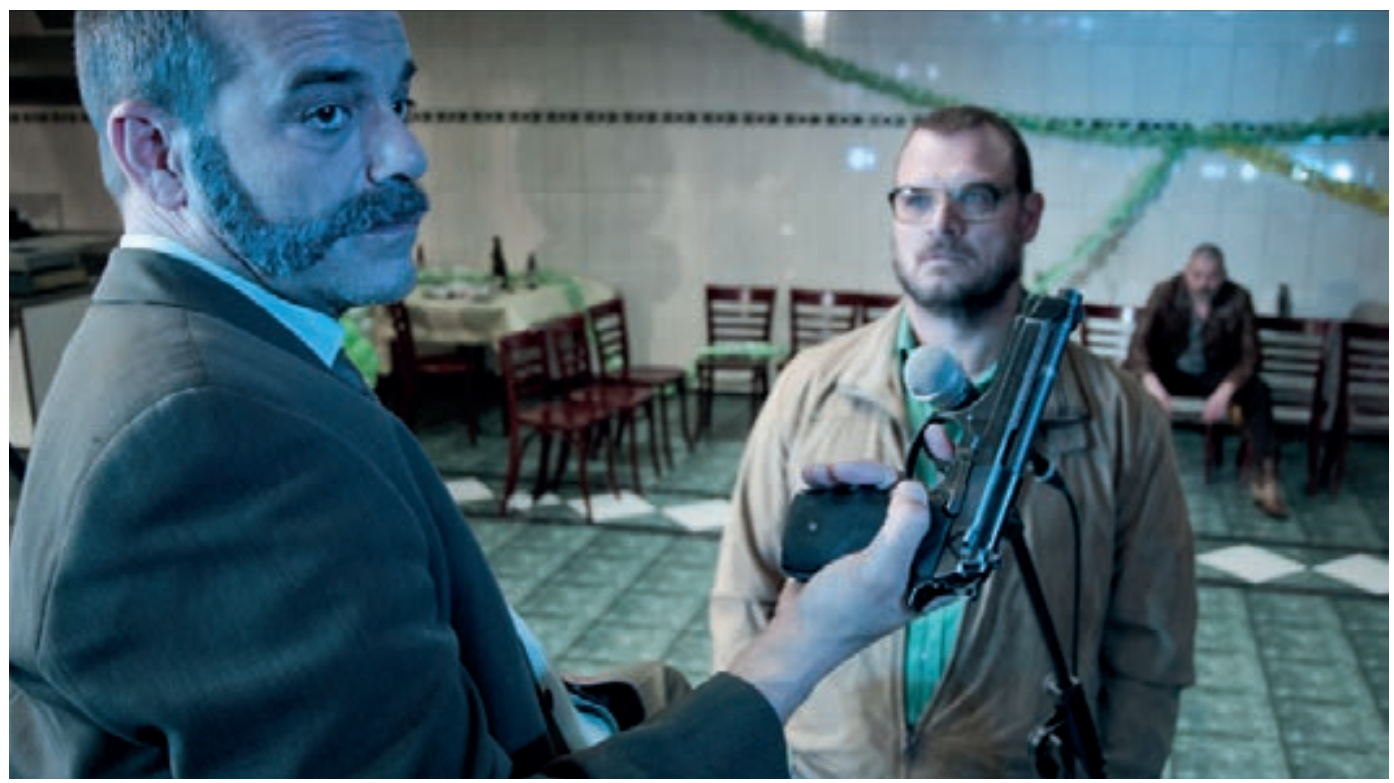

Plate 17. DE WEDEROPSTANDING VAN EEN KLOOTZAK 


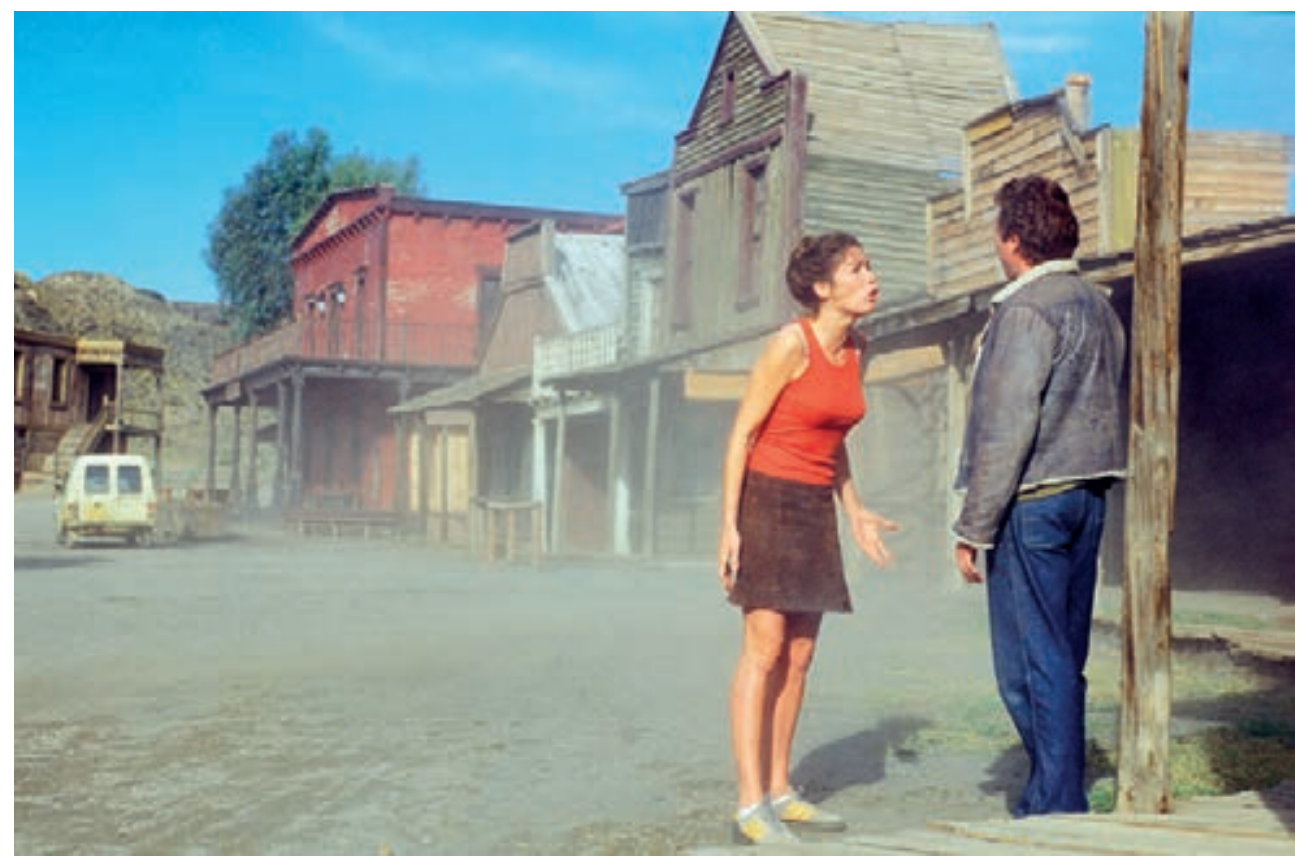

Plate 18. GRIMM

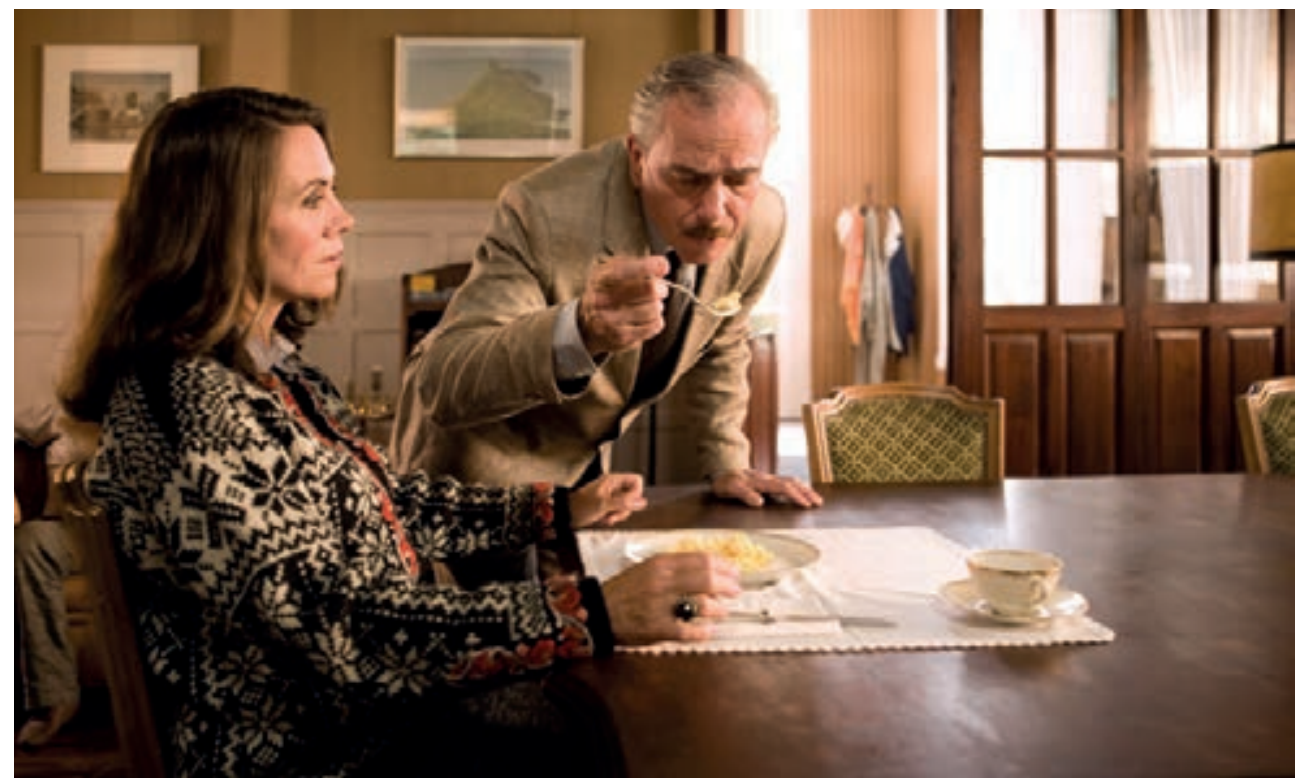

Plate 19. DE LAATSTE DAGEN VAN EMMA BLANK 


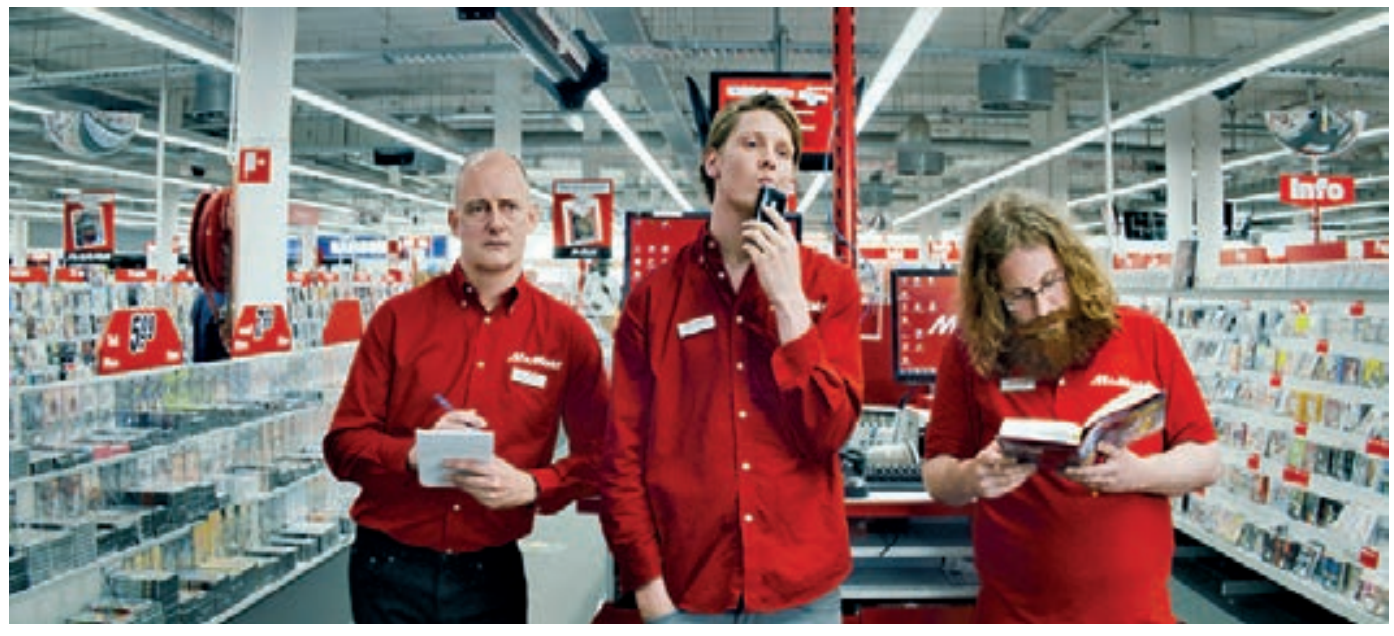

Plate 20. AANMODDERFAKKER

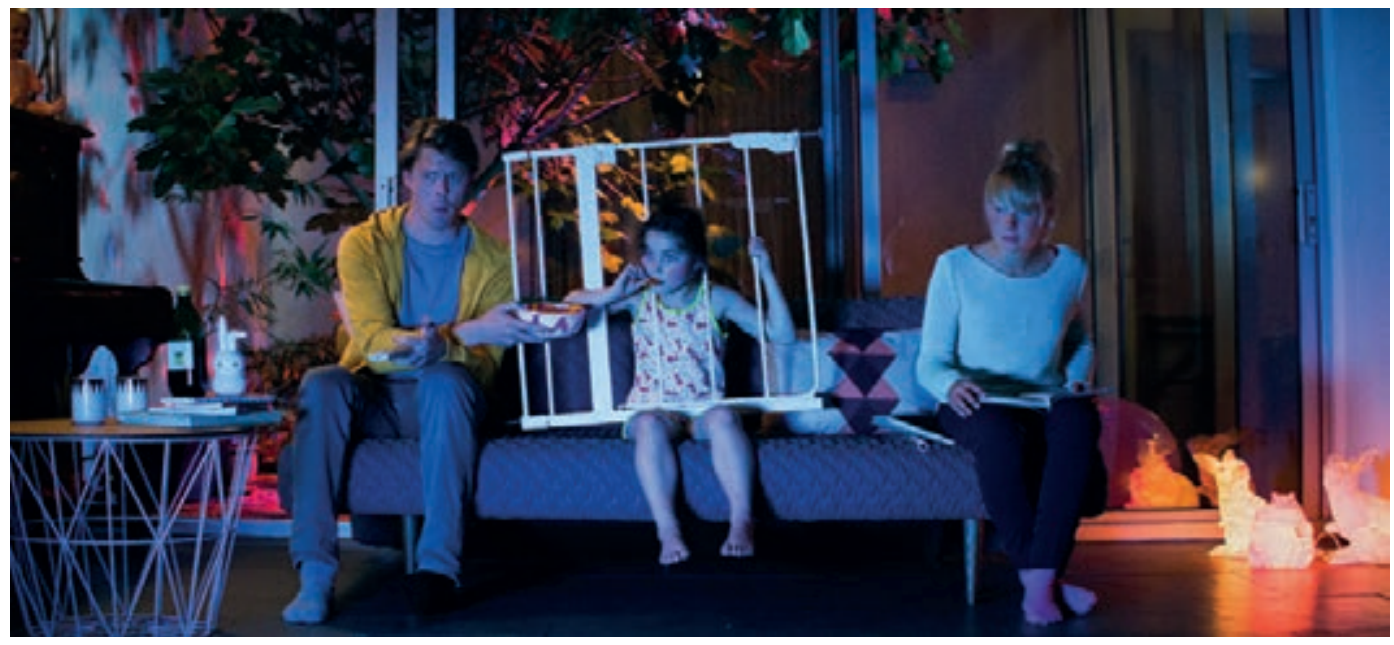

Plate 21. AANMODDERFAKKER 


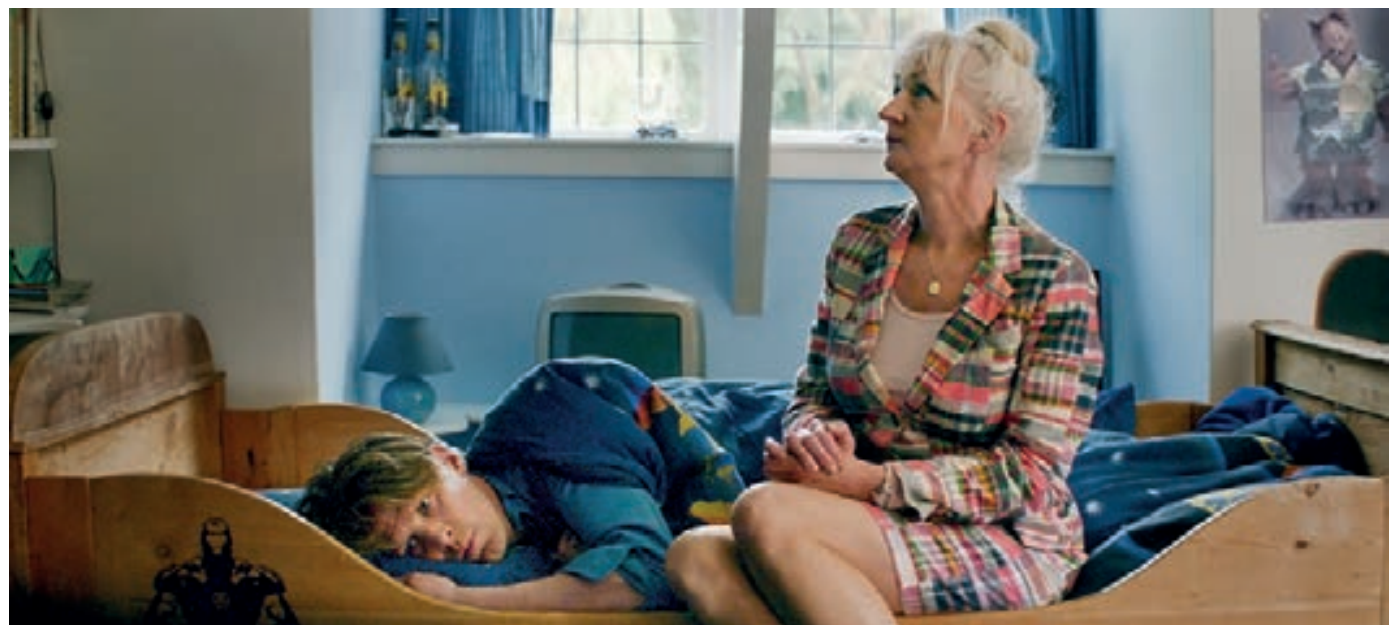

Plate 22. AANMODDERFAKKER

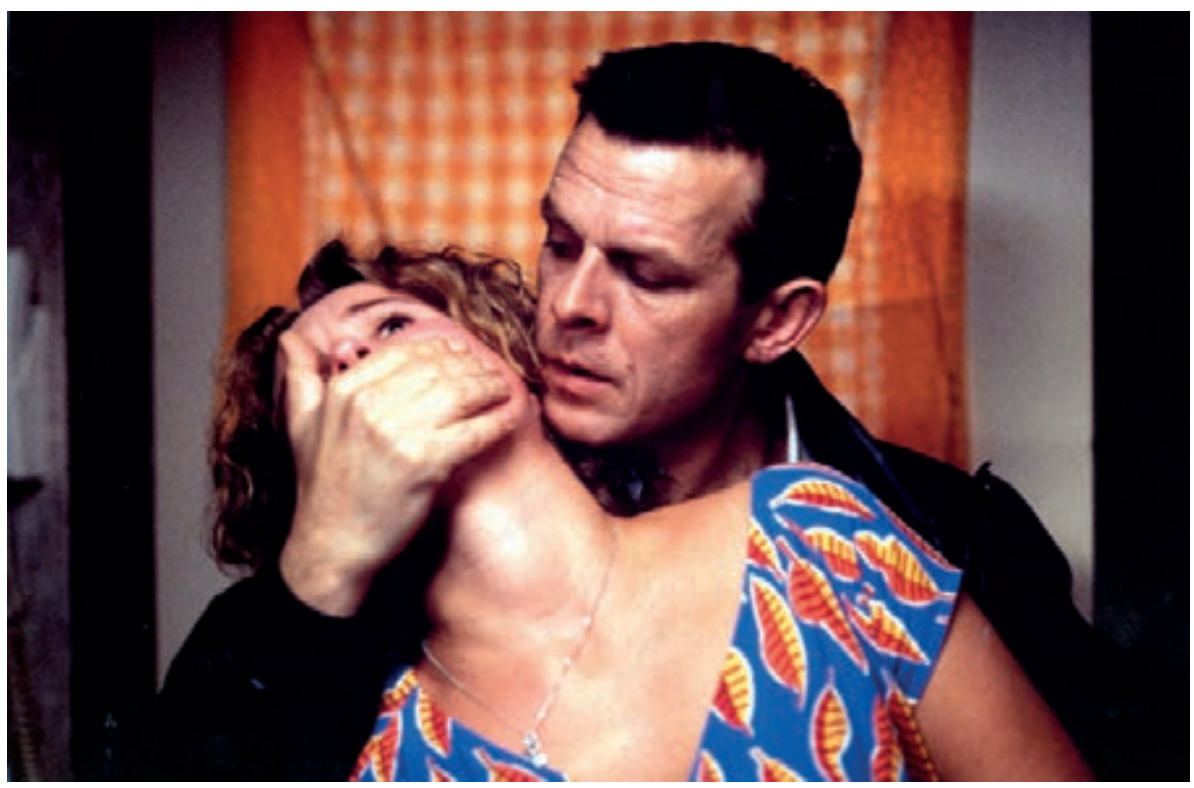

Plate 23. DE JURK 


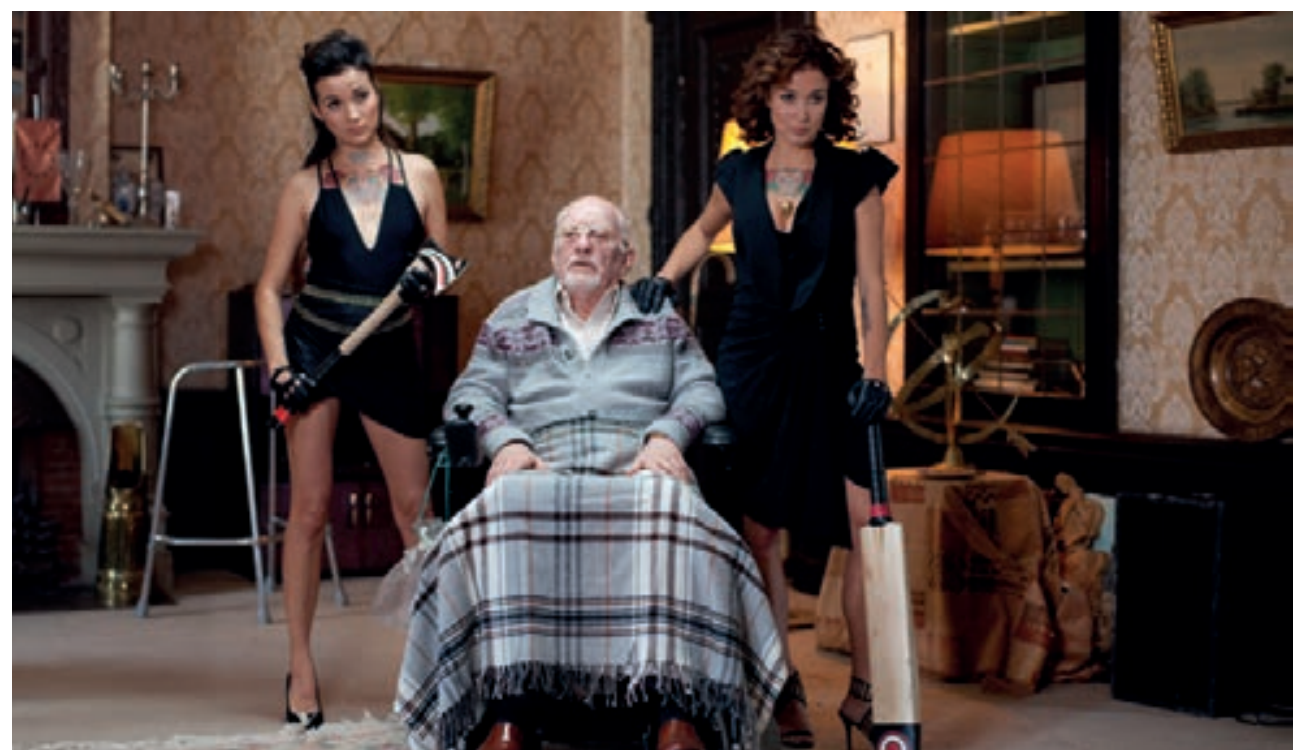

\section{Plate 24. BLACK OUT}

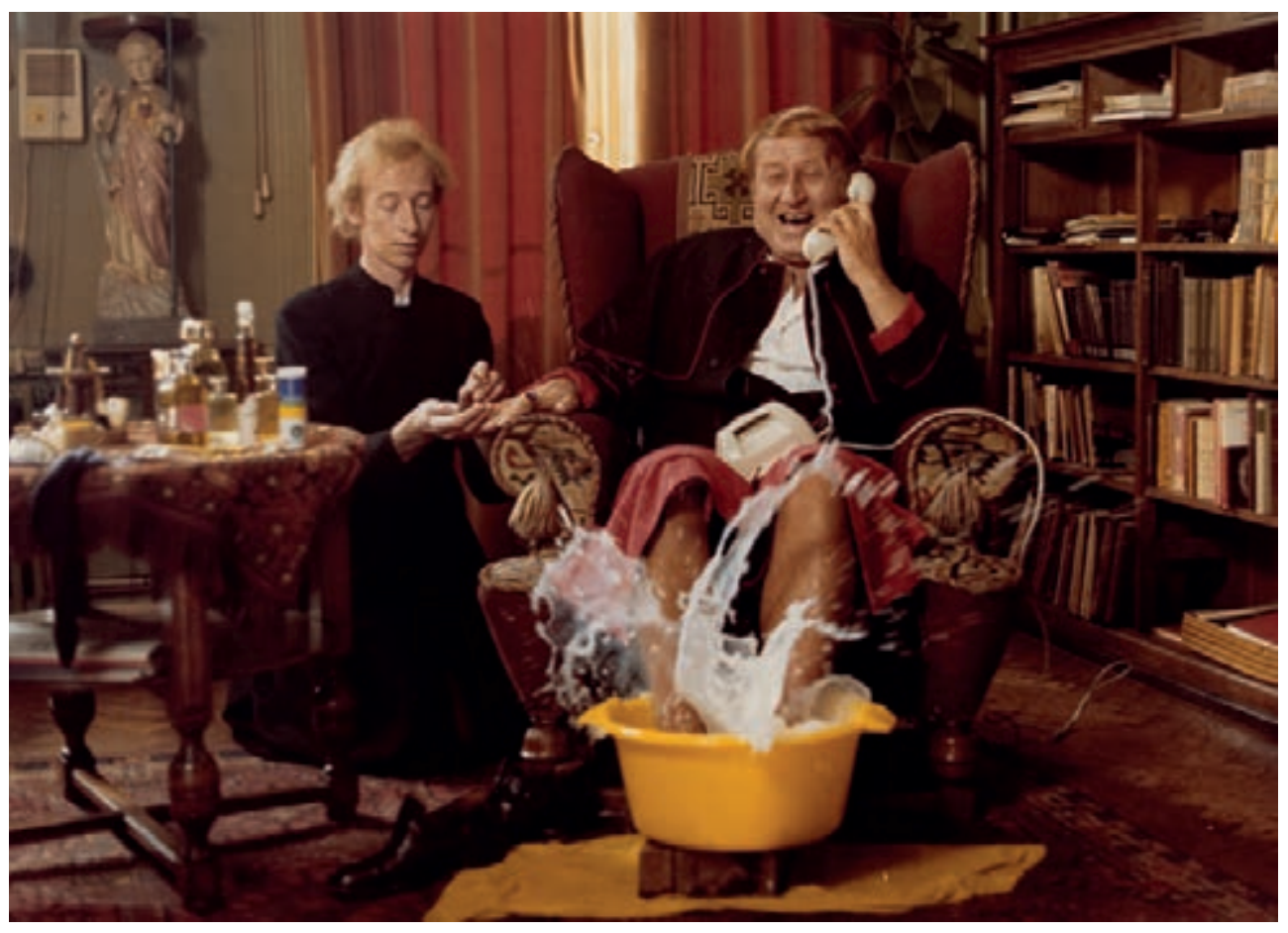




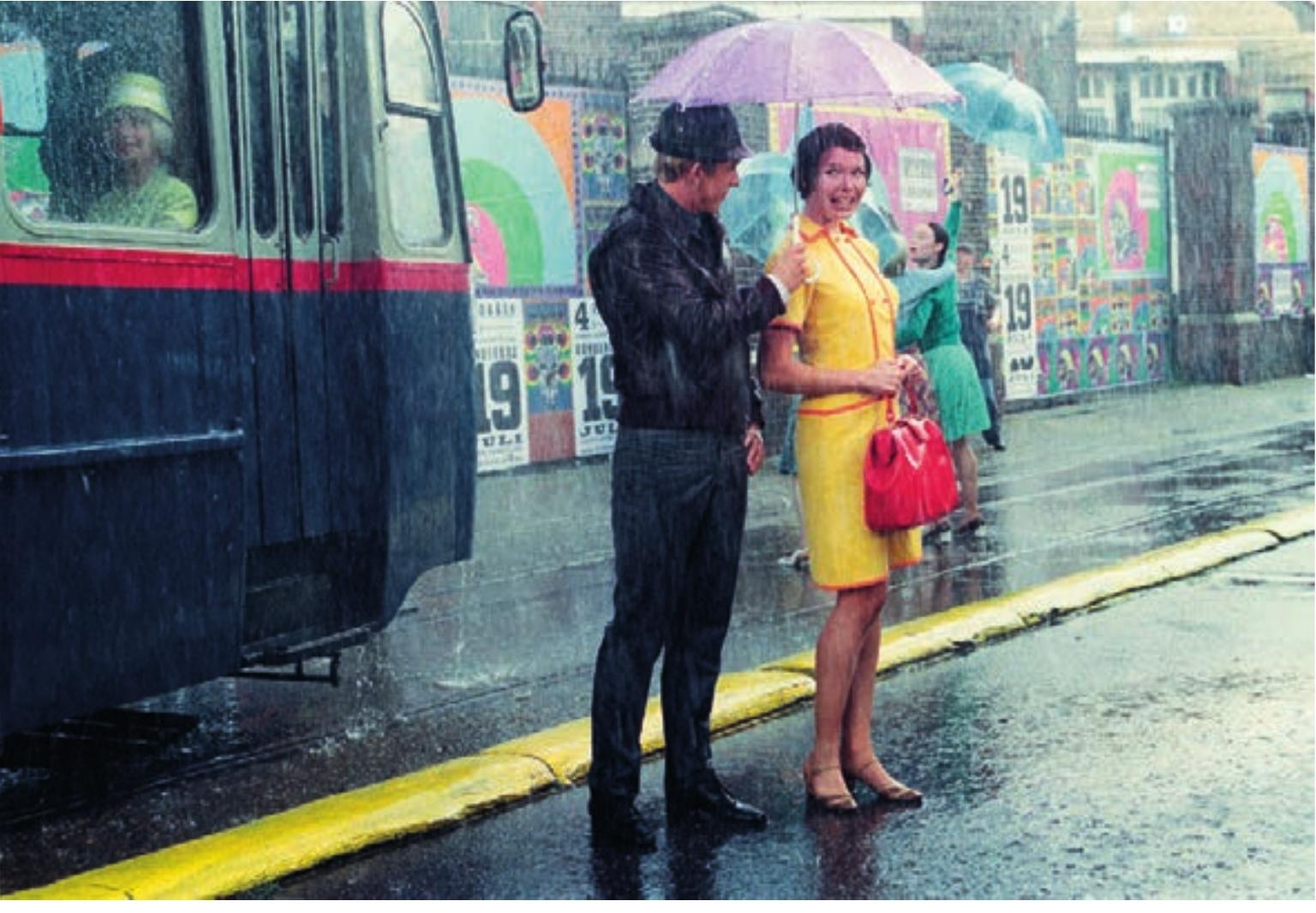

Plate 26. JA ZUSTER, NEE ZUSTER

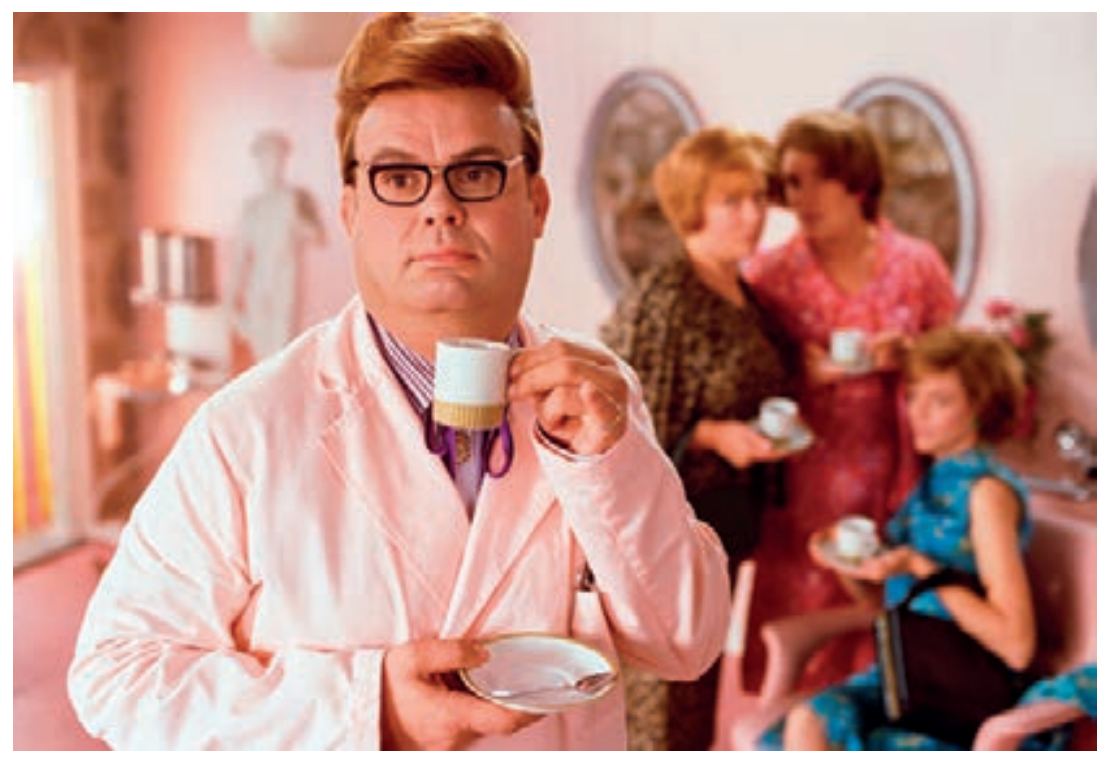

Plate 27. JA ZUSTER, NEE ZUSTER 


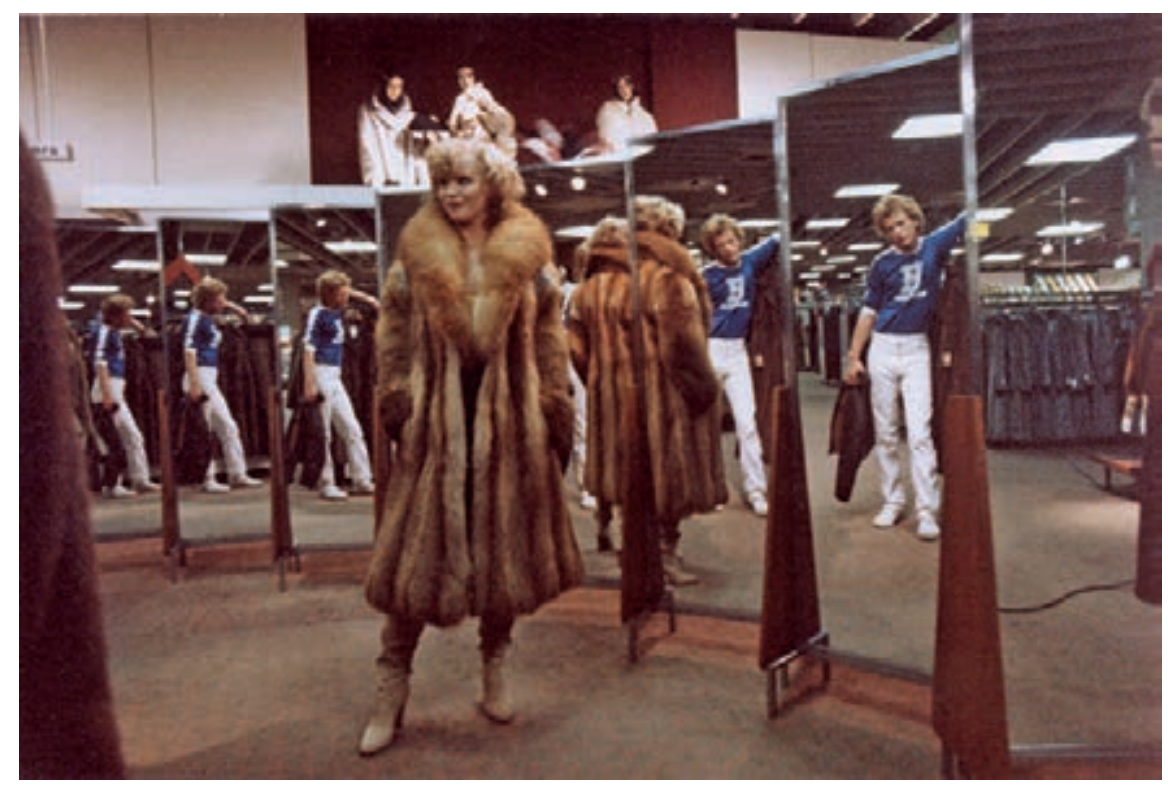

Plate 28. SPETTERS

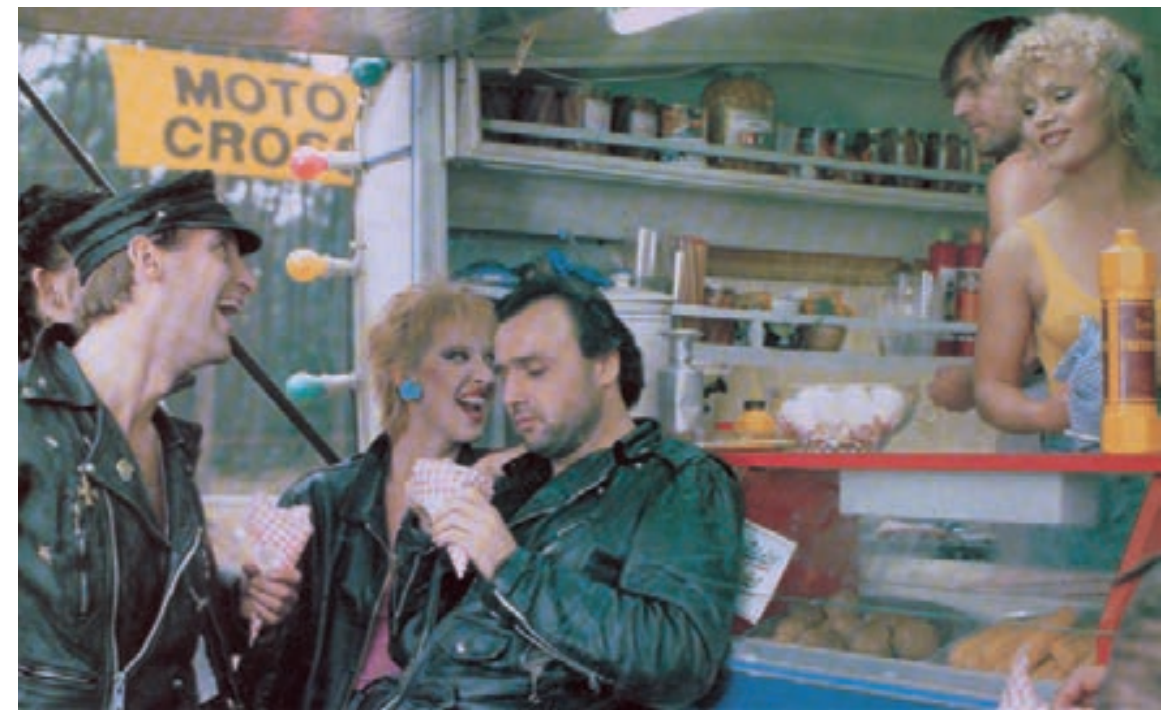

Plates 29. SPETTERS 


\section{NOTES}

\section{INTRODUCTION}

1 SOldaAT VAN ORANJE was not included because the jury had decided that no more than one title of a director could be mentioned. In the case of Verhoeven, TURKS FRUIT was already selected.

2 In his Docupedia.nl, published as a Ketelhuis-cahier, Hans Beerekamp discusses ten fundamental types of documentary in Dutch cinema, like the rhetorical documentary, the visual essay, abstract expressionism, found footage, the 'voice of God,' and so on. In addition to this, the work by film historian Bert Hogenkamp has to be singled out for its thoroughness. In three volumes on the Dutch documentary film as a 'genre,' he covered the years between 1920-1990.

3 Henk van der Linden made many films between the years 1944 and 1985, based upon literary characters popular with young people, like Dik Trom and Pietje Bell as well as the comic strip heroes Billy Turf and the couple Sjors and Sjimmie. Karst van der Meulen made a number of fine family pictures in the 1970s and 1980s, like Peter En De Vliegende autobus [Peter ANd the Flying AutoBUS] (1976), MARTIJN EN DE MAGIËr [MARTIJN AND THE MAgician] (1979), and THOMAS EN SENIOR OP HET SPOOR VAN BRUTE BEREND [THOMAS AND SENIOR ON THE TRACK OF BRUTAL BEREND] (1985).

4 In particular, SPIJT! (Dave Schram, 2013) has been hugely successful, winning, in addition to a great number of prizes, the European Film Young Audience Award. See Schmidt and Veenendaal for a useful overview of Dutch youth and family films.

5 As a fan of cartoonist Gummbah I yield to the temptation to quote his caption at an unremarkable photo of a man and woman sitting at a dinner table: 'After an hour the WHORE!!!-meter still shows a total zero, remarkable for a Dutch film.' [Na een uur staat 'HOERRR!!!-teller nog altijd stijf op nul, opmerkelijk voor een Nederlandse film.'] (de Volkskrant, 23 December 2013). 
6 Ivo Smits and Katarzyna Cwiertka, two professors in Japanese Studies from Leiden University, edited a volume on the culture of cuteness in Japan, entitled Hello Kitty \& Gothic Lolita's.

7 Another journalistic initiative worth mentioning is a publication in English on experimental film in the Netherlands, edited by Anna Abrahams et al., but as the subject already suggests, it is not about narrative cinema. It contains a few essays and interviews with 16 filmmakers.

8 'Mirror of Holland' was not only the name of a documentary short made by Haanstra in 1950, but it was also the theme of one of the main programmes of the Netherlands Film Festival for its 3oth anniversary in 2010.

9 The NFF has a system to check whether a film qualifies as a Dutch film. Out of the 30 possible points, a film has to score at least 14 . The film is granted 4 points if the director has Dutch nationality or has been living and working in the Netherlands for at least two years; also 4 points for the main producer; 2 points if the 334 scriptwriter meets this condition; 2 points if Dutch is the main language of the film; 1 point for the director of photography, 1 for the musical composer, 1 for the editor, etc.

10 In a personal communication, Hans Beerekamp suggested that genre films might also give hints of national preoccupations. This goes beyond the obvious fact that gangster films, to name one genre, like LEK [LEAK] (Jean van de Velde, 200o), De DOMinee [The PREACHER] (Gerrard Verhage, 2004), NACHTRit [Night Run] (Dana Nechushtan, 2008) and De Heineken Ontvoering [THe HeineKen KIDNAPPING] (Maarten Treurniet, 2011) are inspired by actual persons or events from the Netherlands. The point for Beerekamp is rather that these Dutch gangster films seem unaffected by (international) conventions of the genre. When LEK was once shown to film critics from Thailand, they did not really get that the revelation about a policeman acting as an informer for the mob was presented as a shocking dénouement. For them, as was already suggested by a numerous earlier pictures, the corruption of the police force is a given condition, not the surprising twist in a gangster movie.

11 AllemaAl Film was made by IDTV Docs, and broadcast by the AVRO in 2007.

12 Moreover, referring to the films by both Van Warmerdam and Jos Stelling, Bas Agterberg remarks that the acting style in their films is inspired by commedia dell'arte rather than naturalistic theatre (127).

13 Henk's actions bear a great resemblance to the attempts by the tramp to lose a foundling in THE KID (Charles Chaplin, 1921).

14 Henk has taken an old man out of the park who acts as a kind of substitute grandfather.

15 Jewish humour, says Stephen Pollard, is usually self-depreciating and focuses upon one's own foibles, like in the cases of Woody Allen and Jerry Seinfeld, who are 'at times neurotic, self-obsessed, tight, obsessive and always eccentric.' 

article/detail/2653585/1997/10/o8/Filmproducent-wil-All-stars-niet-inzendenvoor-Oscar.dhtml. DE WISSELWACHTER was only showing for a few weeks in Amsterdam and about three years in Rome, as Stelling related during an interview, broadcast on the website cinema.nl, 22 August 2005.

Noteworthy is Van der Oest's debut feature De NIEUWE MOEDER [THE NEW MOTHER] (1996) which is as melancholic as witty. Juris from Riga travels with his son, Elvis, who has stopped talking since his mother's death, to Holland in order to locate a female pen pal from the past. In voice-over we hear excerpts from the letters they wrote to each other between the early 1960 s and 1972. To illustrate that the humour in the film is relatively deadpan, let me quote one scene. On his way, Juris has to find some place to eat. Outside one restaurant he sees a sign that reads 'All dishes, $\mathbf{1 2 . 5 0}$ guilders,' so he orders 'All the dishes at once.' The waiter names some of the dishes (Fried Rice Special, Russian-style Eggs, and so on), but Juris asks, 'Is that all the dishes you have?' The waiter says, 'Is that not enough?' and he brings them many more plates of food. Another customer remarks that times have changed. 'In the past Eastern Europeans used to get one order of toast for two to share, and now they are eating meals that cost 150 guilders, at least.' Then Juris realizes what he has inadvertently done, and that he needs to figure out how to leave the restaurant without paying.

19 To warn against the underestimation of play, Huizinga states that play is 'a given magnitude, existing before culture existed itself' (4) and that it 'becomes the accompaniment, the complement, in fact an integral part of life in general' (8). He adds to this that we may move in play 'below the level of the serious, as the child does; but we can also move above it - in the realm of the beautiful and the sacred' (19).

20 I already mentioned in the preface that if a quote is in italics, it means that the characters actually use English words, so then the quote is literal. If not in italics, it is a translation, either by me or from a subtitled version.

21 In her explanation of the key principles of 'romantic irony,' Lilian Furst uses this image of the clown walking the tightrope, 'poised dangerously between explicitness and impenetrability' (14).

22 They discuss, as Billig asserts, anecdotes and bon mots, but not jokes qua jokes. Although Joe Miller's Jests, or The Wits Vade-Mecum (1739), containing many jokes about farting and copulation, was popular, the philosophers neglected the study completely (Billig, 67).

23 Of upper-class descent himself, the Earl of Shaftesbury made a distinction between well-bred and ill-bred forms of ridicule. Or, as George Campbell claimed in The Philosophy of Rhetoric (1856), banter, or coarse talk/humour, is what others do, but 'we' do raillery, 'a finer form of ridicule' (qtd. in Billig, 48). 
24 The idea of an 'innocent joke' as such seems to belie Freud's 'sweeping claim that there were no such things as innocent dreams or innocent lapses of memory' (Billig, 153).

25 Of course, an innocent pun can function tendentiously in context, because the speaker's apparently witty remark might possess some ulterior, even hidden purposes (Billig, 157).

26 In the words of Martin Sommer: '[E]en keurslijf aan voorgeschreven linkse standpunten.'

27 However, on reflection, there is a common denominator between DE STILTE ROND CHRISTINE M. and FLODDER. In Gorris' film, Nelly Frijda plays the role of An, one of the suspects, whereas the part of Ma Flodder in Maas' comedy will turn her into a national celebrity.

28 Rademakers' DE DANS VAN DE REIGER is a borderline case, which I decided not to include in the end. The well-known author Hugo Claus had written the script, 336 based upon one of his theatre plays, which he had subtitled 'a macabre comedy in two parts.' Although the comic aspects are not lost entirely, Rademakers had in mind to make a film with a certain international allure. Its three main actors were renowned from international productions, by among others, François Truffaut, Ingmar Bergman, and Eric Rohmer, and cameraman Sacha Vierny had shot several Alain Resnais' films. DE DANS VAN DE REIGER can bear some comparison to Resnais' 'art' film L'ANNÉE DERNIÈRE A MARIENBAD [LAST YEAR IN MARIENBAD] (1961), and because of its obvious artistic ambitions, it falls outside the scope of this study. Its baroque absurdity makes DE DANS VAN DE REIGER too much unlike other Dutch movies and, except for the Resnais' comparison, it rather recalls the extravaganza of some of the films by Federico Fellini. Together with Weisz' HET GANGSTERMEISJE, also influenced by Fellini, DE DANS VAN DE REIGER may be a good starting point for another book on Dutch cinema, as a more 'serious' sequel to this one.

\section{CHAPTER 1}

1 The Polish-American film producer Samuel Goldwyn is supposed to have made similar statements: 'If you've got a message, send a telegram' and 'Pictures are entertainment, messages should be delivered by Western Union.'

2 See the Glossary of Comedy Terms by Patrick Bromley, http://comedians.about. com/od/glossary/g/bluehumor.htm.

3 Another example of popular comedians exploiting sexual innuendo is the wellknown couple Johnny \& Rijk (Johnny Kraaykamp and Rijk de Gooyer), who played the main parts in Ko Koedijk's GeEN PANIEK [No PANIC] (1973). In this film, the ex-convict Johnny is looking for clothing suitable for his job as a handyman. The 
effeminate salesman asks him to visualize his kind of work so he can properly advise him. Describing his activities as a plumber who visits a woman with a 'blockage,' John shows that he first goes down on his knees 'to get at her sink.' Subsequently, he lies on his back in the clothing store, meanwhile making pulling gestures, because of 'all the hairs and the dirt' and finally, he says he gets mud all over himself. Another scene in GEEN PANIEK is at least as suggestive. Tante Toetje, who runs a brothel, has a telephone conversation with the American businessman Bill Silkstocking, a role played by Eddie Constantine, an actor who by that time had also worked with Jean-Luc Godard in ALPHAVILLE (1965) and Rainer Werner Fassbinder in WARNUNG VOR EINER HEILIGEN NUTTE [BEWARE OF A HOLY WHORE] (1971). Bill has told Toetje that he is stuck in the Okura hotel and her reply, which is the more hilarious, because of her poor English: 'What do you mean, you cannot cum? You always cum when you are in Amsterdam; you are one of the quickest cummers I know überhaupt.'

4 This joke with De Gier and his cat is repeated in the film's successor, DE RATEL-

5 Similarly, WAT ZIEN IK?! features the utterly naive character Bob, who is from a bourgeois background. He is getting married to the ex-prostitute Nel, but he is kept unaware of her former occupation and hence does not know that the wedding party is attended by her ex-colleagues.

6 The choice for Buñuel as a figure of comparison is deliberate, for he made LE JOURNAL D'UNE FEMME DE CHAMBRE [DIARY OF A CHAMBERMAID] (1964).

7 Of all the clients, the 'chambermaid' will be the only one who has a second scene, at the very end of the film. Greet has just waved goodbye to Nel, the bride, and her groom and all the wedding guests, but her own place has been turned into a total mess. At that moment the bell rings and the guy climbs the stairs, asking her whether his presence is inconvenient. She is about to sigh, but when he sees the 'fabulous disorder' he is delighted with joy, presuming that she has done this for him. 'Madame, am I permitted to clean up all of this?' whereupon her face changes expression. She replies: 'All of it' and the joyful music sets in again. The movie ends with a 'What are I seeing?! Dust. Dirty, filthy girl.'

8 Apparently the scriptwriter has seen IRMA LA DOUCE (Billy Wilder, 1963), in which police agent Nestor gets extremely jealous at the impotent Lord X, forgetting that he had created the type himself.

9 The point of departure for SCHATJEs! was more or less autobiographical, as Van Hemert admitted (56). In his confessional book De Bruut, he is sarcastic about practically anyone in the film industry, including his father, Willy van Hemert. When watching his father approach his actors in his usual passionate manner, the son could only think that he would do it differently (17). His father had only wanted to pay for his study at the Film Academy if he were to become a television cameraman, but pig-headed as the son was, he chose scriptwriting instead (18). 
Willy van Hemert's most successful series were DE KLEINE WAARHEID [LITTLE WHITE LIE] (1970-1972), BARTJE (1972-1973) and DAGBOEK VAN EEN HERDERSHOND [DIARY OF A SHEPHERD DOG] (1978-1980). He made one film only, but that happened to be the very first Dutch feature in colour, JENNY (1958), which is mentioned in chapter 4 .

10 The words 'the army arrives' have to be put in perspective. Director Ruud van Hemert would have liked to have a large number of troops on the set, but due to a restricted budget, he only had a handful of soldiers in a jeep. That is filmmaking in the Netherlands, Van Hemert complained. You can only dream of the film you would have liked to make.

11 Some of the slasher milestones are HALLOWEEN (John Carpenter, 1978) and its many sequels, or the 'high slasher,' THE SILENCE OF THE LAMBS (Jonathan Demme, 1991); the manifestation of the devil within a female body can be seen as a reaction to the doubts that men feel about their religion, like Father Karras in 338 THE ExORCIST (William Friedkin, 1973).

12 The plot of FLODDER is reminiscent of the popular American sitcom THE BEVERLY HILLBILLIES, broadcast between 1962 and 1972, about a backwoods family which goes from rags to riches when they are transplanted to the affluent Beverly Hills, after the discovery of oil on their land.

13 The need for booze is underscored by the fact that the dog is called 'Whisky.'

14 This principle can also cover the humour of the aforementioned André van Duin, known for his madcap facial expressions, which he also used for his comic character, an ape called Jaap Aap.

15 In films like Animal House (John Landis, 1978), Porky's and AMERICAN Pie, the male adolescents do not aim to establish a romantic relationship but to get bodily satisfaction. The biggest fear for the high-school boys in AMERICAN PIE is that they would enter college as virgins (Desser, 59).

16 Carroll has a problem with this amoral version of humour, and his criticism really holds water. The amoralist overlooks any notion of context, and disregards who is telling the joke and for what reason. The joke about a financially savvy rabbi told by one Jew to another Jew is not the same joke as when it is recited by a skinhead 'with transparent malice' (89).

17 Carroll makes this remark about the 'nearly Neanderthal' in reference to Al Bundy from the American sitcom MARRIED WITH CHILDREN that aired for 11 seasons, from 1987 to 1997, and to Homer Simpson from THE SiMPSONs, an American adult animated sitcom since 1989 .

18 Some of the other cameo appearances are by people who exert a specific nostalgic fascination. Paul Elstak was a DJ producer whose claim to fame were the happy hardcore hits in the mid-1990s. There is a very brief appearance of the actor Antonie Kamerling in his very last role, but he is dressed as 'Peter Kelder,' the character he played in more than 600 episodes of the long-lasting soap GoEDE 
TIJDEN, SLECHTE TIJDEN in the years 1990 to 1993 as well as a brief comeback in 1995.

19 FILMPJE! should be vulgar, but, for commercial reasons, not too vulgar, so that it could still be rated for 12 years old and up. A test audience could help the makers to find a balance. De Leeuw, who played the double role of both Annie and Bob, had built himself a reputation on national television of behaving like the rascal who likes to play some ding dong ditch. He liked to shock the audience, but modestly, for the sympathy of the public should not be lost. The fame of the characters apparently sufficed as paramount compensation for the absence of a solid story, since the film fared quite well at the box office.

After Annie and Bob have been in court to settle for a divorce, she gives him two plane tickets in the hope that he will go with her, but he chooses the daughter of a gangster boss. This criminal has plans to kill Bob, for he is not his preferred son-in-law. Meanwhile, a lobster, containing cocaine, lands accidently on Annie's head and she will be pursued by a gangster. Annie and Bob will end up at the very same sunny island.

21 A pun: 'de rookworst van Oss' sounds a bit like 'De tovenaar van Oz' (the Wizard of $\mathrm{Oz})$.

22 Kuipers' idea is confirmed by writer Arnon Grunberg who in his daily column on the front page of de Volkskrant on 6 March 2015 writes that class is the big taboo in the Netherlands. If one wants to make Holland a less segregated country, Grunberg argues, citizens have to learn how to interact with people from another class. That is to say, one has to get used to the idea that the cultural other - the Antillian, the Muslim - is not necessarily on a lower rung of the social ladder.

\section{CHAPTER 2}

1 Terstall had already made a comedy about a right-wing politician in the mid1990s, in a decade preceding the rise of Pim Fortuyn. His WaLHALLA was not successful, however.

2 This privileging of the right-wing characters has an analogy with the gangster from the early 1930s, like LitTle CAeSAR (Mervyn LeRoy, 1931), Public ENEMY (William Wellman, 1931) and SCARFACE (Howard Hawks, 1932). Even though the criminal had to die a violent death to discourage his behaviour, it was his performance which made the films so hugely enjoyable, since the upright characters were usually quite boring.

3 The household at Rowanda's place is noisy, with boys playing the PlayStation; they eat in front of the television set, even when they have guests; and their meals do not have a particular name, but are simply called 'rice with chicken and vegetables.' Moreover, at night clubs all black women move their body in a sexy way 
and it takes little effort to persuade them to engage in a quick sexual encounter. Black men are portrayed as lustful, figuring out the best strategies to have the most female lovers simultaneously. Similarly, the white, upper-class culture of the 'Old South' is also portrayed in a stereotypical fashion, which to some extent parallels the banal depiction of De Bijlmer. Since all the scenes in the Old South are shown from the scornful perspective of David, the strict etiquette comes across as stiffening and silly. If he does not give in to the wishes of his parents, his father is so angry that he expels him from his home. When he takes his parents to De Bijlmer to meet with Rowanda's family, his father acts clumsily and later complains hypocritically about not being served the expensive drinks he brought with him.

4 Kaaskop (literally: 'cheese head') a derisive word for Caucasian Dutch people.

5 Being bothered about time is not in the way of the Moroccans, which is also the climax of the film. Abus has a job as a train conductor, but since he was dozing off as he was having a lunch break, he and his friends miss their train.

6 George Sluizer's psychological thriller SpOoRLOOs (1988), one of the scariest movies ever made according to Stanley Kubrick, has near the end elements of the road movie, when the Frenchman who had kidnapped Saskia a couple of years before, drives her boyfriend Rex from the Netherlands to France to reveal to him what he, Raymond, had done to her.

7 The opening film of NFF 2015 was J. KeSSELS (Erik de Bruyn, 2015), a road movie with, as the writer-protagonist P.F. ('Franske') Thomése himself admits, many 'disruptive plot twists'. This pulp novelist makes a car trip with his favourite character, the chain smoker J. Kessels who is a lover of country music and always wears a Willem II football club shirt. Travelling in Kessels' old Chrysler Kamikaze, they are asked to find a meatball seller, who happens to be a supporter of NAC Breda, the big rival of Willem II. This Perry with an eyepatch has run off to Sankt Pauli and in the stadium of this cult football team from Germany, they spot him amidst bare-breasted women. Writer Thomése experiences several hallucinatory scenes during a visit to the red-light district of Hamburg, mainly because he is still infatuated with a blonde girl he knew as a teenager. His main reason for making the trip is that he hopes to meet her once again, some thirty years after a traumatic event at a pinball machine. Absurd as this may sound, the film also has a subplot about a corpse in the coffin of the Chrysler (or 'hrysler', because the $\mathrm{C}$ is missing). Not all critics were positive about this film, but some who were (mildly) enthusiastic mentioned that J. KESSELS reminded them of FEAR AND LOATHING IN LAS VeGAS (Terry Gilliam, 1998).

8 When a Muslim truck driver is doing his prayers with Dunya, Desie stands behind them, slightly mocking them by reciting 'I can feel the spirit,' with her hands in the air. 
9 IN VOOR- EN TEGENSPOED was based upon the BBC series IN SICKNESS AND IN HEALTH, which started in 1985. It was written by Johnny Speight, who also invented TILL DEATH Do Us PART, the source of inspiration for ALL IN THE FAMILY.

\section{CHAPTER 3}

1 Because of the success of STERREN STRALEN OVERAL, Rutten was considered an excellent choice to make a film with the comedian Wim Sonneveld, which was meant to exploit the latter's huge popularity. Sonneveld had created the figure of Willem Parel, an organ grinder who spoke with a heavy Amsterdam accent, for the weekly radio programme SноwвоAт. For no less than two years, this figure had delivered 10-minute monologues which had attracted millions of listeners. In Rutten's film HET WONDERLIJKE LEVEN VAN WILLEM PAREL [THE WONDERFUL LIFE OF WILLEM PAREL] (1955), Sonneveld plays a stage personality who mentions in an opening voice-over that he has 'cut the knot' (we see an axe cut a knot in a rope): Parel should disappear, for this creation has come to overshadow his own fame. He guesses that this decision will not make the world turn 'upside down' (we see the city topsy-turvy for a few seconds), but when he is sitting in his dressing room and throws a toy organ against the poster of Parel, he sees in the mirror that the character fades from the image. Parel has come alive and will undertake many actions for which Sonneveld will be held responsible (he has, among others, to pay for the ordering of 173 glasses of beer). Rutten's film turns into a loose string of sketches and songs - with one classic, the so-called 'Poen-lied' ['Money Song,' or rather 'Shekels Song'] - and after Parel has returned to the poster at last, a film producer enthusiastically proposes to make a film with Sonneveld. The latter then suggests the idea to make a film about Parel, stepping down from the poster, which is greeted by the producer-in-the-film as a brilliant idea. 'And this,' as the voice-over says quite redundantly, 'is the film you have seen.' Film critics, however, were not so much taken by the actual execution of the film, and considered HET WONDERLIJKE LEVEN VAN WILLEM PAREL as an unbalanced collection of sketches. Thirty years later, Woody Allen was to make THE PURPLE ROSE OF CAIRO (1985), which has a similar starting point - a character stepping from the silver screen, forcing the actor to come into action - but Allen's script was more cohesive. Dittrich also favourably mentions DOoD WATER (Gerard Rutten, 1934) and PYGMALION (Ludwig Berger, 1937).

3 In her analysis of KOMEDIE OM GELD, Ansje van Beusekom mentions that the first part of the film features 'mostly realistic sequences, shot on location in Amsterdam.' In the second part, Ophüls employs 'a subtle expressionistic approach to the modernist architecture and designs, magnifying the impact of the trappings of wealth' (66). 
4 The close comparison between people and animals will be a building block for another of Haanstra's projects, the documentary BIJ DE BEESTEN AF [INSTINCT FOR SURVIVAL] (1972).

5 Another possible reason for FANFARE's lack of success abroad was suggested to Blokker by an American who asked him whether everyone in Holland had ugly faces, and, as Blokker had to admit, only Andrea Domburg could be considered kind of attractive in Haanstra's film (Hendriks, 85-86).

6 For Ealing Studios, Mackendrick directed five films, WHISKY GALORE! (1949), THE MAN IN THE White Suit (1951), Mandy (1952), The Maggie (1954), and The LADYKILLERS (1955), the latter remade by the Coen brothers in 2004. Another of his well-known films is the splendid SwEET SMELL OF SuCCESS (1957), with Burt Lancaster and Tony Curtis.

7 DORP AAN DE RIVIER can also be qualified as a 'Carl-Theodor Dreyer light,' especially considering the scene when Van Taeke orders his children to bid farewell to

342 their mother in her coffin, which is visually reminiscent of Dreyer's ORDET [THE WORD] (1955).

8 According to Dutch standards, DORP AAN DE RIVIER was a frankly daring picture, but perhaps too daring and slightly complex and fragmentary. Pressured by critics who complained that the film consisted mainly of anecdotes and lacked a tight structure, a voice-over by Deaf Cis was inserted. Reluctantly, Claus wrote this text, which he considered as a poor substitute to compensate for the removal of the scene with the farmer.

9 Jan Blokker himself also points at the influence of Lili Veenman, Rademakers' assistant and his wife to be.

10 By the way, the official English title of the film, THAT Joyous Eve, is a translation of the beginning of the third line of the song, 'Het heerlijk avondje ....'

11 Would it be possible to consider the tango scene between the main protagonist, Erik, and his friend, Alex, who has chosen the side of the German enemy in SoLDAAT VAN ORANJE [SOLDIER OF ORANGE] (Paul Verhoeven, 1977) as a visual quote from this tango in MAKKERS STAAKT UW WILD GERAAS?

12 There is another couple with marital problems in the film. Leo Wiegman is a civil servant who has organized the evening to show himself off for the eyes of the local community. At one point, his wife, initially absent, arrives and he is visibly annoyed to be seen in her company. His attempts to avoid her, of course, has a counterproductive effect, and only adds embarrassment to his irritation.

13 'Nooit was ik zo verliefd. Ik sprak je naam duizendmaal. (Nel, Nel, Nel). Nooit was er een ander. Je was mijn ideaal.'

14 Another reason for the impression of authenticity made by EEN ZWOELE ZOMERAVOND is that the actors often used autobiographical experiences in their performances. The play (1978-1979) which was the basis for the 1982 film was inspired 
by the marital problems between actors Helmert Woudenberg and Marja Kok. The latter had been responsible for the script (Van Schayk, 138).

15 Some other films which are a mixture of theatrical affinity and formal cinematic means might be ZUS \& Zo [LIKE THIS, LIKE THAT] (Paula van der Oest, 2001, nominated for an Academy Award as Best Foreign Language Film), inspired by Chekhov's play Three Sisters and the debut feature of Nanouk Leopold, ÎLES FLOTTANTES [French for 'Floating Islands,' but also the name for a dessert, meringue with warm vanilla sauce] (2001). Actors with a background in theatre, like Jacob Derwig, Halina Reijn, Sylvia Poorta, Maria Kraakman, Manja Topper, Anneke Blok and Theu Boermans, play the main parts. Both films take an ironic stance towards modern (family) relationships. ÎLES FLOTTANTES ends with a formal repetition from an ironic contrast in the film's beginning. The camera steadily pans from left to right, showing the three girlfriends tanning themselves on a solarium, with the walls in-between signifying that they are not completely comfortable with each other. In a next shot, the three are frontally staged before a mirror, discussing their love affairs and checking out who has the darkest tan. This is a remarkable study for several reasons. Cavell was trained as a philosopher and started writing about cinema in a period when film was not taken very seriously as an object of study, certainly not for men of his academic reputation. Moreover, he did not examine so-called (European) art cinema, as scholars might be supposed to do at that time, but instead was an enthusiastic student of pictures made in the first Golden Age of Hollywood. In his opinion, these films do not just offer escapist material, but provide food for philosophical thought as well: Frank Capra can be juxtaposed with Immanuel Kant. For Cavell, 'film exists in a state of philosophy' (13).

17 'Als men zegt dat ... Rademakers een filmer van scènes is, en niet van films, dan komt dat deels omdat Rademakers zich meer interesseert in wat er voor de camera gebeurt, dan wat er met de camera gebeurt. ... [H] ij schroomt niet zo'n scène wat langer te laten duren dan in het draaiboek was voorzien' (Bernink, 29).

According to the cultural critic and psychoanalytic philosopher Slavoj Žižek, the readiness to believe in things against our rational knowledge is ideology at its purist, which according to him is best proven by the case of the animated hit film Kung Fu PANDA (Mark Osborne and John Stevenson, 2008). 'The fat panda dreams of becoming a kung fu warrior. He is chosen by blind chance (beneath which lurks the hand of destiny, of course), to be the hero to save his city, and succeeds. But the film's pseudo-Oriental spiritualism is constantly undermined by a cynical humour. The surprise is that this continuous making fun of itself makes it no less spiritual: the film ultimately takes the butt of its endless jokes seriously. A well-known anecdote about Niels Bohr illustrates the same idea. Surprised at seeing a horseshoe above the door of Bohr's country house, a visiting scientist said he didn't believe that horseshoes kept evil spirits out of the house, to which 
Bohr answered: 'Neither do I; I have it there because I was told that it works just as well if one doesn't believe in it!' This is how ideology functions today: nobody takes democracy or justice seriously, we are all aware that they are corrupt, but we practise them anyway because we assume they work even if we don't believe in them' (Žižek, 'Berlusconi,' 6-7).

19 Internet Movie Database (IMDb) plot summary.

20 Gooische VRouwen (2005-2009) can be taken as a Dutch version of American television series like SEX IN THE CITY (1998-2004) and DESPERATE HoUSEWIVES (2004-2012). The series was developed by Linda de Mol, a popular television personality, who has also had her own magazine since 2003, simply called Linda. De Mol played Cheryl, but the most beloved character among viewers was Willemijn Lodewijckx, played by Annet Malherbe, Alex van Warmerdam's wife in real life. Malherbe left the show after two seasons, and does not feature in the film, either.

21 In both the opening and final scenes in Gooische VRouwen 2, we see that the 344 girlfriends have become elderly people who still want to keep up appearances.

22 Significantly, Nelly Frijda declined the offer to be cast as Martin's Aunt Greet, for it might be too much of a replay of her role as Ma Flodder. Now Beppie Melissen plays the aunt, who surpasses Martin in vulgarity. When Cheryl has been given the booby certificate, for example, she says in public: 'I have never had one, but I do not really need one. My breasts are still very perky. I still get compliments on a regular basis.'

23 It is quite vulgar to refer to 'dear Kitty' here, a phrase that is well-known in the Netherlands as the customary opening to the entries in Anne Frank's diary.

24 She herself mentions that she is every boy's wet dream' after she is locked up with Max, unzips his pants and says: 'I feel like sex at first sight.'

25 In HARTENSTRAat [HEART STREET] (Sanne Vogel, 2014) which owes a great deal to You've Got MAIL (Nora Ephron, 1998), Daan considers his neighbour Katje 'narcissistic' and annoying because of her obsession with fruit juice, almond milk and symmetry. Under a pseudonym, she wins his heart via the delightful texts she sends him via a dating site. When she makes herself known, he is angry because she killed his 'fantasy girl': he wanted a girl who thought Buster Keaton's face funny and tragic at the same time. But in the meantime she has started to like Buster Keaton and, she confesses, deep down she longs for a man who has a dirty stain on his shirt as a sign of imperfection. She wins him over when she helps his daughter at a most crucial moment. He runs to her place, and then provides this warning: 'You have to know that I sing in my sleep. Eternal Flame from the Bangles, always the same refrain.' That, however, does not stop her. HARTENSTRAAT is one of a series of rom-coms made in the wake of the ALL IS ... films. Other titles are, the quite successful Soof (Antoinette Beumer, 2013), MANNENHARTEN [MEN IN THE CiTY] (Mark de Cloe, 2013), SMOORVERLIEFD [MADLY IN LOVE] (Hilde van Mieghem, 2013), TOSCAANSE BRUILOFT [TOSCAN WEDDING] (Johan Nijenhuis, 
2014), and PAK VAN MIJN HART [A LOAD OFF MY MIND] (Kees van Nieuwkerk, 2014).

26 In SUPERMAN II (Richard Lester, 1980), Lois Lane also discovers Superman's actual identity. Lester had replaced Richard Donner, the director of SUPERMAN (1978), who was fired by the producers. In 2006, Donner's version premiered after all. The tone of this cut was more serious than Lester's quite comical theatrical version. In Donner's later release, Lois Lane jumps out of the window of a building, betting that Superman will show up whenever Clark Kent is around. And, of course, the Man of Steel saves her in time.

27 This quote is from the poet Robert Frost, originally, but also quoted by Ten Hooven, 11.

28 KARAKTER won the Academy Award for Best Foreign Language Film, but in 1990 Van Diem had already won the Student Academy Award for his 45-minute ALASKA (1989).

\section{CHAPTER 4}

1 In the case of exaggeration, something is presented as 'bigger, greater, better or worse ... beyond its normal or due proportions.' Exaggeration can be split into two main categories: specific details might be exaggerated, such as a huge nose, or the entire frame might be rendered disproportionate (see Edwards and Graulund, 67).

2 One can also make a film about lovers of cult cinema, as Iván López Núñez did with My LifE ON PlANET B (2012), in the vein of a B-movie naturally. This film won the MovieSquad Award, a prize from the youth jury, at the Netherlands Film Festival.

3 ANDY, BLOED EN BLOND HAAR was actually selected for an 'Egzotik' evening during the Netherlands Film Festival in 2015.

4 Between Sontag's essay from 1964 and Sedgwick's study from 1990, shifts have unmistakably taken place in the use of the term 'camp.' A paramount influence was Vito Russo's study The Celluloid Closet from 1981, in which he searched for clues and suggestions of homosexuality in films. The way two cowboys value each other's gun in RED RIVER (Howard Hawks, 1948) can be read as a play on sexual innuendo. The way Messala, played by Stephen Boyd, looks at the title hero in BEN-Hur (William Wyler, 1959) speaks of homoerotic desire. An 'innocent' viewer may recognize nothing peculiar in such scenes, focused as he may be on the progression of the storyline, but the (gay) viewer with a camp sensitivity may detect references to the 'desire that dare not speak its name.'

5 Two of the series of SAD MOVIES were released in 1966. The 10-minute RAPE (1966) was about a man persecuting a nun in the woods. Of the actual rape we do 
not see anything, except some clothes flying through the air. TuLIPS only lasts for two and a half minutes. Except for the shot of a woman announcing the film, we have one shot of a vase of tulips on a credenza. The camera zooms in on the tulips, and we see a leaf fall off. BON APPETIT and SUMMER IN THE FIELDS are from 1967. The latter is briefly discussed in chapter 8 .

6 As a heterosexual man who believes that SHOwGIRLS is really a good film, Hunter has set himself the aim "to "straighten out" the camp interpretation and dismiss gay fans as delinquent misreaders' (478).

7 JA ZUSTER, NEE ZUSTER won the Audience Award for Best Feature at the International Lesbian and Gay Film Festival in San Francisco in 2003.

8 Actually, the young Floris uses the hippie catchphrase 'Johnson, molenaar.' Johnson was the US president in the 1960s, and the Dutch word 'molenaar,' meaning miller, sounds very much like 'moordenaar,' murderer. When the protesters called the president a 'murderer,' they risked a penalty, thus they opted for 'molenaar.'

346 | 9 For the sake of completeness, it has to mentioned that straightforward adventure stories were considered practically impossible in 2004, the year FLORIS was released. Soon hereafter, film heroes who had been parodied in the vein of Floris, like Batman and James Bond, were to be re-invented by completely starting 'anew' so that one could take them serious again. The title of Christopher Nolan's movie from 2005 says it all: BATMAN BEgINS; likewise CASINO ROYALE (2006) by Martin Campbell goes back to the days when James Bond still had to become James Bond.

10 Films like SPETTERS and All STARS, discussed in chapter 6, are exempted from the stereotype of the feminized male but offer the commonplace of the closeted gay instead. There are some more daring treatments of gay themes in Dutch cinema, like VOOR EEN VERLOREN SOLDAAT [FOR A LOST SOLDIER] (Roeland Kerbosch, 1992) and Jongens [Boys] (Mischa Kamp, 2014), but they fall outside the scope of this study about humour.

11 Deliberate camp movies from abroad such as the Australian PRISCILLA, QUEEN OF THE DESERT (Stephen Elliott, 1994), the Canadian LES AMOURS IMAGINAIRES [HeARTbEats] (Xavier Dolan, 2010) or the films by the Spanish Pedro Almodóvar have been very successful, but were released, at least in the Netherlands, in arthouse theatres, whereas all the Dutch titles mentioned, except for Ruven's DE TRANEN VAN MARIA MACHITA, in this chapter had a run in commercial cinemas.

\section{CHAPTER 5}

1 It has become a staple within porn that the woman longingly requests the man to come, often on her breasts or in her face. Thus the visibility is clearly motivated: he ejaculates outside her because the woman wants it that way (Aydemir, 110). 
2 A 'scandalous' impact can also be subject to displacement. In the early 1970 s the notorious anal scene featuring the use of butter in LAST TANGO IN PARIS (Bernardo Bertolucci, 1972) was much discussed because of its sexual content. Nowadays, it can still be considered controversial, but rather because the man's act is taken for a form of sexual abuse of the girl in the eyes of a present-day, more gender-conscious public.

3 Scorpio Films was a production company founded in 1965 by Pim de la Parra and Wim Verstappen, who were often referred to as 'Pim \& Wim.' Given the limited number of Dutch films at the time, they made clear that quantity should preside over quality: it is more important that one is filming than what exactly one is shooting. Their first (very) low-budget film, made in 1966, will be discussed in chapter 8. Verstappen directed, De la Parra produced, as was also the case with BLuE MoviE. At other productions, they interchanged their roles. FrANK \& EvA, also discussed in this chapter, was directed by De la Parra and produced by Verstappen. Unexpectedly, they made a lot of money with BLuE Movie, but Pim \& Wim parted ways due to a financial conflict. The shooting of Verstappen's DAкотA (1974) was troublesome and had annoyed De la Parra, because it was unnecessarily costly. The love affair between female star Monique van de Ven and director of photography Jan de Bont had, among other things, led to an unworkable situation, so that the latter had to be fired. In turn, De la Parra's deep-felt wish to shoot a picture in Surinam resulted in a project that went irresponsibly over budget, according to Verstappen. De la Parra's WAN PIPEL [ONE PeOPLE] was released in 1976, but Scorpio Films soon ceased to exist.

4 In 1965 Verstappen had already had a dispute with the Film Commission. A screening of Mattijn Seip's SCHERMERHOORN, which Verstappen had produced, had initially been forbidden, because of a presumed violation of morality. In the film, the protagonist, played by the popular singer Ramses Shaffy, was befriended to a minor, but despite paedophilic suggestions, there were no obscene acts. Banning the film was considered awkward, however, since the film had received an official subsidy. The Minister of Culture then decided, as a compromise, that SCHERMERHOORN could only be shown in private screenings without selling admission tickets (Den Drijver, 75-77).

5 The Ministry of Culture could not be of any assistance to the Film Commission because BLUE MOVIE had been produced with private money, without any official subsidy.

6 Because of its bleakness, TURKS FRUIT has more in common with the Italian/ French production LAST TANGO IN PARIS (Bernardo Bertolucci, 1972) than with the more sweet-toned American film LOVE STORY (Arthur Hiller, 1970).

7 Even though Curiël knew beforehand that it would be a hell of a job to make a film with Brood, who was a regular drug user and often showed up late, he dearly wanted to make this picture, because he regarded Brood as the embodiment of 
an 'anti-authoritarian' attitude. Since Brood lacked real acting discipline, many scenes had to be improvised on the spot. The film got an unfavourable reception, according to Curiël in a short documentary by Robbert Bianchi found among the extras of the DVD, because film critics thought of Brood as a macho who always got too much attention.

8 Brouwers gained a reputation as the character Sjef van Oekel in the anarchistic television programmes made by Wim T. Schippers, such as DE FRED HACHÉ SHOW and VAN OEKEL'S DISCOHOEK. All lines by Van Oekel were scripted, and no attempt was made to disguise the fact that he read his text aloud from a sheet of paper. In VAN OEKEL'S DISCOHOEK he was host to many musical artists, and especially the appearance of Donna Summer, singing 'The Hostage,' has become legendary.

9 Brood kept aloof from cinema, except for some occasional minor performances, as in ZusJE (discussed in chapter 7) or in the documentary ROCK 'N' ROLL JUNKIE 348 (Jan Eilander and Eugene van den Bos, 1994). Jean van de Velde's Wild RomANCE (2006), made five years after Brood's death, focuses upon the early years of his career, from 1974 to 1979 .

10 According to Van Gogh, the performance by Ariane Schluter, playing Sara, is 'un-Dutch' in its sensitivity, and on the commentary track of the DVD he said that he considered her achievement far superior to the social-realistic drama of Mrs. (Marieke) Heebink, main actress of the 'ridiculous' (Van Gogh's words) 1000 Rosen [1,000 Roses] (Theu Boermans, 1994).

11 In Van Gogh's INTERVIEW, the political journalist Pierre has to interview, to his utter frustration, the film star Katja. During the interview, which becomes a verbal battle, he tells her that she is all 'air, sawdust and silicone' inside. When she is on the phone, he secretly reads from her diary and asks why there is death everywhere. Katja is prepared to answer his question on condition that he tell her his deepest secret. He tapes her confession that she has cancer, and she tapes his revelation that he has staged a car accident, leading to his wife's death. After he has phoned his newspaper with the big news and left her house, she says from her balcony that the diary belonged to her girlfriend Ellen, and she adds to this that the police are on the way to arrest him.

12 Together with the Dutch crew, Buscemi launched a 10-point manifesto on the Sarajevo film festival in 2007 as a homage to Van Gogh, containing rules such as: Any film can be made for any budget; films have to be shot digitally; the success of a film is everyone's responsibility; the catering should always be excellent as good food improves the atmosphere and the motivation on a set.

13 In addition to Buscemi's version of INTERVIEW, BLIND DATE was remade by Stanley Tucci, also in 2007. The last film in the 'Triple Theo' project was SoMEWHERE Tonight (Michael Di Jiacomo, 2011), based upon Van Gogh's 06. 
14 Icarus is a character from Greek mythology who is a symbol of hubris. In the myth, Icarus' father, the inventor Daedalus, has constructed artificial wings made of feathers and wax. He warns Icarus not to fly too high, but his son ignores the warning and, approaching too near the sun, falls to his death when the sun's heat melts the wax keeping the wings together.

15 The hilarious speedboat race between inspector Eric Visser and the diver-perpetrator through the canals in AMSTERDAMNED is hugely enjoyable. At one point, Eric's chase is interrupted because a boat is going under the bridge at a very slow pace. The boat has a brass band on board playing the tune from FANFARE, with Bert Haanstra himself as conductor. The scene is not just an homage, but it also represents the 'progress' of Dutch cinema. Slow-paced provincialism has given way to fast action in the capital city. Moreover, what was incredibly popular in 1958 is now the cause of an annoying delay for the protagonist (and for us as well, since we want Eric to keep up with the suspect).

16 Some of the few films which have achieved to keep a balance between horror and comedy are Evil DeAD II (Sam Raimi, 1987), THE Frighteners (Peter Jackson, 1996), SHAUN OF THE DEAD (Edgar Wright, 2004). The oxymoronic qualification of the latter film as a 'zom-rom-com' - a zombie romantic comedy - suggests the delicateness of the enterprise.

17 The fact that the sceptic girl is the first one to die holds a parallel to the convention - found in slasher films like HALLOWEEN (John Carpenter, 1978) and its selfreflexive parody SCREAM (Wes Craven, 1996) - that the usual victims of the male killer are girls/women who flaunt their sexuality. Typically, as Carol Clover has argued in her study Men, Women, and Chainsaws, the woman who is able to rescue herself, the 'final girl,' is often a boyish woman, not fully feminine.

More than 25 years after its release, the then influential film critic Peter van Bueren emphasized the enduring vitality of TURKS FRUIT: 'Je ziet aan de kleding, auto's en het straatbeeld dat de film niet gisteren is gemaakt, maar de vitaliteit blijft. ... TURKS FRUIT heeft vaart en al die jonge aankomende regisseurs van nu kunnen een puntje zuigen aan de manier waarop Verhoeven het verhaal vertelt. Aards, fris, levenslustig, vlot, raak.'

\section{CHAPTER 6}

1 The Productiefonds voor de Nederlandse Film was founded in 1956 (see chapter 3 ), and it could grant subsidies to filmmakers on the basis of a (draft of the) scenario. In 1993 this Productiefonds fused with the Fonds voor de Nederlandse Film, in existence since 1983 , to the Nederlands Filmfonds.

2 Fientje is also the name of the girl who runs a snack bar in KERMIS IN DE REGEN [FAIR IN THE RAIN] (Kees Brusse, 1962). 
3 See Schoots VAn FANFARE tot SPETTERS for an adequate analysis of the controversies surrounding the films by Van Brakel, Sluizer, Zwartjes and Verhoeven.

4 Following upon Eef's 'Mine will not get erect when you are looking on,' Hans says: 'Me neither.' Eef: 'What do you mean?' Hans: 'One has to scratch open that pimple of yours before you take a piss.' Eef: 'My pimple is bigger than your lame willy.' This dialogue was the prelude to that aforementioned scene of the 'game' won by Hans.

5 This being part of a team is also at stake in VENTOUX (Nicole van Kilsdonk, 2015), which can be called 'ALL STARS on two-wheelers.' In the summer of 1982, five adolescent boys agreed to climb Mont Ventoux, known as 'Bald Mountain,' although one decides to exchange his bicycle for a small van. One of them tragically dies because he takes too many risks during the descent. Thirty years later, the four remaining friends, middle-aged by now, return to the mountain to commemorate the unfortunate accident. They have changed, but the tone of jokes has not: 'David, shave your legs, you will go faster.'

6 Another 'comic' scene proves to the guys that women do not understand a man's sport like soccer. When Johnny and Hero are playing the game of who can mention the largest number of unsuccessful forward players at Feyenoord (Mike Obiku, Dave Mitchell, Clyde Best ...), Claire also gives it a try but mentions the hockey player Floris-Jan Bovelander. When the two boys laugh at her suggestion, she asks 'What's wrong with hockey?' which in their opinion is further evidence that women and soccer is an unfortunate combination.

7 After they have played their $5^{\mathbf{O O}^{\text {th }}}$ game, they decide to play one game a year, a so-called Swift Boys 8 memorial day on the first Sunday in April. During the end credits, however, each and every player leaves a message at Bram's answering machine to excuse their participation.

8 Sjors \& Sjimmie [George \& Jimmy] is a Dutch adaptation of the American newspaper comic strip Winnie Winkle. Frans Piët's comic strip, which began in 1938, chronicles the adventures of Sjors, a blonde boy, and Sjimmie, his thick-lipped and not so bright black friend. The strip became hugely popular, and when Piët stopped drawing the strip in 1968 , the series was continued by a variety of other artists, including Jan Kruis, Jan Steeman and Robert van der Kroft.

9 The idea of the feminized gay male is also activated by Camiel himself, when his boyfriend takes a huge suitcase for a trip: 'Joan Collins takes less luggage when she emigrates.'

10 I would like to entertain the hypothesis of a political analysis of SIMON. Is it a coincidence that the year 1988 was chosen as the first phase of the friendship between Camiel and Simon? Everything seems idyllic, and they celebrate the victory of the Dutch football team, whose captain is the 'Black Tulip' Ruud Gullit. In that period, the idea of a happy melting pot was still vibrant. By 2002, quite a number of voices were proclaiming the multicultural society had become a fail- 
ure, and as a result Netherlands had become a less tolerant country. According to such a reading, Simon's illness can be aligned with an atmosphere of xenophobia. At the same time, such an analysis is too simplistic. For Camiel and Simon are reunited in the Fortuyn era, and their friendship becomes even more intense due to the illness. Moreover, their 'impossible' chemistry has an analogy in the popularity the homosexual dandy Fortuyn enjoyed with the common people who, like Simon, tend to speak their opinions frankly. Marco is played by Daan Ekkel. The death at a brain tumour of his twin brother Willem in 2002 at the age of 36 inspired Terstall to make SiMON.

12 During a birthday party, Anita is being interrogated by Hannie: 'Where did you use to work?' 'On the Keileweg' [before 2005 Keileweg was a well-known red light area in Rotterdam]. 'At a company, or ...?' 'Yeah, sort of a company. But I also acted in some movies.' 'Oh, lovely.' 'Well, it wasn't really about love. The pay was all right. It's all over and done with, though. I got pregnant, so they didn't want me anymore. Because then they can't get their fist in anymore.'

13 DE MARATHON was much appreciated by the public, for it won an Audience Award at the Netherlands film festival in a year when the competition was tough.

14 In turn, one might say that WONDERBROEDERS [MIRACLE BROTHERS] (Johan Timmers, 2014) is the 'slimmed-down version' of DE MARATHON. Like Koopal's film, the script was by Martin van Waardenberg. This time it was about five friars in a convent who are told they have to move because their place will be turned into a wellness centre. WONDERBROEDERS was not received as favourably as DE MARATHON, for basically two reasons. First, since the lives of monks are quite slow-paced, the rhythm of the film is likewise, and consequently WONDERBROEDERS lacks the quick-wittedness of DE MARATHON. Second, and even more important, the 'feel good' humour in Koopal's film was derived from the fact that the men had to perform better than one could imagine, whereas the friars in Timmers' film are revealed to possess all-too-human vices, especially when a young sister shows up.

15 The police inspector who investigates the crime committed by Max' boss tells him that it was an historical inevitability that the video store went bankrupt: 'Who still rents movies at a video store? I download them. Why pay for something you can get for free online. Right?'

16 According to James MacDowell a distinctive feature of the 'quirky' is its tone. 'The common mixture of comic registers means we can simultaneously ... laugh at its flat treatment of melodramatic situations and still be invited to be moved by character's misadventures. Its aesthetic can both seem self-conscious and promote an appreciation of nä̈veté' (10).

17 ClOACA (Willem van de Sande Bakhuyzen, 2003), originally based upon a theatrical play written by Maria Goos, is a drama rather than a comedy, because one of the four long-time friends who all face a midlife crisis decides not to support the 
quite reclusive Pieter who has gotten into the orbit of a scandal. In the end, Joep backs off because he does not want to jeopardize his political career for helping Pieter. His fear of bad press can be summed up in his cowardly phrase: 'A homo is one thing, but an embezzling homo is another thing.' At the same time, Joep provides the film's best comic moments, for he keeps trotting on about all the details that annoyed him in his failed marriage. Even when he is taking a shower, he does not remain silent: 'Sometimes I need a pump. I must have bought at least six bicycle pumps over the last 20 years. But I can never find one when I need it. What does she do with them?' Or, when the theatre director Maarten reveals that Joep's daughter Laura is performing in his upcoming play, Joep guesses correctly that she will appear naked. 'Make her wear a dress,' Joep asks in the company of the other two friends, but Maarten replies: 'That is not possible. In my concept.' Angry by the prospect of Laura's nudity, Joep no longer holds back, explaining that the plays bore his friends to death: 'We have four double espressos before we 352 go to your shows. That's a total of 24 espressos. And yet an hour later, Tom is napping on Pieter's shoulder.'

\section{CHAPTER 7}

1 Let me emphasize that it can include seriousness, which means that it does not necessarily do so. A film like DE ZAAK M.P. [THE M.P. CASE] (Bert Haansta, 1960) is a farce about a young man, Kamiel, who is considered by his father-in-law, Philidoor, as only a 'slipper hero.' He steals the statue of Manneken Pis, the 'first citizen' of Brussels, and then stages the recovery of the small monument so that he is hailed as a true hero. Thus he gains his father-in-law's respect. In the meantime, Philidoor, presuming that Dutch football supporters have stolen the statue, has a role in the disappearance of the statue of Hans Brinker to pay the Dutch their due. In turn, Kamiel is also responsible for the recovery of Hans Brinker. If this all sounds jolly, it indeed is devoid of seriousness. And unlike absurdism, it is too complacent to have any potential to disorient the viewer.

2 Stelling approached cabaret performer Freek de Jonge after he had seen his first solo show De komiek [The Comedian], but De Jonge suggested that his second show, De tragiek [The Tragedy], was more apt for an adaptation. And so they set it up, although eventually DE ILLUSIONIST would turn into a sequel to De tragiek.

3 De Jonge himself apparently also thought that DE ILLUSIONIST was his and not Stelling's picture. This misconception resulted into a difficult shooting and editing process. This led to the hilarious situation that when DE ILLUSIONIST was awarded the Golden Calf, De Jonge decided to refuse the prize without consulting Stelling who, of all people, had been the initiator of what then was called De Nederlandse Filmdagen. 
4 As Stelling said in the interview on cinema.nl: 'Met humor pomp je er lucht in.'

5 His second-best achievement in the category of tragic films with comic interludes would be DUSKA (2007), about the film critic Bob who is visited by Duska, a Russian film geek he met at a film festival. Since Bob is hoping to date a cashier at a theatre, the arrival of a foreign guest with whom he cannot communicate is most inconvenient. He undertakes a number of attempts to get rid of the visitor, but time and again Duska returns to Bob's place.

6 As Stelling correctly observed in the interview with cinema.nl: for him, Jim van der Woude, who played the pointsman, was not an actor performing actions; he restricted himself to filming Van der Woude's face, his appearance.

7 Bozz posts an ad that promises a free coffee when you fill up your car, but gets angry when the man in the wheelchair wants to make use of the offer as well. Bozz and Boy start outbidding each other, and initially Bozz seems set to win the public's favour. Later, it becomes very crowded at his neighbour's place after Boy has discovered a huge billboard that offers a full tank with a 'full service' [een grote beurt] and a more-than-life-sized picture of Bozz's attractive daughter, Gal.

8 Seunke became the director of the Jakarta International Film Festival in 2003 and is affiliated with the Film Academy in the capital of Indonesia.

9 Westdijk's second film, SIBERIA (1998), which was made three years later, seems the opposite of ZuSJE, for the two male protagonist take life very lightly. Unscrupulously, they seduce female tourists, rob them after having sex with them and tear the photographs from their passports as proof of their conquests. Life is little more than a bet for them. Their hollowness is underscored by 'hollow' cinematography: fast cutting, high angles, slow-motion scenes, time-lapse photography, random black-and-white inserts, and a hip soundtrack by Junkie XL. Although things change when one of them becomes besotted with Lara, who claims she is from Siberia, the cinematography remains as pompous as ever. SIBERIA never becomes a true drama, nor, by the way, a true comedy - it is 'just zip-zip,' according to 'groggo' on IMDb.

10 Ever since OH Boy! and ZusJe, a number of Dutch films exploring the thin line between film and real life have been released. To give a selection of titles: In FLIRT (Jaap van Eyck, 2005), Kim is about to make a documentary on extramarital affairs, although her aim is to argue that polygamy is outdated. In LEF [GUTS] (Ron Termaat, 1999), Olivier is writing a script for his friend Luc, but he is fantasizing about himself as Alain Delon in the main role, although he has to admit that he is more like Buster Keaton. In NEw KIDS TURBo (2010), producer Reinout Oerlemans has run out of money, so the New Kids are invited into the studio to tell how their film would have progressed. Then, all of a sudden, Oerlemans has money to spend after all, and the film continues where it had more or less left off. In DE BOEKVERFILMING [BASED ON THE NOVEL] (Eddy Terstall, 1999), a young aspiring director, known for an experimental film with small pigs, is assigned 
to adapt a book by a Jewish writer. He has selected three dark-haired actresses as possible candidates for the lead part, and uses every opportunity to contact them. He tells one of them: 'If you have had a fling with an actress, you can photograph her more beautifully.' In the end, he is so severely beaten up by the former boyfriend of the girl he has chosen, that the director has to be replaced by Mike van Diem, one of the real-life filmmakers who has a cameo appearance in DE BOEKVERFILMING.

11 The rehearsal scenes are especially humorous; an actor is cutting the cucumber with too much flair, according to Martin's taste. It leads to a lengthy discussion between actor and director, and despite Martin's 'try less,' the actor is simply too eager to turn it into something special. It drives Martin crazy: 'Make him normal. The film is called REAL LIFE for a reason.'

12 HeT ECHTE LEVEN lasts 84 minutes, but on the DVD, there is a 57 -minute version of the film by 'Martin Zomer,' in which all the 'rest scenes' have been deleted, 354 like 'superfluous' rehearsals and the failed takes. Without the 'rest scenes,' the film looks very shallow, and thus all the seemingly irrelevant inserts constitute the strength of Westdijk's final product. Moreover, his film won the Golden Calf for Best Direction and another for Best Montage. These Golden Calf awards were well-deserved, for the sudden transitions in (the status of) scenes near the end are arguably the best part of HET ECHTE LEVEN.

13 Michel Vermey who was cast as the disabled son, only played in two Flemish television series after MET GROTE BLIJDSCHAP, which was his debut. In one of the series, he played a handicapped rocker.

14 In an earlier scene, his sister was modelling for Alfred. She then proposes to give him money so he can take Moniek to Mexico to spice up their relationship. His sister's only request: 'Paint my belly smaller as thanks.'

15 RENT A FRIEND is subtitled a 'romantic comedy about money,' which is an ironic inverse of the regular romantic comedy, for one of its lessons is that one should never follow the 'cold path' of money, but always one's heart.

16 When his girlfriend, Moniek, suggests that no one wears sombreros in Mexico anymore, Alfred answers that it is his artistic licence.

17 Moniek stares intensely at a painting and then guesses: 'A Mexican skiing?' 'No, a Mexican walking the railway tracks.' 'But railway tracks have sleepers.' 'But I hadn't finished.'

18 Another indication of the 'weakness' of laughter: it is an involuntary spasm, for the muscles of one's face 'suddenly begin playing like a clock at midday or a jackin-the-box' (Hannoosh, 29)

19 The comic does not reside in the act, for then the clumsy person would also laugh himself, and he usually does not. Thus, the comic is an attribute of the laughing subject; it is a consequence of being a witness to the act (Hannoosh, 32). 
Of a number of overhead shots in SuzY Q (Martin Koolhoven, 1999), the most remarkable one is near the end, when the teenager Suzy lifts her head and looks upstairs, straight into the camera, as if addressing some deity for help. There is much reason to ask for help, since there is little to enjoy in her life as the youngest of three children in a dysfunctional family. Her father feels himself a 'joker' because he is out of a job, and since he thinks his wife has stopped loving him he mistreats his one daughter because she refuses his request for tenderness. According to her mother, as she tells the oldest son, Zwier, Suzy has obviously provoked her husband. The one joy Suzy has is her meeting with - the film is set in the 1960s - a young Mick Jagger and Marianne Faithfull in their hotel room, but all family members disqualify this adventure as a silly fantasy. The worst thing is yet to happen: after Zwier's pet rat, Victor, has been caught in a mousetrap - also shown in a shot from above - Suzy's oldest brother beheads her pet turtle and he then serves the family turtle soup. In another overhead shot, a bit later, we see Zwier lying dead in the bathtub with red-coloured water. Suzy walks outside onto her balcony and hanging over the banisters she looks upstairs. For a brief moment we think she might be addressing God, but in the next shot it is revealed that the girl of the family living above her is hanging over the banisters as well, watching Suzy, so that the overhead shot turned out to be her point-of-view shot. In another overhead shot we see that Suzy bends her head. While her facial expression is sad, then, quite ironically, the song 'Happy Together' by The Turtles (!) starts playing.

21 Originally, AANMODDERFAKKER was made as a TV movie to be broadcast in 2015, but it got a theatrical release as well. This release was slightly advanced to profit from the positive publicity the film had at the Netherlands Film Festival where it won three Golden Calf awards in October 2014, for Best Film, Best Actor, and Best Screenplay.

22 In the week AANMODDERFAKKER premiered, EEN VLUCHT REGENWULPEN [A FLIGHT OF RAINBIRDS] (Ate de Jong, 1981) was re-released in a restored copy, another film about a socially immature protagonist. Maarten is a 34-year-old biologist who is socially inept and too shy to talk to women. Though he wants to avoid encounters with women, he knows he has to overcome his reluctance due to a nightmare in which he hears God's voice, which tells him that if he does not sleep with a woman with the aim of procreation within seven days, he will die. The many differences notwithstanding, like the fact that Maarten at least has some professional ambitions, EEN VLUCHT REGENWULPEN can to some extent be taken as a precursor to AANMODDERFAKKER, but one in which the protagonist struggles with the sense of sin that marks religious fervour. Maarten will only succeed in losing his virginity after his mother, whom he worshipped ever since his childhood (as we gather from a series of flashbacks), has passed away, and after he has come to realize that Christianity is 'all deceit.' When the woman asks after coitus 
what it felt like, he answers: 'I thought I was on the verge of dying.' This final line in EEN VLUCHT REGENWULPEN is ironic, for two reasons: first, even though having sex was the sole solution to escape God's death sentence, Maarten's experience of it made him feel that he was about to die, and, second, because an orgasm is often called the 'little death,' and for Maarten this association is not taken metaphorically but literally.

23 Since Tommy has the ambition to become the new floor manager, he decreases his number of smoking breaks. At the same time, he suggests removing THE BREAKFAST Club (John Hughes, 1985) from the store, a 'classic from the eighties,' according to Thijs, which proves to the latter that Tommy has become a 'commercial rat.'

24 The one time we see Thijs prepare a meal, he wears a pair of goggles while cutting onions.

25 NRC critic Coen van Zwol was not too enthusiastic about AANMODDERFAKKER 356 because the film plays too self-consciously with the conventions of romantic comedies. Thus, he argues, the viewer has no anchor to identify with the protagonist. Fortunately, Thijs is too late for Lisa, for, as Van Zwol claims, one is constantly thinking: she deserves a much better guy than one who lacks sincere motivation to do practically anything.

26 The cyclical nature of Thijs' life is also subtly hinted at via the reproduction of M.C. Escher's lithograph print Relativity (1953) on the door of his bedroom in his parents' home. The seven stairways in this spatial structure are connected so that character can walk them in an infinite loop.

\section{CHAPTER 8}

1 The spelling of Daalder's first name is not an easy matter, since it changed over the years. In the beginning of his career it was 'Renee' (as found in the credits of his MASSACRE AT CENTRAL High from 1976), though his official name seems to be 'René.' Now he tends to use 'Rene,' e.g., on his website http://projects. renedaalder.com/Biography-Contact.

2 Jan Vrijman made a short on Karel Appel in 1962; Johan van der Keuken made shorts on Lucebert in 1962 and 1967, and scripts by Campert were adapted to the screen, like EEn zondag [A Sunday] (Van der Keuken, 1960), HELDEN IN EEN SCHOMMELSTOEL [HEROES IN A ROCKING CHAIR] (1963) and HET GANGSTERMEISJE [THE GANGSTERGIRL] (1966), the latter two directed by Frans Weisz.

3 Under the pseudonym W. Limetree, Wim van der Linden was to make, together with Wim T. Schippers (as Bill Masters), one of the most absurd films in Dutch cinema history, the 12-minute short BON APPETIT (1967), the last in a series of four so-called SAD MoviEs (the first one had won the 'Golden Handkerchief,' 
according to the punning credits). This English-language, black-and-white film is wilfully sloppy: a bit slapstick-like, with a few unorthodox zoom shots; it has canned laughter, and the auditive track has brusque transitions, including some overly loud sounds, like bird whistling or the screeching of tyres, while the car drives slowly. Before a man enters a restaurant, he steps into dog shit. In the restaurant, he pushes some food from a plate with his coat; another man has his tie in the soup, another man's toupee falls into the soup terrine, and a piece of meat, visibly tied to a cord, flies through the air into the cleavage of a young lady. In the restaurant, the man orders the whole menu and starts eating it with boorish sounds. 'Hey, waiter, my plate is wet.' 'That is your soup, sir.' Near the end, the man collapses while he is eating a huge dessert. When the police arrive to take care of the victim, a voice-over reads aloud the text, printed on the screen: 'See in the next episode How Father Lost and Found His Hat.'

4 Provo was a counterculture movement, founded in 1965 in Amsterdam. Since Provo consisted of pacifists, its members did not use violence, but aimed to provoke the police by way of (ludic) humour. For example, they pretended to smoke marijuana in public, but they were really lighting up tea or herbs. When the police arrested them, they exposed the ignorance of the authorities on the subject of cannabis. Among their most famous actions was a protest against the upcoming wedding between the Crown Princess Beatrix and the German Claus von Amsberg employing pamphlets and a fake speech. On the day of the wedding some Provo members used smoke bombs to disturb the procession. For the Provos, anarchy was an inspirational source of resistance. The Provos also compiled a series of 'White Plans' to address problems in the city of Amsterdam, advocating changes such as replacing motorized vehicles with bikes, and they encouraged people to squat in empty buildings. Provo officially disbanded itself in May 1967.

5 Hans Tuynman was a member of Provo who had been imprisoned since 30 March 1966 for distributing pamphlets to promote a demonstration which had been banned by the mayor. He was released on 21 June 1966 .

6 This quote is taken from the description of Jeff Lebowski, aka the 'Dude,' by Cowboy Sam, the narrator from THE Big LEBOWSKI (Joel and Ethan Coen, 1998). In this film, the quote is hilarious because the Dude is described as if he is totally in tune with the year 1991, while he seems to have stepped straight from the 1960 s because of his hippie appearance and his fondness for the music of Creedence Clearwater Revival.

7 We will see that Manuel is meeting other women, too, so he apparently is only charming Ans for strategic reasons.

8 Terpstra's film was based upon a book by Heere Heeresma. Just as the writer Heeresma was never really in the league of the big authors, the adaptations of his work also float slightly beneath the radar. His Geef die mokeens door, Jet was the basis for НЕB MEDELIJ, JET! (Frans Weisz, 1975); four stories from Zwaarmoedige verhalen voor bij 
de centrale verwarming [Melancholy Tales] were adapted into the film of the same title (1975) by directors Bart van der Lecq, Guido Pieters, Ernie Damen and Nouchka van Brakel. Een dagje naar het strand was first made as the British film A DAY AT THE BEACH (Simon Hesera, 1972) and later by Theo van Gogh in 1984. Han de Wit gaat in ontwikkelingshulp was adapted into HAN DE WIT (Joost Ranzijn, 1990).

9 In TEOREma (Pier Paolo Pasolini, 1968), the famous 'intruder' film made one year after DE VERLOEDERING VAN DE SWIEPS, the nameless guest not only 'takes' out of narcissistic pleasure (like Manuel did), but also has a 'radical gift' on offer for all household members. His gift of love injects their lives with new energy, Marc De Kesel claims, but once the guest has disappeared, their existence is disjointed once again. His love, once a magnificent revelation, becomes an unremitting source of torment and moral distress (De Kesel, 105).

10 The idea of the freebooter versus bourgeois culture is a recurrent opposition in Dutch cinema of the 1960 s and 1970s. Several characters from chapter 5 could 358 | be cited as Manuel's 'nephews': the bohemian artist Erik from TuRKs FRUIT, the protagonists in the films by 'Pim and Wim,' Herman Brood in CHA CHA, but also the vociferous outcasts in THE FAMILY (Lodewijk de Boer, 1973) or the re-use of the free-spirited writer Wessel Franken from HET GANGSTERMEISJE in ALLE DAGEN FEEST [EVERY DAY A PARTY] (1976), this time directed by Ate de Jong, Otto Jongerius, Paul de Lussanet and Orlow Seunke. Of all these characters, it can be said that they all bear the imprint of their times, (slightly) outdated according to present-day standards.

11 Bert Haanstra's DOKTER PUlder ZaAit PAPAVERs [DOCTOR PUlder SOWS POPPIES] (1975) can be considered to be a 'light' version of this imbrication between bourgeois decorum and perversity. An old study friend, Hans van Inge Liedaerd, pays Dr. Pulder a visit 'for old time's sake,' but the visit is a cover so he can steal expensive medicine from Pulder's supply. After the death of the 'junkie,' the decent doctor becomes intrigued by Hans' lifestyle and gets acquainted with one of his girlfriends. To the dismay of his wife and his son, the doctor sheds his decorum and gets interested in sowing poppies, to fulfil a plan Hans never had the chance to carry out.

12 This part is a revised version of an article I published in Senses of Cinema 70 (2014).

13 There is a remarkable correspondence, Hans Beerekamp suggested to me, between the housing estate in DE NOORDERLINGEN and Zonnedael, the residential area in FLODDER. They were both artificially constructed in the city of Almere to ridicule the dream of the socially engineered society.

14 In his latest film, SCHNEIDER vs. BAX (2015), empty landscapes are used as a starting point once again. In front of Bax' house, there is open water with reed that has been chopped off to create the effect of a geometric pattern (Van Warmerdam, qtd. in Linssen, 6). 
15 The marital problems aggravate after Martha has decided to completely resist the attempts at seduction by Jacob. When she is in bed, the statue of Saint Frances, miraculously, comes alive and it/he gestures to her not to eat the food her husband has brought her. Saint Frances even comes down from his pedestal to pray at Martha's bedside.

16 The oxymoron 'middle-of-the-road absurdism' has been introduced by the Dutch cartoonist Gummbah (real name Gert-Jan van Leeuwen) in jest to describe his own (drawing) praxis as well as to qualify his theatre programme Poelmo, slaaf van het zuiden [Poelmo, Slave of the South] (2002), which he created with Hans Teeuwen and Pieter Bouwman. The category of 'middle-of-the-road absurdism' has to be taken with a grain of salt. I use a deliberately peculiar term here to put the idea of categorization as such into perspective. If Van Warmerdam attempts to escape (fixed) meanings quite successfully, his work of course is not to be reduced to some category.

17 The cinema of Andersson does not work according to the conventional principle of the eyeline match. This principle entails that we have an alternation of shots. In one shot we see a character looking, in another shot we see what the character is looking at. In Andersson's tableau-like cinema, there are nonetheless many onlooking characters in the background of the shot, standing behind a tree, in a doorpost, or peeping through a window. They offer, so to speak, a 'compensation' for the lack of reverse shots.

18 Is the train conductor in DE JURK simply obsessed by women who wear this particular dress or is that a coincidence? Or is it a regular habit to harass women, regardless of the clothes they wear?

19 Allemaal Film, devoted to the history of Dutch cinema, was broadcast on television by the AVRO in nine episodes in 2007. It was produced by IDTV and presented by actor Jeroen Krabbé.

20 Van Warmerdam mentioned this anecdote in an interview with Marja Pruis.

21 Actually there are a few exceptions to the rule, apart from the surreal scene with the ashtrays. Each and every time internally focalized shots are presented as distorted, this distortion is clearly motivated. When the father looks at his wife through a glass of wine, we get a subjective shot on Duifje, out of focus. We get Abel's internal focalization in the scene when his father comes to the door of Zus' home, dressed up as a mailman 'bringing a long parcel.' Peeping through a small distorted glass, we see the father/mailman from a fish-eye perspective. So, when we see a shot that coincides with a character's deformed perception, this distortion does not have a psychological cause as in the case of surrealism, but because an object, like a glass of wine, has affected the observation.

22 Another good example of this type of absurdism is the fourth, and best, story from ZWAARMOEDIGE VERHALEN VOOR BIJ DE CENTRALE VERWARMING (1975), directed by Nouchka van Brakel - see also note 8 above. It is about a shopkeeper 
in a small boat hiding under a bridge. He hears a postman above him and asks for assistance. This postman lends him his knife to cut the rope of the boat loose, but because there is iron wire woven into the rope, he ruins the knife. The postman is angry, and he wants at least 100 guilders in compensation since the knife is a heirloom. The shopkeeper refuses, for he does not want to pay for a 'human memory.' When the shopkeeper paddles away, the postman cycles along the water, while the wind makes his cape blow up. Since he cannot shed his persecutor, the shopkeeper proposes a deal: a sandwich and the bike for his boat. They swap places, but it turns out that the postman has let the air out of the bicycle tires. The shopkeeper is angry, but then the postman suggests a reconciliation: step into the boat, and while they both take shelter under the cape, they row towards an orange sun, which becomes bigger and bigger until the screen is completely orange.

23 Not only does GRIMM end on a spaghetti western set, but the countryman in 360 KLEINE TEUN is watching westerns on his television regularly and SCHNEIDER VS. BAX is a kind of 'polder western.' Moreover, Borgman is narratively positioned as a man from nowhere, without history. His identity remains as enigmatic as The Man with No Name from the spaghetti westerns made by Sergio Leone, greatly appreciated by Van Warmerdam. When he was permitted to choose five of his favourite films for screenings in EYE, THE GOOD, THE BAD, AND THE UGLY (Sergio Leone, 1967) was among them, in addition to PSYCHO, DELIVERANCE, UN FLIC and THE FRENCH CONNECTION.

24 The really superb first half of ABEL is the closest Dutch cinema got to the suffocating atmosphere found in Gerard Reve's classic novel De Avonden [The Evenings] from 1947. This novel was actually adapted into a film by Rudolf van den Berg. in 1989, so forty-two years after its publication and three years after ABEL. Over the years, Reve's De Avonden had gained quite a number of dedicated followers, for whom the idea of a new adaptation was a form of 'sacrilege': according to them, no filmmaker should be so bold as to visualize this beloved milestone, for its literary style and tone is inimitable. The book consists of an account of the last ten days of the year 1946 in Amsterdam, portraying the quite uneventful life of 23-year-old Frits van Egters. The novel registers his daily routines at home with his parents, his dull work in an office, a reunion at his secondary school, and some occasional visits he pays to friends. Out of boredom, Frits pesters other people by pointing out their ugly features, like the Maurits' lack of an eye or his brother Joop's receding hairline. These nasty remarks are clear examples of his penchant for ironic and sardonic retorts. Even though Van den Berg's DE AVONDEN uses wide-angle lenses in a number of dream sequences, has uncommon camera angles in a few scenes, and plays with out-of-focus shots when Frits hears about a suicide, the most memorable scenes are those in which the camera simply registers the scenery. The (dinner) scenes with his parents are particularly 
outstanding, partly due to the fine performances by Thom Hoffman as Frits, Rijk de Gooyer as the father and Viviane de Muynck as the mother. Frits is irritated by, among other things, his father's near deafness and his eating habits. When his father uses his own 'dirty' spoon to pour sugar into his porridge, he points out in an agitated manner that there is a specific sugar spoon, and fills his father's cup almost to the brim. Despite his annoyance, Frits remains at his parents' residence, perhaps out of some peculiar compassion. When his mother has erroneously bought some fruit juice instead of wine, he is irritated by her mistake, but also calls out: 'Cranapple, cranapple, eternal God, see my mother, see her unmeasurable goodness. She thought she bought wine.... And protect him, he is my father.... The grave yawns, time buzzes.'

25 Van Warmerdam loves scenes with light. SCHNEIDER VS. BAX takes place on a sunny day before the evening starts. The little house in the film has a glass roof to ensure the inside is illuminated by natural light. He is fond of westerns and the genre's preferred moment of the day is to paraphrase one of the best-known titles, 'high noon' (Van Warmerdam, qtd. in Linssen, 7).

In post-production, the sharpness of the blue skies in SCHNEIDER Vs. BAX was made a bit grainy to avoid the appearance of nostalgia for old postcards (Linssen, 7).

27 This has been pointed out to me by Theodoor Steen.

28 Catherine Shoard used these terms to express her annoyance at the small (social) aspirations of BORGMAN.

29 Van Warmerdam is particularly delighted by the simple structure of classic westerns: 'The landscape. And then a man. Just a man in the landscape. A figure in space. With a gun. Sun. A lot of light. And shadows. And then another man. Also with a gun.' This simplicity can be contrasted with the intricate plots of thrillers: 'One is excited while reading them, but the dénouement is often slightly disappointing. That makes reading thrillers quite tiring' (Van Warmerdam, qtd. in Linssen, 7).

30 See Komrij in his reflection upon this review in the essay 'Kooiman is mijn beste vriend' from Papieren Tijgers.

31 These perverse and macabre impulses are hardly articulated in other Dutch 'home invasion' films which are rather ludic and melancholic like DUSKA (Jos Stelling, 2007), in which the film critic Bob does not know how to get rid of an unexpected Russian guest who has no bad intentions, but whose plan to stay over inhibits Bob's attempts to date a cashier. MATTERHORN (Diederik Ebbinge, 2013), which won the UPC Publieksprijs (UPC Audience Award) at the Rotterdam International Film Festival, is a mild-mannered comedy about a religious widower who invites a taciturn stranger into his house. This hospitality is met with suspicion by his Calvinist neighbours. It will turn out that the two are tormented souls, but their being together will have a comforting effect upon both of them. Even though 
MATTERHORN is stylistically close to the deadpan approach of Van Warmerdam, De ONTMAagding VAN Eva VAN END [The DEFlowering of Eva VAN END] (Michiel ten Horn, 2012) is closer to Van Warmerdam because of a slightly disturbing tone. The young teenager Eva is a typical wallflower, reminiscent of Dawn Wiener from Welcome to THE Dollhouse (Todd Solondz, 1996). She is not only neglected by her peers, but also by her own parents and her two elderly brothers. The arrival of an exchange student from Germany who is zen-like, vegetarian and very attractive has an impact upon all family members. His presence makes them explore their noble side as well as their frustrations. Due to the transformative effect of his being there, the net result is that Eva will finally get noticed. Most of the time the camera is at her eye level, but in one of the last scenes every other family member is at eye level, while she brings them coffee and/or something to eat, whilst her head is cut off. This time everyone has to look up to Eva.

\section{CHAPTER 9}

1 Another great example is the episode from Tarantino's second film, PULP FICTION (1994), when a gun goes accidentally off in a car and the head of the boy in the back seat is blown to pieces. His brains are all over the car, but instead of an emphatic response, the shooter, Vincent Vega, starts blathering about the fact that he could not help it that his gun went off because the driver was so careless as to apparently hit a tiny object on the road. The characters, and in extension of them the spectators, are more or less supposed to react to such a gruesome scene with a feeling of disgust, but in fact a laugh is closer at hand because of the super cool, and therefore incongruous, response by Vincent.

2 The opening scene of the Dutch crime thriller LEK [LEAK] (Jean van de Velde, 200o) seems to be indebted to this scene from RESERVOIR DOGS, as the gangster boss Haveman is singing a karaoke version of André Hazes' popular torch song 'Kleine Jongen' ['Little Boy'], while a guy is being hanged.

3 The matter has never been truly solved whether the grotesque should be considered as a genre or as a stylistic feature/tradition. If it is a genre, it should be called 'het groteske' in Dutch; if it is a stylistic tradition, 'de groteske.' There seems to be a slight preference for the latter notion (Van Buuren, 24).

4 Edwards and Graulund examine the infamous horror film THE HUMAN CENTIPEDE (Tom Six, 2009), already mentioned in chapter 5 . In this film an insane German doctor creates a Siamese triplet by grafting living creatures together from mouth to anus, which is a grotesque 'disruption of basic bodily functions, namely the ability to rid the body of natural waste' (61). Six's depiction of the grotesque body can be read as a humorous reflection on the horror genre itself, for the 'absurd conceit of the film is laughable and the extreme bad taste of the film is 
sensational and bound to shock audiences of more sophisticated tastes' (62).

Ian Kerkhof changed his name in 1999 officially to Aryan Kaganof - Kaganof being the family name of his biological father.

6 In an interview in De Wereld Draait Door, Birgit Schuurman, actress in BLACK OUT, implied that earlier Dutch action-crime-comedies still had affinity with children's television series like BASSIE \& ADRIAAN and PEPPI \& KOKKI.

7 Spike Lee, quoted in Army Archerd, 'Spike Lee Disses Tarantino's “Nigger” Usage,' Variety [2011], reprinted at http://www.daveyd.com/spikepolitics.html.

8 The gangsters in BLACK OUT are only equalled, if not topped, in weirdness by the drug dealer Kalpa, a minor but seminal character in PRINS [PRINCE] (Sam de Jong, 2015). Kalpa is a skinny sociopath with bleached hair and a goofy grimace. One reviewer, Steve Davis of the Austin Chronicle, compared him to the giggling killer in KISS OF DEATH (Henry Hathaway, 1947), played by Richard Widmark. On the one hand, Kalpa does not shy away from dirty work, like slaughtering pigs in his own basement, but on the other hand, he adorns himself with blingbling and is keen on showing off with his flamboyant purple Lamborghini. By promising the teenage protagonist Ayoub a joyride in his car as well as by offering him fashionable sneakers, Kalpa is able to exert a decisive influence on the Dutch Moroccan boy in a film which looks like an extended music video. Many scenes are in slow motion and a great number of shots are frontally staged, with characters facing the camera. The electronic music score is thumping at times, although Andrea Bocelli's 'Con te partirò' is included on the soundtrack as well. In one scene the camera moves in circles around Ayoub and his friends, while the rhythm is disrupted by jump cuts. Moreover, there is also a fascinating zoom in on Ayoub, which then very slowly dissolves into an unstable point-of-view shot of Ayoub on a moped. As fascinating is the scene in which Ayoub points a gun at one of his bullies, for the point-of-view shot is suddenly superimposed with a mental image of his recently deceased father: Ayoub decides to let the bullies go unharmed. PRINs has been praised for its visual bravado, which is, as sometimes noted by critics, at the expense of narrative consistency, for the story easily shifts moods, from gloomy to optimistic, from retro-aesthetics to scenes shot in fluorescent light.

9 Once called by American essayist Susan Sontag the 'most important experimental filmmaker' of his time, Frans Zwartjes made his most significant films, in which he explored erotics and cruelty, in the 1970s. His work was grainy, consisted of brusque edits and he often worked with performance artists, adorned with heavy make-up.

Kyodai MAKes THE BIg Time ends with a static shot, slightly high angle, of no less than 8 minutes, showing a woman, Stef, on a bed, after she has heard that her former boyfriend Kyodai has died. She listens to a record of Al Green's 'For the Good Times,' twice; we see her drink alcohol and weep. 
11 If there is a precursor in Dutch cinema to this Ronnie, then the slightly cartoonish Jack from LEK could be a candidate. The main reason why LEK is not discussed in this study is that the film is, apart from its representation of gangsters Haveman and Jack, fairly serious in tone.

12 In the case of dramatic or tragic irony, the audience watches a drama unfold, whilst the viewers already know its destined outcome, and thus they see the characters 'at the mercy of the plot' (Colebrook, 14). The tragedy of Oedipus is a good example.

13 Whereas in dramatic and cosmic irony this 'other meaning' is plot or destiny, in verbal irony 'the other meaning is either what the speaker intends or what the hearer understands' (Colebrook, 15).

14 See the blog by Trevor Gilks: When Judah starts to make peace with his crime, 'a very cohesive message starts to form: Be a phony, lie, steal, kill people, take a dump on Woody Allen's sister.... The world is your oyster, and the only things 364 holding you back are the arbitrary moral codes you impose upon yourself. If you think there's a heavenly force that's going to reward you for your good behavior, you're a blind fool.'

15 Another Woody Allen film which explores this 'irony of fate' is Match POINT (2005), which starts with a voice-over by tennis coach Chris: 'The man who said "I'd rather be lucky than good" saw deeply into life. People are afraid to face how great a part of life is dependent on luck. It's scary to think so much is out of one's control. There are moments in a match when the ball hits the top of the net, and for a split second, it can either go forward or fall back. With a little luck, it goes forward, and you win. Or maybe it doesn't, and you lose.' Chris, from humble origins, marries into the British upper class, but falls in love with Nola, the girlfriend of his brother-in-law. To prevent Nola from revealing their secret affair, he kills her in a scene which has references to Dostoevsky's 1866 novel Crime and Punishment. He wants to make it look like a robbery, and therefore he first kills Nola's neighbour, the old Mrs. Eastby, and steals some of her jewellery. Knowing that Nola is on her way home, he shoots Nola as if she is no more than the accidental witness to the robbery, not the intended victim. Despite the cunning plan, there is a detective who gets it absolutely right after he has had a dream, but then the luck factor does its work for Chris. A drug addict has been found murdered with a stolen ring on him that belonged to Mrs. Eastby. That way, the ball bounces forward after all.

16 Structurally this Peter, playing an important supporting role, is in a similar position as the retiring sheriff in the darkly comic NO COUNTRY FOR OLD MEN (Joel and Ethan Coen, 2007), who has some quasi-reflexive voice-overs on how to keep the peace in the old times and in the harsher present days ('I always knew I had to be willing to die to even do this job'). 
17 If PLAN C is a grotesque-irony about a character who suffers from 'moments of extremis,' NACHTRIT [NigHTRUN] (Dana Nechushtan, 2006) is the tragic version. A cab driver grabs the opportunity to buy a scarce and expensive licence, but when the law is altered soon thereafter, it becomes a worthless piece of paper. He is now in serious trouble since he owes a number of people a great amount of money.

18 CARNA (1969) lasted 12 minutes; DE VAL [THE FALL] (1970), inspired by a novel by Albert Camus, was close to half an hour. The third short in this period was the bizarre 34-minute ANTENNA (1970), bordering on blasphemy. A voice-over is rereading an apocryphal version of Genesis; in beautiful widescreen (Techniscope) shots we see how a priest makes advances at the young girl, Antenna; finally, after an intertitle reads 'When the echo of evil had been silenced,' Jesus Christ, played by the French actor Pierre Clémenti, is introduced, driving in a Daf, featuring a flag with the text 'SOS Total Mental Service.'

19 Koolhoven's SuzY Q has a reference to Sunlight soap as well: The jobless father sets up a grocery store at home because he has nothing to do. The mother encourages the children to please their father and playact as customers. Suzy knocks on his door and asks whether she can smell a piece of soap. He then brings her Sunlight soap, but she complains that it stinks. Her father replies: 'But, Madame, this is an old-fashioned, delicious odour.' Suzy, however, only wants to pay 50 cents instead of the required 90 cents.

When DE BLINDE FOTOGRAAF has distorting shots, it is via a specific device: we see the main character in a distorting mirror or a magnifying glass enlarges one of his eyes.

21 Insofar DE MANTEL DER LIEFDE was a revengeful comment upon those 1970s box-office successes which ushered in banality, it was a smart streak of irony to cast a great number of actors who had featured in these films: Ronnie Bierman was prostitute Greet and Henk Molenberg the 'chambermaid' in WAT ZIEN IK?!, Hans Boskamp, playing Moses here, had a role in TURKS FRUIT; Willeke van Ammelrooy had played main parts in, among other films, MIRA and FRANK EN EvA. In addition to that, the roles of Jesus and of the naked baker were performed by actors who had built a reputation in children's programmes.

22 A different version of 'the irony of irony' in DE VIERDE MAN was published in Journal of Dutch Literature 4, 2 (2013).

\section{CONCLUSION}

1 When interviewed by Pieter Webeling, the essayist Bas Heijne told that the majority of Dutch humour is derived from the 'anxiety that someone else feels himself superior to you, or out of the conviction that the other is utterly stupid.' In FLOD- 
DER, he continues, 'the aggression is directed at those inhabitants who are both rich and pretentious. We tend to sympathize with the Flodders for [starlike] airs are being chastised in the Netherlands. It is a raunchy form of humour which directly originates from the paintings by Breughel. Many people cannot use the term "intellectual" without the prefix pseudo- or quasi-. This is grounded in frustration: do not think that you know things better than I do. This way we constantly take each other's measure - in order to save the other from unseemly feelings of superiority.'

2 One of the gaps that is being exploited is the one between 'being a body and having a body,' as Critchley asserts. For him, humour marks 'the return of the physical into the metaphysical' (43).

3 Zupancic adds to this: 'Yet the comic point is that what is behind is - Surprise, surprise! - nothing but what we would expect' (209).

4 The comic, which is usually 'discovered in a spectacle or situation that remains 366 | unformulated in words ... appears to involve only two subjects because the role of joker and victim, or joker and audience, are played by the same person' (Beeman, 46).

5 That the joker makes use of the third person to arouse his own laughter is according to Freud proven by the fact 'that a person who has begun by telling a joke with a serious face afterwards joins in the other person's laughter with a moderate laugh' (Jokes, 156).

6 My personal experience with Van Warmerdam films is that they become funnier the more often one sees them, which is hardly ever the case with regular comedies. They lend themselves to 'rewatchability,' just as is the case with THE BIG LEBOWSKI. 


\section{BIBLIOGRAPHY}

Abrahams, Anna, Mariska Graveland, Erwin van ‘t Hart and Peter van Hoof (eds.), mm2: Experimental Film in the Netherlands Since 196o. Trans. Kate Simms and Martin Cleaver (Amsterdam: Filmbank/uitgeverij de Balie, 2004).

Abrams, M.H., Glossary of Literary Terms. $8^{\text {th }}$ ed. (Boston: Wadsworth, 2005).

Agterberg, Bas, 'MARIKen van Nieumeghen/Mariken,' in Mathijs (ed.), 121-29.

Albers, Rommy, and Soeluh van den Berg, Jean Desmets droomfabriek: De avontuurlijke jaren van de film (1907-1916) (Rotterdam: naio10, 2014).

Albers, Rommy, Jan Baeke and Rob Zeeman (eds.), Film in Nederland (Amsterdam: Ludion/Filmmuseum, 2004).

Archerd, Army, 'Spike Lee Discusses the Term Nigger,' http://www.daveyd.com/ spikepolitics.html.

Aydemir, Murat, Images of Bliss: Ejaculation, Masculinity, Meaning (Minneapolis: University of Minnesota Press, 2007).

Bain, Alexander, The Emotions and the Will (London: John W. Parker and Son, 1859).

Bakhtin, Mikhail, Rabelais and His World. 1965. Trans. Hélène Iswolsky (Bloomington: Indiana University Press, 1993).

Bakker, Kees, Joris Ivens and the Documentary Context (Amsterdam: Amsterdam University Press, 1999).

Bal, Mieke, Double Exposures: The Subject of Cultural Analysis (New York: Routledge, 1996).

Baudelaire, Charles, 'On the Essence of Laughter, and, in General, on the Comic in the Plastic Arts,' in Selected Writings on Art \& Artists (1855). Trans. P.E. Charvet (Cambridge: Cambridge University Press, 1981), 140-61.

Bazin, André, 'Cinematic Realism and the Italian School of Liberation,' in Bert Cardullo (ed.), André Bazin and Italian Neorealism. Trans. Hugh Gray (London: Continuum Books, 2011), 29-50. 
Bazin, André, ‘Theater and Cinema - Part Two,' What Is Cinema? Ed. and trans. Hugh Gray. 2 vols. (Berkeley: University of California Press, 2004), vol. 1, 95-124.

Beekman, Bor, 'What Did You Kill, Bungalow Bill?,' de Volkskrant, 28 May 2015, V4-5. Beeman, Naomi, 'Uncanny Laughter: Reworking Freud's Theory of Jokes with E.T.A. Hoffmann's “The Sandman," in Gallagher (ed.), 29-55.

Beerekamp, Hans, Docupedia.nl:Zekere tendensen in de Nederlandse documentaire (Amsterdam: Stichting Het Ketelhuis, 2011).

Bergan, Ronald, The Coen Brothers (London: Phoenix, 2000).

Bergson, Henri, Laughter: An Essay on the Meaning of the Comic. Trans. Cloudesley Brereton and Fred Rothwell (London: Macmillan, 1935).

Bernink, Mieke, Fons Rademakers: Scènes uit leven en werk (Abcoude: Uniepers, 2003). Bhabha, Homi K., 'The Other Question: The Stereotype and Colonial Discourse,' in John Caughie (ed.), The Sexual Subject: A Screen Reader in Sexuality (London: Routledge, 1992), 312-31.

368 | Billig, Michael, Laughter and Ridicule: Towards a Social Critique of Humour (London: Sage, 2005).

Bishoff, Ruud, Hollywood in Holland: De geschiedenis van de Filmfabriek Hollandia 1912-1923 (Amsterdam: Thoth, 1988).

Blokker, Bas, 'SHOuf SHOUf HABIBı! is vrolijke komedie én wrang drama,' NRC Handelsblad, 28 January 2004.

Blom, Ivo, Jean Desmet and the Early Dutch Film Trade (Amsterdam: Amsterdam University Press, 2003).

Bloxham, Andy, 'British Humour "Dictated by Genetics,"' The Telegraph, 10 March 2008.

Booth, W.C., A Rhetoric of Irony (Chicago: University of Chicago Press, 1974).

Bordwell, David, 'Nolan vs. Nolan,' Observations on Film Art (2012), http://www.davidbordwell.net/blog/2012/08/19/nolan-vs-nolan/.

Breton, André, 'Lightning Rod,' in André Breton, Anthology of Black Humour (London: Telegram, 2009), 19-25.

Buruma, Ian, Murder in Amsterdam: The Death of Theo Van Gogh and the Limits of Tolerance (New York: Penguin Press, 2006).

Busch, Gerhard, 'Elk shot is een plaatje: DE WEDEROPSTANDING VAN EEN KLOOTZAK van Guido van Driel,' cinema.nl, 21 February 2013, http://www.cinema.nl/artikelen/9915758/elk-shot-is-een-plaatje.

Calhoun, Dave, 'Borgman,' Time Out, 18 April 2013, http://www.timeout.com/london/ film/borgman.

Carroll, Noël, Humour: A Very Short Introduction (Oxford: Oxford University Press, 2014).

Cavell, Stanley, Pursuits of Happiness: The Hollywood Comedy of Remarriage (Cambridge, MA: Harvard University Press, 1981).

Cliteur, Paul, De filosofie van mensenrechten (Nijmegen: Ars Aequi Libri, 1997). 
Clover, Carol, Men, Women and Chain Saws: Gender in the Modern Horror Film (Princeton: Princeton University Press, 1993).

Cohan, Steven, and Ina Rae Hark, 'Introduction,' in Steven Cohan and Ina Rae Hark (eds.), The Road Movie Book (London: Routledge, 1997), 1-14.

Colebrook, Claire, Irony (London: Routledge, 2004).

Collin, Robbie, \#Cannes2013, https://twitter.com/robbiereviews/status/ 336038608018477056.

Collins, Christopher, Reading the Written Image: Verbal Play, Interpretation, and the Roots of Iconophobia (University Park: The Pennsylvania State University Press, 1991).

Connolly, Kate, 'The Final Cut,' The Guardian, 26 October 2007.

Cooper, Anthony, Ashley, Earl of Shaftesbury, Characteristicks of Men, Manners, Opinions, Times. Volume 1 (1711). Foreword by Douglas Den Uyl. Indianapolis: Liberty Fund, 2001.

Creed, Barbara, The Monstrous-Feminine: Film, Feminism, Psychoanalysis (London: Routledge, 1993).

Critchley, Simon, On Humour (London: Routledge, 2002).

De Kesel, Marc, 'Dorp met hondinnetje: Over Lars von Trier, DogviLle,' in Sjef Houppermans, Marc De Kesel, Peter Verstraten (eds.), Scènes uit een huwelijk: Psychoanalyse \& Film (Amsterdam: Dutch University Press, 2006), 93-111.

DeAngelis, Michael, 'Introduction,' in DeAngelis (ed.), 1-26.

DeAngelis, Michael (ed.), Reading the Bromance: Homosocial Relations in Film and Television (Detroit: Wayne State University Press, 2014).

Den Drijver, Ruud, Circus Bloteman: Biografie van Wim Verstappen, Filmpionier uit de West (Amsterdam: Stichting Wim Verstappen Scorpio Films, 2015).

Desser, David, 'Slapstick Comedy,' in Lester Friedman, David Desser, Sarah Kozloff, Martha P. Nochimson and Stephen Prince (eds.), An Introduction to Film Genres (New York and London: W.W. Norton \& Company, 2014), 33-79.

Dibbets, Karel, Sprekende films: De komst van de geluidsfilm in Nederland, 1928-1933 (Diss. Universiteit van Amsterdam/Amsterdam: Otto Cramwinckel, 1993).

Dibbets, Karel, and Frank van der Maden (eds.), Geschiedenis van de Nederlandse film en bioscoop tot 1940 (Weesp: Het Wereldvenster, 1986).

Dittrich, Kathinka, Achter het doek: Duitse emigranten in de Nederlandse speelfilm in de jaren dertig (Houten: Unieboek, 1987).

Dittrich, Kathinka, 'De speelfilm in de jaren dertig,' in Dibbets and Van der Maden (eds.), 105-44.

Driessen, Kees, Canon van de Nederlandse film (Utrecht: Stichting Nederlands Filmfestival, 2007).

Dyer, Richard, 'It's Being So Camp as Keeps Us Going' (1977), in A Culture of Queers (London: Routledge, 2002), 49-62. 
Dyer, Richard, 'It's in His Kiss! Vampirism as Homosexuality, Homosexuality as Vampirism,' in A Culture of Queers (London: Routledge, 2002), 70-89.

Ebert, Roger, 'Review of THE DisCREET CHARM OF THE BouRGEOISIE,' RogerEbert. com (25 June 2000), http://www.rogerebert.com/reviews/great-movie-the-discreetcharm-of-the-bourgeoisie-1972.yyy

Edwards, Justin D. and Rune Graulund, Grotesque (London: Routledge, 2012).

Ekker, Jan Pieter, 'Aardappelwestern over een verloren generatie,' de Volkskrant, 8 June 1999.

Ekker, Jan Pieter, 'Hybride horrorfilm met theatercoryfeeën: DE PoEL van Chris W. Mitchell,' cinema.nl, 1 May 2014.

Freud, Sigmund, 'Humour,' in The Standard Edition of the Complete Psychological Works of Sigmund Freud: The Future of an Illusion, Civilization and Its Discontents, and Other Works. Volume XXI (1927-1931). Trans. James Strachey (London: Vintage, 2001), 161-66.

370 Freud, Sigmund, Jokes and Their Relation to the Unconscious, in The Standard Edition of the Complete Psychological Works of Sigmund Freud. Volume VIII (1905). Trans. James Strachey (London: Vintage, 2001).

Furst, Lilian R., Fictions of Romantic Irony (Cambridge, MA: Harvard University Press, 1984).

Gallagher, David, 'Introduction,' in Gallagher (ed.), 1-11.

Gallagher, David (ed.), Comedy in Comparative Literature: Essays on Dante, Hoffman, Nietzsche, Wharton, Borges and Cabrera Infante (Lewiston: Edwin Mellen Press, 2010).

Gilks, Trevor, 'CRIMES AND Misdemeanors,' Every Woody Allen Movie website (2012), http://thedailyhatch.org/2013/o8/28/woody-wednesday-a-great-review-ofthe-movie-crimes-and-misdemeanors/.

Graveland, Mariska, 'AANMODDERFAKKER: Lapzwanserum ad infinitum,' De Filmkrant 370 (November 2014), 26.

Graveland, Mariska, Fritz de Jong and Paul Kempers (eds.), De broertjes van ZusJE: De nieuwe Nederlandse film 1995-2005 (Amsterdam: International Theatre \& Film Books, 2006).

Grunberg, Arnon, 'Voetnoot: Klasse,' de Volkskrant, 6 March 2015, 1.

Hannoosh, Michele, Baudelaire and Caricature:From the Comic to an Art of Modernity (University Park: Pennsylvania State University Press, 1992).

Heesen, Hans, Wie zijn ogen niet gebruikt, is een verloren mens: In gesprek met George Sluizer (Amsterdam: Nijgh en Van Ditmar, 2012).

Heijmans, Toine, 'Gordon en RTL hebben geen spijt van grappen,' De Volkskrant, 29 November 2013, 5 .

Hendriks, Annemieke, De pioniers: Interviews met 14 wegbereiders van de Nederlandse cinema (Amsterdam: International Theatre \& Film Books, 2006). 
Hermsen, Joke J., Stil de tijd: Pleidooi voor een langzame toekomst (Utrecht: De Arbeiderspers, 2009).

Hofstede, Bart, Nederlandse cinema wereldwijd:De internationale positie van de Nederlandse film (Amsterdam: Boekmanstudies, 2000).

Hogenkamp, Bert, De Documentaire Film 1945-1965. De bloei van een filmgenre in Nederland (Rotterdam: Uitgeverij 010, 2003).

Hogenkamp, Bert, De Nederlandse documentaire film 1920-1940 (Amsterdam/Utrecht: Van Gennep/Stichting Film en Wetenschap, 1988).

Hogenkamp, Bert, De Nederlandse documentaire film, 1965-199o: De ontwikkeling van een filmgenre in het televisietijdperk (Amsterdam: Boom, 2015).

Home, Henry, Lord Kames, Elements of Criticism (1762) (New York: Collins \& Hannay, 1829).

Hooven, Marcel ten, 'De lege tolerantie - inleiding: Op zoek naar een nieuwe inhoud voor verdraagzaamheid,' in Marcel ten Hooven (ed.), De lege tolerantie: Over vrijheid en vrijblijvendheid in Nederland (Amsterdam: Boom, 2001), 11-36.

Huizinga, Johan, Homo Ludens: A Study of the Play-Element in Culture (1938) (London, Boston and Henley: Routledge \& Kegan Paul, 1980).

Hunter, I.Q., 'Beaver Las Vegas: A Fan Boy's Defence of SHowgIRLs' (2000), in Mathijs and Mendik (eds.), 472-81.

Hutcheon, Linda, 'Introduction,' in Linda Hutcheon (ed.), Double Talking: Essays on Verbal and Visual Ironies in Canadian Contemporary Art and Literature (Toronto: ECW Press, 1992), 11-38.

Hutcheon, Linda, Irony's Edge: The Theory and Politics of Irony (London: Routledge, 1994).

Hutcheon, Linda, A Poetics of Postmodernism: History, Theory, Fiction (New York: Routledge, 1988).

Jameson, Fredric, Postmodernism, or, The Cultural Logic of Late-Capitalism (Durham: Duke University Press, 1991).

Kayser, Wolfgang, The Grotesque in Art and Literature (New York: Columbia University Press, 1957).

Keyser, Gawie, 'Recensie: SPETTERs,' De Groene Amsterdammer, 11 May 2012, http:// blogs.groene.nl/film/?p=1036.

Komrij, Gerrit, 'Kooiman is mijn beste vriend,' Papieren tijgers (1978) (Amsterdam: De Arbeiderspers, 1980), 142-48.

Kuipers, Giselinde, Good Humor, Bad Taste: A Sociology of the Joke. Trans. Kate Simms (Berlin: Mouton de Gruyter, 2006).

Lacan, Jacques, 'The Meaning of the Phallus' (1958). Trans. Jacqueline Rose. In Juliet Mitchell and Jacqueline Rose (eds.), Feminine Sexuality: Lacan and the École Freudienne (New York: W.W. Norton, 1982), 74-85.

Lang, Candace D., Irony/Humor: Critical Paradigms (Baltimore: Johns Hopkins University Press, 1988). 
Lau, Matt, 'Beauty, the Satiric and a Few Desperate Housewives,' The Symptom: Online Journal for Lacan.com (2006), http://www.lacan.com/symptom8_articles/lau8. html.

Linssen, Céline, Hans Schoots and Tom Gunning, Het gaat om de film! Een nieuwe geschiedenis van de Nederlandsche Filmliga, 1927-1933 (Amsterdam: Bas Lubberhuizen, 1999).

Linssen, Dana, 'Alex van Warmerdam over SCHNEIDER vs. BAX: "Kindermoordenaar, dat vond ik gewoon een lekker woord,"' De Filmkrant 376 (May 2015), 6-7.

Linthorst, Gerdin, 'Eerst vakmanschap dan kunst: Het werk van Orlow Seunke,' Ons Erfdeel 36 (1993), 563-68.

MacDowell, James, 'Wes Anderson, Tone, and the Quirky Sensibility,' New Review of Film and Television Studies 10.1 (2012), 6-27.

Mathijs, Ernest, 'Introduction: Cinema in the Low Countries and the Question of Cultural Identity,' in Mathijs (ed.), 1-13.

372 Mathijs, Ernest (ed.), The Cinema of the Low Countries (London: Wallflower Press, 2004).

Mathijs, Ernest, and Xavier Mendik (eds.), The Cult Film Reader (Maidenhead: Open University Press/McGraw-Hill Education, 2008).

McHale, Brian, Postmodernist Fiction (New York: Methuen, 1987).

Mendik, Xavier, 'Turks Fruit/Turkish Delight,' in Mathijs (ed.), 109-118.

Merhi, Vanessa M., Distortion as Identity from the Grotesque to L'humour Noir: Hugo, Baudelaire, Lautreamont, Jarry (New Brunswick: Rutgers University Press, 2006).

Miller, Joe, Jests, or The Wits Vade-Mecum: Being a Collection of the Most Excellent Bon Mots, Brilliant Jests, and Striking Anecdotes in the English Language (1739) (London: Scott, Webster, and Geary, 1840).

Mulisch, Harry, Het ironische van de ironie: Over het geval G.K. van het Reve (Den Haag: Manteau, 1976).

Polizzotti, Mark, 'Introduction: Laughter in the Dark' (1996), in André Breton, Anthology of Black Humour (London: Telegram, 2009), 9-15.

Pollard, Stephen, 'Booker Prize: It's a Funny Old Thing, Jewish Humour ...,' The Telegraph, 14 October 2010, http://www.telegraph.co.uk/culture/books/bookerprize/8063053/Booker-Prize-Its-a-funny-old-thing-Jewish-humour-....html.

Ramaer, Joost, Afgemeten en uitgebeend: Leven en werk van Alex van Warmerdam (Amsterdam: Boekmanstudies, 2010).

Reve, Gerard, De taal der liefde (Amsterdam: Athenaeum-Polak \& Van Gennep, 1972).

Rodriguez, Hector, 'The Playful and the Serious: An Approximation to Huizinga's Homo Ludens,' The International Journal of Computer Game Research 6.1 (2006), http://gamestudies.org/o601/articles/rodriges.

Rukhelman, Svetlana, 'The Laughter of Gods and Devils: Edith Wharton and the Coen Brothers on Deception, Disappointment, and Cosmic Irony,' in Gallagher (ed.), 89-111. 
Russo, Vito, The Celluloid Closet: Homosexuality in the Movies (New York: Harper \& Row, 1987).

Ruven, Paul, and Robbert Vos, De nieuwe regisseurs (Amsterdam: Stone Hollywood Publishers, 2012).

Schmidt, Esther, and Sabine Veenendaal, Van ABELTJE tot Zoop: Over het succes van de Nederlandse jeugdfilm (Hoorn: Hoogland \& Van Klaveren, 2011).

Schoots, Hans, Bert Haanstra: Filmer van Nederland (Amsterdam: Balans, 2010).

Schoots, Hans, Living Dangerously: A Biography of Joris Ivens (Amsterdam: Amsterdam University Press, 2000).

Schoots, Hans, Van FANFARE tot SPETTERS: Een cultuurgeschiedenis van de jaren zestig en zeventig (Amsterdam: Bas Lubberhuizen, 2004).

Sconce, Jeffrey, 'Irony, Nihilism, and the New “Smart” Film,' Screen 43.4 (2002), 349-69.

Sconce, Jeffrey, “"Trashing” the Academy: Taste, Excess, and an Emerging Politics of Cinematic Style,' Screen 35.4 (1995), 371-93.

Sedgwick, Eve Kosofsky, Between Men:English Literature and Male Homosocial Desire (New York: Columbia University Press, 1985).

Sedgwick, Eve Kosofsky, Epistemology of the Closet (Berkeley: University of California Press, 1990).

Shoard, Catherine, 'Cannes 2013: BorgMAN - First Look Review,' The Guardian, 19 May 2013.

Smits, Ivo, and and Katarzyna Cwiertka, Hello Kitty \& Gothic Lolita's: Schattigheidscultuur uit Japan (Leiden: Leiden University Press, 2012).

Sommer, Martin, 'Alles in het nette,' de Volkskrant, 4 September 2004.

Sontag, Susan, 'Notes on "Camp,"' in Against Interpretation and Other Essays (London: Eyre \& Spottiswoode, 1967), 275-89.

Steen, Theodoor, 'Audio Interview: Jos Stelling,' Salon Indien, 10 March, 2012. Podcast. http://www.salonindien.nl/2012/audio-interview-jos-stelling/

Stufkens, André, Passages: Joris Ivens en de kunst van deze eeuw (Nijmegen: Museum Het Valkhof, 1999).

Swift, Jonathan, 'A Modest Proposal' (1729), in A Tale of a Tub and Other Satires (London: J.M. Dent \& Sons, 1978), 255-64.

Tarkovsky, Andrey, Sculpting in Time: Reflections on the Cinema. Trans. Kitty HunterBlair (Austin: University of Texas Press, 1989).

Taylor, Paul A., Žižek and the Media (Cambridge: Polity Press, 2010).

Thomson, Philip, The Grotesque (London: Methuen, 1972).

Trevitte, Chad, 'Perversity and Post-Marxian Thought in Buñuel's Late Films,' FilmPhilosophy 16.1 (2012), 213-31.

Truffaut, François, 'Une certaine tendance de cinema français,' Cahiers du cinéma 31 (1954): 13-17. 
Udris, Jan, 'De Stilte Rond Christine M./A Question of Silence,' in Mathijs (ed.), 157-65.

Van Alphen, Ernst, 'Geschreven realiteit: Willem Frederik Hermans en de fotografie,' in De toekomst der herinnering: Essays over moderne Nederlandse literatuur (Amsterdam: Van Gennep, 1993), 157-82.

Van Alphen, Ernst, 'Introduction: The Gender of Homosexuality,' Thamyris: Mythmaking from Past to Present 2.1 (1995), 3-10.

Van Beusekom, Ansje, 'Komedie om Geld/The Trouble With Money,' in Mathijs (ed.), 61-67.

Van Beusekom, Ansje, Kunst en Amusement: Reacties op de film als een nieuw medium in Nederland, 1895-1940 (Haarlem: Arcadia, 2001).

Van Bueren, Peter, “'Geperverteerde” film uit 1973 nog steeds fris,' de Volkskrant, 18 September 1997.

Van Buuren, Maarten, De boekenpoeper: Over het groteske in de literatuur (Assen: Van

374 | Gorcum, 1982).

Van der Burg, Jos, 'Mike van Diem over DE SuRPRISE: Terugkeer van de verloren zoon,' De Filmkrant 376 (May 2015), 12-13.

Van Gelder, Henk, Hollands Hollywood:Alle Nederlandse speelfilms van de afgelopen zestigjaar (Amsterdam: Luitingh - Sijthoff, 1995).

Van Hemert, Ruud, De Bruut (Broek op Langedijk: Gigaboek, 2011).

Van Schayk, Margot, Hallo Medemens! De geschiedenis van het Werkteater (Amsterdam: Theater Instituut Nederland/Strengholt, 2001).

Van Scheers, Rob, Paul Verhoeven: De biografie (Amsterdam: Meulenhoff, 2008).

Van Zwol, Coen, 'Stap nou eens over die drempel van volwassenheid heen, man! Je bent 32!' NRC Handelsblad, 6 November 2014.

Verdaasdonk, Dorothée, Beroep: Filmregisseur: Het verkrijgen van continuïteit in een artistiek beroep (Diss. Erasmus Universiteit Rotterdam, 1990).

Verdaasdonk, Dorothée, 'Marginality a Characteristic of Artistic Product: The Need of Personal Networks to Sustain an Artistic Career,' in Klaus Beekman (ed.), Institution \& Innovation (Amsterdam and Atlanta: Rodopi, 1994), 37-54.

Verstraten, Peter, Film Narratology (Toronto: University of Toronto Press, 2009).

Visser, Frits, JA ZUSTER, NEE ZUSTER: Leesboek (Amsterdam: Nijgh \& Van Ditmar, 1999).

Wagner, Phil, 'John Ford Made ... Monsters? The Grotesque Tradition in Ford's Work,' Senses of Cinema 48 (August 2008), http://sensesofcinema.com/2008/featurearticles/john-ford-monsters/.

Wampole, Christy, 'How to Live without Irony,' New York Times, 17 November 2012, http://opinionator.blogs.nytimes.com/2012/11/17/how-to-live-without-irony/? $\mathrm{php}=$ true\&_type=blogs\&_r=0.

Webeling, Pieter, 'De humor van Bas Heijne: Ik heb niet zo veel met cabaret,' Volkskrant Magazine, 23 March 2013. 
Weinman, Jenna, 'Second Bananas and Gay Chicken: Bromancing the Rom-Com in the Fifties and Now,' in DeAngelis (ed.), 29-51.

Weishaar, Schuy R., Masters of the Grotesque: The Cinema of Tim Burton, Terry Gilliam, the Coen Brothers and David Lynch (Jefferson: McFarland, 2012).

Williams, Linda, Figures of Desire: A Theory and Analysis of Surrealist Film (Urbana and London: University of Illinois Press, 1981).

Williams, Linda, 'Film Bodies: Gender, Genre, and Excess,' Film Quarterly 44.4 (1991), $2-13$.

Williams, Linda, Hard Core: Power, Pleasure and the 'Frenzy of the Visible' (Berkeley: University of California Press, 1989).

Williams, Linda, Screening Sex (Durham: Duke University Press, 2008).

Willis, Sharon, High Contrast: Race and Gender in Contemporary Hollywood Film (Durham: Duke University Press, 1997).

Žižek, Slavoj, 'Berlusconi in Tehran,' London Review of Books, 23 July 2009, 3-7.

Žižek, Slavoj, Enjoy Your Symptom! Jacques Lacan in Hollywood and Out (New York: Routledge, 1992).

Žižek, Slavoj, The Indivisible Remainder: An Essay on Schelling and Related Matters (London: Verso, 1996).

Žižek, Slavoj, Looking Awry: An Introduction to Jacques Lacan through Popular Culture (Cambridge, MA: MIT Press, 1991).

Žižek, Slavoj, The Plague of Fantasies (London and New York: Verso, 1997).

Zupancic, Alenka, The Odd One In: On Comedy (Cambridge, MA: MIT Press, 2008). 



\section{FILMOGRAPHY}

06. Dir. Theo van Gogh. Sc. Johan Doesburg. Cin. Tom Erisman. Perf. Ariane Schluter, Ad van Kempen. Dino Filmprodukties, 1994.

aAnmodderfakker. Dir. Michiel ten Horn. Sc. Anne Barnhoorn. Cin. Jasper Wolf. Perf. Gijs Naber, Roos Wiltink, Joke Tjalsma, Yannick van de Velde. Pupkin Film, 2014.

AB EL. Dir. Alex van Warmerdam. Sc. Alex van Warmerdam, Otakar Votocek, Frans Weisz. Perf. Alex van Warmerdam, Annet Malherbe, Olga Zuiderhoek, Henri Garcin. Cin. Marc Felperlaan. First Floor Features, 1986.

ALL StARs. Dir. Jean van de Velde. Sc. Mischa Alexander, Jean van de Velde. Cin. Jules van den Steenhoven. Perf. Danny de Munk, Antonie Kamerling, Daniel Boissevain, Peter Paul Muller. M+B Film BV, 1997.

alleen maAr nette mensen. Dir. Lodewijk Crijns. Sc. Robert Vuijsje, Lodewijk Crijns. Cin. Menno Westendorp. Perf. Géza Weisz, Imanuelle Grives, Jeroen Krabbé, Annet Malherbe. Topkapi Films, 2012.

Alles IS Liefde. Dir. Joram Lürsen. Sc. Kim van Kooten. Cin. Lex Brand. Perf. Carice van Houten, Jeroen Spitzenberger, Michiel Romeyn, Wendy van Dijk. Motel Films, Fu Works, Kemna Casting, 2007.

ALLeS IS faMilie. Dir. Joram Lürsen. Sc. Kim van Kooten. Cin. Lex Brand. Perf. Carice van Houten, Benja Bruijning, Thijs Römer, Jacob Derwig. Topkapi Films, 2012.

amsterdamned. Dir. Dick Maas. Sc. Dick Maas. Cin. Marc Felperlaan. Perf. Huub Stapel, Monique van de Ven, Hidde Maas, Wim Zomer. First Floor Features, 1988. 
BLACK OUt. Dir. Arne Toonen. Sc. Melle Runderkamp. Cin. Jeroen de Bruin. Perf. Raymond Thiry, Kim van Kooten, Edmond Classen, Simon Armstrong, Renée Fokker. Hazazah Pictures, Orange Film, 2012.

BLIND DATE. Dir. Theo van Gogh. Sc. Kim van Kooten, Theo van Gogh. Cin. Tom Erisman. Perf. Peer Mascini, Renée Fokker, Roeland Fernhout. Bergen Film \& TV, Theo van Gogh Produkties, 1996.

Blue movie. Dir. Wim Verstappen. Sc. Wim Verstappen, Charles Gormley. Cin. Jan de Bont. Perf. Hugo Metsers, Carry Tefsen, Helmert Woudenberg, Kees Brusse, Ursula Blauth. Scorpio Verstappen Films, 1971.

BODY AND soul. Dir. René Daalder. Sc. René Daalder. Cin. Jan de Bont. Perf. Gerard Oosterman. Scorpio Films N.V., 1966.

BON APPETIT. Dir. Wim T. Schippers (as Bill Masters), Wim van der Linden (W. Limetree). Sc. Wim T. Schippers. Cin. [not mentioned]. Perf. Emile van Konijnenburg, Puck Steinvoorte, Maurits Eichelsberg. Luxafilm, 1967.

BORGMAN. Dir. Alex van Warmerdam. Sc. Alex van Warmerdam. Cin. Tom Erisman. Perf. Jan Bijvoet, Hadewych Minis, Jeroen Perceval, Sara Hjort Ditlevsen. Graniet Film, Epidemic, Angel Films, 2013.

BRos before hos. Dir. Steffen Haars, Flip van der Kuil. Sc. Steffen Haars, Flip van der Kuil. Cin. Joris Kerbosch. Perf. Tim Haars, Daniël Arends, Sylvia Hoeks, Henry van Loon, Huub Smit. Eyeworks Film \& TV Drama, 2013.

CAMPING. Dir. Thijs Chanowski. Sc. Werkteater. Cin. Frans Bromet. Perf. Peter Faber, Olga Zuiderhoek, Rense Royaards, Joop Admiraal. Amstel Film, Chanowski Produkties, 1978.

CHA CHA. Dir. Herbert Curiël. Sc. Herbert Curiël, Herman Brood, Lene Lovich, Nina Hagen. Cin. Frans Bromet. Perf. Herman Brood, Nina Hagen, Lene Lovich, Les Chappell, Dolf Brouwers. Black Tulip, 1979.

CHEZ Nous. Dir. Tim Oliehoek. Sc. Frank Houtappels, Joan Nederlof. Cin. Rolf Dekens. Perf. Alex Klaasen, Peter Faber, Achmed Akkabi, Thomas Acda, Isa Hoes. BosBros TV- Film Productions, Ciné Cri de Coeur, 2013. 
CISKE DE RAT. Dir. Wolfgang Staudte. Sc. Wolfgang Staudte. Cin. Prosper Dekeukelaire. Perf. Kees Brusse, Dick van der Velde, Johan Kaart, Jenny Van Maerlant, Riek Schagen. Nederlandse Filmproductie Maatschappij, 1955.

CLOACA. Dir. Willem van de Sande Bakhuyzen. Sc. Maria Goos. Cin. Guido van Gennep. Perf. Pierre Bokma, Peter Blok, Jaap Spijkers, Gijs Scholten van Aschat. IDTV, 2003 .

DE AVonden. Dir. Rudolf van den Berg. Sc. Jean Ummels. Cin. Willy Stassen. Perf. Thom Hoffman, Rijk de Gooyer, Viviane de Muynck, Kees Hulst, Pierre Bokma. Praxino Pictures II, 1989.

de blinde fotograAf. Dir. Adriaan Ditvoorst. Sc. Adriaan Ditvoorst. Cin. Jan de Bont, Pim Tjujerman. Perf. Gees Linnebank, Roelant Radier, Elisabeth Hoytink, Frans Vorstman, Rudi Falkenhagen. Holland Prod, 1973.

de boekverfilming. Dir. Eddy Terstall. Sc. Eddy Terstall. Cin. Willem Nagtglas. Perf. Nadja Hüpscher, Femke Lakerveld, Alette Dirkse, Dirk Zeelenberg. DKP/Amsterdam, 1998.

De boezemvriend. Dir. Dimiri Frenkel Frank. Sc. Dimitri Frenkel Frank. Cin. Frans Bromet. Perf. André van Duin, Leen Jongewaard, Geert de Jong, Manouk van der Meulen, Jerome Reehuis, Vanessa. André van Duin Produkties, Joop van den Ende Filmproducties, 1982.

de dans van de Reiger. Dir. Fons Rademakers. Sc. Hugo Claus. Cin. Sacha Vierny. Perf. Jean Desailly, Gunnel Lindblom, Van Doude, Mien Duymaer Van Twist. Atlas Film, Jadran Film, Rademakers Productie BV, 1966.

De gelukkige huisvrouw. Dir. Antoinette Beumer. Sc. Marnie Blok, Karen van Holst Pellekaan. Cin. Bert Pot. Perf. Carice van Houten, Waldemar Torenstra, Joke Tjalsma, Jaap Spijkers. Eyeworks Film \& TV Drama, 2010.

DE ILLUsionist. Dir. Jos Stelling. Sc. Freek de Jonge, Jos Stelling. Cin. Theo van de Sande. Perf. Freek de Jonge, Jim van der Woude, Gerard Thoolen, Catherina Wolthuizen. Jos Stelling Produkties BV, 1983.

DE INBRe Ker. Dir. Frans Weisz. Sc. Chiem van Houweninge, Rob du Mée. Cin. Ferenc Kálmán-Gáll. Perf. Rijk de Gooyer, Jennifer Willems, Jon Bluming, Willeke van Ammelrooy. Parkfilm, 1972. 
De Johnsons. Dir. Rudolf van den Berg. Sc. Leon de Winter. Cin. Theo Bierkens. Perf. Monique van de Ven, Esmée de la Bretonière, Kenneth Herdigein, Rik van Uffelen. Meteor Film Productions, B.V. Lenox Holding Amsterdam, 1992.

DE JURK. Dir. Alex van Warmerdam. Sc. Alex van Warmerdam. Cin. Marc Felperlaan. Perf. Henri Garcin, Ariane Schluter, Alex van Warmerdam, Ricky Koole, Eric van der Donk. Graniet Film, 1996.

DE LIFT. Dir. Dick Maas. Sc. Dick Maas. Cin. Marc Felperlaan. Perf. Huub Stapel, Willeke van Ammelrooy, Siem Vroom, Gerard Thoolen. Sigma Pictures, 1983.

De mantel der liefde. Dir. Adriaan Ditvoorst. Sc. Adriaan Ditvoorst. Cin. Mat van Hensbergen. Perf. Joost Prinsen, Hans Boskamp, Moniek Toebosch, Rijk de Gooyer, Henk Molenberg, Jules Croiset. Luton Films, 1978.

De MARAthon. Dir. Diederick Koopal. Sc. Martin van Waardenberg, Gerard Meuldijk. Cin. Jeroen de Bruin. Perf. Stefan de Walle, Martin van Waardenberg, Marcel Hensema, Frank Lammers, Mimoun Oaïssa. Eyeworks Film \& TV Drama, 2012.

DE MINDER GELUKKIGE TERUGKEER VAN JOSZEF KATÚS NAAR HET LAND VAN REMBRANDT. Dir. Wim Verstappen. Sc. Wim Verstappen, Pim de la Parra. Cin. Wim van der Linden, Jan de Bont, Frans Bromet. Perf. Rudolf Lucieer, Etha Coster, Barbara Meter, Roelof Kiers. Scorpio Films N.V., 1966.

de Nieuwe moeder. Dir. Paula van der Oest. Sc. Paula van der Oest, Stan Lapinski. Cin. Birgit Hillenius. Perf. Janis Reinis, Arijs Adamsons, Geert de Jong. SNG Films, 1996.

DE NOORDERLINGEN. Dir. Alex van Warmerdam. Sc. Alex van Warmerdam. Cin. Marc Felperlaan. Perf. Rudolf Lucieer, Loes Wouterson, Jack Wouterse, Annet Malherbe, Alex van Warmerdam. First Floor Features, 1992.

De ontmaAgding VAn eva VAN END. Dir. Michiel ten Horn. Sc. Anne Barnhoorn. Cin. Jasper Wolf. Perf. Vivian Dierickx, Rafael Gareisen, Tomer Pawlicki, Abe Dijkman, Jacqueline Blom, Ton Kas. Pupkin Film, 2012.

De StILTE ROND CHRIStINe M. Dir. Marleen Gorris. Sc. Marleen Gorris. Cin. Frans Bromet. Perf. Edda Barends, Nelly Frijda, Henriëtte Tol, Cox Habbema, Dolf de Vries. Sigma Pictures, 1982. 
De SURPRISE. Dir. Mike van Diem. Sc. Mike van Diem, Karen van Holst Pellekaan. Cin. Rogier Stoffers. Perf. Jeroen van Koningsbrugge, Georgina Verbaan, Jan Decleir, Henry Goodman. N279 Entertainment, FATT Productions, Prime Time, Riva Filmproduktion, Fastnet Films, Isabella Films, 2015.

De tranen van maria machita. Dir. Paul Ruven. Sc. Mike van Diem, Paul Ruven. Cin. Mark van Aller. Perf. Ellen ten Damme, Ali Cifteci, Jacques Herb, Heddy Lester. Nederlandse Filmacademie, 1991.

de Verloedering van de swieps. Dir. Erik Terpstra. Sc. Heere Heeresma. Cin. Mat van Hensbergen. Perf. Ramses Shaffy, Hetty Verhoogt, Wies Andersen. Parkfilm, 1967.

de vierde man. Dir. Paul Verhoeven. Sc. Gerard Soeteman. Cin. Jan de Bont. Perf. Jeroen Krabbé, Renée Soutendijk, Thom Hoffman, Geert de Jong. Nedfilm \& Television B.V., 1983 .

de wederopstanding van een klootzak. Dir. Guido van Driel. Sc. Guido van Driel, Bas Blokker. Cin. Lennert Hillege. Perf. Yorick van Wageningen, Juda Goslinga, Goua Robert Grovogui, René Groothof, Jeroen Willems. Topkapi Films, Menuet, 2013.

De Wisselwachter. Dir. Jos Stelling. Sc. Jos Stelling, George Brugmans, Hans de Wolf. Cin. Frans Bromet, Goert Giltay, Theo van de Sande, Paul van den Bos. Perf. Jim van der Woude, Stéphane Excoffier, John Kraaykamp Sr., Josse De Pauw. Jos Stelling Produkties, 1986.

DIK тRoм. Dir. Arne Toonen. Sc. Luuk van Bemmelen, Wijo Koek, Mischa Alexander. Cin. Jeroen de Bruin. Perf. Michael Nierse, Marcel Musters, Eva van der Gucht, Thijs Römer, Loes Haverkort. Eyeworks Film \& TV Drama, Inspire Pictures, 2010.

dokter pulder zaAit Papavers. Dir. Bert Haanstra. Sc. Anton Koolhaas. Cin. Anton van Munster. Perf. Kees Brusse, Ton Lensink, Dora van der Groen, Henny Orri. Bert Haanstra Films, 1975.

DORP AAN DE RIVIER. Dir. Fons Rademakers. Sc. Hugo Claus. Cin. Eddy van der Enden. Perf. Max Croiset, Bernhard Droog, Jan Teulings, Mary Dresselhuys. Nationale Filmmaatschappij, 1958.

DUNYA \& DESIE. Dir. Dana Nechushtan. Sc. Robert Alberdingk Thijm. Cin. Bert Pot. Perf. Maryam Hassouni, Eva van de Wijdeven, Christine van Stralen, Theo Maassen, Rachida Iaallala. Lemming Film, A Private View, 2008. 
DUSKA. Jos Stelling. Sc. Hans Heesen, Jos Stelling. Cin. Goert Giltay. Perf. Gene Bervoets, Sergey Makovetskiy, Sylvia Hoeks. Eyeworks Egmond Film, Jos Stelling Films, 2007.

een vlucht regenwulpen. Dir. Ate de Jong. Sc. Ate de Jong. Cin. Paul van den Bos. Perf. Jeroen Krabbé, Willeke van Ammelrooy, Marijke Merckens, Henriëtte Tol. Sigma Pictures, 1981.

een zwoele zomeravond. Dir. Frans Weisz, Shireen Strooker. Sc. Marja Kok. Cin. Robby Müller. Perf. Marja Kok, Helmert Woudenberg, Gerard Thoolen, Hans Man in 't Veld, Joop Admiraal. Werkteater, 1982.

FANFARE. Dir. Bert Haanstra. Sc. Jan Blokker Sr., Bert Haanstra. Cin. Eddy van der Enden. Perf. Hans Kaart, Bernhard Droog, Albert Mol, Wim van den Heuvel, Ineke 382 | Brinkman. Sapphire Film, 1958.

FILMPJe! Dir. Paul Ruven. Sc. Paul Ruven, Paul de Leeuw. Cin. Theo Bierkens. Perf. Paul de Leeuw, Rijk de Gooyer, Olga Zuiderhoek. Joop van den Ende TV Producties BV, Filmpje BV, 1995 .

FLodder. Dir. Dick Maas. Sc. Dick Maas. Cin. Marc Felperlaan. Perf. Nelly Frijda, Huub Stapel, René van ‘t Hof, Tatjana Simic, Lou Landré. First Floor Features, 1986.

FLOdder IN AMERIKA! Dir. Dick Maas. Sc. Dick Maas. Cin. Marc Felperlaan. Perf. Nelly Frijda, Huub Stapel, René van 't Hof, Tatjana Simic, Lou Landré. First Floor Features, 1992.

FLo RIS. Dir. Jean van de Velde. Sc. Gerard Soeteman, Jean van de Velde. Cin. Jules van den Steenhoven. Perf. Michiel Huisman, Birgit Schuurman, Linda van Dyck, Victor Löw. Nijenhuis \& de Levita Film en TV BV, 2004.

frank \& eVa: living apart together. Dir. Pim de la Parra. Sc. Pim de la Parra, Charles Gormley. Cin. Frans Bromet. Perf. Hugo Metsers, Willeke van Ammelrooy, Lex Goudsmit, Sylvia Kristel. Scorpio Films N.V., 1973.

ge en PaNiek. Dir. Ko Koedijk. Sc. Kees van Kooten. Cin. Ray Parslow. Perf. John Kraaykamp Sr., Rijk de Gooyer, Hetty Blok, Eddie Constantine. City Film, 1973.

GOOISCHE VROUWEN. Dir. Will Koopman. Sc. Frank Houtappels. Cin. Tom Erisman. Perf. Linda de Mol, Peter Paul Muller, Tjitske Reidinga, Susan Visser, Lies Visschedijk, Alex Klaasen. Talpa Fictie N.V., 2011. 
GoOISCHE VROUWEN 2. Dir. Will Koopman. Sc. Frank Houtappels. Cin. Tom Erisman. Perf. Linda de Mol, Peter Paul Muller, Tjitske Reidinga, Susan Visser, Lies Visschedijk, Alex Klaasen. Talpa Fictie N.V., 2014.

GRIJPSTRA \& DE GIER. Dir. Wim Verstappen. Sc. Wim Verstappen. Cin. Marc Felperlaan. Perf. Rijk de Gooyer, Rutger Hauer, Willeke van Ammelrooy, Donald Jones, Jaap Stobbe, Olaf Wijnants. Nedfilm \& Television B.V., 1979.

GRIMM. Dir. Alex van Warmerdam. Sc. Alex van Warmerdam. Cin. Tom Erisman. Perf. Jacob Derwig, Halina Reijn, Carmelo Gómez, Ulises Dumont. Graniet Film, 2005.

hartenstraAt. Dir. Sanne Vogel. Sc. Judith Goudsmit. Cin. Ezra Reverda. Perf. Marwan Kenzari, Bracha van Doesburgh, Egbert-Jan Weeber, Tygo Gernandt, Benja Bruijning. Bridge Entertainment Group, RTL Entertainment, 2CFILM, 2014.

Help! De dokter Verzuipt. Dir. Nikolai van der Heyde. Sc. Felix Thijssen. Cin. Jörgen Persson. Perf. Jules Croiset, Willeke van Ammelrooy, Martine Bijl, Piet Bambergen. Fuga Film Produkties, 1974.

het eChte Leven. Dir. Robert Jan Westdijk. Sc. Robert Jan Westdijk. Cin. Menno Westendorp. Perf. Sallie Harmsen, Ramsey Nasr, Loek Peters, Loes Haverhort. IDTV Film, 2008.

het gangstermeisje. Dir. Frans Weisz. Sc. Remco Campert, Jan Blokker Sr., Frans Weisz. Cin. Gerard van den Berg. Perf. Paolo Graziosi, Astrid Weyman, Kitty Courbois, Gian Maria Volonté. Jan Vrijman Cineproduktie, 1966.

het SCHNITZelparadius. Dir. Martin Koolhoven. Sc. Marco van Geffen. Cin. Guido van Gennep. Perf. Mounir Valentyn, Bracha van Doesburgh, Mimoun Oaïssa, Yahya Gaier, Sabri Saad El Hamus. Lemming Film, 2005.

het WonderliJke LeVen VAN WILlem Parel. Dir. Gerard Rutten. Sc. Eli Asser, Joop Geesink. Cin. Bob Crispijn. Perf. Wim Sonneveld, Peronne Hosang, Femke Boersma, Hans Kaart. Dollywood Studio, 1955.

hoge hakken, echte Liefde. Dir. Dimitri Frenkel Frank. Sc. Dimitri Frenkel Frank. Cin. Paul van den Bos. Perf. Rijk de Gooyer, Monique van de Ven, Geert de Jong. Verenigde Nederlandsche Filmcompagnie, 1981. 
IK ben Joep meloen. Dir. Guus Verstraete, jr. Sc. Vince Powell. Cin. Mat van Hensbergen. Perf. André van Duin, Corry van Gorp, Frans van Dusschoten. Andre van Duin Produkties, Joop van den Ende Filmproducties, 1981.

îles flottantes. Dir. Nanouk Leopold. Sc. Nanouk Leopold. Cin. Benito Strangio. Perf. Maria Kraakman, Manja Topper, Halina Reijn. Circe Films, Motel Films, 2001.

INTERVIEW. Dir. Theo van Gogh. Sc. Theodor Holman. Cin. Thomas Kist. Perf. Pierre Bokma, Katja Schuurman. Column Film, 2003.

ja zUSter, Ne zuster. Dir. Pieter Kramer. Sc. Frank Houtappels, Pieter Kramer. Cin. Piotr Kukla. Perf. Loes Luca, Paul R. Kooij, Tjitske Reidinga, Waldemar Torenstra, Paul de Leeuw. BosBros Film- TV Productions, 2002.

384 JENNY. Dir. Willy van Hemert. Sc. Erich Waschneck, Hanns H. Fischer, Carlotta Textor, Willy van Hemert. Cin. Otto Baecker. Perf. Ellen van Hemert, Maxim Hamel, Teddy Schaank, Kees Brusse, Andrea Domburg, Ko van Dijk. Standaard-Films, 1958.

KLEINE TEUN. Dir. Alex van Warmerdam. Sc. Alex van Warmerdam. Cin. Marc Felperlaan. Perf. Alex van Warmerdam, Annet Malherbe, Ariane Schluter. Graniet Film, 1998.

Komedie OM GELD. Dir. Max Ophüls. Sc. Walter Schlee, Max Ophüls, Max de Haas. Cin. Eugen Schüfftan. Perf. Herman Bouber, Rini Otte, Cor Ruys. Will TuschinskiCinetone, 1936.

KOMt eEN VROUW BIJ DE DoKTER. Dir. Reinout Oerlemans. Sc. Gert Embrechts. Cin. Lennert Hillege. Perf. Barry Atsma, Carice van Houten, Anna Drijver. Eyeworks Film \& TV Drama, 2009.

KUtzooı. Dir. Lodewijk Crijns. Sc. Lodewijk Crijns. Cin. Hans Bouma. Perf. Randy Groeneschey, Leto van Olffen, Paulo Sorber. Nederlandse Film en Televisie Academie, 1995 .

LAP ROUge. Dir. Lodewijk Crijns. Sc. Lodewijk Crijns. Cin. Menno Westendorp. Perf. Egbert Joosten, Herman Joosten, Emmanuelle Maridjan-Koop. Nederlandse Film en Televisie Academie, 1997.

MAKKERS STAAKT UW WILD GERAAS. Dir. Fons Rademakers. Sc. Jan Blokker Sr., Fons Rademakers. Cin. Eddy van der Enden. Perf. Ellen Vogel, Guus Hermus, Guus Oster, Yoka Berretty, Ank van der Moer, Jan Teulings. Nederlandse Filmproductie Maatschappij, 1961. 
MAMA IS Boos! Dir. Ruud van Hemert. Sc. Ruud van Hemert. Cin. Theo van de Sande. Perf. Peter Faber, Geert de Jong, Adelheid Roosen, Rijk de Gooyer. Independent Films, 1986.

MAN IN DE WAR. Dir. Joost Ranzijn. Sc. Jane Waltman. Cin. Erik van Empel. Perf. Peter Bos, Rosmarie Blaauboer, Carl van der Plas, Gusta Gerritsen. Zirkelfilms, 1984.

Matterhorn. Dir. Diederik Ebbinge. Sc. Diederik Ebbinge. Cin. Dennis Wielaert. Perf. Ton Kas, René van 't Hof, Ariane Schluter, Porgy Franssen. Column Film, 2013.

Met GRote bliJdschap. Dir. Lodewijk Crijns. Sc. Kim van Kooten, Lodewijk Crijns. Cin. Joost van Gelder. Perf. Jaap Spijkers, Jack Wouterse, Renée Soutendijk, Michel Vermey. Motel Films, 2001.

mijn nachten met susan, olga, albert, julie, piet \& Sandra. Dir. Pim de la Parra. Sc. Carel Donck, Harry Kümel, Pim de la Parra, Charles Gormley. Cin. Marc Felperlaan. Perf. Willeke van Ammelrooy, Hans van der Gragt, Nelly Frijda, Serge-Henri Valcke. Scorpio Films N.V., 1975.

MOordWIJVen. Dir. Dick Maas. Sc. Dick Maas. Cin. Guido van Gennep. Perf. Bracha van Doesburgh, Sanne Wallis de Vries, Hadewych Minis, Hans Kesting. Parachute Pictures/TDMP, 2007.

NAAKt over de schutting. Dir. Frans Weisz. Sc. Rinus Ferdinandusse, Rob du Mée. Cin. Ferenc Kálmán-Gáll. Perf. Rijk de Gooyer, Jon Bluming, Jennifer Willems, Sylvia Kristel, Adèle Bloemendaal, Ton Lensink. Parkfilm, 1973.

NAAR DE KLOTE! dir. Ian Kerkhof. Sc. Ton van der Lee, Ian Kerkhof. Cin. Joost van Gelder. Perf. Fem van den Elzen, Tygo Gernandt, Hugo Metsers III, Thom Hoffman, Mike Libanon, Jorinde Moll. Sahara Film, 1996.

NACHTRIT. Dir. Dana Nechushtan. Sc. Franky Ribbens. Cin. Bert Pot. Perf. Frank Lammers, Fedja van Huêt, Peggy Jane de Schepper. Waterland Film \& TV.

NEW KIDS TURBO. Dir. Steffen Haars, Flip van der Kuil. Sc. Steffen Haars, Flip van der Kuil. Cin. Joris Kerbosch. Perf. Huub Smit, Wesley van Gaalen, Tim Haars, Steffen Haars, Flip van der Kuil. Eyeworks Film \& TV Drama, 2010.

OBER. Dir. Alex van Warmerdam. Sc. Alex van Warmerdam. Cin. Tom Erisman. Perf. Alex van Warmerdam, Jaap Spijkers, Mark Rietman, Thekla Reuten, Ariane Schluter, Lyne Renée, René van 't Hof. Graniet Film, La Parti Productions, 2006. 
он воY! Dir. Orlow Seunke. Sc. Orlow Seunke. Cin. Marc Felperlaan. Perf. Orlow Seunke, Kees van Kooten, Monique Smets, Peer Mascini, Jim van der Woude. First Floor Features, 1991.

PARANoIA. Dir. Adriaan Ditvoorst. Sc. Adriaan Ditvoorst. Cin. Jan de Bont. Perf. Kees van Eyk, Pamela Koevoets, Rudolf Lucieer, Mimi Kok. Parnasse Produkties Amsterdam, 1967 .

PHILEINE Zegt SORRY. Dir. Robert Jan Westdijk. Sc. Robert Jan Westdijk. Cin. Bert Pot. Perf. Kim van Kooten, Michiel Huisman, Hadewych Minis, Tara Elders. Fu Works, Motel Films, 2003.

PLAN C. Dir. Max Porcelijn. Sc. Max Porcelijn. Cin. Coen Stroeve. Perf. Ruben van der Meer, René van ‘t Hof, Ton Kas, Kees Hulst, Rifka Lodeizen. LEV Pictures, CTM Films, 2012.

PRINs. Dir. Sam de Jong. Sc. Sam de Jong. Cin. Paul Özgür. Perf. Ayoub Elasri, Elsie de Brauw, Olivia Lonsdale, Sigrid ten Napel, Freddy Tratlehner. 100\% Halal, Vice Media, 2015 .

RABat. Dir. Jim Taihuttu, Victor Ponten. Sc. Jim Taihuttu, Victor Ponten. Cin. Lennart Verstegen. Perf. Nasrdin Dchar, Marwan Kenzari, Achmed Akkabi, Stéphane Caillard. Habbekrats, 2011.

RENT A FRIEND. Dir. Eddy Terstall. Sc. Eddy Terstall. Cin. Stefan Bijnen. Perf. Marc van Uchelen, Rifka Lodeizen, Nadja Hüpscher, Peer Mascini. Jordaan Film, 2000.

SCHATJes! Dir. Ruud van Hemert. Sc. Ruud van Hemert, Thijs Ockersen. Cin. Theo van de Sande. Perf. Peter Faber, Geert de Jong, Akkemay, Frank Schaafsma, Rijk de Gooyer. Meteor Film Productions, 1984.

SCHNEIDER VS. BAX. Dir. Alex van Warmerdam. Sc. Alex van Warmerdam. Cin. Tom Erisman. Perf. Tom Dewispelaere, Alex van Warmerdam, Maria Kraakman, Annet Malherbe, Loes Haverkort. Graniet Film, 2015.

SHouf SHouf HABIBı! Dir. Albert ter Heerdt. Sc. Albert ter Heerdt, Mimoun Oaïssa. Cin. Steve Walker. Perf. Mimoun Oaïssa, Touriya Haoud, Mimoun Ouled Radi, Mohammed Chaara. Theorema Films, 2004.

sıMon. Dir. Eddy Terstall. Sc. Eddy Terstall. Cin. Willem Nagtglas. Perf. Cees Geel, Marcel Hensema, Rifka Lodeizen, Nadja Hüpscher. Spaghetti Film B.V., 2004. 
SINT. Dir. Dick Maas. Sc. Dick Maas. Cin. Guido van Gennep. Perf. Bert Luppes, EgbertJan Weeber, Huub Stapel, Caro Lenssen. Tom de Mol Productions, Parachute Pictures/TDMP, 2010.

SPET TE RS. Dir. Paul Verhoeven. Sc. Gerard Soeteman. Cin. Jost Vacano. Perf. Hans van Tongeren, Toon Agterberg, Maarten Spanjer, Renée Soutendijk, Rutger Hauer, Jeroen Krabbé. VSE Film BV, 1980.

SUMMER IN THE fields. Dir. Wim T. Schippers, Wim van der Linden. Sc. Wim T. Schippers. Cin. W. Crocus. Perf. Will van Selst, Sarah Brackett. Julius Patsenhofer, 1967.

suzY Q. Dir. Martin Koolhoven. Sc. Frouke Fokkema. Cin. Menno Westendorp. Perf. Carice van Houten, Linda van Dyck, Jack Wouterse, Roeland Fernhout, Michiel Huisman. Staccato Films, 1999.

Theo \& thea en de ontmaskering Van het tenenkaAsimperium. Dir. Pieter Kramer. Sc. Arjan Ederveen, Tosca Niterink. Cin. Erik Zuyderhoff. Perf. Arjan Ederveen, Tosca Niterink, Marco Bakker, Adèle Bloemendaal. Van den Beginnen, 1989.

TURKS FRUIT. Dir. Paul Verhoeven. Sc. Gerard Soeteman. Cin. Jan de Bont. Perf. Rutger Hauer, Monique van de Ven, Tonny Huurdeman, Hans Boskamp. Verenigde Nederlandsche Filmcompagnie, 1973.

tussenstand. Dir. Mijke de Jong. Sc. Jolein Laarman. Cin. Ton Peters. Perf. Elsie de Brauw, Marcel Musters, Stijn Koomen, Jeroen Willems. Lemming Film, 2007.

VENTOUX. Dir. Nicole van Kilsdonk. Sc. Bert Wagendorp, Nicole van Kilsdonk. Cin. Anton Mertens. Perf. Kasper van Kooten, Wilfried de Jong, Martijn Lakemeier, Alex Hendrickx. KeyFilm, 2015.

VET HARD. Dir. Tim Oliehoek. Sc. Jan Verheyen, Wijo Koek, Jean-Claude van Rijckeghem. Cin. Rolf Dekens. Perf. Jack Wouterse, Jaak Van Assche, Kurt Rogiers, Bracha van Doesburgh. Fu Works, Clockwork Pictures, Thura Film, Motel Films, 2005.

vox POPULı. Dir. Eddy Terstall. Sc. Eddy Terstall. Cin. Gábor Deák. Perf. Thom Jansen, Ton Kas, Femke Lakerveld, Esmarel Gasman. Spaghetti Film BV, 2008.

WAT ZIEN IK!? Dir. Paul Verhoeven. Sc. Gerard Soeteman. Cin. Jan de Bont. Perf. Ronnie Bierman, Sylvia de Leur, Piet Römer, Bernhard Droog. Verenigde Nederlandsche Filmcompagnie, 1971. 
WILDE Mossels. Dir. Erik de Bruyn. Sc. Erik de Bruyn. Cin. Joost van Gelder. Perf. Fedja van Huêt, Frank Lammers, Frederik Brom, Will van Kralingen, Angelique de Bruijne. Argus Film Produktie BV, 2000.

WILdschut. Dir. Bobby Eerhart. Sc. Felix Thijssen. Cin. Paul van den Bos. Perf. Hidde Maas, Jack Monkau, Josse de Pauw, Annick Christiaens, Werther Van Der Sarren. Cine, Kunst en Kino, Maggan Films, Vista, 1985.

Wonderbroeders. Dir. Johan Timmers. Sc. Martin van Waardenberg. Cin. Jeroen de Bruin. Perf. Kees Hulst, Ton Kas, Egbert Jan Weeber, Thomas Acda, Martin van Waardenberg, Noortje Herlaar. Eyeworks Film \& TV Drama, 2014.

zomвıвı. Dir. Erwin van den Eshof, Martijn Smits. Sc. Tijs van Marle. Cin. Joost van Herwijnen. Perf. Gigi Ravelli, Yahya Gaier, Mimoun Ouled Radi. Talent United Film \& 388 | TV, 2012.

zus Je. Dir. Robert Jan Westdijk. Sc. Robert Jan Westdijk, Jos Driessen. Cin. Bert Pot. Perf. Kim van Kooten, Roeland Fernhout, Ganna Veenhuysen. Grote Broer Filmwerken, 1995 .

ZWAARMOEDIGE VERHALEN VOOR BIJ DE CENTRALE VERWARMING. Dir. Bas van der Lecq, Guido Pieters, Ernie Damen, Nouchka van Brakel. Sc. Guus Luijters. Cin. Theo van de Sande. Perf. Rijk de Gooyer, Johnny Kraaykamp Sr., Hugo Metsers, Pleuni Touw. Sigma Pictures, 1975 . 


\section{PHOTO CREDITS}

Cover

BORGMAN @ Drafthouse Films. Design: Brandon Schaefer.

Plate 1

FANFARE ( The Art of Poster Gallery, Piotr Dabrowski's collection. Design: Franciszek Starowieyski.

Plate 2

DE WISSELWACHTER ( ) Jos Stelling Films, Collection EYE. Photo: Michael Kooren.

Plate 3

De WisselWaChTER @ Jos Stelling Films, Collection EYE. Photo: Michael Kooren.

\section{Plate 4}

DE WiSSElWACHTER ( ) Homework Studio, Warsaw. Design: Joanna Gorska and Jerzy Skakun.

\section{Plate 5}

DE NoORderLingen $\odot$ Graniet Film, Collection EYE. Photo: Fran van der Hoeven.

\section{Plate 6}

DE NOORDERLINGEN @ Graniet Film. Photo: Fran van der Hoeven.

Plate 7

DE NOORDERLINGEN @ Graniet Film. Design: Alex van Warmerdam. 
Plate 8

FLODDER IN AMERIKA! @ First Floor Features, Collection EYE. Photo: Victor Arnolds.

Plate 9

NEW Kids Turbo @ Eyeworks Film \& TV Drama. Photo: Victor Arnolds.

Plate 10

Het SCHNitZelPARADijs @ Lemming Film, Collection EYE. Photo: Victor Arnolds.

\section{Plate 11}

Een ZWOele zomeravond @ Het Werkteater, Collection EYE. Photo: Anneclaar Bijleveld.

Plate 12

390 JA zUSTER, NEE zUSTER @ BosBros Film. Photo: Victor Arnolds.

Plate 13

CHA CHA @ Black Tulip Films, Collection EYE. Photo: Herbert Curiel, Jr.

Plate 14

DE MARATHON ( E) Eyeworks Film \& TV Drama. Photo: Pief Weyman.

Plate 15

OBER ( $\odot$ Graniet Film. Photo: Victor Arnolds.

Plate 16

BORGMAN $\odot$ Graniet Film. Photo: Victor Arnolds.

Plate 17

De Wederopstanding VAN EEN KLOOTZAK @ T Topkapi Films. Photo: Pief Weyman.

Plate 18

GRIMM ๑ Graniet Film. Photo: Victor Arnolds.

Plate 19

DE LAATSTE DAGEN VAN EMma Blank @ Graniet Film. Photo: Victor Arnolds.

Plate 20

AANMODDERFAKKer @ P Pupkin Film. Photo: Jasper Wolf. 


\section{Plate 21}

AANMODDERFAKKER @ Pupkin Film. Photo: Jasper Wolf.

Plate 22

AANMODDERFAKKER (C) Pupkin Film. Photo: Jasper Wolf.

\section{Plate 23}

DE JURK () Graniet Film. Photo: Fran van der Hoeven.

\section{Plate 24}

BLACK Out @ Hazazah Pictures. Photo: Victor Arnolds.

Plate 25

DE MANTEL DER LIEFDE @ Erven Ditvoorst. Collection EYE.

Plate 26

JA ZUSTER, NEE ZUSTER @ BosBros Film. Photo: Victor Arnolds.

\section{Plate 27}

JA ZUSTER, NEE zUSTER (C) BosBros Film. Photo: Victor Arnolds.

Plate 28

SPETTERS $\odot$ MGM, Collection EYE. Photo: Sabina Sarnitz.

Plate 29

SPETTERS @ MGM, Collection EYE. Photo: Sabina Sarnitz. 



\section{INDEX OF CONCEPTS}

Absurdism 149, 230, 234-5, 273, 276,

Comedy of remarriage 128, 133-7

279-82, 286, 295, 315, 330, 336n28, 352n1, 359n16, 359n22

Cult 58, 153-4, 160, 162, 165, 174, 190, $330,345 \mathrm{n} 2$

Anachronism 10, 84, 173-4, 198, 288

Anti-bourgeois 178, 182, 187, 190, 192, 198, 263, 268-9

Banality 31, 48, 64, 74-5, 83, 131, 142, 190, 264, 281, 289, 295, 322-3, 332, $340 \mathrm{n} 3,365 \mathrm{n} 21$

Bromance 219-21, 226

Calvinism 20, 233, 254, 271-2, 274-5, 288, 330, 361n 31

Camp 40, 149, 152-6, 161-2, 165, 167, 169-74, 289, 329-30, 345n4, 346n6 deliberate 146, 156, 165-7, 169, 172-4, 288, 328, 346n11 naïve $155^{-6}, 174,190$

Canon 13-4, 114, 153-4

Caricature 75, 146 278, 316

Carnivalesque 26, 40, 48, 63, 74, 83, 91

Cartoon 54, 73, 75, 333n 5

Cartoonish 24, 54, 73, 79, 207, 216, 294, 296, 301-2, 364n11

Dédoublement 249

Demand 29, 39, 57-8, 61, 94, 140, 161, 183, 194, 211, 268, 289-90, 301, 306, 317,331

Desire 33, 36, 51, 56-8, 62-3, 66, 76, 91, 143-4, 162-3, 166, 171, 182, 209-10, 221, 223-4, 226-7, 247, 267, 270-2, $279,281,324,345 \mathrm{n} 4$

Drive 57

Exaggeration 49, 71, 76, 78, 84, 91, 101, 109, 119, 126, 151, 153, 161, 170, 207, 295, 299-300, 325, 328, 345n1

Excess 23, 35, 67, 71, 91-2, 98, 147-8, 155, 63-5, 167, 173, 198, 273, 275, 288, 302

Femme céleste 321

Fetishism 136-7, 156, 224

Focalization 89, 94, 184, 217, 270, 275, 359n21

Censorship 179-80, 182, 293

Cinema Egzotik 154, 345n3 
Grotesque 6o, 149, 290, 294-9, 302, 305-6, 309, 316-8, 322-5, 327, 332, $362 n_{3}, 262 n_{4}$

caricature 296, 299-301, 325, 332 irony 296, 305-8, 310-1, 324, 332, 364n16, 365n17 satire $296,311,316-7324,332$, $365 \mathrm{n} 18$

Hard-core art 177-8

Hollandse School 20-2

Homosexual panic 204, 209-10, 213-4

Homosexuality 155, 157, 173-4, 209-14, 216, 218, 221, 345n 4

394 | Homosocial relations 207-9, 212, 217-8, 220, 223-4, 226-7

Horror 9-10, 22, 50, 54-5, 57-8, 153-4, $163,196-8,282,284-6,324,362 n_{4}$

Horror comedy 54-5, 153, 195-8, 288, 307, 322, 349n16

Humour

amoral 35, 71, 74, 338n16

black 40, 245, 286, 305, 324, 331

blue $45^{-6}$

bodily 26

British 22-3

Freudian 37-40, 331-2

incongruity (theory) 29-31, 71, 80, 98, 100, 139, 141, 192, 276, 294, 328, 362n1

Jewish 22, 334n15

low-class $13,35,79-80$

relief (theory) 31-2, 41, 61, 71, 79, 120, 138, 197, 213, 284

scatological 26, 46

superiority (theory) 27-9, 31, 34, 37, 39, 74, 79, 109, 116, 206, 249-50, $255,327,331,365^{-66 n 1}$

Hyperbole 40, 70-1, 73-4, 79, 206-7, 2967, 301-2
Iconophobia $274-5$

Irony

cosmic 253-4, 259, 289, 305-6, $364 n 13$

deadpan 9, 20-1, 38, 40, 149, 222, 247, 255-6, 266, 273, 279, 283, 324, $330,332,335,361-2 \mathrm{n} 31$

dramatic 164

free-floating 142-4, 329

of fate $305-7,317,324,364 \mathrm{n} 15$

of irony $322-3,365 \mathrm{n} 22$

romantic $335 \mathrm{n} 21$

unstable 281,288

Joke 9, 22, 28-41, 53, 61, 64, 66, 68, 70-1, 73-4, 77, 79-80, 83, 86, 96, 98-100, 107-9, 131, 134, 139-40, 146, 157, 159-60, 164, 170-1, 174, 182-4, 187-8, 196-7, 202, 208-9, 215-8, 220, 226, 253-5, 259, 274-5, 284, 288, 293, 302, 317, 327, 330-2, 335n22, 336n24, 337n4, 338n16, 343-4n18 35on $5,366 \mathrm{n}_{4}, 366 \mathrm{n}_{5}$

Freudian 33-4, 37-8 40, 327, 330-2, $336 \mathrm{n} 24$ racial $33,36,83,86,96,107-9$, $338 \mathrm{n} 16$ sexist $33,64,66,139-40$

Laughter 26-29, 31-2, 38-40, 45, 48, 51, $54,56,61,63,72,74,83,95,97-9$, 208, 114, 131, 142, 144, 147-8, 152, 169, 195-6, 208, 211, 232-3, 249-50, 255-6, 293-4, 299, 301, 313-4, 325, $327,330-1,354 \mathrm{n} 18,356-7 \mathrm{n}_{3}, 366 \mathrm{n} 5$ carnival $26,63,83$ subversive 40

Melodrama 115, 144, 156, 162-3 165, 296, $351 \mathrm{n} 16$ 
National cinema $17,19-20$

Neo-realism 263

Neurotic comedy 115, 128, 138, 141, 255, 329, 334n15

Nouvelle violence 294, 299-300, 303

On/scenity 177

Ontological status 244, 246, 255, 258, 330

Overidentification 99

Paracinema 153

Parody 77, 79, 144, 152, 158, 16o-1, 165, 173, 265, 283, 346ng, 349n17

Pastiche 10, 173, 284-6

Persiflage 40, 151-2, 158, 160, 182

Pillarization 146-8, 329

Play / play-act 62, 65, 69, 72, 118-9, 139, 229-30, 239-40, 242-5, 250-1, 253-4, 264, 279-80, 286-7, 289, 318-9, 330$1,335 \mathrm{n} 19,345^{\mathrm{n}} 4$

Plurality 282, 330

Porn chic 182-3

Porn movie 181-2

Primary and secondary level 243-4, 251, 254-5

Psychoanalysis $33,57-8,138-9,270-1$

Quirky 225, 258, 310, 351n16

Rewatchability 366n6

Ridicule 27-30, 32-4, 37, 56, 64, 71-2, 74, 99-100, 105, 108, 142, 166, 182-3, 198, 208, 239, 269, 283, 293, 301-3, $311,324-5,331-2,335^{n 23}, 358 \mathrm{n} 13$

Road movie 84, 101-5, 282, 286, 340n6, 340n7

Sarcasm 17, 24, 54-5, 118, 194, 206, 219, 269, 311, 317, 319, 331, 337ng
Satire $25,40,63,101,170,173,207$, 238-9, 265, 268-9, 271, 289, 294, 296, 311, 316-7, 322-5, 332

Sex scenes 61, 178-80, 192, 186, 300 Slasher 57, 196, 338n11, 349n17

'Smart' cinema 247-8

Stereotype 28, 65, 71, 91, 98-100, 109, 160-1, 171, 203, 211, 215, 218, 283, 329, 340n $3,346 \mathrm{n} 10$ class $28,65,71,92,34003$ ethnic 91-2, 98-100, 109, 283, 328-9 gender 203, 211, 218 sexual 150-1, 171, 203, 215, 346n1o

Strategic ambiguity 87, 90-2, 109, 144, 329

Superego 37

Superhero films 145

Surrealism 149, 270-1, 275, 295, 312, $318,322-4,359 n 21$

Tendentious thought $33,327-8,336 \mathrm{n} 25$

Tolerance $35^{-6}, 65,73,84,146-8,174$, 206, 329, 350-1n10

Tongue-in-cheek 95, 115, 128, 137, 169, 173, 265-7, 320, 322

Unconscious $33,37,58,270,275$

Wit 29, 33, 45, 157, 160-1, 166, 173-4, 33o, 335n18, 336n25, 351n14

Zombie film 58, 77, 195, 197, 257, 349n16 



\section{INDEX OF FILMS}

o6 17, 193-95, 348n13

o6/05 193

9 Songs 178

2001: A Space Odyssey 144

À bout de souffle $263-4$

A Day at the Beach $357-8 \mathrm{n} 8$

A Serious Man 253

Aanmodderfakker 10, 256-9, 355n21, $355^{\mathrm{n} 22}, 35^{6 \mathrm{n} 23}, 35^{6 \mathrm{n} 24}, 35^{6 \mathrm{n} 25}$, $356 \mathrm{n} 26$

Abel 275-9, 287, 359n21, 36on24, Ai no korîda 177

Alibi 92

All about Eve 155

All in the Family 108, 341ng

All Stars 23, 210-4, 346n10, 350n5, 35on6, 350n7

All Stars 2: Old Stars 102

All that Heaven Allows 156

Alleen maar nette mensen 339-40n3

Allemaal film 20, 334n11, 359n19

Alles is familie 133,137

Alles is liefde 24, 132-7, 144-6, 148, 170, 197

Amazones 138

American Beauty 174
American History X 205, 225
Amsterdamned 196, 349n15

An American in Paris 181

Animal House 338n15

Annie 53

Antenna $365 \mathrm{n} 18$

Antonia 15

Basic Instinct 151, 189, 206

Batman Begins 346ng

Because of the Cats 154

Being John Malkovich 247

Belle de Jour 269, 271

Ben-Hur 345n 4

Bin-Jip 284

Black Out 76, 296-301, 324, 363n6, $363 n 8$

Blackwater Fever 102

Bleeke Bet 48, 114-5

Blind Date (1996) 194, 348n13

Blind Date (2007) 348n13

Blue Movie 14, 24, 179-82, 203, 289, $347 \mathrm{n} 3$

Blue Velvet 151

Boda secreta 18

Body and Soul $265-8$ 
Boefje 114-5

Bon Appetit 346n 5, 356-7n 3

Borgman 10, 15, 41, 284-7, 289, 305, $324,360 n 23,361 \mathrm{n} 28$

Boven de bergen 101

Brandende liefde 14, 186

Braveheart 225

Bringing Up Baby 133-5, 299

Brokeback Mountain 174

Bros before Hos 219-27, 351n15

Camping 230-1, 254

Carna $365 \mathrm{n} 18$

Casino Royale 346ng

398 | Cha Cha 191-2, 198, 347-8n7

Charade 149

Charley 193

Chez Nous 170-2

Ciske de rat (1955) 9, 18, 24, 114-5, 117-

9, 122-3, 144, 262

Ciske de rat (1984) 24, 53, 122-23

Cléo: de 5 à 7104

Clerks 225-6

Cloaca 351-2n17

Coach 92

Costa! 225

Crimes and Misdemeanors 307

Cruising 205

Dakota $347 \mathrm{n} 3$

De 1,2,3 rhapsodie $\mathbf{2 6 1 - 2}$

De aanslag $14-5$

De Antikrist 313

De avonden 42, 360-1n24

De blinde fotograaf $311-3,323,365$ n 20

De boekverfilming 353-4n10

De boezemvriend 46-7

De dans van de reiger 42, 336n28

De Fred Haché Show 47, 348n8

De gelukkige huisvrouw 138-40

De gulle minnaar 14
De illusionist 231-4, 330, 352n3

De inbreker 154, 313

De Jantjes 48, 114

De Johnsons 154

De jurk 280-2, 359n18

De lift $195^{-6}$

De mantel der liefde 205, 311, 313-17, $324,332,365 \mathrm{n} 21$

De marathon 217-20, 224, 227, 351n12, $351 \mathrm{n} 13,351 \mathrm{n} 14$

De Masters 92, 148

De minder gelukkige terugkeer van Joszef Katús naar het land van Rembrandt 262-5, 268

De nacht van de wansmaak 153, 205

De nieuwe moeder 101-2, 335n 18

De Noorderlingen 20, 23, 271-4, 281, $283,358 \mathrm{n} 13$

De ontmaagding van Eva van End $362 n 31$

De overgave 165

De poel 196

De Poolse bruid 17

De president 92

De ratelrat $337 \mathrm{n} 4$

De smaak van water 238

De stilte rond Christine M. 38-40, $336 \mathrm{n} 27$

De surprise 148-49

De tranen van Maria Machita 162-5, 184, 346n11

De val 365n18

De verloedering van de Swieps 268-9, 358ng

De vierde man 317-24, 332, 365n22

De vliegende Hollander 234

De wederopstanding van een klootzak 302-5, 324

De wigwam 16

De wisselwachter 23, 234-6, 255, 330, $335 \mathrm{n} 17,353 \mathrm{n} 6$ 
De witte waan 323

De zaak M.P. 352n1

Dennis P. 24

Det Sjunde Inseglet 124-5

Die Hard 302

Dik Trom 170, 327

Django 224

Django Unchained 224

Dokter Pulder zaait papavers 358n11

Dorp aan de rivier 41, 123-5, 342n7, $342 n 8$

Down 195

Dr. Jekyll and Mr. Hyde 58

Du Levande 272-3

Dunya \& Desie 101-5, 110, 340n8

Duska 353n 5

E.T. 53,96

Easy Rider 103, 221

Een dagje naar het strand $357-8 \mathrm{n} 8$

Een maand later 41

Een stille liefde 101

Een vlucht regenwulpen 355-6n22

Een vrouw als Eva 205

Een zwoele zomeravond 128-31, 141,

147, 342n12, 342n13, 342-43n14

El ángel exterminador 270

Election 247

Ellis in Glamourland 169

Emmanuelle 190

En route 102

Enter the Void 302

Escape from Alcatraz 225

Evil Dead II 349n16

Ex Drummer 205

Fanfare 9, 13, 23-4, 114-5, 117, 119-

$25,144,147,151-3,189,262,315$, $342 n 5,349 n 15$

Fargo 307-8, 332

Fight Club 299
Filmpje! 24, 76, 78-9, 83, 137, 153, 165, 254, 339n19, 339n20, 339n21

First Blood 222-3, 225-6

Flanagan 313,317

Flesh + Blood 206

Flirt 353n10

Flodder 13, 24-5, 28, 30, 33-7, 39-40, 45, 58-66, 68, 70-3, 77-80, 83, 92, 99, 105, 107, 109-10, 131, 140-1, 147, 153, 173, 181, 204, 216, 295, 324, 327-9, 336n27, 338n12, 344n22, $358 \mathrm{n} 13,365^{-6 \mathrm{n} 1}$

Flodder 366

Flodder in Amerika! 24-38, 40, 66

Floris 167-9, 173, 346n8, 346ng

Floris (tv) $167-8$

Forrest Gump 66-8, 70

Foxy Brown 224, 297

Frank \& Eva: Living Apart Together 1879, $347 \mathrm{n} 3$

Funny Games 28-9, 284-5

Gamle Maend I Nye Biler 76

Gangsterboys 92, 165

Geen paniek 336-7n3

Giant 149

Glamourland (tv) 141-2

Gluckauf 42

Gooische Vrouwen 138, 140-3, 145-6, 170, 344n22

Gooische Vrouwen 2 138, 141, 344n 21

Gooische Vrouwen (tv) 344n20

Grijpstra en de Gier 47

Grimm 282, 286, 324-5, 360n25

Gycklarnas Afron 124

Halloween 338n11, 349n17

Han de Wit 357-8n8

Happiness 247

Hartenstraat 148, 171, 344n25

Heb medelij, Jet! 101, 357-8n8 
Hellzapoppin' 237

Help! De dokter verzuipt! 24, 46-7, 124

Het diner 24

Het echte leven 242-5, 255, 290, 330, $354 \mathrm{n} 12$

Het gangstermeisje 20, 313, 336n28, $356 \mathrm{n} 2,358 \mathrm{n} 10$

Het meisje en de dood 234

Het paard van Sinterklaas 14

Het schnitzelparadijs $84,92-5$

Het wapen van Geldrop 102

Het wonderlijke leven van Willem Parel 341n1

Het zakmes 14

400 | His Girl Friday 133

Hitte/Harara 102

Hoge hakken, echte liefde 48, 53, 55

Holland's Got Talent (tv) 36, 216

Hollow Man 206

Hoogste tijd 113

Höstsonaten 151

How to Survive a Broken Heart 165

Humpday 221

Ik ben Joep Meloen 46, 131

Ik kom wat later naar Madra 13, 311

I Love You, Man 221

Ik ook van jou 186

Îles flottantes 343n15

In voor- en tegenspoed (tv) 108,341 ng

Inglourious Basterds 197

Intensive Care 153, 205

Interview (2003) 194, 348n11

Interview (2007) 194, 348n13

Intouchables 330

Irma la Douce $337 \mathrm{n} 8$

Irréversible 205, 302

It Happened One Night $133-5$

J. Kessels 340n7

Ja zuster, nee zuster $165^{-7}, 169-70$ 346n7
Jackie 102

Jackie Brown 297

Jaws 225

Jenny $155^{-6}$, 338n9

Jongens 346 n10

Joy 65

Kankerlijers 245

Karakter 13, 15, 22-3, 148, 345n28

Kauwboy 14

Keetje Tippel 122

Kermis in de regen $349 n 2$

Kill Bill 297

Kill List 284

Kiss Me Deadly 224

Kleine Teun 250, 275-6, 278-9, 287, 289, 360 n 23

Knocked Up 221

Komedie om geld 18, 115-7, 141, 341n3

Komt een vrouw bij de dokter 186-7

Kort Amerikaans 14

Kreatief met Kurk (tv) 151-3, 160-1, 182

Kung Fu Panda 343-44n18

Kutzooi 244-5, 255

Kyodai Makes the Big Time 300, 363n10

L'age d'or 270

L'inconnu du lac 178

La grande bouffe 28

La vie d'Adèle 178

Lang \& gelukkig 165,169

Lap rouge 244-5, 255

Last Tango in Paris 177, 347n2, 347n6

Lawrence of Arabia 178

Le charme discret de la bourgeoisie 269, 271

Le mépris 301

Le samourai 149

Leedvermaak 113

Lef 353n10 
Lek 334n10, 362n2

Lemming 284

Lena 65

Les parapluies de Cherbourg 162,167

Les amours imaginaires 346 n11

Little Caesar 339n2

Living 13

Lock, Stock and Two Smoking Barrels 299

Lois \& Clark: The New Adventures of Superman 145-46

Love Actually 136

Love Story $347 \mathrm{n} 6$

Luger 193

Makkers staakt uw wild geraas 123 , 125-9, 131, 135-6, 138, 141, 144-5, 197, 342n10, 342n11

Mama is boos! $48,56-8$

Man in de war 20-2, 41, 334n13, 334n14

Man of the West 264

Mariken van Nieumeghen 234

Marnie 149

Married with Children 108, 338n17

Mary Poppins 151

Massacre at Central High 18, 356n1

Match Point 364n15

Matterhorn 42, 171, 224, 361-2n31

Mean Streets 41

Meet Me in St. Louis 181

Merijntje Gijzen's jeugd 114

Met grote blijdschap 245-6, 354n13

Midnight Cowboy 221

Mijn nachten met Susan, Olga, Albert, Julie, Piet \& Sandra 189-90

Mijn vader woont in Rio 14

Minoes 14

Mission Impossible 171

Modern Times 109

Monte Carlo 101-2

Moordwijven 76-9, 138, 146-7
My Life on Planet B 345n2

'n Beetje verliefd 92

Naakt over de schutting 154, 313

Naar de klote! 296, 300-2, 324

Nachtrit 334n10, 365n17

Naked 205

Nattvardgästerna 124

Natural Born Killers 285

New Kids Nitro 73-4, 77

New Kids Turbo 24, 48, 66-71, 73-80, $83,99,131,147,225,296-7,324$, 353n10

Night of the Living Dead 58

No Country for Old Men 364n16

No Trains, No Planes 234

Nosferatu 58

Notting Hill 257

Nymph()maniac 177-8

Ober 239-40, 251-5, 258-9, 278, 284, $287,289,305-6,330$

Oh Boy! 236-40, 254, 327, 330, 353n10

Once Upon a Time in the West 94, 151

Ongewijde aarde 180

Op hoop van zegen (1934) 114

Op hoop van zegen (1986) 123

Oranje Hein 114

Paisà 263

Paradise Now 18-9

Paranoia 311, 313

Pentimento 205

Pervola, sporen in de sneeuw 238

Phileine zegt sorry 344n23, 344n24

Pizza Maffia 92

Plan C 224, 306-11, 324, 332, 365n17

Polonaise 102

Porky's 73, 338n15

Prins 363n8

Priscilla, Queen of the Desert 346n11 
Prospero's Books 18

Psycho 58, 75, 36on 23

Public Enemy 339n2

Pulp Fiction 78, 224-6, 285, 303, 310-1, 362n1

Rabat 41, 84, 102, 106-8, 110

Rain Man 246

Rape $345^{-6 n} 5$

Red River 345n4

Regen 114

Rent a friend 246-50, 255-6, 258, 290, 330, 354n14, 354n15, 354n16, $354 \mathrm{n} 17$

402 | Reservoir Dogs 293-4, 297, 303, 362n2

Revolver 94

RoboCop 206, 324

Rocco e suoi fratelli 95

Rocky 225

Roma città aperta 263

Romeo and Juliet 92-4

Rooie Sien 122, 193

Roos en Rana 101-2

Sad Movies 156, 345-6n 5, 356-7n3

Safe 247

Sahara Sandwich 165

Scarface (1932) 339n2

Scarface (1984) 225, 297

Schatjes! 48, 53-8, 60, 62, 79, 83, 147, 337-8ng, 338n10

Schermerhoorn $347 \mathrm{n} 4$

Schneider vs. Bax 287, 358n14, 36on23, $361 \mathrm{n} 25,361 \mathrm{n} 26$

Shame 177

Shaun of the Dead 257, 349n16

Sherlock Jones 46

Sherlock Jr. 238-9

Shortbus 178

Shouf Shouf Habibi! 84, 92, 95-101, 109, 148, 329, 340n 5
Showgirls 162, 206-7, 346n6

Siberia 353ng

Simon 17, 214-7, 227, 35ong, 350-1n10, $351 \mathrm{n} 11$

Sint $195^{-8}$

Sl8n8 196

Snackbar 92, 224

Snatch 299

Snowfever 225

Solaris $304-5$

Soldaat van Oranje 13, 18, 20, 203, 333n1, 342n11

Some Like it Hot $127,145,158$

Somewhere Tonight $348 \mathrm{n} 13$

Sommarnattens Leende 124

South Park 74

Speed 171

Spetters 24, 41, 201-10, 226-7, 289, 322$3,332,346 \mathrm{n} 10$

Spijt! 333n 4

Spion van Oranje 83,138

Spoorloos 13, 19, 42, 340n6

Starship Troopers 206-7

Steamboat Bill, Jr. 237

Steptoe and Son 122

Sterren stralen overal $115,341 \mathrm{n} 1$

Stiefbeen en zoon 122

Submission 193

Sullivan's Travels 103

Summer in the Fields $156,345^{-6 n} 5$

Superbad 221

Superman $145,345 \mathrm{n} 26$

Superman II 345 n26

Sur Place 165

Suzy Q 42, 355n20, 365n19

Swiebertje 122

Ted $224-5$

Teorema 284, 358ng

The 40-Year-Old Virgin 221

The Awful Truth 133, 136 
The Beverly Hillbillies 338n12

The Big Lebowski 225-6, 309, 357n6, 366n6

The Boston Strangler 303

The Breakfast Club 356n23

The Dark Knight Rises 91

The Deer Hunter 224

The Delivery 101-2

The Dukes of Hazzard 154

The Exorcist 338n11

The French Connection 198, 36on23

The Frighteners 349n16

The Godfather 106-8, 298

The Graduate 93-94

The Hangover 223, 298

The Human Centipede (First Sequence)

$$
\text { 196, 362-3n4 }
$$

The Human Centipede 2 (Full

Sequence) 196-7

The Kid 334n13

The Kiss 177

The Lady Eve 133

The Last Picture Show 201-2

The Magnificent Seven 94

The Maltese Falcon 155

The Music-Box 22

The Paradise Suite 42

The Persuaders 303

The Philadelphia Story 133

The Purple Rose of Cairo 341n1

The Royal Tenenbaums 247-8

The Sheik 151

The Shining 54, 58, 62

The Silence of the Lambs 338n11

The Simpsons $338 \mathrm{n} 17$

The Sixth Sense 302

The Sound of Music 156, 158

The Wizard of Oz 17-9, 103, 339n21

Thelma and Louise 103

Theo \& Thea (TV) $157,173-4$
Theo \& Thea en de ontmaskering van het tenenkaasimperium 156-60

Things to Do in Denver When You're Dead 299

Thunderbolt and Lightfoot 221

Tirza 102

Toestanden 113

Trouble in Paradise 155

Tulips $346 \mathrm{n} 5$

Turks fruit 14, 18, 24, 182-6, 188, 198, 202, 205, 313, 333n1, 347n6, 349n18, 358n10, 365n21

Tussenstand 131-2, 224

Twee vrouwen 18, 205

Tystnaden 178

Uit het leven van Dik Trom 114

Un chien andalou 270, 318

Un prophète 41

Une histoire de vent 16

Ushi Must Marry 165

Van geluk gesproken 41

Van God los 17, 227

Ventoux 35 on 5

Vertigo 328

Vet hard 75-6, 78, 80, 83, 296, 310-1, $324,327-8$

Voor een verloren soldaat $346 \mathrm{n} 10$

Vox populi 83-7, 108-9

Vreemd bloed 42

Walhalla 339n1

Wan Pipel 347n3

Warnung vor einer Heiligen Nutte 336$7 \mathrm{n} 3$

Wat zien ik!? 24, 46, 48-53, 61, 79, 139, 147, 323-4, 332, 337n $5,365 \mathrm{n} 21$

Welcome to the Dollhouse $362 n_{31}$

What's Eating Gilbert Grape 246

Wilde mossels 17, 42, 226-7 
Wildschut 154

Willem van Oranje 17

Wolf 41-2

Wonderbroeders $351 \mathrm{n} 14$

Wonderland (tv) 36

\section{Zombibi 197}

Zomerhitte 14, 186

Zus \& Zo 343n15

Zusje 17, 240-2, 244, 254-5, 348ng

Zwaarmoedige verhalen bij de centrale

verwarming $357-8 \mathrm{n} 8$, 359-6on 22

Zwart water 196

404 


\section{INDEX OF NAMES}

Abrams, M.H. 289

Abu-Assad, Hany 18

Admiraal, Joop 129

Agresti, Alejandro 18

Akerman, Chantal 165

Alberti, Willeke 122, 193

Allen, Woody 307, 334n15, 341n1, 364n14, 364n15

Almodóvar, Pedro 346n11

Andersson, Roy 23, 273, 275, 359n17

Appel, Karel 262, 356n2

Aristotle 27

B., Mohammed 193

Babuscio, Jack 155-6

Bain, Alexander 31-2

Bakhtin, Mikhail 26, 48, 6o, 63, 83, 295-6

Bal, Mieke 10

Barrie, J.M. 256

Baudelaire, Charles 249, 255

Bava, Mario 154

Bazin, André 113, 263

Beattie, James 29

Beerekamp, Hans 10, 20, 333n2, 334n10, 358n13

Belafonte, Harry 298
Bergman, Ingmar 113, 124-5, 129, 151,

153, 178, 231, 336

Bergman, Ingrid 151

Bergson, Henri 26-7, 32-3, 48, 71-4, 99,

327, 331

Berkeley, Busby 155, 162

Bernink, Mieke 16, 136

Bianchi, Robbert 348n7

Bierman, Ronnie 365n21

Bijkerk, Luc 313

Billig, Michael 27-32, 327, 329, 331, $335^{\mathrm{n} 22}, 335^{\mathrm{n} 23}, 336 \mathrm{n} 24,336 \mathrm{n} 25$

Blokker, Bas 35

Blokker, Jan 122, 128, 342n5, 342n9

Booth, Wayne 125, 288-9

Bordwell, David 90-1, 329

Boskamp, Hans 365n21

Boudou, Khalid 95

Breton, André 286, 305, 331

Brinkman, Elco 194

Bromet, Frans 261

Brood, Herman 190-2, 347-8n7, 348ng, 358n10

Brouwers, Dolf 192, 348n8

Brusse, Kees 179, 348

Buñuel, Luis 51, 269-71, 275, 284, 290, $318,337 \mathrm{n} 6$ 
Buruma, Ian 146-8, 192

Buscemi, Steve 194, 348n12, 348n13

Campbell, George 335n23

Campert, Remco 262, 356n2

Camus, Albert 309, 365n18

Capra, Frank 45, 133

Carpenter, John 154, 338n11, 349n17

Carroll, Noël 28, 74, 108, 236, 338n16, $338 \mathrm{n} 17$

Cassavetes, John 132

Cavell, Stanley 133-4, 343n16

Chaplin, Charlie 22, 27, 109, 334n13

Chekhov, Anton 323, 343n15

406 | Cliteur, Paul 84

Clover, Carol 57, 349n17

Coen, Joel and Ethan 225, 253, 307-10, 342n6, 357n6, 364n16

Cohen, Sacha Baron 74

Colebrook, Claire 305-6, 364n12, $364 \mathrm{n} 13$

Collin, Robbie 284

Collins, Christopher $274^{-5}$

Collins, Joan 169, 350ng

Connolly, Kate 194

Constantine, Eddie 337n 3

Coolen, Antoon 123

Cooper, Tommy 194

Corneille 262

Creed, Barbara 58

Critchley, Simon 9, 22, 27-8, 30, 33, 42, 61-2, 79, 108, 331-2, 366n2

Curiël, Herbert $347-8 \mathrm{n} 7$

Daalder, René 18, 261-2, 356n1

Danniel, Danniel 20

Dardenne, Jean-Pierre and Luc 19

DeAngelis, Michael 221

De Bont, Jan 198, 261-2, 265, 347n3

De Breij, Claudia 230

De Jong, Mijke 19, 132
De Jonge, Freek 86, 230, 233-4, 352n2, $352 \mathrm{n} 3$

De la Parra, Pim 47, 264, 347n 3

De Leeuw, Paul 66, 78, 83, 137-8, 339n19

De Mol, Linda 344n2o

Debie, Benoit 302

Den Drijver, Ruud 16, 180, 347n 4

Dittrich, Kathinka 16, 115-7, 341n2

Ditvoorst, Adriaan 262, 311-3, 317, 323-4

Doense, Jan 153

Domburg, Andrea 342n 5

Dostoevsky, Fyodor 364n15

Douglas, Michael 151

Dreyer, Carl-Theodore 342n7

Dröge, Gert-Jan 141-2

Dumont, Bruno 19

Dyer, Richard 58, 154-6, 160-2, 174, 328,330

Earl of Shaftesbury 29, 31, 335n23

Eco, Umberto 181-2

Ekker, Jan Pieter 196, 227

Elstak, Paul 67, 338n18

Escher, M.C. $356 \mathrm{n} 26$

Fallaux, Emile 194

Farrelly, Peter and Bobby 19, 66, 73

Fassbinder, Rainer Werner 113

Fellini, Federico 20, 262, 336n28

Ferrell, Will 224-5

Flaubert, Gustave 295

Ford, John 45

Fortuyn, Pim 83, 193, 216, 339n1, 3501n10

Freud, Sigmund 33-4, 37-40, 133, 327, $330-2,336 \mathrm{n} 24,366 \mathrm{n} 5$

Frijda, Nelly 336n27, 344n22

Furst, Lilian $335 \mathrm{n} 21$

Fuseli, Henri 285 
Garland, Judy 155

Geels, Laurens 23

Godard, Jean-Luc 191-2, 263, 311

Goderie, Jac 75

Goedemondt, Ronald 230

Goldwyn, Samuel 336n1

Gooyer, Rijk de 55, 108, 336-7n3, 36o$1 \mathrm{n} 24$

Gordon 36, 216

Goudsblom, Johan 35

Graaff, Bart de 66

Grant, Cary 133, 145, 299

Graveland, Mariska 17, 257

Grunberg, Arnon 339n22

Gullit, Estelle 75

Gummbah 333n5, 359n16

Haanstra, Bert 16, 128, 334n8, 342n4, $342 n 5,349 n 15$

Hamer, Bent 23, 275

Hannoosh, Michele 249-5o, 354n18, 354n 19

Heeresma, Heere $357-8 \mathrm{n} 8$

Heesen, Hans 16

Heijne, Bas 365-6n1

Hepburn, Audrey 162

Hermans, Toon 23, 230

Hermans, W.F. 311-2

Hermsen, Joke 109

Hill, Walter 154

Hirsi Ali, Ayaan 193

Hobbes, Thomas 27-9, 31

Hofstede, Bart 16

Hogenkamp, Bert 333n2

Holland, Kim 75

Honigmann, Heddy 13

Hopper, Dennis 151

Huijbregts, Marc-Marie 137, 170

Huizinga, Johan 24-5, 299-30, 254, 335n19

Hunter, I.Q. 162, 206-7, 346n6
Hurt, William 23

Hutcheon, Linda 125, 157, 269, 288-9, 305-6, 311

Ivens, Joris 13,16

Jameson, Fredric 157, 173

Joling, Gerard 157-8

Junkie XL 94

Kaandorp, Brigitte 230

Kafka, Franz 295-6, 312

Kamerling, Antonie 338-9n18

Karaty, Dan 36

Kas, Ton 87

Kasander, Kees 18

Kaurismäki, Aki 19, 23, 149, 252, 275

Kayser, Wolfgang 295-6

Keaton, Buster 27, 236-9, 344n25, 353 n10

Kerkhof, Ian 300-2, 363n 5

Kieviet, C. Joh. 170

Klaasen, Alex 170-1

Komrij, Gerrit 288, 361n3o

Konrád, György 238

Kooijman, Jan 171

Kooiman, Dirk Ayelt 288, 361n3o

Koolhaas, Rem 261-2

Koot, Rolf 23

Kouwenaar, Gerrit 262

Krabbé, Jeroen 359n19

Krabbé, Tim 313

Kristel, Sylvia 154, 190, 237

Kuipers, Giselinde 28-9, 35, 79-80, 339n22

Lacan, Jacques 40, 161

Lammers, Frank 76

Landré, Joop 128

Lee, Spike $297,363 n 7$

Leone, Sergio 224, 293, 36on23 
Leopold, Nanouk 19

Linthorst, Gerdin 238

Lloyd, Harold 27, 236

Lord Kames 29

Lucebert 262, 356n2

Lucieer, Rudolf 262

Lynch, David 284

Maas, Dick 19, 45, 62, 71, 77, 98-9, 147, $195,327,329$

Maas, Hidde 154

Maassen, Theo 66, 76

MacDowell, James 351n16

Mackendrick, Alexander 122, 342n6

408 Malherbe, Annet 344n2o

Mathijs, Ernest 18

McHale, Brian 157, 255

Melissen, Beppie 344n22

Mendik, Xavier 182-3

Merhi, Vanessa A. 305

Meyer, Anita 171-2

Meyering, Samuel 261

Mioch, René 75

Mol, Albert 48, 166-7

Molenberg, Henk 365n21

Molière 72

Mourali, Chazia 75

Nijenhuis, Johan 195

Nolan, Christopher 91

Olaf, Erwin 195

Ophüls, Max 115-6

Ozu, Yasujiro 154, 300

Piët, Frans $350 n 8$

Plato 27

Polizzotti, Mark 331

Pollard, Stephen 334n15
Rabelais, François 295

Rademakers, Fons 16, 124, 128, 135-6, 336n28, 342ng, 343n17

Ramaer, Joost 16

Ranzijn, Joost 20

Reve, Gerard 322-3, 360-1n24

Rockatansky, Max 153

Roelfs, Jan 18

Rossellini, Roberto 263

Rukhelman, Svetlana 253

Russo, Vito 345n 4

Ruven, Paul 162, 165

Scheffer, Paul 84, 147-8, 329

Schippers, Wim T. 17, 348n8, 356n 3

Schmidt, Annie M.G. 166-7

Schoots, Hans 16-7, 48, 226-7, 262, 35003

Schram, Dave 10

Schuurman, Birgit 363n6

Sconce, Jeffrey 153-4, 247-8

Sedgwick, Eve Kosofsky 162, 207, 209, 345n 4

Seinfeld, Jerry 334n15

Seunke, Orlow 230, 236, 238-9, 254, 353n8

Shaffy, Ramses 268, 347n 4

Sirk, Douglas 115, 156, 162

Six, Tom 196-7

Sluizer, George 16, 19, 350n 3

Smith, Sydney 29-31

Soeteman, Gerard 48, 167, 321

Sommer, Martin 336n26

Sonneveld, Wim 230, 341n1

Sontag, Susan 153, 155, 174, 190, 289, $345 \mathrm{n} 4,363 \mathrm{n} 9$

Spencer, Herbert 31

Stapel, Huub 173

Staudte, Wolfgang 18, 115

Stealers Wheel 293

Steen, Theodoor $233,361 \mathrm{n} 27$ 
Steffaro, Julius 50-1

Stelling, Jos 20, 230, 233-4, 254-6, $327,330,334 \mathrm{n} 12,335 \mathrm{n} 17,35^{2 \mathrm{n} 2}$, 352n3, 353n4, 353n6

Stone, Sharon 151

Strooker, Shireen 264

Sturges, Preston 23, 40-1

Swift, Jonathan 316

Tarantino, Quentin 66, 73-4, 168, 224, 293-4, 296-8, 301-3, 305, 324, $363 n 7$

Tarkovsky, Andrei 153, 302, 304-5, 324

Teeuwen, Hans 66, 76, 230, 359n16

Ten Hooven, Marcel 146-7, 345n27

Terstall, Eddy 24, 87, 230, 256, 339n1, $351 \mathrm{n} 11$

Thielemans, Toots 185

Thomése, P.F. 340n7

Thomson, Philip 294-6, 305, 311, 322

Thoolen, Gerard 130, 238-9

Truffaut, François 261, 336n 28

Tuynman, Hans 263, 357n 5

Udris, Jan 38

Valentino, Rudolph 151

Van Alphen, Ernst 10, 171, 270

Van Ammelrooy, Willeke 365n21

Van Beusekom, Ansje 16, 341n3

Van Brakel, Nouchka 19, 350n3, 359$60 n 22$

Van Bueren, Peter 349n18

Van Buuren, Maarten 295, 362n3

Van Dam, René 16

Van den Oetelaar, André 305-6

Van der Horst, Herman 13

Van der Keuken, Johan 13, 262, 356n2

Van der Linden, Henk 14, 333n 3

Van der Linden, Wim 262, 356n 3

Van der Meulen, Karst 14, 333n 3
Van der Vlugt, Bram 238

Van der Woude, Jim 236, 327, 353n6

Van Diem, Mike 149, 345n28, 353-4n10

Van Driel, Guido 302, 304

Van Duin, André 46-7, 131, 153, 327, 338n14

Van Gelder, Henk 17, 180

Van Gogh, Theo 94-5, 192-5, 198, 274, 348n10, 348n12

Van Heijningen, Matthijs 313

Van Hoogdalem, Doesjka 194

Van Houten, Carice 138-9

Van Munster, Bert 18

Van Nieuwenhoven, Jeltje 13

Van Os, Ben 18

Van Schayk, Margot 231, 342-3n14

Van Scheers, Rob 16, 48-9, 322

Van 't Hek, Youp 230

Van 't Hof, René 256

Van Warmerdam, Alex 16, 19-20, 23-4, 37-8, 230, 250, 252, 255-6, $25^{8}$, 269, 271-9, 281-2, 285-90, 311-2, $322,324-5,330-1,334 \mathrm{n} 12,344 \mathrm{n} 2 \mathrm{O}$, 358n14, 359n16, 359n2o, 36on23, 361n25, 361n29, 361-2n31, 366n6

Van Zwol, Coen 356n 25

Veenman, Lili 342n9

Veerman, Hans 227

Verdaasdonk, Dorothée 16, 313

Verhoeven, Paul 16, 19-20, 48-9, 198, 203-7, 317, 320-4, 332, 333n1, 349n18, 350n 3

Vermey, Michel 354n13

Verstappen, Wim 16, 47, 179-81, 233, $262-5,347 \mathrm{n} 3,347 \mathrm{n} 4$

Verstraten, Peter 207, 217

Vestdijk, Simon 179

Vinkenoog, Simon 262

Von Weber, Carl Maria 314

Vrijman, Jan 262, 356n2 
Wampole, Christy 142

Wayne, John 161

Weeber, Egbert-Jan 171

Weinman, Jenna 221

Weishaar, Schuy R. 309-10

Weisz, Frans 20, 42, 101, 113, 122,

129, 154, 262, 313, 336n28, 356n2, 357-8n8

Welles, Orson 153,312

Wigman, Denis 18

Wilder, Billy 23, 40, 127, 158, 337n8

Williams, Linda 163, 177-8, 270-1, 312

Willis, Bruce 302

Willis, Sharon 224, 293-4, 297

410 Wonder, Stevie 189

Zijderveld, Anton 329

Žižek, Slavoj 57, 67, 145, 179, 329, 3434n18,

Zupancic, Alenka 40, 100, 147, 273, 328, $366 \mathrm{n} 3$

Zwerenzino, Quentin 196 